\title{
Southwest Regional Partnership on Carbon Sequestration \\ Phase II
}

\author{
Topical Report \\ for the period 09/01/07 through 09/30/10
}

\section{Geologic Demonstration at the Aneth Oil Field, Paradox Basin, Utah}

by

James Rutledge

Los Alamos National Laboratory

DOE Contract No.: DE- FC26-05NT42591

$\begin{array}{ll}\text { Submitting Organization: } & \text { New Mexico Institute of Mining and Technology } \\ & \text { 801 Leroy Place } \\ & \text { Socorro, New Mexico } 87801\end{array}$

December 2010

Prepared for U.S. Department of Energy's National Energy Technology Laboratory and New Mexico Institute of Mining \& Technology 


\section{DISCLAIMER}

This report was prepared as an account of work sponsored by an agency of the United States Government. Neither the United States Government nor any agency thereof, nor any of their employees, makes any warranty, express or implied, or assumes any legal liability or responsibility for the accuracy, completeness, or usefulness of any information, apparatus, product, or process disclosed, or represents that its use would not infringe privately owned rights. Reference herein to any specific commercial product, process, or service by trade name, trademark, manufacture, or otherwise does not necessarily constitute or imply its endorsement, recommendation, or favoring by the United States Government or any agency thereof. The views and opinions of authors expressed herein do not necessarily state or reflect those of the United States Government or any agency thereof. 


\section{ABSTRACT}

The Southwest Regional Partnership (SWP) on Carbon Sequestration designed and deployed a medium-scale field pilot test of geologic carbon dioxide $\left(\mathrm{CO}_{2}\right)$ sequestration in the Aneth oil field. Greater Aneth oil field, Utah's largest oil producer, was discovered in 1956 and has produced over 455 million barrels of oil $\left(72\right.$ million $\left.\mathrm{m}^{3}\right)$. Located in the Paradox Basin of southeastern Utah, Greater Aneth is a stratigraphic trap producing from the Pennsylvanian Paradox Formation. Because it represents an archetype oil field of the western U.S., Greater Aneth was selected as one of three geologic pilots to demonstrate combined enhanced oil recovery (EOR) and $\mathrm{CO}_{2}$ sequestration under the auspices of the SWP on Carbon Sequestration, sponsored by the U.S. Department of Energy. The pilot demonstration focuced on the western portion of the Aneth Unit as this area of the field was converted from waterflood production to $\mathrm{CO}_{2}$ EOR starting in late 2007. The Aneth Unit is in the northwestern part of the field and has produced 149 million barrels $\left(24\right.$ million $\mathrm{m}^{3}$ ) of the estimated 450 million barrels $(71.5$ million $\mathrm{m}^{3}$ ) of the original oil in place - a 33\% recovery rate. The large amount of remaining oil makes the Aneth Unit ideal to demonstrate both $\mathrm{CO}_{2}$ storage capacity and EOR by $\mathrm{CO}_{2}$ flooding.

This report summarizes the geologic characterization research, the various field monitoring tests, and the development of a geologic model and numerical simulations conducted for the Aneth demonstration project. The Utah Geological Survey (UGS), with contributions from other Partners, evaluated how the surface and subsurface geology of the Aneth Unit demonstration site will affect sequestration operations and engineering strategies. The UGS' research for the project are summarized in Chapters 1 through 7, and includes (1) mapping the surface geology including stratigraphy, faulting, fractures, and deformation bands, (2) describing the local Jurassic and Cretaceous stratigraphy, (3) mapping the Desert Creek zone reservoir, Gothic seal, and overlying aquifers, (4) characterizing the depositional environments and diagenetic events that produced significant reservoir heterogeneity, (5) describing the geochemical, petrographic, and geomechanical properties of the seal to determine the $\mathrm{CO}_{2}$ or hydrocarbon column it could support, and (6) evaluating the production history to compare primary production from vertical and horizontal wells, and the effects of waterflood and wateralternating-gas flood programs.

The field monitoring demonstrations were conducted by various Partners including New Mexico Institute of Mining and Technology, University of Utah, National Institute of Advanced Industrial Science and Technology, Japan, Los Alamos National Laboratory and Cambridge Geosciences. The monitoring tests are summarized in Chapters 8 through 12, and includes (1) interwell tracer studies during water- and $\mathrm{CO}_{2}$-flood operations to characterize tracer behavoirs in anticipation of $\mathrm{CO}_{2}$-sequestration applications, (2) $\mathrm{CO}_{2}$ soil flux monitoring to measure background levels and variance and assess the sensitivity levels for $\mathrm{CO}_{2}$ surface monitoring, (3) testing the continuous monitoring of self potential as a means to detect pressure anomalies and electrochemical reaction due to $\mathrm{CO}_{2}$ injection, (4) conducting time-lapse vertical seismic profiling to image change near a $\mathrm{CO}_{2}$ injection well, and (5) monitoring microseismicity using a downhole string of seismic receivers to detect fracture slip and deformation associated with stress changes.

Finally, the geologic modeling and numerical simulation study was conducted by researcher at the University of Utah. Chapter 13 summarizes their efforts which focused on developing a site-specific geologic model for Aneth to better understand and design $\mathrm{CO}_{2}$ storage specifically tailored to oil reservoirs. 


\section{CONTENTS}

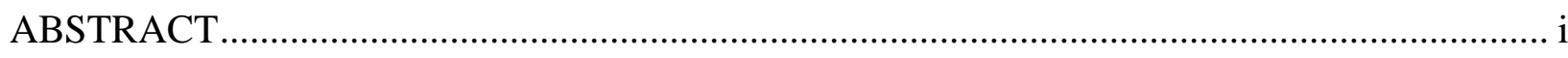

CHAPTER 1 - INTRODUCTION OF SURFACE AND SUBSURFACE GEOLOGICAL CHARACTERIZATION OF THE ANETH UNIT, GREATER ANETH FIELD, PARADOX

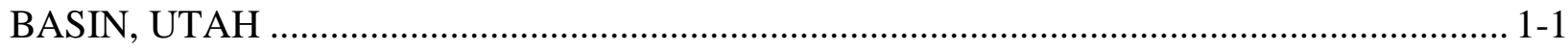

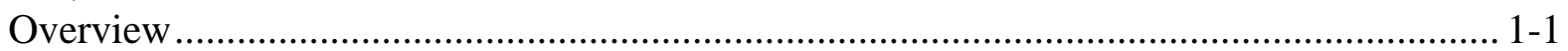

Greater Aneth Field Synopsis ......................................................................................... 1-2

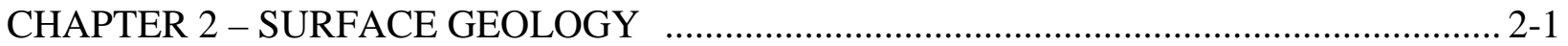

Geologic Map of the Aneth Area, Montezuma Creek and Navajo Canyon Quandrangles ... 2-1

Structural Elements............................................................................................................ 2-1

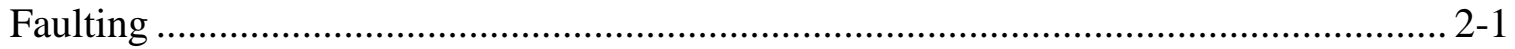

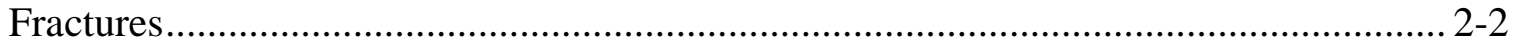

Deformation Bands .................................................................................................. 2-2

CHAPTER 3 - SUBSURFACE STRUCTURAL AND THICKNESS MAPPING...................... 3-1

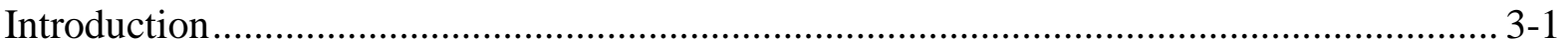

Structural and Stratigraphic Analysis ....................................................................... 3-1

Aquifers....................................................................................................... 3-1

Navajo Sandstone............................................................................................ $3-1$

DeChelly Sandstone........................................................................................... 3-1

Reservoir - Desert Creek Zone.................................................................................... 3-2

Seal - Gothic Shale ............................................................................................... 3-2

CHAPTER 4 - RESERVOIR CHARACTERIZATION OF THE DESERT CREEK ZONE OF THE PARADOX FORMATION, ANETH UNIT: LITHOFACIES, LITHOLOGY, PORE TYPES, AND DIAGENESIS …………………........................................................ 4-1

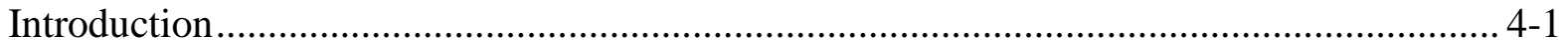

Lithofacies and Lithology .................................................................................................. 4-2

Carbonate Buildups............................................................................................ 4-2

Phylloid-algal lithofacies ...................................................................................... 4-2

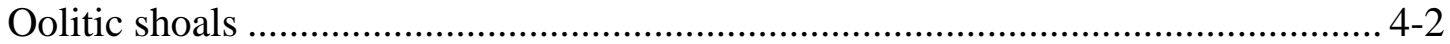

Platform Interior Carbonate Muds and Sands................................................................. 4-2

Relief on Carbonate Buildups and Flooding Surfaces .............................................. 4-3

Pore Types and Diagenesis .............................................................................................. 4-3

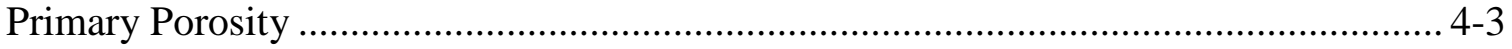

Diagenetic Environments................................................................................... 4-4

Evidence of Faulting .............................................................................................. 4-4

Assessment of Fractures and Stylolites............................................................................ 4-5

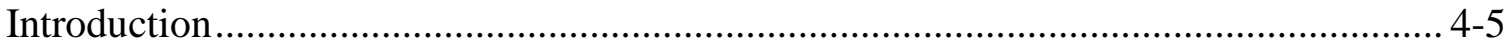

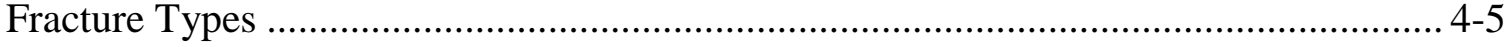

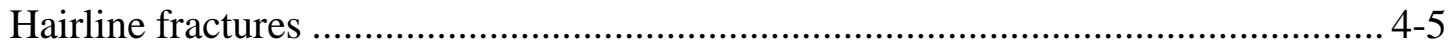

Vertical fractures............................................................................................. 4-5

Inclined fractures .............................................................................................. 4-5 


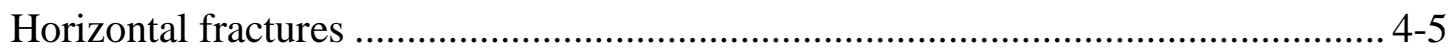

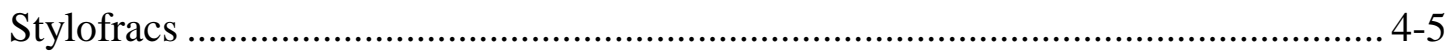

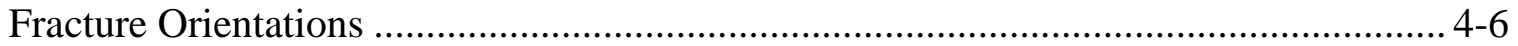

Relative Number of Fractures............................................................................. 4-6

Discussion: Inferences on Fracture Permeability …………............................................ 4-6

Porosity and Permeability Cross Plots ................................................................................... 4-6

\section{CHAPTER 5 - THE GOTHIC SHALE IN THE ANETH UNIT: SEAL FOR}

HYDROCARBONS AND CO ${ }_{2}$ GEOLOGIC SEQUESTRATION .......................................... 5-1

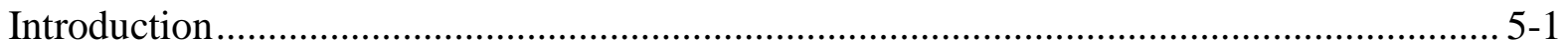

General Core Description ........................................................................................ 5-2

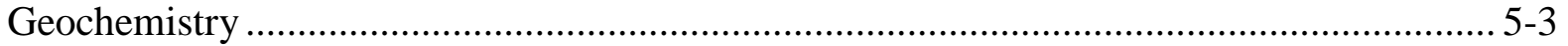

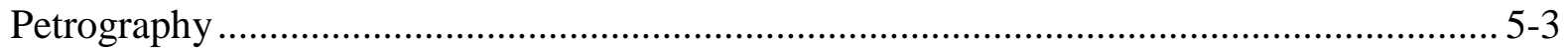

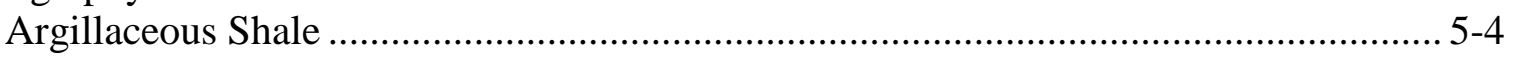

Argillaceous Mudstone ............................................................................................. 5-4

Silty Calcareous/ Argillaceous Mudstone................................................................... 5-5

Phosphatic Argillaceous Mudstone.......................................................................... 5-5

Analysis of Natural Fractures .................................................................................... 5-5

Petrophysical Properties................................................................................................... 5-6

Basic Reservoir Parameters ………………………............................................ 5-6

Mercury Injection Capillary Pressure and Pore Aperture Distributions ........................... 5-6

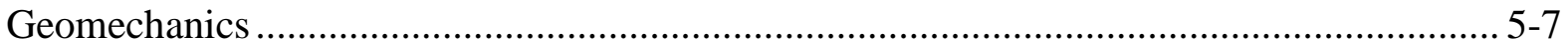

Young's Modulus and Poisson's Ratio ...................................................................... 5-7

Compressional Testing......................................................................................... 5-8

CHAPTER 6 - EVALUATION OF PRODUCTION HISTORY CURVES FROM THE ANETH

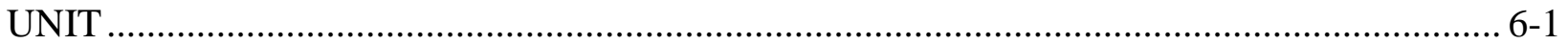

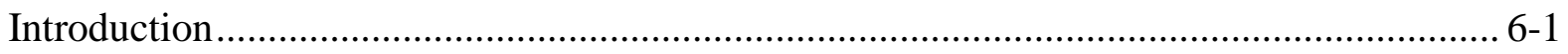

Production History Curves.................................................................................................... 6-1

Individual Wells................................................................................................ 6-1

Section 14 Horizontal Laterals and WAG .................................................................... 6-1

Sections 25 and 26 Horizontal Laterals and Waterflood ............................................... 6-2

Comparison of Waterflood to WAG in Wells with Horizontal Laterals ........................... 6-2

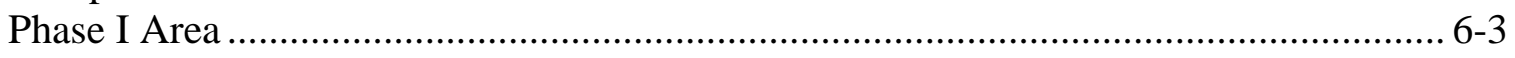

Phase II Area ................................................................................................. 6-3

CHAPTER 7 - SUMMARY AND CONCLUSIONS OF SURFACE AND SUBSURFACE

GEOLOGICAL CHARACTERIZATION OF THE ANETH UNIT, GREATER ANETH FIELD,

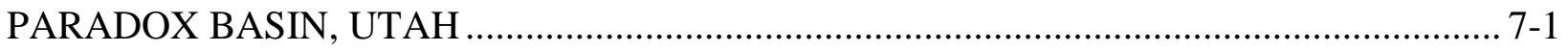

Surface Geology.................................................................................................... 7-1

Subsurface Structural and Thickness Mapping.................................................................. 7-2

Reservoir Characterization of the Desert Creek Zone ...................................................... 7-2

The Gothic Shale in the Aneth Unit: Seal for Hydrocarbons and $\mathrm{CO}_{2}$ Geologic

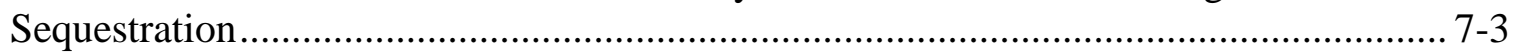

Evaluation of Production History Curves from the Aneth Unit ........................................... 7-4 
CHAPTER 8 - TRACER TESTING AT THE ANETH, UTAH PETROLEUM FIELD .......... 8-1

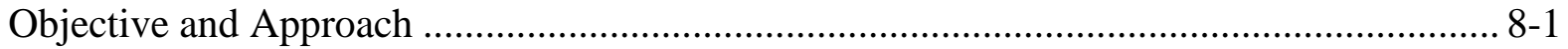

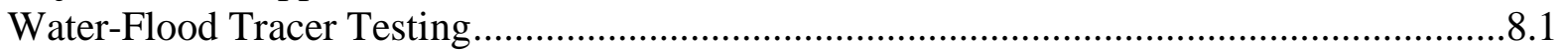

$\mathrm{CO}_{2}$-Flood Tracer Testing.........................................................................................

Comparison of the Performance of the $\mathrm{CO}_{2}$-Flood Tracers............................................ 8-6

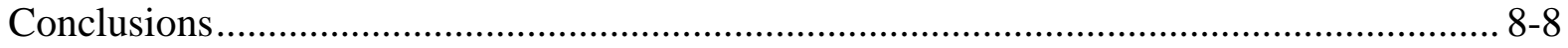

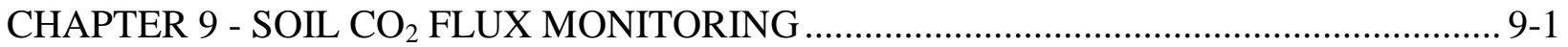

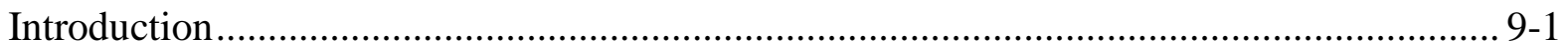

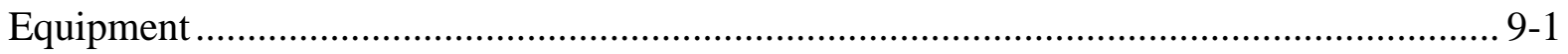

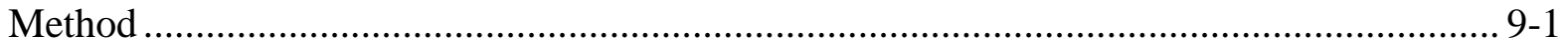

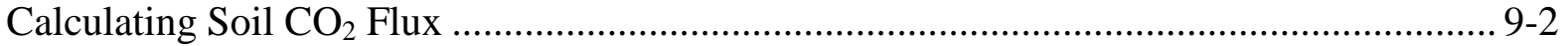

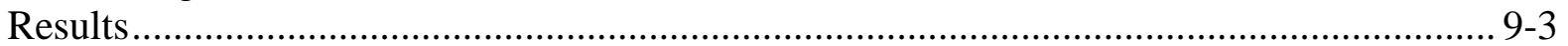

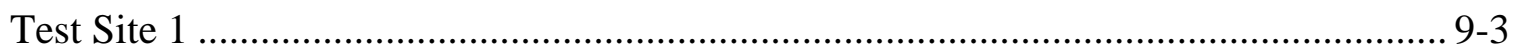

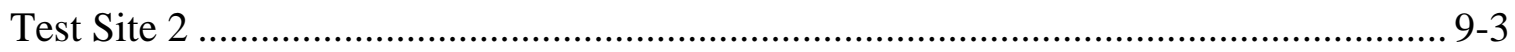

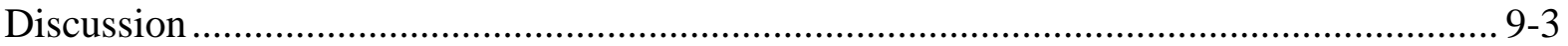

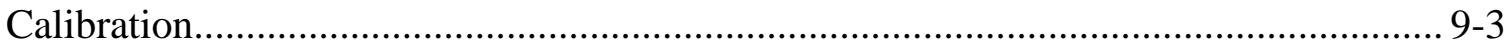

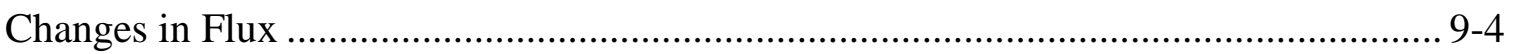

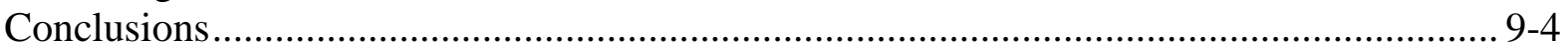

CHAPTER 10 - SELF-POTENTIAL MONITORING AT THE ANETH TEST SITE............ 10-1

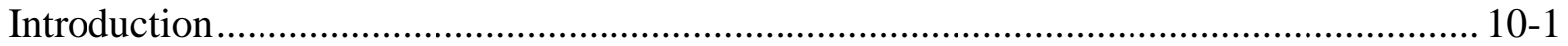

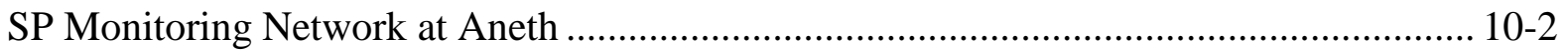

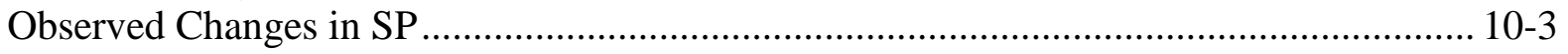

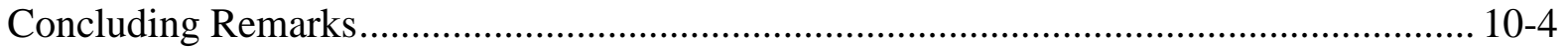

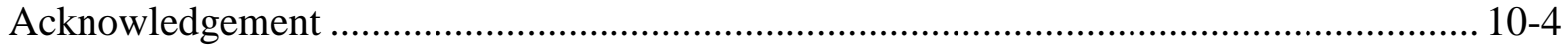

CHAPTER 11 - TIME-LAPSE OFFSET VSP MONITORING OF $\mathrm{CO}_{2}$ ENHANCED OIL

RECOVERY AT THE ANETH OIL FIELD .......................................................... 11-1

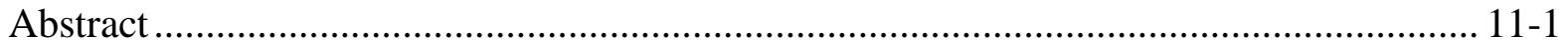

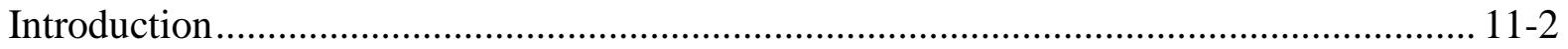

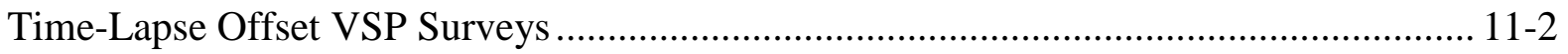

Relocation of Offset VSP Sources ................................................................................ 11-3

Balancing Time-Lapse VSP Data .......................................................................... 11-4

Depth Migration of Time-Lapse Offset VSP Data …................................................ 11-5

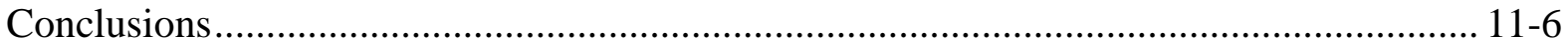

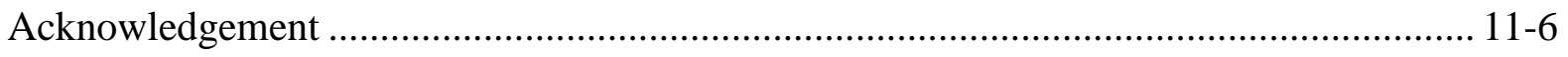

CHAPTER 12 - MICROSEISMIC MONITORING OF $\mathrm{CO}_{2}$ ENHANCED OIL RECOVERY

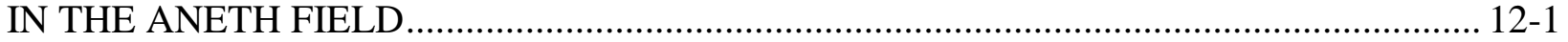

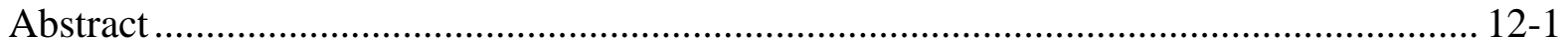

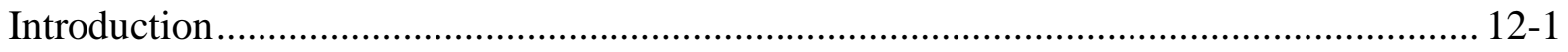

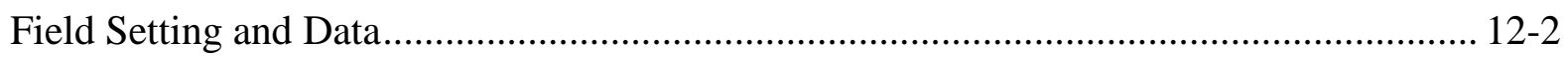

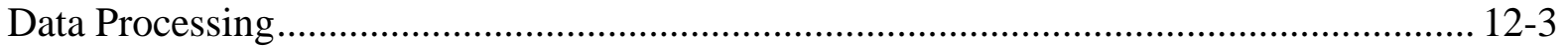

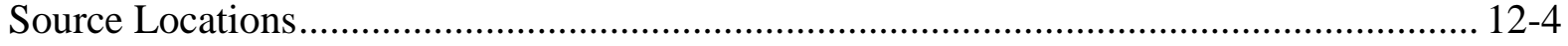

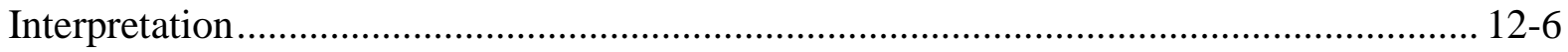




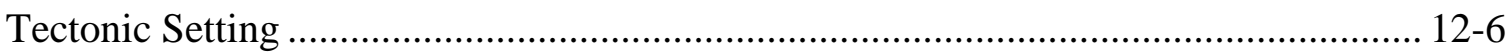

Space Time Development of the Seismicity and Microearthquake Recurrence.............12-7

Correlations of Seismicity with Injection and Production............................................. 12-8

Concluding Remarks..................................................................................................... 12-9

Acknowledgements................................................................................................. 12-10

CHAPTER 13 - GEOLOGIC MODEL DEVELOPMENT AND NUMERICAL SIMULATION

OF THE ANETH SITE, UTAH................................................................................. 13-1

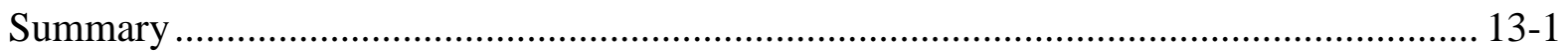

Data Acquisition ........................................................................................................... 13-3

Digitizing Well Logs................................................................................................... 13-4

Petrophysical Properties Estimation ................................................................................ 13-6

Estimation of Porosity........................................................................................... 13-7

Porosity and Permeability Relationship ...................................................................... 13-8

Geologic Model Development........................................................................................... 13-9

Grid Conversion and Upscaling for PFloTran Simulator .......................................... 13-12

Numerical Simulations........................................................................................ 13-14

Grid Generation for Numerical Simulation ........................................................... 13-14

Preliminary Simulation Results ........................................................................... 13-16

Optimizations to prevent over-pressuring ................................................................ 13-17

Over-pressuring behavior with $1 \mathrm{MMt} / \mathrm{year}$....................................................... 13-17

Seeking the maximum injection rate............................................................. 13-18

Investigations on permeability uncertainty .......................................................... 13-22

Seeking the minimum number of injection wells ................................................... 13-23

Optimizations on WAG Scheme to Enhance Residual Trapping ................................. 13-25

Concluding Remarks............................................................................................... 13-31

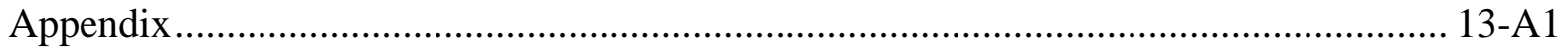

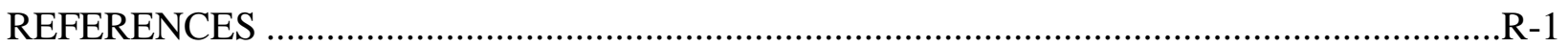




\section{FIGURES}

Figure 1-1. Oil and gas fields in the Paradox Basin of Utah, Colorado, and Arizona................. 1-4

Figure 1-2. Units, best practices, and cumulative production, Greater Aneth field, Utah........... 1-5

Figure 1-3. Land ownership and base map of wells in the Aneth Unit ................................. 1-5

Figure 1-4. Typical geophysical log of Desert Creek zone, Paradox Formation, from the Aneth

Unit E-118 well......................................................................................... 1-6

Figure 2-1. Geologic map of the Montezuma Creek and Navajo Canyon 7.5 minute quandrangles ................................................................................................ 2-3

Figure 2-2. Stratigraphic section exposed in the Aneth area ...................................................... 2-4

Figure 2-3. Small fault located south of the Aneth Unit.............................................................. 2-5

Figure 2-4. Deformation bands in porous sandstone of the Morrison Formation ....................... 2-6

Figure 2-5. Rose diagrams of deformation band orientations in the Aneth Unit........................ 2-7

Figure 3-1. Stratigraphic column for the Aneth Unit and surrounding areas .............................. 3-3

Figure 3-2. Structure contour map of the Jurassic Navajo Sandstone, a fresh water aquifer in the

Greater Aneth area...................................................................................... 3-4

Figure 3-3. Isopach map of the Navajo Sandstone .................................................................. 3-5

Figure 3-4. Structure contour map of the Permian DeChelly Sandstone..................................... 3-6

Figure 3-5. Isopach map of the DeChelly Sandstone ................................................................. 3-7

Figure 3-6. Structure contour map of the Desert Creek zone of the Pennsylvanian Paradox

Formation........................................................................................................... 3-8

Figure 3-7. Isopach map of the Desert Creek zone of the Paradox Formation........................... 3-9

Figure 3-8. Structure contour map of the Gothic shale of the Paradox Formation.................... 3-10

Figure 3-9. Isopach map of the Gothic shale of the Paradox Formation .................................... 3-11

Figure 4-1. Block diagram displaying depositional environments within the Desert Creek zone on the Aneth platform ....................................................................................... 4-8

Figure 4-2. Phylloid-algal buildup lithofacies ………......................................................... 4-9

Figure 4-3. Oolitic shoals lithofacies ....................................................................................... 4-10

Figure 4-4. Contact between quartz sandstone and possible exposure surface ......................... 4-11

Figure 4-5. Photomicrographs of primary porosity types ...................................................... 4-12

Figure 4-6. Typical diagenetic sequence through time for the Desert Creek zone based on thin section analysis

Figure 4-7. Photomicrographs of early diagenesis ........................................................ 4-14

Figure 4-8. Photomicrographs of post-burial diagenesis .......................................................... 4-15

Figure 4-9. Fractures, breccia, hydrothermal alteration near possible fault zone....................... 4-16

Figure 4-10. Examples of fracture types in the Desert Creek zone, Aneth Unit ....................... 4-17

Figure 4-11. Bar graphs showing relative numbers of fractures per foot by well ..................... 4-19

Figure 4-12. Aneth Unit permeability versus porosity cross-plots ............................................. 4-20

Figure 5-1. Interpreted geophysical log and core description, Aneth Unit No. H-117 well..... 5-11

Figure 5-2. Kerogen type determination of the Gothic shale................................................... 5-12

Figure 5-3. Kerogen quality determination of the Gothic shale ............................................... 5-12

Figure 5-4. Methane adsorption isotherm and adsorption Langmuir plots................................ 5-13 
Figure 5-5. Graph of x-ray diffraction data from the Gothic shale $5-14$

Figure 5-6. Photomicrographs and SEM images of argillaceous shale lithotype, Gothic shale

Figure 5-7. Medium magnification of corresponding LSCM images of a surface broken perpendicular to bedding in the Gothic shale $5-16$

Figure 5-8. Backscattered electron images of the Gothic shale. $5-17$

Figure 5-9. Photomicrographs and SEM images of argillaceous mudstone in Gothic shale.... 5-18 Figure 5-10. Photomicrographs and SEM images of silty calcareous/argillaceous mudstone in Gothic shale 5-19

Figure 5-11. Photomicrographs and SEM images of phosphatic argillaceous mudstone in Gothic shale..... $5-20$

Figure 5-12. Backscattered electron images of the Gothic shale. $5-21$

Figure 5-13. Additional views of the inclined shear fracture zone displayed on various BSE, XPL, and LSCM images. $5-22$

Figure 5-14. Mercury injection capillary pressure and pore aperture distributions $5-23$

Figure 5-15. Vertical and horizontal dynamic Young's modulus as a function of vertical and horizontal static Young's modulus, respectively...

Figure 5-16. Vertical and horizontal dynamic Poisson's ratio as a function of vertical and horizontal static Poisson's ratio, respectively.....

Figure 5-17. Results of unconfined compression stress testing. $5-26$

Figure 5-18. Continuous unconfined compressive strength profile of the Gothic shale core from the Aneth Unit No. H-117 well.

Figure 6-1. Location map of the Aneth unit showing the current WAG area, Phase I and Phase II areas, and areas of horizontal drilling.

Figure 6-2. Monthly oil, gas, and water production (1958 - 2006) from the A-214 and E-414 wells

Figure 6-3. Monthly oil produced, water injected (1958 - 2006) and gas-to-oil ratio for all wells in section 14 (WAG area). 6-6

Figure 6-4. Oil and gas production (1984 - 2006) shown as BOE and water production for wells in sections 25 and 26.

Figure 6-5. Comparison of BOE production from sections 25 and 26 where wells have horizontal laterals in the Deseret Creek and are under waterflood. $6-8$

Figure 6-6. Monthly oil produced, water injected (1958 - 2006), and gas-to-oil ratio (GOR) for all the wells in sections 17 and 18 (Phase I area) 6-9

Figure 6-7. Monthly oil produced, water injected (1958 - 2006), and gas-to-oil ratio (GOR) for all the wells in sections 13 and 14 (Phase II area)..... 6-10

Figure 8-1. Wells used for waterflood tracer test .......................................................... 8-2

Figure 8-2. The return curve for well D-214 for tracer 1,3,5-naphthalene trisulfonate............. 8-3 Figure 8-3. $\mathrm{CO}_{2}$-flood test site showing the tagged injectors and the breakthrough patterns .... 8-4 Figure 8-4. Return curves of PDCH tracer injected into C-414 .......................................... 8-5 Figure 8-5. Return curves of n-propanol tracer injected into C-414..................................... 8-5

Figure 8-6. Return curves of PMCP tracer injected into B-314 ......................................... 8-6

Figure 8-7. Return curves of isopropanol tracer injected into B-314 .................................. 8-6 Figure 8-8. Return curves of PDCH and isopropanol tracers injected into C-414 and produced in 
D-414

Figure 8-9. Return curves of PDCH and n-propanol tracers injected into C-414 and produced in D-414. 8-8

Figure 9-1. Soil $\mathrm{CO}_{2}$ monitoring equipment................................................................... 9-9

Figure 9-2. Sample plot of $\mathrm{CO}_{2}$ concentration data as the soil $\mathrm{CO} 2$ flux is being measured ......9.8

Figure 9-3. Aneth Phase-I CO2 flux monitoring site with node locations ............................... 9-9

Figure 9-4. Example of higher concentration of vegetation in a soil collar .......................... 9-10

Figure 9-5. Aneth Phase-II CO2 monitoring site with node locations ................................. 9-11

Figure 9-6. Summary of mean soil flux data for Phase I and Phase II sites .......................... 9-12

Figure 9-7. Trends in flux measurements sequenced.................................................... 9-13

Figure 10-1. Layout of self-potential monitoring network at the Aneth test site ................... 10-5

Figure 10-2. Photograph showing three one-meter holes for electrodes ............................... 10-6

Figure 10-3. Observed self-potential from May 2008 to May 2010 for three electrodes near the

C313 injection well

10-7

Figure 10-4. Observed self-potential from May 2008 to May 2010 for three electrodes near the C124 abandoned well 10-8

Figure 11-1. Photograph of the geophone deployment in well C313SE ............................... 11-8

Figure 11-2. Geometry of the monitoring well, injection well, theVSP source locations ........ 11-9

Figure 11-3. Trajectory of $\mathrm{CO}_{2}$ injector well $\mathrm{C} 313$.................................................... 11-10

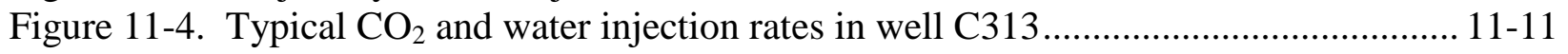

Figure 11-5. A velocity model constructed from a sonic well log..................................... 11-12

Figure 11-6. First-arrival times and arrival-time differences for 20-m movement of source.11-13

Figure 11-7. Velocity differences between inverted and initial velocity models .................. 11-14

Figure 11-8. Double-difference tomography results of source re-locations ......................... 11-15

Figure 11-9. Double-difference tomography results of the velocity difference profiles ........ 11-17

Figure 11-10. Comparison of repeat upgoing waves for balanced and unbalanced data ....... 11-19

Figure 11-11. Comparison of migration image differences for balanced and the original, unbalanced time-lapse data

Figure 11-12. Wave-equaltion migration images for tomography-based and surveyed source locations

Figure 11-13. Time-lapse migration image profiles for various offsets ............................. 11-23

Figure 11-14. Profiles showing significant changes in migration images within the reservoir from 2007 to 2008 and from 2008 to 2009

Figure 12-1. Map of study area and well field for western portion of the Aneth Unit .......... 12-10

Figure 12-2. P-wave sonic log and velocity model..................................................... 12-11

Figure 12-3. Aneth event count for 1-year monitoring period........................................... 12-12

Figure 12-4. Example of Aneth microseismic waveforms ............................................. 12-13

Figure 12-5. P-wave arrivals observed over lower portion of the geophone array................ 12-14

Figure 12-6. P-wave raypaths for a source beneath the Desert Creek reservoir.................... 12-14

Figure 12-7. Microseismic source locations ................................................................ 12-15

Figure 12-8. RMS residuals and converged depths versus Vp/Vs..................................... 12-16

Figure 12-9. Reflected phases for microseismicity: raypaths, observations and synthetics... 12-16 
Figure 12-10. Time-space development of Aneth microseismicity, south group.................. 12-17

Figure 12-11. Gutenberg-Richter recurrence plot for Aneth microseismicity...................... 12-18

Figure 12-12. Microseismicity and Desert Creek injection and production volumes ............ 12-18

Figure 12-13. Microseismicity and salt water disposal volumes ..................................... 12-19

Figure 12-14. Microseismicity and the June 6, 2008 Bluff M3.7 earthquake...................... 12-20

Figure 13-1. Location of Aneth Unit ............................................................................ 13-3

Figure 13-2. Location of wells with selected neutron porosity logs.................................... 13-4

Figure 13-3. Upscaled neutron porosities .................................................................. 13-6

Figure 13-4. Measured ambient porosity and log porosity estimates from H-117 well .......... 13-7

Figure 13-5. Measured ambient porosity and log porosity estimates from E-418 well........... 13-8

Figure 13-6. Cross-plot of permeability and porosity measurements................................. 13-9

Figure 13-7. Stratigraphic distribution of geologic formations within the Aneth Unit ......... 13-10

Figure 13-8. Grid settings for the Desert Creek formation............................................... 13-10

Figure 13-9. Simulated upscaled porosity fields within the Aneth unit model boundary ...... 13-11

Figure 13-10. Permeability field based on the log-linear relationship between permeability and

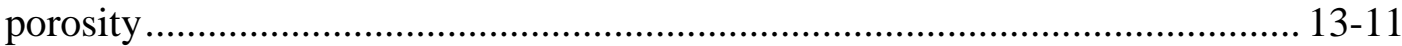

Figure 13-11. Porosity field after orthogonal grid conversion and upscaling simulator in the Aneth Unit model boundary ................................................................... 13-12

Figure 13-12. Porosity field prepared for the numerical simulation after orthogonal grid

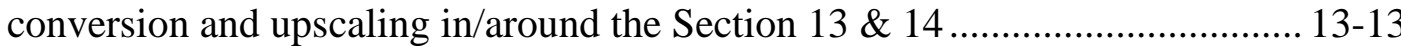

Figure 13-13. Permeability field prepared for the numerical simulation after orthogonal grid conversion and upscaling in/around the Section $13 \& 14 \ldots \ldots \ldots \ldots \ldots \ldots \ldots \ldots \ldots . . . . . . . .13-13$

Figure 13-14. Porosity distribution represented on coarse and fine grid ............................. 13-15

Figure 13-15. Pressure profiles at the end of the injection period ( 0.5 years) ...................... 13-16

Figure 13-16. Saturation profiles at the end of the injection period (100 years) .................. 13-17

Figure 13-17. Pressure iso-surface drawn at the end of injection (1 year) ........................... 13-18

Figure 13-18. Pressure profile at 1 year, Case 1 (iso-surface, $p=44.2 \mathrm{MPa}$ ) ........................ 13-19

Figure 13-19. Pressure profile at 1 year, Case 2 (iso-surface, $p=44.2 \mathrm{MPa}$ ) ........................ 13-20

Figure 13-20. Pressure profile at 1 year, Case 2 (iso-surface, $p=35 \mathrm{MPa}$ ) .......................... 13-20

Figure 13-21. Pressure profile at 1 year, Case 3 (iso-surface, $\mathrm{p}=44.2 \mathrm{MPa}$ ) ........................ 13-21

Figure 13-22. Saturation profile at 100 years, Case 4, total injection rate of $0.25 \mathrm{MMt} / \mathrm{yr} . . . .13-21$

Figure 13-23. Pressure and saturation profile of Case 1 with artificially increased permeability .................................................................................... 13-22

Figure 13-24. Pressure and saturation profile of Case 2 with artificially increased

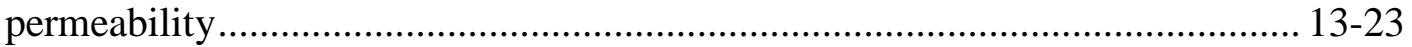

Figure 13-25. Pressure iso-surface at $28 \mathrm{MPa}$ of the 6-well configuration .......................... 13-24

Figure 13-26. Hysteric S-P $\mathrm{P}_{\mathrm{c}}-\mathrm{K}_{\mathrm{r}}$ relations ................................................................. 13-27

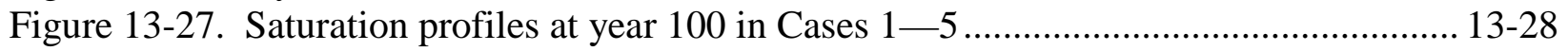

Figure 13-28. Dissolved $\mathrm{CO}_{2}$ Concentration at year 100 in Case 1.................................. 13-29

Figure 13-29. $\mathrm{CO}_{2}$ phase distribution during simulation period in Case 1.......................... 13-29

Figure 13-30. $\mathrm{CO}_{2}$ mass in the SC phase during simulation period ................................... 13-30

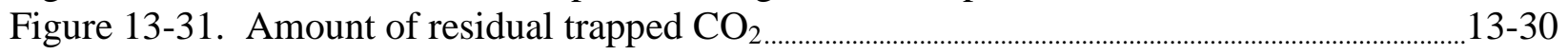




\section{TABLES}

Table 5-1. Basic geochemical measurements from the Gothic shale .................................... 5-9

Table 5-2. Methane adsorption isotherm for the Gothic shale............................................. 5-9

Table 5-3. Summary of petrophysical reservoir measurements from the Gothic shale............ 5-10

Table 5-4. Summary of multistress anisotropy measurements from the Gothic shale ............ 5-10

Table 8-1. Tracers used in the $\mathrm{CO}_{2}$-flood tracer test ..................................................... 8-4

Table 9-1. Aneth Phase I soil $\mathrm{CO}_{2}$ flux data................................................................... 9-6

Table 9-1. Aneth Phase II soil $\mathrm{CO}_{2}$ flux data................................................................... 9-7

Table 11-1. Inversion results VSP source locations using double-difference tomography ...... 11-7

Table 12-1. Microseismic median relative source locations errors and mean RMS residuals . 12-4

Table 13-1. Summary of well log digitizing work........................................................... 13-5

Table 13-2. Summary of ambient porosity and gas permeability measurements from core plug

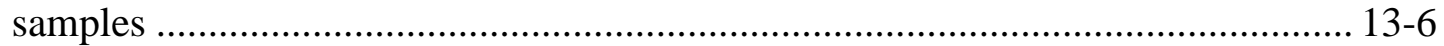

Table 13-3. Volume averaged porosity and permeability.............................................. 13-14

Table 13-4. Well location and depth......................................................................... 13-15

Table 13-5. Injection rate distributions among 14 wells.................................................. 13-18

Table 13-6. Maximal pressure vs. number of injection wells ........................................... 13-24

Table 13-7. WAG schemes investigated....................................................................... 13-27

Table 13-A1. Petrophysical data from core plug samples .............................................. 13-A1

Table 13-A2. Well logs and digitizing work in the Aneth Unit....................................... 13-A6 


\title{
CHAPTER 1 \\ INTRODUCTION \\ OF
}

\section{SURFACE AND SUBSURFACE GEOLOGICAL CHARACTERIZATION OF THE ANETH UNIT, GREATER ANETH FIELD, PARADOX BASIN, UTAH}

\author{
by \\ Thomas C. Chidsey, Jr., \\ Utah Geological Survey
}

\section{Overview}

Greater Aneth oil field, Utah's largest oil producer, was discovered in 1956 and has produced over 455 million barrels (72 million $\mathrm{m}^{3}$ ) of oil (Utah Division of Oil, Gas, and Mining, 2010). Located in the Paradox Basin of southeastern Utah (figure 1-1) within the Colorado Plateau, Greater Aneth is a stratigraphic trap, with fractures and small faults. Because it represents an archetype of a mature western U.S. oil field, Greater Aneth was selected to demonstrate combined enhanced oil recovery (EOR) and carbon dioxide $\left(\mathrm{CO}_{2}\right)$ sequestration under the auspices of the Southwest Regional Partnership on Carbon Sequestration, sponsored by the U.S. Department of Energy.

Greater Aneth produces oil and gas from the Pennsylvanian (Desmoinesian) Paradox Formation. The Paradox forms a complex reservoir representing a variety of depositional environments (open-marine shelf, shallow-marine beach and shoals, algal mounds, and lowenergy restricted shelf) that produce significant heterogeneity. There is evidence of hydrothermal dolomite, brecciation, and minor faults that may affect fluid flow.

Greater Aneth field is divided into four units (figure 1-2). The 25-square-mile $\left(65-\mathrm{km}^{2}\right)$ Aneth Unit (T. 40 S., R. 23 to 24 E., Salt Lake Baseline and Meridian [SLBL\&M]) in the northwestern part of Greater Aneth field had no significant $\mathrm{CO}_{2}$ injection prior to the project. The unit encompasses an area of $\sim 27$ miles $\left(\sim 70 \mathrm{~km}^{2}\right)$ (figure 1-3). The majority of the unit is located on Navajo Nation land, except for all or parts of sections 11, 13, 14, 23, and 24 of T. 40 S., R. 23 E., SLBL\&M, which are U.S. Bureau of Land Management (BLM) parcels (figure 1-3). Production had declined by $50 \%$ over the past 20 years in spite of waterflood and horizontal drilling projects. However, the Aneth Unit has produced 149 million barrels ( 24 million $\mathrm{m}^{3}$ ) of the estimated 450 million barrels $\left(71.5\right.$ million $\mathrm{m}^{3}$ ) of oil in place-a $33 \%$ recovery rate (Babcock, 1978a; Utah Division of Oil, Gas, and Mining, 2010). The large amount of remaining oil, combined with a nearby $\mathrm{CO}_{2}$ pipeline, made the Aneth Unit ideal to (1) demonstrate both $\mathrm{CO}_{2}$ storage capability and EOR by flooding the reservoir with the $\mathrm{CO}_{2}$, and (2) extensively monitor the effects of injection from reservoir to surface. Therefore the Aneth Unit, operated by Resolute Natural Resources and Navajo Nation Oil \& Gas Co., Inc., was selected as a demonstration site for the Southwest Regional Partnership on Carbon Sequestration - Phase II: Field Demonstrations project. The $\mathrm{CO}_{2}$ injection pilot site was located in sections 13 and 14 of T. 40 S., R. 24 E., SLBL\&M (figures 1-2 and 1-3).

This report provides an overview of the Aneth Unit demonstration sequestration site and 
how its geology affects sequestration operations and engineering strategies. It is an abridged version of a detailed Utah Geological Survey (UGS) Final Report which includes numerous appendices and plates (Chidsey, 2009). The following chapters summarize the UGS's research and results for the project including (1) mapping the surface geology, (2) description of the local stratigraphy, (3) mapping the reservoir, seals, and overlying aquifers, (4) geological characterization of the reservoir, (5) geochemical, petrographic, and geomechanical description of the seals, and (6) evaluation of production history.

\section{Greater Aneth Field Synopsis}

The Greater Aneth field stratigraphic trap produces primarily from the Desert Creek zone sealed by the organic-rich, overlying Gothic shale, both within the Paradox Formation (figure 14). Within the field, the Desert Creek reservoir zone is divided into two subzones: a lower interval composed predominantly of phylloid-algal buildup lithofacies, and an upper interval composed of oolitic-peloidal calcarenite lithofacies (Peterson and Ohlen, 1963; Babcock, 1978a, 1978b, 1978c, 1978d; Peterson, 1992; Moore and Hawks, 1993). These subzones create a westnorthwest-trending reservoir buildup. The primary reservoir at Greater Aneth field consists of limestone (algal boundstone/bafflestone and oolitic, peloidal, and skeletal grainstone and packstone) and finely crystalline dolomite.

The net reservoir thickness of the Desert Creek zone at Greater Aneth is 50 feet $(15 \mathrm{~m})$ over a 48,260-acre (19,530 ha) area. Porosity averages $10 \%$ in interparticle, moldic, and intercrystalline networks enhanced by fractures; permeability averages 10 millidarcies (mD), ranging from 3 to $30 \mathrm{mD}$. The drive mechanism is fluid expansion and solution gas; original water saturation was $24 \%$. The bottom-hole temperature averages $125^{\circ} \mathrm{F}\left(52^{\circ} \mathrm{C}\right)$ (Peterson and Ohlen, 1963; Babcock, 1978a, 1978b, 1978c, 1978d; Peterson, 1992; Moore and Hawks, 1993).

The produced oil is a dark green, paraffinic crude. The oil was originally sweet but now is sour due to sulfate-reducing bacteria introduced during waterflood operations. The API gravity of the oil ranges from $40^{\circ}$ to $42^{\circ}$; the original gas-oil ratio was 665 cubic feet/bbl. The viscosity of Greater Aneth oils ranges 0.53 to 0.54 centipoise. The pour point of the crude oil is $10^{\circ} \mathrm{F}\left(-12^{\circ} \mathrm{C}\right)$. The average weight percent sulfur and nitrogen of produced hydrocarbon liquids are 0.2 and 0.04, respectively (Stowe, 1972; Peterson, 1992). Greater Aneth reservoirs produce associated gas that is fairly uniform in composition, averaging $62 \%$ methane, $18 \%$ ethane, $11 \%$ propane, $5.5 \%$ butane and iso-butane, $2.5 \%$ pentane and iso-pentane, less than $1 \%$ hexane and higher fractions, $0.2 \%$ carbon dioxide, and occasionally a trace of hydrogen sulfide and helium (Stowe, 1972; Moore and Hawks, 1993). The gas heating value averages 1450 British thermal units/cubic foot (Btu/ $\left.\mathrm{ft}^{3}\right)$ (1.53 million joules). The total dissolved solids in the produced water ranges from 103,000 to $304,000 \mathrm{mg}$; the resistivity of the water is 0.35 ohm-meters at formation temperature (Peterson, 1992).

Greater Aneth field was discovered in February 1956 with the completion of the Texaco \#1 Navajo C well, NW1/4NE1/4 section 23, T. 40 S., R. 24 E., SLBL\&M (figure 1-2), which had an initial flowing potential (IFP) of 568 bbls of oil per day (BOPD) $\left(90 \mathrm{~m}^{3}\right.$ ) and 4376 thousand cubic feet of gas per day (124 thousand cubic meters per day [MCMPD]). The original reservoir field pressure was 2170 pounds per square inch (psi [14,960 kPa]) (Moore and Hawks, 1993). Currently, 453 producing (or shut-in) wells and 112 abandoned producers are in the field. Cumulative production as of April 1, 2010, was 455,391,399 bbls of oil (72,407,232 $\left.\mathrm{m}^{3}\right), 400.2$ billion cubic feet of gas (BCFG) (11.3 billion cubic meters of gas [BCMG]), and 1,576,798,920 
bbls of water (BW) $\left(250,711,028 \mathrm{~m}^{3}\right)$ (Utah Division of Oil, Gas, and Mining, 2010). In place total oil reserves for Greater Aneth field is estimated at 1100 million barrels (175 million $\mathrm{m}^{3}$ ) (Babcock, 1978a, 1978b, 1978c, 1978d; Peterson, 1992).

Waterflood operations are used in all four Greater Aneth field units (figure 1-2) - the largest waterflood program in Utah. There are about 300 water injection wells in the field (over 500 injection wells in the past). Both fresh and produced water are used. The waterflood programs at Greater Aneth field units utilizing vertical wells will recover 15 to $20 \%$ of the original oil in place (OOIP) or approximately 230 million BO (37 million $\mathrm{m}^{3}$ ) (Babcock, 1978a, 1978b, 1978c, 1978d; Peterson, 1992).

Carbon dioxide flooding began in the McElmo Creek Unit in 1985 (figure 1-2). The production response was evident after between one and two years through a water-alternatinggas (WAG) program. The Devonian Ouray Formation and Mississippian Leadville Limestone, at McElmo Dome field on the eastern edge of the Paradox Basin in southwest Colorado, supply $\mathrm{CO}_{2}$ to Greater Aneth field (and Permian Basin fields) via an 8-inch pipeline (figures 1-1). A pilot $\mathrm{CO}_{2}$ flood using horizontal wells (lateral) was conducted in the eastern part of the Aneth unit in 1998. Incremental recovery from $\mathrm{CO}_{2}$ flooding is estimated at 33 million $\mathrm{BO}$ (5.3 million $\mathrm{m}^{3}$ ) or an incremental recovery efficiency of $9.3 \%$.

An extensive and successful horizontal drilling program has been conducted in Greater Aneth field. These drilling programs were carried out primarily in the Aneth (in 1996) and Ratherford (in 1994) Units in the northwest and southeast parts of the field, respectively (figure 1-2). Northwest-southeast-directed horizontal wells, perpendicular to the fault/fracture zones, have successfully increased production in these units. 


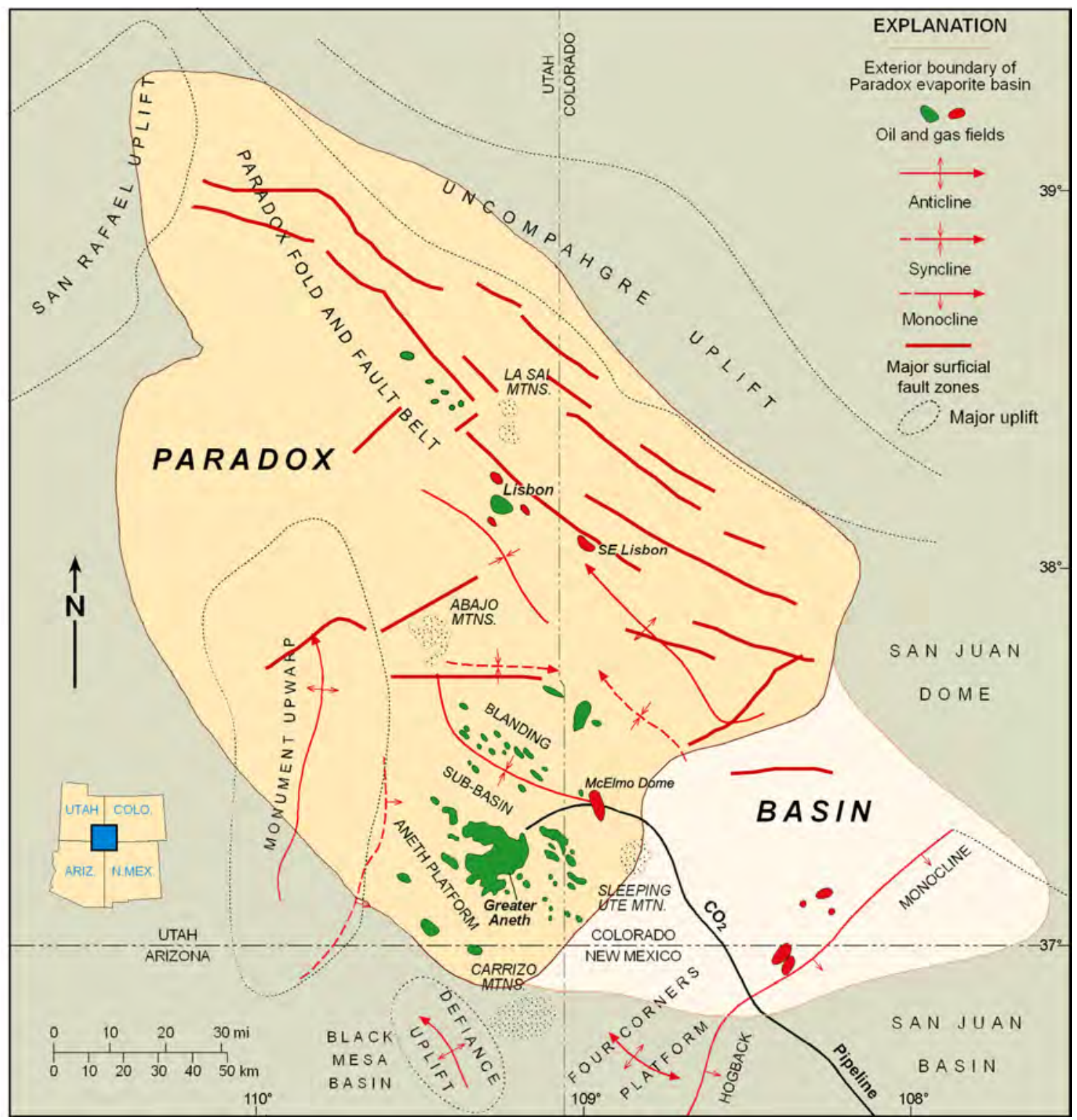

Figure 1-1. Oil and gas fields in the Paradox Basin of Utah, Colorado, and Arizona (modified from Kitcho, 1981; Harr, 1996). The Paradox Formation play is shaded yellow. 


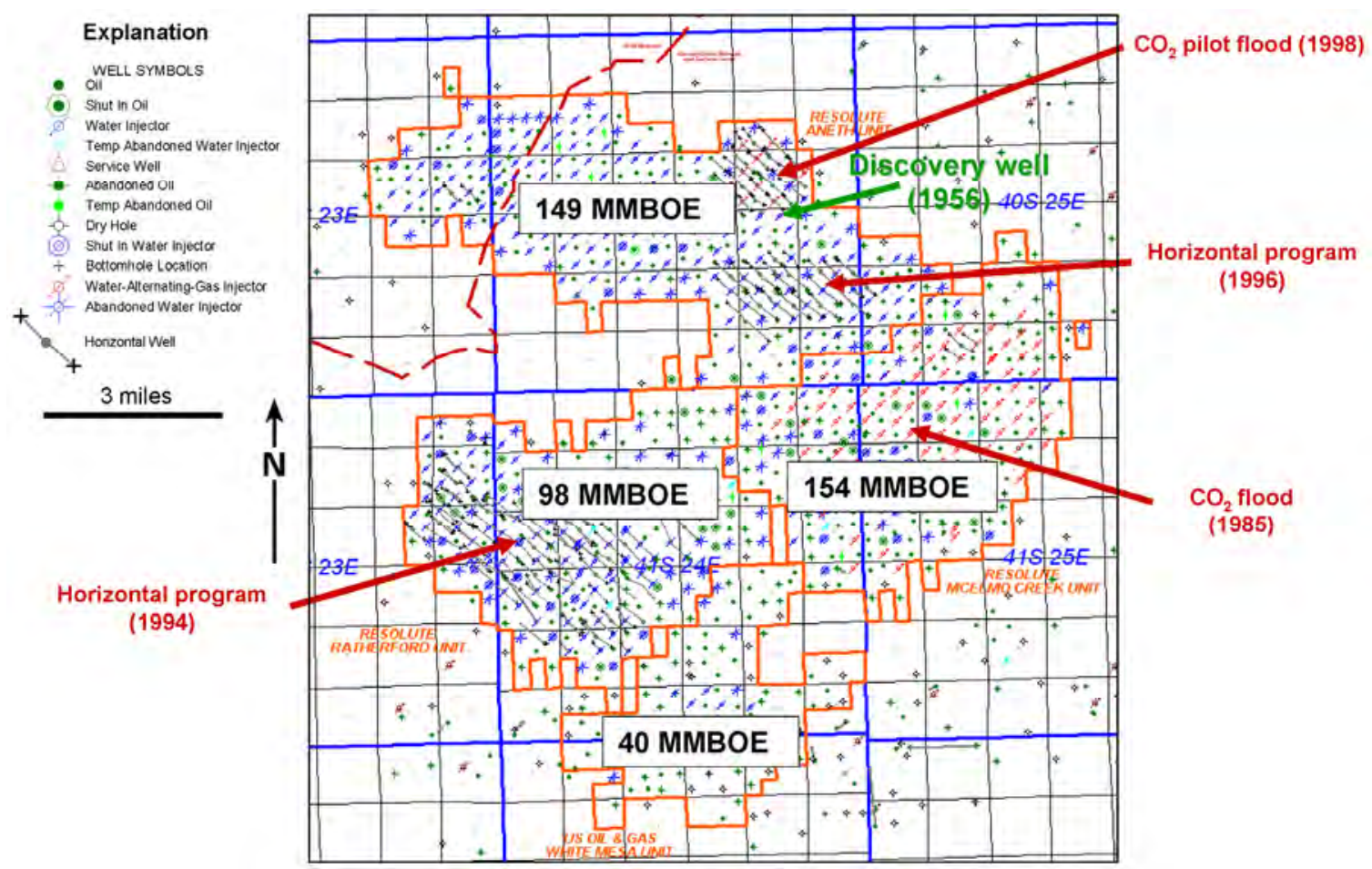

Figure 1-2. Units, best practices, and cumulative production, Greater Aneth field, Utah. After Resolute Natural Resources unpublished map (2007).

\section{ANETH UNIT, SAN JUAN COUNTY,UTAH}
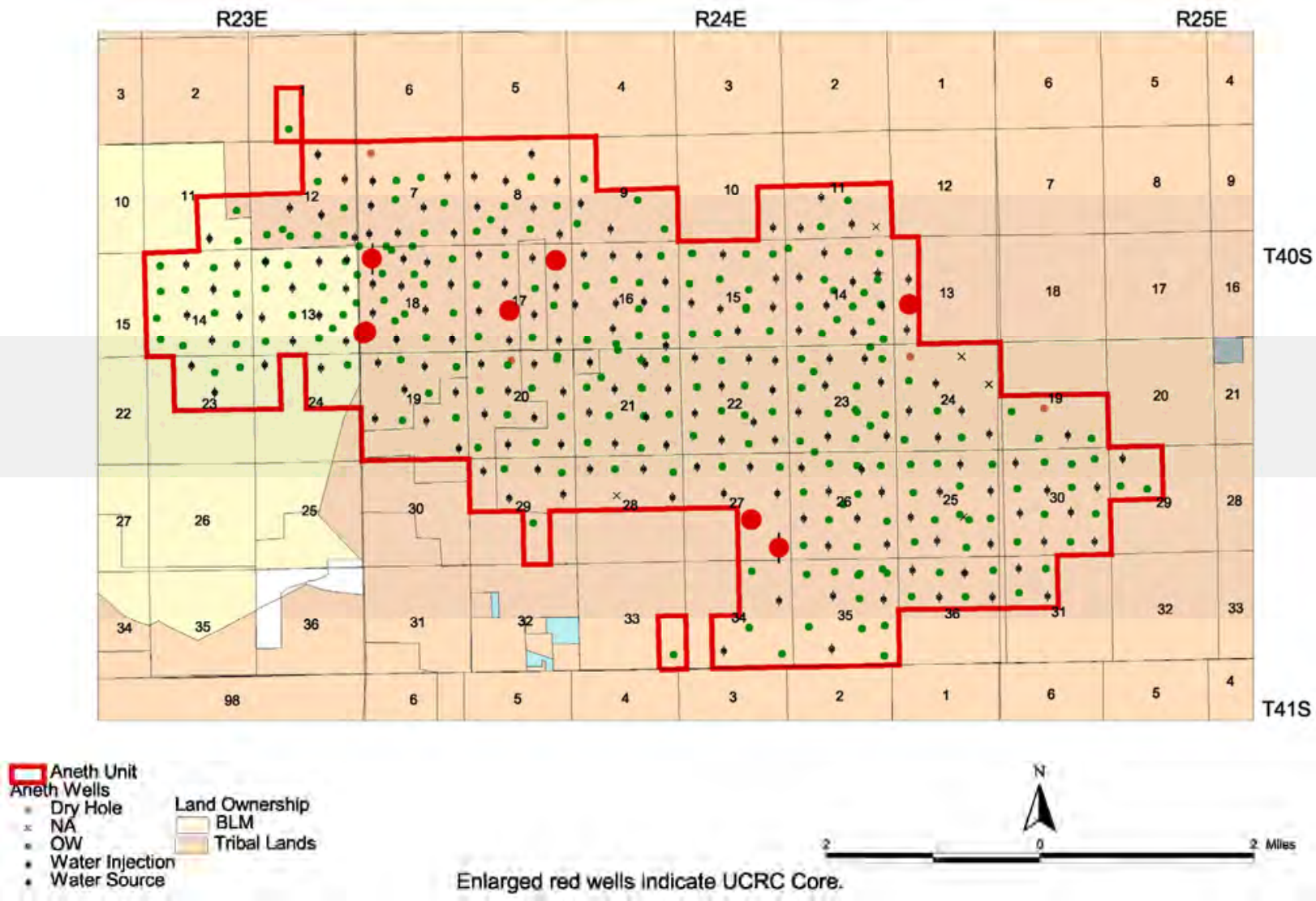

Figure 1-3. Land ownership and base map of wells in the Aneth Unit. Also displayed are wells from which cores were described as part of this study. 


\section{Greater Aneth Field}

Texaco Inc.

Aneth Unit E-418

SW SW Sec. 18 T. 40 S R. 24E

San Juan County, Utah

KB 5070

\section{Cumulative Oil Production $=233,000$ BO}

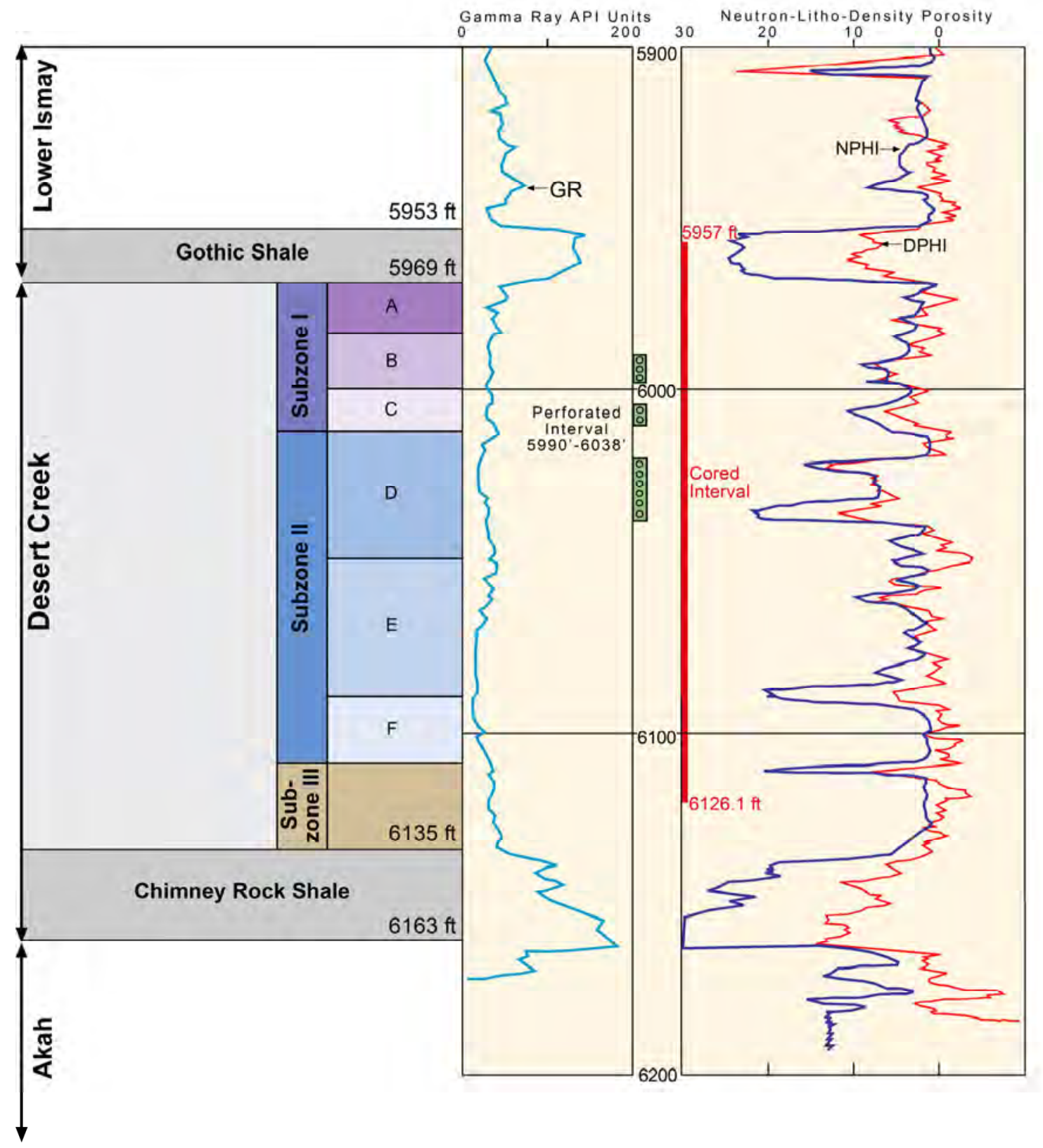

Figure 1-4. Typical gamma ray-compensated neutron/density log for the Desert Creek zone of the Paradox Formation from the Aneth Unit No. E-418 well (NW1/4SW1/4SW1/4 section 18, T. 40 S., R. 24 E., SLBL\&M), Greater Aneth field, San Juan County, Utah. Producing (perforated) interval between depths of 5990 and 6038 feet. 


\title{
CHAPTER 2 SURFACE GEOLOGY
}

\author{
by \\ Craig D. Morgan, Stephanie Carney, and Michael Vanden Berg, \\ Utah Geological Survey

\section{Geologic Map of the Aneth Area, Montezuma Creek and Navajo Canyon Quandrangles}

The surface geology of the Aneth Unit area (figure 2-1; plate 1 in the UGS Final Report [Chidsey, 2009]) was mapped (excluding detailed Quaternary deposits) with special emphasis on (1) fracture patterns, types, and orientation, and (2) zones of possible alteration by hydrothermal and $\mathrm{CO}_{2}$-bearing solutions. Special emphasis was given to structural elements that could act as potential pathways for migration of $\mathrm{CO}_{2}$ from the injection site or from the reservoir after injection. A stratigraphic section from near the base of the Recapture Shale Member of the Jurassic Morrison Formation through the Cretaceous Dakota Sandstone was measured and described to provide detailed information about the lithology of the bedrock geology in the Aneth Unit (see Chidsey, 2009). The section helped to define the bed boundaries used in the geologic map of the area.

The Montezuma Creek and Navajo Canyon quadrangles, which contain the Aneth Unit, consist of Jurassic Morrison through Cretaceous Dakota Sandstone outcrops and Quaternary sediments (figures 2-1 and 2-2). The Recapture Shale and Salt Wash Members of the Morrison Formation are easily eroded and form low-lying hills of red shale and lenticular channel sandstone beds. The Brushy Basin Member of the Morrison Formation and the Burro Canyon Formation form steep variegated slopes beneath the Dakota Sandstone, which caps most of the mesas in the area. The Quaternary deposits in the Aneth area are very complex and were not mapped in detail.

\section{Structural Elements}

The Aneth area lies on the Aneth platform along the southern flank of the Blanding subbasin of the Paradox Basin. Strata in the Aneth area dip $<5^{\circ}$ to the northeast and are relatively structurally undeformed. Dips appear to flatten slightly in the northern portion of the Aneth Unit, perhaps reflecting a deeper underlying structure.

\section{Faulting}

No large-displacment, laterally extensive faults were found that offset surface strata in the Aneth Unit. Several lineaments were observed on aerial photographs, but no evidence of these potential faults (or regional jointing) was found at the surface. A few small, localized, normal faults in the Morrison Formation were identified, but displacements were minor and they are interpreted to be very shallow localized slope failure. For example, two very small, parallel faults, with less than 6 feet $(2 \mathrm{~m}$ ) of slip, were located in section 26, T. 40 S., R. 23 E., SLBL\&M (figure 2-3). These faults occurred in a porous sandstone unit of the Morrison and both had a very fine grained, clay-like fault gouge (figure 2-3). These small faults are confined to the one sandstone unit and can only be traced less than 15 feet $(5 \mathrm{~m})$ along strike. 


\section{Fractures}

Based on our field reconnaissance we felt that fractures we observed at the surface were not reliable indicators of deeper fracture orientations and intensity. The surface strata in the Aneth area are dominantly shale and siltstone with interbedded fluvial channel sandstone deposits. The sandstones are extensively fractured and often form large blocks that eventually move down shale slopes. The majority of the surface fractures appear to be related to valley incision as a result of uplift and erosion of the soft underlying and overlying shale, and probably do not reflect the type of fracturing that could be expected in the subsurface in more competent units. We investigated the Bluff Sandstone in Recapture Creek (a thick, competent member) west of the Aneth Unit and found only rare fracturing.

\section{Deformation Bands}

The dominant structural feature observed at the surface in the Aneth Unit is deformation bands (figure 2-4). Deformation bands are miniature, fault-like fractures that occur in highly porous ( $>15 \%$ porosity) rocks and sediment such as sandstone and sands (Fossen and Bale, 2007; Torabi and Fossen, 2009). Bands are typically only a few millimeters in width, but can reach lengths of several feet to hundreds of feet long. They typically accommodate displacement on the scale of millimeters to centimeters and occur as single bands or in clusters. Large clusters of deformation bands can usually be linked to the occurrence of large offset faults, though each band within the cluster does not necessarily represent a slip-surface (Fossen and others, 2007). Deformation bands can form in response to tectonic stresses, sediment burial and compaction, soft-sediment deformation, and other events that cause localized strain (Mollema and Antonellini, 1996; Davis, 1999).

Numerous sets of deformation bands were recognized in the Aneth Unit area during the surface geological mapping. Therefore, special emphasis was given to the study of deformation bands in order to determine if any of these structural elements could act as potential pathways or barriers to migration of $\mathrm{CO}_{2}$ from the injection site or from the reservoir after injection. Detailed structural analysis of deformation bands in sandstones of the Morrison Formation and Dakota Sandstone was conducted. More than 1100 deformation bands were described and their orientations measured using a Brunton compass. The deformation band trends were then analyzed by creating rose diagrams and plotting them on a map of the area (figure 2-5). A rose diagram was made for each 1 square mile section of the Aneth Unit where bands were documented.

Deformation bands in the Aneth Unit occur mostly in the porous sandstone of the Salt Wash and Brushy Basin Members of the Morrison Formation and, less often, in the Dakota Sandstone. Individual bands are only a few millimeters in width, but some are greater than several feet long. They occur as long, single bands, as clusters of long, parallel sets of two or more (up to 10-15) widely spaced bands, and as zones of closely spaced (inch scale) parallel sets of bands (figure 2-4). We observed no obvious indications of slip or movement (offset or slickensides) on any of the bands documented in the study area. The overall trend of deformation bands in the entire Aneth Unit is northwest-southeast (figure 2-5), though trends are more random in the southeast part of the unit. In the vicinity of the pilot injection site, section 13 of T. 40 S., R. 23 E., SLBL\&M, deformation bands have an average trend of $99^{\circ}$. 


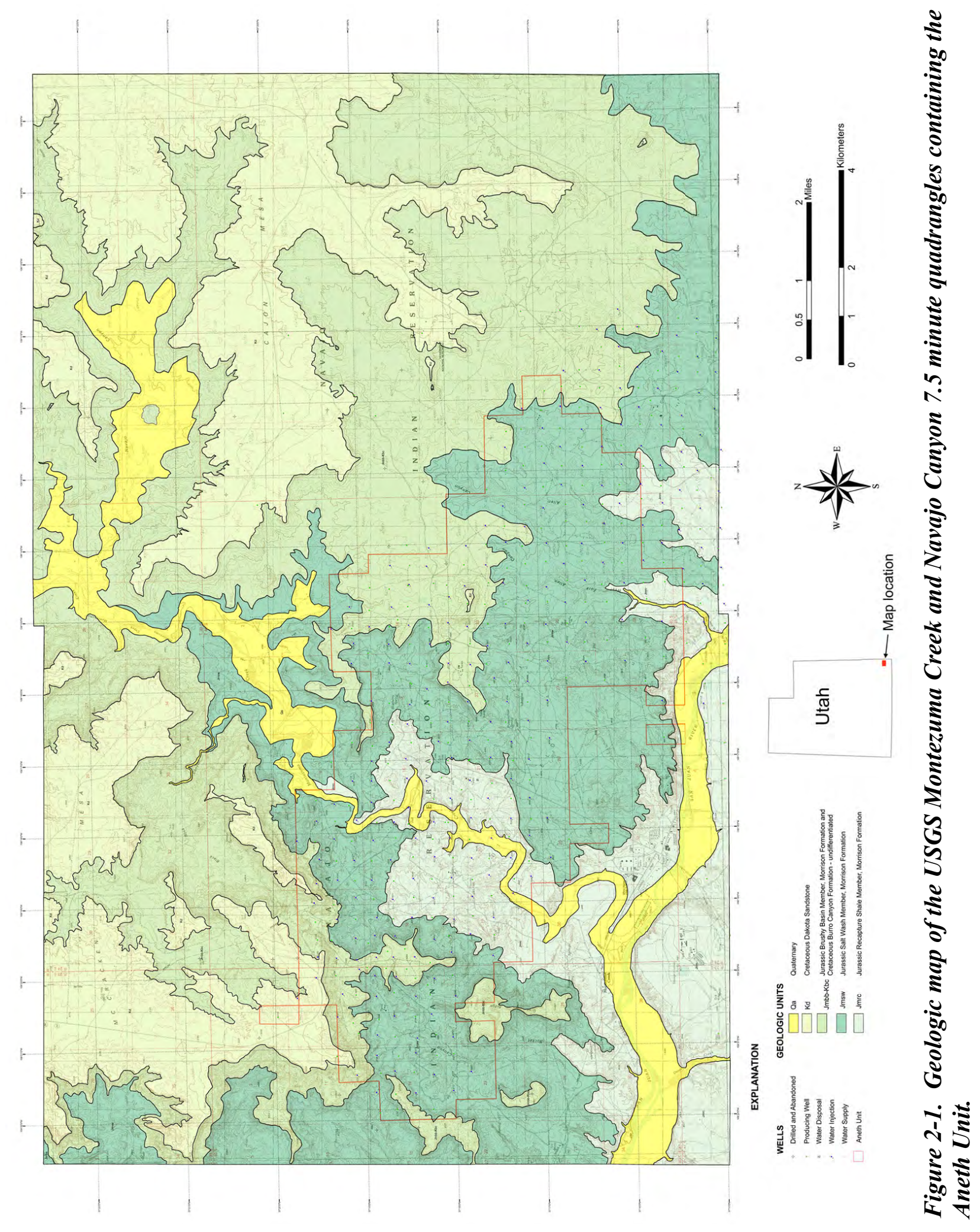




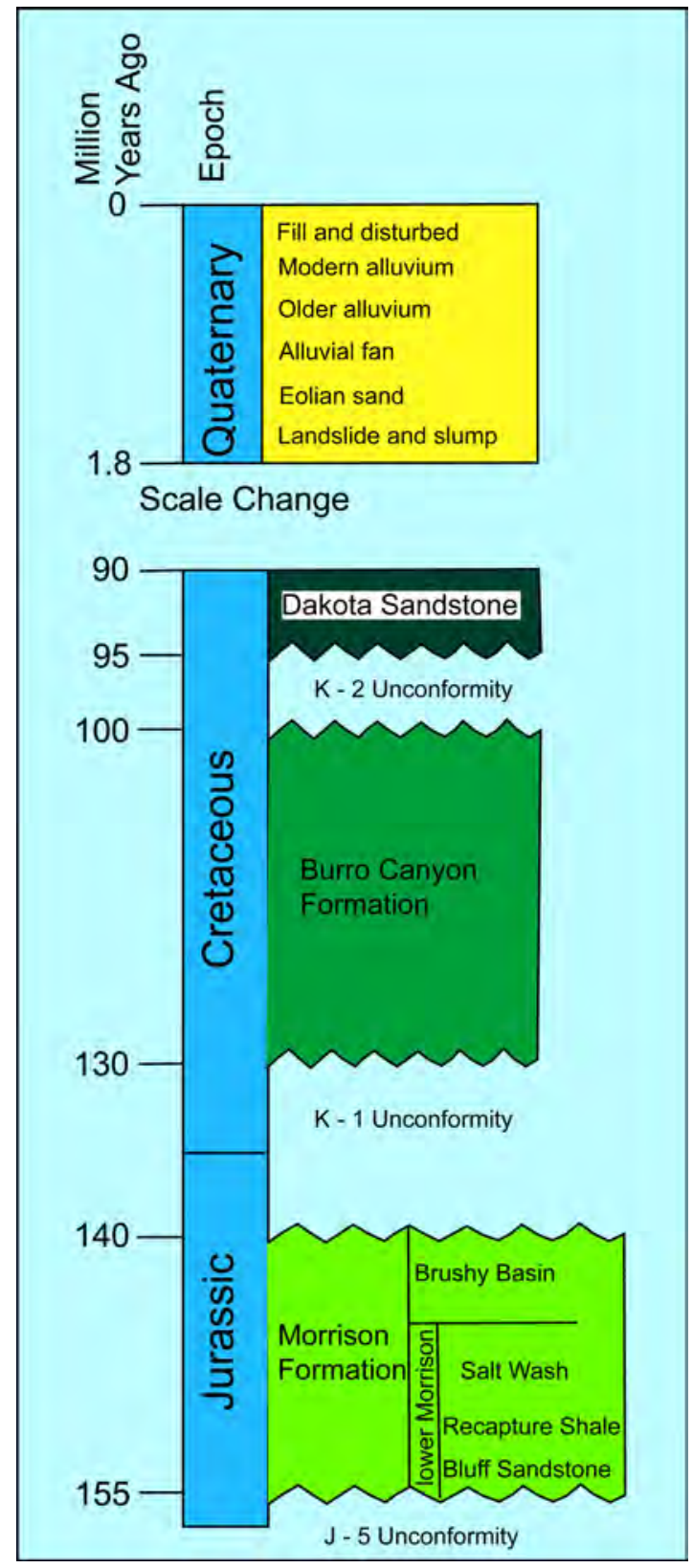

Figure 2-2. Stratigraphic column of units exposed in the Aneth area, San Juan County, Utah. 


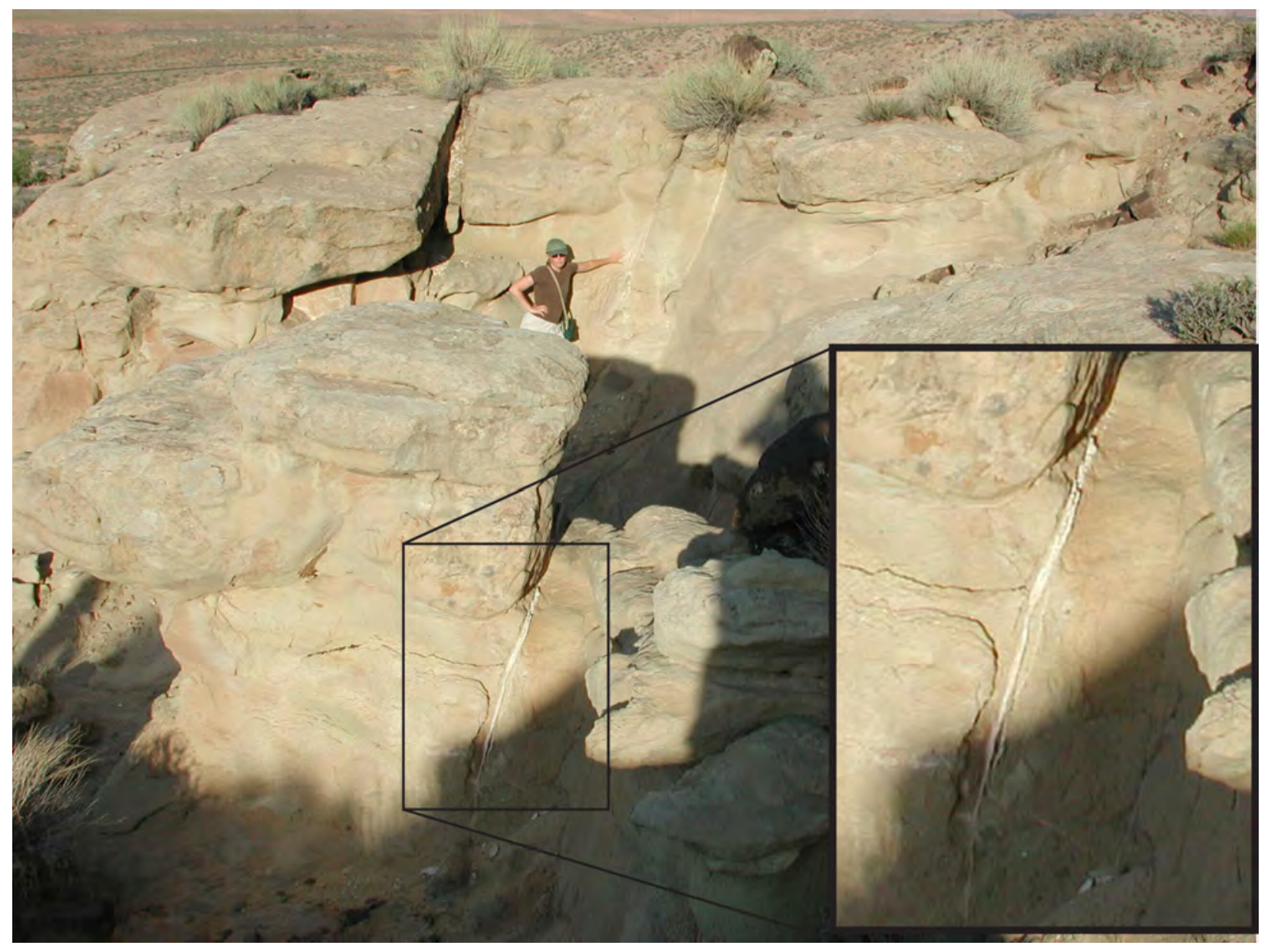

Figure 2-3. Photograph of small (<6 feet [2 m] slip) fault located south of the Aneth Unit. Inset is close up of clay-like gouge within the fault. 

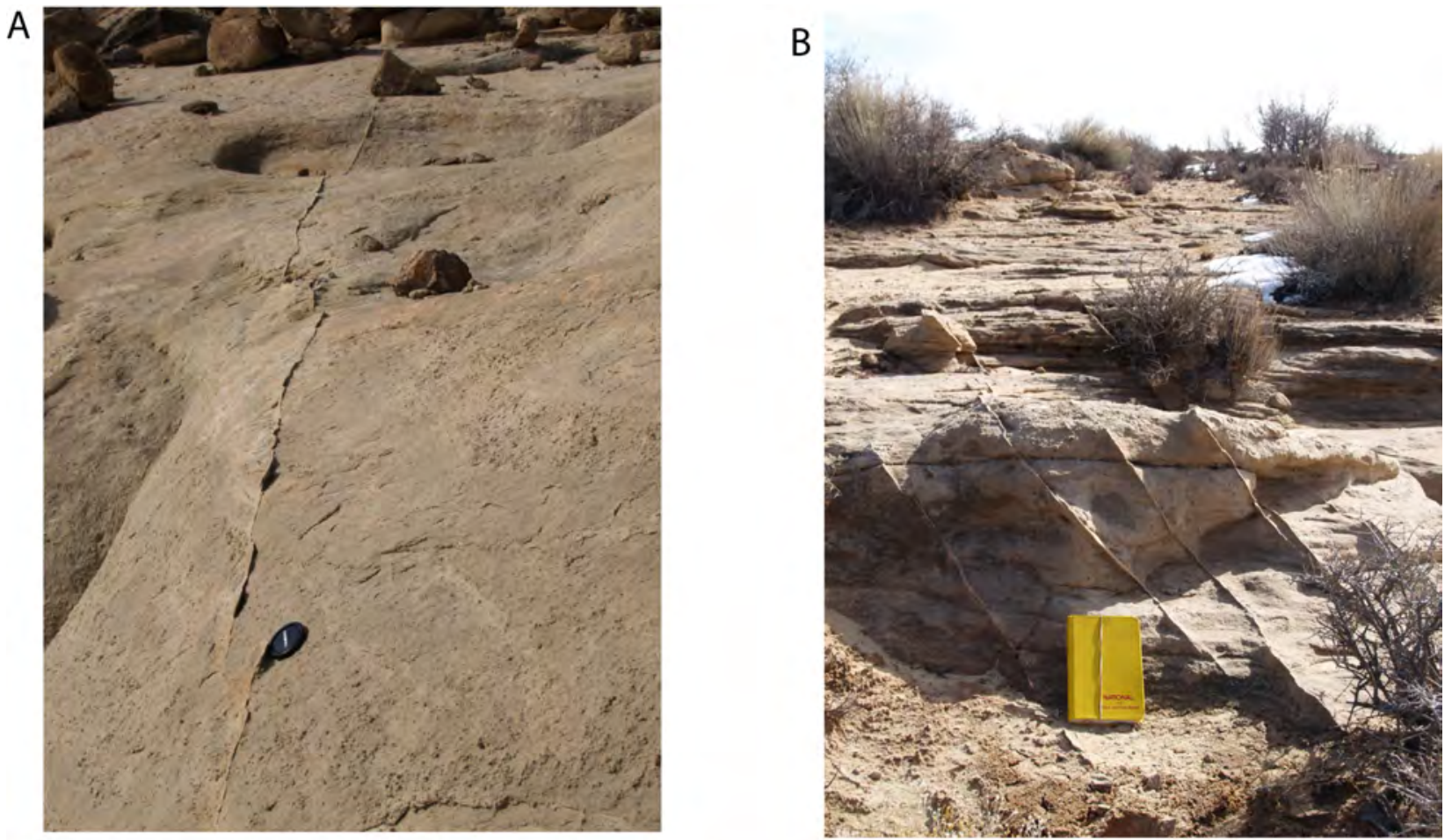

C

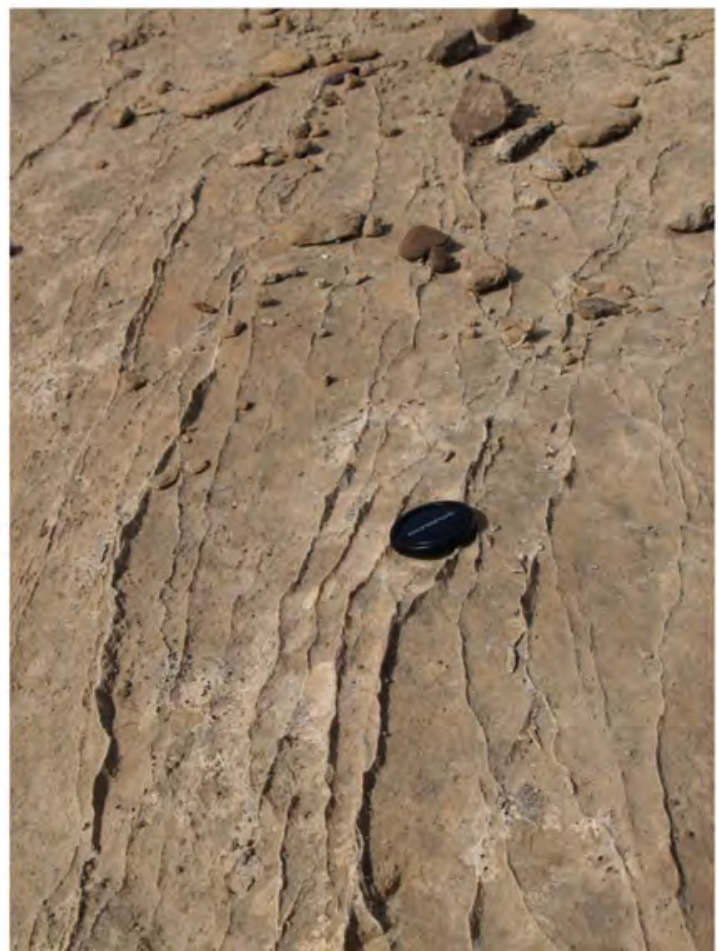

Figure 2-4. Photographs showing deformation bands in porous sandstone of the Morrison Formation. (A) A single band several tens of feet long. Camera lenscap for scale. (B) Parallel set of bands. (C) Set of closely spaced, mostly parallel bands. 


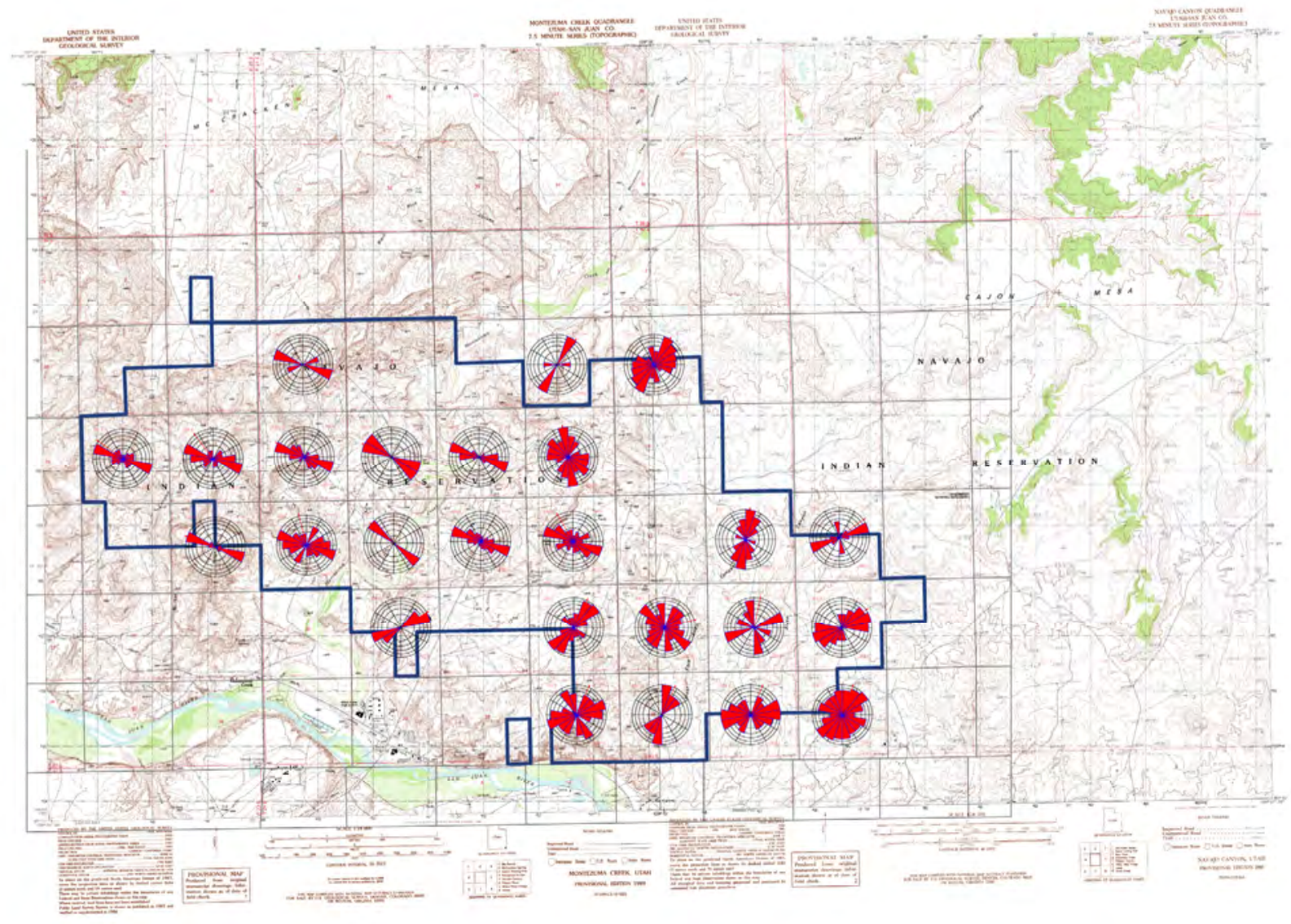

Figure 2-5. Rose diagrams of deformation band orientations, grouped by township/ range sections. The boundary of the Aneth Unit is in blue. 


\title{
CHAPTER 3 SUBSURFACE STRUCTURAL AND THICKNESS MAPPING
}

\author{
by \\ Stephanie Carney, \\ Utah Geological Survey
}

\section{Introduction}

Structure contour and isopach maps were created to gain insight into the geological structure and depositional trends in the $\mathrm{CO}_{2}$ flood/sequestration demonstration reservoir, the seal of the reservoir, and the aquifers of Aneth Unit. These maps were used to identify undetected faults or folds in the subsurface that could pose potential risk to long term sequestration of $\mathrm{CO}_{2}$ in the Aneth Unit reservoir. Maps were produced for the Desert Creek, Gothic shale, and Ismay zones of the Pennsylvanian Paradox Formation and the Jurassic Navajo and Permian DeChelly Sandstones (figure 3-1). The Desert Creek zone is the major producing oil reservoir at Greater Aneth field and is the primary $\mathrm{CO}_{2}$ sequestration target (figures 1-4 and 3-1). The Ismay zone is a minor producing oil reservoir in the field. The Gothic shale is a stratigraphic seal above the Desert Creek. The shallow Navajo Sandstone is part of the larger Navajo aquifer, which is the principal fresh water, bedrock aquifer in the greater Aneth area (Spangler and others, 1996). The Navajo aquifer is confined above by shale and siltstone of the Jurassic Wanakah and Morrison Formations and below by the Triassic Chinle and Moenkopi Formations. The DeChelly Sandstone is part of the Coconino-DeChelly aquifer system and is generally a saline aquifer in the Aneth area (Robson and Banta, 1995; Spangler and others, 1996). It is confined above by the Chinle and Moenkopi Formations and below by the Permian Halgaito Formation.

\section{Structural and Stratigraphic Analysis}

\section{Aquifers}

Navajo Sandstone: The Navajo Sandstone is an eolian erg deposit characterized as a subfeldspathic arenite to quartz arenite with very high porosity. Figure 3-2 shows the structure contour map of the Navajo Sandstone. The map shows an area of higher elevations in the center of the map, which is consistent with the general expression of the underlying carbonate buildup complex in the Paradox Formation. The structure contour map shows no major deviations in contours and therefore no discernable faults or folds. Figure 3-3 shows the isopach map for the Navajo Sandstone. Thickness of the Navajo ranges from 270 to 428 feet $(82-130 \mathrm{~m})$ and the unit thins to the southeast.

DeChelly Sandstone: The DeChelly Sandstone is also eolian in origin, quartz-rich with thin interbeds of siltstone, mudstone, and carbonate, and is a saline aquifer in the Aneth area. The structure contour map for the DeChelly is shown in figure 3-4, and like the Navajo, shows the general shape of the underlying carbonate buildups of the Paradox Formation with an area of higher elevation in the central portion of the map. Figure 3-5 shows the isopach map for the DeChelly Sandstone. Thickness of the DeChelly ranges from 55 to 127 feet (17-39 m) and the unit appears to thin toward the northwest. 


\section{Reservoir - Desert Creek Zone}

Figure 3-6 is the structure contour map of the Desert Creek zone. The geometry of the Desert Creek carbonate buildup complex can clearly be seen in the Aneth area as a northwestsoutheast-trending structural high. There are a few possible faults discernable from the map, most notably a northeast-southwest trending fault that can be seen where abrupt contour changes occur in the southwest corner of section 18, T. 40 S., R. 24 E., SLBL\&M (shown within the black box on figure 3-6) and a possible faulted area in section 30, T. 40 S., R. 25 E., SLBL\&M. Fracturing and other evidence in core from the Aneth Unit No. E-418 well (also shown within the box on figure 3-6), described in Chapter 4, supports the idea that faulting occurred in this area. However, the northeast-southwest strike of the faulted block as seen on the structure contour maps does not match the known structural trend of other, deeper faults in the area. Mike Tryggestad (Resolute Natural Resources, verbal communication, 2009) reports that threedimensional (3D) seismic of Greater Aneth field shows basement faults of Mississippian and Pennsylvanian age that strike northwest-southeast. Also, this northeast-striking fault does not appear in structure contour maps of overlying strata such as the DeChelly and Navajo Sandstones, and therefore, is likely a localized structure with minimal displacement.

The isopach map for the Desert Creek zone shows thickness ranging from 131 to 204 feet (40-62 m) (figure 3-7). Data are sparse for the lower bounding formation top, the Chimney Rock shale of the Paradox Formation, as most well logs in the Aneth Unit do not extend beyond the Desert Creek zone. Therefore, the isopach map is less complete than for the Ismay zone or Gothic shale. Several discrete zones of thickness, colored light green on figure 3-7, likely represent carbonate buildups. A notable carbonate buildup is clearly seen in section 13, T. 40 S., R. 23 E., SLBL\&M. This buildup occurs within the sequestration demonstration site.

\section{Seal - Gothic Shale}

The Gothic shale is the seal for the Desert Creek oil reservoir and pilot $\mathrm{CO}_{2}$ sequestration reservoir. The structure contour map for the Gothic is shown in figure 3-8 and the isopach map is shown in figure 3-9. Again the lateral extent and shape of the underlying Desert Creek carbonate buildup complex is seen in the structure contour map as elevated areas within the Aneth Unit. The possible northeast-striking fault seen in both structure contour maps for the Ismay and Desert Creek zones is also evident in the Gothic structure contour map. This fault could be a potential migration pathway for $\mathrm{CO}_{2}$ between the Ismay and Desert Creek reservoirs, but since the fault does not appear to extend outside of the Paradox Formation, the risk of leakage into overlying strata is small.

The Gothic shale ranges from 7 to 28 feet $(2-8.5 \mathrm{~m})$ thick and thins to the southeast indicating slightly shallower water to the southeast during the time of deposition. An area of very thin shale occurs in section 23, T. 40 S., R. 24 E., SLBL\&M, which is coincident with a thickened zone on the Desert Creek isopach map. This indicates that the shale was likely deposited on a high-relief carbonate buildup. 


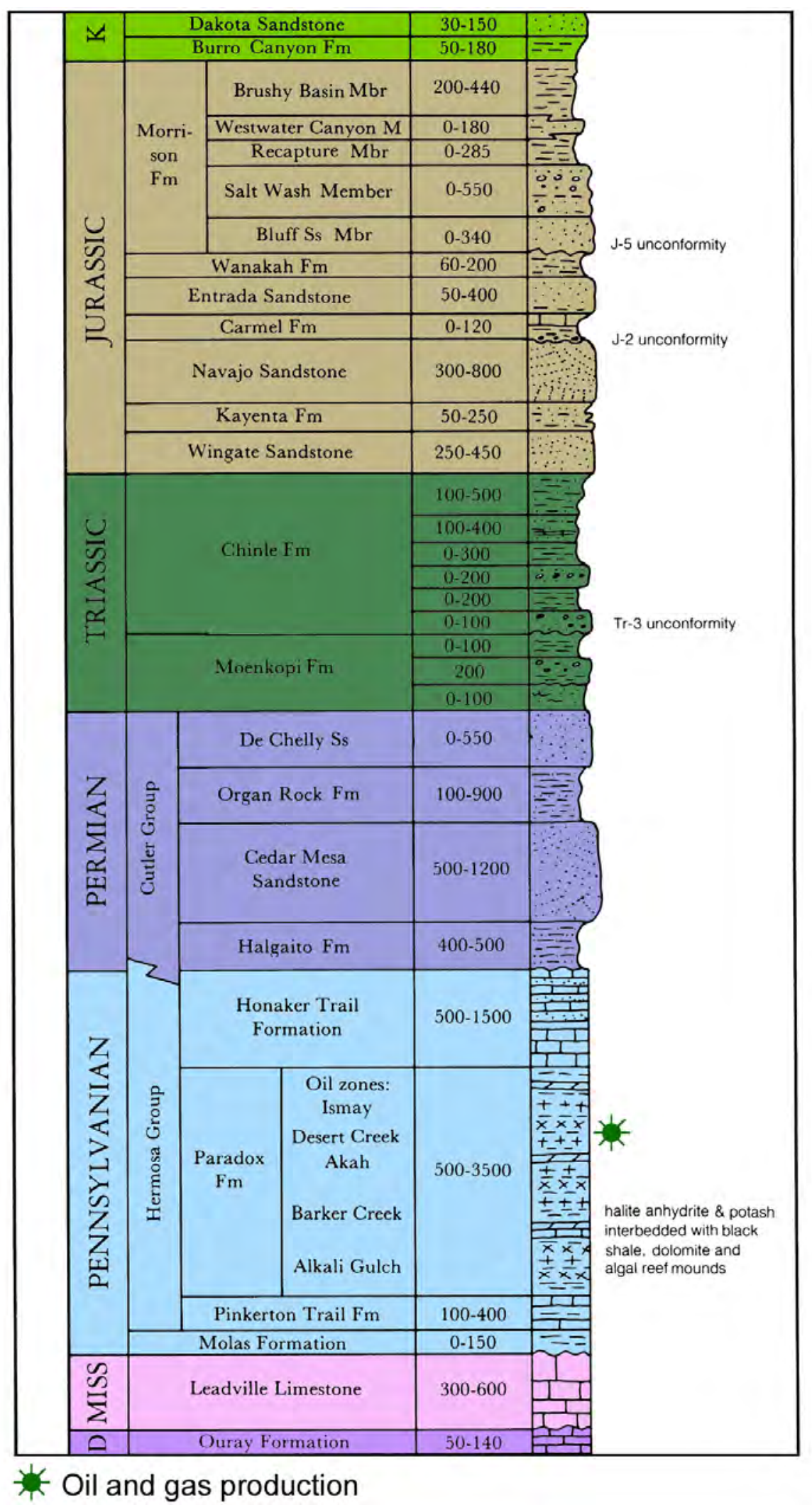

Figure 3-1. Stratigraphic column for the Aneth Unit and surrounding areas. Modified from Hintze and Kowallis, 2009. 


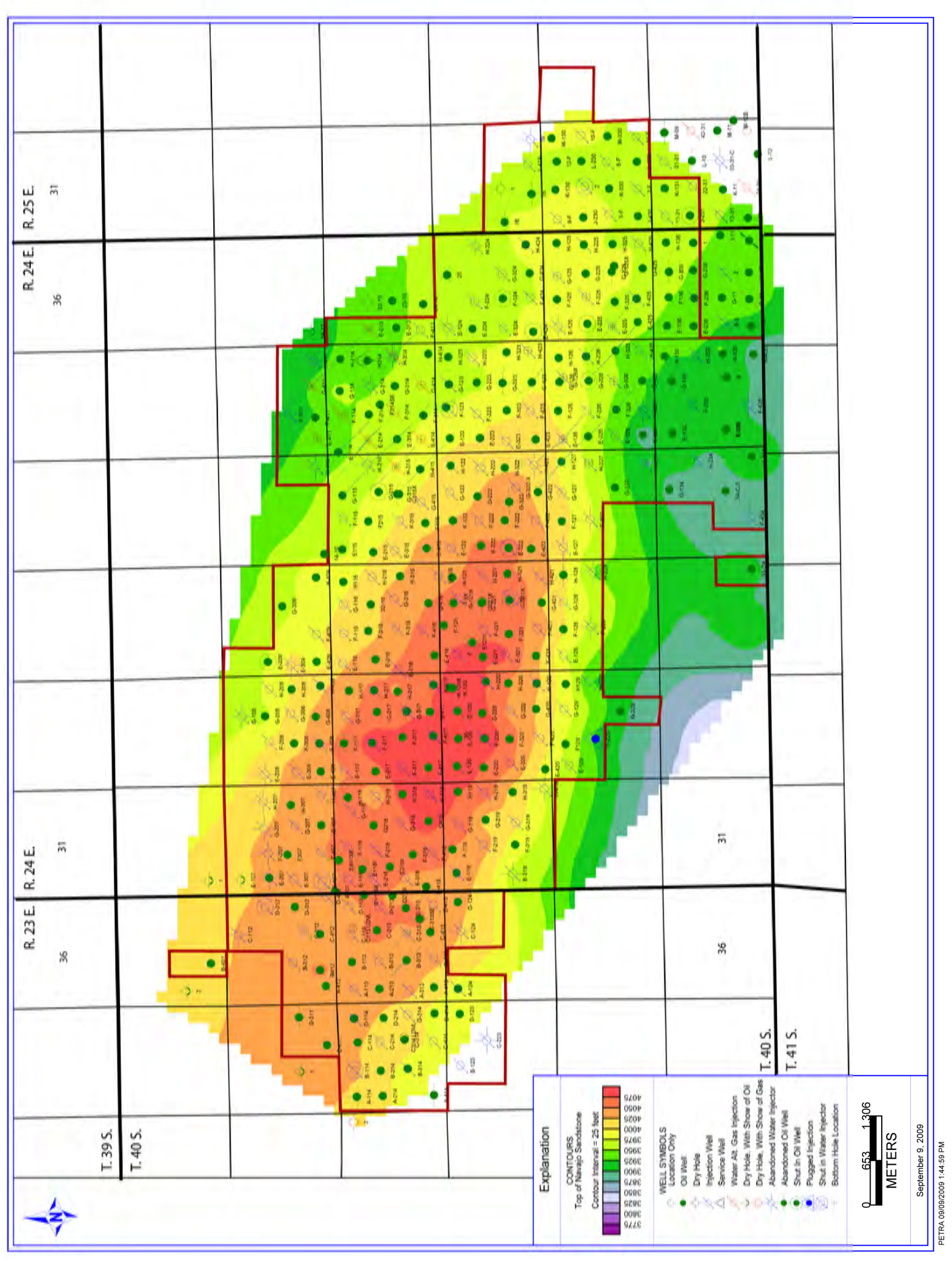

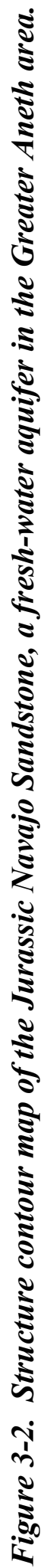




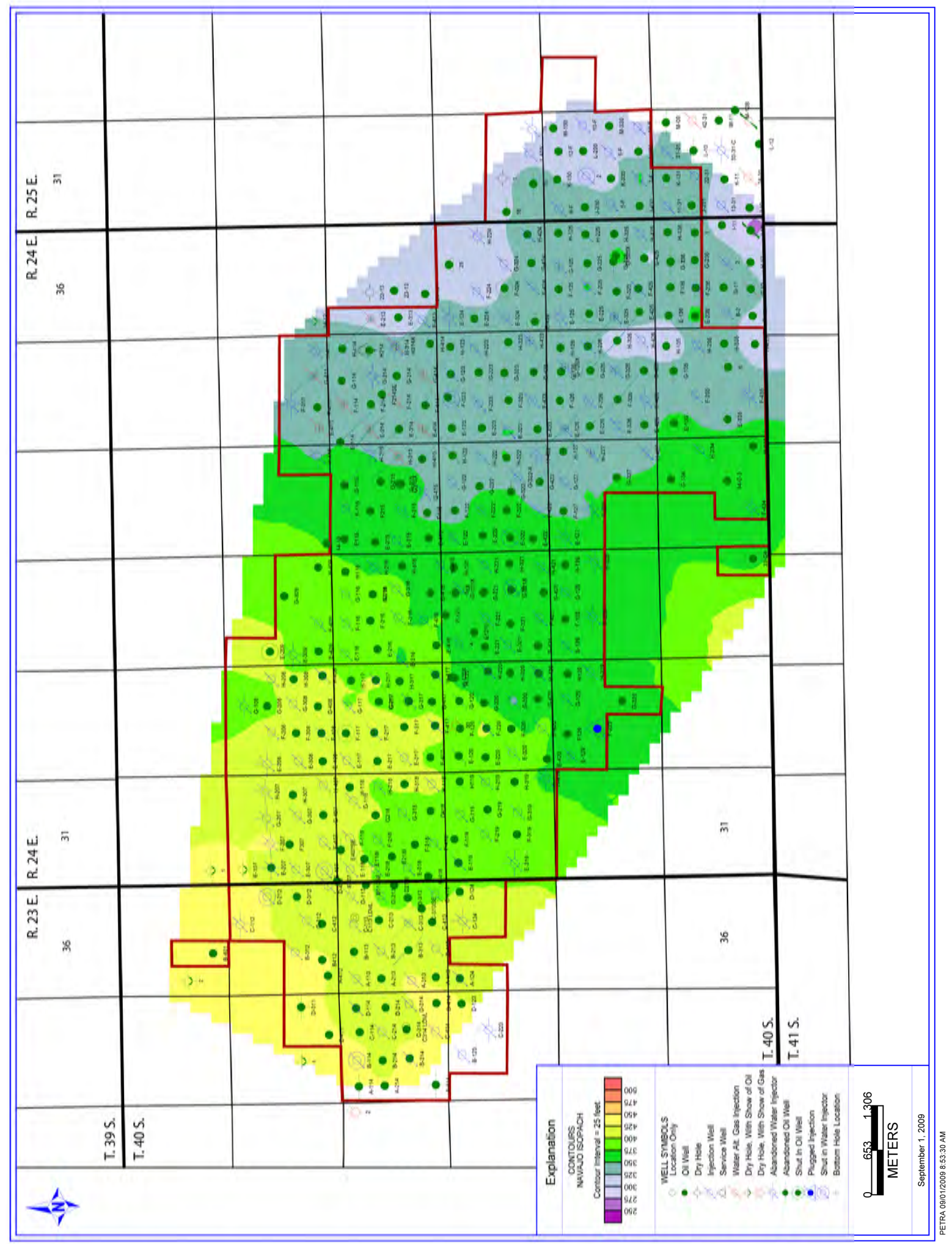

है 


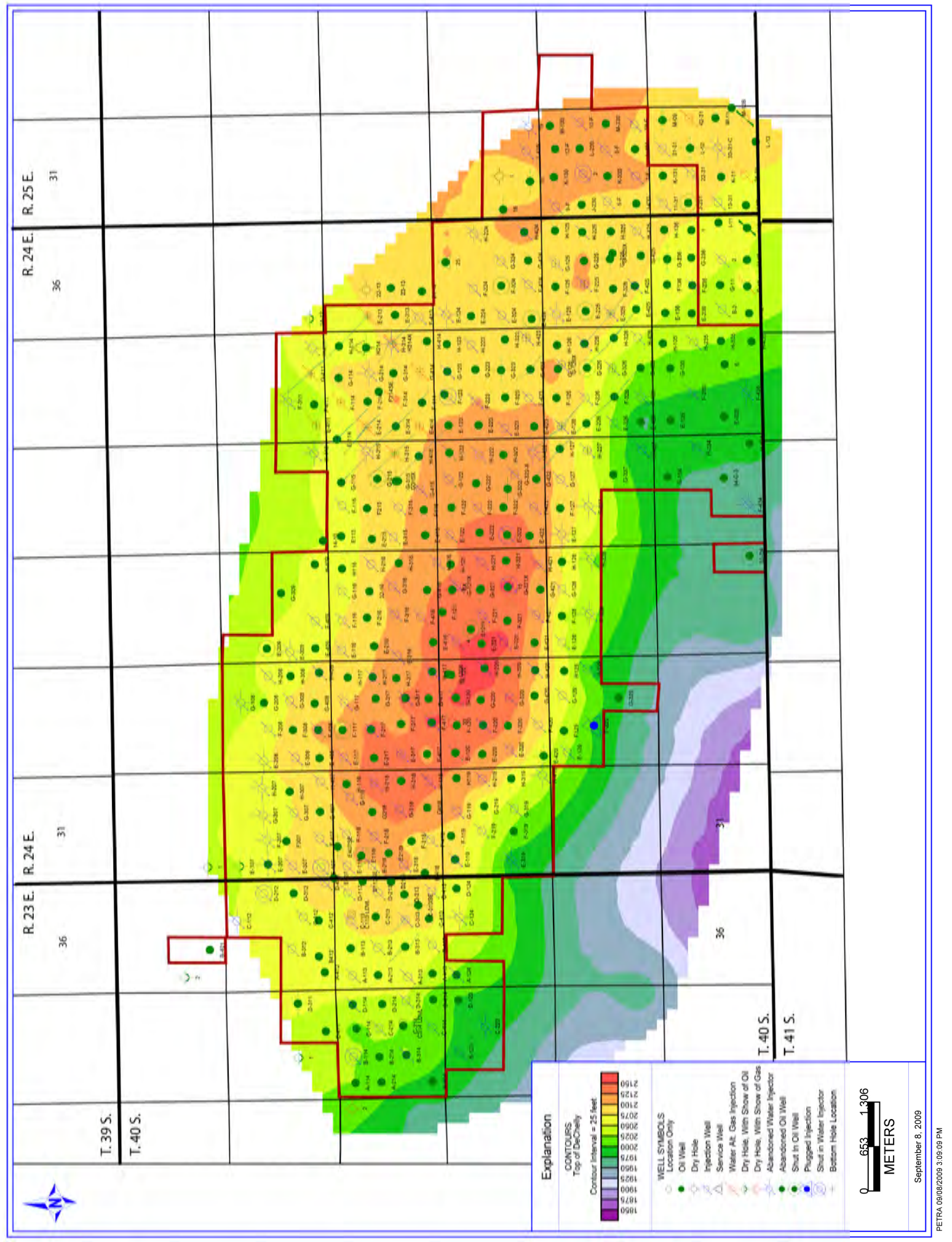

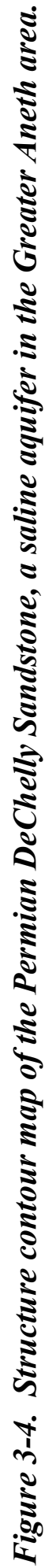




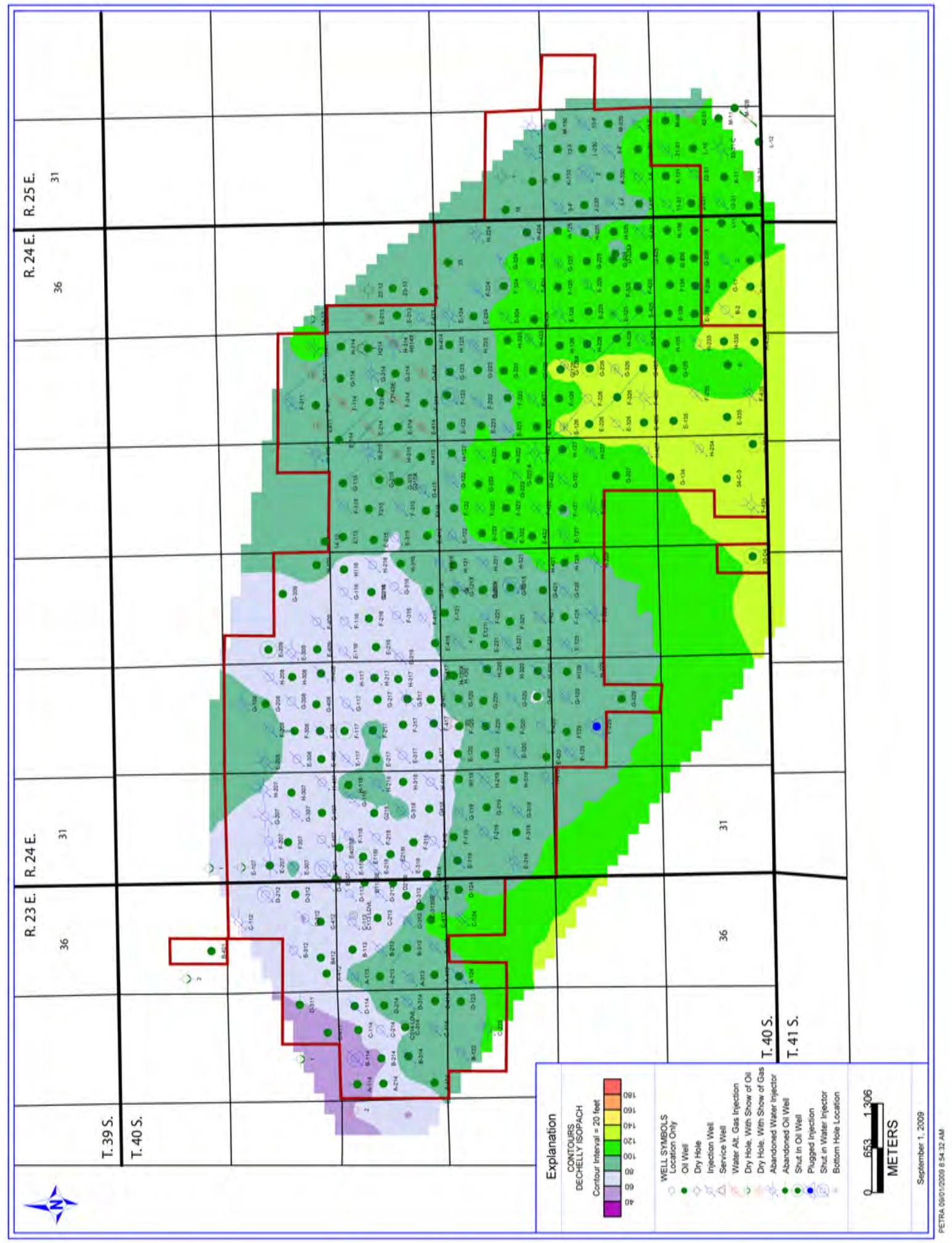

है 

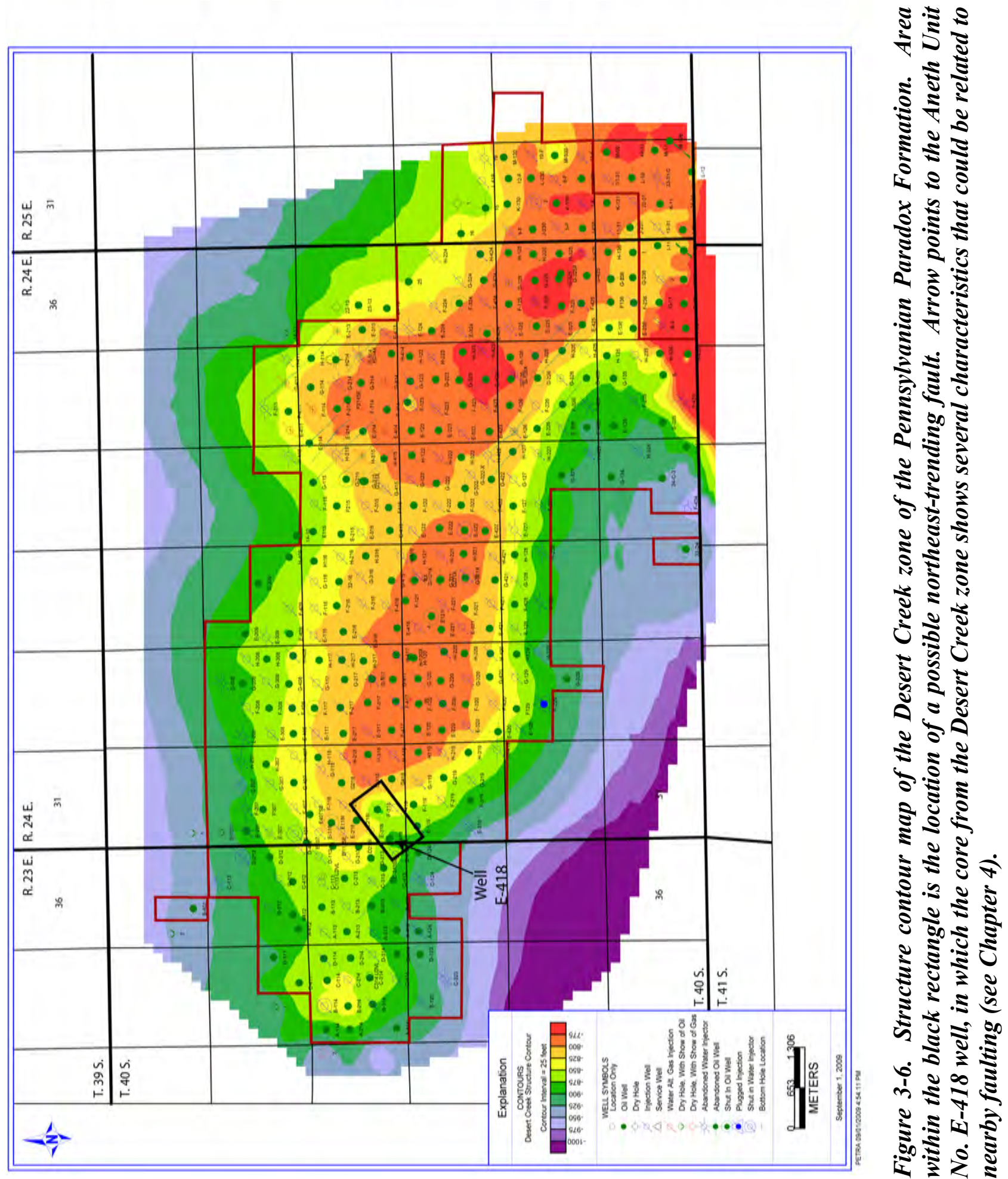


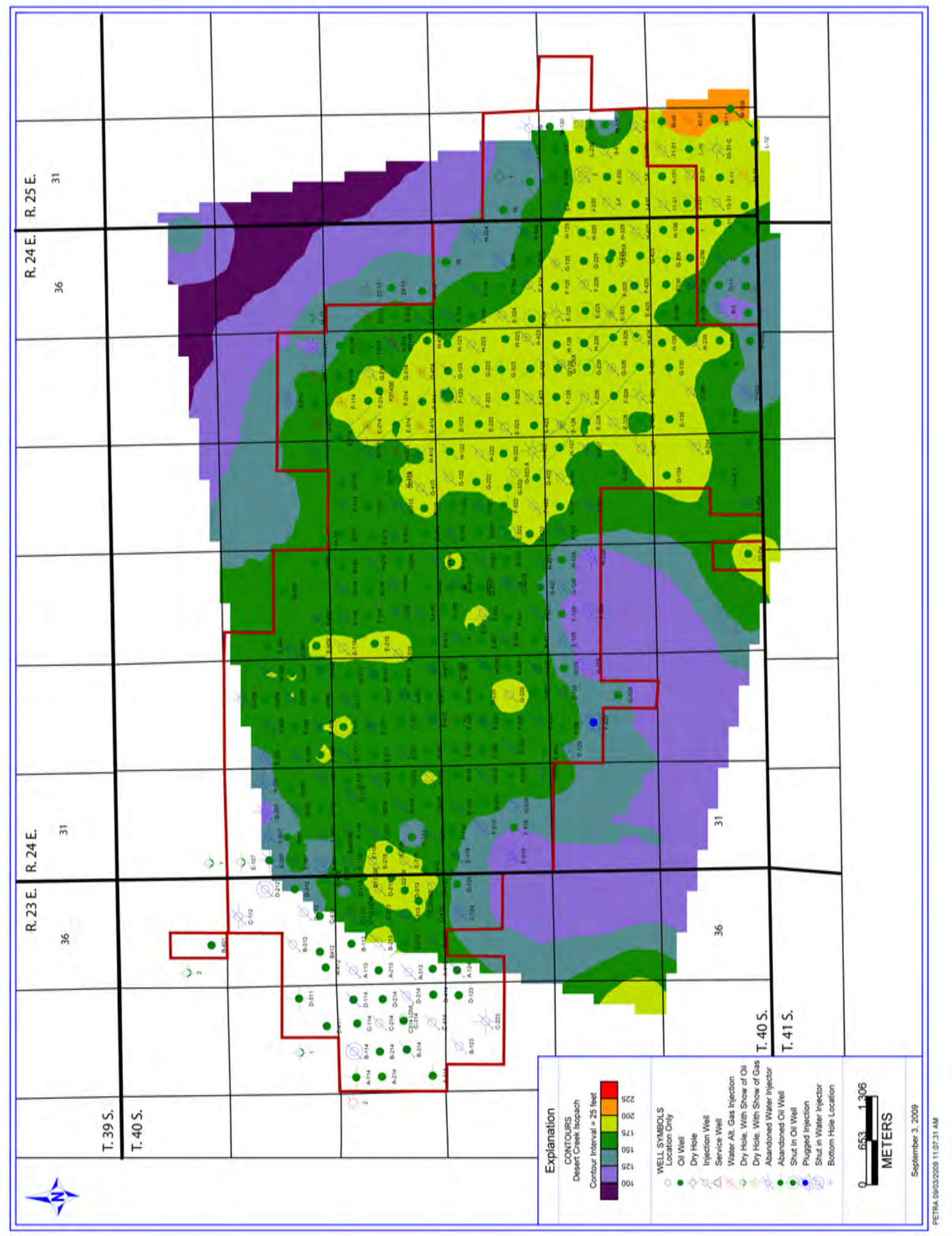

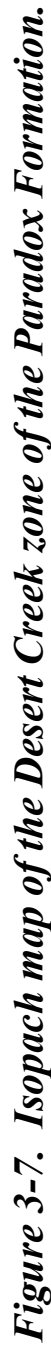




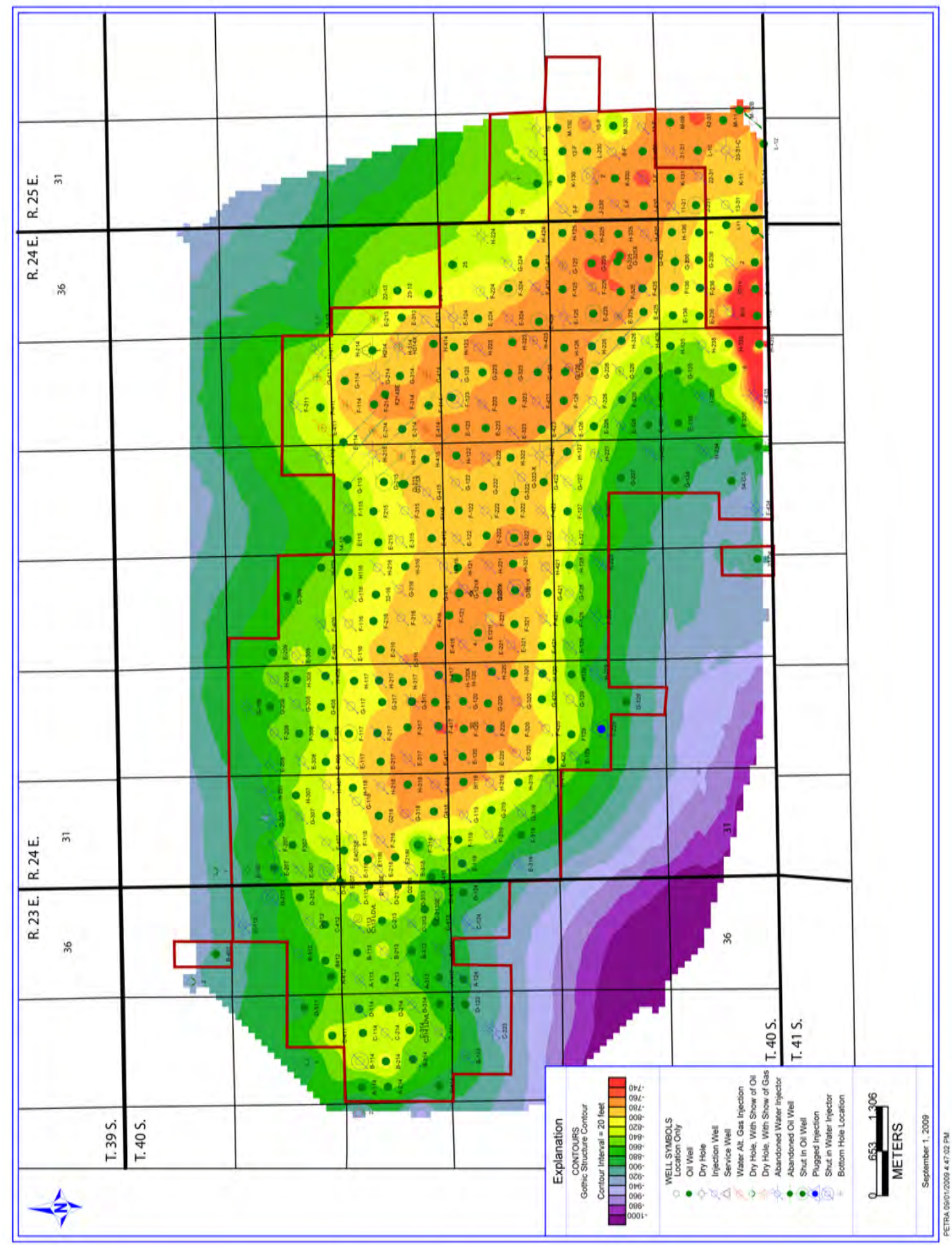

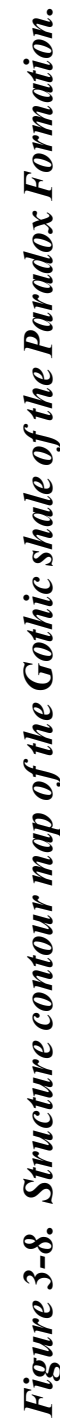




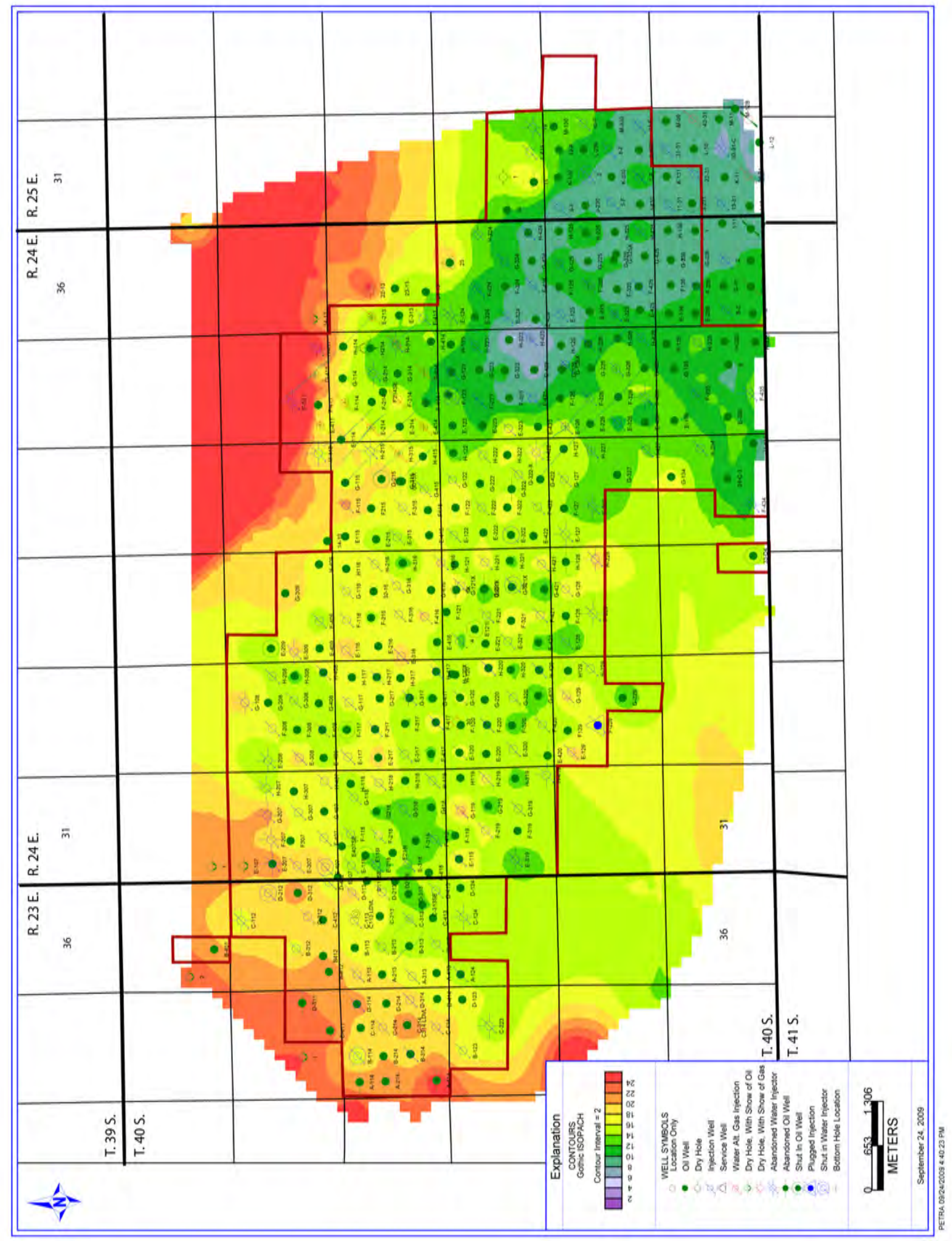

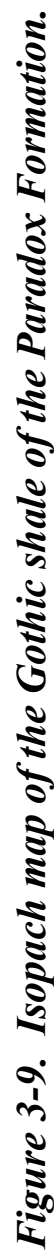




\title{
CHAPTER 4 \\ RESERVOIR CHARACTERIZATION OF THE DESERT CREEK ZONE OF THE PARADOX FORMATION, ANETH UNIT: LITHOFACIES, LITHOLOGY, PORE TYPES, AND DIAGENESIS
}

\author{
by \\ Thomas C. Chidsey, Jr., Utah Geological Survey, \\ David E. Eby, Eby Petrography \& Consulting, Inc., \\ John C. Lorenz, Geoflight LLC, (formerly with Sandia National Laboratories), and \\ Scott P. Cooper, Cooper Geological Consulting (formerly with Sandia National Laboratories)
}

\section{Introduction}

The Desert Creek zone of the Paradox Formation at Greater Aneth field was deposited in a warm, shallow sea as a horseshoe-shaped buildup of reef-like mounds composed primarily of the green algae Ivanovia capped by banks of oolitic sands, similar to the present-day Bahama open-marine, carbonate platform. Past geophysical well-log interpretations and published cross sections divide the Desert Creek into several correlatable reservoir subzones and units, as well as a few seals, across the field. However, caution is urged when using this type of information alone to generate reservoir models for $\mathrm{CO}_{2}$ sequestration and movement over time at Aneth and other fields. Geological characterization on a local scale focused on reservoir heterogeneity, quality, and lateral continuity, as well as possible compartmentalization within the Aneth Unit. This utilized representative core and modern geophysical well logs to typify the Desert creek zone.

Examination of available slabbed conventional cores from Aneth Unit wells (see UGS Final Report, Chidsey, 2009) reveals a complex reservoir consisting of limestone (oolitic, peloidal, and skeletal grainstone and packstone, and algal boundstone/bafflestone) and finely crystalline dolomite. These lithotypes represent a variety of depositional environments (openmarine shelf, shallow-marine beach and shoals, algal mounds, low-energy restricted shelf, and so forth) that produce reservoir heterogeneity beyond what is determined from well logs. Fractures in cores are relatively common and there is evidence (hydrothermal dolomite and brecciation) of minor but important faults that may affect fluid flow. Cores reveal additional potential seals within the Desert Creek (mudstone and very fine grained sandstone units).

In Greater Aneth field, determining the nature, location, and extent of reservoir heterogeneity is the key to increasing oil recovery and $\mathrm{CO}_{2}$ storage potential. Three factors (apart from structural features) create reservoir heterogeneity: (1) variations in lithofacies and lithology, (2) mound relief and flooding surfaces, and (3) diagenesis. The extent of these factors and how they are combined affect the degree to which they create $\mathrm{CO}_{2}$ storage capacity and barriers to $\mathrm{CO}_{2}$ flow. 


\section{Lithofacies and Lithology}

\section{Carbonate Buildups}

Greater Aneth field is a complex of productive carbonate buildups that developed in shallow-shelf and shelf-margin areas of the Paradox Basin (figure 4-1). The controls on the development of each buildup type were water depth, prevailing wave energy, and paleostructural position. Stratigraphic hydrocarbon traps within the Aneth complex of carbonate buildups are associated with phylloid-algal and oolitic shoals buildup lithofacies.

Phylloid-algal buildup lithofacies: The depositional fabric for phylloid-algal lithofacies is bafflestone. Rocks representing this lithofacies contain in-situ phylloid-algal plates (Ivanovia and Kansasphyllum) (figure 4-2), encrusting forams (for example Tetrataxis), soft peloidal mud, and minor amounts of internal sediment (mud or grains deposited after storms [suspended load]). The principal buildup process for phylloid-algal growth occurred during high stands of sea level. Phylloid algal mounds generally developed on the platform-interior carbonate muds and sands. Calcified phylloid-algal plates sheltered abundant primary "vugs," with mounds of phylloid algae building upward within the available accommodation space. As mounds grew, detrital skeletal material was shed and deposited as dipping beds along the exterior flanks and interior lagoons. The floors of the interior lagoons consisted of muddy marine limestone with fossils. During low stands of sea level, these buildups experienced considerable porosity modification. Leached cavities, vugs, and seepage-reflux dolomites developed in the mound and flank sediments. Troughs representing tidal channels formed on the tops of buildups during times of subaerial exposure. Bafflestone within these lithofacies has excellent reservoir properties where primary shelter porosity is well developed. However, anhydrite and cements often plug pores.

Oolitic shoals: The depositional fabrics of the oolitic shoal lithofacies include grainstone (figure 4-3) and packstone. Beside ooids, rocks representing this lithofacies typically contain the following diagnostic constituents: coated grains, hard peloids, bioclastic grains, shell lags, and intraclasts. Oolitic shoal lithofacies generally developed above phylloid-algal buildup complexes and represent the major hydrocarbon-producing reservoirs in Greater Aneth field. This lithofacies represents a high-energy environment where shoals and/or islands developed as a result of regularly agitated, shallow marine processes on the shelf. Ooid shoals tend to initiate on topographic highs such as phylloid-algal buildups. Characteristic features of oolitic shoal lithofacies include medium-scale cross-bedding and bar-type, carbonate sand-body morphologies.

\section{Platform-Interior Carbonate Muds and Sands}

The platform-interior carbonate mud and sand lithofacies are widespread across the shallow shelf at Aneth and include a variety of sub-lithofacies such as upper shoreface, peritidal, storm-dominated shallow marine, low-energy open marine, and restricted shallow marine. These lithofacies represent low to moderate energy environments. Mud and sand were deposited in subtidal (burrowed) and pellet/skeletal shoal settings. The depositional fabrics of the platforminterior carbonate mud and sand lithofacies include grainstone, packstone, wackestone, and mudstone. Rocks representing this lithofacies typically contain the following diagnostic 
constituents: soft pellet muds, hard peloids, grain aggregates, bryozoans, crinoids, fusulinids, and associated skeletal debris. Quartz sand and silt are found in a unit near the upper Desert Creek zone representing an upper shoreface environment. The platform-interior carbonate mud and sand lithofacies can contain reservoir-quality rocks if dolomitized. Several units containing the bryozoan Chaetetes have good porosity on well logs, but core observations show the porosity is ineffective.

\section{Relief on Carbonate Buildups and Flooding Surfaces}

The nature of the original surfaces of phylloid-algal mounds can add to the reservoir heterogeneity of these buildups. For example, multiple troughs formed by tidal currents may contain good quality grainstones. However, these grainstones are typically separated by poor quality carbonate fabrics which were deposited adjacent to the troughs. In addition, these deposits may not be connected to one another in other parts of the buildup surfaces. Thus, what might appear as the same units in core or on geophysical logs from one well to another, may be time equivalent but separate in terms of fluid flow.

Subaerial exposure of the buildups may have produced karst zones (depending on prior mound relief) favorable to reservoir development. Relative sea level rise produced flooding surfaces or time lines, usually thin shales, which act as barriers or baffles to fluid flow (figure 44). As many as eight correlative flooding surfaces have been identified in some buildups. Lithotypes between these surfaces are genetically related in time and space, thus correlation of these sequences must not cross time lines (Weber and others, 1995).

\section{Pore Types and Diagenesis}

The diagenetic fabrics and porosity types found in the various hydrocarbon-bearing rocks in Greater Aneth field can be an indicator of reservoir flow capacity, and potential for waterand/or $\mathrm{CO}_{2}$-flooding and storage capacity. We analyzed the reservoir diagenetic fabrics and porosity types within the Aneth Unit to: (1) predict facies patterns, (2) determine the sequence of diagenetic events, and (3) provide data input for the reservoir modeling and simulation studies. Diagenetic characterization focused on reservoir heterogeneity, quality, and compartmentalization within the Aneth Unit. Of special interest was the determination of the most effective pore systems for $\mathrm{CO}_{2}$-storage capacity.

\section{Primary Porosity}

The framework grains of carbonate buildups consist predominantly of oolites and phylloid-algal plates, with lesser amounts of brachiopods, bryozoans, pelloids, ostracods, and forams. They yield primary porosity such as shelter (figure 4-5A), interparticle (figure 4-5B), and intraparticle (particularly in bryozoan-dominated buildups) (figure 4-5C) pore types. Where these pore types are well developed, the reservoirs have excellent hydrocarbon and $\mathrm{CO}_{2}$ storage and fluid-flow capacity. Within the Aneth Unit grainstones within oolitic shoal lithofacies represent the major reservoir where primary interparticle porosity is well developed. 


\section{Diagenetic Environments}

Most shallow-shelf/shelf-margin carbonate buildups, or mounds, had relief with exposure occurring when sea level fell. This setting produced four major, generally early, diagenetic environments: (1) fresh-water (meteoric) vadose zone (above the water table, generally at or near sea level), (2) meteoric phreatic zone (below the water table), (3) marine phreatic zone, and (4) mixing zone. An ideal diagenetic sequence based on our analysis of Desert Creek thin sections from the Aneth Unit is presented in figure 4-6. The typical early diagenetic events occurred in the following order: (1) early marine cementation (figures 4-7A) which may include firstgeneration micrite and fibrous isopachous cementation, second-generation botryoidal cementation, and third-generation radiaxial cementation (note: early-marine cements are not always present), (2) post-burial, replacement, rhombic dolomite cementation due to seepage reflux (figure 4-7B), (3) vadose and meteoric phreatic diagenesis including leaching/dissolution (figure 4-7C and 4-7D), and fresh-water cementation (dogtooth, stubby, and small equant calcite [figure 4-7E]), (4) mixing-zone dolomitization, (5) syntaxial cementation (figure 4-7F), (6) anhydrite cementation/replacement, and (7) minor silica replacement. Locally, seepage reflux dolomitization can enhance both reservoir flow and storage capacity. Those reservoirs with excellent storage capacity may be considered candidates for $\mathrm{CO}_{2}$ flooding and storage.

Post-burial diagenesis (figure 4-6) included additional syntaxial cementation, silicification, compaction (figure 4-8A), late coarse calcite spar formation (figure 4-8B), saddle dolomite cementation (figure 4-8C), stylolitization, additional anhydrite replacement (figure 48D), late dissolution (microporosity development), minor bitumen plugging, and fracturing. There is an observed progression from least to most important (syntaxial cementation to anhydrite replacement) which relates to increased reservoir heterogeneity in the Desert Creek reservoirs. Some of these diagenetic products create barriers and baffles to fluid flow, such as the case where pores and pore throats are sometimes plugged or bridged by lathes of late anhydrite cement and bitumen (or solid hydrocarbons). They are not observed on seismic records, are difficult to predict, and locally influence reservoir performance, storage capacity, and drainage.

\section{Evidence of Faulting}

Some reservoirs suggest the presence of nearby faults that are undetected on seismic or on geophysical well logs (see Chapter 3 for characteristics based on structural contour mapping). The rocks may display the following characteristics: (1) intense brecciation, fracturing, and stylolitization (figures 4-9A and 4-9B), (2) saddle dolomite replacement and vugs replaced with saddle dolomite (figure 4-9C), (3) microporosity, (4) well-terminated quartz (figure 4-9C), and (5) bitumen. These features likely developed late, along solution fronts originating by the action of hydrothermal solutions from depth (carbon dioxide escaping from Mississippian Leadville Limestone or from deep decarboxylation of organic matter). The faults are probably small, normal, unmapped, and trend northeast-southwest across the Aneth Unit but may be significant in that they can create additional barriers and baffles to flow. 


\section{Assessment of Fractures and Stylolites}

\section{Introduction}

Numerous natural fractures and stylolites in the Desert Creek zone are observed in four cores from the Aneth Unit (Aneth Unit Nos. E-418, H-117, 27-C3, and 27-D-4 wells, figure 1-3). The features most commonly observed include petal (induced), hairline, vertical, inclined, and horizontal fractures, and stylofracs.

\section{Fracture Types}

Hairline fractures: Hairline fractures as defined herein are cracks in the rock that are often obscure (hard to trace). Hairline fractures typically have less than $0.1 \mathrm{~mm}$ total width (figure 410A). They typically have an unknown height because the top and base are unknown due to their obscure nature, though sometimes these parameters can be seen. Where broken open, these fractures are not mineralized, though their surfaces often have stains that suggest they are not freshly broken rock. Where they intersect a slab face or core surface they are usually slightly broken, suggesting there is remnant porosity within the fracture. Under high reservoir pressures a system of interconnected hairline fractures (microfracs) could be a significant contribution to reservoir permeability.

Vertical fractures: Several types of vertical to near-vertical fractures with several orientations are present in the core. Some of the fractures are associated with the numerous stylolites, while others are apparently tectonic-related extension fractures (figure 4-10B). Most of these vertical fractures are partially mineralized, leaving remnant porosity capable of high-capacity fluid flow along the fracture aperture. Vertical fractures were also observed in chert nodules. Additional vertical fractures are illustrated in the section describing relative fracture orientations.

Inclined fractures: Inclined fractures are common in the Aneth cores. The larger inclined fractures are commonly stepped, suggesting minor shear offset (figure 4-10C). Smaller inclined fractures are mineralized but still provide planes of mechanical weakness in the rock, along which the core often broke during coring and recovery. The fracture planes are commonly not mineralized, yet some show a dark-stained, dissolution texture that indicates they are not fresh breaks related to coring.

Horizontal fractures: Several zones of horizontal fractures are present in the Aneth cores (figure 4-10D). Some of these may be extension related from stress relief after coring; others appear to be natural. If extensive, horizontal fractures have the potential to connect vertical fractures into a 3D, high-permeability, fracture network.

Stylofracs: Many of the vertical fracture planes have been modified during the geologic history since fracturing. One common type of fracture modification is by the same type of pressure solution that forms stylolites, turning the fracture plane into a compound feature called a "stylofrac" (figure 4-10E). The characteristics of stylofracs in the Aneth cores suggest that a minimum amount of dissolution has occurred, and they therefore have more potential permeability than the more common, well-developed horizontal stylolites. The stylofracs 
probably record a phase of horizontal tectonic compression, possibly related to the compression that created the slickenlined planes in the Gothic shale described in Chapter 5.

\section{Fracture Orientations}

There are at least three, probably four orientations of fractures (figure 4-10F); roughly these are (1) horizontal, (2) vertical, parallel to the vertical stylolites, (3) vertical, normal to the vertical stylolites, and (4) vertical, oblique to everything else. Some pieces of core had vertical fractures that could be related to each other, if one set is taken as an arbitrary $0^{\circ}$ strike, at $0^{\circ}, 30^{\circ}$, and $80^{\circ}$. So there are as many as three different vertical fracture orientations (figure 4-10F). Additional fracture orientation relationships were documented in the core and will be analyzed in further detail.

\section{Relative Number of Fractures}

Fracture numbers in the charts shown on figure 4-11 are normalized to measurable core length within each well. These should be viewed as relative numbers as there are inherent sampling biases in determining absolute numbers of fractures, particularly in zones that have been highly fractured and turned to rubble or within zones of highly obscure hairline fractures. However, it is possible to obtain a qualitative understanding of fracture intensity from the charts.

The data shown in figure 4-11A shows fracture type by well and figure 4-11B is a combination of all vertical and horizontal fractures. These data indicate that the Aneth Unit No. 27-C3 well is more highly fractured relative to the other wells. This will be followed up with a review of the local geology and structure to determine the controls on the increased fracturing within this well. A quick review of hairline fractures indicates little relative difference between wells. All hairline fractures were not counted in some core sections of the wells because of their obscure nature, plus their occasional overabundance in zones of fracture swarms.

\section{Discussion: Inferences on Fracture Permeability}

The bottom line of course is how these fractures will affect $\mathrm{CO}_{2}$ injection and/or oil production. The large number of intersecting fractures suggests that fracture permeability should not be highly anisotropic, but that it should be significantly higher than matrix permeability except in the high-porosity zones - fractures were not common in the high-porosity zones. Fractures should provide good conductivity across what would otherwise be highly compartmentalizing stylolites. Horizontal fractures may provide good connectivity between otherwise isolated vertical fractures; intersecting sets of vertical fractures will create pseudoradial drainage if the in-situ stress anisotropy isn't so strong that it preferentially closes the fracture set normal to the maximum horizontal stress.

\section{Porosity and Permeability Cross Plots}

Porosity and permeability data from 92 core plugs were obtained from the six Desert Creek well cores described and used to construct cross-plots for the Aneth Unit (figure 4-12 and 4-13, see Chidsey, 2009 for data and all graphs). Data classes within the plots include lithology, carbonate fabric, lithofacies, and $\mathrm{CO}_{2}$ storage potential. Cross-plots are used to (1) identify 
reservoir heterogeneity, (2) predict lithofacies, (3) infer porosity and permeability trends where core-plug data are not available, (4) match diagenetic processes, pore types, and mineralogy, and (5) determine the most effective units for $\mathrm{CO}_{2}$ storage.

In terms of lithology (figure 4-12A), the cross-plot shows a wide distrubution. Siltstone with little porosity or permeability, as expected, has basically no $\mathrm{CO}_{2}$ storage potential. Limestone generally has the best potential along with a few exceptional dolomite samples. However, these data are skewed towards limestone in that most core plugs are limestone, the dominant lithology in the Desert Creek zone at Aneth. Grainstone, followed by packstone, is the best carbonate fabrics for $\mathrm{CO}_{2}$ storage potential (figure 4-12B). The cross-plots confirm that phylloid-algal bafflestones that are so production in many Paradox Basin fields, have relatively poor potential as both an oil reservoir and for $\mathrm{CO}_{2}$ storage. Deposition and diagenesis have produced such a wide variety of lithofacies and sublithofacies described in the Aneth Unit cores, that in order to simplify reservoir analysis we grouped together those with similar characteristics or found in the same depositional settings to reduce the number to eight. The three most common lithofacies from which core plugs were taken are (1) high- to moderate-energy shoal/bank, (2) low-energy shallow marine, and (3) shallow water, phylloid-algal buildup. The cross-plot (figure 4-12C) shows that the high- to moderate-energy shoal/bank and low-energy shallow marine facies have the best potential for $\mathrm{CO}_{2}$ storage. Foreshore/shoreface, low-energy restricted and deep water lithofacies have poor potential. Phylloid-algal buildup lithofacies have moderate to poor potential.

Figure 4-12D is designed to check the $\mathrm{CO}_{2}$ storage potential as determined by visual examination of the six cores. With a few minor exceptions where intervals were thought to be baffles but instead have good $\mathrm{CO}_{2}$ storage potential, the cross-plot confirms the descriptive evaluation. In general, the Aneth Unit H-117 and 27-D-4 wells appear to have the best overall $\mathrm{CO}_{2}$ storage potential. The Aneth Unit E-313 and $\mathrm{H}-418$ wells appear to have the poorest overall $\mathrm{CO}_{2}$ storage potential. 


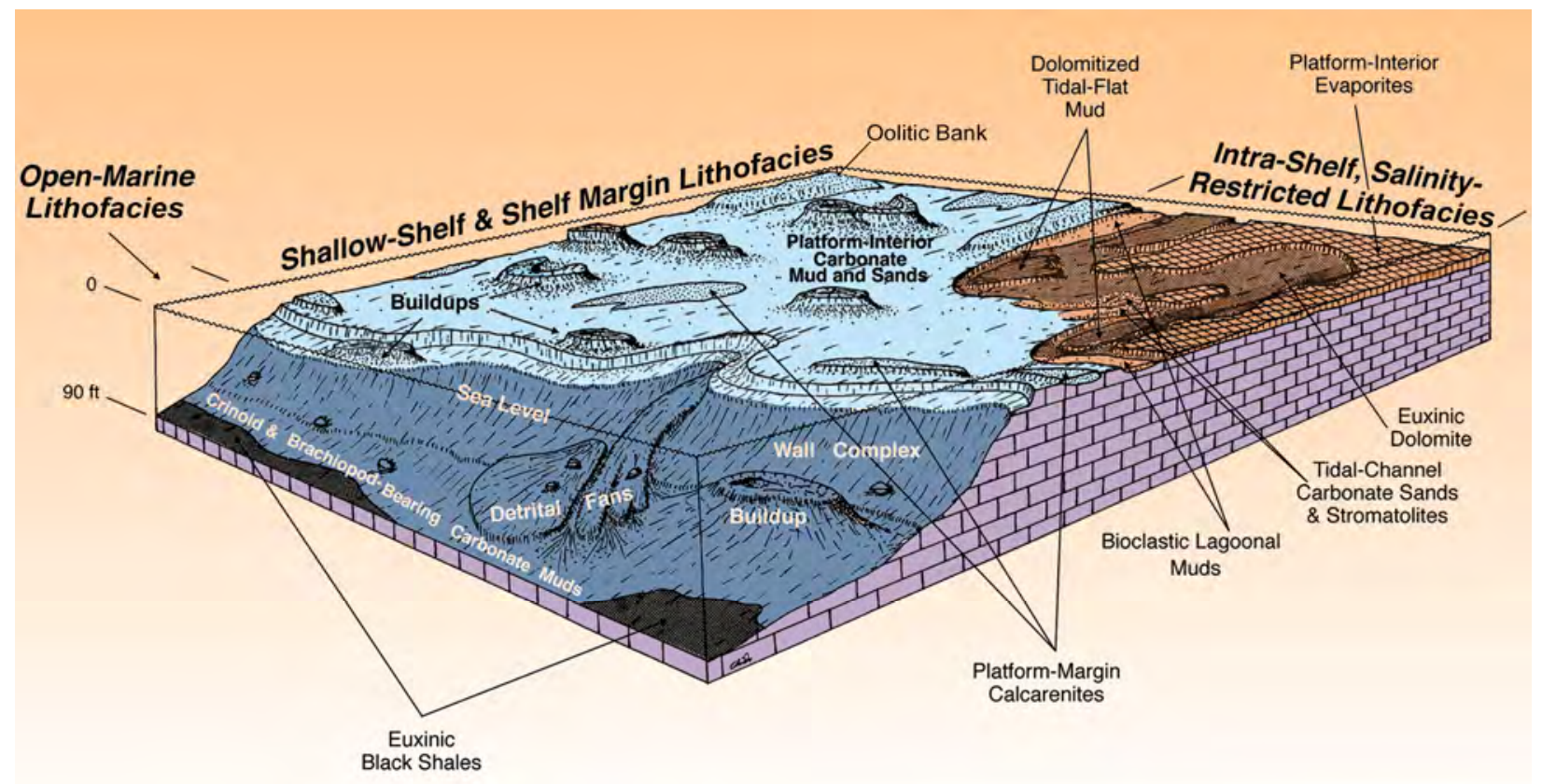

Figure 4-1. Block diagram displaying depositional environments within the Desert Creek zone on the Aneth platform. After Chidsey and others (1996). 


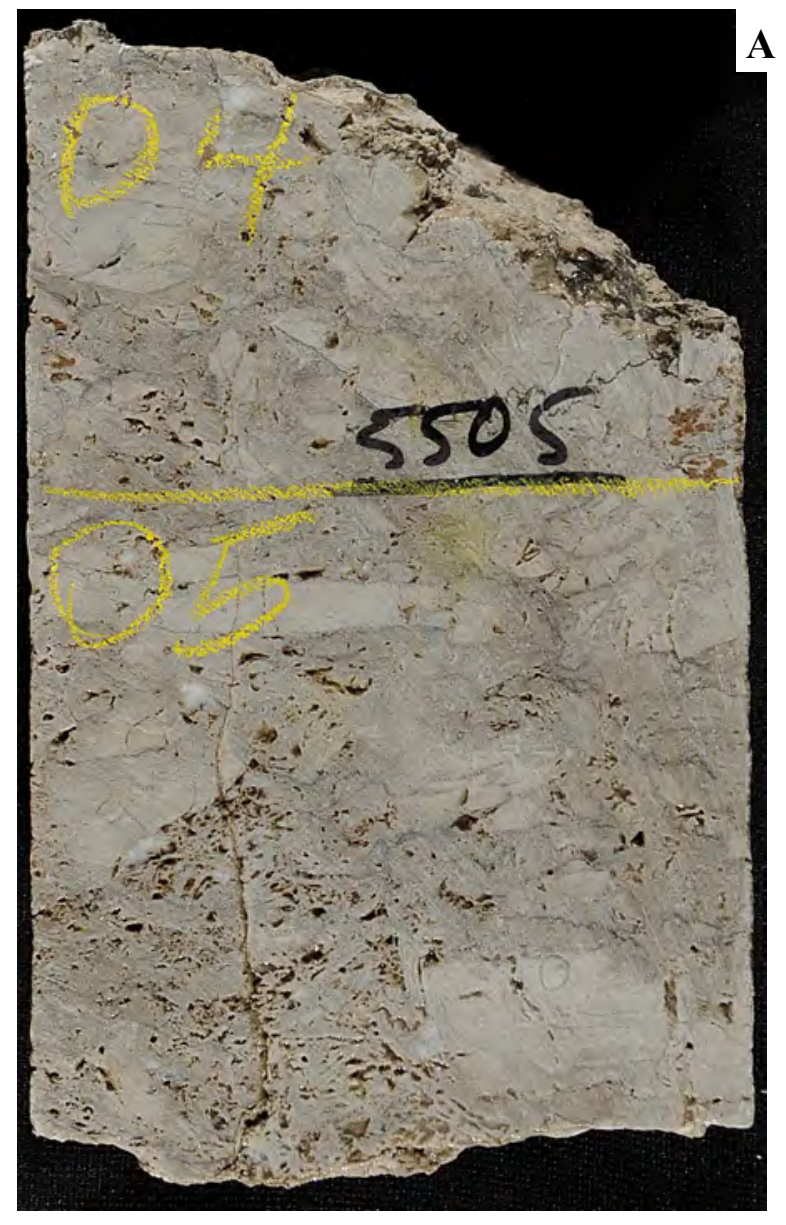

Figure 4-2. Phylloid-algal buildup lithofacies. A-Conventional core slab of a phylloid-algal bafflestone with porosity. $B-$ Photomicrograph (plane light) of phylloid algal plates of Ivanovia. Aneth Unit No. H117 well (figure 1-3), 5504.8-5505.3 feet.

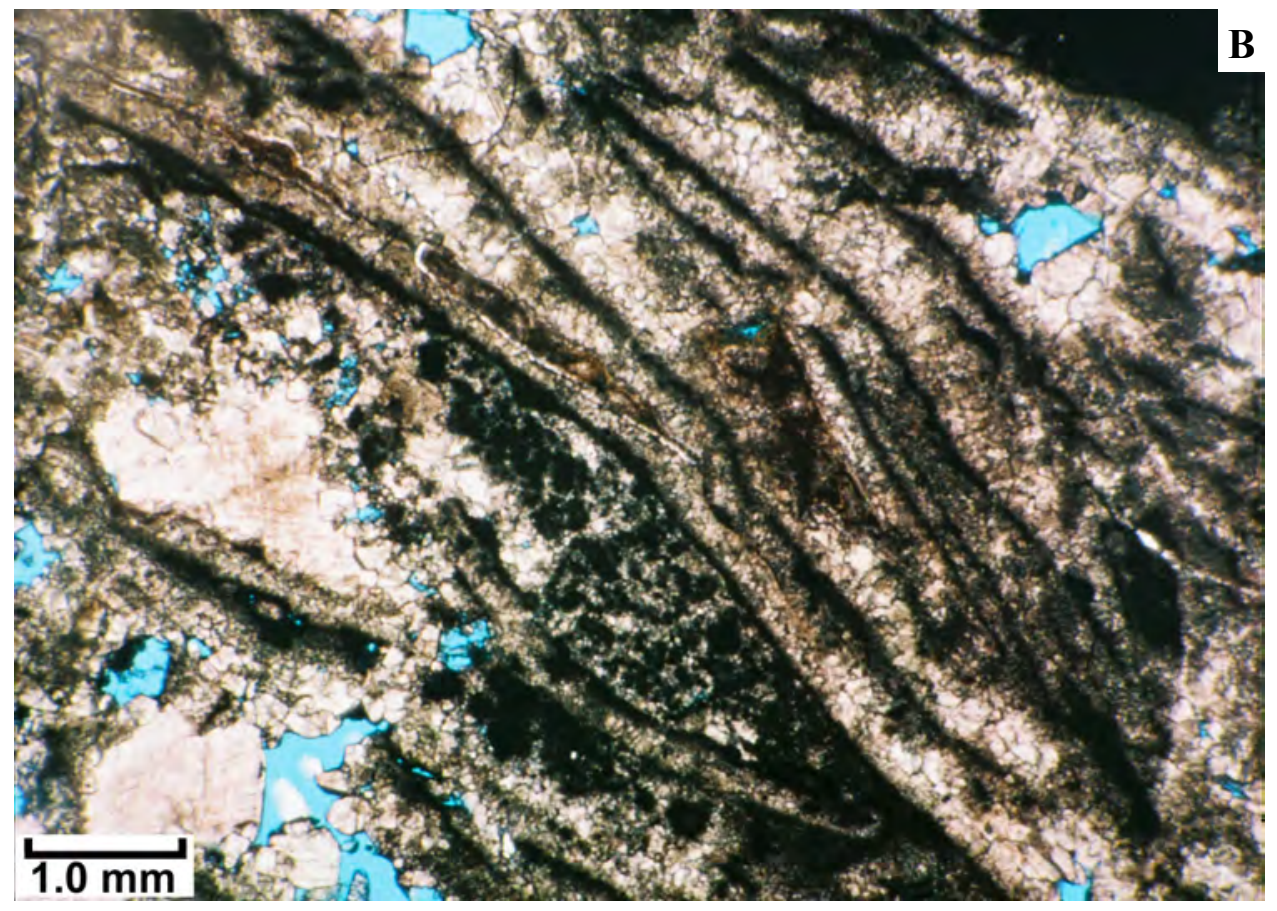




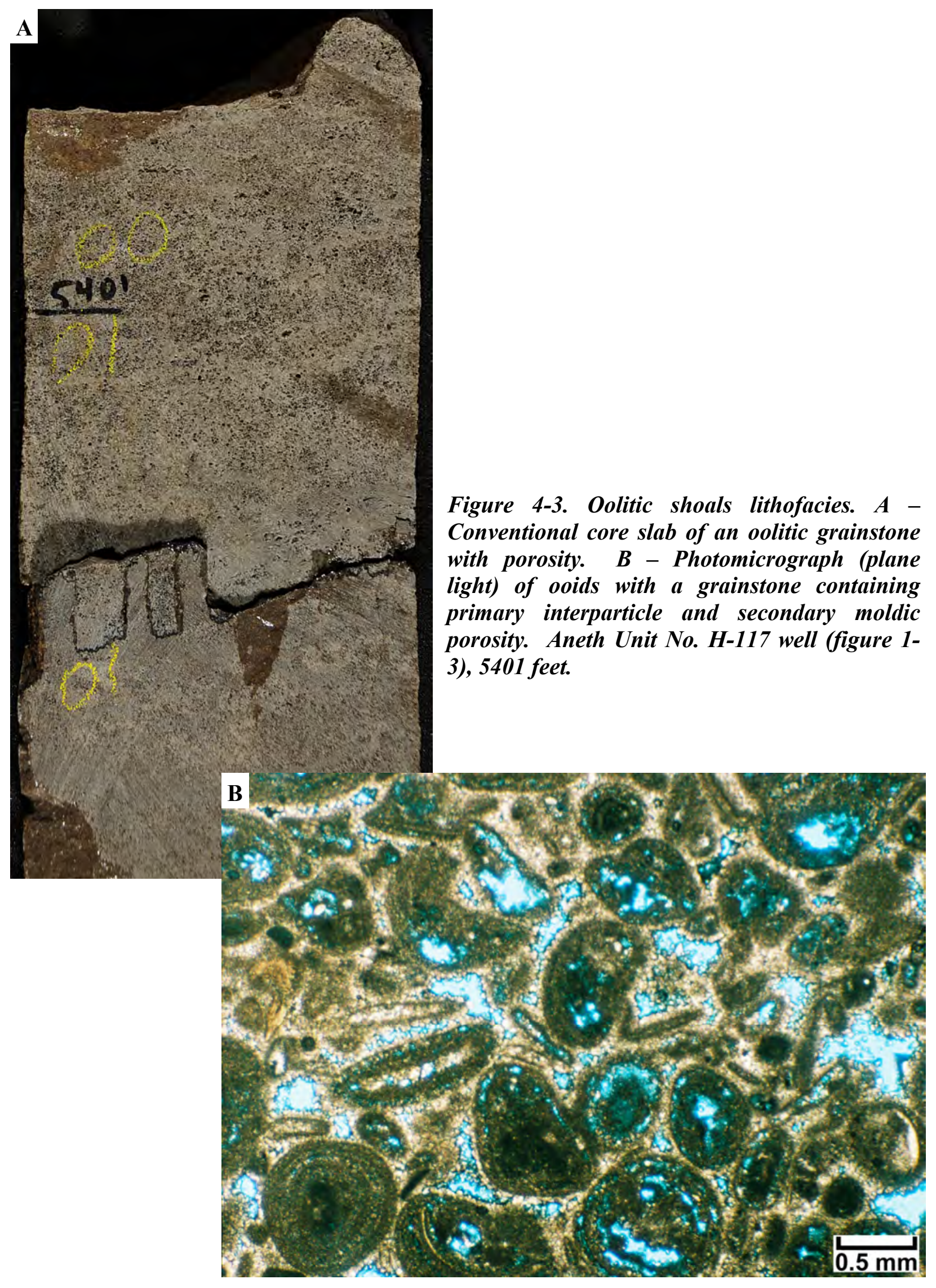




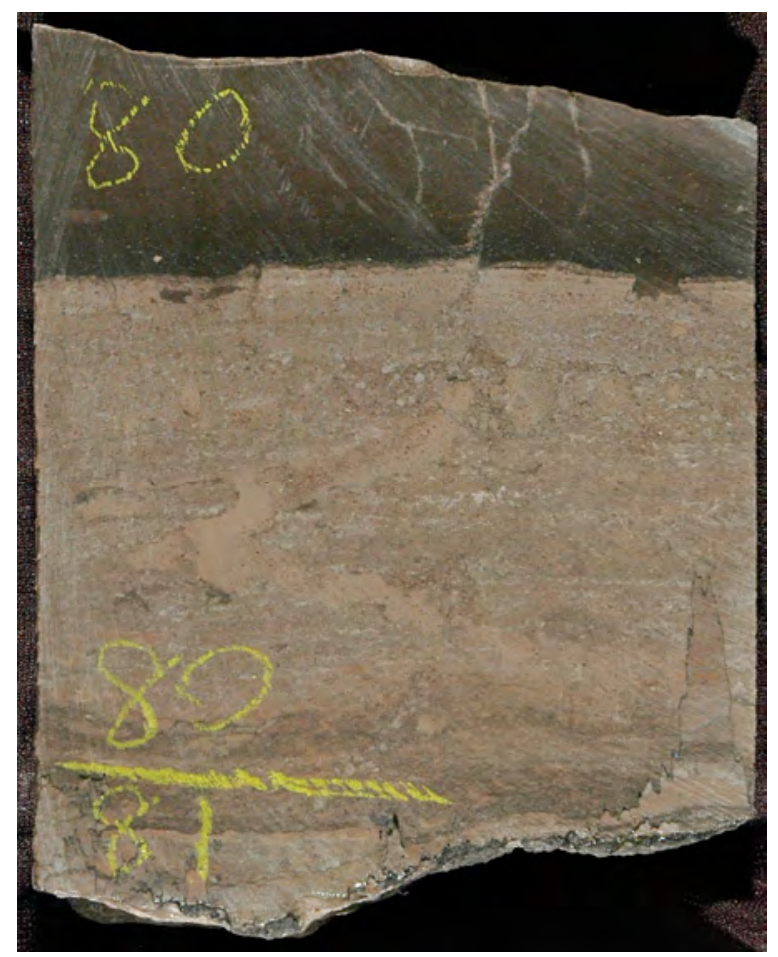

Figure 4-4. Contact between quartz sandstone and possible exposure (flooding) surface. Aneth Unit No. E-418 well (figure 1-3), 5980-5981 feet. 


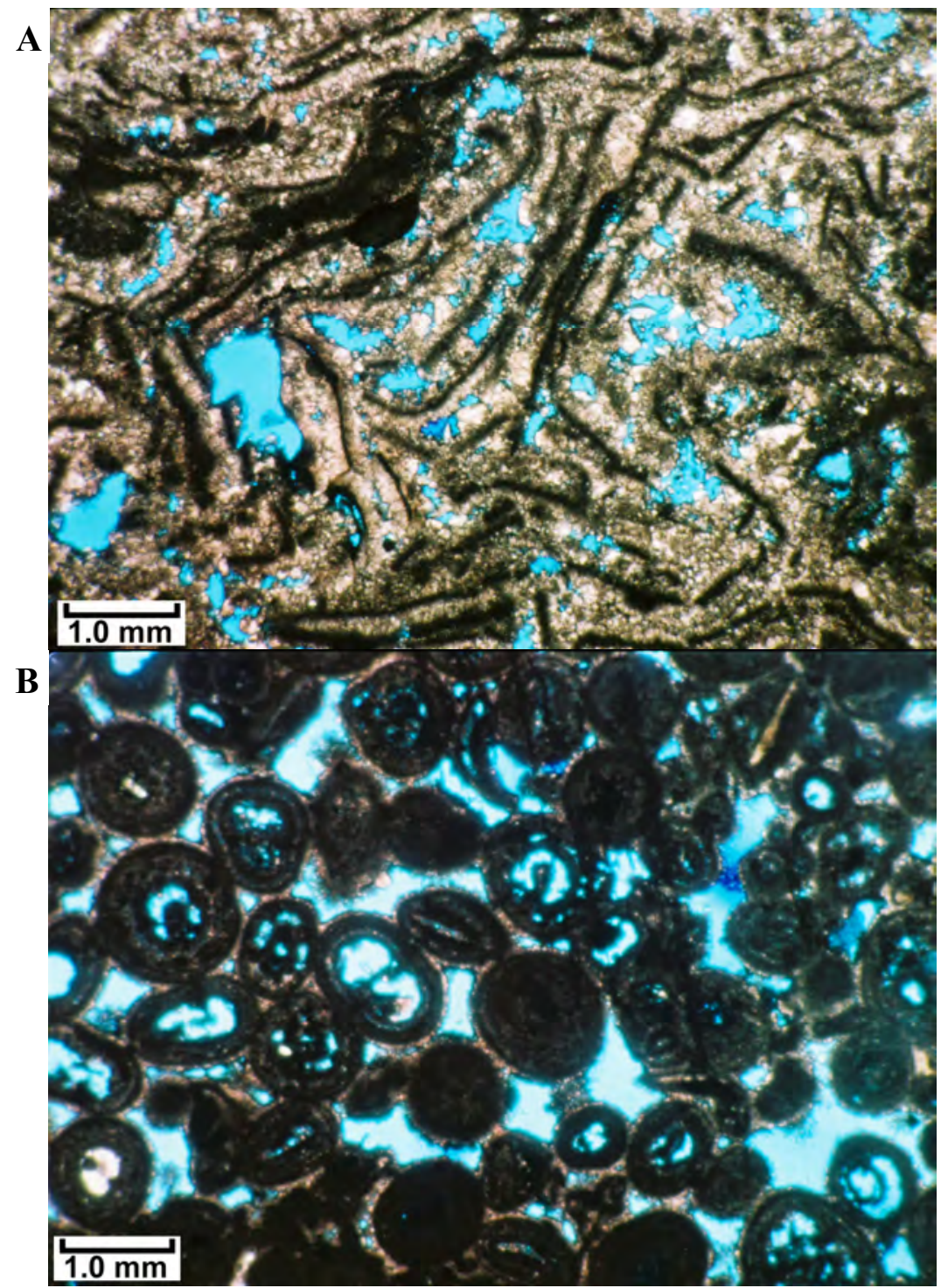

C

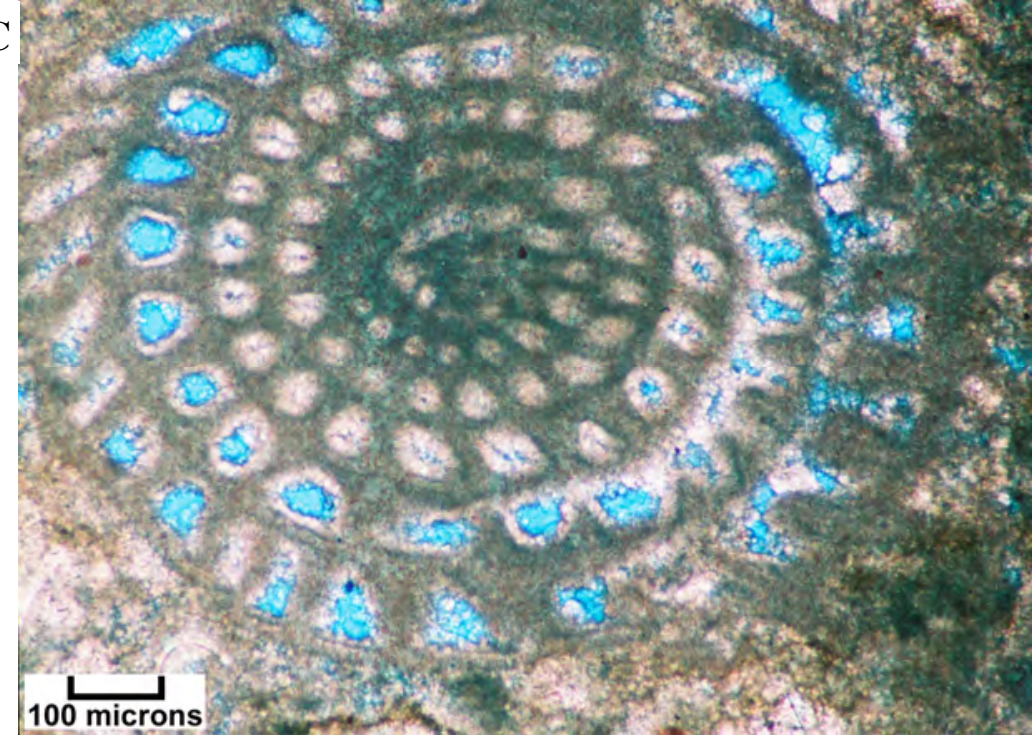

Figure 4-5. Photomicrographs of primary porosity types. A Photomicrograph (plane light) of shelter porosity (blue areas) between phylloid-algal plates within an algal bafflestone fabric. Aneth Unit No. F-317 well (figure 1-3), 5455 feet. B Photomicrograph (plane light) of interparticle porosity(blue areas) between ooids within an oolitic grainstone fabric. Aneth Unit No. H-117 well (figure 13), 5400 feet. $C$ Photomicrograph (plane light) of intraparticle porosity (blue areas) within the chambers of a large fusulinid in skeletal/ peloidal packstone/wackestone fabric. Aneth Unit No. H-117 well (figure 1-3), 5480 feet. 


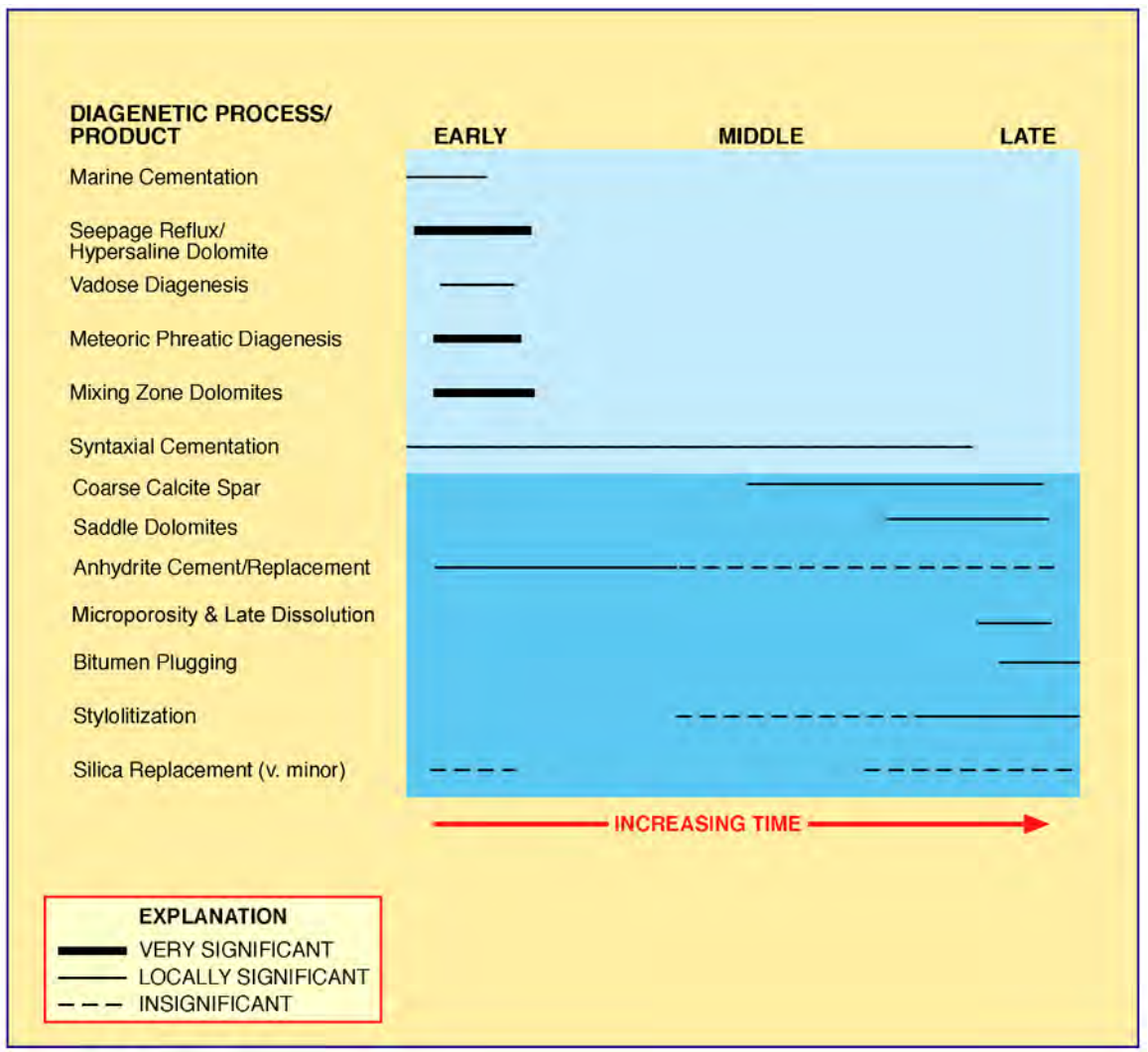

Figure 4-6. Typical diagenetic sequence through time for the Desert Creek zone based on thin section analysis. 

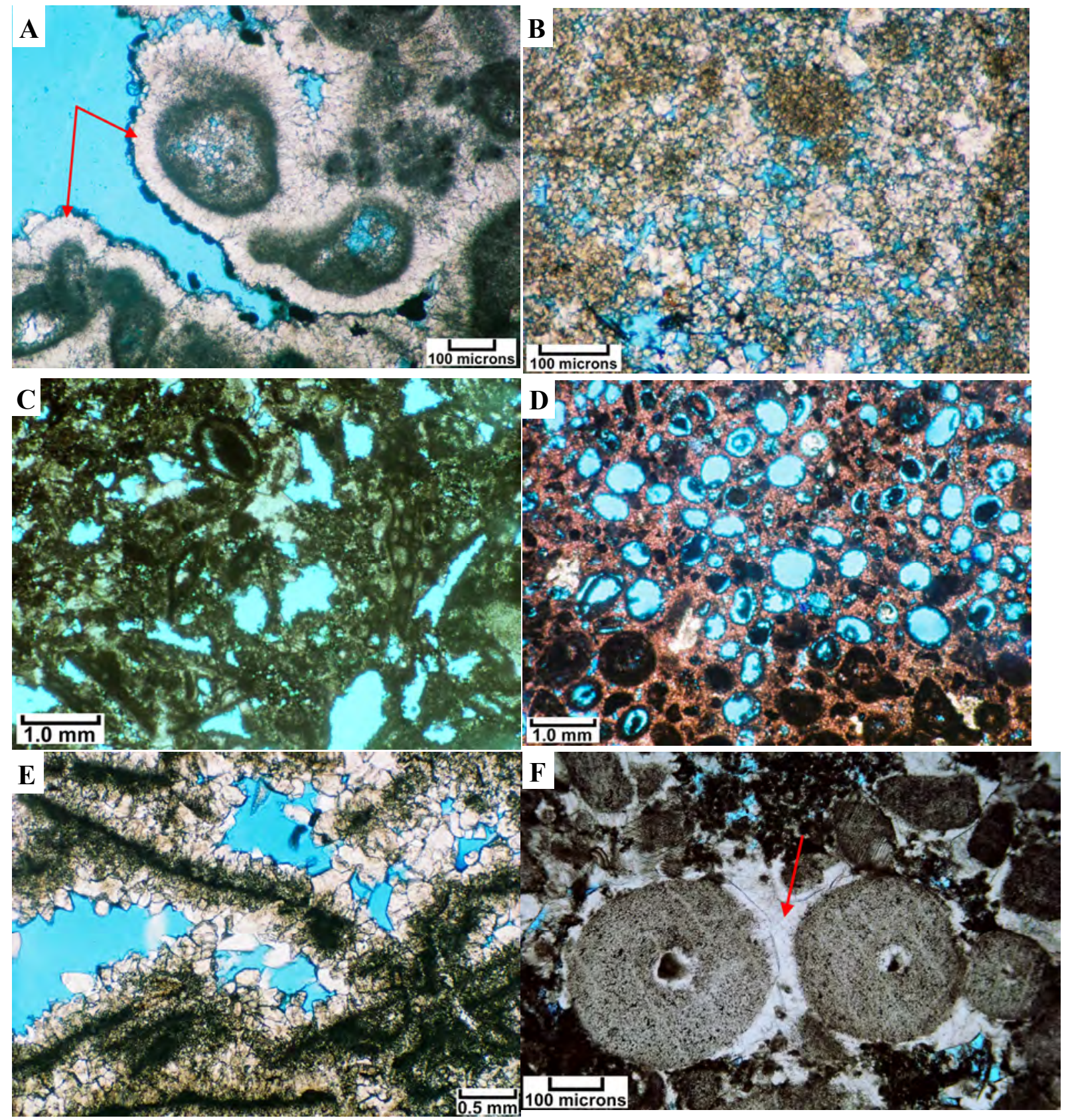

Figure 4-7. Photomicrographs (plane light) of early diagenesis. A-Rinds of early marine isopachous cement (red arrows) on ooids and skeletal grains, thus filling interparticle pores (blue) of an oolitic/skeletal grainstone fabric. Aneth Unit No. H-117 well (figure 1-3), 5441 feet. B Extensive dolomitization and microintercrystalline porosity (blue) in an original peloidal packstone/wackestone fabric. Note brown rounded areas representing "ghosts" of peloids. Aneth Unit No. F-317 well (figure 1-3), 5395 feet. $C$ - Moldic and vuggy porosity (blue) in a skeletal/ peloidal packstone/wackestone fabric with skeletal fragments including crinoid, phylloid-algal plates, small benthic forams, and fusilinids; peloids include both hard and soft varieties. Aneth Unit No. 27-C-3 well (figure 1-3), 5738 feet. D-Oomoldic porosity (blue) in an oolitic grainstone fabric. Sparry mosaic calcite cement between ooid molds and grains results in an isolated "heartbreak" porosity system. Aneth Unit No. 27-D-4 well (figure 1-3), 5621 feet. E - "Dogtooth" spar filling shelter pores (blue) between phylloid-alagal plates in a phylloid-algal bafflestone fabric. Aneth Unit No. F-317 well (figure 1-3), 5472 feet. F-white syntaxial calcite cement (red arrow) overgrowths surrounding two discrete ossicles within a crinoidal grainstone fabric. Aneth Unit No. 27-C-3 well (figure 1-4), 5806 feet. 

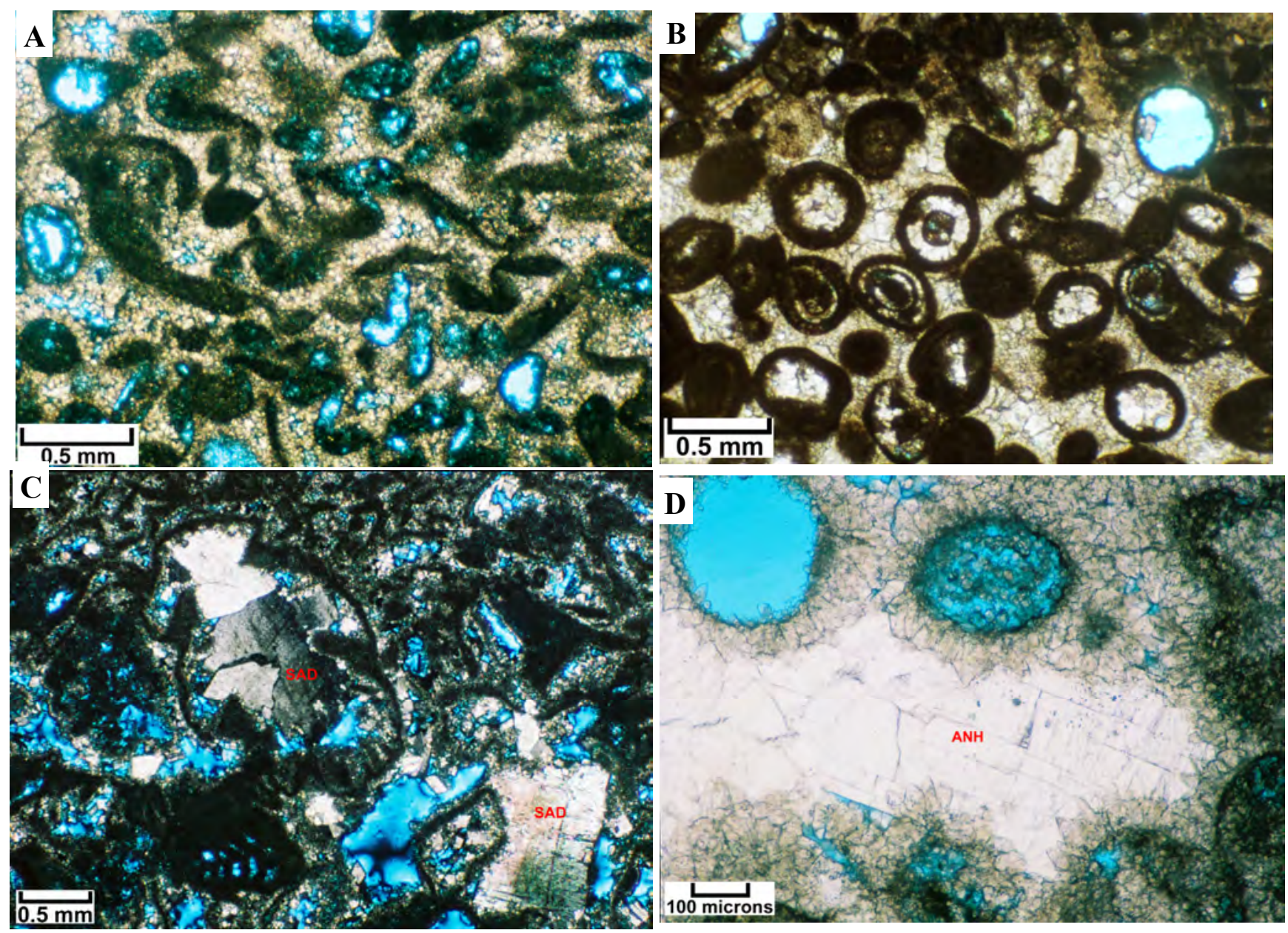

Figure 4-8. Photomicrographs of post-burial diagenesis. A- "Elephant trunks and tails"texture formed by the compaction of ooid molds (plane light). Aneth Unit No. E-313 well (figure 1-3), 5785 feet. $B$-Late calcite cement completely filling the original interparticle pores between ooids and oomoldic pore s(plane light). Aneth Unit No. 27-D-4 well (figure 1-3), 5507 feet. C-Saddle dolomite (SAD) within skeletal molds (cross nicols). Note sweeping extinction within the curved saddle dolomite crystal in the center. Aneth Unit No. F-317 well (figure 1-3), 5440 feet. D Closeup of large, late, anhydrite replacement crystals (ANH) within an oolitic grainstone (plane light). Note two large remaining oomolds (blue). Aneth Unit No. H-117 well (figure 1-3), 5413 feet. 

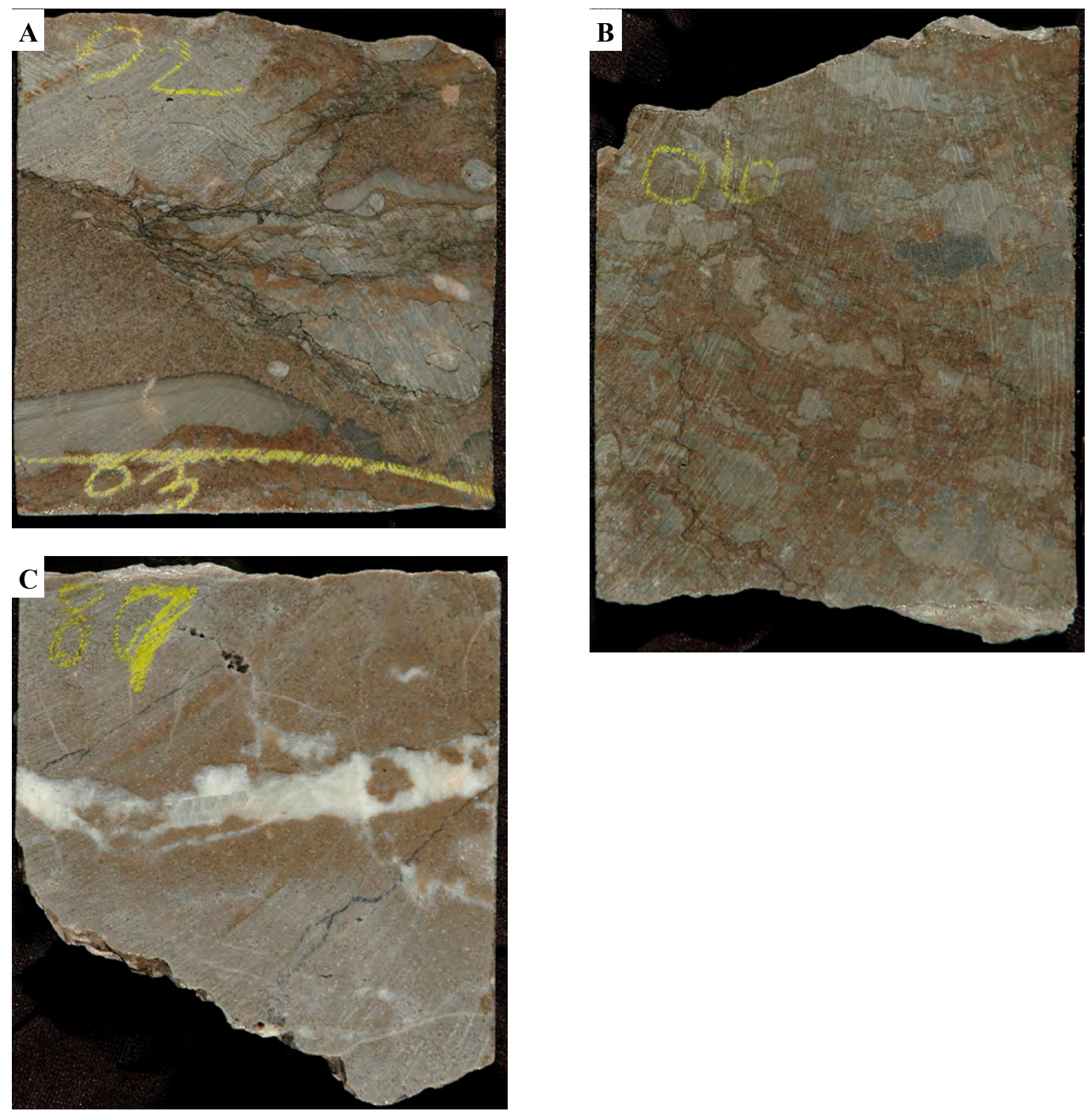

Figure 4-9. Evidence of possible fault zone near the Aneth Unit No. E-418 well (figure 1-3). $A$-Dolomite replacement bounded by stylolite and fracture swarms, 6002 feet. B-Breccia with limestone clasts surrounded by stylolites and dolomite, 6006 feet. C-Saddle dolomite hydrothermal alteration replacement and vugs lined with saddle dolomite, well-terminated quartz, and bitumen, 5987 feet. 

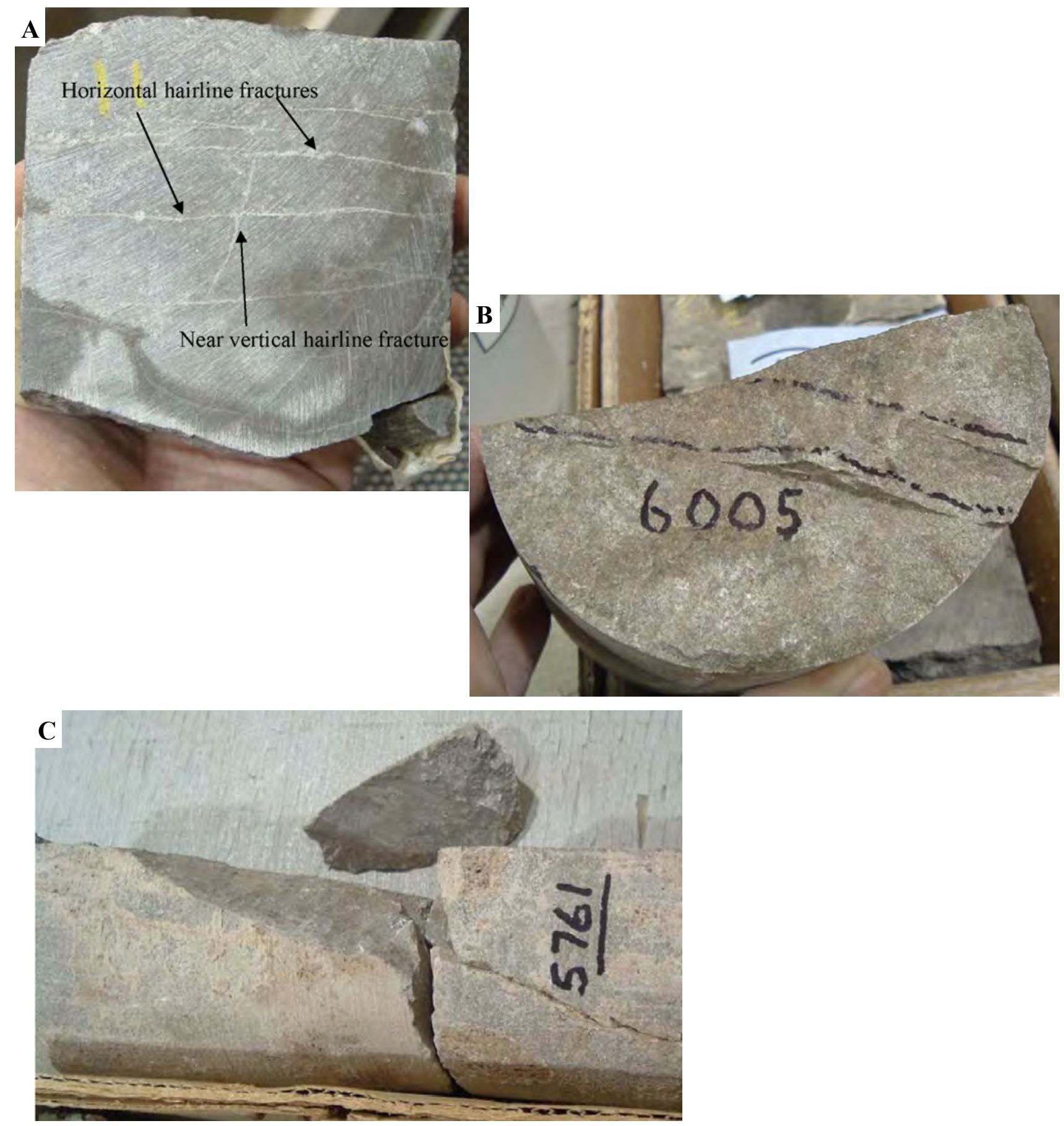

Figure 4-10. Examples of fracture types in the Desert Creek zone, Aneth Unit. A-Near vertical and horizontal hairline fractures. Aneth Unit No. E-418 well (figure 1-3), approximately 6011 feet. B - Pair of parallel vertical fractures, spacing is less than 1 inch. Aneth Unit No. E-418 well (figure 1-3), 6005 feet, view is downhole. C-Inclined fractures with step surface indicating potential shear. Aneth Unit No. 27-C3 well (figure 1-3), 5761 feet. D-Horizontal fractures. Aneth Unit No. 27-C3 well (figure 1-3), 5820 feet. E Example of a stylofrac evidenced by an opening along the stylofrac plane and subsequent filling with calcite. Aneth Unit No. E-418 well (figure 1-3), 5983 feet. F - Three orientations of vertical fractures intersecting in one core piece. This section of core is rubble, likely due to the numerous fractures present. Fractures are highlighted with black marker lines parallel to the fractures. Aneth Unit No. 27-C3 well (figure 1-3), 5781 feet. 

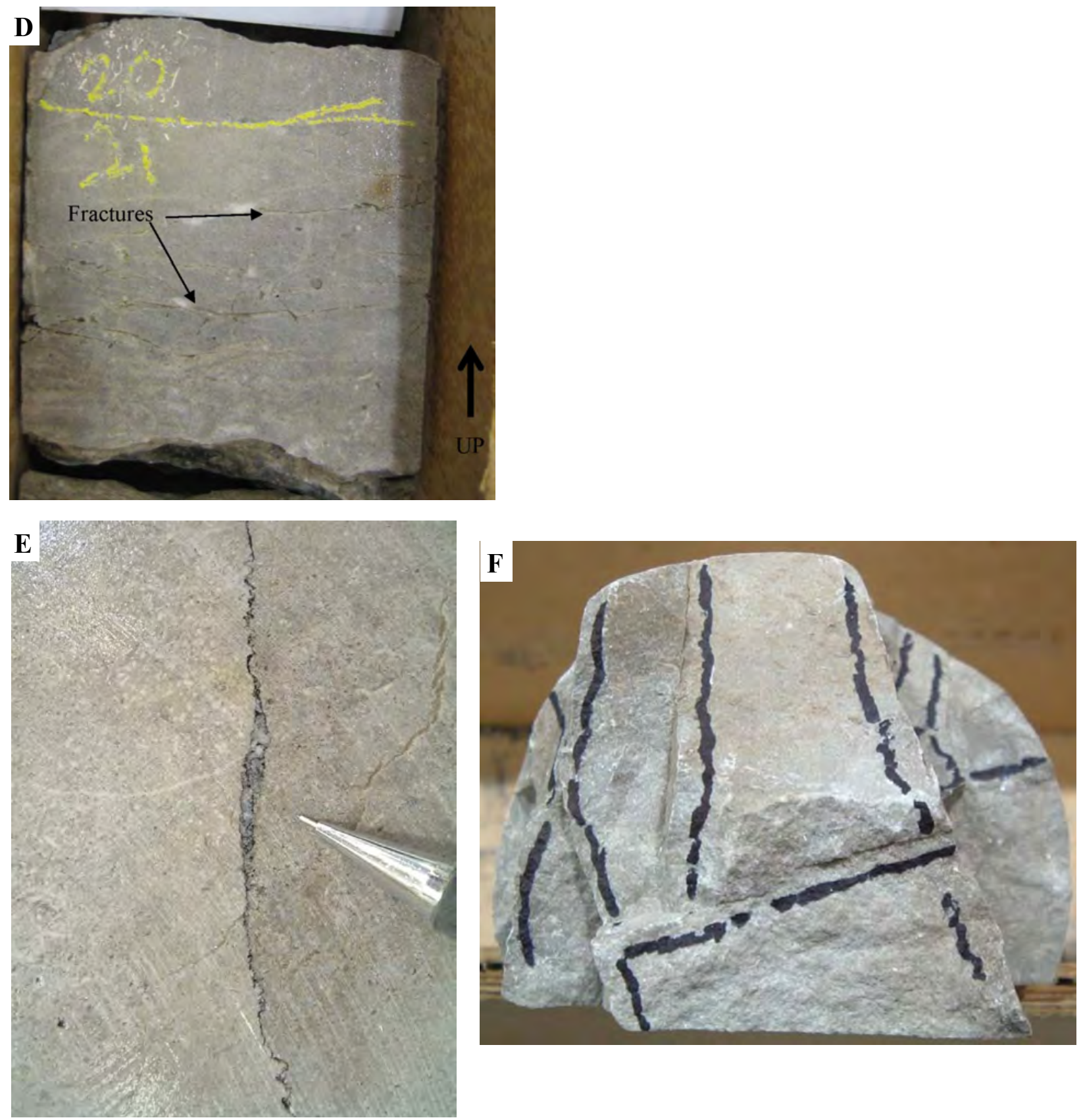

Figure 4-10. Continued. 

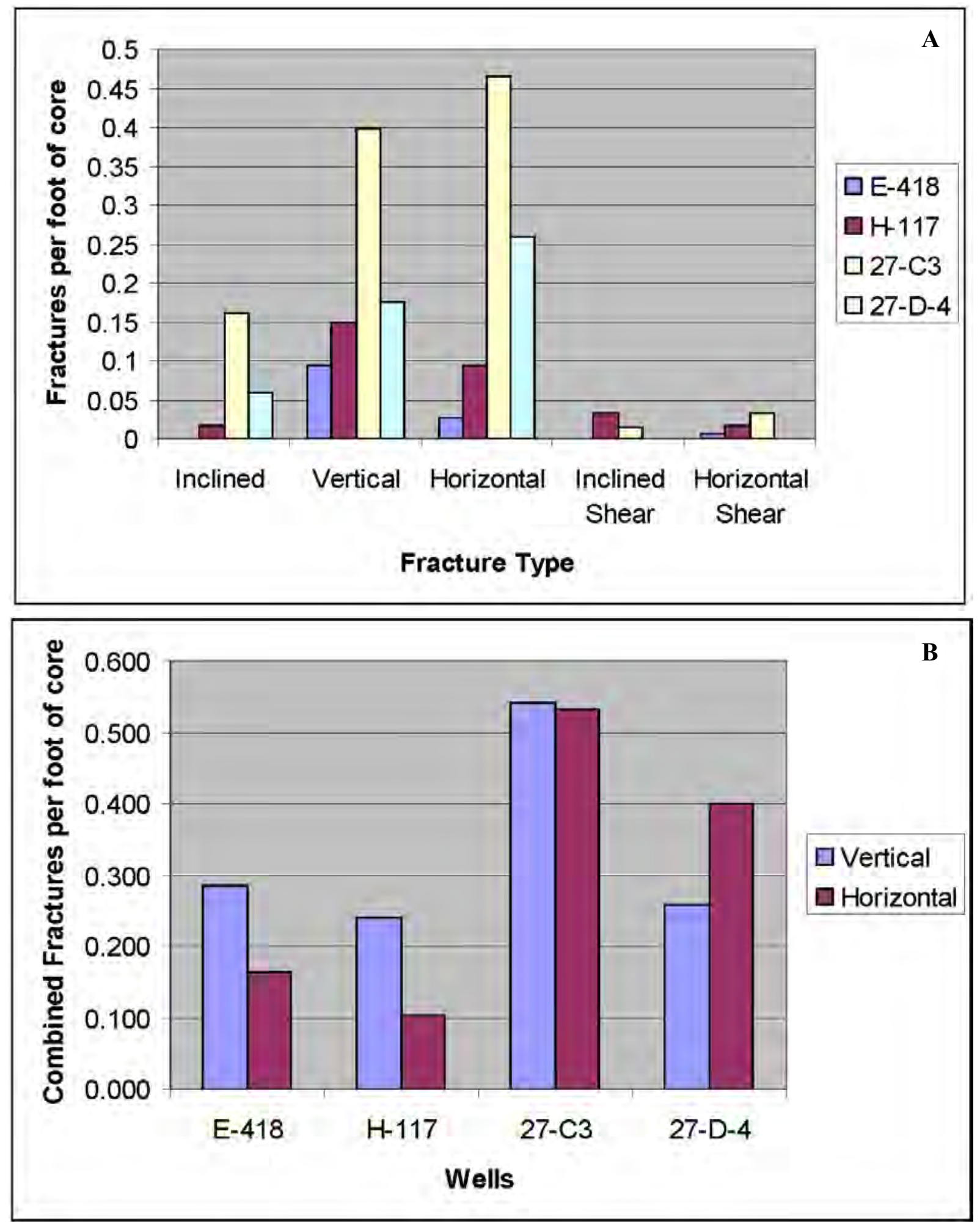

Figure 4-11. Bar graphs showing relative numbers of fractures per foot by well. $A$ Fracture types. Only larger scale fractures were tabulated here; hairline fractures are eliminated. From this graph Aneth Unit No. 27-C3 well has more fractures per unit length than the other wells. Note shear fractures are found in the Gothic shale and discussed on Chapter 5. B - Combination of all vertical and horizontal fractures (hairline and larger) showing the Aneth Unit No. 27-C3 well is the most highly fractured well overall. 

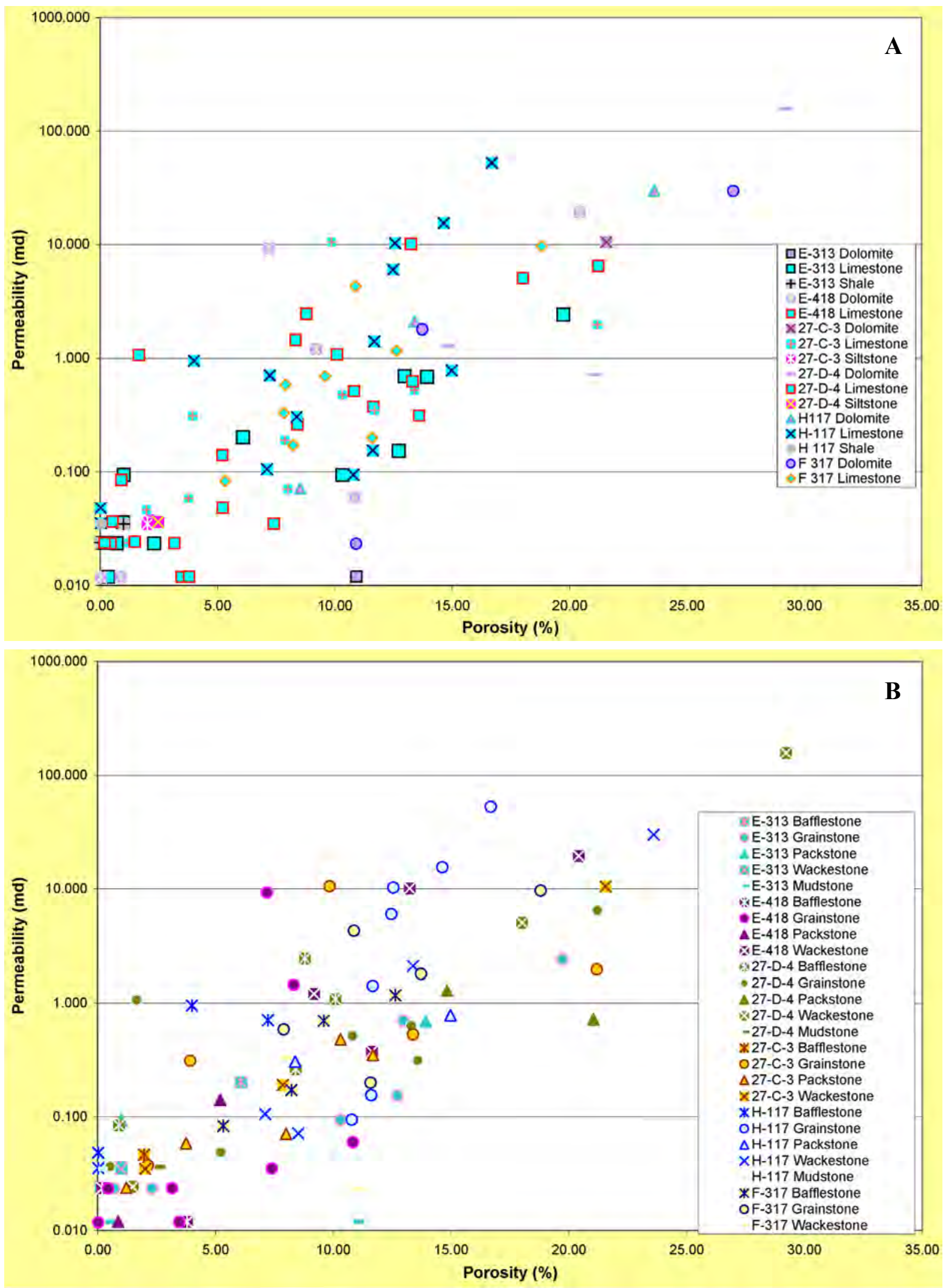

Figure 4-12. Aneth Unit permeability versus porosity cross-plot by (A) lithology, (B) carbonate fabric, (C) lithofacies, and (D) $\mathrm{CO}_{2}$ storage potential. 


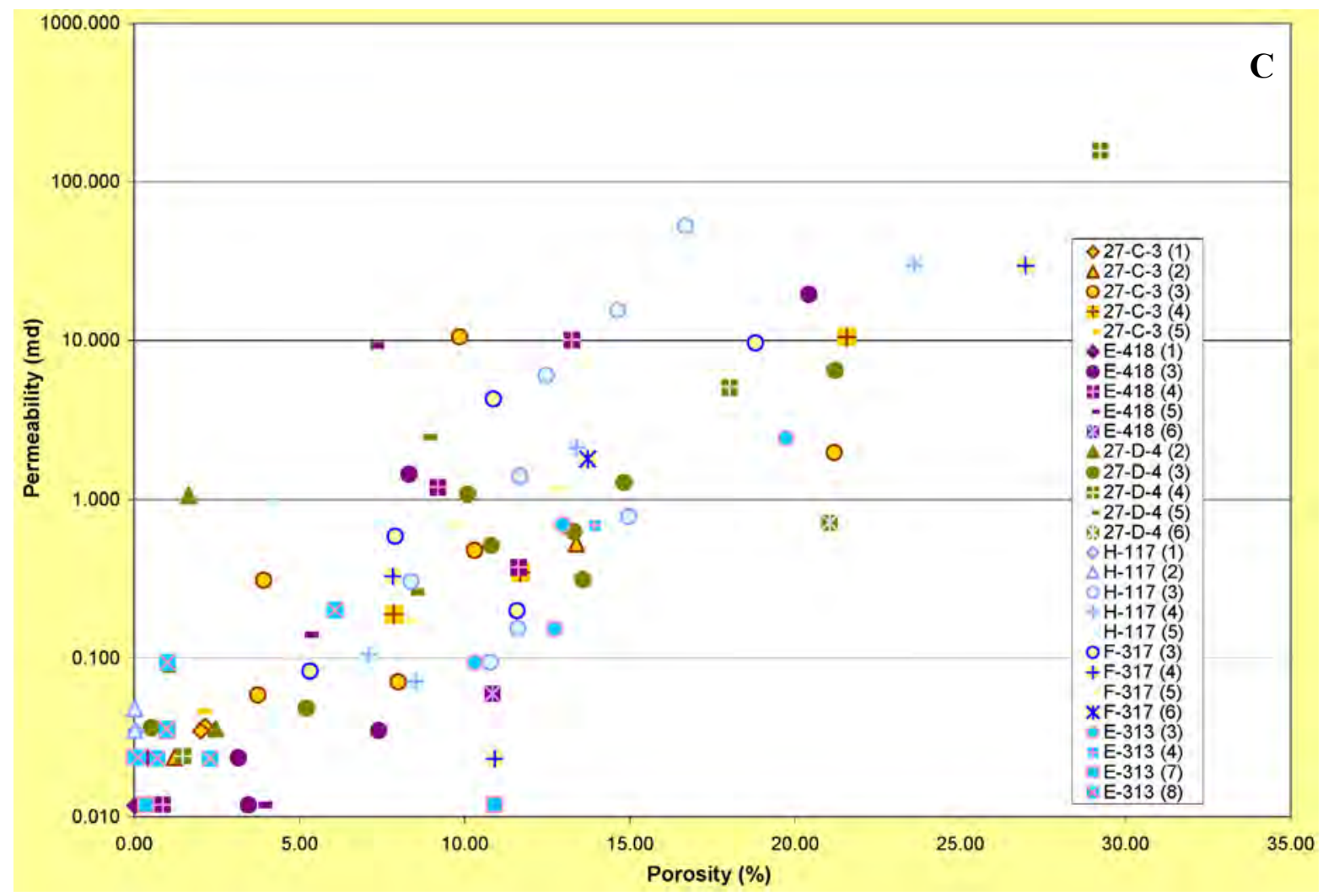

Note: (1) Foreshore/Shorface, (2) High-moderate energy, shallow marine, (3) High-moderate energy, shoal/bank, (4) Low energy, shallow marine, (5) Shallow water, phylloid-algal buildup, (6) Low energy, restricted, (7) Deep water anoxic basin, (8) Grain flow in deep water

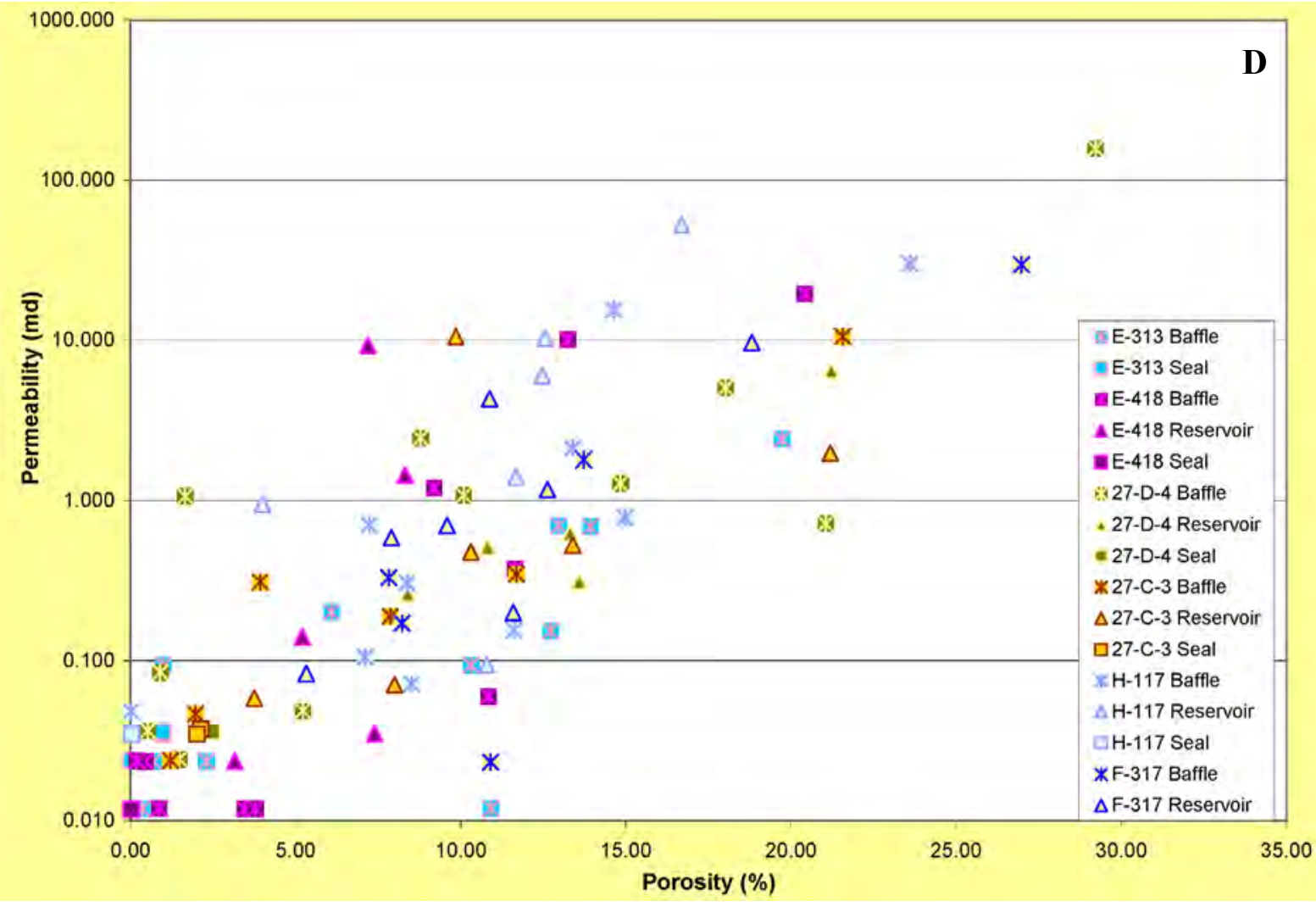

Figure 4-12. Continued. 


\title{
CHAPTER 5 THE GOTHIC SHALE IN THE ANETH UNIT: SEAL FOR HYDROCARBONS AND $\mathrm{CO}_{2}$ GEOLOGIC SEQUESTRATION
}

\author{
by \\ Thomas C. Chidsey, Jr., Utah Geological Survey, \\ Jason Heath, New Mexico Institute of Mining and Technology, \\ Thomas Dewers, Sandia National Laboratories, \\ Schlumberger TerraTek, \\ John C. Lorenz, Geoflight LLC, (formerly with Sandia National Laboratories), and \\ Scott P. Cooper, Cooper Geological Consulting (formerly with Sandia National Laboratories)
}

\section{Introduction}

A reservoir seal can be defined as a body of rock that is capable of significantly impeding the migration or movement of oil, natural hydrocarbon gas, and $\mathrm{CO}_{2}$ (Couples, 2005). Diffusion in this case is not considered an important means for moving hydrocarbon or $\mathrm{CO}_{2}$. Key relationships to consider in understanding seals include those between porosity and (1) stress, (2) permeability, and (3) capillary breakthrough pressure (Alpin and Larter, 2005). These relationships are affected by the seal's petrographic (grain size, mineral composition, and clay fraction) and geochemical (organic content and maturity) characteristics. The ability of mudrock (shale), salt, and anhydrite to prevent $\mathrm{CO}_{2}$ (and hydrocarbon) leakage is a critical factor for the geological storage of anthropogenic $\mathrm{CO}_{2}$ (Lu and others, 2009). For effective storage of $\mathrm{CO}_{2}$ produced from coal-fired power plant point sources, retention times of 10,000 years are required (Lindeberg, 2002). Therefore, it is critical to understand if the seal can remain effective for long periods of time (Lu and others, 2009). For large-scale geologic $\mathrm{CO}_{2}$ storage, additional questions not part of a typical hydrocarbon reservoir seal analysis must be addressed. These include:

1) Can the impact of preexisting seal fractures and flaws on $\mathrm{CO}_{2}$ transport be adequately characterized prior to $\mathrm{CO}_{2}$ injection?

2) What chemical alterations of seal rock minerals and/or organic matter would occur from interaction with $\mathrm{CO}_{2}$-rich fluids, and how would they affect sealing capacity?

3) What rate and amount of $\mathrm{CO}_{2}$ leakage would be acceptable?

4) What geomechanical impacts accompany $\mathrm{CO}_{2}$ injection?

A major challenge is identifying local micro- to meso-scale imperfections or flaws in seals that could allow $\mathrm{CO}_{2}$ to migrate from potential storage sites, which may cover areas up to hundreds of square miles. The Southwest Regional Partnership on Carbon Sequestration investigated these questions at the Aneth Unit demonstration site to develop and test conceptual and numerical models of sealing behavior with a focus on understanding pre-existing natural imperfections and the potential formation of new imperfections.

At Greater Aneth field, Paradox Formation shale, halite, and anhydrite serve as vertical reservoir seals; lateral seals are permeability barriers created by unfractured, off-mound (nonbuildup) mudstone and wackestone. Within the Paradox Formation, the Gothic shale seals the underlying Desert Creek reservoir zone at Greater Aneth and other nearby fields. The Gothic is 
widespread throughout the Paradox Basin but is only exposed in the San Juan River Canyon west of the Aneth area. In the Aneth Unit, the Gothic shale is remarkably uniform, consisting of black to gray, laminated to thin-bedded, dolomitic marine shale. It ranges in thickness from 5 to 27 feet (1.5-8.2 m), averaging 15 feet (3.6 m) (figure 3-9) and generally thins over the carbonate buildup complex in the Desert Creek zone; the structural contours also reflect the Desert Creek thickness (figure 3-8).

The following activities were conducted on the Gothic shale: (1) general core description, (2) geochemistry, (3) petrography, (4) analysis of natural fractures, (5) petrophysical properties (basic reservoir parameters, mercury injection capillary pressure and pore aperture distributions), and (6) geomechanics. The study results can be used to to determine the geologic controls on seal efficiency, effects of pressure changes on seal efficiency due to $\mathrm{CO}_{2}$ injection and storage, and chemical interaction between $\mathrm{CO}_{2}$ and the seal at its contact with the reservoir through time.

\section{General Core Description}

Core from the Aneth Unit H-117 No. well (figure 1-3) contains nearly a complete (16 feet [4.9 m]), unslabbed section of Gothic shale (figure 5-1A). Therefore, this core was ideal for detailed representative analysis of the Gothic seal for the Desert Creek reservoir in the Aneth Unit. Detailed geological description of core is essential to define lithologic units and, in combination to petrological analysis, provides the fundamental mineralogical, textural, or diagenetic factors defining the seal. In the Gothic shale, seemingly subtle variations in mineralogical character, cementation, or depositional environment may result in important changes in seal capacity or result in mechanical boundaries. These subtle differences may in turn control fracture spacing, distribution, orientation, and conductivity.

The Gothic shale strata consist of a fairly monotonous interval of dark brown to gray, faintly wavy laminated, calcareous mudstone (see figure 5-1B for detailed core description). They contain various amounts of terrigenous quartz, chert, feldspar, micas, illitic and chloritic clays, phosphate, some carbonaceous material, and fossil fragments. Fossils present are both megafossil and microfossil varieties (transported and indigenous) including calcareous bivalves and ostracods, inarticulate brachiopods, phosphatic conularioids, conodonts, arenaceous foraminifera, and possible spores of indeterminate origin. Diagenetic products include abundant pyrite and varying amounts of rare to common dolomite/ankerite. Modest amounts of clay microporosity likely occur, but the permeability is in the nannodarcy range. The basal portion of the Gothic appears clearly most organic with elevated total organic content (TOC) where a clear flooding surface transgressed over older mottled carbonates with possible pisolitic content. In some instances, the basal mudstone appears to erode the underlying limestones, and a basal lag rich in bivalves and pyrite is obvious there. Above this basal lag, the lower portion of the Gothic seems to contain a wider assemblage of phosphatic constituents-conodonts, conularioids, and indistinct (fish) fragments.

The Gothic depositional environment was offshore marine. The slow deposition still received clastic influx from a distal source. This source was likely dysaerobic, organic-rich material diluted by terrigenous clastics. 


\section{Geochemistry}

In the Colorado part of the Paradox Basin, the Gothic shale produces hydrocarbon shale gas. To understand the Gothic's effectiveness as a seal, a full understanding of any hydrocarbon potential as well as the long-term reactivity of organic content with $\mathrm{CO}_{2}$ is required. Meaningful estimates of shale gas-in-place reserves-and subsequent deliverability of this gas-require accurate formation evaluation. These data are obtained by measuring the volume and rate of gas released by laboratory isotherm adsorption measurements. Lost gas analysis is then made to estimate original gas-in-place. Gas analysis and geochemical characterization provide fundamental complimentary information for gas composition, organic content, kerogen type, and kerogen maturity. Specifically, the following tests were conducted: (1) Rock-Eval pyrolysis, (2) total organic component analysis, (3) calculated vitrinite reflectance, and (4) adsorption isotherms (tables 5-1 and 5-2). All Gothic geochemical and isotherm adsorption measurements are included in Chidsey (2009).

In the Aneth Unit, Gothic shale has a TOC between 2.8 and 4.4\%. The content of free hydrocarbons (gas and oil, $\mathrm{S}_{1}$ ) in the Gothic ranges from 1.9 to $2.4 \mathrm{mg} / \mathrm{g}$, and amount of hydrocarbons generated through thermal cracking of nonvolatile organic matter $\left(\mathrm{S}_{2}\right)$ ranges from 5.2 to $9.5 \mathrm{mg} / \mathrm{g}$. The amount of $\mathrm{CO}_{2}$ (in milligrams $\mathrm{CO}_{2}$ per gram of rock) produced during pyrolysis of kerogen $\left(\mathrm{S}_{3}\right)$ ranges from 0.6 to $0.8 \mathrm{mg} / \mathrm{g}$, and has important implications for geologic storage $\mathrm{CO}_{2}$ in the Desert Creek zone below. Kerogen type determination from TOC and Rock-Eval pyrolysis data show the Gothic contains type II and mixed type II-III kerogen (figure 5-2) while kerogen quality suggest it to be gas prone (figure 5-3). Types I and II will generate oil; type III gas; and type IV little or no hydrocarbon. Isotherm methane adsorption and Langmuir measurements (table 5-2 and figure 5-4) show gas versus pressure to evaluate adsorbed and interstitial gas content. Gas content ranges from 6.9 to 51.2 standard cubic feet per ton (0.22-1.60 scc/gm) at pressures from 37 to 662 psia (0.26-4.56 MPa).

$\mathrm{X}$-ray fluorescence and diffraction analyses were also performed on the Gothic core. Xray fluorescence data for selected 2-foot intervals over the length of the core show $41 \%$ silicon dioxide, $26 \%$ calcium oxide, $10 \%$ aluminum oxide, $7 \%$ iron oxide, $5 \%$ magnesium oxide, $4 \%$ potassium oxide, and 3\% sulfur trioxide plus various small amounts of trace oxides. Semiquantitative X-ray diffraction (XRD) analysis is used to define clay composition, clay expandability, and to build log correlations. Certain shale lithofacies can only be verified by XRD analysis. XRD results from bulk and oriented (clay fraction dominant) samples are shown in figure 5-5. All data are referenced to the magnitude of the quartz peak. Offsets are imposed on the data for the purpose of comparison. The bulk analysis (powder) plot (left) shows the consistency of mineralogical composition over the range of the core. The indistinct illite peak is consistent as are the strong quartz, calcite, and dolomite peaks. The individual sample plots (right) illustrate the difference in results between the glycol treated samples and non-treated samples. XRD analysis of the glycol treated samples in some cases resulted in a definite illite peak while in other cases enhanced the existing illite peak. In both cases the presence of a small percentage of expandable clays (approximately 10\%) such as smectite is inferred.

\section{Petrography}

Thin section and scanning electron microscope (SEM) analysis are fundamental to petrological description. Thin section analyses of Gothic shale samples are used for petrological 
description of the lithofacies and to establish a baseline correlation of petrophysical properties related to the geologic/petrologic descriptions. They are used as a screening tool for important seal parameter investigations such as diagenetic alteration, cementation, and fracture fills. SEM imaging involves high-magnification imaging of small, representative reservoir samples, and is required to identify clay morphology, kerogen location, and for pore characterization. All thin section photomicrographs, SEM images, and petographic descriptions are included in Chidsey (2009). The Gothic shale contains abundant carbonates and clays. High seal capacity is indicated by the high clay content and cementation/compaction.

Two other techniques employed are laser scanning confocal microscopy (LSCM) and backscattered electron imaging (BSE). LSCM is a technique for obtaining high-resolution optical images with depth selectivity. The key feature of confocal microscopy is its ability to acquire in-focus images from selected depths, a process known as optical sectioning. Images are acquired point-by-point and reconstructed with a computer, allowing three-dimensional reconstructions of topologically complex objects. For opaque specimens this is useful for surface profiling (Wikipedia, 2009). BSE is also a technique for obtaining high-resolution optical images with depth selectivity that show more contrast and structural details. Backscattered electrons have higher energies than secondaries, and are produced when electrons from the primary beam are "bounced" back out of the sample by elastic collisions with atoms. The number of electrons a given material will backscatter is proportional to the mean atomic number of the component elements. Materials composed of larger, heavier atoms will backscatter more electrons, producing brighter gray tones in the images than less dense materials (differences in average atomic mass of 0.1 amu can be resolved). Backscattered electrons thus produce an image that is related to material composition, providing both spatial and chemical information.

\section{Argillaceous Shale}

Argillaceous shale lithotypes in Gothic shale show a clay matrix supporting a few elongate chert stringers (figure 5-6A). These likely represent microfossils, scattered pyrite, and silt, as well as silt-sized calcite crystals. Pyrite is concentrated parallel to bedding (figure 5-6B). The SEM overview of this texture shows uniform, non-laminated argillaceous shale (figure 56C). A few siliceous and calcareous fragments float in a matrix of crenulated clays. LSCM images of a surface perpendicular to bedding in argillaceous shale show topography in corresponding oblique and map views on figure 5-7. The map view shows green, yellow-orange, and red fluorescing material at different magnifications. Red material is typically spherical and probably co-located with pyrite framboids. Green fluorescing material is the most abundant organic material, reflective of a primary depositional process that distributed the organic material. BSE images of argillaceous shale show the presence and distribution of pyrite, dolomite, calcite, smectite, illite, chlorite, and plagioclase (figure 5-8).

\section{Argillaceous Mudstone}

Argillaceous mudstone in Gothic shale shows weak laminations defined by micas and compacted cherty microfossils (figure 5-9A). Mudstone contains silt-sized calcite particles. The argillaceous matrix also supports dispersed, medium, silt grains and compacted cherty

microfossils in argillaceous mudstone matrix. Such forms are characteristic throughout this 
interval of Gothic shale, and commonly indicate microcrystalline quartz as a matrix cement. Reflected UV light display swarms of intercrystalline micropores (figure 5-9B). Brighter fluorescence inside the microfossil is attributed to mineral fluorescence. SEM images of argillaceous mudstone display distinct grain orientation (figure 5-9C). Compacted packets of clays are the main textural feature, separated by planar parting surfaces. The clay-rich matrix hosts numerous micropores; authigenic pyrite is ubiquitous. Mudstone matrix has wavy parting planes between clay packets (figure 5-9D). Replaced microfossils are lined with kerogen residue. Matrix clays are likely illite and/or mixed layer illite-smectite. The matrix also shows unaltered and altered carbonaceous material (figure 5-9D).

\section{Silty Calcareous/Argillaceous Mudstone}

Silty calcareous/argillaceous mudstone consists of finely disseminated carbonaceous material and abundant silt grains (figure 5-10A). The dominant textural components in the matrix are quartz silt, silt-sized calcite, mica flakes, and authigenic pyrite that float in a predominantly clay matrix (figure 5-10B). SEM images of calcareous argillaceous mudstone confirm the presence of many calcite particles and quartz silt grains. Cement-coated clay flakes preserve the microporous structure (figure 5-10C). Elongate pores parallel parting planes and the micropore network consisting of voids with sizes from 2-10 microns, and flattened in shape. Carbonaceous material is often preserved and commonly associated with pyrite (figure 5-10D). Intercrystalline porosity developed through alteration of organics.

\section{Phosphatic Argillaceous Mudstone}

Phosphatic argillaceous mudstone is a common component of the Gothic shale. It contains flattened, amalgamated pellets that are phosphatic in composition (figure 5-11A). Phosphatic argillaceous mudstone also includes compacted chert, siliceous fossils, micas, and flattened fecal pellets in a mixed siliceous/argillaceous matrix with siliceous cement component (figures 5-11B). Micropores appear under UV light (figure 5-11B). SEM images of phosphatic, argillaceous mudstone show the clay packets that make up the matrix are separated along parting surfaces, contributing to a fissile texture (figure 5-11C). Flattened phosphatic/organic pods have granular internal textures along horizontal parting planes (figure 5-11D). BSE images of phosphatic argillaceous mudstone show pyrite, dolomite, calcite, quartz, smectite, and illite/smectite (figure 5-12).

\section{Analysis of Natural Fractures}

Fracture analysis includes the evaluation of natural and induced fracture systems, fracture orientation, and mineral composition of fracture fill. Typical tabulated data from the fracture analysis includes general fracture type, fracture dip orientation, type of mineral fill, type of oil stain, apparent fracture dip, fracture porosity, fracture spacing, and fracture intensity. Fractures present in the Gothic shale will be an important factor in $\mathrm{CO}_{2}$ containment. Natural fractures include three inclined shear fractures or fracture zones and one horizontal shear fracture. Fractures are slickensided and partially mineralized.

Inclined shear fracture zones, possible permeability pathways, are undulous and contain multiple fracture surfaces; overall dip ranges from $30^{\circ}$ to $44^{\circ}$. Slickenlines rake obliquely across 
the dip of the shear planes, and are probably parallel on successive planes. They suggest significant horizontal tectonic compression at some point during the geologic history of the strata. These sub-horizontal shear planes were observed in both the Gothic shale and upper Desert Creek zone. The inference is that this may be a zone of incipient or limited detachment.

Thin sections and LSCM images reveal both extension and shear fractures (figures 5-13; annotation below thin section images - crossed-polars thin section photomicrograph [XPL], unstained thin section [no annotation], LCSM and BSE previously defined). Dilational jogs and crack-seal textures are visible in the images. Fracture set orientations indicate maximum principal compressive stress is oriented vertically. The sense of shear is dextral.

Fluorescent organics are co-located with mineralization in fractures. Preliminary microprobe analysis indicates that carbonates and sulfates dominate fracture mineralization (see BSE images on figure 5-13). Fracture mineralization contains microporosity and does not show strong crystal orientation. Vertical fractures are extensional. Cross-cutting relationships could not be discerned; perhaps the mineralization occurred synchronously in the two types of fractures.

This evaluation shows that organic material is co-located with fracture mineralization in the Gothic shale. This raises the question of how organics and carbonate might be affected geochemically by $\mathrm{CO}_{2}$-rich fluids. Induced dehydration features/fractures are not present in situ; however, they may indicate the potential creation of fracture zones if separate or dissolved phase $\mathrm{CO}_{2}$ can affect surface forces of the clay particles and their expanded versus collapsed texture (Andreani and others, 2008).

\section{Petrophysical Properties}

Shales are heterogeneous and strongly anisotropic. Sampling along the entire Gothic core interval was of fundamental importance for subsequent analysis of any hydraulic fracturing (that could be required for later $\mathrm{CO}_{2}$ storage) containment from the Desert Creek zone below.

\section{Basic Reservoir Parameters}

Petrophysical measurements were conducted to determine the density, porosity, permeability, saturations (gas, oil, and water), and bound water of the Gothic shale (table 5-3). All these petrophysical data and graphs are included in Chidsey (2009). These measurements are fundamental for seal capacity, as well as gas-in-place and gas productivity evaluations for potential gas shale reservoirs. The tests characterize the gas-filled and the effective porosities, the fluid saturations including mobile hydrocarbons (such as condensates), the "as received"

matrix permeability to gas. Pressure decay permeability measures to 10 nanodarcy accurately under reservoir net confining stress conditions and permits effective permeability to be measured at residual fluid pressure without moving fluid in the pore system.

The fact that porosity ranges from 2.7 to $3.4 \%$ and pressure-decay permeability is no greater than $0.000146 \mathrm{mD}$ is significant. These and other basic matrix petrophysical parameters indicate the Gothic shale is a highly effective reservoir seal.

\section{Mercury Injection Capillary Pressure and Pore Aperture Distributions}

The seal capacity of the Gothic matrix - the $\mathrm{CO}_{2}$ column heights retained by capillarity - 
was quantified by mercury injection capillary pressure measurements to understand and predict variations in seal capacity. Capillary pressure data applications include (1) differentiation of pay from non-pay, (2) evaluation of transition zones and free-water level, (3) wettability determination, (4) relative permeability calculation, (5) determination of pore throat size distribution, and of course (6) cap rock - seal capacity analysis.

The Gothic shale has very high seal capacity based on mercury injection capillary pressure and pore aperture distributions analysis (figure 5-14A and 5-14B; see Chidsey [2009] for all test data and graphs). These data show that clay content and high carbonate cementation/compaction lead to small pore throat diameters. The Gothic shale should support very large $\mathrm{CO}_{2}$ or hydrocarbon columns (1500 to 2600 feet [500-860 m]). The sample (the outlier) with the highest seal capacity was from the depth of 5378 feet (1639 m).

\section{Geomechanics}

Rock mechanics tests were performed to assess the variability of elastic properties and insitu stresses. Shales, in particular, are strongly heterogeneous and anisotropic, and thus their elastic properties are different in the vertical and horizontal directions. This contrast in elastic properties is not directly measured by geophysical well logs, but can have a dominant impact on predictions of in-situ stress. Therefore, the evaluation of anisotropic material properties and the in-situ stress throughout the core (for example, in-situ stress variations with respect to reservoir units and seals) is of fundamental importance. In-situ stress analysis of the Gothic shale was conducted to obtain a reasonable profile of the in-situ stress tensor (magnitude and orientation). In-situ stress analysis and mechanical property measurements provide fundamental data for evaluation of fracture containment when the Desert Creek reservoir below is hydraulically fractured for $\mathrm{CO}_{2}$ storage. Multistress anisotropy measurements are summarized in table 5-4. All geomechanical data and graphs produced from the study are included in Chidsey (2009).

\section{Young's Modulus and Poisson's Ratio}

Young's modulus is a measure of the stiffness of an isotropic elastic material. It is defined as the ratio of the uniaxial stress over the uniaxial strain in the range of stress in which Hooke's Law holds. Young's modulus is the ratio of stress, which has units of pressure, to strain, which is dimensionless; therefore Young's modulus itself has units of pressure. Figure 515 displays vertical dynamic Young's modulus as a function of vertical static Young's modulus (A) and horizontal dynamic Young's modulus as a function of horizontal static Young's modulus (B).

Poisson's ratio compares the contraction or transverse strain (normal to the applied load), to the extension of axial strain (in the direction of the applied load). Figure 5-16 displays vertical dynamic Poisson's ratio as a function of vertical static Poisson's ratio (A) and horizontal dynamic Poisson's ratio as a function of horizontal static Poisson's ratio (B).

These graphs and analysis from Young's modulus and Poisson's ratio suggest that the Gothic shale in the Aneth Unit is not brittle, as is the case in other areas of the Paradox Basin where it produces gas. Therefore, the Gothic is less likely to respond to hydraulic fracturing of the underlying Desert Creek zone. 


\section{Compressional Testing}

Figure 5-17A is a plot of axial stress difference versus radial and axial strains, measured during unconfined compression testing. The figure describes the evolution of rock deformation (that is, axial and radial strains) and failure (that is, yield stress, peak stress and residual strength - when available) during unconfined compression loading. Figure 5-17B is plot of axial stress difference versus volumetric strain, measured during unconfined compression testing. The figure describes the evolution of the rock deformation (dilation versus compaction) and the yield stress during unconfined compression loading. Axial stress difference versus axial strain, measured during unconfined compression testing is displayed on figure 5-17C. The figure describes the evolution of the axial modulus (Young's modulus) during unconfined compression loading. The averaged radial strain versus axial strain, measured during unconfined compression testing is shown on figure 5-17D. The figure describes the evolution of the transverse modulus (Poisson's ratio) during unconfined compression loading.

Continuous unconfined compressive strength profiles show a relatively uniform homogenous Gothic shale package - 20,000 psi (137,900 kPa) (figure 5-18). Compressional testing suggests some degree of hydraulic fracture containment. 
Table 5-1. Basic geochemical measurements from the Gothic shale in the Aneth Unit No. H117 well.

\begin{tabular}{|c|c|c|c|c|c|c|c|c|c|c|c|}
\hline $\begin{array}{c}\text { Depth } \\
\text { ft. }\end{array}$ & $\begin{array}{c}\text { As-Received } \\
\text { Bulk Density } \\
\text { g/cc }\end{array}$ & $\begin{array}{c}\text { TOC } \\
\text { Wt. \% }\end{array}$ & $\begin{array}{c}\mathbf{S}_{1} \\
\mathbf{m g} / \mathbf{g}\end{array}$ & $\begin{array}{c}\mathbf{S}_{2} \\
\mathbf{m g / g}\end{array}$ & $\begin{array}{c}\mathbf{S}_{\mathbf{3}} \\
\mathbf{m g} / \mathbf{g}\end{array}$ & Tmax & HI & OI & $\begin{array}{c}\mathbf{S}_{1} / \\
\text { TOC }\end{array}$ & PI & Calc Ro \\
\hline 5379.40 & 2.570 & 2.89 & 2.09 & 6.45 & 0.73 & 445 & 224 & 25 & 72 & 0.24 & 0.85 \\
\hline 5382.80 & 2.561 & 2.81 & 2.16 & 5.97 & 0.64 & 451 & 213 & 23 & 77 & 0.27 & 0.96 \\
\hline 5386.90 & 2.572 & 2.23 & 1.93 & 5.15 & 0.84 & 444 & 231 & 38 & 87 & 0.27 & 0.83 \\
\hline 5390.80 & 2.522 & 4.42 & 2.39 & 9.46 & 0.76 & 449 & 214 & 17 & 54 & 0.20 & 0.92 \\
\hline
\end{tabular}

Table 5-2. Methane adsorption isotherm for the Gothic shale at 5390.8 feet.

\begin{tabular}{|c|c|c|c|}
\hline Dry Basis & & TOC $=4.42 \%$ & \\
\hline Sample Weight $=$ & & As-Received Moisture & \\
\hline Particle Size $=<$ & & & \\
\hline Temperature $=1$ & & & \\
\hline & & Methane Adsorption & \\
\hline & & $\underline{\mathrm{Ga}}$ & \\
\hline (psia) & $(\mathrm{MPa})$ & (scf/ton) & (scc/gm) \\
\hline 37 & 0.26 & 6.9 & 0.22 \\
\hline 75 & 0.52 & 12.1 & 0.38 \\
\hline 124 & 0.85 & 17.7 & 0.55 \\
\hline 201 & 1.39 & 25.5 & 0.80 \\
\hline 287 & 1.98 & 32.8 & 1.02 \\
\hline 376 & 2.59 & 40.2 & 1.25 \\
\hline 471 & 3.25 & 45.0 & 1.40 \\
\hline 561 & 3.87 & 49.0 & 1.53 \\
\hline 662 & 4.56 & 51.2 & 1.60 \\
\hline Langmu & & $V_{L}=89.1 * P_{L} /\left(P_{L}+4\right.$ & \\
\hline & & & \\
\hline (psia) & $(\mathrm{MPa})$ & (scf/ton) & (scc/gm) \\
\hline 475.7 & 3.28 & 89.1 & 2.8 \\
\hline
\end{tabular}


Table 5-3. Summary of petrophysical measurements from the Gothic shale.

\begin{tabular}{|c|c|c|c|c|c|c|c|c|c|c|c|}
\hline $\begin{array}{l}\text { Depth } \\
\text { (ft) }\end{array}$ & $\begin{array}{c}\text { As } \\
\text { Received } \\
\text { Bulk } \\
\text { Density } \\
(9 / \mathrm{cc})\end{array}$ & $\begin{array}{c}\text { As } \\
\text { Received } \\
\text { Grain } \\
\text { Density } \\
(9 / \mathrm{cc})\end{array}$ & $\begin{array}{c}\text { Dry } \\
\text { Grain } \\
\text { Density } \\
\left({ }^{g} / \mathrm{cc}\right)\end{array}$ & $\begin{array}{l}\text { Porosity } \\
\text { (\% of } \\
\text { Bulk } \\
\text { Volume) }\end{array}$ & $\begin{array}{l}\text { Water } \\
\text { Saturation } \\
\text { (\% of Pore } \\
\text { Volume) }\end{array}$ & $\begin{array}{c}\text { Gas } \\
\text { Saturation } \\
\text { (\% of } \\
\text { Pore } \\
\text { Volume) }\end{array}$ & $\begin{array}{c}\text { Mobile Oil } \\
\text { Saturation } \\
\text { (\% of Pore } \\
\text { Volume) }\end{array}$ & $\begin{array}{l}\text { Gas Filled } \\
\text { Porosity } \\
\text { (\% of } \\
\text { Bulk } \\
\text { Volume) }\end{array}$ & $\begin{array}{c}\text { Bound } \\
\text { Hydrocarbon } \\
\text { Saturation } \\
\text { (\% of Bulk } \\
\text { Volume) }\end{array}$ & $\begin{array}{l}\text { Bound Clay } \\
\text { Water } \\
\text { (\% of Bulk } \\
\text { Volume) }\end{array}$ & $\begin{array}{l}\text { Pressure- } \\
\text { Decay } \\
\text { Permeability } \\
\text { (mD) }\end{array}$ \\
\hline 5379.40 & 2.570 & 2.623 & 2.648 & 3.35 & 19.55 & 60.61 & 19.84 & 2.03 & 1.14 & 6.56 & 0.000146 \\
\hline 5382.80 & 2.561 & 2.597 & 2.621 & 2.72 & 24.73 & 50.88 & 24.39 & 1.38 & 1.33 & 7.01 & 0.000133 \\
\hline 5386.90 & 2.572 & 2.615 & 2.649 & 3.51 & 30.07 & 47.71 & 22.22 & 1.67 & 0.90 & 7.42 & 0.000138 \\
\hline 5390.80 & 2.522 & 2.573 & 2.614 & 4.30 & 36.18 & 46.05 & 17.77 & 1.98 & 1.47 & 7.46 & 0.000141 \\
\hline
\end{tabular}

Table 5-4. Summary of multistress anisotropy measurements from the Gothic shale.

$\begin{array}{cccccccc}\text { Depth (ft) } & \text { Orientation } & \begin{array}{c}\text { AR Bulk } \\ \text { Density } \\ \text { (g/cm^3) }\end{array} & \begin{array}{c}\text { Effective Mean } \\ \text { Stress (psi) }\end{array} & \begin{array}{c}\text { Young's Modulus - Young's Modulus } \\ \text { Transverse (psi) }\end{array} & \begin{array}{c}\text { Poisson's Ratio - Poisson's Ratio } \\ \text { - Axial (psi) }\end{array} & \begin{array}{c}\text { Shear Modulus- } \\ \text { Transverse }\end{array} \\ & & 2.568 & 1994 & 2.897 \mathrm{E}+06 & 5.680 \mathrm{E}+06 & 0.186 \\ \text { - Axial }\end{array}$

Notes: Transverse - Perpendicular to Bedding Plane. Axial - Parallel to bedding plane. 
A

Aneth Unit No. $\mathrm{H}-117$

NE NE Sec. 17 T. 40 S R. 24E

San Juan County, Utah KB 4553'

Cumulative Production = 479,197 BO, 296,878 MCFG, 1,871,016 BW
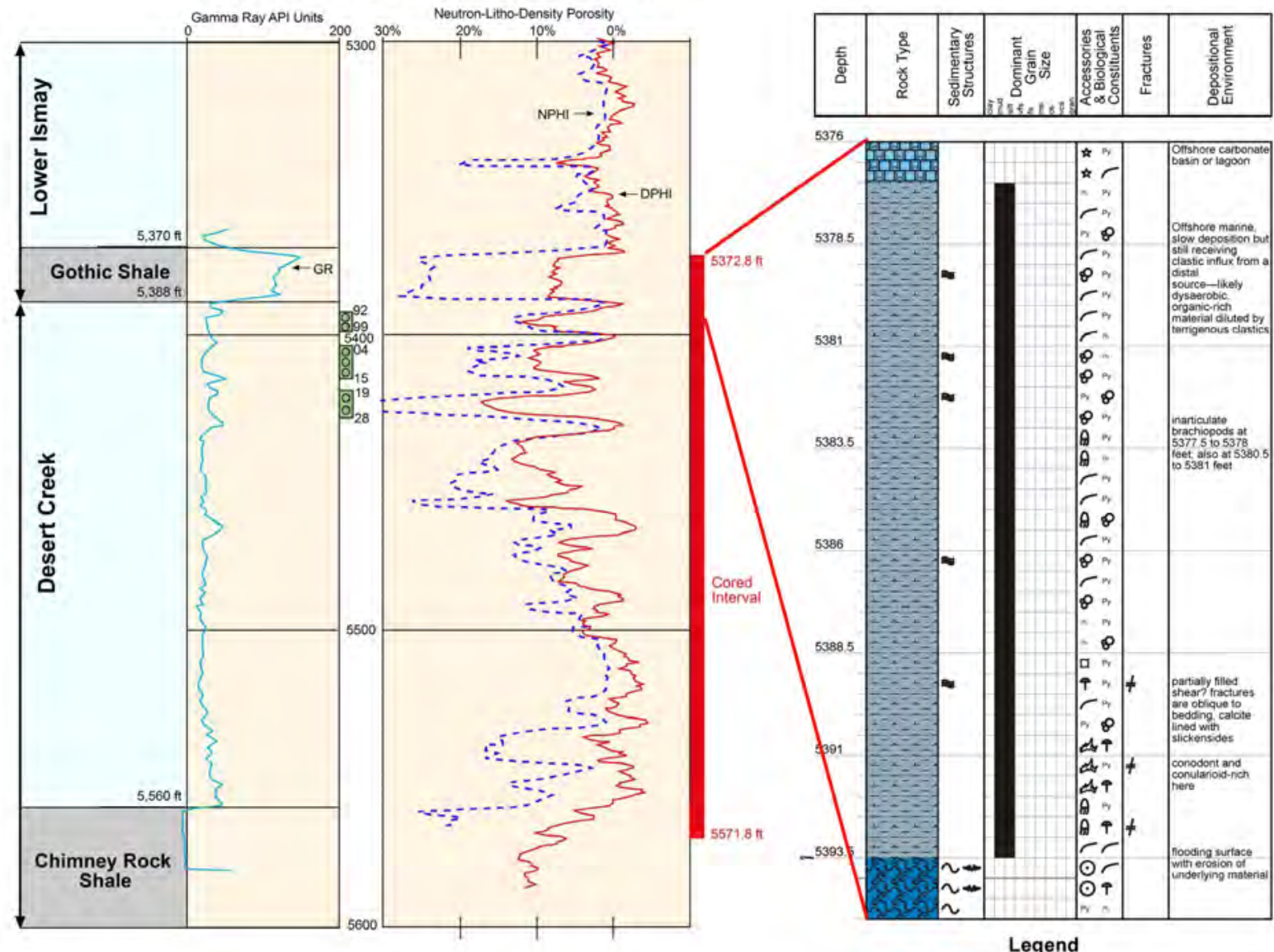

B
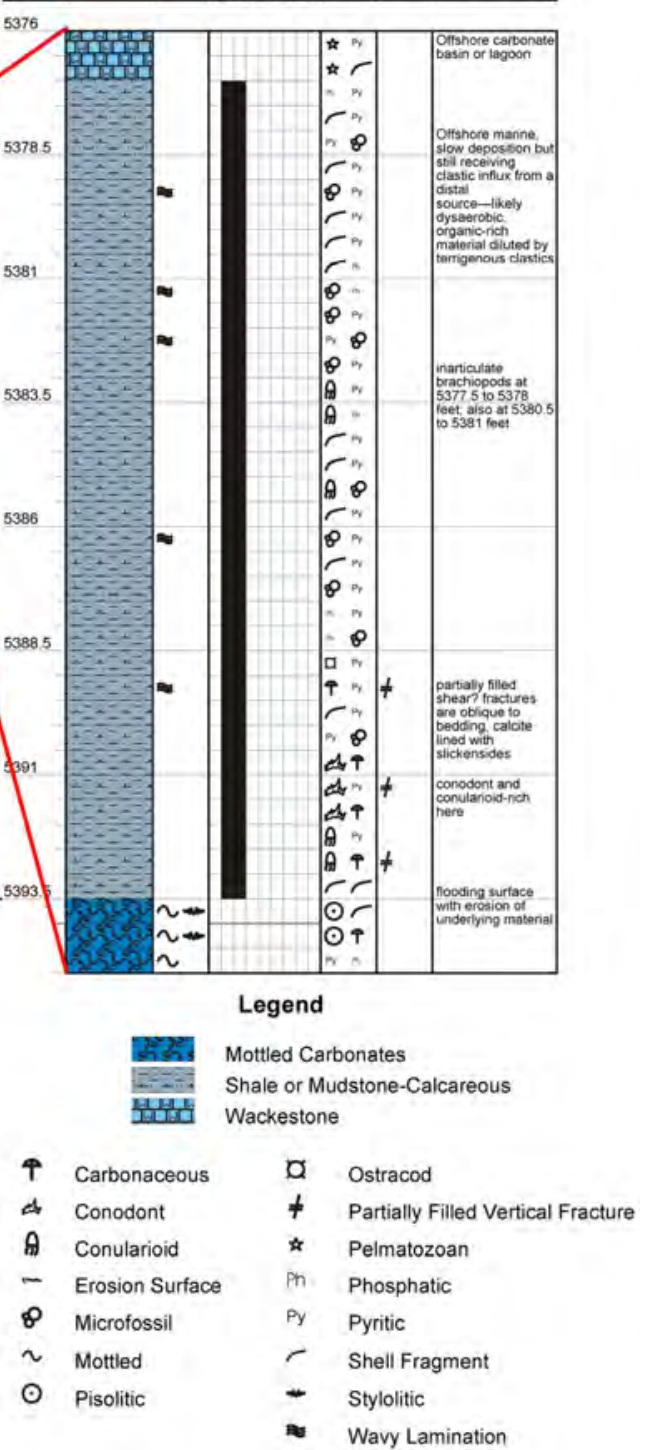

Figure 5-1. Aneth Unit No. H-117 well, NENE section 17, T. 40 S., R. 24 E., SLBL\&M. AInterpreted geophysical log; cored interval of the Desert Creek zone and Gothic shale shown in red. B-Gothic shale core description. 


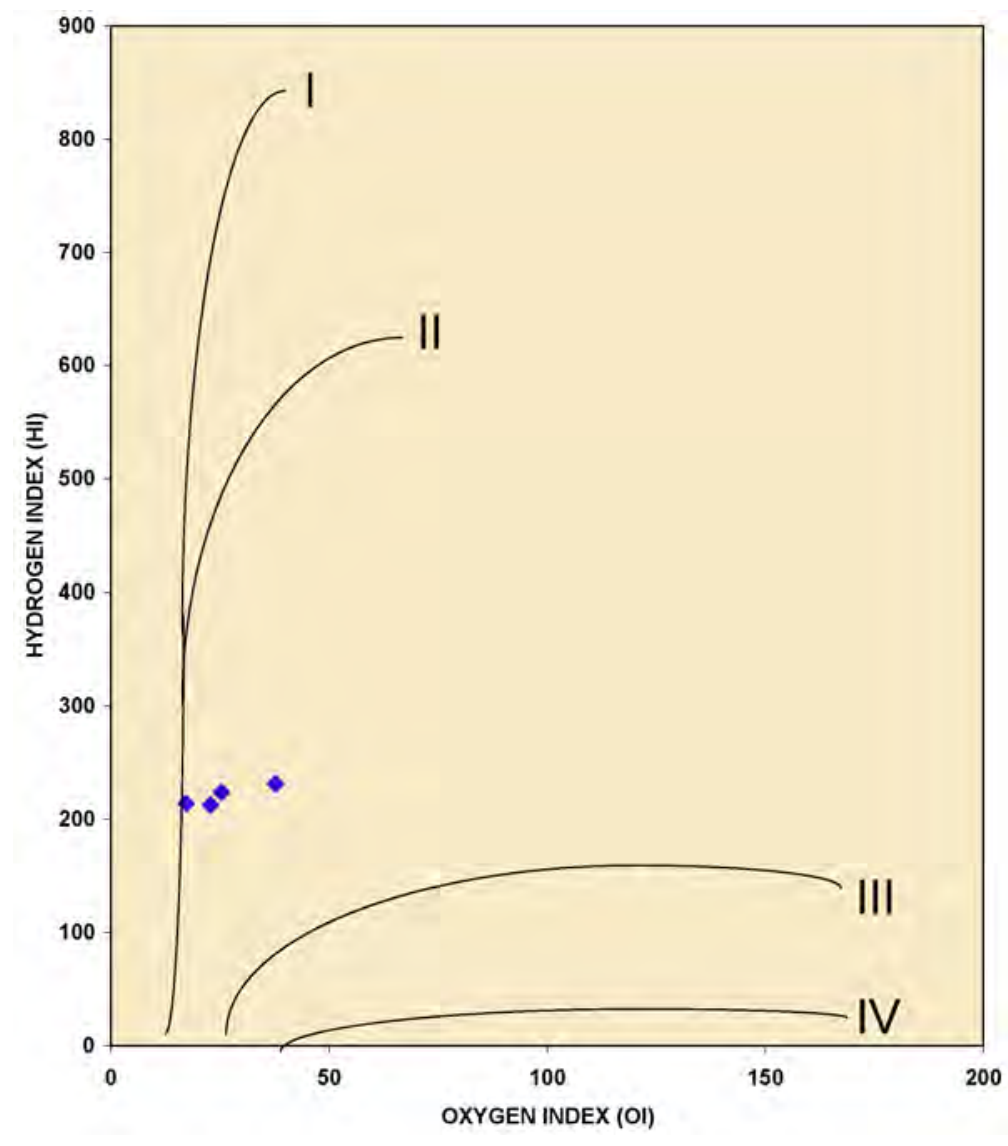

Figure 5-2. Kerogen type determination of the Gothic shale from TOC and Rock-Eval pyrolysis data. The data indicate the Gothic contains type II and mixed type II/III kerogen.

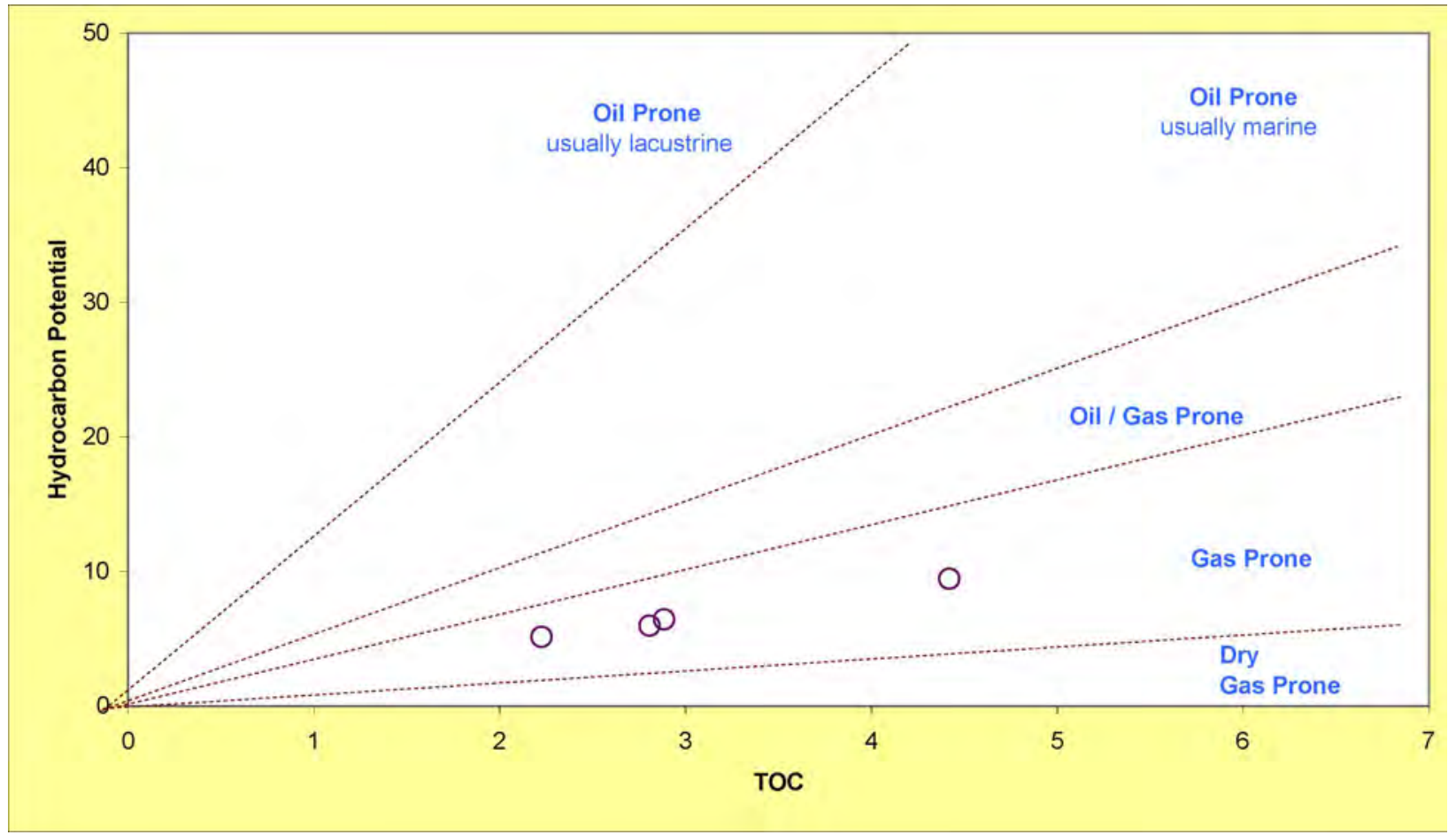

Figure 5-3. Kerogen quality determination of the Gothic shale from TOC and Rock-Eval pyrolysis data. The data indicate the Gothic contains gas prone kerogen. 

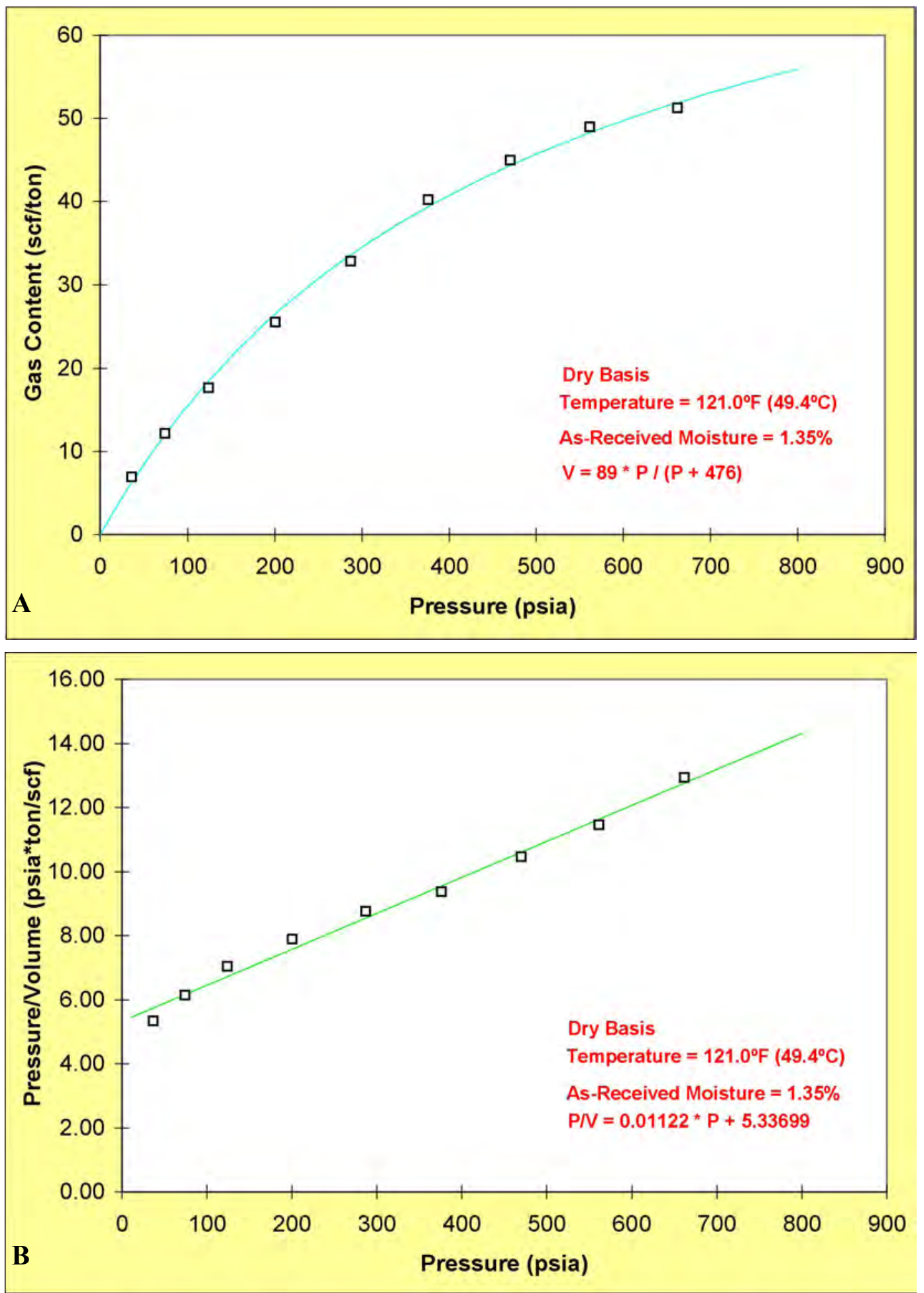

Figure 5-4. A-Methane adsorption isotherm. B-Adsorption Langmuir plot. Gothic shale sample from 5390.8 feet. 


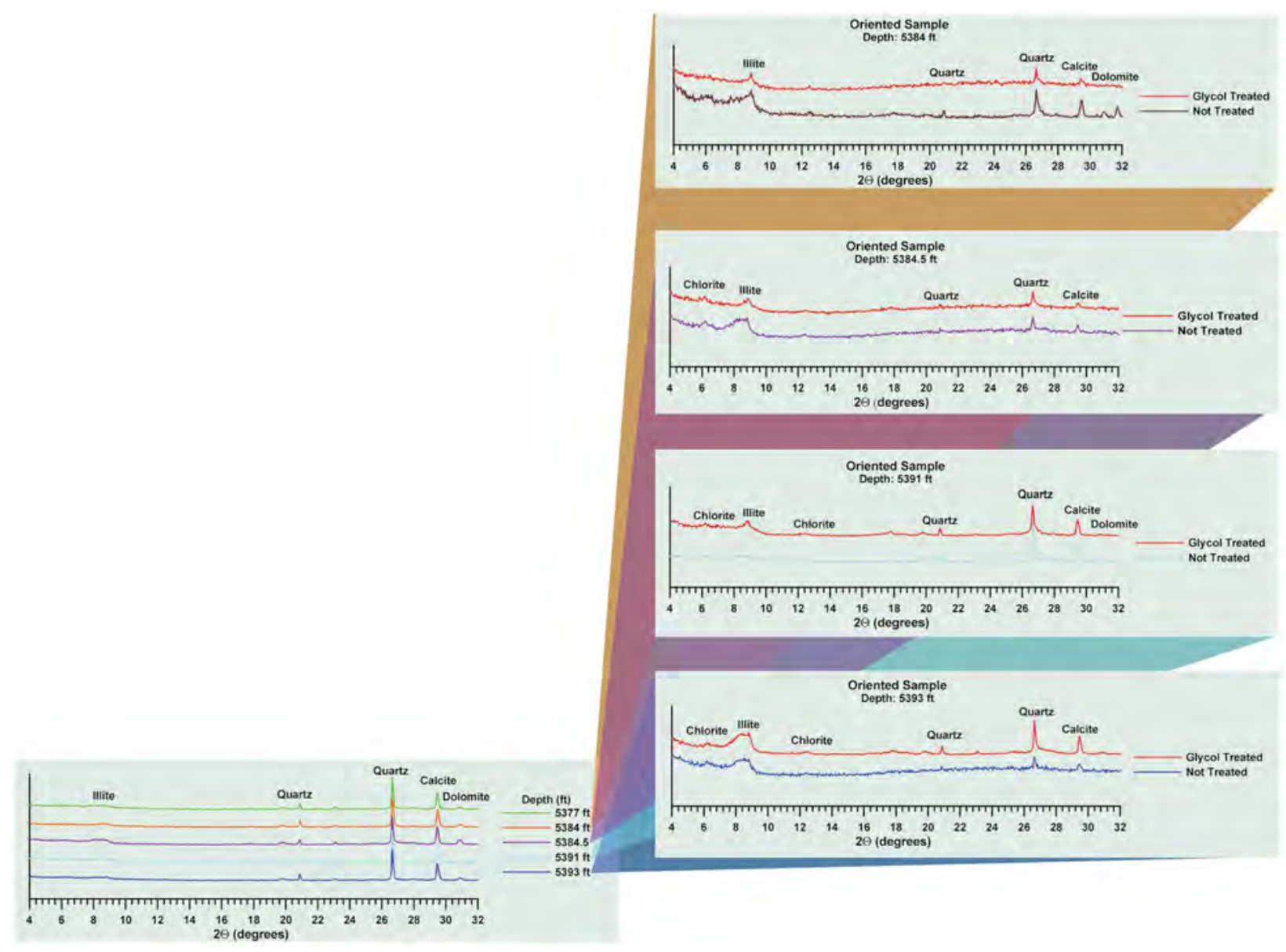

Figure 5-5. Graph of x-ray diffraction data from the Gothic shale. 

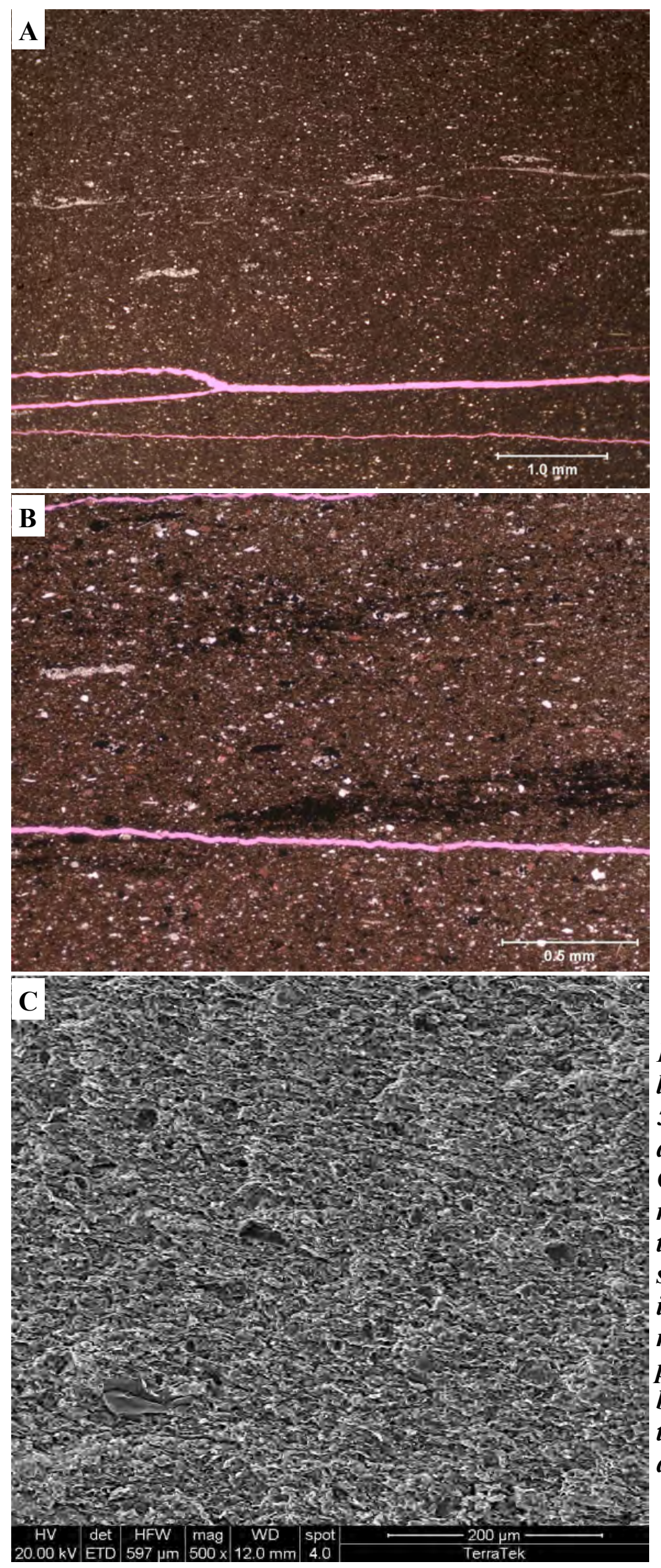

Figure 5-6. Argillaceous shale lithotype in Gothic shale from 5379.4 feet. A-photomicrograph of argillaceous shale lithotype in Gothic shale shown at low magnification. The magenta lines at the bottom of the image are induced stress-release fractures. $B$-Same image as 5-6A at slightly higher magnification. Black streaks are pyrite concentrated parallel to bedding. $C-S E M$ overview of texture in uniform, non-laminated argillaceous shale. 

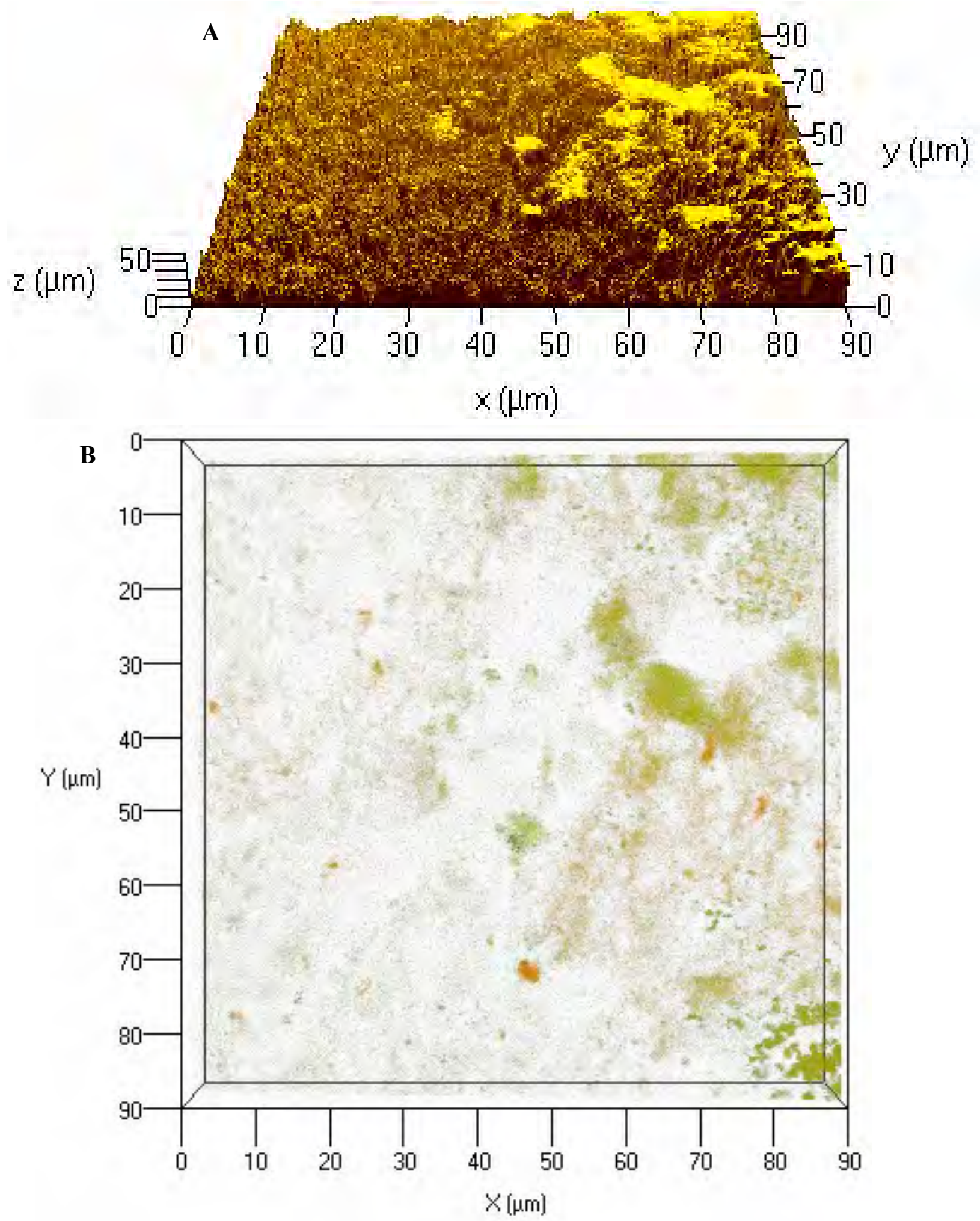

Figure 5-7. Medium magnification of corresponding LSCM images of a surface broken perpendicular to bedding in the Gothic shale from 5380.0 feet. A - Image showing topography in an oblique view. $B-A$ relatively high resolution image of green, yelloworange, and red fluorescing material. 

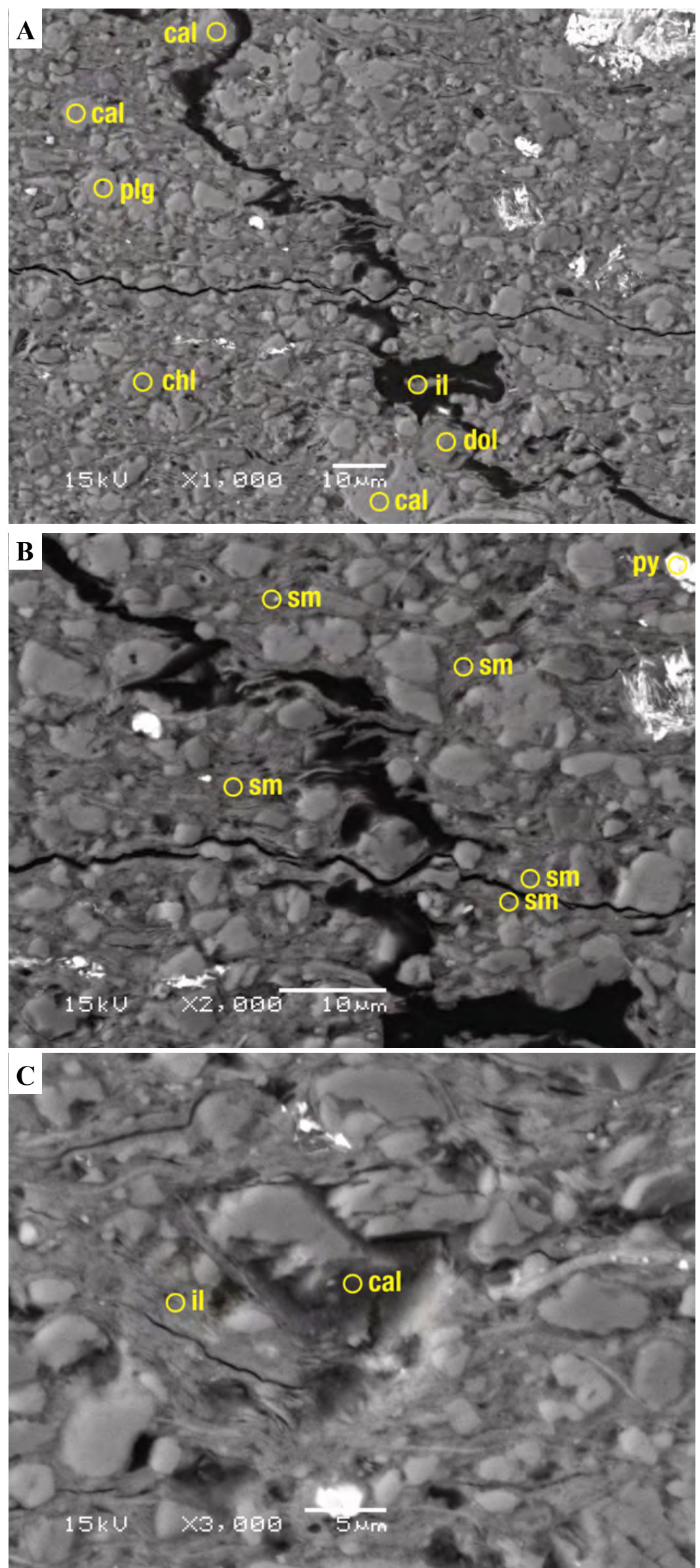

Figure 5-8. Backscattered electron images of the Gothic shale from 5387.1 feet, from low (A) to medium (B), to high magnification (C), showing various mineral constiuents. 

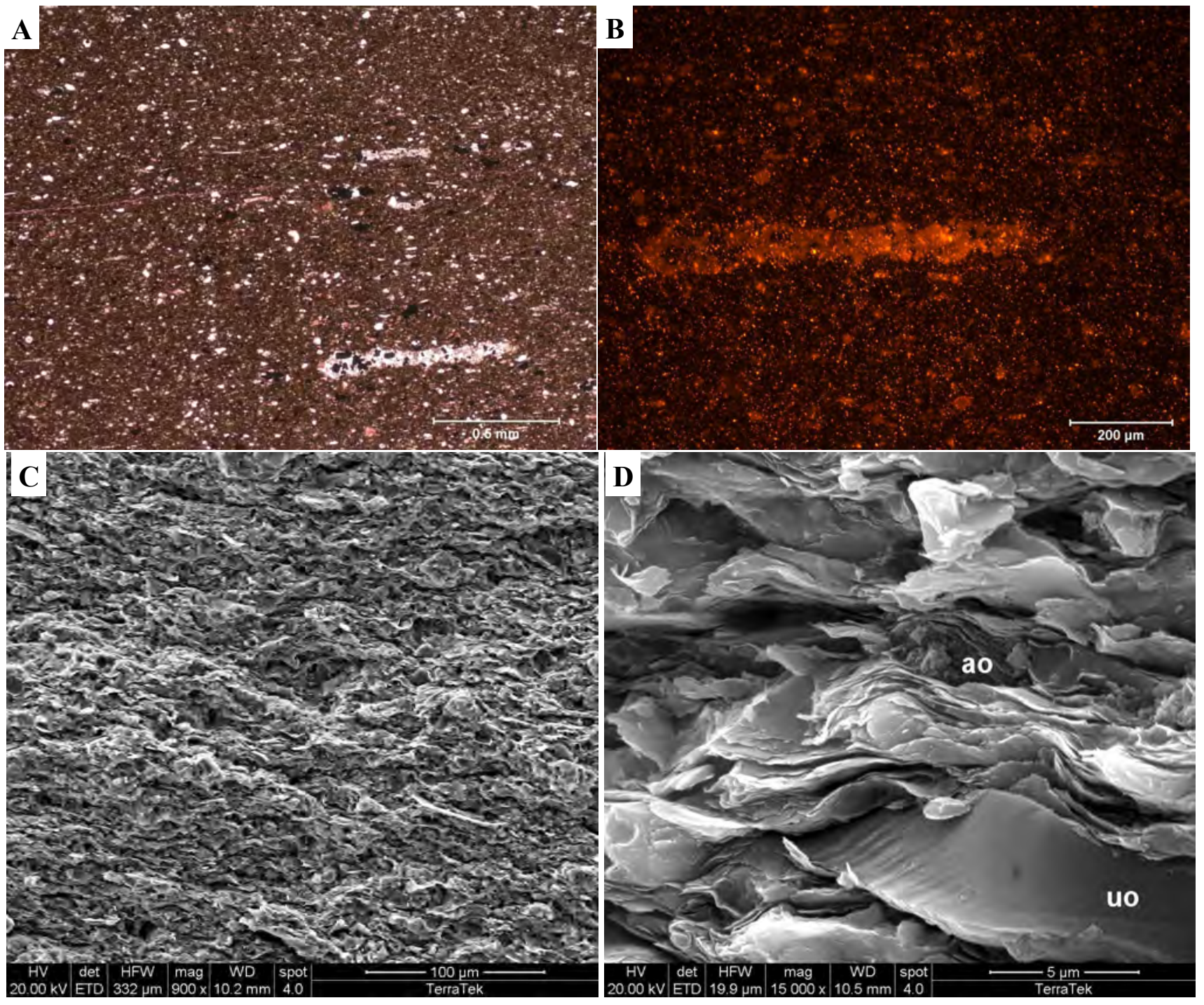

Figure 5-9. Argillaceous mudstone in Gothic shale from 5382.8 feet. A-Photomicrograph of argillaceous mudstone showing weak lamination defined by micas and compacted cherty microfossils (white, lower right). Pink specks in the matrix are stained, silt-sized calcite particles. B - Reflected UV light with rhodamine filter showing a compacted cherty microfossil (grain at center) in the argillaceous mudstone matrix and swarms of orange pinpoints that indicate intercrystalline micropores. Brighter fluorescence inside the microfossil is attributed to mineral fluorescence. C-SEM overview of argillaceous mudstone highlighting distinct grain orientation. D-SEM matrix detail showing unaltered and altered carbonaceous material. The smooth particle at lower right (иo) represents a discrete carbonaceous grain with little alteration. At top center, a particle representing a different class of organics, embedded between clay flakes (ao), displays fuzzy, rough texture. 

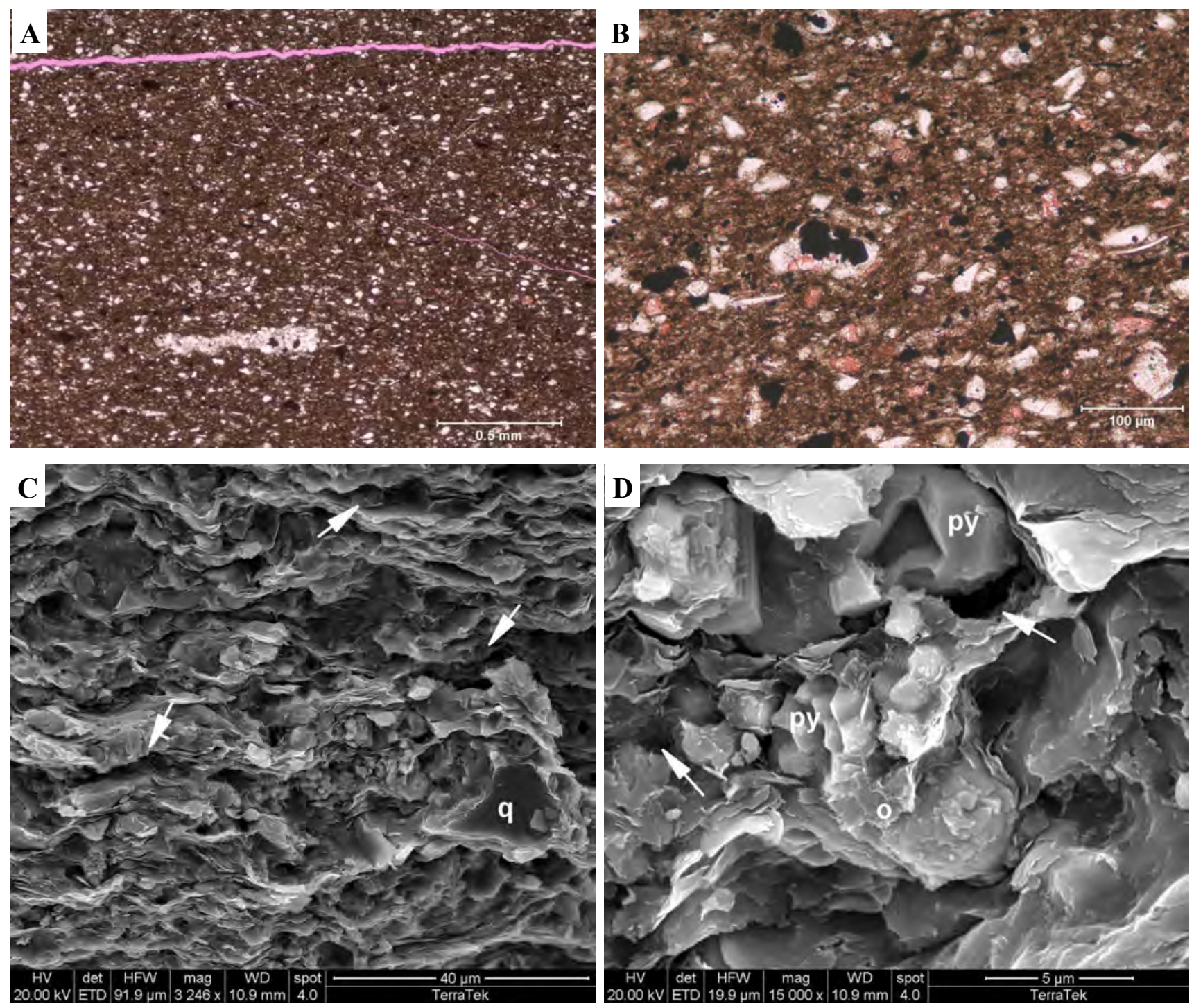

Figure 5-10. Silty calcareous/argillaceous mudstone in Gothic shale from 5386.9 feet. A Photomicrograph of silty calcareous/argillaceous mudstone with induced fracture at the top of the image (magenta). Finely disseminated carbonaceous material is visible in the matrix, as are abundant silt grains, calcite crystals (pink), and pyrite. Note cherty microfossil at bottom of image. $B$ - Photomicrograph showing matrix detail highlighting dominant textural components. Quartz silt, silt-sized calcite (red), mica flakes, and authigenic pyrite float in a predominantly clay matrix. C-This medium magnification SEM view of the matrix shows elongate pores parallel to parting planes (arrows). The micropore network is also visible, consisting of voids with sizes from 2-10 microns, and flattened in shape. The irregular grain at right is quartz (q). D - Image illustrates a common association of pyrite with carbonaceous material. The perforated flakes of organics (o) surround pyrite crystals (py). Intercrystalline porosity (arrows) is believed to have developed through alteration of organics. 

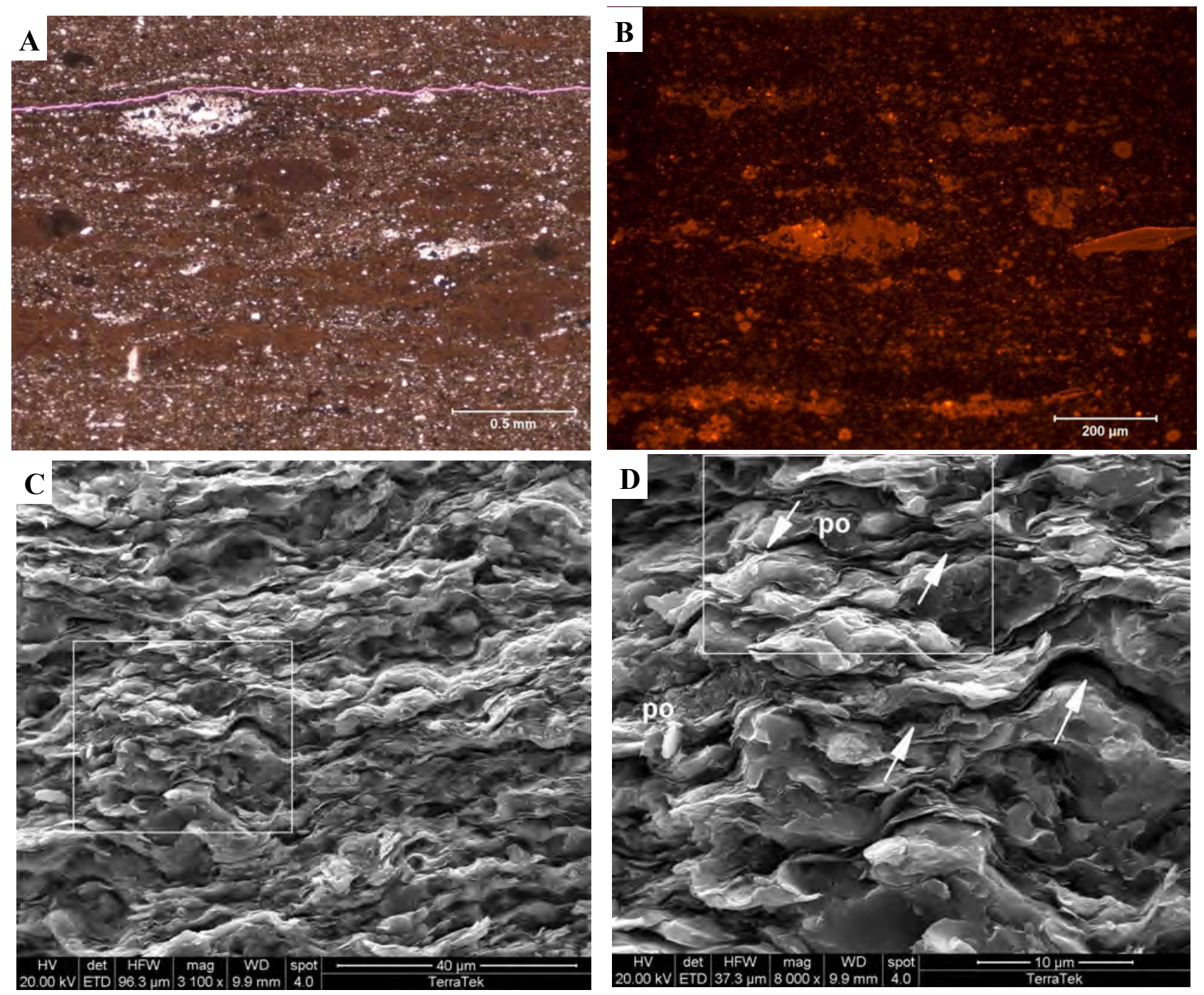

Figure 5-11. Phosphatic argillaceous mudstone in Gothic shale from 5390.8 feet. A Photomicrograph of overview showing flattened, amalgamated pellets (lighter brown), which SEM show to be phosphatic in composition. The matrix overview highlights compacted siliceous forms (white) composed of chert, and flattened fecal pellets in a mixed siliceous/argillaceous matrix. The lighter brown matrix color and abundance of siliceous fossils, as well as phosphatic pellets suggest a siliceous matrix cement component. B-Closer view showing microfossils, micas, a fecal pellet (pe) and a conodont supported by argillaceous matrix under reflected $U V$ light. Note the matrix micropores appearing as bright orange dots. Dull orange is mineral fluorescence. (Reflected UV light with rhodamine filter). C-Medium magnification SEM view of phosphatic, argillaceous mudstone. Clay packets that make up the matrix are separated along parting surfaces, contributing to a fissile texture. The sample splits easily along closely spaced $(<1 \mathrm{~mm})$, brittle, wavy partings. The boxed area is enlarged in the image 5-11D. D - SEM detail of part of the image 5-11C highlighting two flattened phosphatic/organic pods (po) with granular internal texture arranged along horizontal parting planes (arrows). 

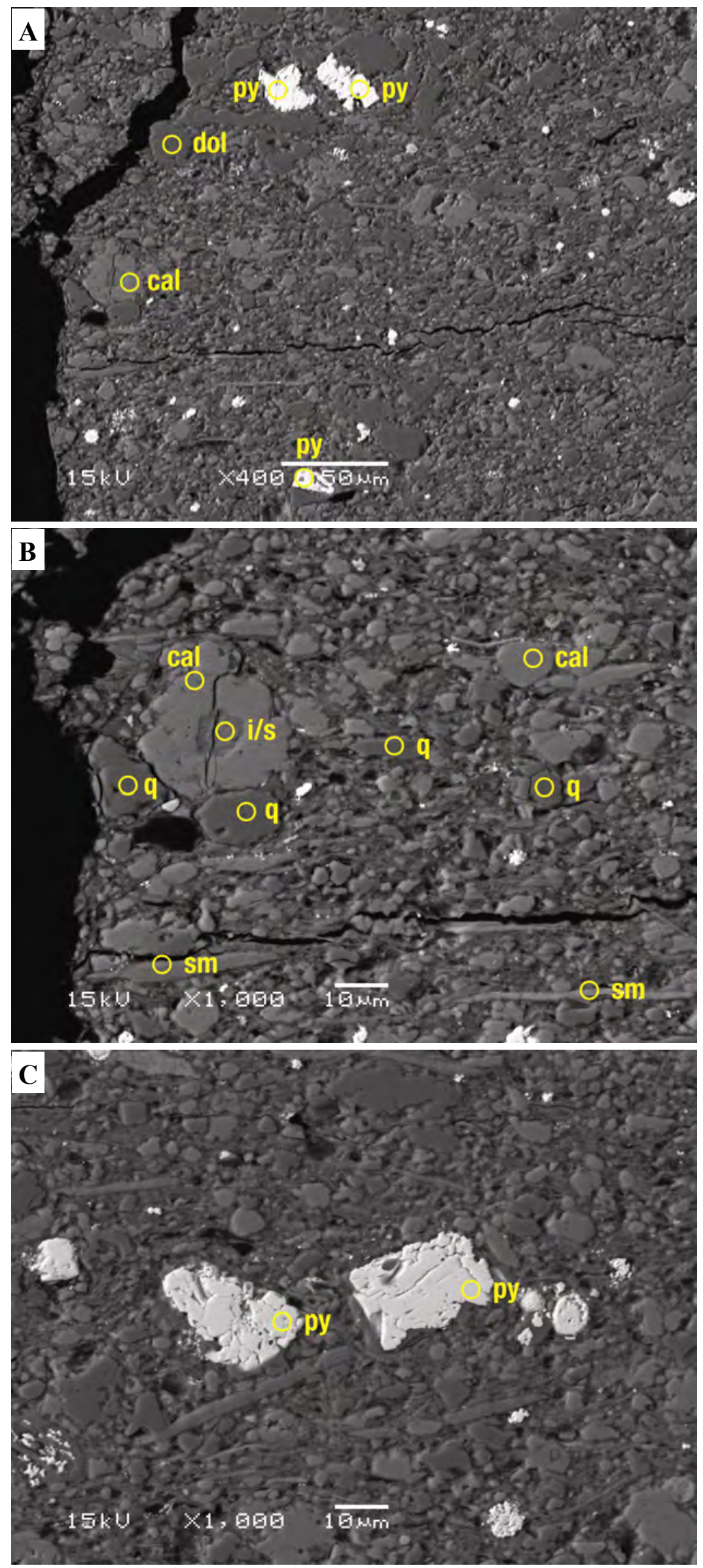

Figure 5-12. Backscattered electron images of the Gothic shale from 5392.4 feet, from low (A) to medium (B), to high magnification (C), showing various mineral constiuents. 


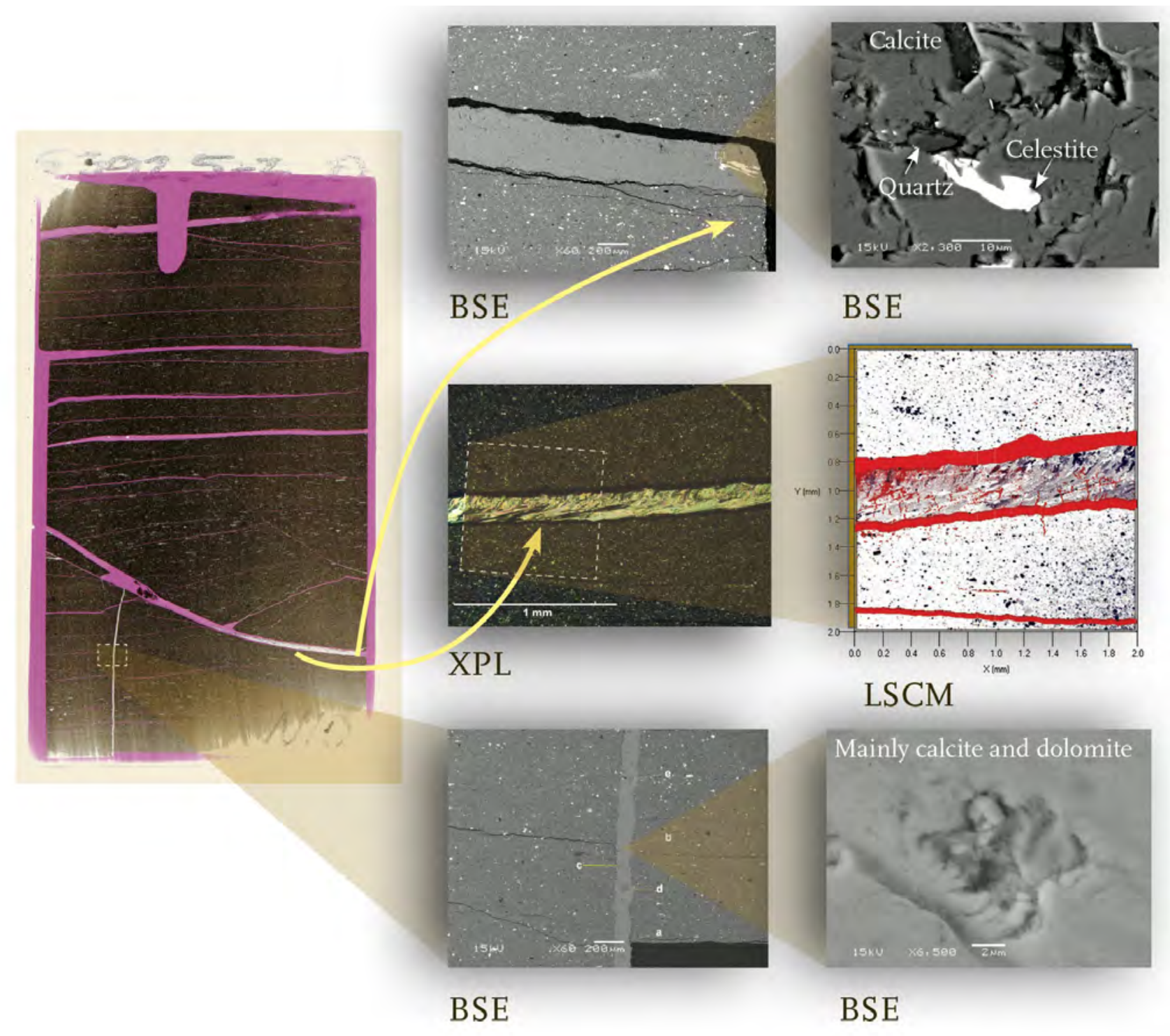

Figure 5-13. Additional views of the inclined shear fracture zone from 5392.30 to 5392.5 feet displayed on various BSE, XPL, and LSCM images at different magnifications derived from the thin section shown on the left. 

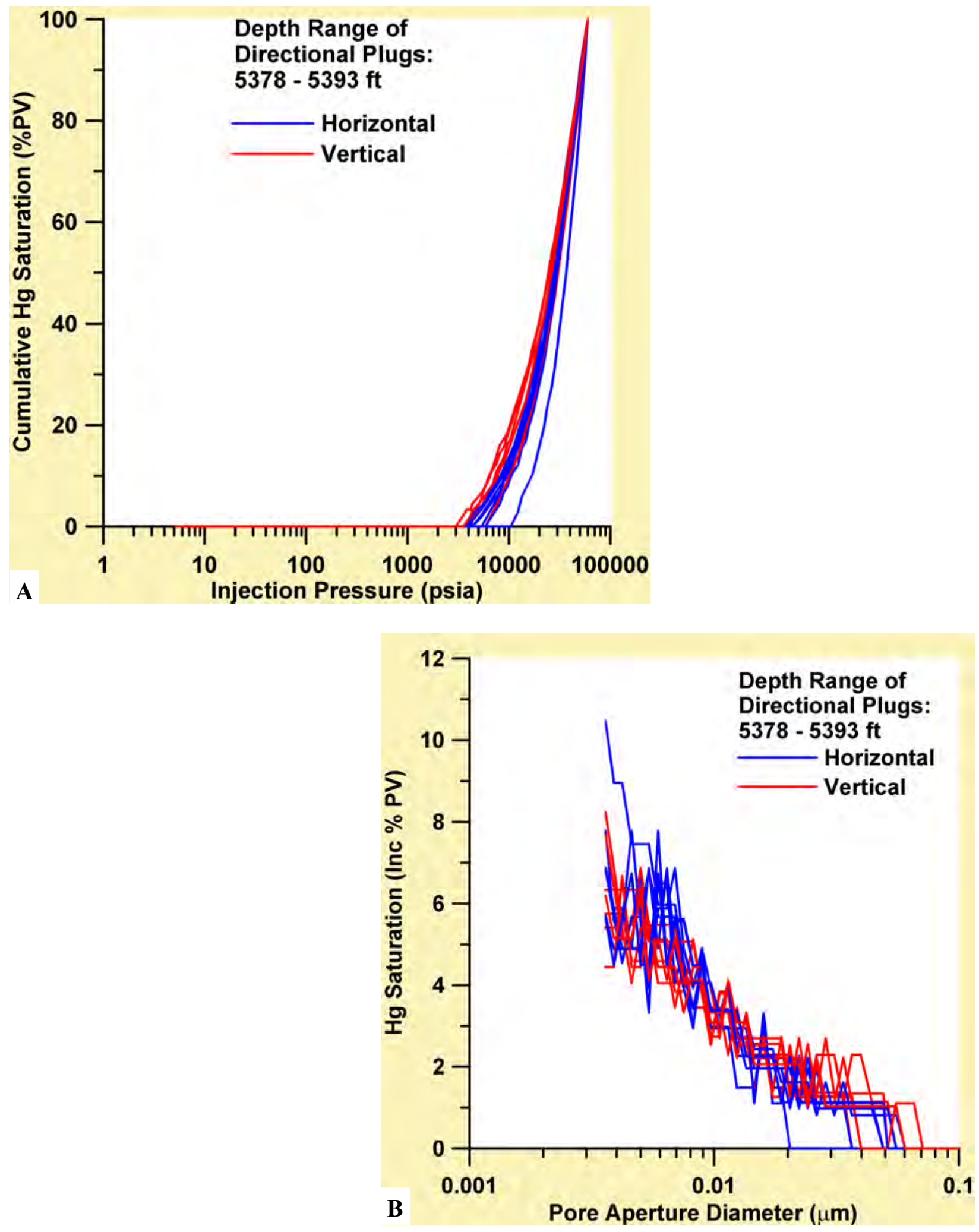

Figure 5-14. Mercury injection capillary pressure and pore aperture distributions. $A$ Cumulative mercury saturation versus injection pressure. $B$ - Mercury saturation versus pore aperture diameter. 

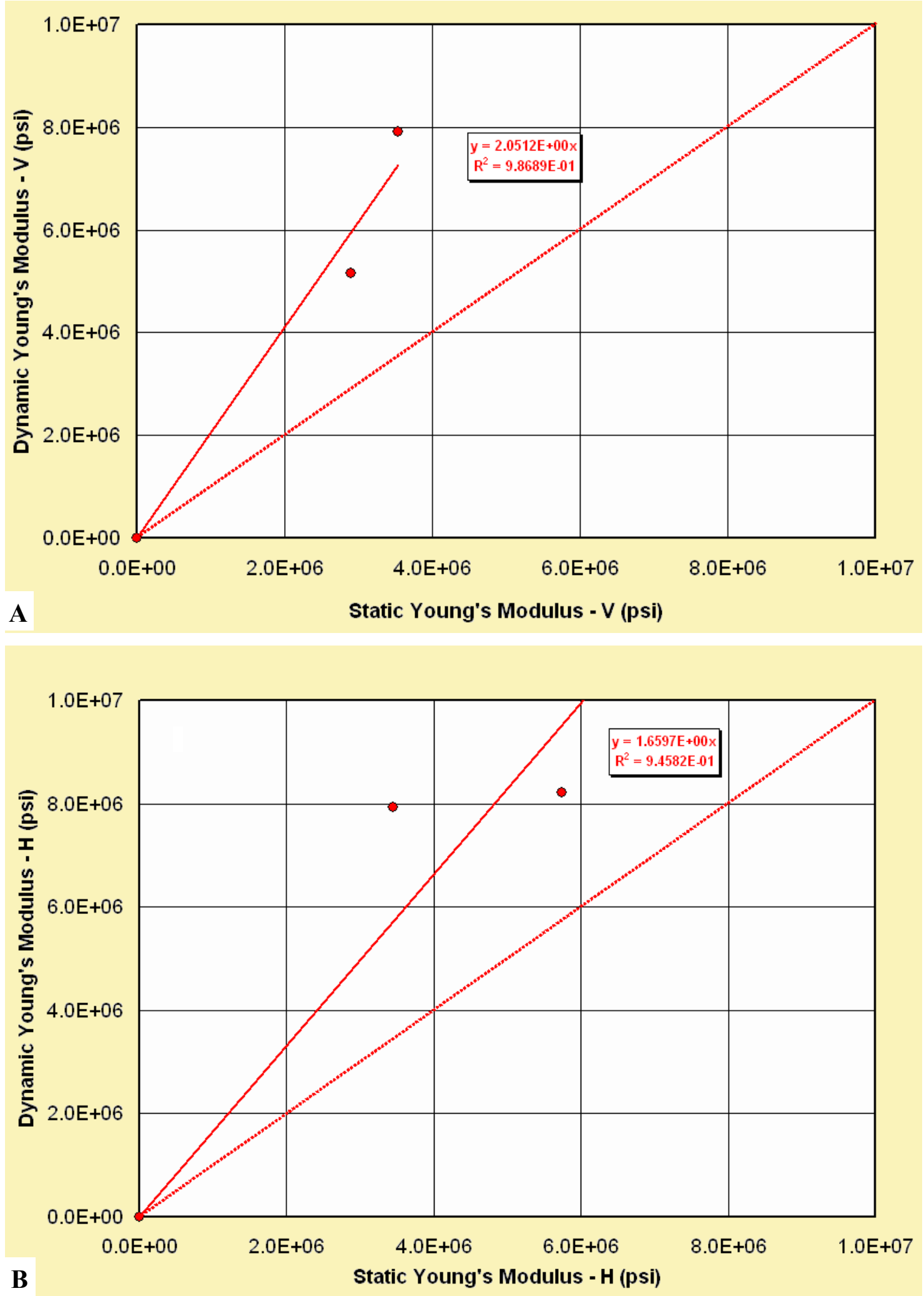

Figure 5-15. A-Vertical dynamic Young's modulus as a function of vertical static Young's modulus. B - Horizontal dynamic Young's modulus as a function of horizontal static Young's modulus; depth 5381.18 to 5398.85 feet. 


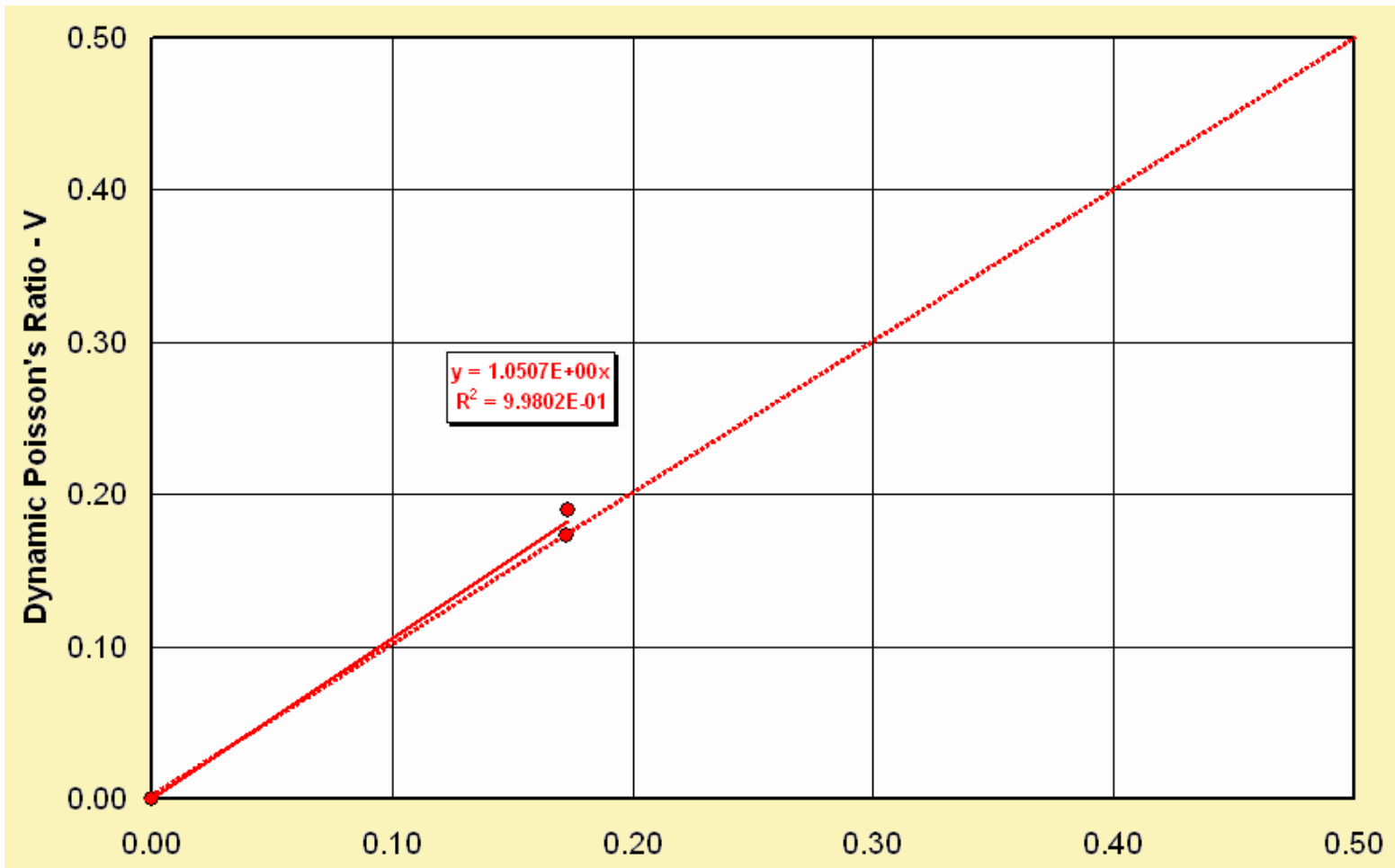

A

Static Poisson's Ratio - V

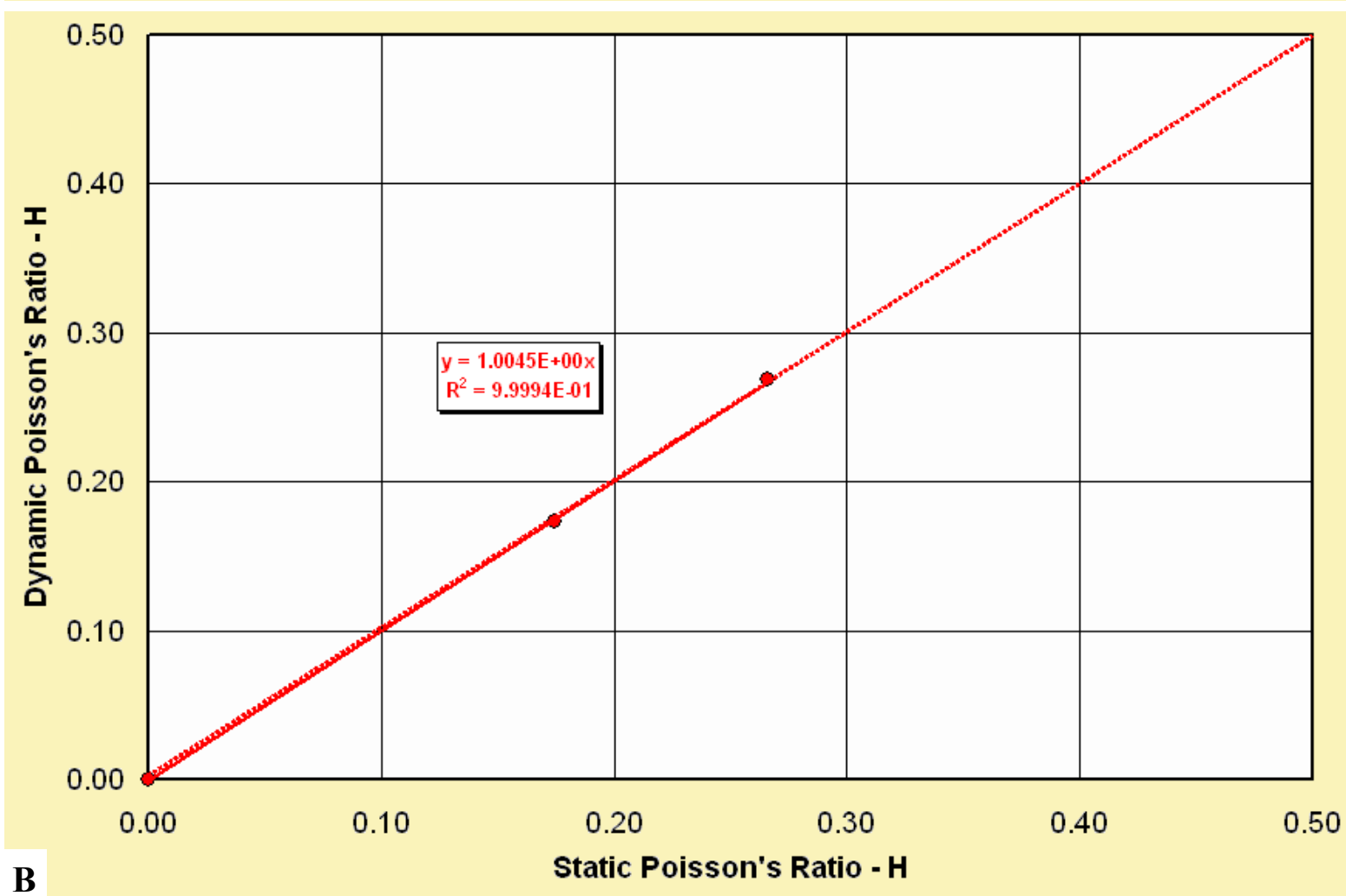

Figure 5-16. A - Vertical dynamic Poisson's ratio as a function of vertical static Poisson's ratio. B - Horizontal dynamic Poisson's ratio as a function of horizontal static Poisson's ratio; depth 5381.18 to 5398.85 feet. 
A

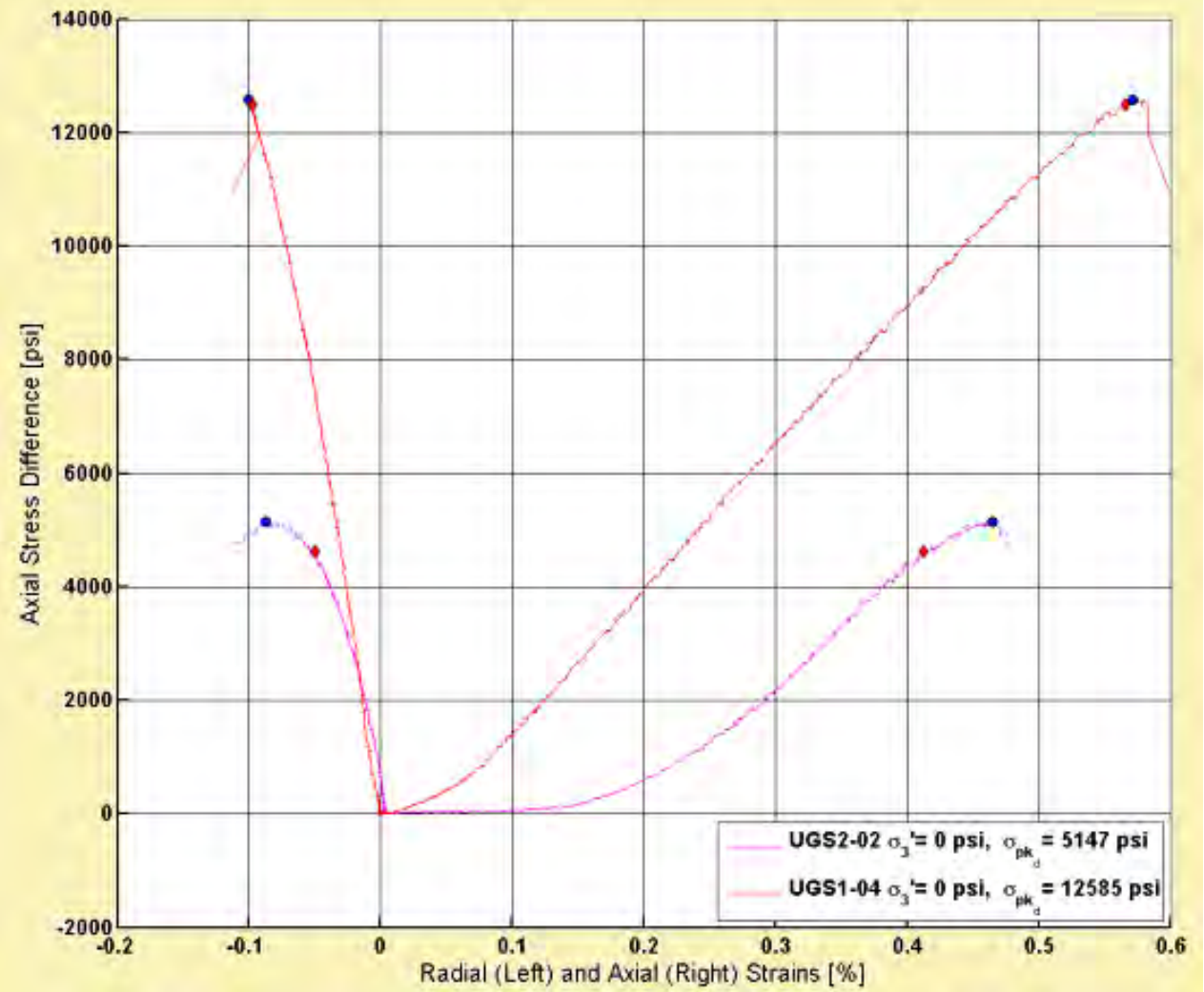

B

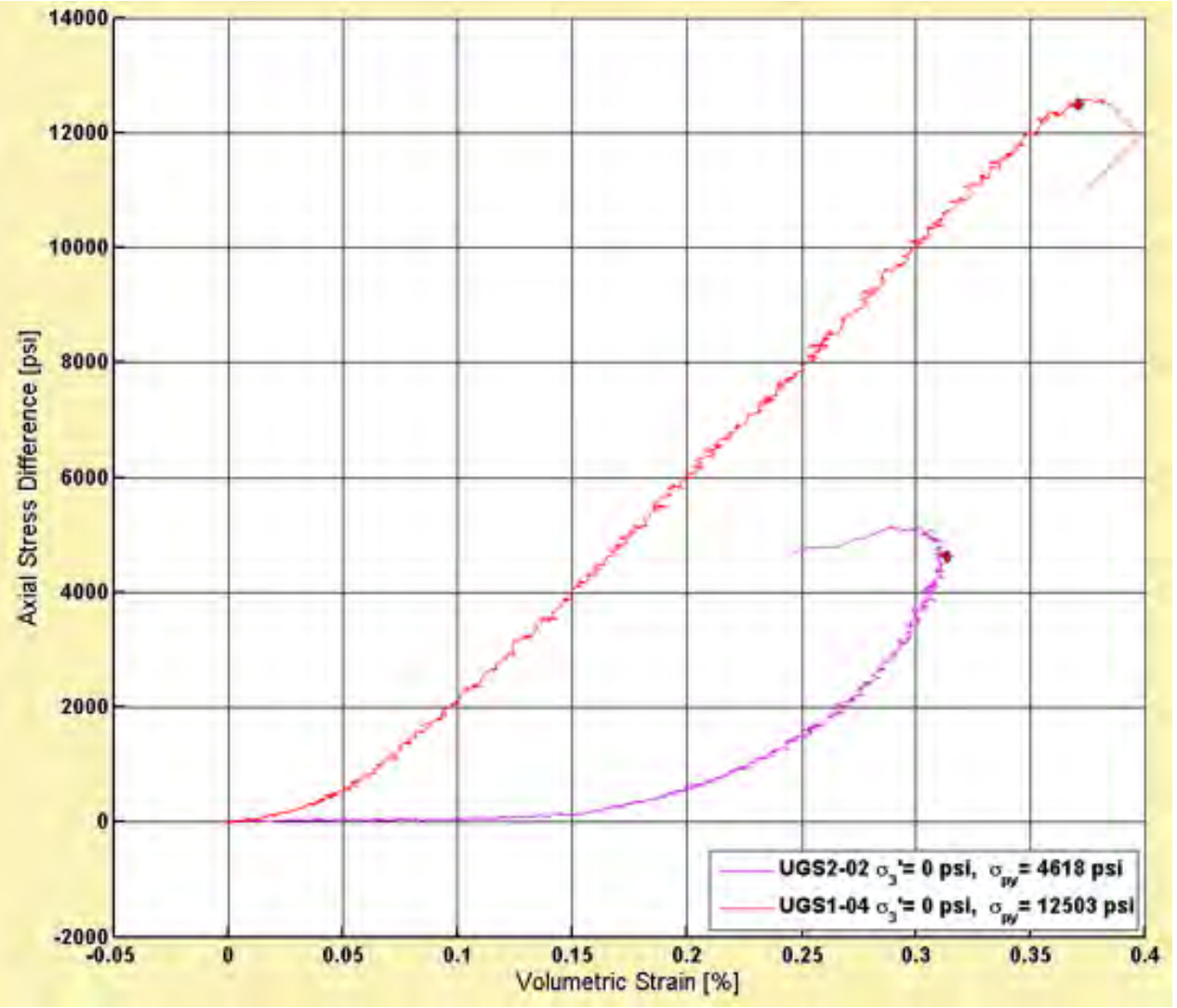

Figure 5-17. Results of unconfined compression testing. A-Axial stress difference versus radial and axial strains. B-Axial stress difference versus volumetric strain. $C$-Axial stress difference versus axial strain. D-Averaged radial strain versus axial strain. 
C

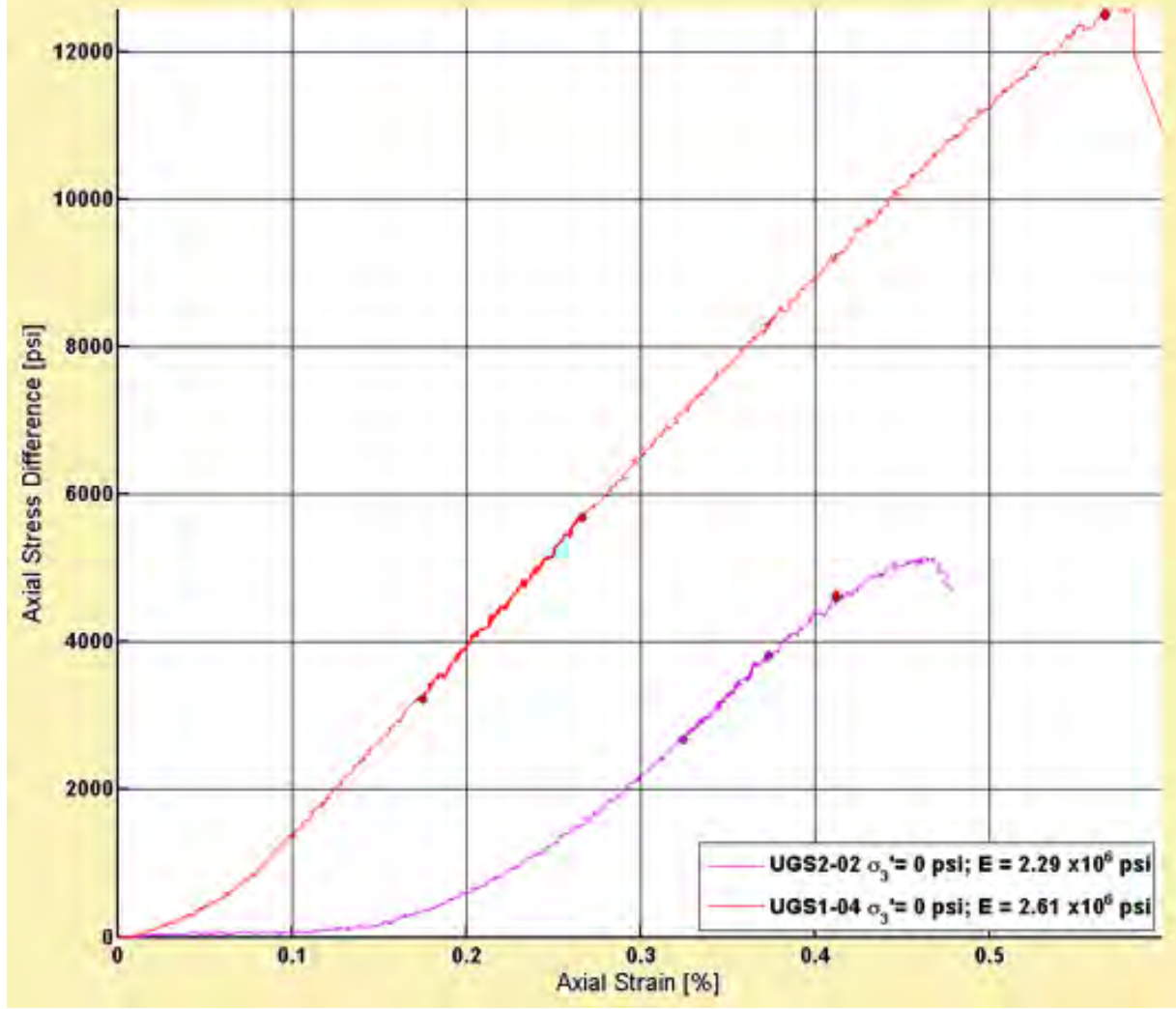

D

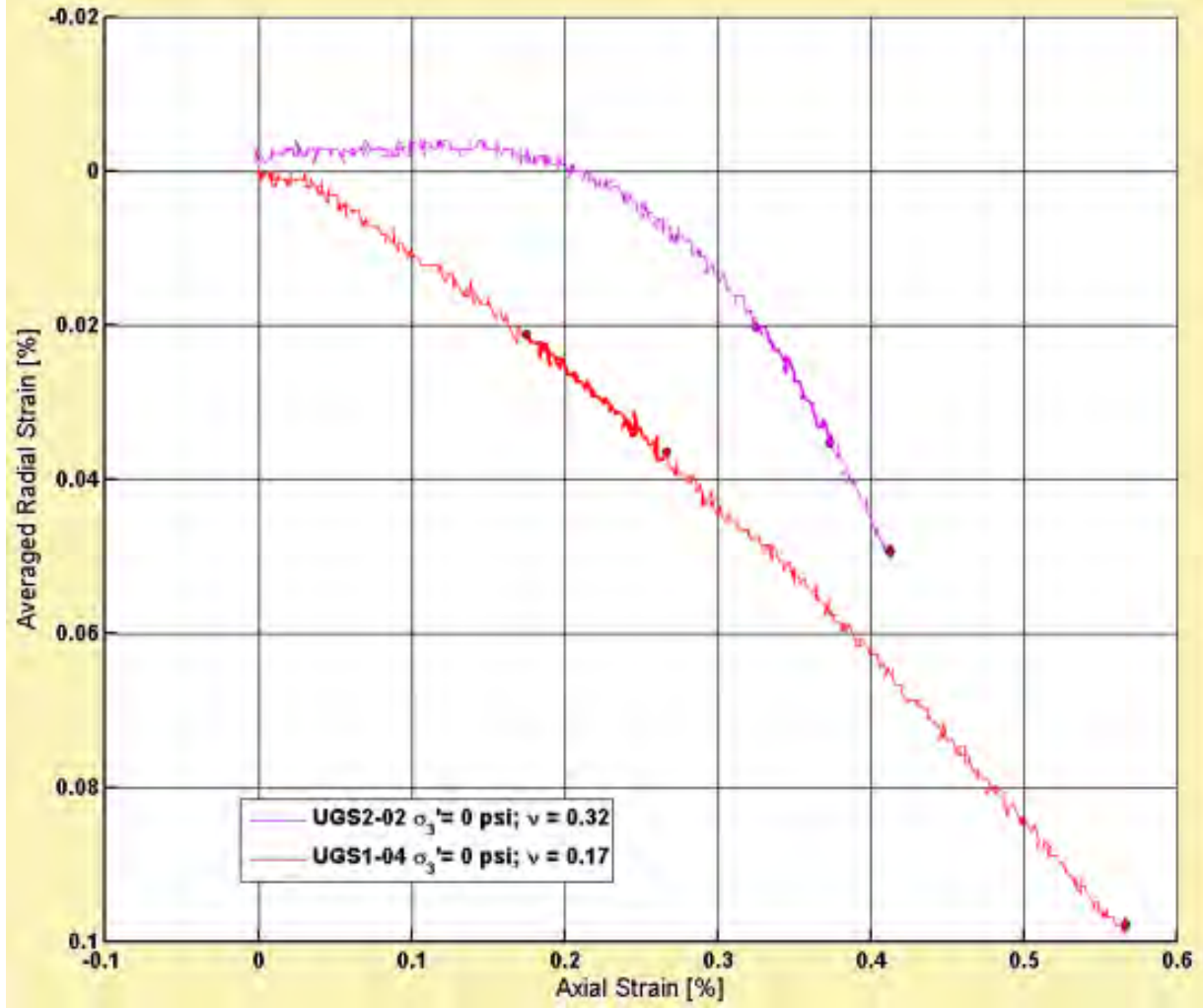

Figure 5-17. Continued. 


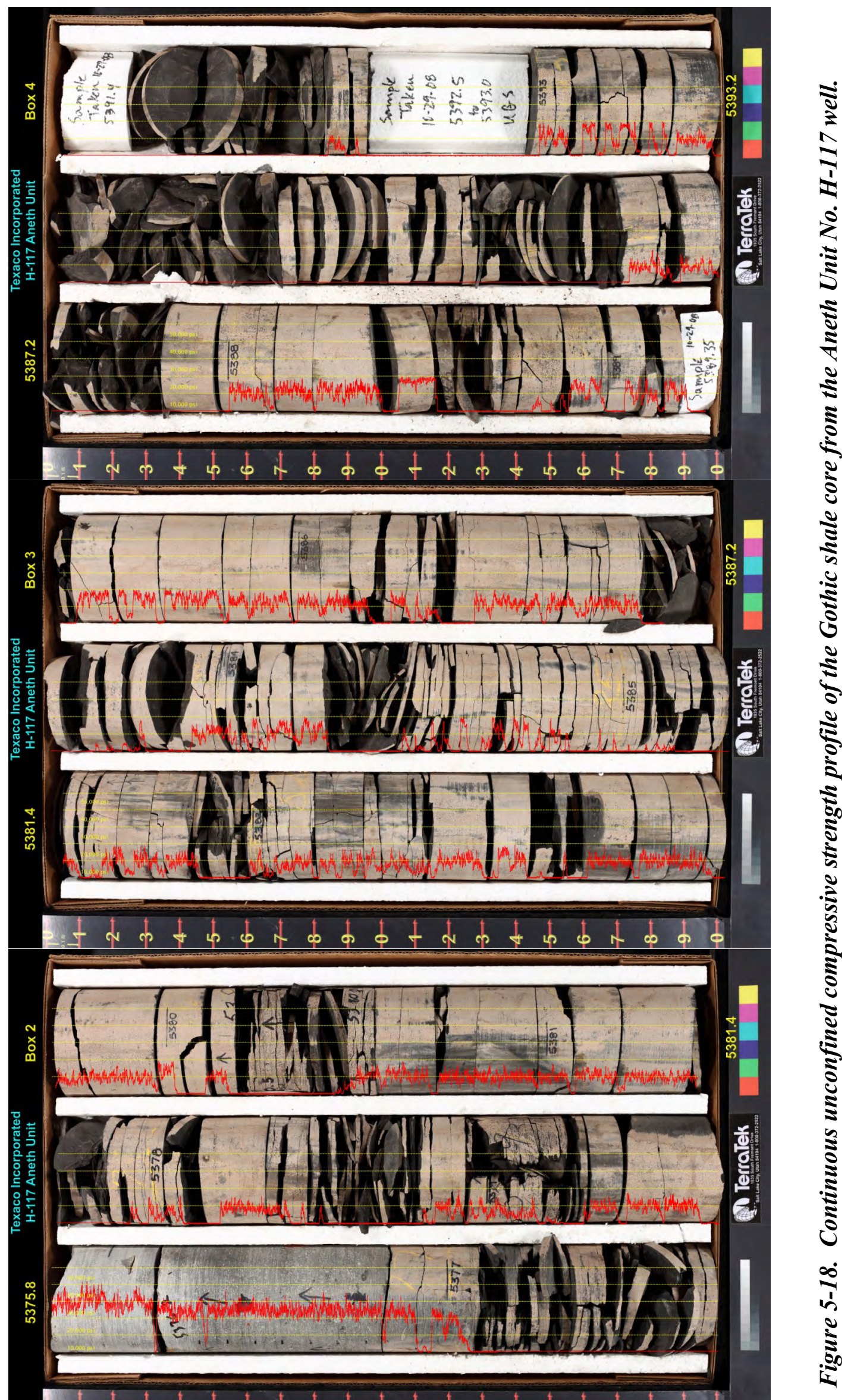




\title{
CHAPTER 6 EVALUATION OF PRODUCTION HISTORY CURVES FROM THE ANETH UNIT
}

\author{
by \\ Craig D. Morgan, \\ Utah Geological Survey
}

\section{Introduction}

In the Aneth Unit horizontal laterals were drilled from the wells in section 14 (T. 40 S., R. 24 E., SLBL\&M) and in 1998 a small $\mathrm{CO}_{2}$ tertiary-recovery WAG operation was started. Horizontal laterals were also drilled from the wells in sections 25 and 26, beginning in 1996, but those wells continued to be waterflooded. Two additional WAG operations began in late 2007 in the western portion of the Aneth Unit, designated Phase I and Phase II. Phase I involves sections 17 and 18, T. 40 S., R. 24 E. SLBL\&M, while Phase II involves adjoining sections 13 and 14, T. 40 S., R. 23 E., SLBL\&M.

Monthly production of oil, gas, and water, and monthly water injection data were compiled for wells in the Phase I and Phase II areas and in sections 14, 25, and 26, T. 40 S., R. 24 E. SLBL\&M, (figure 6-1). Graphs for individual wells and for each section were constructed to evaluate the characteristics of primary production as well as production resulting from the WAG flood in wells with horizontal laterals versus waterflood in wells with horizontal laterals.

\section{Production History Curves}

\section{Individual Wells}

Oil, gas, water production, and water injection volumes were graphed for each well (see Chidsey [2009] for discussion of methods and all graphs). Figure 6-2A is the monthly oil, gas, and water production history curves for the Aneth A-214 (SWNW section 14, T. 40 S., R. 23 E., SLBL\&M) well and is an example of a currently producing oil well. Figure 6-2B is a graph of the oil, gas, and water production, and water injected volumes for the Aneth E-414 (SWSW section 14, T. 40 S., R. 24 E., SLBL\&M) well, and is an example of an oil well that was converted to an injection well. Oil production has generally declined, with some periods of level to slightly increasing production, while water production has steadily increased. Water injection began in section 14 in 1962, and may be responsible for the slow production decline in the well. The well was converted to water injection in February 1980, and to WAG injection in October 1998.

\section{Section 14 Horizontal Laterals and WAG}

Oil was first produced from section 14 in 1958, and secondary waterflood operations began in 1962. Oil, gas, and water production declined until 1962 when oil production increased and the GOR decreased in response to the waterflood. The decrease in GOR may be the result of increased reservoir pressure putting some of the gas back into solution. Water production increased beginning in 1968, and may be a result of water from the injector wells. Horizontal 
laterals were drilled in the Ismay and Desert Creek zones in 1995, and the WAG tertiary oil recovery (EOR) program was begun in October 1998 (in section 14, S1/2S1/2 section 10, E1/2E1/2 section 15, and W1/2W1/2 section 13, T. 40 S., R. 24 E., SLBL\&M).

Oil, gas, and water production, and water injection data were collected and graphed for all the wells in section 14. Gas injection data were not readily available from the operator or DOGM. Section 14 was producing from wells with 80-acre (32 ha) spacing until the 1970s when the section was in-filled at 40 -acre (16 ha) spacing. All of the producing wells that were drilled in the 1950s have been converted to water injection.

Figure 6-3 shows the cumulative production and injection history for all the wells in section 14. Oil production increased and the GOR declined when the waterflood was first initiated. Water breakthrough first occurred in 1973, but the volume of water produced dropped shortly afterward as older wells were converted to injection and newer wells were placed on production. Oil production started to decline soon after the new wells came on line. Production increased in 1995 when horizontal legs were drilled from many of the existing wells and the WAG program began in 1998. Production levels remained relatively flat for several years after gas injection began, but have been in decline since 2002. Since gas injection began, the monthly water produced has exceeded the monthly volume of water injected in spite of less water being injected.

\section{Sections 25 and 26 Horizontal Laterals and Waterflood}

For sections 25 and 26, production data starting in 1984 were obtained from the DOGM Web site. The DOGM data do not include injection data. No attempt was made to collect older data for sections 25 and 26. The goal was to compare the production of wells with horizontal laterals that are being waterflooded to wells having horizontal laterals that are under WAG flood, which occurred after 1984. Production from 1984 to 1992 was declining slightly in section 25 (figure 6-4A) and was a flat rate in section 26 (figure 6-4B). For ease of comparison, production is shown as barrels of oil equivalent (BOE) and a 12-month average is calculated from the monthly production data. In the early to mid-1990s, new perforations in the Desert Creek zone were added to most of the wells in sections 25 and 26. The additional perforations provided a slight increase in production. In the mid to late 1990s, the operator drilled horizontal laterals in the Desert Creek zone in most of the wells in sections 25 and 26. The horizontal laterals provided a significant increase in production, but shortly thereafter production began a slow decline.

\section{Comparison of Waterflood to WAG in Wells with Horizontal Laterals}

Horizontal laterals were drilled from vertical wells in section 14 in 1995, into both the Ismay and Desert Creek zones. Production increased as a result of the laterals encountering banked oil, oil that lies between injector wells, and stranded oil that was not adequately drained by the vertical wells. Horizontal laterals were drilled from existing wells in sections 25 and 26 during 1997 and 1998. The wells in section 14 were converted to WAG in 1998 while the wells in section 25 and 26 remained under waterflood. Comparing production from section 14 to production from sections 25 and 26 demonstrates the incremental increase obtained from the WAG. The B-313 well was also used for the comparison because it has horizontal laterals and is in the Phase II area, which is currently in waterflood but scheduled to be converted to WAG. 
The production data are a 12-month average of BOE normalized to when horizontal laterals were drilled in each section or well (figure 6-5). All three sections and the B-313 well show significant production increases with the addition of horizontal laterals. Section 25, 26, and the B-313 well all show decline shortly after the initial production increase. Section 14 has a longer period of flat production after the initial increase. The resulting increased volume of oil during this period is the result of the WAG versus waterflooding.

\section{Phase I Area}

Resolute Natural Resource Company plans to expand the Aneth WAG program to the western portion of the unit. Phase I is scheduled for sections 17 and 18, T. 40 S., R. 24 E. Production was first established in both sections in 1958, and water injection began in 1962 for section 17 (figure 6-6A), and 1964 for section 18 (figure 6-6B). After water injection began, oil production increased from both sections until 1975 and has declined since then. Water breakthrough did not occur until 1982 (section 17) and 2003 (section 18), 12 years and 39 years, respectively, after water injection began. The long period (39 years) between beginning water injection and water breakthrough in section 18 may be due to a large reservoir volume and high oil saturation. Another possibility is that some of the water is going out of zone into underlying and/or overlying rocks. If injected water is going out of zone it does not appear to have adversely affected oil production.

\section{Phase II Area}

Phase II consists of sections 13 and 14, T. 40 S., R. 23 E., SLBL\&M. The oil production curves show potentially significant differences in the response to the waterflood in section 13 (figure 6-7A) compared to section 14 (figure 6-7B). In section 13, oil production was improved by the waterflood, reaching a peak in 1977, about 12 years after the waterflood began. Water breakthrough did not occur until 1985. Since 1977, oil production has steadily declined.

Oil production in section 14 reached a peak in 1965, just three years after waterflooding began in the section. Oil production has steadily declined since 1965, except from 1982 through 1984 when additional wells were drilled in the section. Water breakthrough occurred in 1966, just four years after the waterflood began. 


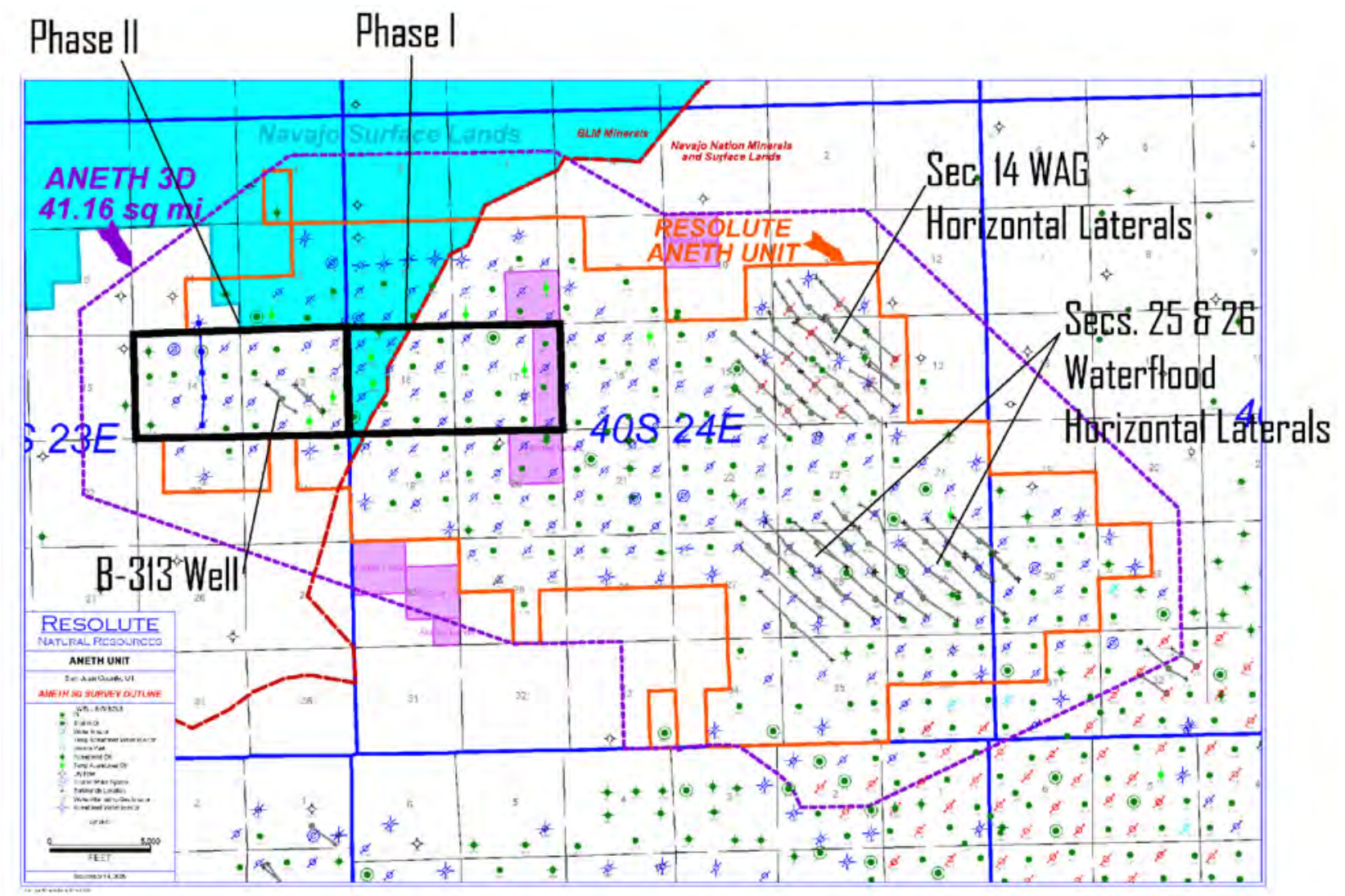

Figure 6-1. Location map of the Aneth Unit showing the section 14 WAG area, Phase I and Phase II areas, and areas of horizontal drilling. Modified from Resolute Natural Resources Company map. 

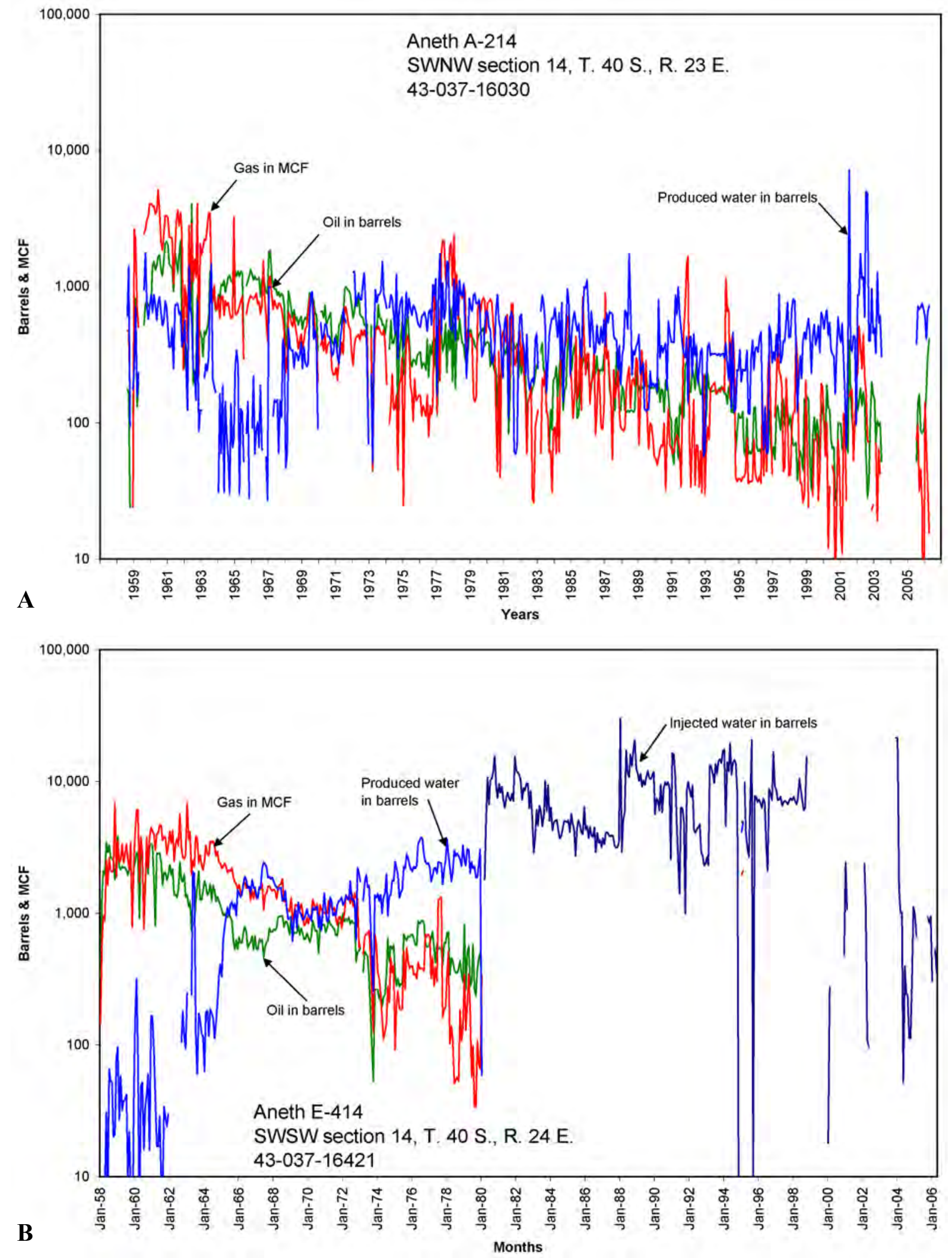

Figure 6-2. Monthly oil, gas, and water production (1958-2006) from the (A) A-214 well, a typical producing oil well in the Aneth Unit, and (B) the Aneth E-414 well. This well was converted to water injection in 1980 and then water-alternating-gas injection in 1998. Gas injection data not shown. 


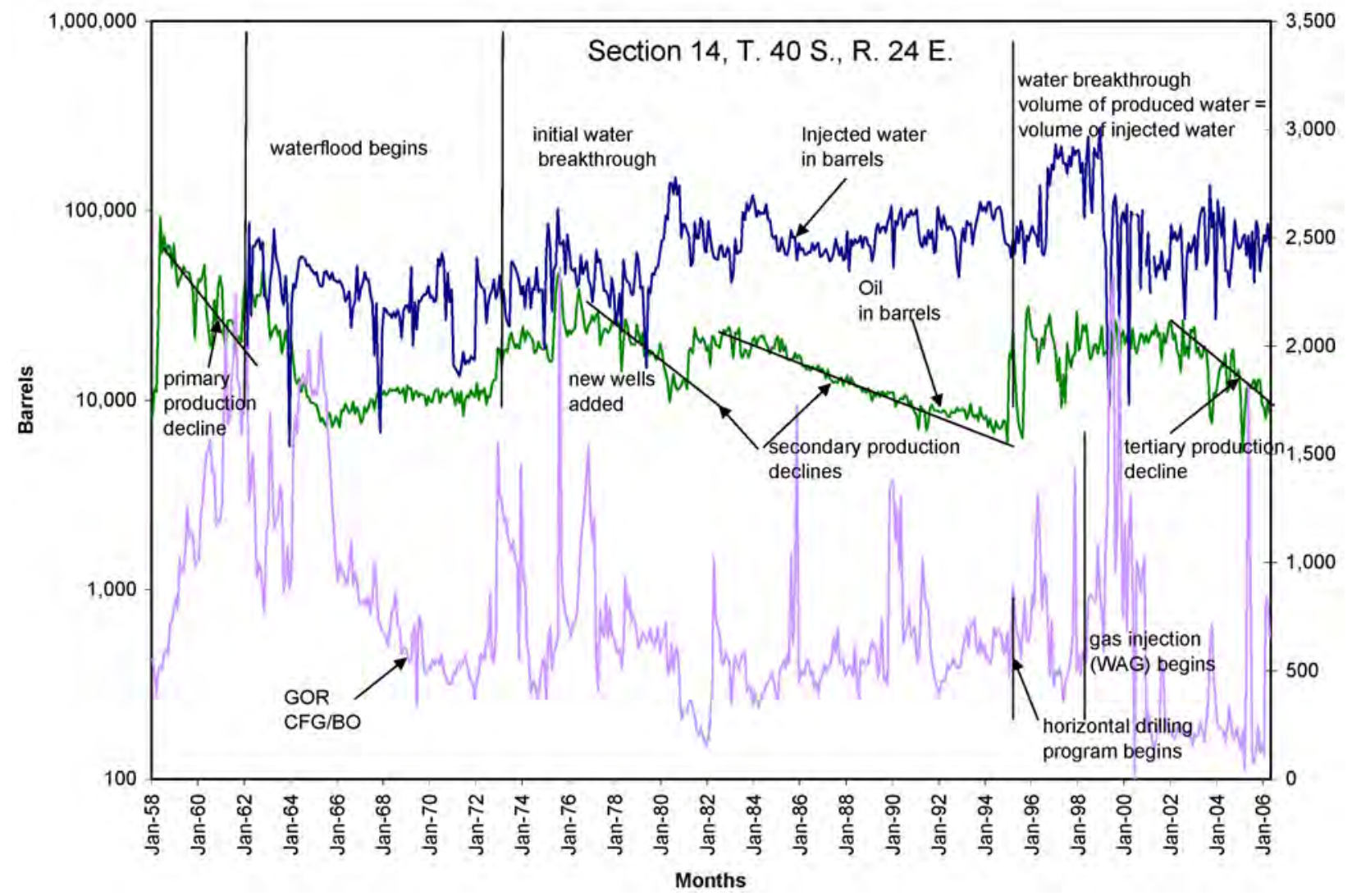

Figure 6-3. Monthly oil produced, water injected (1958 - 2006) and gas-to-oil ratio (GOR) for all wells in section 14 (WAG area). Three years after secondary recovery waterflood operations began, the monthly oil production began to increase and the GOR decreased. Horizontal legs were drilled in existing wells and tertiary water-alternating-gas operations began in 1998, resulting in several years of level oil production. 

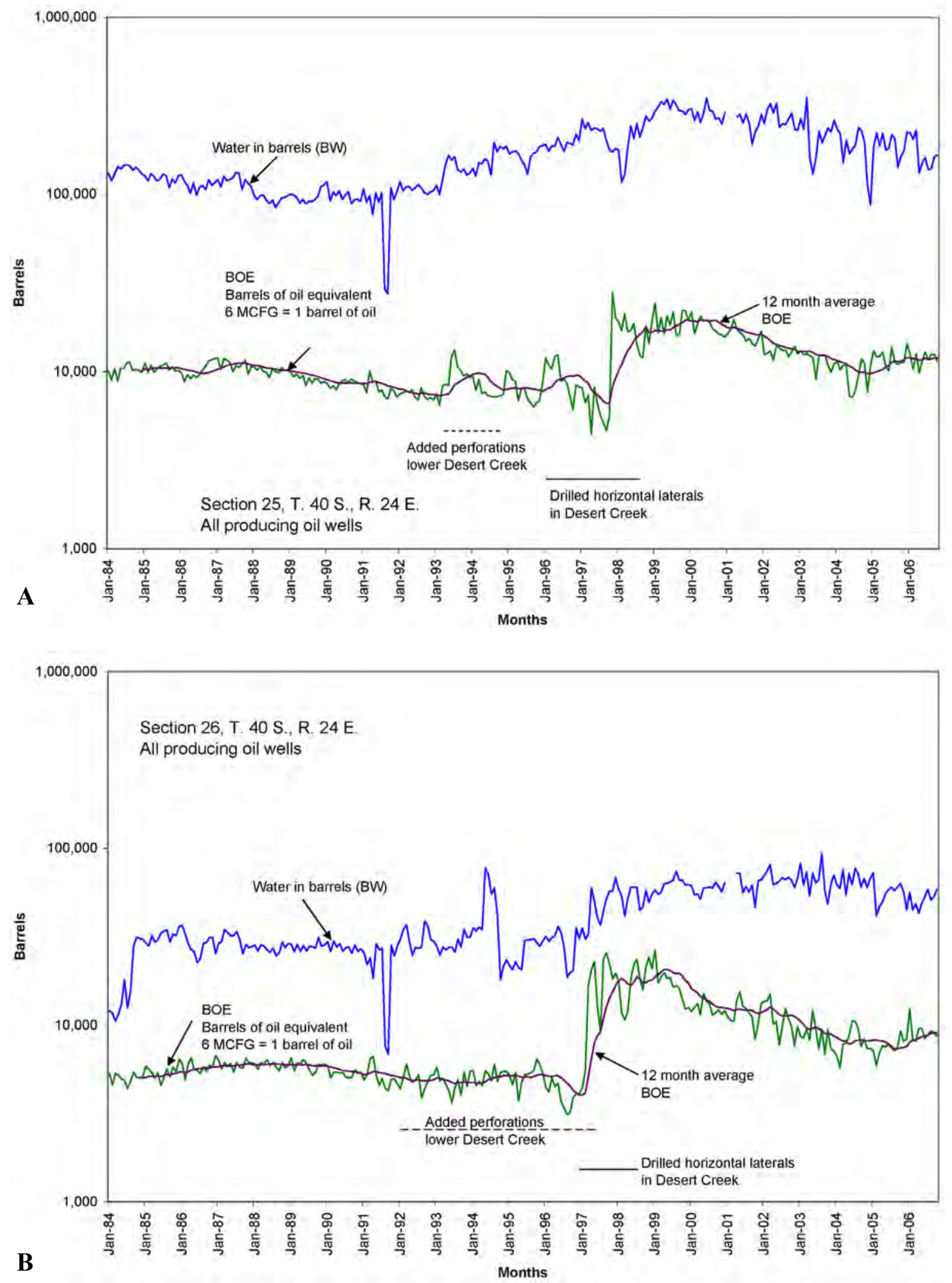

Figure 6-4. Oil and gas production (1984 - 2006) shown as BOE and water production for wells in (A) section 25 and (B) section 26. Production remained fairly flat through the 1980s and early-1990s in both sections. Additional perforations were added in mid-1990s, slightly increasing the production rate in section 25 but appeared to have little effect on the production rate in section 26. Horizontal laterals were drilled in late-1990s in these sections, greatly increasing the production. 


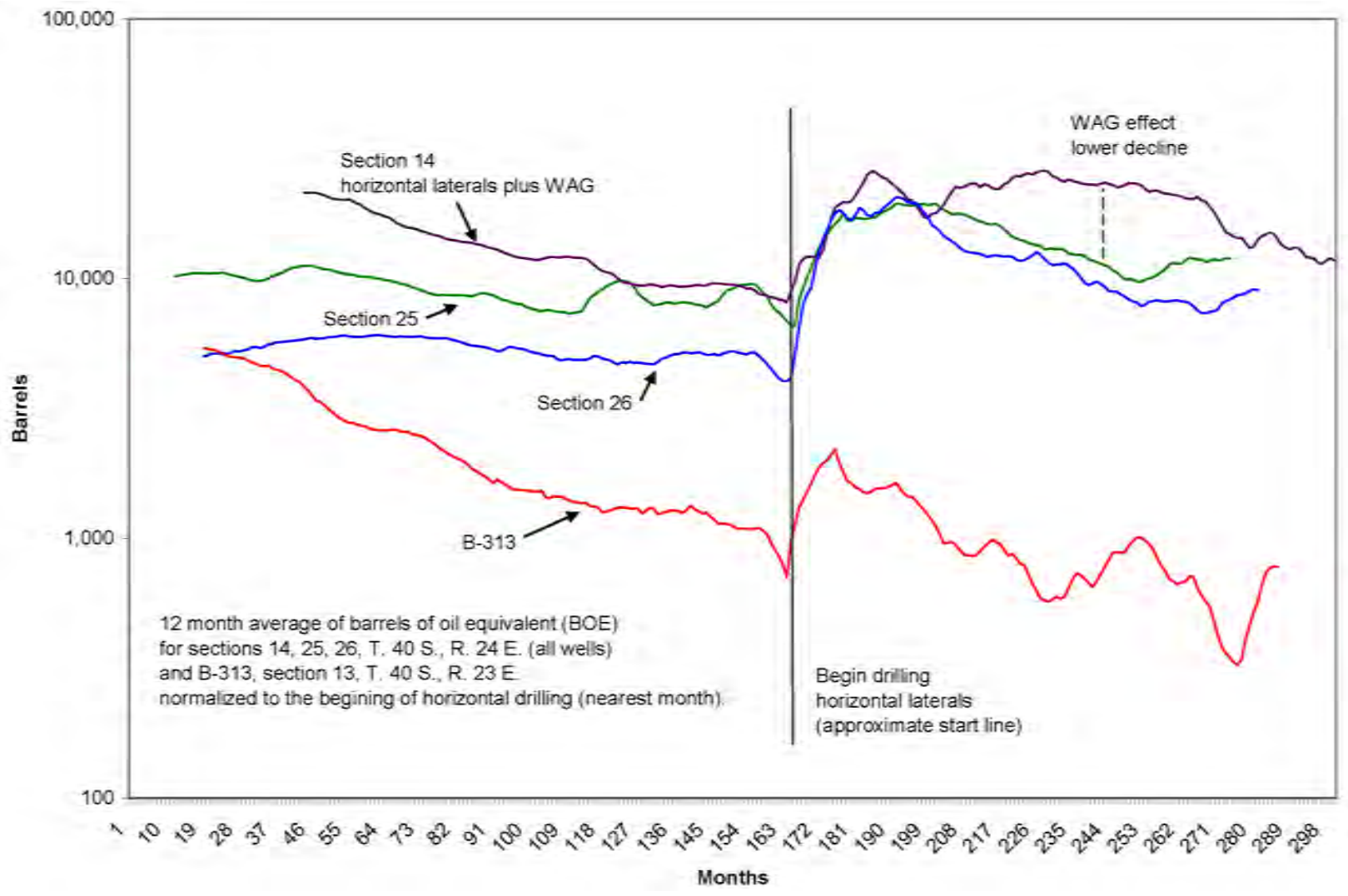

Figure 6-5. Comparison of $\mathrm{BOE}$ production from sections 25 and 26 where wells have horizontal laterals in the Deseret Creek and are under waterflood. Section 14 wells have horizontal laterals in the Ismay and Desert Creek and were converted to WAG after the laterals were drilled. Well B-313 has horizontal laterals and is in the Phase II WAG. Notice the incremental increase in production in section 14 due to the WAG flood. 

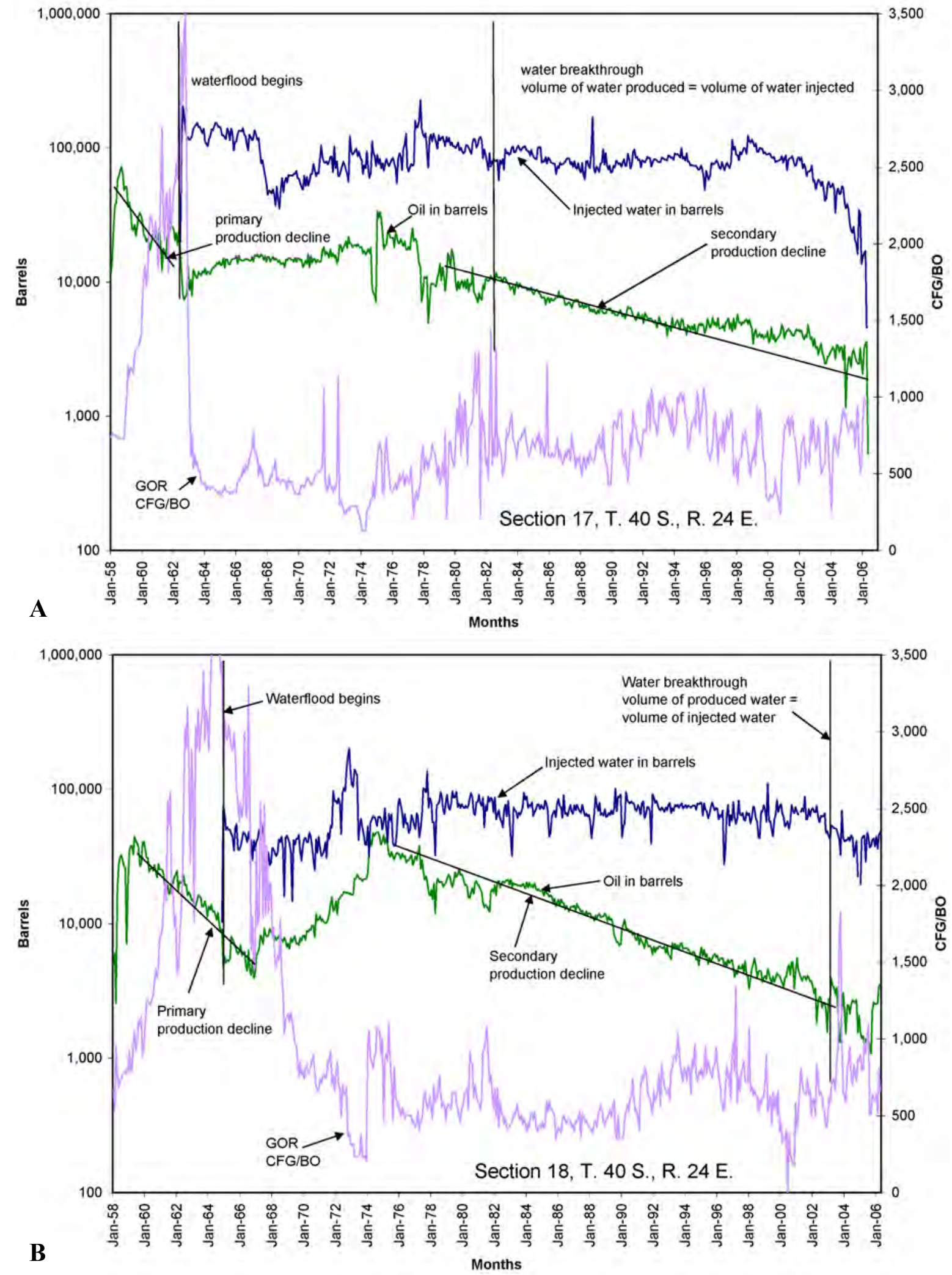

Figure 6-6. Monthly oil produced, water injected (1958 - 2006), and gas-to-oil ratio (GOR) for all the wells in (A) section 17 and (B) section 18 (Phase I area). The monthly oil production increased and the GOR decreased after secondary waterflood operations began. In section 18, water breakthrough occurred 39 years after water injection began. This may be the result of a large reservoir volume or some injected water may be moving out of the reservoir into overlying and/or underlying rocks. 

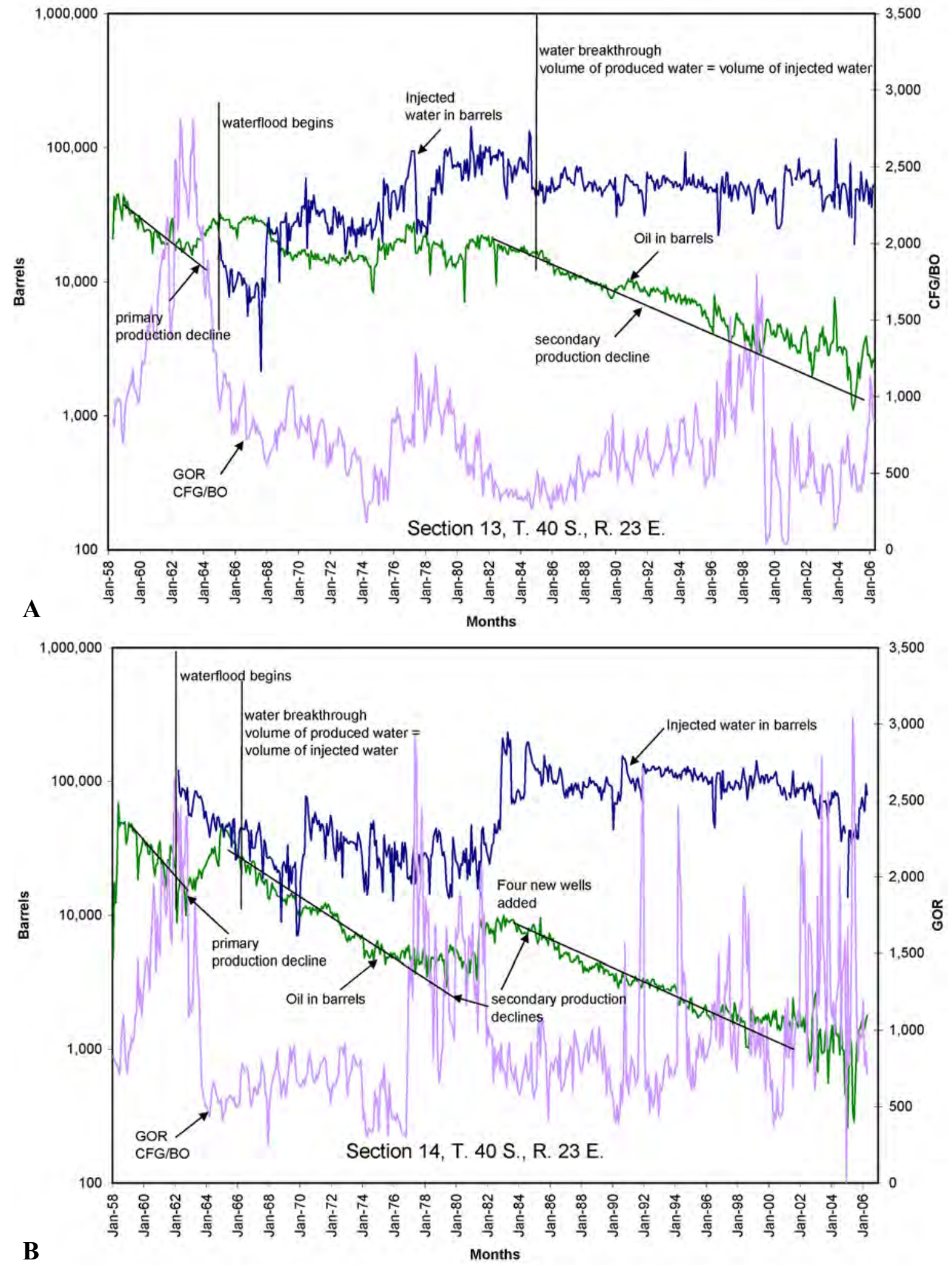

Figure 6-7. Monthly oil produced, water injected (1958-2006), and gas-to-oil ratio (GOR) for all the wells in (A) section 13 and (B) section 14 (Phase II area). In section 13, monthly oil production increased and the GOR decreased before secondary waterflood operations began, possibly due to the addition of new wells. In section 14, shortly after secondary recovery waterflood operations began, water breakthrough occurred and oil production began to decrease. 


\section{CHAPTER 7 \\ SUMMARY AND CONCLUSIONS \\ OF \\ SURFACE AND SUBSURFACE GEOLOGICAL CHARACTERIZATION OF THE ANETH UNIT, GREATER ANETH FIELD, PARADOX BASIN, UTAH}

Greater Aneth oil field, Utah’s largest oil producer, represents an archetype of a mature western U.S. oil field. Located in the Paradox Basin of southeastern Utah, Greater Aneth is a stratigraphic trap, with fractures and small faults. The field produces oil and gas from the Pennsylvanian (Desmoinesian) Paradox Formation. The Paradox forms a complex reservoir representing a variety of depositional environments (open-marine shelf, shallow-marine beach and shoals, algal mounds, and low-energy restricted shelf) that produce significant heterogeneity. There is evidence of hydrothermal dolomite, brecciation, and minor faults that may affect fluid flow.

The Aneth Unit in the northwestern part of the field had no significant $\mathrm{CO}_{2}$ injection. Production had declined by 50\% over the past 20 years in spite of waterflood and horizontal drilling projects. However, the unit has produced 149 million barrels ( 24 million $\mathrm{m}^{3}$ ) of the estimated 450 million barrels (72 million $\mathrm{m}^{3}$ ) of oil in place - a 33\% recovery rate (Babcock, 1978a; Utah Division of Oil, Gas and Mining, 2010). The large amount of remaining oil, combined with a nearby $\mathrm{CO}_{2}$ pipeline, made the Aneth Unit ideal to (1) demonstrate both $\mathrm{CO}_{2}$ storage capability and EOR by flooding the reservoir with the $\mathrm{CO}_{2}$, and (2) extensively monitor the effects of injection from reservoir to surface. Therefore, the Aneth Unit was selected as a demonstration site for the Southwest Regional Partnership on Carbon Sequestration - Phase II: Field Demonstrations project.

The Utah Geological Survey evaluated the surface and subsurface geology of the Aneth Unit demonstration site and how it would affect sequestration operations and engineering strategies. The research for the project includes (1) mapping the surface geology, (2) description of the local stratigraphy, (3) mapping the reservoir, seals, and overlying aquifers, (4) geological characterization of the reservoir, (5) geochemical, petrographic, and geomechanical description of the seals, and (6) evaluation of production history.

\section{Surface Geology}

- The bedrock geology of the Montezuma Creek and Navajo Canyon quadrangles was mapped and the primary focus was to evaluate faults, fractures, and deformation bands that could serve as potential pathways for leakage of injected $\mathrm{CO}_{2}$ from the deep Pennsylvanian Paradox Formation. Based on the data collected and analyzed, there appear to be no major structural damage zones or faults that are likely to act as migration pathways for $\mathrm{CO}_{2}$ from the reservoir to the surface.

- The exposed bedrock geology consists of strata of the Jurassic Recapture Shale Member of the Morrison Formation through the Cretaceous Dakota Sandstone, which dip gently ( $<5$ degrees) to the northeast. 
- No significant faulting was mapped in the area. The only faults found in the area are small with $<3$ feet $(1 \mathrm{~m})$ of slip. These faults do not appear to penetrate into the subsurface beyond shallow depths and were likely caused by gravity-driven, surficial deformation.

- The majority of fractures in the sandstone beds appear to be related to gravity as a result of uplift and erosion of the soft underlying and overlying shale, reflecting the direction of cliff retreat and may not be a reliable indicator of deeper fracture patterns.

- The deformation bands are confined within porous sandstones at the surface and are not coincident with any major faults or damage zones that extend into the subsurface. Deformation bands observed in the study area generally have a strong northwestsoutheast orientation. These features would likely create barriers to lateral fluid flow in a reservoir confined to a single sandstone body and would not likely act as conduits for fluid flow. The bands likely formed in response to either compaction of the sediment after burial or from tectonic stresses associated with the Laramide orogeny.

\section{Subsurface Structural and Thickness Mapping}

- The paleogeographic geometry and extent of the Pennsylvanian carbonate buildup complex is evident in the structure contour maps of all three zones of the Paradox Formation studied. The general shapes of subsidiary buildups are also reflected, to a lesser extent, in the overlying strata of the Permian DeChelly and Jurassic Navajo Sandstones.

- Structures such as faults and folds are virtually absent from the Aneth Unit. One notable exception is a possible northeast-southwest-striking fault seen in the Ismay, Gothic, and Desert Creek structure contour maps in the location of section 18, T. 40 S., R. 24 E., SLBL\&M. This potential fault, however, does not appear in the overlying DeChelly or Navajo Sandstone structure contour maps, and therefore is believed to be a small fault having minimal displacement that is localized in the Paradox Formation.

- The proposed sequestration reservoir is likely sound and the risk of contaminating overlying aquifers from geologic structures or $\mathrm{CO}_{2}$ migration to the surface is small.

\section{Reservoir Characterization of the Desert Creek Zone}

- Determining the nature, location, and extent of reservoir heterogeneity is the key to determining $\mathrm{CO}_{2}$ storage potential in the Aneth Unit. Three factors create reservoir heterogeneity: (1) variations in lithofacies and lithology, (2) mound relief and flooding surfaces, and (3) diagenesis. The extent of these factors and how they are combined affect the degree to which they create $\mathrm{CO}_{2}$ storage capacity and barriers to $\mathrm{CO}_{2}$ flow.

- Cores from Aneth Unit wells reveal a complex reservoir consisting of limestone (oolitic, peloidal, and skeletal grainstone and packstone, and algal boundstone/bafflestone) and 
finely crystalline dolomite. These lithotypes represent a variety of depositional environments (open-marine shelf, shallow-marine beach and shoals, algal mounds, lowenergy restricted shelf) that produce reservoir heterogeneity beyond what can be determined from well logs.

- The typical early diagenetic events occurred in the following order: (1) early marine cementation, (2) post-burial, replacement, rhombic dolomite cementation due to seepage reflux, (3) vadose and meteoric phreatic diagenesis including leaching/dissolution, and fresh-water cementation, (4) mixing-zone dolomitization, and (5) anhydrite cementation/replacement.

- The relatively large number of fractures, both horizontal and vertical, suggests fracturerelated permeability is significantly higher than matrix permeability but directional flow anisotropy may not be high. The natural fractures in most cases cut across vertical and horizontal stylolites, which tend to compartmentalize a reservoir, and will enhance conductivity across the stylolites. The low probability of intersecting vertical and nearvertical fractures with near-vertical core, unless the fractures are closely spaced, suggests that Desert Creek reservoir strata are intensely fractured and that fractures are likely to be an important factor in subsurface fluid flow, including directionality and volume of flow. Stylolites may impede flow and influence the directionality of fluid flow.

- The most notable and well-documented oil-producing intervals in the Desert Creek zone of the Paradox Basin formed as shallow-water algal buildups. However, they are not significant producers in the Aneth Unit. Grainstones within oolitic shoal lithofacies represent the major reservoir and the best potential $\mathrm{CO}_{2}$ storage capacity. Dolomite with high porosity identified on geophysical well logs but with unidentified low permeability has led to costly and unwise well completion attempts in these intervals that in reality are baffles to poor-quality flow units.

\section{The Gothic Shale in the Aneth Unit: Seal for Hydrocarbons and $\mathrm{CO}_{2}$ Geologic Sequestration}

- The Gothic shale is an effective seal above the Desert Creek reservoir zone within the Pennsylvanian Paradox Formation, Aneth Unit. The Gothic shale ranges in thickness from 5 to 27 feet (1.5-8 $\mathrm{m})$, averaging 15 feet $(4.6 \mathrm{~m})$.

- The core from the Aneth Unit No. H-117 well is an excellent representation of the Gothic shale. The Gothic is remarkably uniform mudstone/shale with grain size ranging between clay and silt. Accessories and biological constituents consist of ubiquitous authigenic pyrite, microfossils, shell fragments, conodonts, and conularoids.

- Total organic carbon ranges from 2.2 to $4.4 \%$ with type II kerogen.

- Lithology consists of argillaceous or calcareous shale and mudstone composed of a clayey to siliceous matrix with weak laminations defined by micas. Within the matrix, calcite crystals, pyrite, quartz, microfossils, flakes of organics, and swarms of 
intercrystalline micropores are common.

- Porosity ranges from 2.7 to $3.4 \%$ and pressure-decay permeability is no greater than $0.000146 \mathrm{mD}$. These and other basic matrix petrophysical parameters indicate the Gothic shale to be a highly effective reservoir seal.

- The Gothic shale should support very large $\mathrm{CO}_{2}$ or hydrocarbon columns based on mercury injection capillary pressure and pore aperture distribution analyses.

- Near the base of the Gothic section, vertical to subvertical extensional fractures are present. Mineralization co-located with these natural fractures is most likely dominated by carbonates and organics.

- Continuous unconfined compressive strength profiles show a relatively uniform homogenous shale package. Compressional testing suggests some degree of hydraulic fracture containment.

\section{Evaluation of Production History Curves from the Aneth Unit}

- Monthly production curves for the sections studied show improved oil recovery resulting from the waterflood. Increasing to flat monthly oil production rates occurred in each section from 2 to 12 years after waterflood operations began.

- Section 14 (Phase II) had the quickest water breakthrough of all the sections studied. The rapid breakthrough may be due to increased formation water production and not a true breakthrough of injected water. However, if the increased water production is a result of breakthrough of injected water, then this area may experience early breakthrough of injected $\mathrm{CO}_{2}$ as well. The long period from the onset of water injection to when water breakthrough occurred in section 18 (Phase I) may be due to some of the injected water getting out of zone.

- If injected water is going out of zone then some of the injected $\mathrm{CO}_{2}$ will get out of zone as well. This may not adversely affect the tertiary oil recovery volume, but may require greater volumes of injected $\mathrm{CO}_{2}$ over time since some of the $\mathrm{CO}_{2}$ will not be recycled. Oil production from section 14, T. 40 S., R. 24 E., SLBL\&M (WAG area) remained steady or increased slightly for about 2.5 years after WAG operations began. A similar response can be expected from WAG operations in Phase I and section 13 of Phase II. 


\title{
CHAPTER 8 \\ TRACER TESTING AT THE ANETH, UTAH PETROLEUM FIELD
}

\author{
by \\ Peter Rose, Ph.D. and Kevin Leecaster \\ Energy and Geoscience Institute at the University of Utah \\ 423 Wakara Way suite 300 \\ Salt Lake City, Utah, USA \\ 801-585-7785 \\ prose@egi.utah.edu
}

\section{Objective and Approach}

The primary objective of this project was to characterize water-flood and $\mathrm{CO}_{2}$-flood tracers in anticipation of their use in $\mathrm{CO}_{2}$-sequestration applications. This would be achieved by using candidate tracers to test fluid-flow patterns within the western portion of the Aneth petroleum field during both a water-flood and a subsequent $\mathrm{CO}_{2}$-flood.

\section{Water-Flood Tracer Testing}

On July 19, 2007, $100 \mathrm{~kg}$ each of the fluorescent tracers 1,3,5-naphthalene trisulfonate (1,3,5-nts) and 2,6-naphthalene disulfonate (2,6-nds) were injected into Aneth water-injection wells C-214 and D-114, respectively (see Figure 8-1). Four surrounding production wells (B214, C-314, D-214, and C-114) were subsequently sampled by subcontractor Durbin Enterprises and sent to the Tracer Development Laboratory at the University of Utah for analysis.

Water samples were received, prepared and analyzed at the EGI tracer laboratory in Salt Lake City using High Performance Liquid Chromatography (HPLC) and fluorescence detection. Before the samples were ready for injection into the HPLC, however, they were prepared using ion exchange. Using this method, water samples were eluted through Weak Anion Exchange (Waters WAX) cartridges. Any tracers present in the fluid would adsorb onto the cartridge resin. The cartridges were then washed with eluents for the purpose of removing interferences that might otherwise obscure the fluorescence signal from the tracers. The tracers were then eluted from the cartridge with an appropriate solvent and thus rendered ready for analysis by HPLC. 


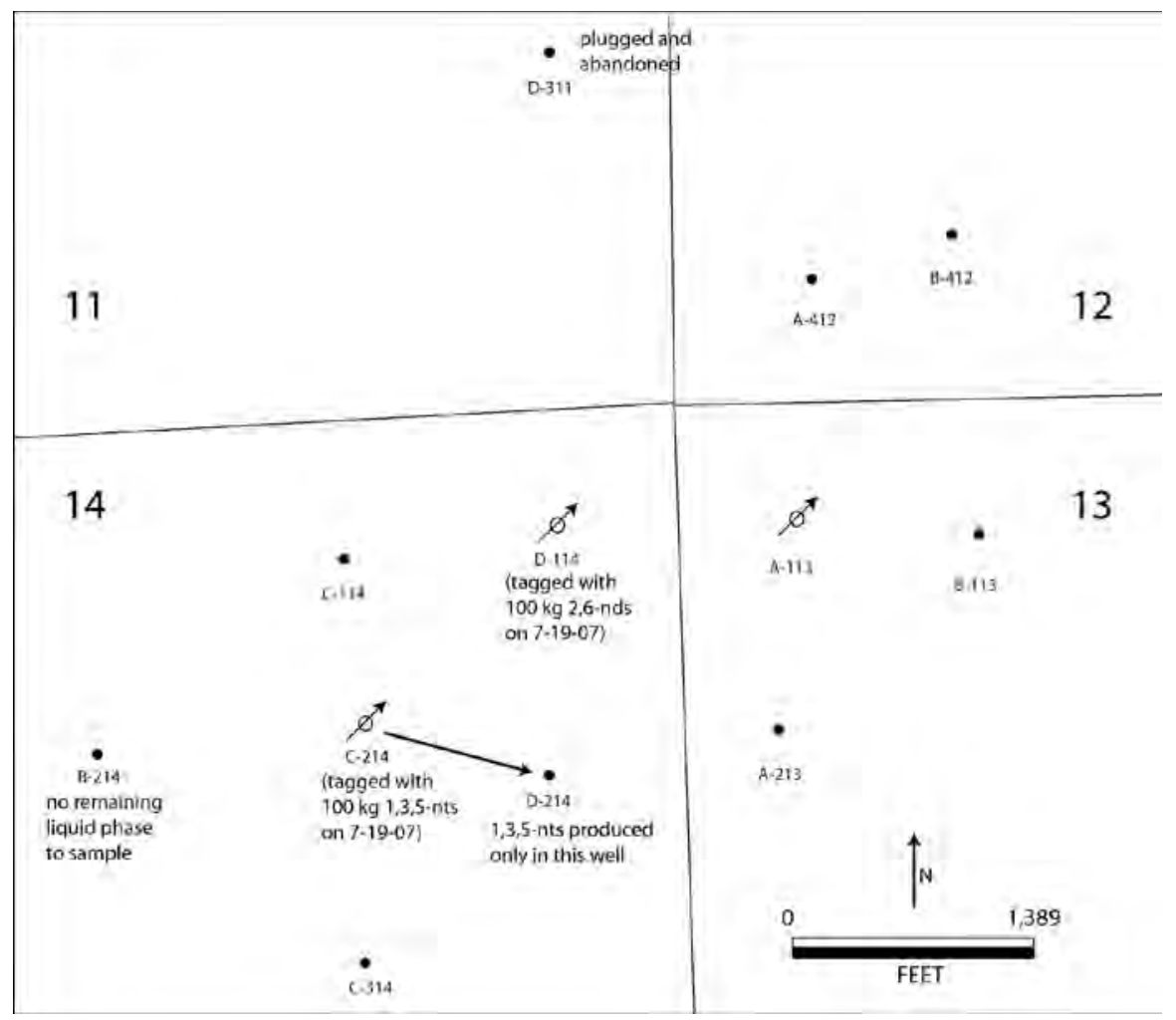

Figure 8-1. Wells within the Aneth oil field showing tracer returns from the July 2007 waterflood tracer test.

On September 17, 2007, breakthrough of 1,3,5-nts was first observed in well D-214, just before the original scheduled termination of the sampling and analysis campaign (see Figure 82). No tracer was observed in any of the other wells. Tracer sampling and analysis was reinitiated in May, 2008. Large shows of the tracer 1,3,5-nts were observed in well D-214 (where that tracer had first appeared six months earlier; see Figure 8-2). No tracer was observed in any of the other wells.

Sampling is the most expensive aspect of this project. As a result, the sampling rate was reduced to a minimum. Sampling frequency is, however, a very important parameter in obtaining good data. The discrete points in Figure 8-2 are the measured data. The dotted line is a fictitious representation of how the tracer curve might have appeared if more data were available.

Alternatively, the curve might have looked very different. Without sufficient data, however, the shape of the return curves is impossible to determine and information from the tracer test is limited. 


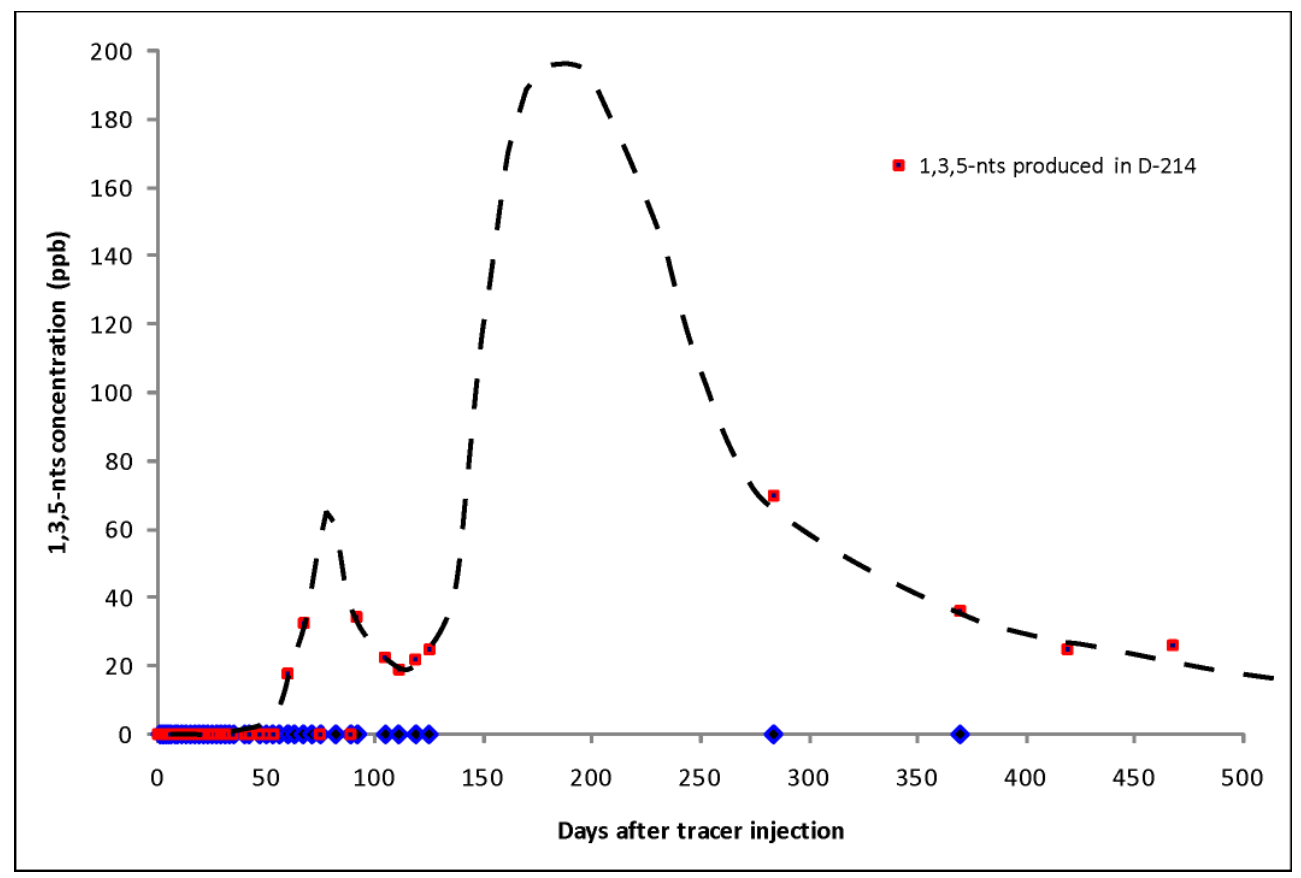

Figure 8-2. The return curve data plotted for the well D-214 that showed returns of the tracer 1,3,5-naphthalene trisulfonate. The dotted line is a fictitious representation of how the return curve might have appeared with a more complete data.

\section{$\mathrm{CO}_{2}$-Flood Tracer Testing}

Following the waterflood, the Aneth field switched to an alternating water and gas (WAG) injection approach, with $\mathrm{CO}_{2}$ being the gas. The tracer testing of the $\mathrm{CO}_{2}$ therefore involved the use of gas-flood tracers, including two perfluorocarbons (PFT's) and two lowmolecular weight alcohols. The PFT's are commonly used in gas-flood tracer testing (personal communication, Hans Torgeson, IFE Norway), but the use of low-molecular-weight alcohols has not been reported in the open literature. This gas-flood tracer test at the Aneth petroleum field therefore provided the opportunity to use a well characterized family of tracers (the PFT's) in combination with a novel family of tracers (the alcohols). If the alcohols were to perform well in the gas-flood of a petroleum field, then they would be excellent, cost-effective candidates for $\mathrm{CO}_{2}$-sequestration tracing applications.

The vapor phase tracers selected for testing were the two water insoluble PFT's perfluoromethylcyclopentane (PMCP) and 1,3-perfluorodimethylcyclohexane (PDCH) along with the water soluble alcohols, n-propanol and iso-propanol (Table 8-1). The perfluorocarbons provide thermal and biological stability, as well as distinctive mass fragments that are easily distinguishable from background interference. But, they are relatively expensive and partition moderately into the oil phase. In contrast, the propanols are inexpensive and thermally stable, but would not be stable in systems with significant biologic activity. Unlike the perfluorocarbons, they do not partition into the oil phase but do partition moderately into groundwater.

The tracer injection was conducted by Resolute Energy and EGI personnel on July 21, 2009. 158 $\mathrm{kg}$ of n-propanol and $9.6 \mathrm{~kg}$ of 1,3-perfluorodimethylcyclohexane $(\mathrm{PDCH})$ were injected into well C-414. $154 \mathrm{~kg}$ of isopropanol and $9.5 \mathrm{~kg}$ of perfluoromethylcyclopentane (PMCP) were 
injected into well B-314 (see Figure 8-3). Four adjacent production wells were sampled over the following six months. Samples were collected from effluent vapors at the wellheads onto carbon absorption tubes and analyzed at the Energy \& Geosciences Laboratory (EGI) laboratory using thermal desorption of the carbon absorption tubes, separation of the tracers via gas chromatography, and mass spectrometric detection.

Table 8-1. Tracers Used in the $\mathrm{CO}_{2}$-Flood Tracer Test

\begin{tabular}{|c|c|c|c|c|c|}
\hline Compound & $\begin{array}{c}\text { Amount } \\
\text { Injected } \\
\mathbf{( k g )}\end{array}$ & Well & $\begin{array}{c}\text { Molecular } \\
\text { Weight }\end{array}$ & $\begin{array}{c}\text { Boiling Point } \\
\left({ }^{\circ} \mathbf{C}\right)\end{array}$ & $\begin{array}{c}\text { Cost } \\
\text { (USD/kg) }\end{array}$ \\
\hline PMCP & 9.5 & B-314 & 300 & 48 & 450 \\
\hline PDCH & 9.6 & C-414 & 400 & 102 & 300 \\
\hline n-propanol & 158 & C-414 & 60 & 97 & 1 \\
\hline isopropanol & 154 & B-314 & 60 & 83 & 1 \\
\hline
\end{tabular}

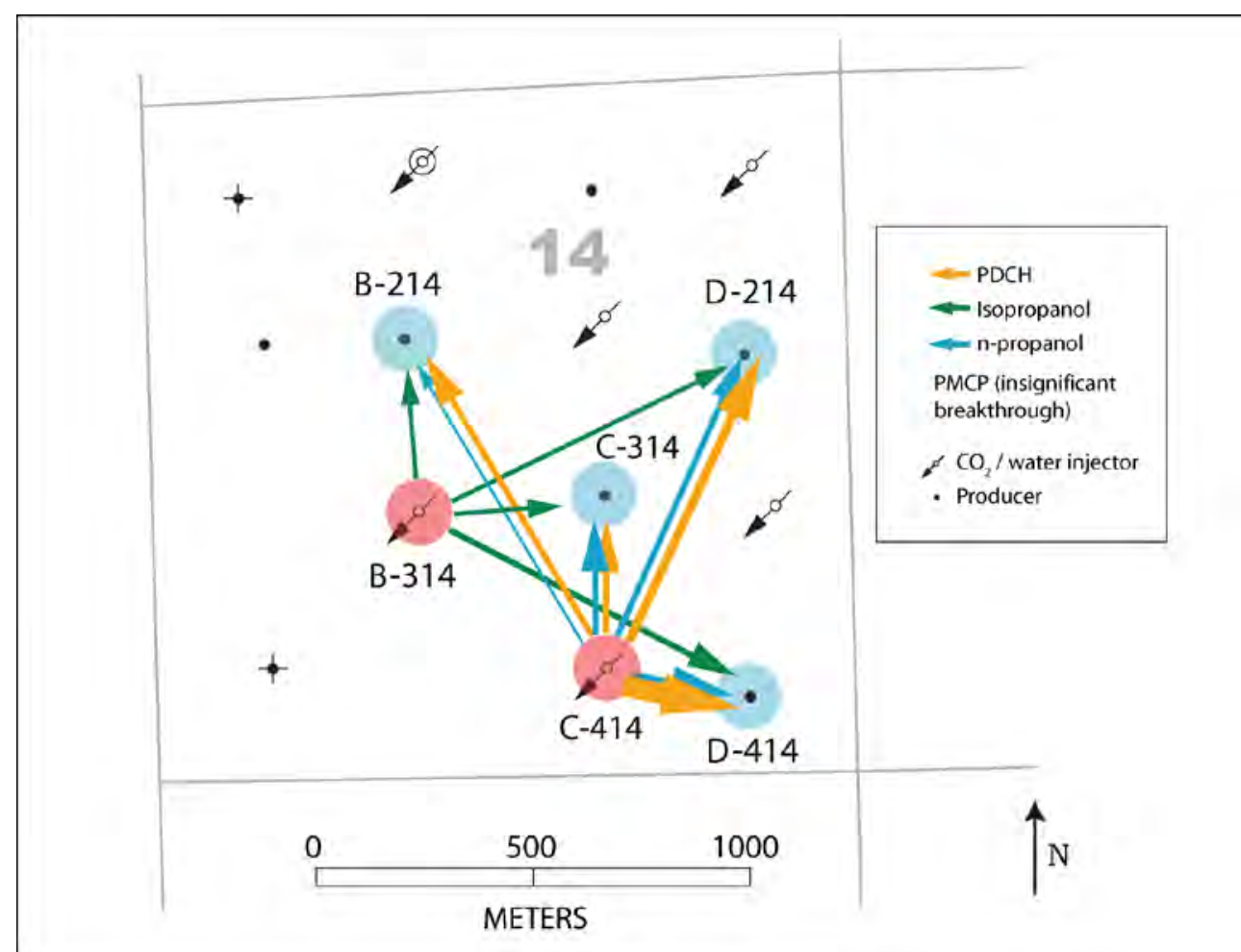

Figure 8-3. $\mathrm{CO}_{2}$-flood test site showing the tagged injectors and the breakthrough patterns. The thicknesses of the arrows reflect the relative amounts of tracer produced at each well.

The sampling plan consisted of weekly collection for the first two months, followed by biweekly sampling for two months, and finally monthly collection over the final two months by Gas Analysis Service personnel. Sampling involved separating the liquid and vapor phases and then injecting an aliquot of the vapor over the carbon-based adsorbent (Carboxen 569, Supelco Analytical) in stainless steel thermal desorption tubes. In order to evaluate the potential of swamping the first carbon absorption tube (CAT's), a $2^{\text {nd }}$ tube was placed in series behind the $1^{\text {st }}$ CAT. 
All of the tracers injected into wells C-414 and B-314 were detected in the sampled gas streams from all four wells (see Figures 4, 5, 6, and 7), although PMCP was detected in only insignificant amounts. Thus, connectivity from the injectors was demonstrated to all of the monitored production wells and indicates that at least some of the injected $\mathrm{CO}_{2}$ flows to all of them. Tracer sampled from production well D-414 had the highest concentrations of any of tracers, which may indicate either a lower sweep efficiency or closer proximity to injector C-414 or both.

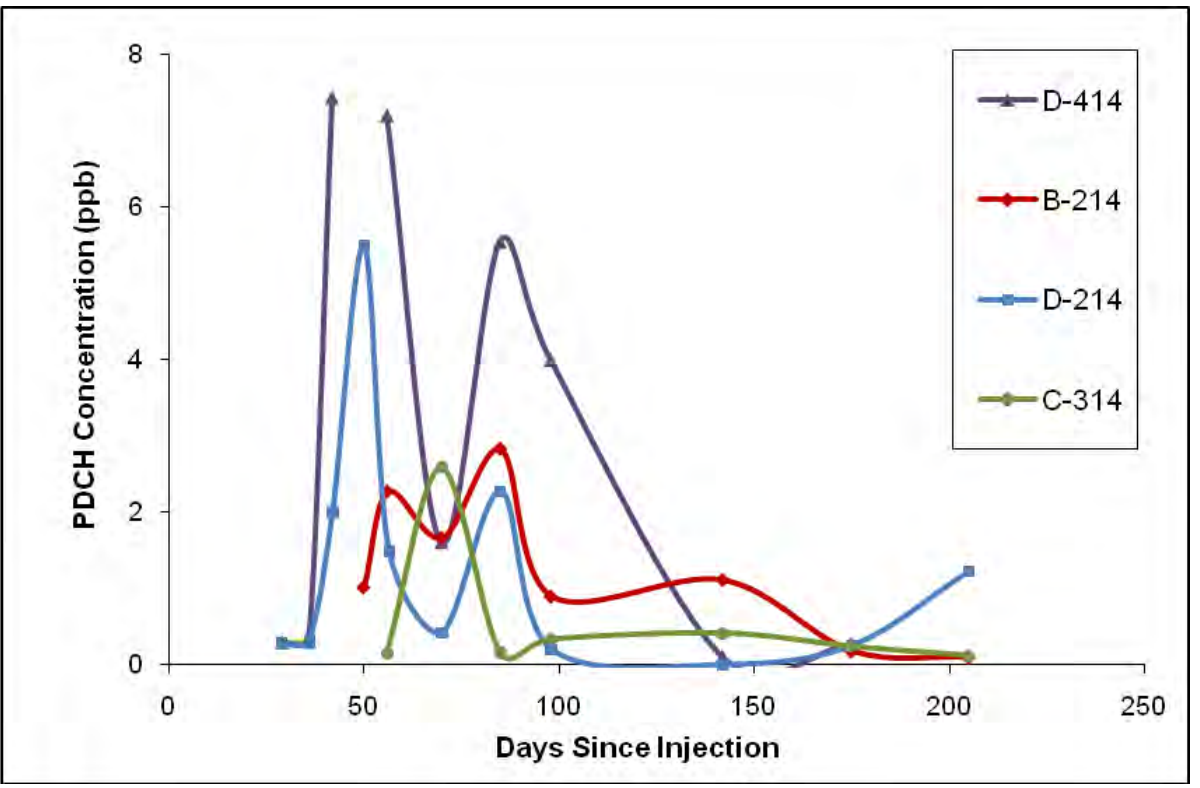

Figure 8-4. Plots of PDCH tracer injected into C-414 and produced in four surrounding production wells.

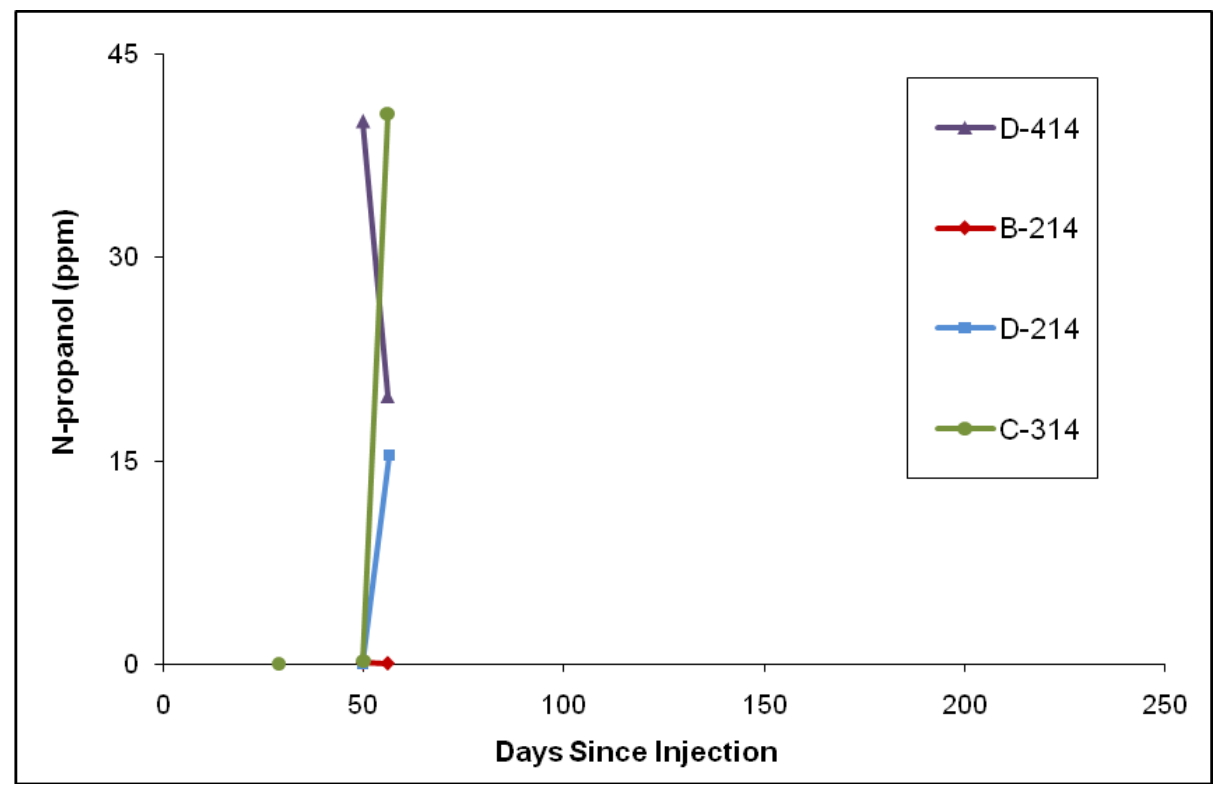

Figure 8-5. Plots of n-propanol tracer injected into C-414 and produced in four surrounding production wells. 


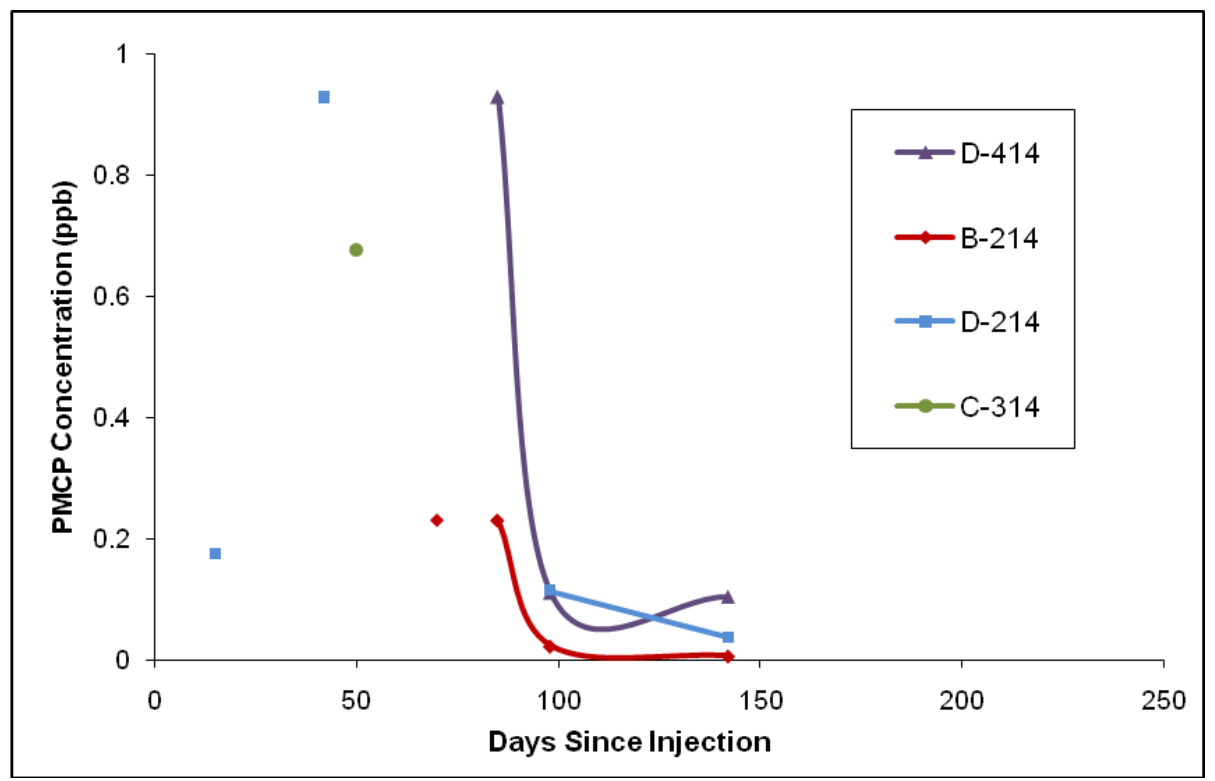

Figure 8-6. Plots of PMCP tracer injected into B-314 and produced in four surrounding production wells.

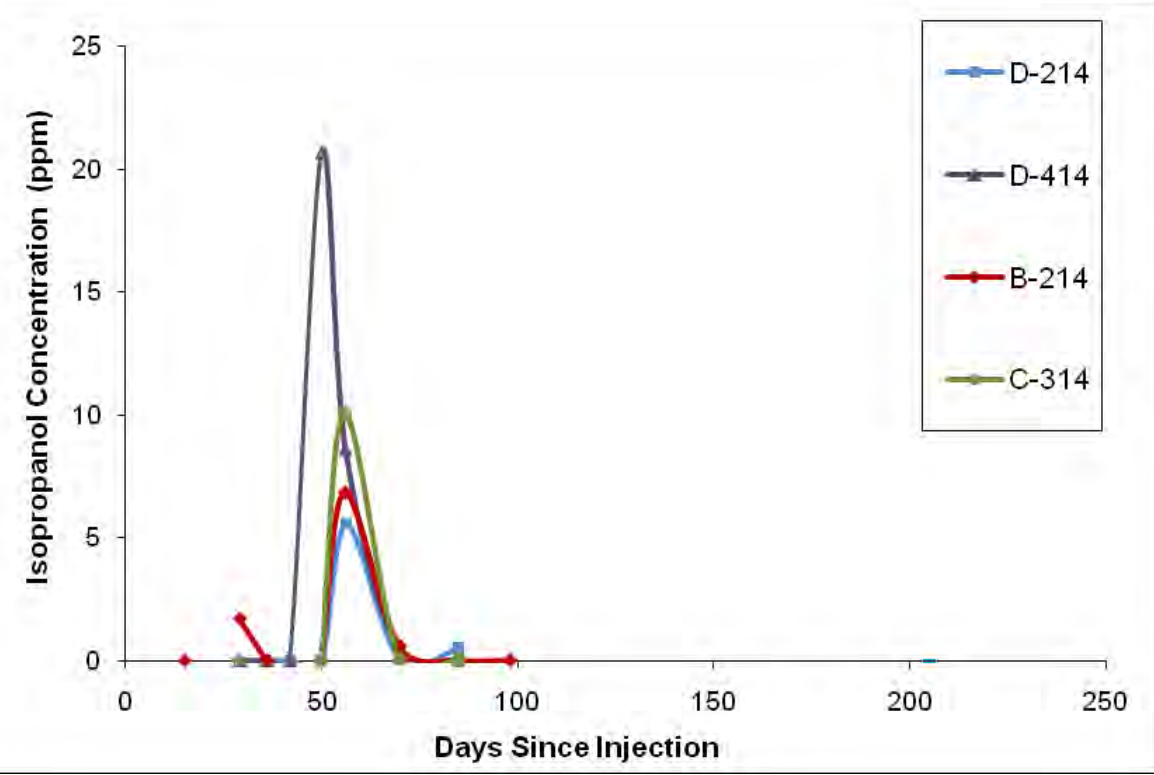

Figure 8-7. Plots of isopropanol tracer injected into B-314 and produced in four surrounding production wells.

\section{Comparison of the Performance of the $\mathrm{CO}_{2}$-Flood Tracers}

Tracers are said to be 'conservative' if they follow the appropriate fluid phase without reacting with either fluids or rock. Likewise, tracers are termed 'reactive' if they thermally decompose, sorb or diffuse within the solid phase, or partition to a second phase. Thus, if the PFT's and the alcohols both behave conservatively within the $\mathrm{CO}_{2}$ phase, their return curves would be very similar. In particular, even if different molar quantities of the tracers were co- 
injected, it would be possible to compare their performance by normalizing for the mass of tracer injected.

Shown in Figure 8-8 are the return curves for the two tracers PDCH and isopropanol that were injected in the same injection well and produced at the same production well. The data show that the tracers were produced at about the same time, indicating that they are interacting similarly with the reservoir. But the plot is deceptive since the tracer concentrations are so different. PDCH is reported in ppb, whereas isopropanol is reported in ppm.

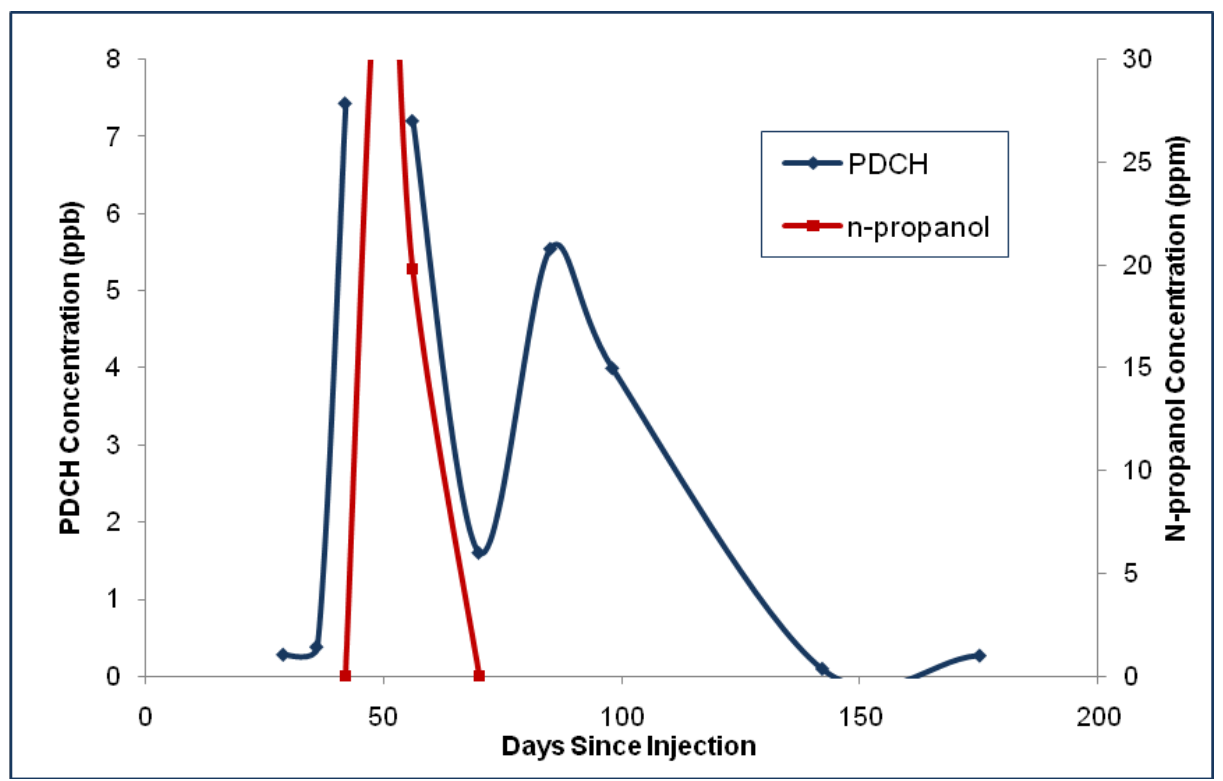

Figure 8-8. Plots of PDCH and isopropanol tracers injected into C-414 and produced in D414.

When the data are reported on the same basis wherein the tracer concentrations are normalized for the amount of tracer injected, the amount of n-propanol is produced in far greater excess (see Figure 8-9). The PFT's, including PDCH, are known to partition to the oil phase in the $\mathrm{CO}_{2}$ flooding of petroleum reservoirs (personal communication, Tom Watson, Brookhaven National Laboratory). In contrast, alcohols, including n-propanol, are used as the nonpartitioning tracer in partitioning tracer tests in petroleum reservoirs. Thus, it is likely that the reason why the production of $\mathrm{PDCH}$ was so much less than that of n-propanol is that the PDCH partitioned to the oil phase and the n-propanol remained largely with the gas $\left(\mathrm{CO}_{2}\right)$ phase. Some of the n-propanol, however, likely partitioned to the aqueous phase as well. 


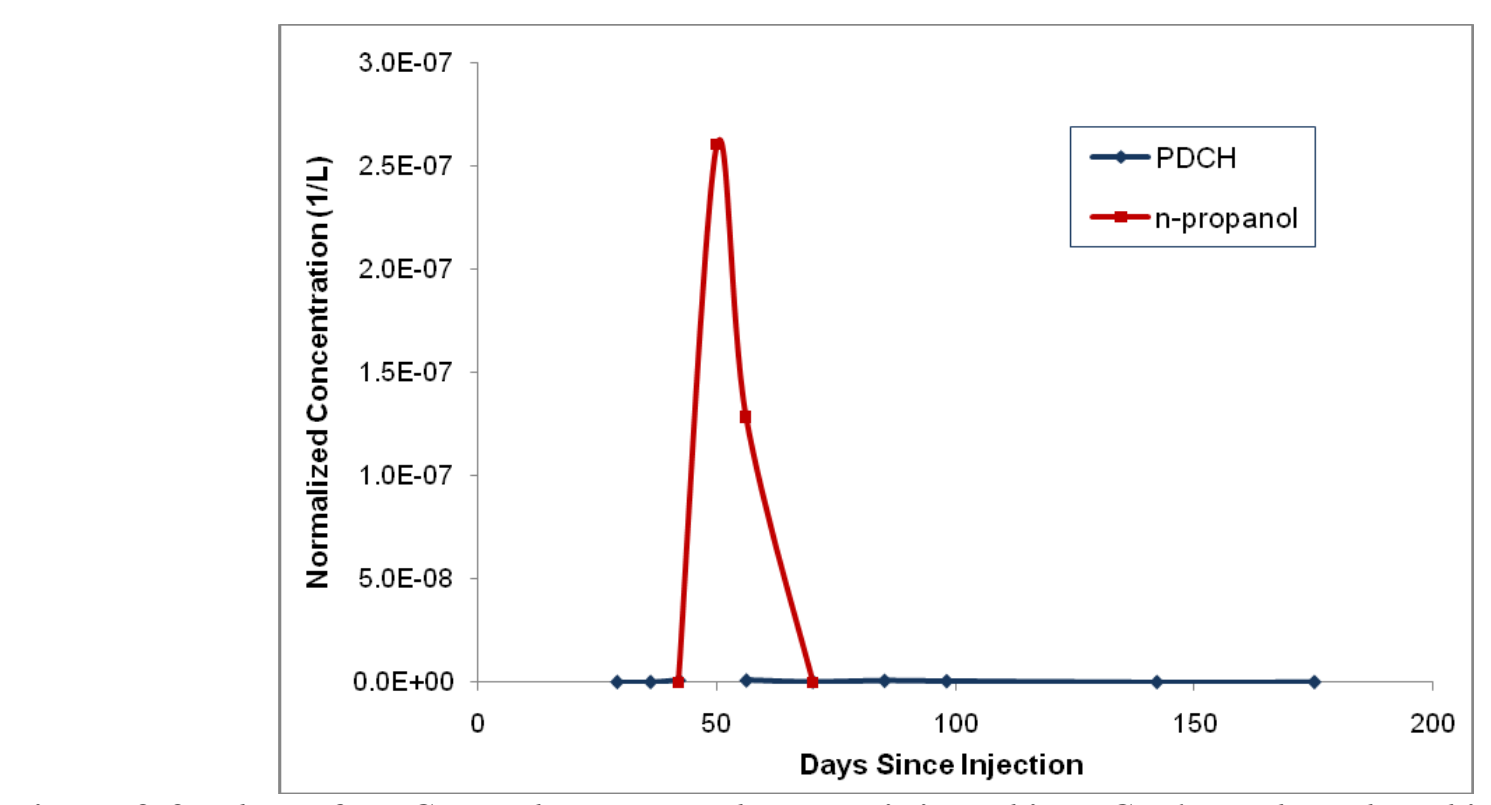

Figure 8-9. Plots of PDCH and n-propanol tracers injected into C-414 and produced in D-414. In this plot, the tracer concentrations were normalized by the mass of tracer injected.

\section{Conclusions}

The naphthalene sulfonates were shown to be effective tracers for characterizing flow patterns between injectors and producers in a water flood at the Aneth petroleum field. In a subsequent $\mathrm{CO}_{2}$ flood, both the perfluorohydrocarbons (PFT's) and propanol performed well in tracing the flow of injected $\mathrm{CO}_{2}$. The propanol was produced in relatively much higher concentration, however, which could be explained by the possible strong partitioning of the PFT's to the oil phase. These tests indicate that various combinations of the naphthalene sulfonates, PFT's, and alcohols could serve as effective tracers in $\mathrm{CO}_{2}$-sequestration applications. 


\title{
CHAPTER 9 \\ SOIL $\mathrm{CO}_{2}$ FLUX MONITORING
}

\author{
by \\ Lee Harris \\ Gas Flooding Processes \& Flow Heterogeneities \\ Petroleum Recovery Research Center \\ 801 Leroy Place \\ New Mexico Institute of Mining and Technology \\ Socorro, NM 87801, USA \\ 575-835-5432 \\ harris@nmt.edu
}

\section{Introduction}

As $\mathrm{CO}_{2}$ is injected into reservoirs for storage several techniques have been developed to verify that the $\mathrm{CO}_{2}$ remains within the reservoir into which it was injected. One of these methods monitors the soil $\mathrm{CO}_{2}$ flux. $\mathrm{CO}_{2}$ naturally exists in the atmosphere and also rises from the soil through biogenic processes, creating a background $\mathrm{CO}_{2}$ level. This study examines several time series of these measurements to provide a good understanding background $\mathrm{CO}_{2}$ levels. In the event that the injected $\mathrm{CO}_{2}$ finds a path to the surface the $\mathrm{CO}_{2}$ flux from the reservoir will be distinguishable from the background flux due to the higher flux rates. The average background fluxes for the two areas in consideration in the Aneth field are $0.42 \frac{\mu \mathrm{mol}}{\mathrm{m}^{2} \mathrm{~s}}$ and $0.36 \frac{\mu \mathrm{mol}}{\mathrm{m}^{2} \mathrm{~s}}$ with standard deviations of $0.26 \frac{\mu m o l}{m^{2} s}$ and $0.19 \frac{\mu m o l}{m^{2} s}$ respectively. According to J. W. Raich and W. H. Schlesinger the flux for a region of desert scrub is $244 \frac{g C}{m^{2} y r}$ which is $0.58 \frac{\mu m o l}{m^{2} s}$ (Raisch and Schlesinger, 1992). This correlates well with what we have found in the Aneth field.

\section{Equipment}

Figure 9-1 is a photo showing the following equipment used to measure soil $\mathrm{CO} 2$ flux.

- LI-COR LI-8100 Automated Soil $\mathrm{CO}_{2}$ Flux System

- LI-8100 $20 \mathrm{~cm}$ Survey Chamber

- PalmOne Lifedrive PDA

- Soil Temperature Probe

- Soil collars made from 8 inch sewer pipe cut at 5 inch length and beveled at one end

- Topcon GMS-2 GPS

\section{Method}

Optimally, every square foot of land above a $\mathrm{CO}_{2}$ storage reservoir should be monitored for $\mathrm{CO}_{2}$ leaks. Since this is not realistic due to the area that would need to be covered and the time that it would take a smaller number of samples are taken at specific nodes strategically placed across the surface of the land above the reservoir. Two different locations in particular 
have a higher probability of $\mathrm{CO}_{2}$ leaks. The first is nearest the injection wells due to piercing the caprock as the well is drilled and installed. Also, the probability of a leak increases near the injection well because of the higher concentration of $\mathrm{CO}_{2}$ in the reservoir below. The second location is along fault lines where natural fractures can provide a path to the surface.

As $\mathrm{CO}_{2}$ is injected into the reservoir there is a possibility that it may slowly leak to the surface. To monitor and detect when this happens a background soil $\mathrm{CO}_{2}$ flux level must be measured to establish the baseline level. To do this the soil $\mathrm{CO}_{2}$ flux is taken prior to injection above the reservoir. If this is not possible then a similar area must be identified with similar vegetation, weather and soil types. The background soil $\mathrm{CO}_{2}$ flux for this area is then measured and established as the background level. In order to find a suitable background level, readings should be conducted at different seasons and times during the day.

Once injection begins, readings should be conducted at regular intervals to detect any change in the soil $\mathrm{CO}_{2}$ flux levels. In this project the soil $\mathrm{CO}_{2}$ flux levels were typically around $0.5 \frac{\mu m o l}{m^{2} s}$, which is reasonable due to the arid landscape (Raich and Schlesinger, 1992). Occasionally the $\mathrm{CO}_{2}$ flux would be as high as double or triple this amount. It was determined that if the $\mathrm{CO}_{2}$ flux was consistently more than about $1.5 \frac{\mu m o l}{\mathrm{~m}^{2} \mathrm{~s}}$ at a specific node, further investigation would be in order.

For this project test nodes were placed in a grid that either spanned an area containing several wells or extended radially outward from the well of interest. Soil collars were placed at each of the locations identified as the test nodes. The $\mathrm{CO}_{2}$ flux was measured at each node with the LI-COR Automated Soil $\mathrm{CO}_{2}$ Flux System. Because the calculations for the flux rely upon the temperature of the soil and because of the large changes in the temperature of the soil during the day and from season to season the soil temperature probe was used at a depth of approximately one to two inches.

Once the data was received, it was reviewed for any increasing trends or unusually high levels of $\mathrm{CO}_{2}$ flux. If a node had higher a flux significantly higher than the mean it was noted and anticipated during the next set of measurements. If a test node consistently had higher levels of $\mathrm{CO}_{2}$ it was investigated further.

\section{Calculating Soil $\mathrm{CO}_{2}$ Flux}

To calculate the soil $\mathrm{CO}_{2}$ flux the volume of the tubing, chamber and soil collar is first calculated. Then air is circulated through the chamber, tubing and soil collar while an inline IR optical sensor measures the concentration of the air. Measurements are taken at specified intervals during the test run. Measurements in this case were taken at one second intervals for approximately two to three minutes. This data is then plotted and a line is fit to the data by regression analysis so that the resulting slope of the line aids in the flux measurement (LI-COR, 2005). In Figure 9-2 an example plot of the raw data is presented for one test at one of the nodes. The green line (the vertical line on the left) is adjustable to allow the user to determine the point at which regression should begin, and the red line on the right adjusts for the upper time limit of the regression. In this example the flux was about $0.68 \frac{\mu \mathrm{mol}}{\mathrm{m}^{2} \mathrm{~s}}$. 


\section{Test Site 1}

\section{Results}

During the initial phase at the Aneth field series of soil $\mathrm{CO}_{2}$ flux measurements, test nodes were placed around two injection wells and one production well during the summer of 2006 (Figure 9-3). A set of data was collected during that summer and then again during the summer of 2007 prior to injection, for use as a baseline. After these data sets were collected, four more sets were collected at different times of the year and adjoining days to get a better understanding of the change in flux over various conditions. Figure 9-3 shows the locations of the test nodes in relation to the production and injection wells. This grid was laid out so that if any leakage occurred, an increasing gradient pattern would be evident as the test nodes approached the injection wells.

The flux data are summarized in Table 9-1. The mean flux for this area was $0.42 \frac{\mu m o l}{m^{2} s}$ with a standard deviation of $0.26 \frac{\mu \mathrm{mol}}{\mathrm{m}^{2} \mathrm{~s}}$. Several test nodes consistently had significantly higher measured flux. A review of soil collar photographs showed that they typically had higher concentrations of grass or other vegetation that was growing in the collars, creating the higher $\mathrm{CO}_{2}$ fluxes. For example, test node 2 had a mean of $1.10 \frac{\mu m o l}{\mathrm{~m}^{2} \mathrm{~s}}$ and typically had a higher flux during each test. Figure 9-4 is a picture of the collar, showing more abundant grass and other vegetation growing compared to the other collars.

Several data values from Table 9-1 are missing. The $11^{\text {th }}$ and $44^{\text {th }}$ test nodes were disturbed by trenching for pipelines and were not available for most of the measurements. During measurements in May 2008 a lightning storm approached, making it dangerous to continue the measurements; we were not able to return the next day to finish. Also in March 2010 the last part of the data could not be collected due to technical difficulties with the batteries and equipment. The test nodes of $25 \mathrm{a}$ and $25 \mathrm{~b}$ were only measured once during March 2010.

\section{Test Site 2}

This site is displayed in Figure 9-5, which involved a single profile line of closely spaced test nodes $(15 \mathrm{~m})$ between two wells. By the two well pads the test-node spacing was reduced to about 1 meter. The test nodes were also placed closer together to increase the probability of detecting a leak if one actually developed. The first tests were performed during the summer of 2008 prior to injection; after injection started, four repeated sets of measurements were collected. Data from these flux measurement are presented in Table 9-2. The overall mean for the test site was $0.36 \frac{\mu m o l}{m^{2} s}$ with a standard deviation of $0.19 \frac{\mu m o l}{m^{2} s}$. At this site there were no test nodes that were consistently high.

\section{Calibration}

\section{Discussion}

During the July 2006, August 2007 and May 2008 tests, calibrations were performed using standardized high precision gas standards. After obtaining measurements that appeared to 
vary significantly within the range of interest, the manufacture, LI-COR, was contacted. Rod Madsen, the LI-COR engineer, said that the fluxes were well within reason for the location of the measurements. He also suggested that the calibrations not be adjusted away from the original factory calibrations because the calibration of this instrument is not known to drift significantly. $\mathrm{S}$

\section{Changes in Flux}

Flux measurements were measured during the winter, summer and spring as well as different times of the day to gain a better understanding of the magnitude of the variance for an area. The seasonal variation for the two site are displayed in Figure 9-6 and an example of the daily variations is illustrated in Figure 9-7. The season to season variance was about the same as the variance that occurs by measuring at different times of the day. The greatest changes occurred during the July 2006 and August 2007 measurements (Figure 9-6). The July 2006 measurements are particularly low because of the high temperatures in Aneth during that season. Many of the negative readings are within the noise of the analyzer and should be treated as being effectively no flux measurements. In August 2007 the measurements were made shortly after a large rain storm. These measurements are sensitive to the moisture in the ground because of the increased biological activity in the soil.

In February 2009 two different sets of measurements were made on two successive days with the testing starting at different times (Figure 9-7). During the morning of February $25^{\text {th }}$ the overall flux was low and had an increasing trend as the day heated up. On the $24^{\text {th }}$ the testing had begun at about the same time the testing ended on the $25^{\text {th }}$; each day's respective flux trends were relatively close. Then as the day progressed on the $24^{\text {th }}$, the flux had gradually decreased, indicating a cyclical pattern. From the trends indicated in the chart it is reasonable to conclude that the flux can be expected to vary by as much as about $0.5 \frac{\mu m o l}{\mathrm{~m}^{2} s}$ each day, which is greater than the average standard deviation for this field.

\section{Conclusions}

Measuring the soil $\mathrm{CO}_{2}$ flux before and during injection has been successful in establishing a solid background level that can be expected during different seasons and at different times of the day. The average flux for both fields in Aneth was $0.39 \frac{\mu m o l}{m^{2} s}$ which is reasonable for an arid location. For this study it was decided that if a flux consistently remained higher than about two to three times the average value, it should receive additional attention. Several test nodes occasionally tested higher in this range, but after the conditions of the individual test nodes were reviewed, it was found that they had higher concentrations of vegetation.

During the previous several years one of the main concerns with performing soil flux measurements has been the possibility of missing a leak due to the small area measured by the soil flux system. If the $\mathrm{CO}_{2}$ leaks from the reservoir and diffuses through the ground and eventually spreads out, then a leak will be recognizable by a slowly increasing flux over a wide area. On the other hand, if a leak occurs near a fracture, it may escape to the surface in a small area only detectable if the $\mathrm{CO}_{2}$ sensors are placed directly over the leak. For future applications it would be advisable to install a system that can monitor $\mathrm{CO}_{2}$ concentrations in the atmosphere on 
a more macroscopic level. Then if the $\mathrm{CO}_{2}$ concentrations increase more localized monitoring can be used to find the actual source of the leak.

Monitoring the soil $\mathrm{CO}_{2}$ flux before and during injection in the Aneth field did not identify any $\mathrm{CO}_{2}$ leaks. A background soil $\mathrm{CO}_{2}$ flux value and its variance were obtained and can be used in the future to help in distinguishing between the background biological $\mathrm{CO}_{2}$ flux and any anomalous soil $\mathrm{CO}_{2}$ flux. 


\begin{tabular}{|c|c|c|c|c|c|c|c|c|}
\hline \multicolumn{9}{|c|}{ Table 9-1. Aneth Phase I Soil CO $\mathrm{O}_{2}$ Flux Data $\left(\frac{\mu m o l}{m^{2} s}\right)$} \\
\hline & Test Node & & & Test Dates & & & & \\
\hline & Jul-06 & Aug- & May- & Feb-09 & Feb-09 & Jul-09 & Mar- & Mean \\
\hline 1 & -0.17 & 1.17 & 0.53 & 0.44 & 0.07 & 0.57 & 0.55 & 0.45 \\
\hline 2 & 0.11 & 4.74 & 0.53 & 0.93 & 0.17 & 0.52 & 0.73 & 1.10 \\
\hline 3 & 0.18 & 2.31 & 0.49 & 0.39 & 0.01 & 0.47 & 0.43 & 0.61 \\
\hline 4 & 0.22 & 2.57 & 0.68 & 0.31 & 0.04 & 0.29 & 0.34 & 0.64 \\
\hline 5 & 0.12 & 1.69 & 0.60 & 0.37 & 0.04 & 0.39 & 0.02 & 0.46 \\
\hline 6 & 0.12 & 0.33 & 0.06 & 0.67 & -0.14 & 0.36 & 0.48 & 0.27 \\
\hline 7 & 0.32 & 2.52 & 0.44 & 0.68 & 0.14 & 0.64 & 0.91 & 0.81 \\
\hline 8 & 0.01 & 1.71 & 0.41 & 0.35 & 0.09 & 0.53 & 0.47 & 0.51 \\
\hline 9 & 0.13 & 1.73 & 0.75 & 0.32 & 0.10 & 0.53 & 0.33 & 0.56 \\
\hline 10 & 0.08 & 1.48 & 0.55 & 0.40 & 0.09 & 0.69 & 0.33 & 0.52 \\
\hline 11 & 0.09 & & & & & & & 0.09 \\
\hline 12 & 0.11 & 2.21 & 0.49 & 0.27 & 0.08 & 0.64 & 0.47 & 0.61 \\
\hline 13 & 0.02 & 2.23 & 0.77 & 0.26 & 0.12 & 0.82 & 0.31 & 0.65 \\
\hline 14 & -0.10 & 0.97 & 0.35 & 0.19 & 0.04 & 1.05 & 0.18 & 0.38 \\
\hline 15 & -0.09 & 0.57 & 0.47 & 0.18 & 0.15 & 0.56 & 0.12 & 0.28 \\
\hline 16 & 0.07 & 1.00 & 0.59 & 0.27 & 0.14 & 0.50 & 0.38 & 0.42 \\
\hline 17 & 0.13 & 0.11 & 0.51 & 0.60 & 0.27 & 0.82 & 3.38 & 0.83 \\
\hline 18 & 0.03 & 2.03 & 0.41 & 0.37 & 0.18 & 0.44 & 0.23 & 0.53 \\
\hline 19 & 0.38 & 2.01 & 1.13 & 0.41 & 0.18 & 0.56 & & 0.78 \\
\hline 20 & 0.02 & 1.52 & 0.54 & 0.44 & 0.26 & 0.55 & 0.24 & 0.51 \\
\hline 21 & -0.08 & 0.74 & 0.14 & 0.13 & 0.06 & 0.21 & 0.26 & 0.21 \\
\hline 22 & -0.25 & 0.38 & -0.04 & -0.03 & 0.10 & 0.72 & 0.22 & 0.16 \\
\hline 23 & 0.04 & 1.00 & 0.39 & 0.23 & 0.27 & 0.44 & 0.27 & 0.38 \\
\hline 24 & -0.18 & 0.63 & 0.60 & 0.09 & 0.16 & 0.20 & 0.31 & 0.26 \\
\hline 25 & 0.14 & 2.67 & 2.26 & 0.38 & 0.20 & 0.61 & 0.61 & 0.98 \\
\hline $25 \mathrm{a}$ & & & & & & & 0.20 & 0.20 \\
\hline $25 b$ & & & & & & & 0.68 & 0.68 \\
\hline 26 & 0.51 & & 0.60 & 0.38 & 0.30 & 0.66 & 0.61 & 0.51 \\
\hline 27 & 0.24 & & & 0.31 & 0.27 & 0.20 & 0.33 & 0.27 \\
\hline 28 & 0.00 & 0.78 & & 0.33 & 0.26 & 0.22 & 0.26 & 0.31 \\
\hline 29 & 0.01 & 0.94 & & 0.30 & 0.39 & 0.16 & 0.23 & 0.34 \\
\hline 30 & 0.50 & 1.58 & & 0.45 & 0.43 & 0.52 & 0.56 & 0.67 \\
\hline 31 & -0.05 & 0.52 & & 0.49 & 0.53 & 0.31 & 0.54 & 0.39 \\
\hline 32 & -0.24 & 0.33 & & 0.08 & 0.42 & -0.24 & -1.44 & -0.18 \\
\hline 33 & -0.26 & 0.38 & & 0.16 & 0.36 & -0.31 & -1.78 & -0.24 \\
\hline 34 & 0.01 & 0.70 & & 0.21 & 0.31 & 0.36 & 0.14 & 0.29 \\
\hline 35 & 0.08 & 0.70 & & 0.41 & 0.37 & 0.21 & 0.18 & 0.33 \\
\hline 36 & 0.00 & 0.49 & & 0.21 & 0.45 & 0.19 & & 0.27 \\
\hline 37 & 0.11 & 1.01 & & 0.14 & 0.26 & 0.23 & & 0.35 \\
\hline 38 & 0.08 & 1.26 & & 0.27 & 0.33 & 0.36 & & 0.46 \\
\hline 39 & 0.11 & 2.11 & & 0.98 & 1.14 & 0.27 & & 0.92 \\
\hline 40 & 0.10 & 1.01 & & 0.49 & 0.29 & 0.51 & & 0.48 \\
\hline 41 & -0.01 & 0.34 & & 0.41 & 0.34 & -0.31 & & 0.15 \\
\hline 42 & -0.16 & 0.38 & & 0.22 & 0.40 & -0.45 & & 0.08 \\
\hline 43 & 0.14 & 1.45 & & 0.54 & 0.48 & 0.25 & & 0.57 \\
\hline 44 & 0.28 & & & & & & & 0.28 \\
\hline 45 & 0.04 & 1.27 & & 0.63 & 0.61 & 0.12 & & 0.53 \\
\hline 46 & -0.15 & 0.60 & & 0.40 & 0.55 & 0.58 & & 0.40 \\
\hline 47 & -0.14 & 0.70 & & 0.07 & 0.35 & 0.06 & & 0.21 \\
\hline 48 & -0.10 & 0.39 & & 0.23 & 0.45 & 0.70 & & 0.33 \\
\hline 49 & -0.18 & 1.02 & & -0.08 & 0.20 & -0.11 & & 0.17 \\
\hline 50 & -0.03 & & & 0.21 & 0.47 & -0.11 & & 0.14 \\
\hline 51 & 0.12 & 1.10 & & 0.14 & 0.64 & 0.02 & & 0.40 \\
\hline 52 & -0.12 & 2.16 & & 0.14 & 0.49 & 0.16 & & 0.57 \\
\hline Mean & 0.05 & 1.27 & 0.57 & 0.34 & 0.28 & 0.35 & 0.35 & 0.42 \\
\hline
\end{tabular}




\begin{tabular}{|c|c|c|c|c|c|c|}
\hline \multicolumn{7}{|c|}{ Table 9-2. Aneth Phase II Soil CO $\mathrm{O}_{2}$ Flux Data $\left(\frac{\mu m o l}{m^{2} s}\right)$} \\
\hline \multirow{2}{*}{$\begin{array}{l}\text { Test } \\
\text { Node }\end{array}$} & \multicolumn{6}{|c|}{ Test Dates } \\
\hline & May-08 & Feb-09 & Feb-09 & Jul-09 & Mar-10 & Mean \\
\hline 1 & 0.51 & 0.27 & 0.35 & 3.51 & 0.53 & 1.03 \\
\hline 2 & 1.32 & 0.52 & 1.41 & 0.89 & 0.59 & 0.95 \\
\hline 3 & 0.43 & 0.24 & 0.41 & 0.75 & 0.35 & 0.44 \\
\hline 4 & 0.69 & 0.23 & 0.39 & 0.11 & 0.45 & 0.37 \\
\hline 5 & 0.12 & 0.27 & 0.30 & 0.23 & 0.21 & 0.23 \\
\hline 6 & 0.13 & 0.15 & 0.11 & -0.05 & 0.07 & 0.08 \\
\hline 7 & 0.36 & 0.25 & 0.35 & 0.19 & 0.24 & 0.28 \\
\hline 8 & 0.30 & 0.21 & 0.22 & 0.17 & 0.26 & 0.23 \\
\hline 9 & 0.36 & 0.20 & 0.22 & 0.16 & 0.16 & 0.22 \\
\hline 10 & 0.49 & 0.14 & 0.35 & 0.38 & 0.13 & 0.30 \\
\hline 11 & 0.43 & 0.32 & 0.26 & 0.19 & 0.30 & 0.30 \\
\hline 12 & 0.89 & 0.37 & 0.39 & 0.01 & 0.22 & 0.38 \\
\hline 13 & 0.57 & 0.36 & 0.23 & 0.06 & 0.42 & 0.33 \\
\hline 14 & 0.11 & 0.35 & 0.35 & 0.00 & 0.26 & 0.21 \\
\hline 15 & 0.33 & 0.39 & 0.21 & 0.28 & 0.54 & 0.35 \\
\hline 16 & 0.54 & & 0.30 & 0.33 & 0.38 & 0.39 \\
\hline 17 & -0.07 & 0.19 & 0.26 & -0.22 & 0.19 & 0.07 \\
\hline 18 & 0.31 & 0.24 & 0.31 & 0.03 & 0.24 & 0.23 \\
\hline 19 & 0.50 & 0.29 & 0.42 & 0.23 & 0.33 & 0.35 \\
\hline 20 & 0.55 & 0.25 & 0.26 & 0.29 & 0.28 & 0.33 \\
\hline 21 & 0.14 & 0.22 & 0.20 & 0.24 & 0.33 & 0.23 \\
\hline 22 & 0.42 & 0.40 & 0.03 & 0.20 & 0.22 & 0.25 \\
\hline 23 & 0.30 & 0.20 & 0.20 & 0.51 & 0.29 & 0.30 \\
\hline 24 & 0.44 & 0.54 & 0.40 & -0.05 & 0.31 & 0.33 \\
\hline 25 & 0.16 & 0.43 & 0.11 & -0.03 & 0.50 & 0.23 \\
\hline 26 & 0.60 & 0.36 & 0.14 & 0.09 & 0.34 & 0.31 \\
\hline 27 & 0.41 & 0.43 & 0.23 & 0.14 & 0.55 & 0.35 \\
\hline 28 & 0.55 & 0.33 & 0.31 & 0.18 & 0.32 & 0.34 \\
\hline 29 & 0.34 & 0.48 & 0.39 & 0.18 & 0.45 & 0.37 \\
\hline 30 & 0.67 & 0.54 & 0.46 & 0.70 & 0.59 & 0.59 \\
\hline 31 & 0.27 & 0.34 & 0.27 & 0.51 & 0.39 & 0.36 \\
\hline 32 & 0.66 & 0.37 & 0.31 & 0.51 & 0.37 & 0.44 \\
\hline 33 & 0.57 & 0.46 & 0.48 & 0.18 & 0.54 & 0.45 \\
\hline 34 & 0.83 & 0.48 & 0.40 & 0.26 & 0.52 & 0.50 \\
\hline 35 & 0.68 & 0.76 & 0.71 & 0.12 & 0.55 & 0.56 \\
\hline 36 & 0.63 & 0.44 & 0.31 & 0.23 & 0.47 & 0.42 \\
\hline 37 & 0.45 & & & & 0.33 & 0.39 \\
\hline Mean & 0.46 & 0.34 & 0.33 & 0.32 & 0.36 & 0.36 \\
\hline
\end{tabular}




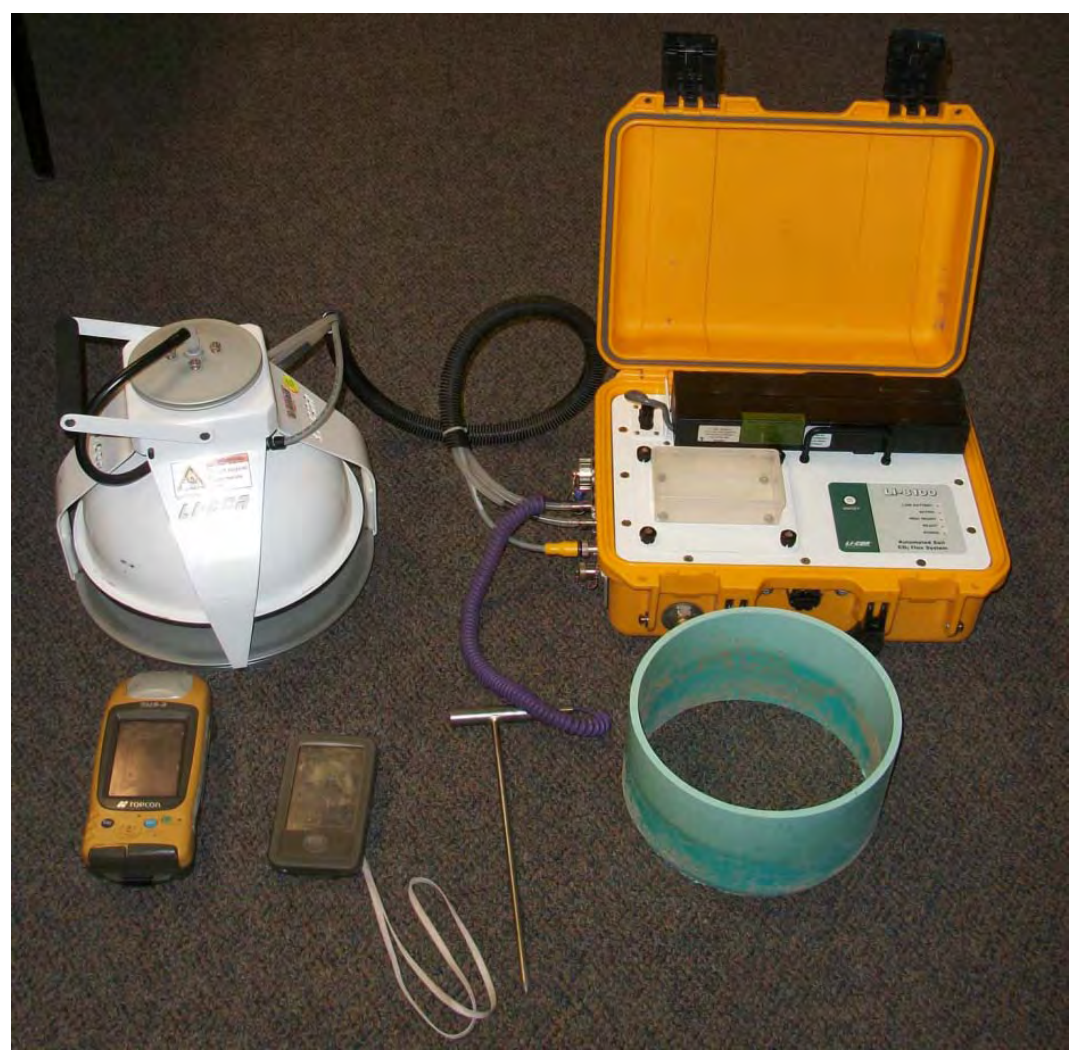

Figure 9-1. Soil $\mathrm{CO}_{2}$ monitoring equipment.

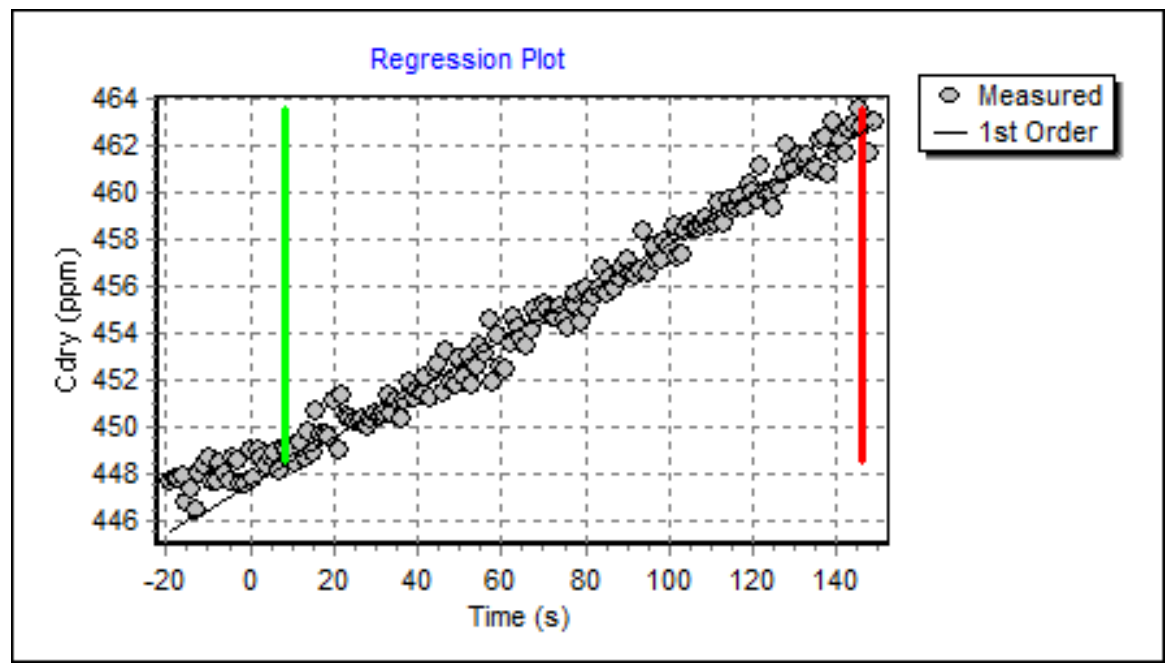

Figure 9-2. Sample plot of $\mathrm{CO}_{2}$ concentration data as the soil CO2 flux is being measured. 


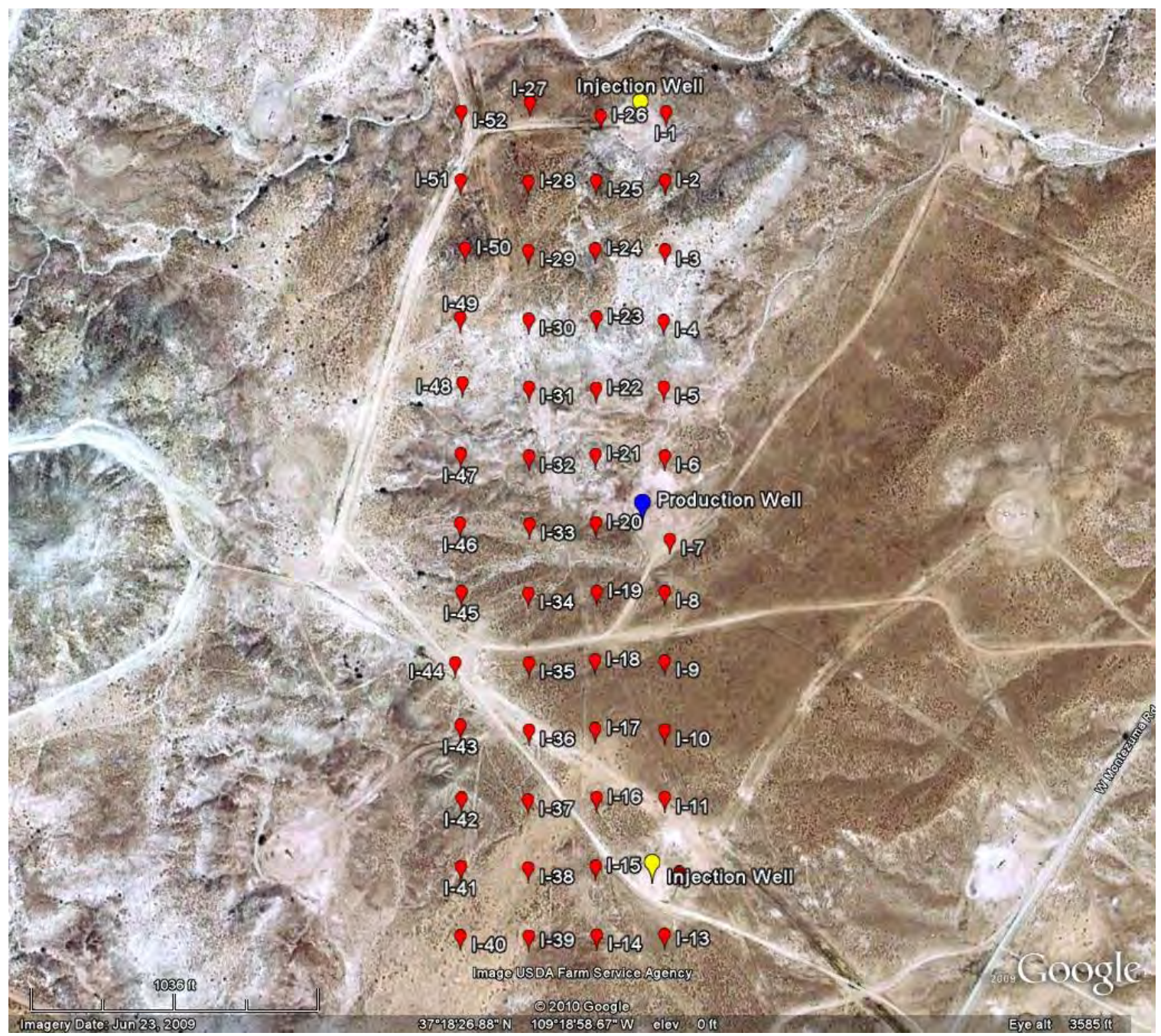

Figure 9-3. Aneth Phase-I $\mathrm{CO}_{2}$ flux monitoring site. The test node locations are shown red. 


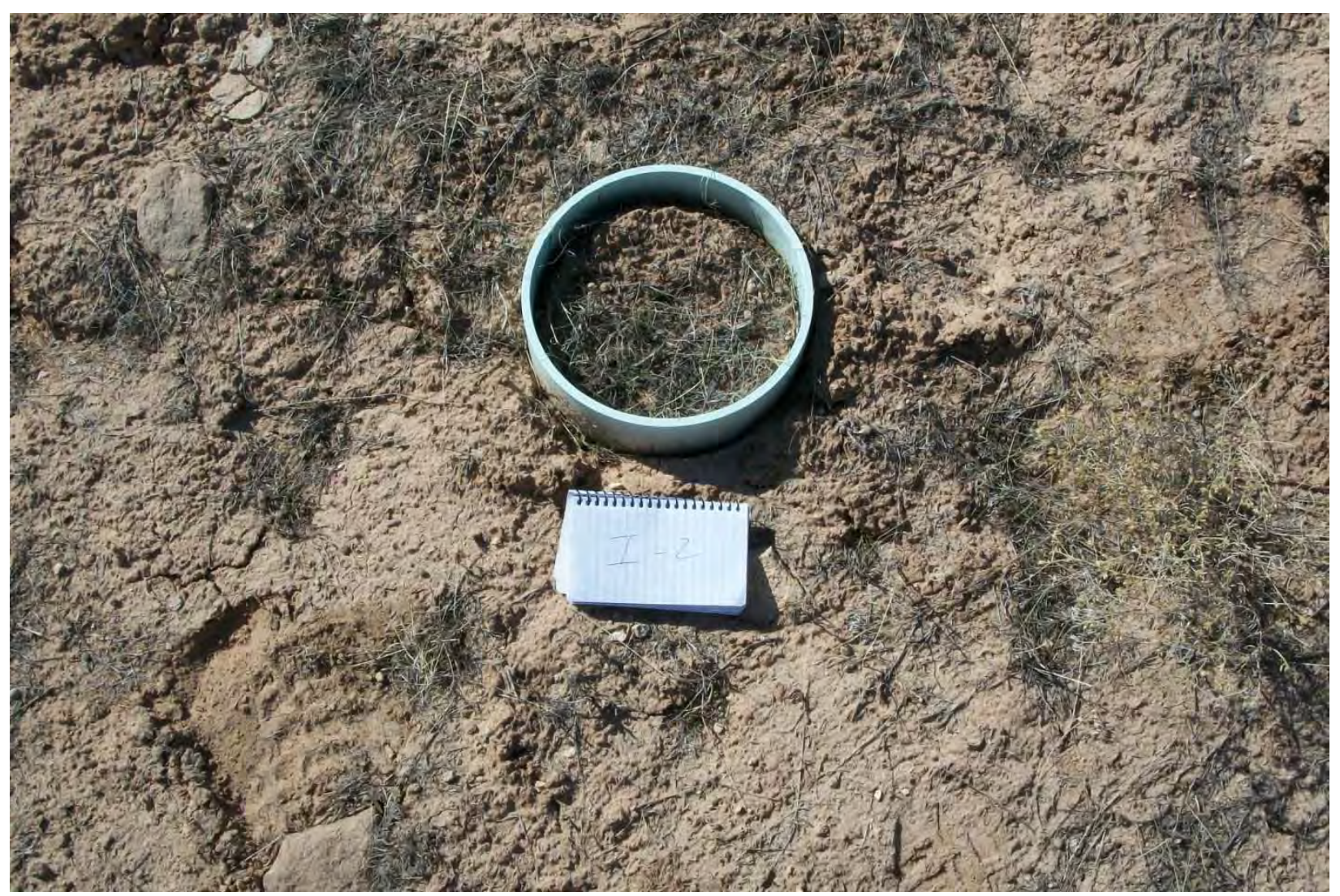

Figure 9-4. Example of higher concentration of vegetation in a soil collar. 


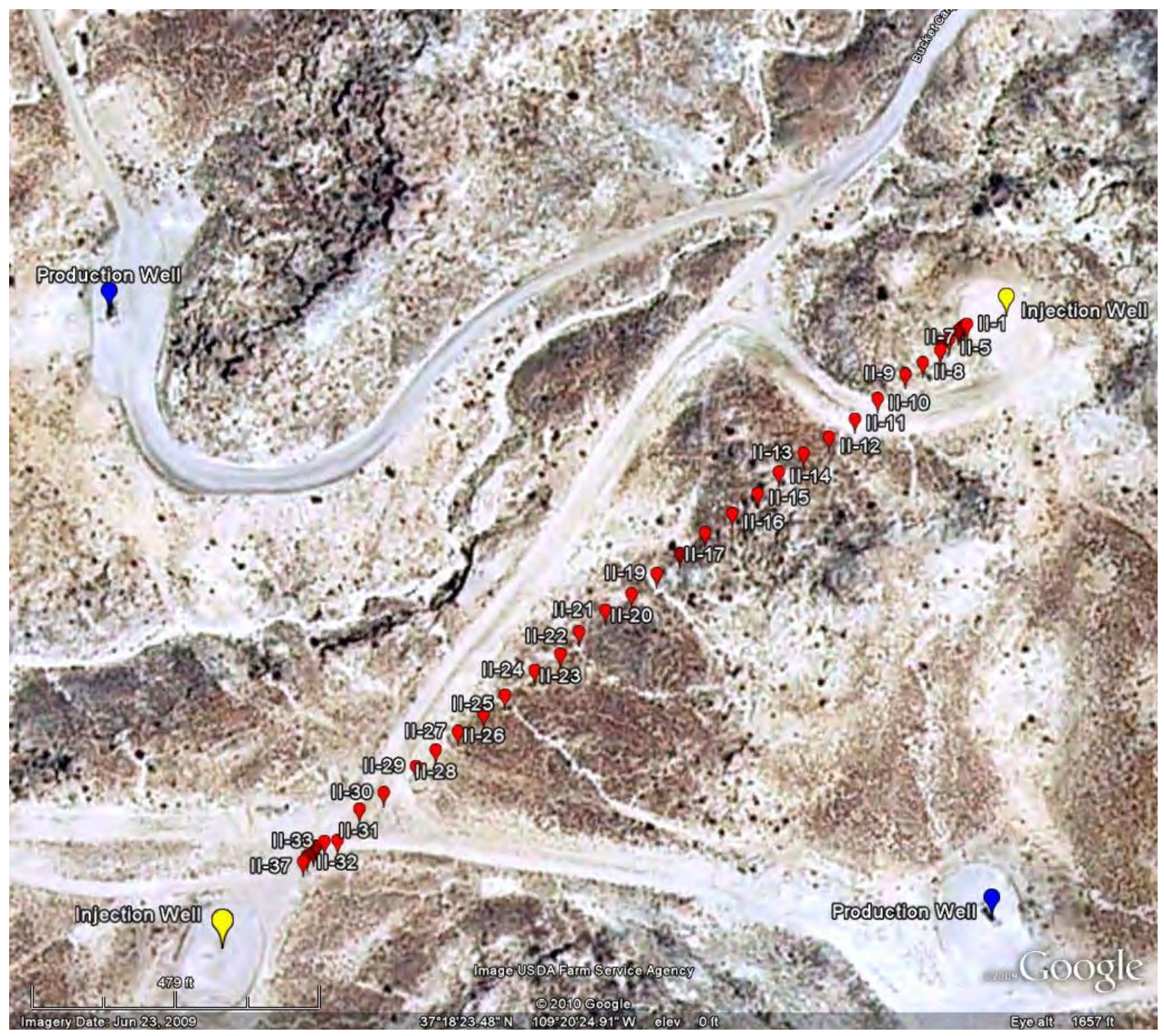

Figure 9-5. Aneth Phase-II $\mathrm{CO}_{2}$ monitoring site. Test node locations are shown red. 


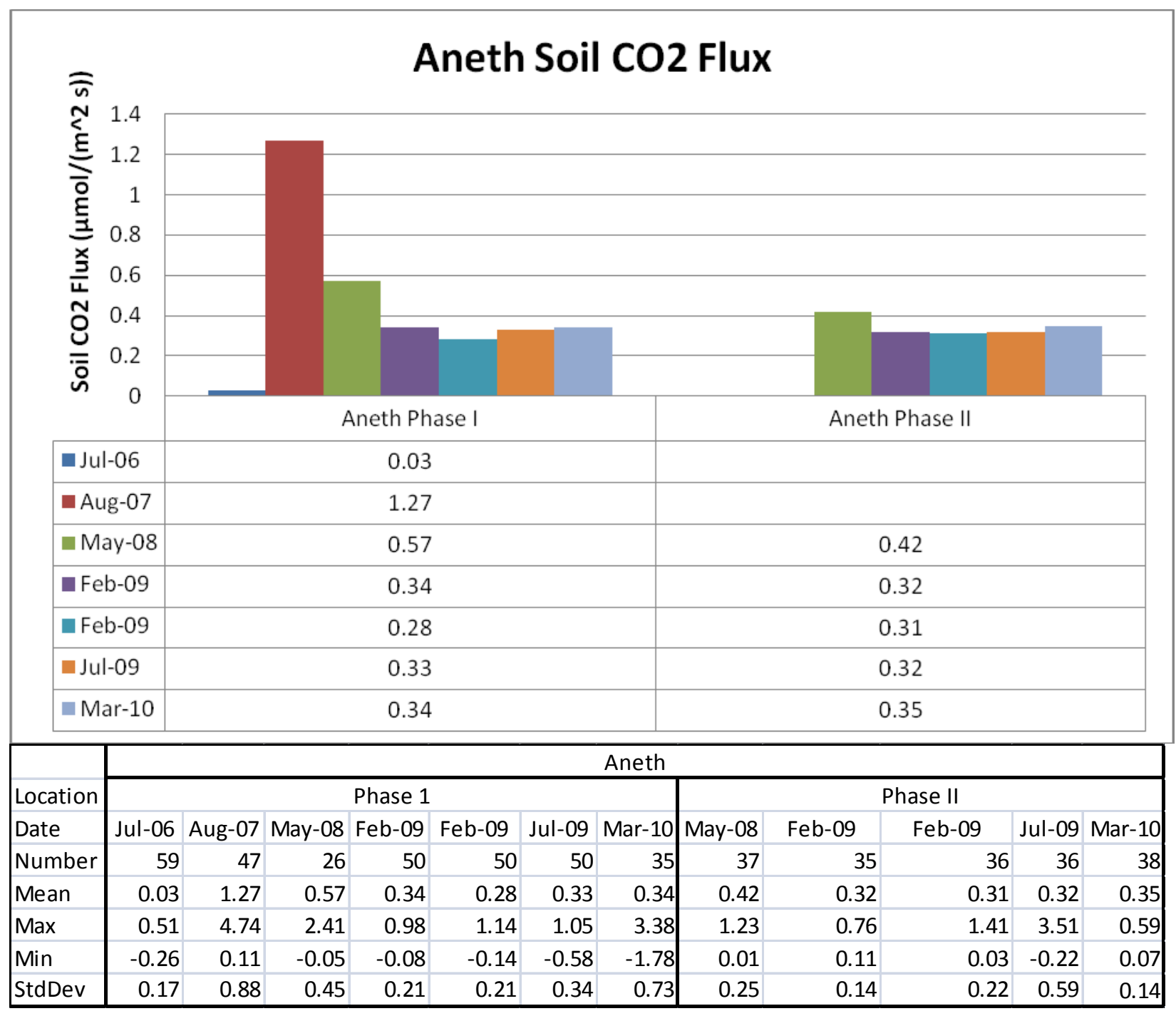

Figure 9-6. Summary of mean soil flux data for each acquisition campaign at the Phase I and Phase II sites. Units are $\mu \mathrm{mol} /\left(\mathrm{m}^{2} \mathrm{~s}\right)$. 


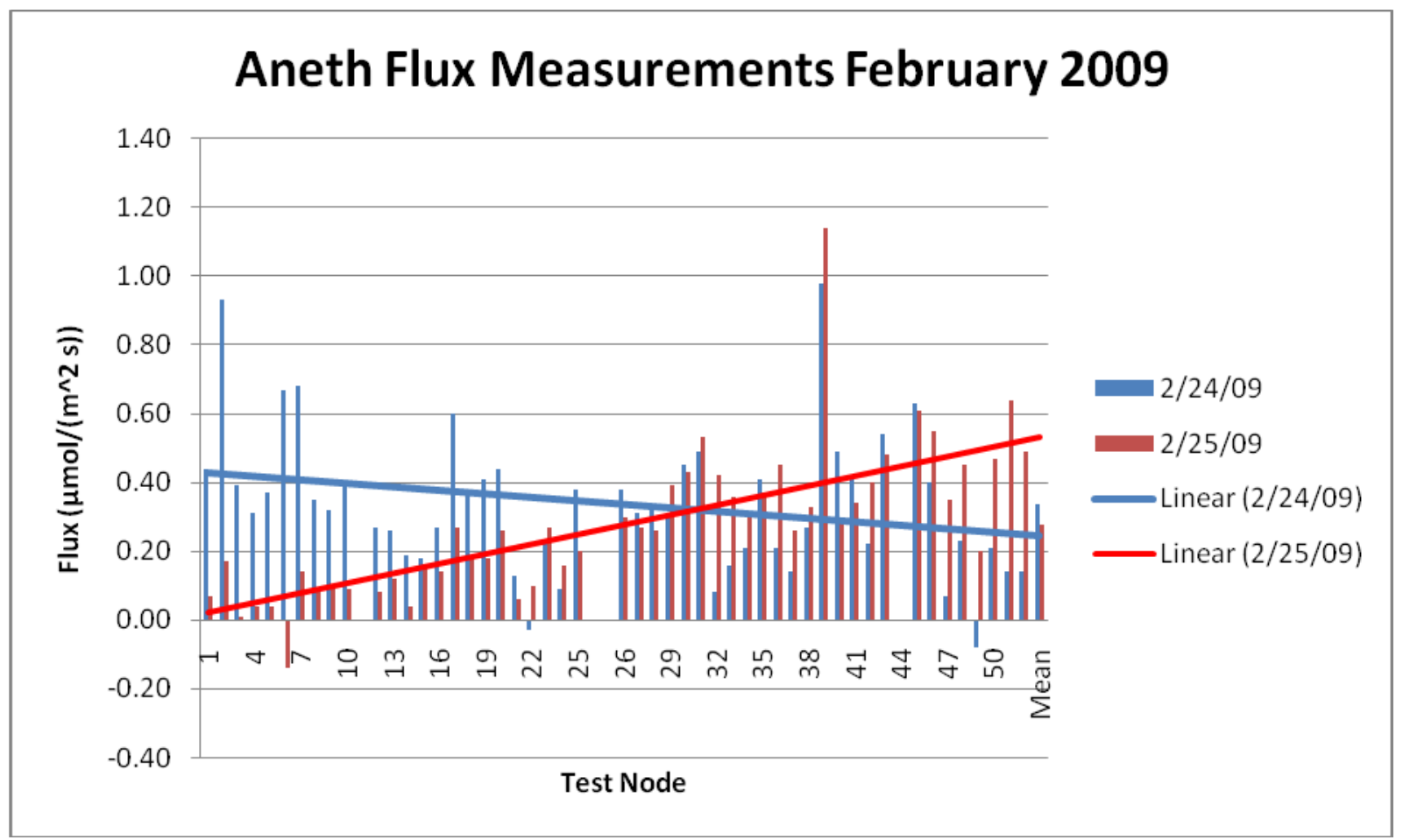

Figure 9-7. Trends in flux measurements sequenced (left to right). The series of measurements were repeated for two consecutive measurement days. 


\title{
CHAPTER 10 \\ SELF-POTENTIAL MONITORING AT THE ANETH TEST SITE
}

\author{
by \\ Yuji Nishi, Norio Tenma, Tsuneo Ishido and Toshiyuki Tosha \\ National Institute of Advanced Industrial Science and Technology (AIST), Japan \\ y.nishi@aist.go.jp
}

\section{Introduction}

Continuous and/or repeat self-potential (SP) measurements are thought to be a promising geophysical technique to monitor pressure changes in an aquifer due to $\mathrm{CO}_{2}$ injection (Ishido et al., 2006). Ishido et al. (2008) carried out numerical simulations of an aquifer system underlying a portion of Tokyo Bay and calculated the temporal changes in geophysical observables caused by changing underground conditions as computed by the reservoir simulation. We used the STAR general-purpose reservoir simulator (Pritchett, 1995) with the CO2SQS equation-of-state package which treats three fluid phases (liquid- and gaseous-phase $\mathrm{CO}_{2}$ and an aqueous liquid phase) to calculate the evolution of reservoir conditions, and then used various "geophysical postprocessors" to calculate the resulting temporal changes in the earth-surface distributions of microgravity, apparent resistivity (from either DC or MT surveys), seismic observables and electrical self-potential (SP).

The applicability of any particular method is likely to be highly site-specific, but these calculations indicate that none of these techniques should be ruled out altogether. In case of SP, $\mathrm{CO}_{2}$ injection does not create large electric signals through electrokinetic coupling within the saline aquifer owing to small coupling coefficients under the high salinity conditions. However, if a substantial pressure disturbance is induced to shallower levels where the interface between shallower fresh- and deeper saline-waters (which works as the boundary between regions of differing streaming potential coefficient) is present, obvious SP changes can appear on the ground surface.

In addition to SP measurements over relatively wide areas, such as monitoring the horizontal extent of a $\mathrm{CO}_{2}$ plume, local SP monitoring is also thought to be worthwhile such as monitoring around a deep injector well. SP anomalies of negative polarity are frequently observed near deep wells. These anomalies appear to be caused by an underground electrochemical mechanism similar to a galvanic cell, the so called "geobattery" (e.g. Begalke and Grabner, 1997): the metallic well casing acts as a vertical electronic conductor connecting regions of differing redox potential. Electrons flow upward though the casing from a deeper reducing environment to a shallower oxidizing environment, and simultaneously a compensating vertical flow of ions is induced in the surrounding formation to maintain charge neutrality. If the redox potential in the deeper region is then increased by injecting an oxidizing substance, the difference in redox potential between the shallower and deeper regions will be reduced, resulting in an SP increase near the wellhead. 
We have been monitoring earth-surface SP during gas injection tests at a few sites in Japan. SP changes were observed at the Yubari test site in Japan, where one well injected $\mathrm{CO}_{2}$ into a coal bed and the $\mathrm{CO}_{2}$ content of the fluid produced from a nearby well was monitored (Tosha et al., 2008). SP increased substantially around the injection wellhead, which we believe was caused by local $\mathrm{pH}$ reduction at depth resulting from dissolution of the injected $\mathrm{CO}_{2}$ in the aquifer fluid. But no significant SP changes attributable to the injection were observed near the production wellhead. This is consistent with the observation that $\mathrm{CO}_{2}$ did not break through into the production well during the experiment. We believe that SP measurements at the earth surface represent a new and promising technique for sensing the approach of $\mathrm{CO}_{2}$ to well casings deep within the subsurface.

\section{SP Monitoring Network at Aneth}

We conducted our SP monitoring test in section 13 of T. 40 S., R. 24 E., SLBL\&M (Figures1-3 and 10-1), focusing on the horizontal injector well C313. Injector C313 was also the focus of the time-lapse VSP monitoring presented in Chapter ??. Considering the depth $(\sim 2 \mathrm{~km})$ of $\mathrm{CO}_{2}$ injection into well $\mathrm{C} 313$, a network of electrodes over sufficiently wide area would have been required if we wanted to observe $\mathrm{SP}$ changes induced by $\mathrm{CO}_{2}$ injection through electrokinetic coupling. However, owing to a limit of measurement instruments available for this project, we designed our monitoring network to focus on SP changes expected to appear near a wellhead through the geobattery mechanism.

We installed sixteen $\mathrm{Ag}-\mathrm{AgCl}$ non-polarizing electrodes (the drift rate of which has been confirmed very low by more than three years continuous measurements at various fields in Japan) at eight locations shown in Figure 10-1. At each of four locations near wells C313, C313SE and C413, three electrodes were installed with different distance from the wellhead (see Figure 10-2); the "near", "middle" and "far" electrodes, denoted with ' $\mathrm{n}$ ', ' $\mathrm{m}$ ' and ' $\mathrm{f}$ ' respectively added to the end of well name, were installed at 2 to 4, 6 to 8 and 14 to 20 meters, respectively from the wellhead. Such an arrangement is suitable to detect change in SP radial profile around the wellhead caused by the geobattery mechanism. Although well C124 had been abandoned and located out of $\mathrm{CO}_{2}$ injection/oil production area, three electrodes were also installed around its old wellhead location as the above well sites to use one of those electrodes as reference and confirm these electrodes' drift. In addition to these twelve (three times four) electrodes, one electrode was installed at each of four locations, which are more than fifty meters away from any of the wells (Figure 10-1).

Each wire from any of sixteen electrodes was deployed through a protect tube and connected to a data logger (Campbell Sci. CR3000). Measured SP data was stored in a memory card, and data recorded at 0:00, 6:00, 12:00 and 18:00 on each day were transmitted to Tsukuba, Japan through "ARGOS" satellite data link for watching the monitoring system.

Although the monitoring system was installed in November 2007, the initial installation had several problems due to limited onsite time of our visit. In May 2008 we carried out a measurement to clarify the character of noise sources and made modifications and adjustments of the monitoring system to reduce large fluctuations present in each channel of the data logger 
(which was turned out to have been brought about through the wires from the electrodes installed near the production well C413). Since then we have been able to get good quality data. Observed SP data for two years from May 2008 to May 2010 are plotted in Figures 10-3 and 10-4. All the SP values are relative to electrode "C124m", the "middle" electrode near the C124 abandoned well. This electrode seems to be appropriate for a reference since it was located a large distance from the injection well C313 and no significant local SP change took place near well C124 during the two years as shown in the top panel of Figure 10-4.

As shown in the lower panel of Figure 10-4, large potential disturbances of the magnitude of one volt or more are present for the electrodes around the C413 production well. As a result of the measurement with high sampling rate in May 2008, very large fluctuations with a cycle of around 3.3 seconds (which is nearly half of the cycle of the production pumping system) turned out to be dominant in the recorded data. We believe that the source of this large low-frequency noise is related to the high-voltage power line for the pumping system and cannot be completely removed by low-pass filtering and averaging procedure.

\section{Observed Changes in SP}

Concerning the data from a set of three electrodes installed near the wellhead of C313 and C313SE, a common feature observed is that the SP decreases approaching the wellhead (Figures 10-3 and 10-4). This feature implies that the electric current flows toward the well, which can be explained by the geobattery mechanism. (As for C413, the same tendency was seen, but this happened to be caused by large nearby noise sources.)

In case of well C313, the electrodes "C $313 n$ " and "C $313 \mathrm{~m}$ " initially had SP of about -120 and $-80 \mathrm{mV}$ respectively, and both of them showed substantial increase: about 100 and $80 \mathrm{mV}$, respectively, approximately during two months after May 2008. (Unfortunately the data for the "C313f" electrode was missed due to an insufficient wire connection up through September 2009.)

This SP change can be also explained by the geobattery mechanism; if the redox potential in the deeper region surrounding the metal slotted liner or casing is increased by $\mathrm{pH}$ reduction resulting from dissolution of the injected $\mathrm{CO}_{2}$ in the reservoir fluid, the difference in redox potential between the shallower and deeper regions will be reduced, resulting in an SP increase near the wellhead.

Unfortunately, we could not get good quality data from November 2007 to May 2008 as mentioned above, during which $\mathrm{CO}_{2}$ injection was initiated and continuous except for about a one-month replacement to water injection in April. We need to consider the effects of these prior activities before further quantitative discussion. For example, water single-phase or water-gas two-phase flow due to the injection will produce the streaming potential in the reservoir and this SP change will be transferred to the wellhead through the electrically-conductive casing. Concerning the injection well, we also need to consider other factors that might contribute to the observations, such as change in electrical potential of the $\mathrm{CO}_{2}$ pipeline connected to the wellhead, which could affect the SP around the wellhead. 
The electrodes around well C313 showed another substantial increase from April 2009, but a similar SP increase also appeared on other electrodes installed in the northern area (the electrodes around well C313SE and the electrodes at "BASE", "No. 1N" and "No. 2N" locations). As shown in Figure 10-3, this increase seems to continue up to April 2010. The increase over the one year ranges from 50 to $200 \mathrm{mV}$.

Owing to the limited spatial distribution of the electrodes, we cannot estimate the spatial extent of this SP increase and cannot discuss the source depth. One thing to be noted is the behavior of the electrodes around well C313SE; the SP difference between "C313SEn" and "C313SEm" and that between "C313SEm" and "C313SEf" seem to gradually increase over the one year. If the resistivity of shallow region around the well is constant, this implies increase in the current density toward the wellhead and resulting increase in the current flowing downward through the metal casing. If this is the case, the source of the SP increase is thought to be located near the earth surface.

\section{Concluding Remarks}

We have carried out continuous SP measurements for more than two years at the Aneth test site. A local negative SP anomaly was present around wells C313 and C313SE, which is thought to be caused by the geobattery mechanism. Around the $\mathrm{C} 313 \mathrm{CO}_{2}$ injection well, a substantial positive change took place during two months starting in May 2008. This change is probably caused by change in the redox potential in the deeper region by $\mathrm{pH}$ reduction resulting from dissolution of the injected $\mathrm{CO}_{2}$ in the reservoir fluid.

At Aneth we started the SP monitoring to detect the arrival of $\mathrm{CO}_{2}$ plume to the $\mathrm{C} 413$ production well or to the C313SE observation well. However, in case of the production well, we could not get good quality data due to the presence of severe noise. The SP monitoring technique focusing on the geobattery mechanism is still under development. We need further field experiments at $\mathrm{CO}_{2}$ injection sites to improve this unique and supplemental technique for $\mathrm{CO}_{2}$ geological storage monitoring.

\section{Acknowledgement}

The authors are indebted to the Resolute National Resources and Los Alamos National Laboratory, who have supported all of our measurements in Aneth. 


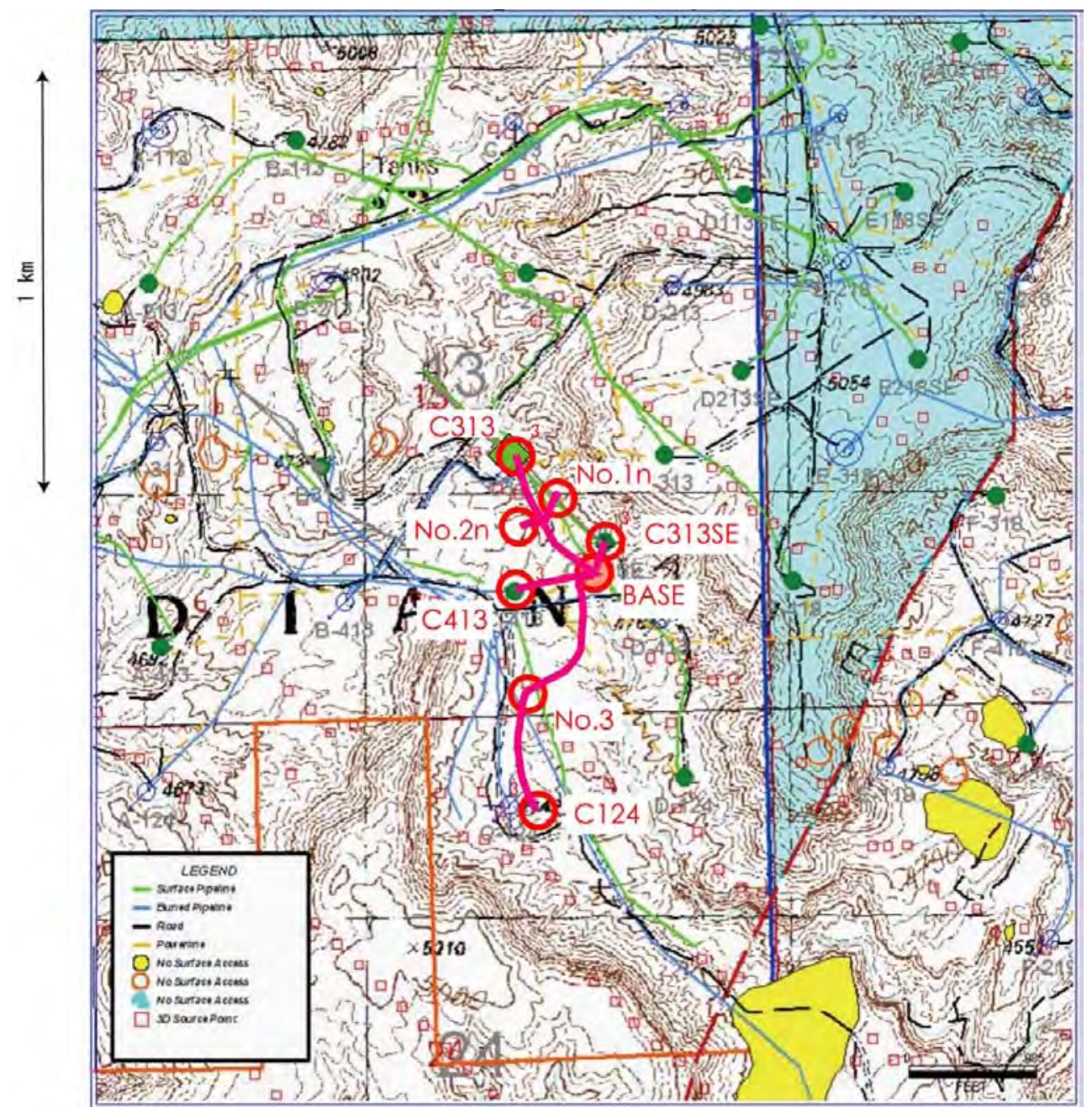

Figure 10-1. Layout of self-potential monitoring network at the Aneth test site. Three electrodes are installed at each of four locations near the C313, C413, C313SE and C124 wells. Single electrode is installed at each of four locations: "No.1n", "No.2n", "No.3" and "BASE" (where a data logger, solar panel, etc. are also installed). 


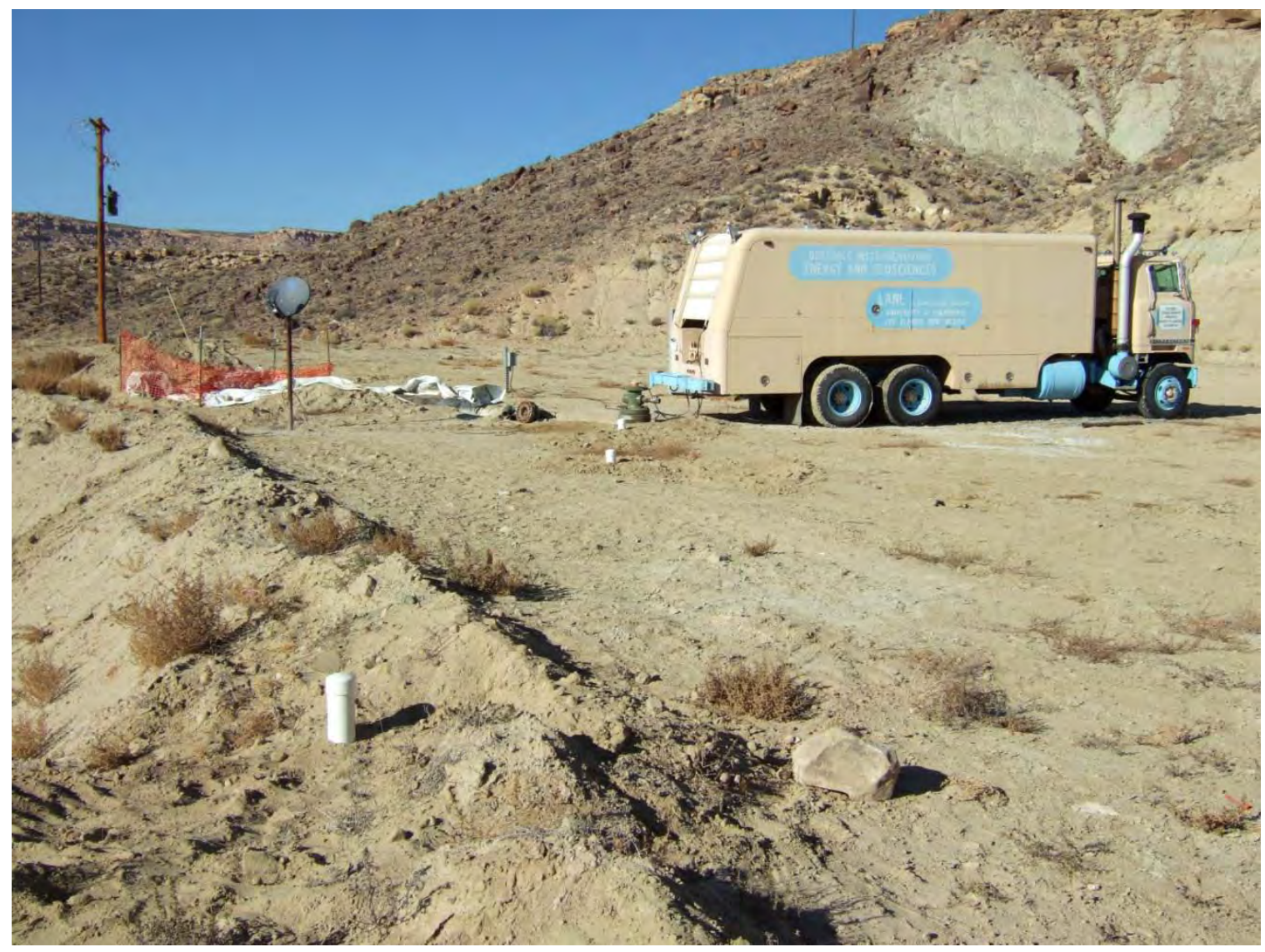

Figure 10-2. Photo showing three white-color caps of one-meter holes for electrodes "C313SEn", "C313SEm" and "C313SEf” installed near the C313SE wellhead. An AgAgCl electrode itself is set on the bottom of the each hole. 


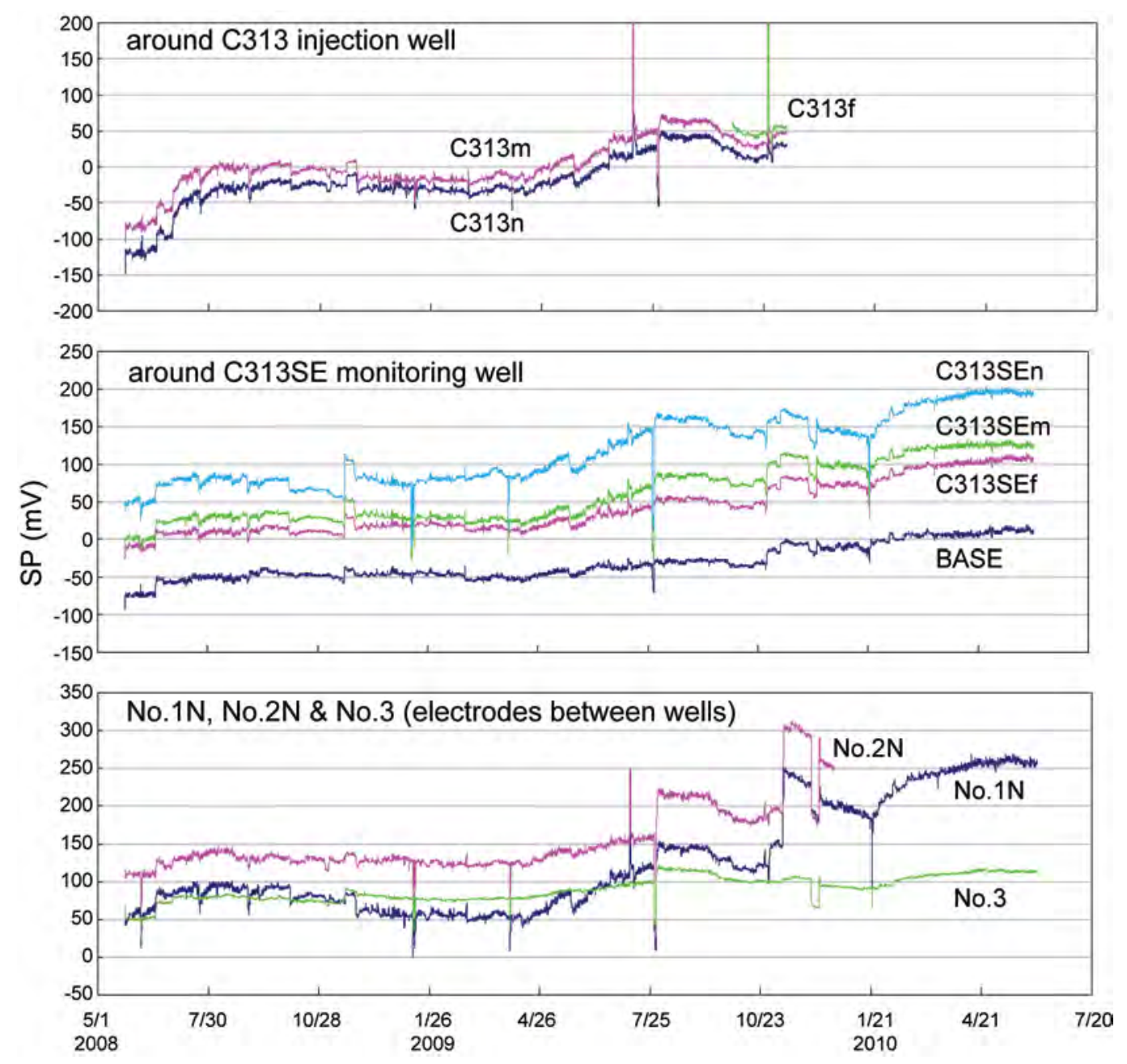

Figure 10-3. Observed self-potential as a function of time from May 2008 to May 2010 for (top) three electrodes near the C313 injection well, (middle) one electrode at "BASE" and three electrodes near the C313SE well and (bottom) one electrode at each of "No.1n", "No.2n" and "No.3". SP values are relative to electrode "C124m". Time scale division is 90 days and vertical axis range is $400 \mathrm{mV}$ in all plots. Abrupt changes such as observed in the late July and early December 2009 are correlated with the large changes at "C413m" and "C413f" shown in the lower panel of Figure 10-4. 


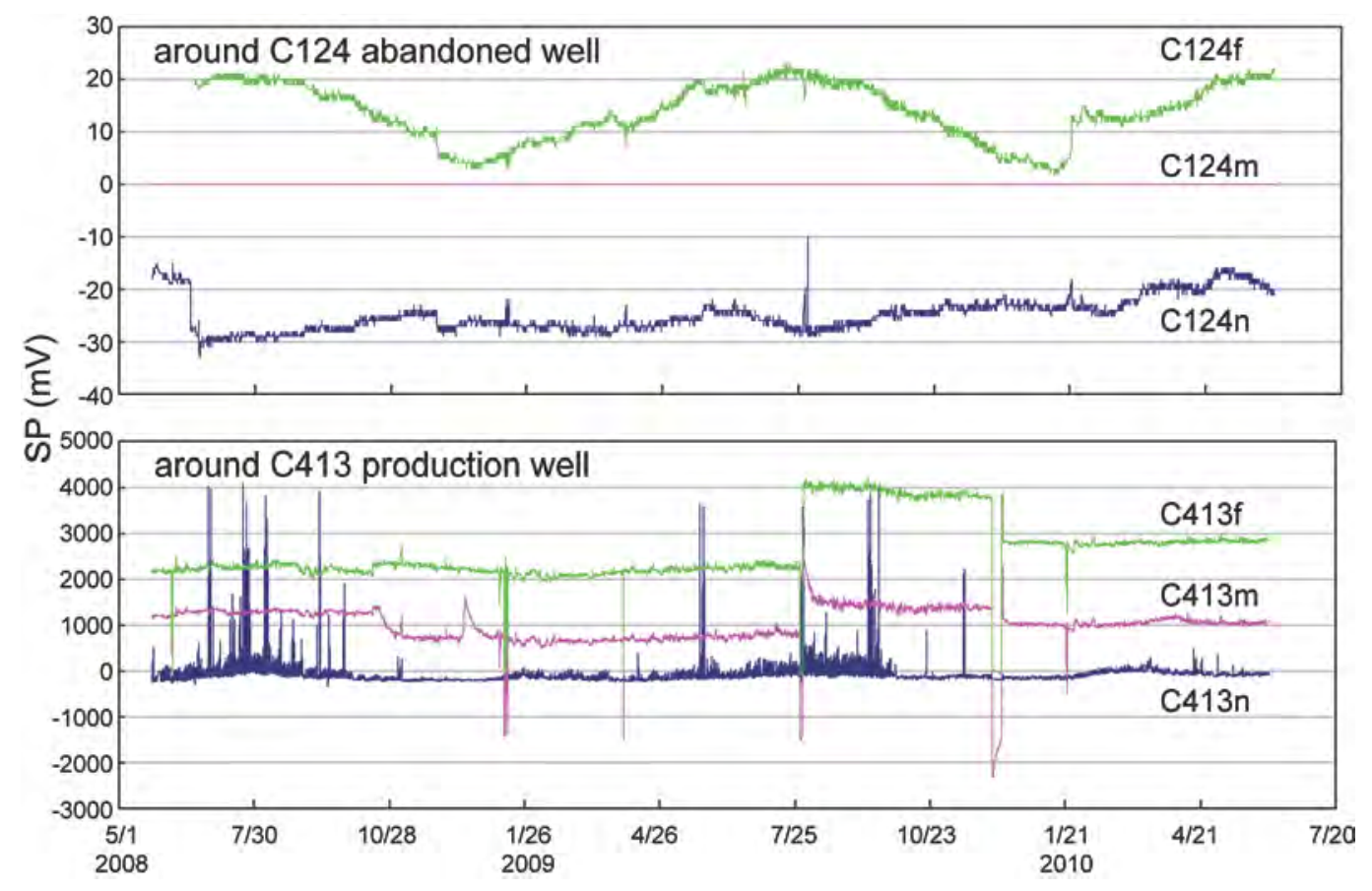

Figure 10-4. Observed self-potential as a function of time from May 2008 to May 2010 for (top) three electrodes near the C124 abandoned well and (bottom) three electrodes near the C413 production well. Time scale division is 90 days. Electrode " $\mathrm{C124m}$ " is used as a reference. SP recorded around the C413 well contains large long-period noise, which is also thought to be caused by fluctuations of nearby "noise source". 


\title{
CHAPTER 11 TIME-LAPSE OFFSET VSP MONITORING OF $\mathrm{CO}_{2}$ ENHANCED OIL RECOVERY AT THE ANETH OIL FIELD
}

\author{
by \\ Lianjie Huang, Zhifu Zhang, Yi Wang, and James Rutledge \\ Los Alamos National Laboratory \\ Geophysics Group, Mail Stop D443 \\ Los Alamos, NM 87545, USA \\ ljh@lanl.gov
}

Janusz Peron, Michelle Zhao, and Arthur Cheng

Cambridge Geosciences, Sugar Land, TX 77478

\begin{abstract}
Remotely tracking the movement of injected $\mathrm{CO}_{2}$ within a geological formation is critically important for ensuring safe and long-term geologic carbon sequestration. To study the capability of vertical seismic profiling (VSP) for remote monitoring of $\mathrm{CO}_{2}$ injection, a geophone string with 60 levels and 96 channels was cemented into a monitoring well at the Aneth oil field in Utah operated by Resolute Natural Resources and Navajo National Oil and Gas Company. The oil field is located in the Paradox Basin of southeastern Utah, and was selected by the Southwest Regional Partnership on Carbon Sequestration, supported by the U.S. Department of Energy, to demonstrate combined enhanced oil recovery (EOR) and $\mathrm{CO}_{2}$ sequestration. The geophones are placed at depths from $805 \mathrm{~m}$ to $1704 \mathrm{~m}$, and the oil reservoir is located approximately from $1731 \mathrm{~m}$ to $1786 \mathrm{~m}$ in depth. A baseline VSP dataset with one zero-offset and seven offset source locations was acquired in October, 2007 before $\mathrm{CO}_{2}$ injection. The offsets/source locations are approximately $1 \mathrm{~km}$ away from the monitoring well with buried geophone string. Two time-lapse VSP datasets with the "same" source locations were collected in July, 2008 after five months of $\mathrm{CO}_{2} /$ water injection into a horizontal well adjacent to the monitoring well, and in January, 2009, respectively. The time-lapse VSP data are preprocessed to balance the phase and amplitude of seismic events above the oil reservoir. Because of some uncertainties in the offset VSP source locations during repeat VSP surveys, we use travel times of downgoing waves and double-difference tomography to invert for the "true" VSP source locations. We conduct wave-equation migration imaging using the pre-processed and balanced time-lapse VSP data and the "true" VSP source locations. The results shows changes in time-lapse migration images along different offsets are different, indicating $\mathrm{CO}_{2}$ migration from the injection wells. The repeatability of VSP surveys is essential to make time-lapse offset VSP as an effective tool for monitoring $\mathrm{CO}_{2}$ injection.
\end{abstract}




\section{Introduction}

It is critically important to reliably monitor the movement of injected $\mathrm{CO}_{2}$ within complex geologic formations. To accurately detect small changes due to $\mathrm{CO}_{2}$ injection, the sources of time-lapse VSP surveys should be located exactly at the same positions. However, there are some uncertainties in offset VSP source locations during repeat VSP surveys at the Aneth oilfield for monitoring $\mathrm{CO}_{2}$ injection. The "true" source locations of repeated VSP surveys must be located for reliable VSP monitoring. We use doubledifference tomography and travel times of downgoing waves to locate the "true" offset VSP source locations. The double-difference (DD) seismic tomography was developed for improving earthquake event locations and imaging the velocity structure simultaneously (Waldhauser and Ellsworth, 2000; Wolfe, 2002; Zhang and Thurber, 2003, 2006, 2009). Zhou, et al. (2010) applied double-difference tomography to microseismic data recorded for monitoring $\mathrm{CO}_{2}$ injection at the Aneth oil field in Utah with a goal of improving the precision of event locations. The DD tomography uses both the absolute and differential arrival times to invert for the velocity structure and event location simultaneously. Zhang and Thurber $(2003,2006)$ tested DD tomography on synthetic and field data set and found that it produced more accurate events locations and velocity structures than standard tomography.

Data balancing is an important step in time-lapse seismic data processing. Data balancing is to transform a repeat seismic dataset to be comparable with the baseline. The challenge of time-lapse data processing is to reveal changes in the reservoir. Crossequalization is a popular technique for this task (Ross, et al, 1996; Schmitt, 1999; Rickett and Lumley, 2001; Stucchi et al., 2005). These approaches to amplitude balancing are to scale time-lapse datasets using the R.M.S. energy or conventional Wiener minimization methods.

We validate and test the feasibility of DD tomography for inverting for offset VSP source locations using synthetic time-lapse offset VSP data. Our synthetic studies show that the inversion results of source locations and velocity profiles are consistent with the model. We apply DD tomography to the time-lapse offset VSP data acquired at the Aneth oil field and relocate the repeat offset VSP source locations for 7 offset VSPs. We balance the VSP data of repeat surveys to the baseline data using the spectral analysis method (Coppens, 1984). We conduct wave-equation migration of balanced upgoing waves using the relocated "true" offset VSP source locations.

\section{Time-Lapse Offset VSP Surveys}

Time-lapse offset VSP monitoring use the same geophone string for microseismic monitoring. The geophone string with 60 levels and 96 channels was cemented into a monitoring well C313SE at the Aneth oil field in Utah operated by Resolute Natural Resources and Navajo National Oil and Gas Company (Figure 12-1). Figure 11-1 is a picture taken when the geophone was cemented into the monitoring well in October, 2007. The geophones are placed at depths from $805 \mathrm{~m}$ to $1704 \mathrm{~m}$, and the oil reservoir is located approximately from $1731 \mathrm{~m}$ to $1786 \mathrm{~m}$ in depth. Figure 11-2 shows the locations 
of the monitoring well, injection well, zero-offset VSP source location 1 and offset VSP source locations 2-8. A baseline VSP dataset with one zero-offset and seven offset source locations was acquired in October, 2007 before $\mathrm{CO}_{2}$ injection. The offsets/source locations are approximately $1 \mathrm{~km}$ away from the monitoring well with buried geophone string. Two time-lapse VSP datasets with the "same" source locations was collected in July, 2008 after five months of $\mathrm{CO}_{2}$ /water injection into a horizontal well (Figure 11-3) adjacent to the monitoring well, and in January, 2009, respectively. Figure 11-4 shows typical $\mathrm{CO}_{2}$ and water injection rates in well $\mathrm{C} 313$. For most of time, the $\mathrm{CO}_{2}$ inject rate is pretty stable.

The time-lapse offset VSP data were acquired by Baker Atlas, and the data were pre-processed by Cambridge Geosciences.

\section{Relocation of Offset VSP Sources}

During time-lapse VSP surveys, there are some uncertainties in the offset VSP source locations. We use double-difference tomography to relocate the offset VSP source locations to their "true" source locations.

Before applying the double-difference tomography to the Aneth VSP datasets, we use synthetic data to validate the feasibility of DD tomography for inverting for source locations of time-lapse offset VSP surveys. We use a finite-difference scheme with perfectly matched layer absorbing boundary conditions to generate synthetic time-lapse offset VSP data. The offsets of VSP sources vary for different surveys. We construct a velocity model using a well log dataset from the Aneth oil field (Figure 11-5).

We generate synthetic data for sixty receivers located in a monitoring well at depth from $800 \mathrm{~m}$ to $1744 \mathrm{~m}$ with a depth interval of $16 \mathrm{~m}$. The source offset of the baseline VSP data, or the distance from the monitoring well to the source location, is $1000 \mathrm{~m}$. Repeat source offsets are $1005 \mathrm{~m}, 1020 \mathrm{~m}$ and $1050 \mathrm{~m}$. We conduct crosscorrelation to obtain differential and absolute first-arrival times of downgoing waves as shown in Figure 11-6.

We first use DD tomography to invert for source locations without inverting for the velocity structure. Initial source offsets are set to be $1000 \mathrm{~m}$ during inversions. Inversion results of the source offsets of synthetic time-lapse offset VSP data are 1004.98 $\mathrm{m}, 1019.78 \mathrm{~m}$ and $1049.63 \mathrm{~m}$, which are very close to the true VSP source offsets. We then employ a hierarchical weighting scheme to invert for source locations and velocity structures simultaneously. The initial velocity model is a layered velocity model with a $10 \%$ increase in velocity within the layer from $1050 \mathrm{~m}$ to $1200 \mathrm{~m}$. The inverted VSP source offsets are $1004.90 \mathrm{~m}, 1020.17 \mathrm{~m}$, and $1050.39 \mathrm{~m}$ for the synthetic time-lapse offset VSP data. Again, they are very close to the correct VSP source offsets.

Figure 11-7 shows the velocity differences between the inverted and initial velocity profiles. For the time-lapse VSP data with a source offset of $1005 \mathrm{~m}$, the updated velocity difference at depth from $1050 \mathrm{~m}$ to $1200 \mathrm{~m}$ is about $400 \mathrm{~m} / \mathrm{s}$. The initial velocity 
is $482 \mathrm{~m} / \mathrm{s}$ higher than the true velocity within that layer. The updated velocity for the VSP data with a source offset of $1050 \mathrm{~m}$ is larger than that for the VSP data with a source offset of $1005 \mathrm{~m}$. Nevertheless, the inversion results of velocity are close to the true velocity models.

For the time-lapse VSP dataset acquired at the Aneth oil field, the seven source locations of offset VSPs are spread in different azimuth directions relative to the monitoring. We position the offset VSP sources along azimuth angles of 90, 135 and 180 degree. The VSP source offset is $1020 \mathrm{~m}$. We then conduct a joint inversion of these synthetic time-lapse offset VSP data. DD tomography results of the VSP source offsets are $1019.80 \mathrm{~m}, 1019.82 \mathrm{~m}$ and $1019.80 \mathrm{~m}$ without inverting for velocity, and their values are $1020.07 \mathrm{~m}, 1020.24 \mathrm{~m}$ and $1020.07 \mathrm{~m}$ when inverting for the source locations and velocity structures simultaneously. The differences between the results from these two difference inversion schemes are insignificant.

We apply the DD tomography to the time-lapse offset VSP datasets from the Aneth oil field. We employ a 2-step inversion scheme. We first invert only for source locations without velocity update. This source location results are used as the initial source location parameters to simultaneously invert for the offset VSP source locations and velocity structures. We use downgoing waves to conduct individual DD tomography for each source offset and joint inversion for all offset data. Our inversion results of the source locations for these two inversion schemes are close to one another. Table 11-1 shows the results of the VSP source offsets from the joint DD tomography, indicating that the VSP source offsets for different surveys are separated up to nearly 25 meters. The source location separations at Offset 6 are the smallest. The largest source location variation is nearly $25 \mathrm{~m}$ that can have significant impacts on time-lapse offset VSP data processing results. The 2008 data for Offset 7 are not available. Figure 11-7 displays the results of the VSP source locations obtained from the joint DD tomography of the timelapse offset VSP data.

Figure 11-9 shows velocity inversion results of joint DD tomography of the timelapse offset VSP data. The velocity difference profiles give the differences between the updated velocity model and the initial velocity model (Figure 11-5). These profiles, from the monitoring well to the source location for each offset, show that there are some velocity variations from the layered velocity model.

\section{Balancing Time-Lapse VSP Data}

There are significant differences in amplitudes of VSP data among the repeat and baseline surveys. Time-lapse VSP surveys are to monitor changes of the reservoir due to $\mathrm{CO}_{2}$ injection. During the data processing, the amplitudes of downgoing waves of timelapse V SP $\mathrm{d}$ ata a re $\mathrm{m}$ atched $\mathrm{t} \mathrm{o}$ one another. The a mplitudes of up going $\mathrm{w}$ aves from

different surveys need be further balanced. We use a spectrum analysis method (Coppens, 1984) to perform amplitude balancing of time-lapse VSP data. 
We first scale the different offset data based on the R.M.S. energy of a windowed upging waves for the baseline survey, which renders amplitudes of upgoing data to keep consistency for all offset VSPs. The first-arrival seismic events in a selected time window are reflected signals from regions above the $\mathrm{CO}_{2}$ injection zone from which seismic wave propagation should not $\mathrm{c}$ hange during $\mathrm{CO}_{2}$ injection. $\mathrm{T}$ hese ev ents a re $\mathrm{u}$ sed as $\mathrm{t}$ he reference to minimize amplitude differences of the time-lapse offset VSP data from the Anther oil field.

Following the above steps, data balancing is performed trace by trace for all timelapse offset VSP offset data from the Aneth O il field. Figure 11-10 is data $b$ alancing result from Offset 6 in 2009. B alanced data amplitude in Figure 11-10(b) is comparable to that of baseline data in Figure 11-10(a).

Figure 11-11 is a comparison of wave-equation migration image differences from original and balanced data for the time-lapse VSP data at Offset 6 . After data balancing, the i mage $\mathrm{d}$ ifferences a bove the $\mathrm{C}_{2}$ injection $\mathrm{z}$ one a re $\mathrm{m}$ ostly s uppressed (compare migration ima ges in Figure $11-11 \mathrm{a}$ and Figure $11-11 \mathrm{~b}$ at de pths a bove $1400 \mathrm{~m}$ ). The migration image differences within the reservoir around the circled region in Figure 11 11(a) is more reliable than that in Figure 11-11(b). This demonstrates the importance of balancing time-lapse offset VSP upgoing waves in detection of reservoir changes us ing wave-equation migration.

\section{Depth Migration of Time-Lapse Offset VSP Data}

We first demonstrate the effect of offset VSP source locations in migration image differences of time-lapse VSP data. Figure 11-12(a) is a wave-equation migration image of the 2009 VSP data for Offset 5 us ing the double-difference tomography source offset location. The difference between the image in Figure 11-12(a) and that obtained using the baseline source location is shown in Figure 11-12(b). This demonstrates a few meters of difference in VSP source locations can cause significant differences in migration imaging profiles. Therefore, the repeatability of offset VSP source locations is critically important for $\mathrm{r}$ eliably d etecting small reservoir changes due $\mathrm{t}$ o $\mathrm{C} \mathrm{O}_{2}$ injection/migration. It is necessary to use the "true" VSP source locations in order to detect small changes due to $\mathrm{CO}_{2}$ injection using time-lapse offset VSP surveys.

We conduct wave-equation migration using the balanced upgoing waves of timelapse offset VSP data for Offsets 2-8 and the offset VSP source locations obtained from double-difference tomography. The migration image of a repeat VSP dataset is subtracted by the baseline migration image for the each offset VSP data to obtain image difference. Figure 1 1-13 shows the differences be tween migration i mages of 2008 a nd 2007 da ta, and those b etween 2009 a nd 2008 da ta. T he i mage di fferences for Offset 7 ar e n ot presented because 2008 VSP data for Offset 7 is not available. The results in Figure 11 13 s how that s ome s ignificant ch anges from 2007 to 2008 in the $\mathrm{CO}_{2}$ injection de pth (1730-1790 $\mathrm{m}$ depth) occur along the profiles from the monitoring well to Offset 2 and to Offset 4. From 2008 to 2009, significant changes are observed along the profiles from the monitoring w ell to $\mathrm{O}$ ffset 3 a nd to $\mathrm{O}$ ffset 6 . A n oil producing w ell is located ne ar the 
monitoring well and along the profile from the monitoring well to Offset 2, and therefore, the migration image changes a long $\mathrm{O}$ ffset 2 from $2007 \mathrm{t}$ o $2008 \mathrm{~m}$ ay be due to the oil production. Figure 11-14 is an illu stration of the profiles from the mo nitoring w ell to different offset VSP source locations with significant changes in migration images within the reservoir from 2007 to 2008 and from 2008 to 2009 . It clearly shows that, except for the profile along $\mathrm{O} f f$ set 2 , the fronts of reservoir changes due to $\mathrm{CO}_{2}$ injection pass the profile from th e mo nitoring $\mathrm{w}$ ell to Offset $4 \mathrm{f}$ rom $2007 \mathrm{t}$ o 2008, a nd they pass the profiles along Offset 3 and Offset 6 from 2008 to 2009 .

\section{Conclusions}

We ha ve de monstrated $t$ hat doubl e-difference $t$ omography can ac curately determine source offsets of time-lapse offset VSP surveys. We have successfully applied the double-difference tomography method to time-lapse offset VSP data acquired at the Aneth oil field in $\mathrm{U}$ tah for $\mathrm{m}$ otoring $\mathrm{C} \mathrm{O}_{2}$ injection. The double-difference tomography gives both source offsets of time-lapse offset VSP surveys and velocity profiles between a VSP source offset and the monitoring well. Our double-difference tomography results of the time-lapse offset VSP data acquired from the Aneth oil field for monitoring $\mathrm{CO}_{2}$ injection show that the source locations for di fferent surveys are s eparated from a few meters to several tens of meters. Accounting for these source location va riations during time-lapse o ffset VSP d ata an alysis can improve $r$ eliability o f time -lapse o ffset V SP monitoring.

We have shown that the spectral analysis method can effectively balance the timelapse offset VSP datasets. After data balancing, amplitudes of the Aneth time-lapse offset VSP $\mathrm{d}$ ata become co mparable to one another. We $\mathrm{h}$ ave $\mathrm{p}$ erformed wave-equation migration of a ll u pgoing $\mathrm{w}$ aves from O ffset 2 to O ffset 8 using balanced da ta a nd the VSP s ource 1 ocations obtained $\mathrm{f}$ rom doubl e-difference $\mathrm{t}$ omography. The time -lapse image differences among different s urveys clearly s how $\mathrm{r}$ eservoir ch anges d ue to $\mathrm{CO}_{2}$ injection. Significant changes in migration images are observed along VSP source Offset 2 and Offset 4 from 2007 to 2008, a nd along Offset 3 and Offset 6 from 2008 to 2009. The change along Offset 2 may due to oil production. The other changes are consistent with anticipated reservoir changes due to $\mathrm{CO}_{2}$ injection.

\section{Acknowledgements}

This work was supported by the U.S. Department of Energy through contract DEAC52-06NA25396 to Los A lamos N ational Laboratory. T his w as a research effort in collaboration $\mathrm{w}$ ith Resolute $\mathrm{N}$ atural $\mathrm{R}$ esources, Inc. a nd t he $\mathrm{S}$ outhwest $\mathrm{R}$ egional Partnership on $\mathrm{C}$ arbon Sequestration that w as supported b y t he U .S. Department of Energy and $m$ anaged by the National Energy T echnology Laboratory. We thank Brian McPherson and Reid Grigg for their support and Michael Tryggestad of Resolute Natural Resources for his help in coordinating the field work and the compiling of injection and well-log data. 
Table 11-1. Inversion results of time-lapse VSP source offsets obtained using doubledifference tomography.

\begin{tabular}{|c|c|c|c|c|c|}
\hline \multirow{2}{*}{$\begin{array}{c}\text { Offset } \\
\text { Number }\end{array}$} & $\begin{array}{c}2007 \\
\text { Baseline } \\
\text { VSP } \\
\text { Offset }(\mathrm{m})\end{array}$ & $\begin{array}{c}\text { Inversion } \\
\text { Offset }(\mathrm{m})\end{array}$ & $\begin{array}{c}\text { Difference } \\
(\mathrm{m})\end{array}$ & $\begin{array}{c}\text { Inversion } \\
\text { Offset }(\mathrm{m})\end{array}$ & $\begin{array}{c}\text { Difference } \\
(\mathrm{m})\end{array}$ \\
\cline { 3 - 6 } & 1029.9 & 1029.1 & -0.8 & 1018.8 & -11.1 \\
\hline 3 & 965.6 & 966.8 & 1.2 & 968.1 & 2.5 \\
\hline 4 & 1062.2 & 1068.1 & 5.9 & 1065.3 & 3.1 \\
\hline 5 & 997.9 & 1017.3 & 19.4 & 1012.3 & 14.4 \\
\hline 6 & 901.3 & 901.5 & 0.2 & 902.3 & 1.0 \\
\hline 7 & 933.3 & & & 908.5 & -24.8 \\
\hline 8 & 1046.0 & 1049.4 & 3.4 & 1046.7 & 0.7 \\
\hline
\end{tabular}




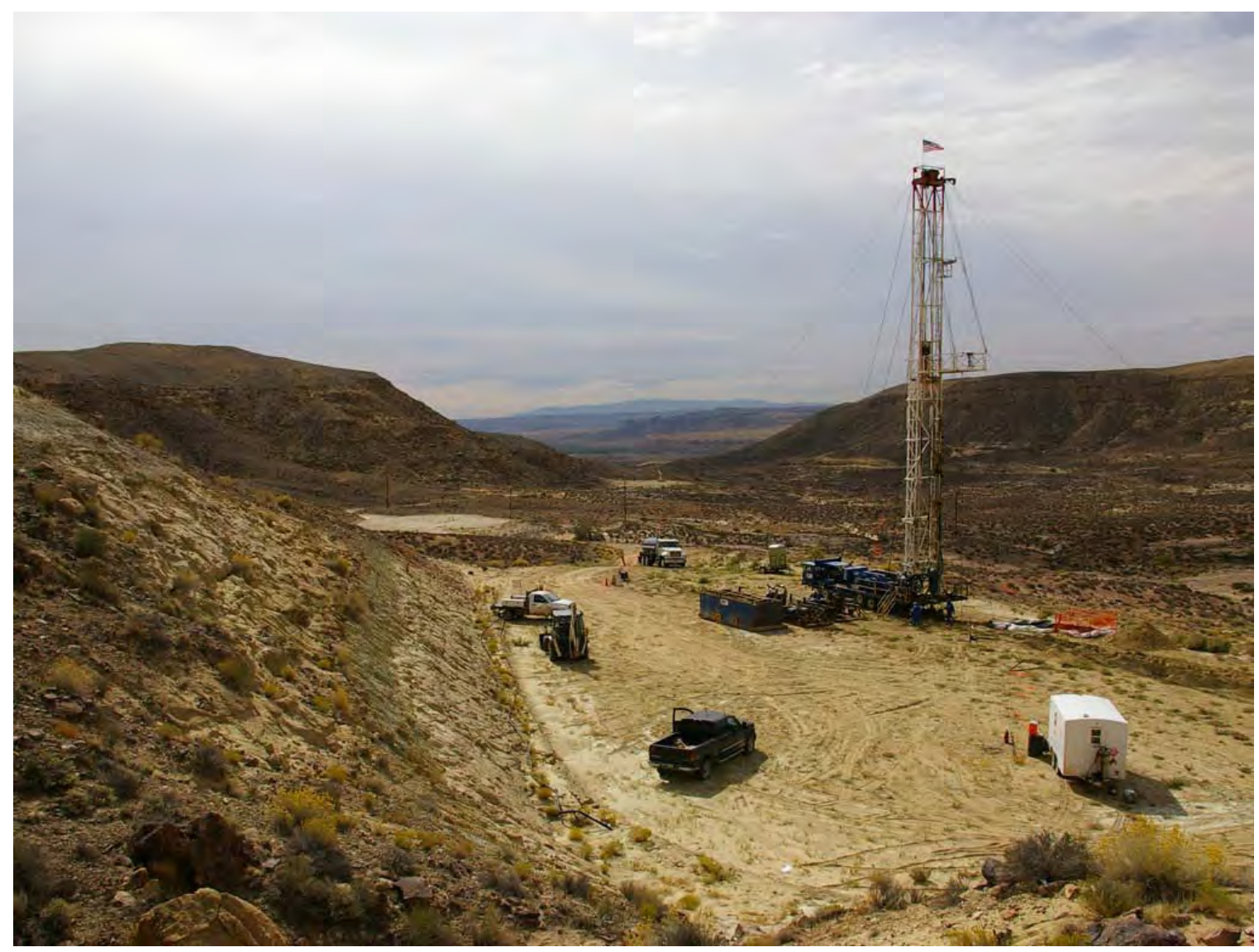

Figure 11-1. A picture taken when the monitoring geophone string was cemented into well C313SE in October, 2007 for microseismic and time-lapse offset VSP monitoring. 


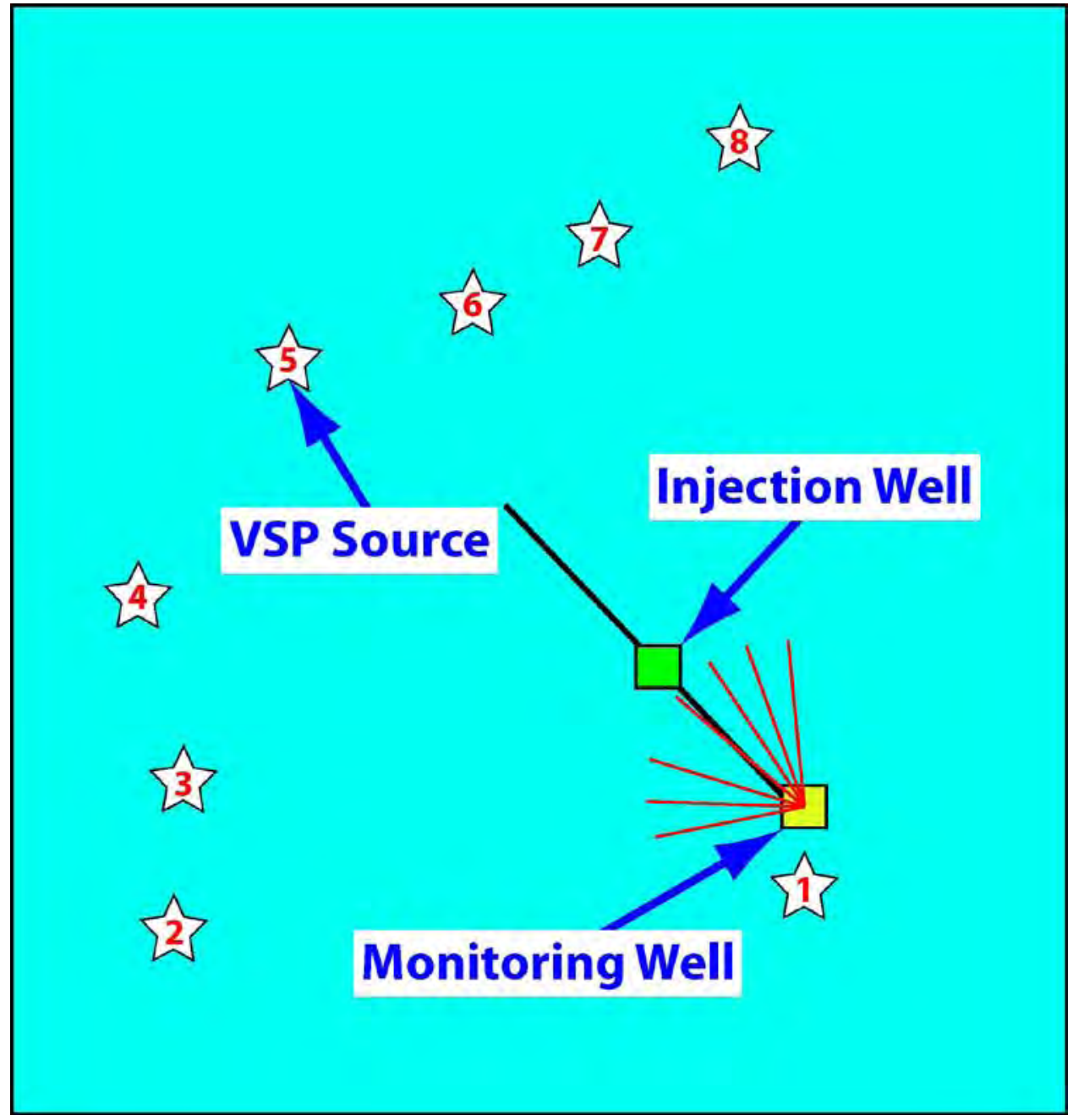

Figure 11-2. Illustration of the locations of the monitoring well, injection well, the zero-offset VSP source location 1 and offset VSP source locations 2 through 8. 


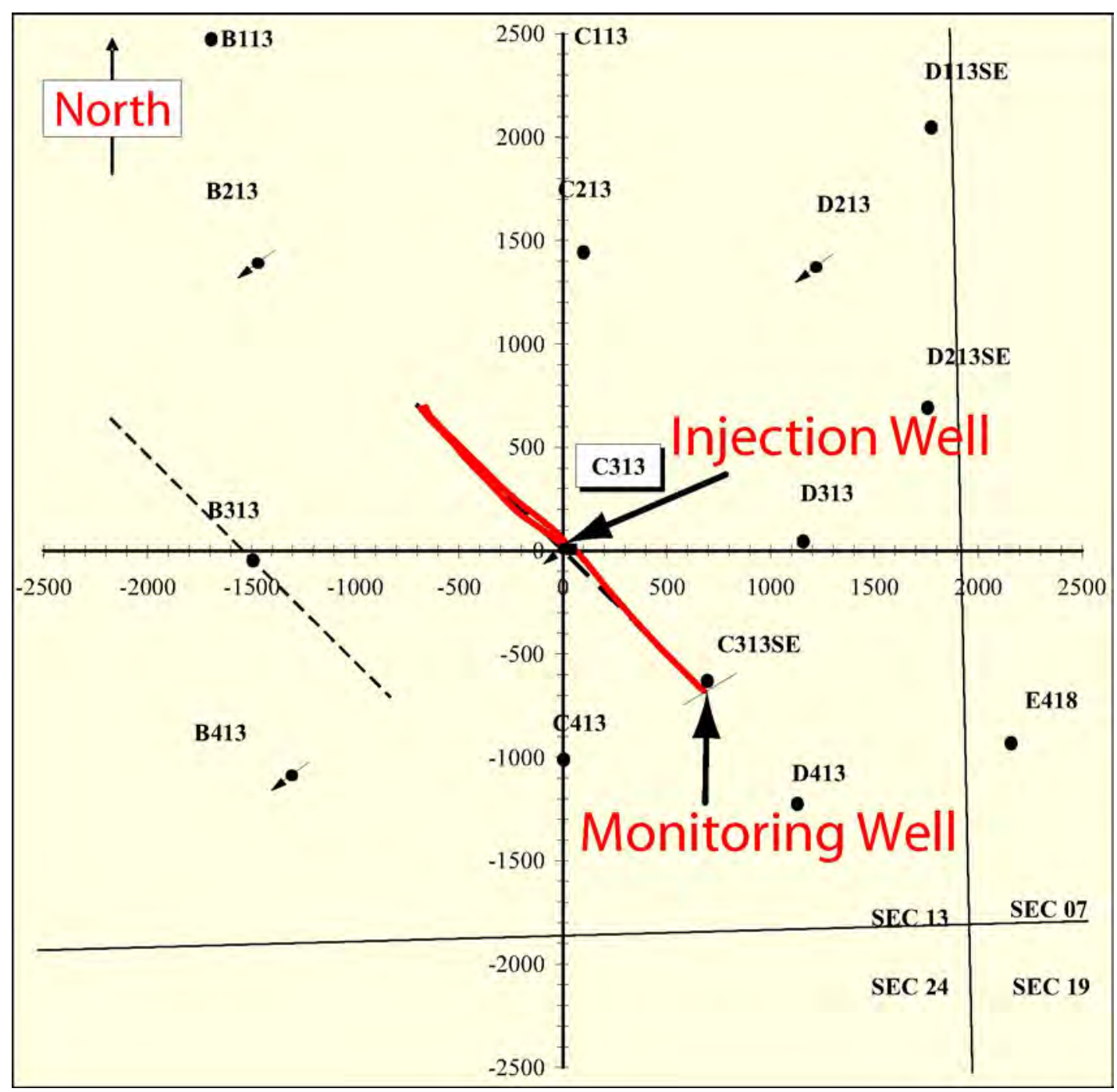

Figure 11-3. $\mathrm{CO}_{2}$ was injected into the reservoir through three horizontal laterals within well C313. 


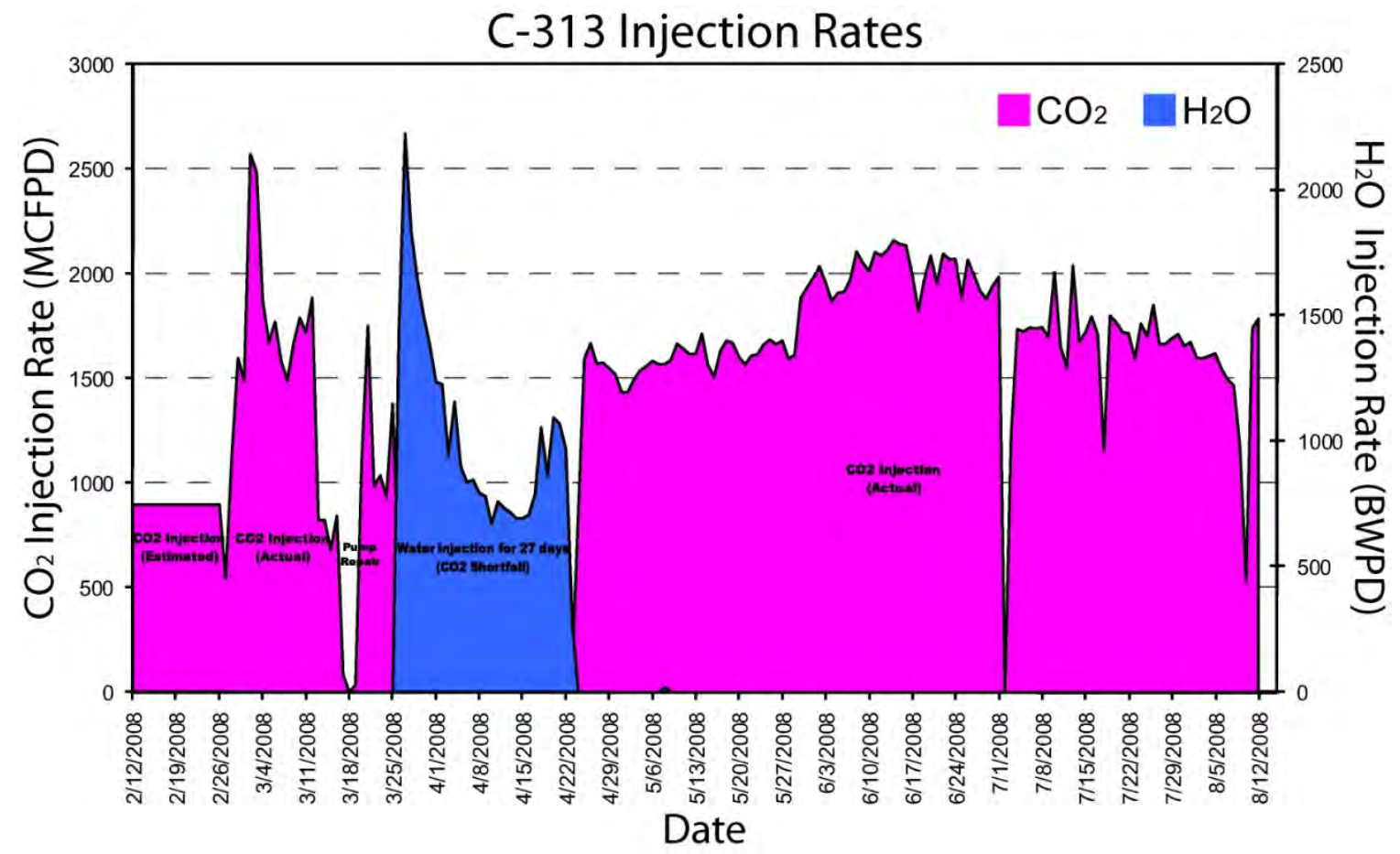

Figure 11-4. Typical $\mathrm{CO}_{2}$ and water injection rates in well C313. 


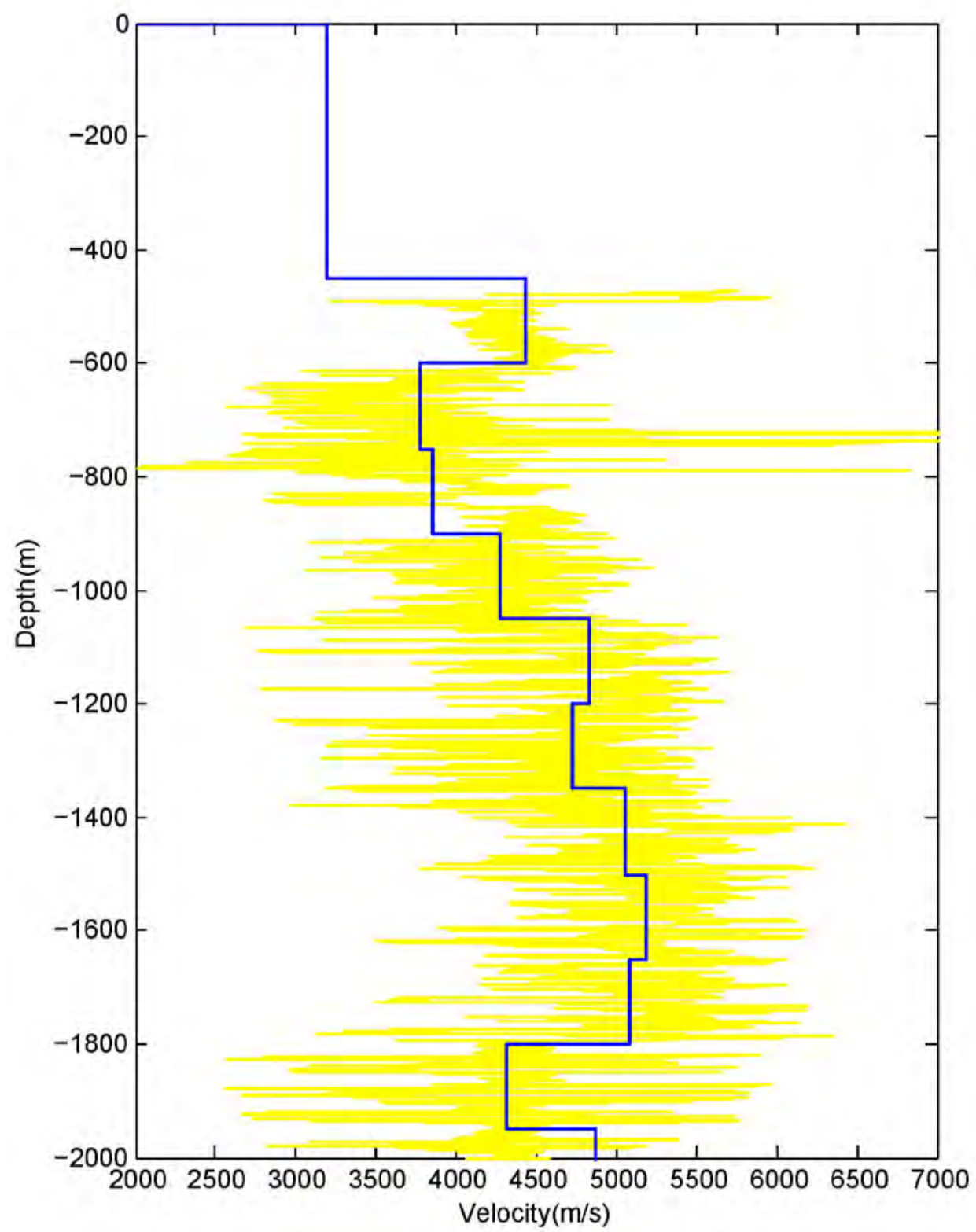

Figure 11-5. A velocity model in blue constructed from a well log in yellow from the Aneth oil field. 


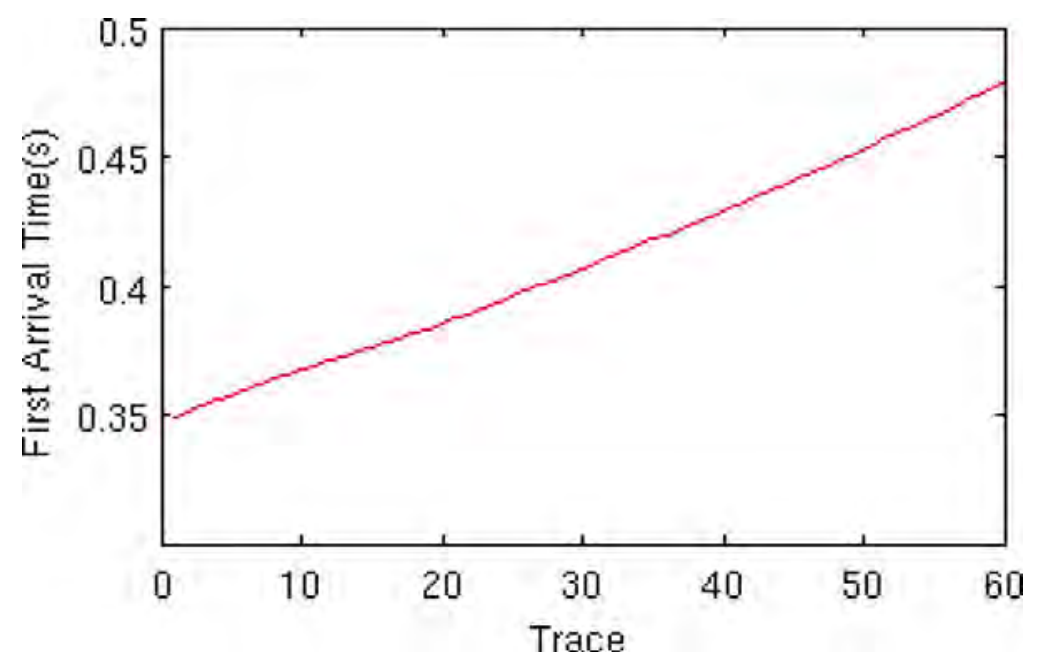

(a)

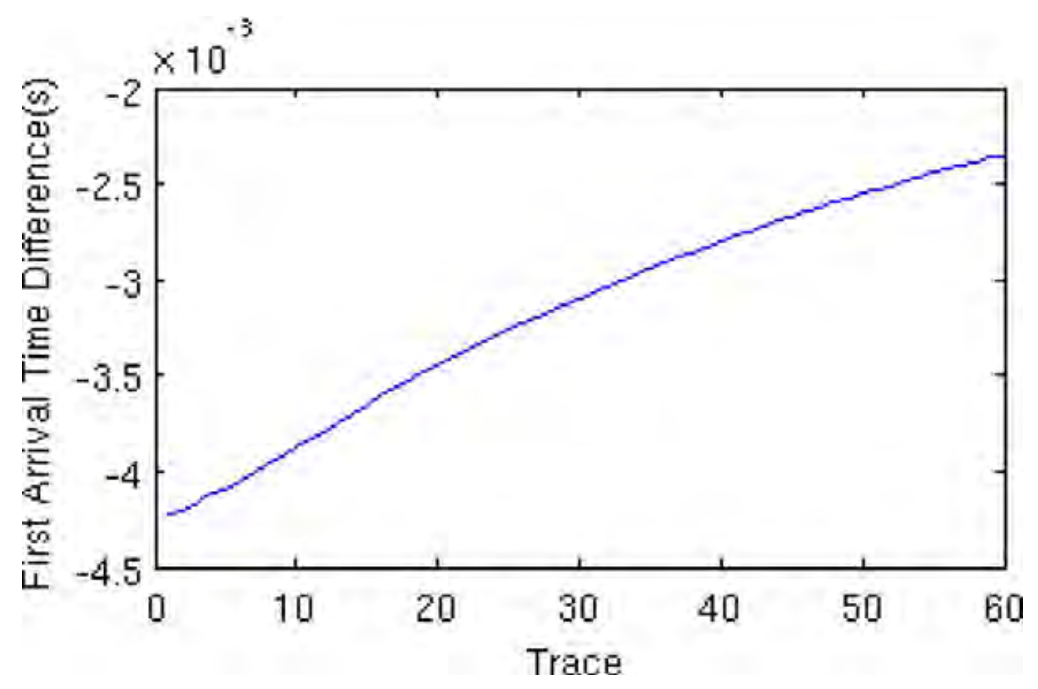

(b)

Figure 11-6. (a) First-arrival times of downgoing waves of synthetic offset VSP data for the source offset of $1000 \mathrm{~m}$. (b) The differences between the first-arrival times of downgoing waves of synthetic VSP data for the source offset of $1000 \mathrm{~m}$ and those for the source offset $1020 \mathrm{~m}$. 


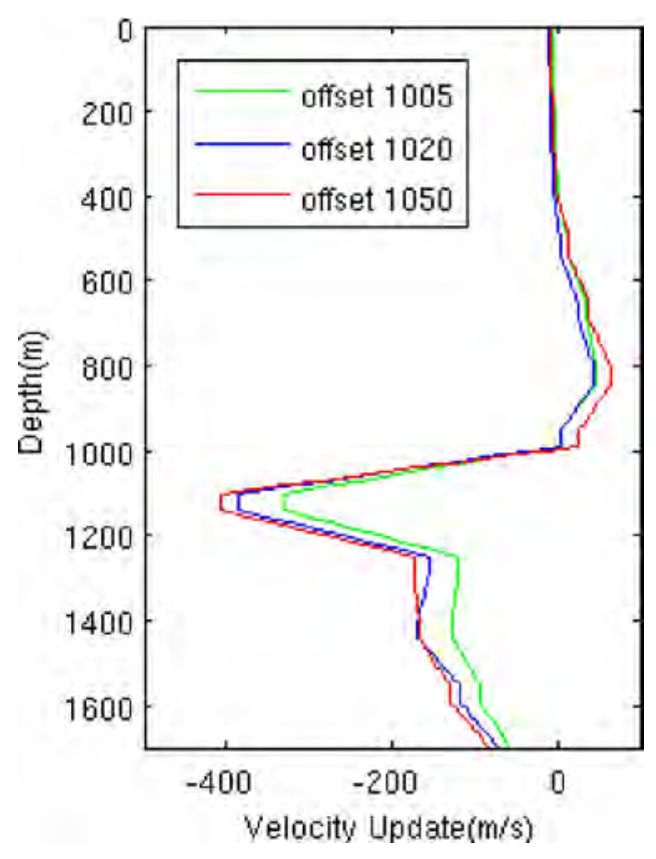

(a)

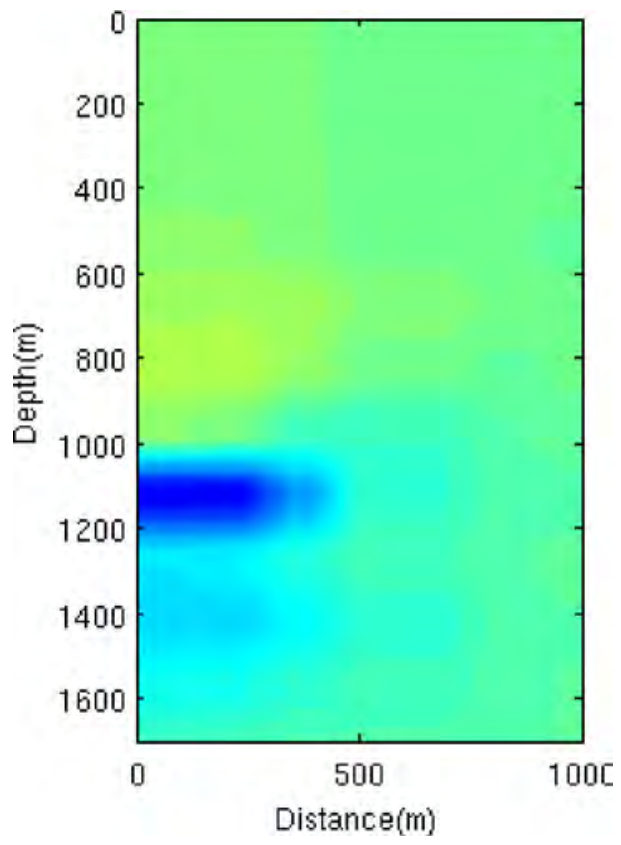

(c)

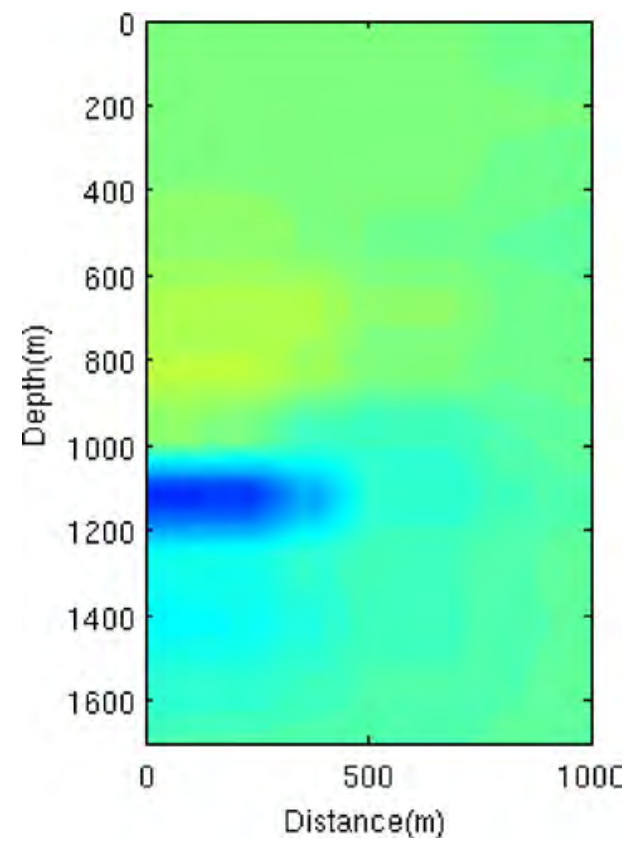

(b)

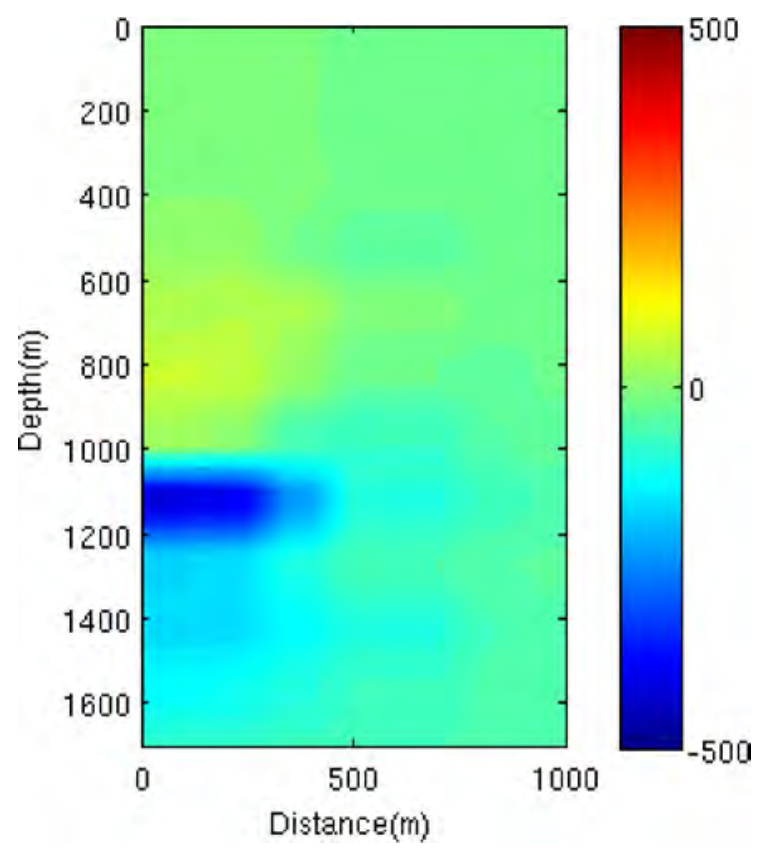

(d)

Figure 11-7. Velocity differences between inverted and initial velocity models. (a) Velocity difference near the monitoring well; (b), (c) and (d) are the profiles of the velocity differences from the monitoring well to the source locations for VSP offset at $1005 \mathrm{~m}, 1020 \mathrm{~m}$ and $1050 \mathrm{~m}$, respectively. 


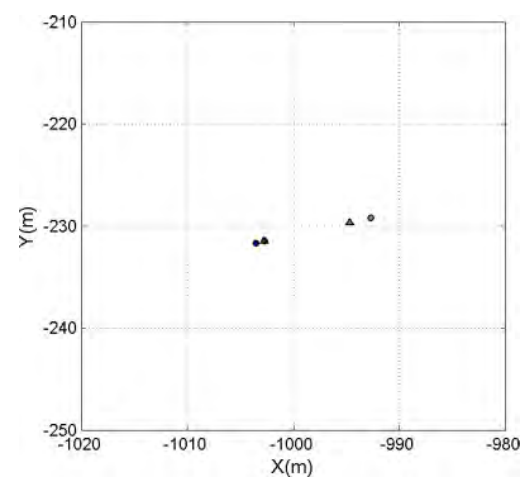

Offset 2

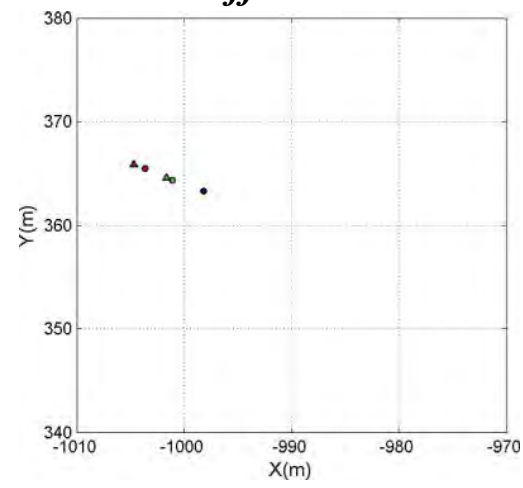

Offset 4
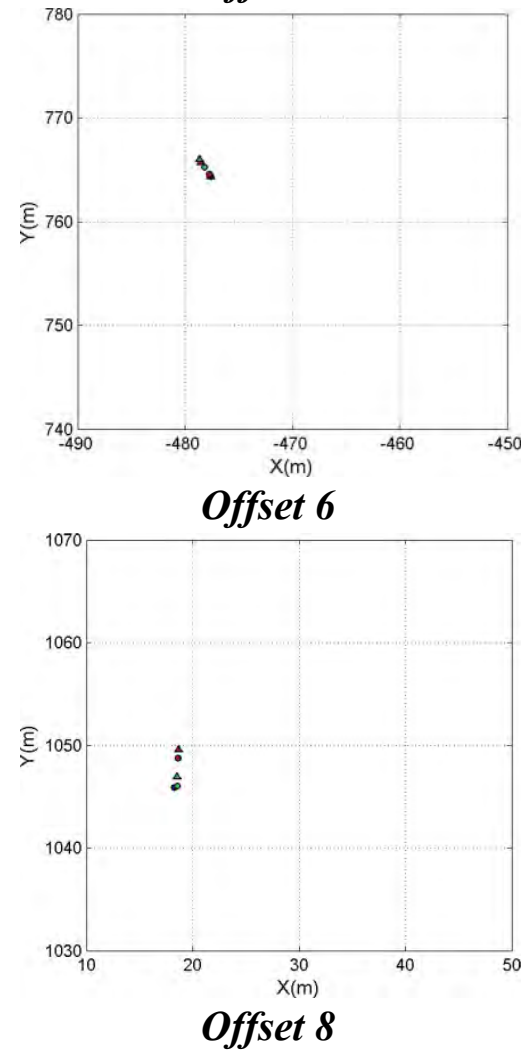

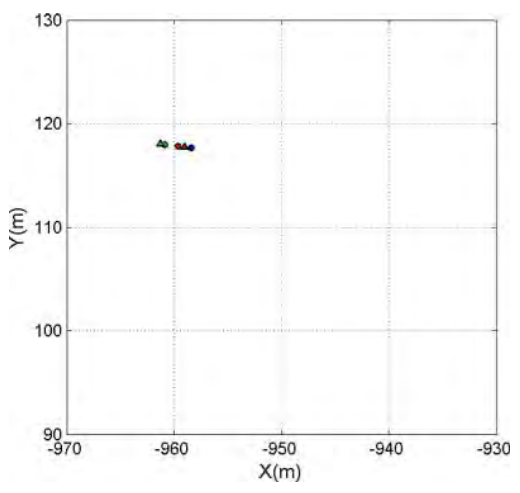

Offset 3

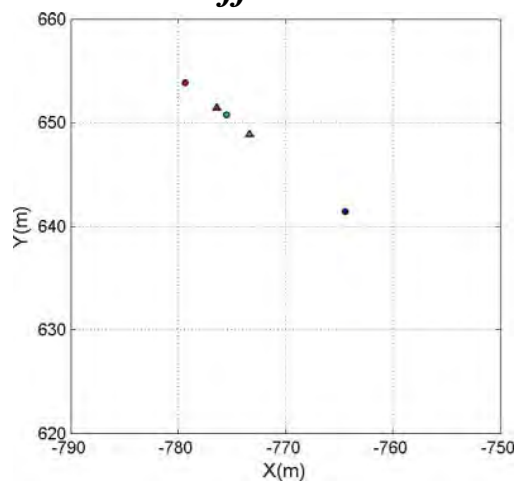

Offset 5

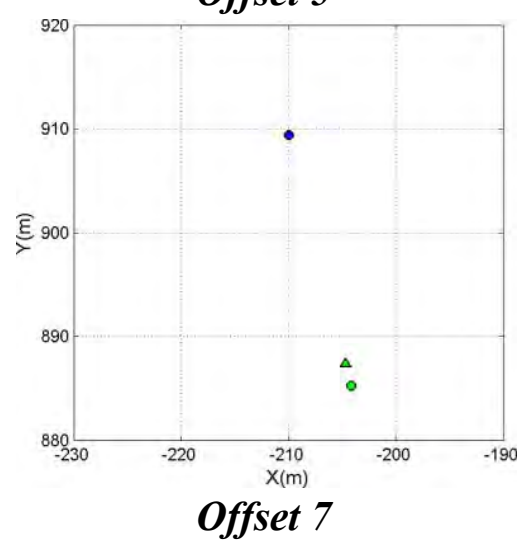

Baseline source locations

Inverted source locations for 2008 data

$\triangle$ Jointly inverted source locations for 2008 data

Inverted source locations for 2009 data

$\triangle$ Jointly inverted source locations for 2009 data

Figure 11-8. Double-difference tomography results of source locations of baseline (2007) and repeat 2008 and 2009 offset VSP data acquired at the Aneth oil field in Utah for monitoring $\mathrm{CO}_{2}$ injection. 


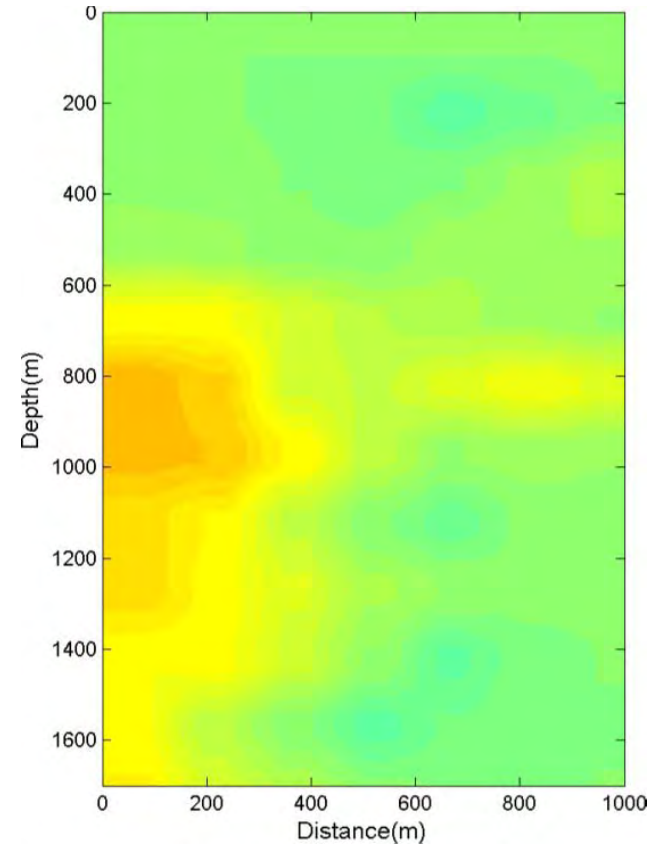

Offset 2

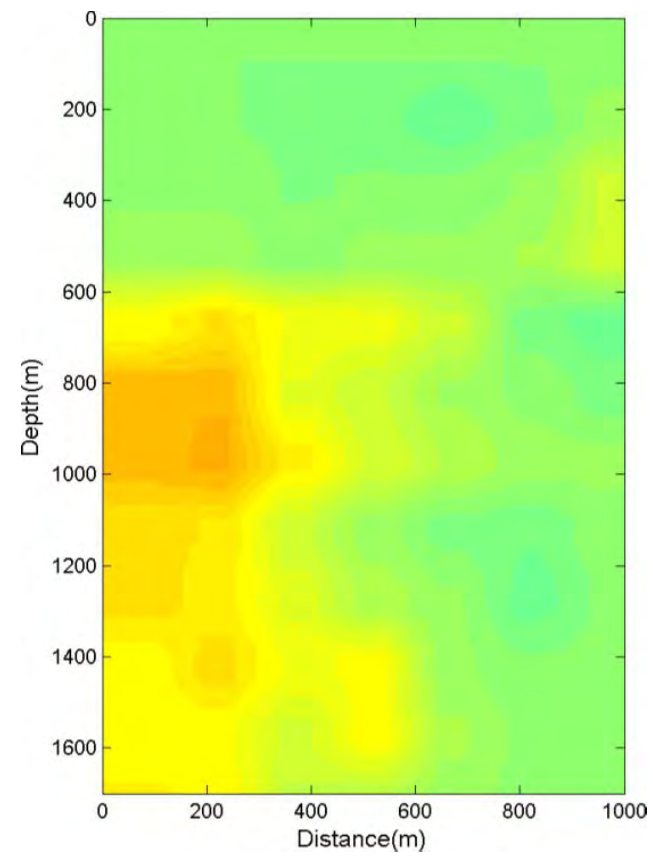

Offset 4

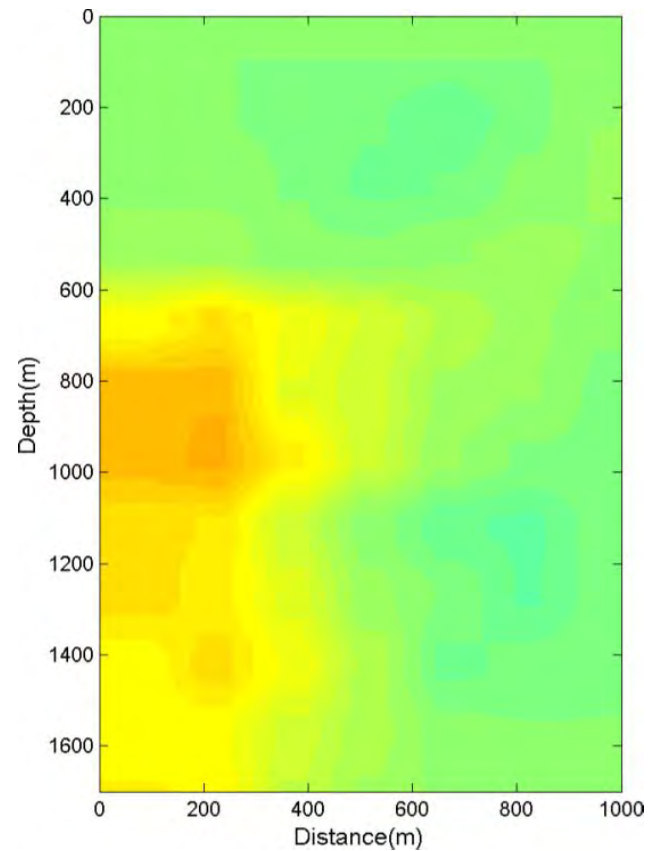

Offset 3

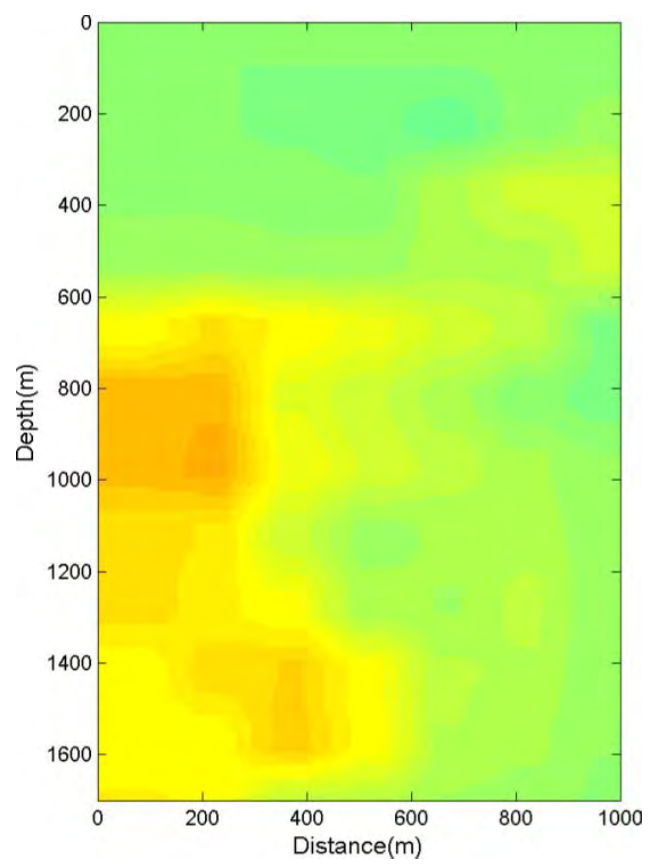

Offset 5 


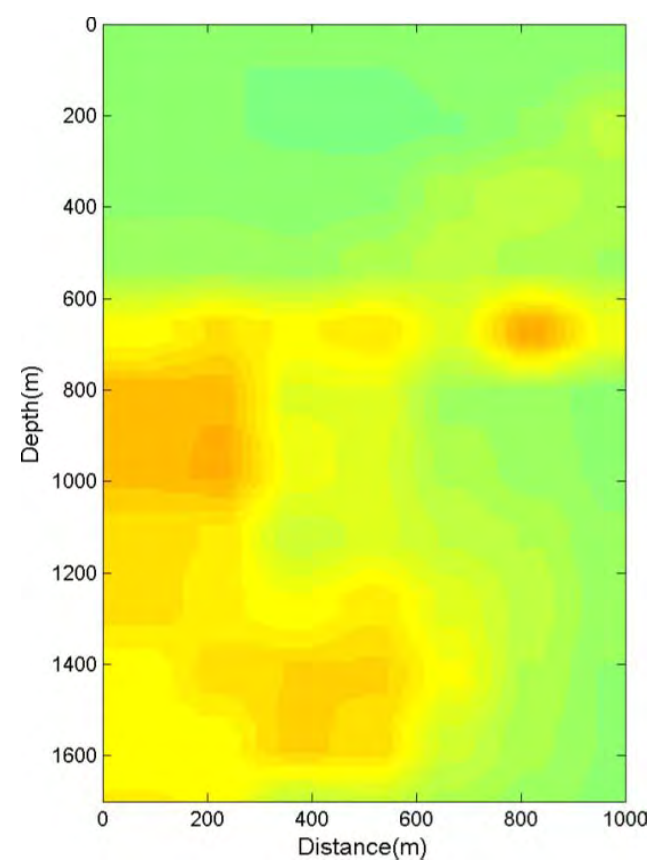

Offset 6

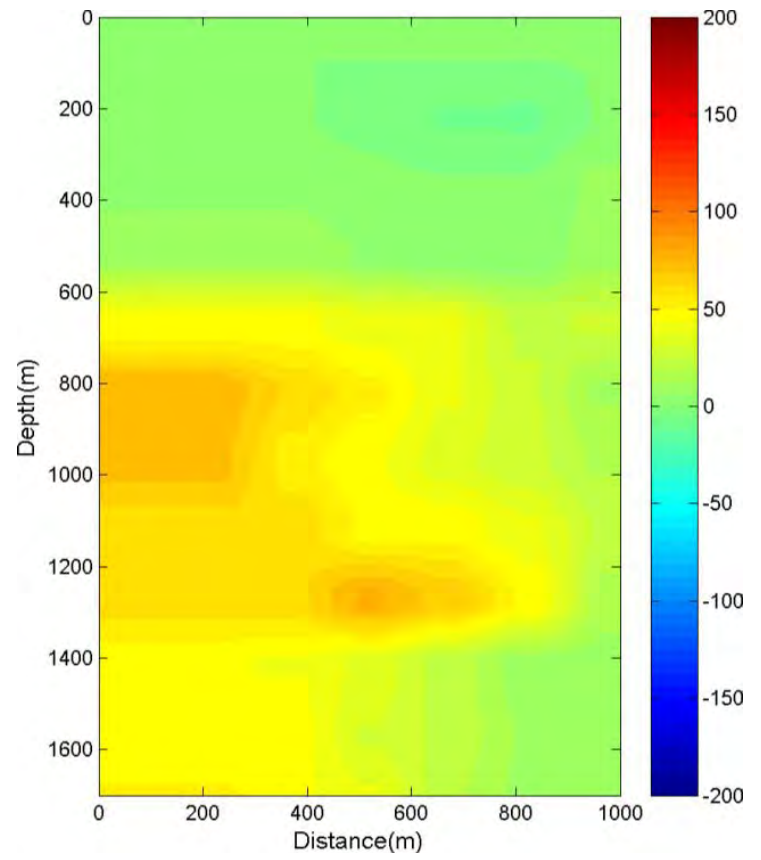

Offset 8

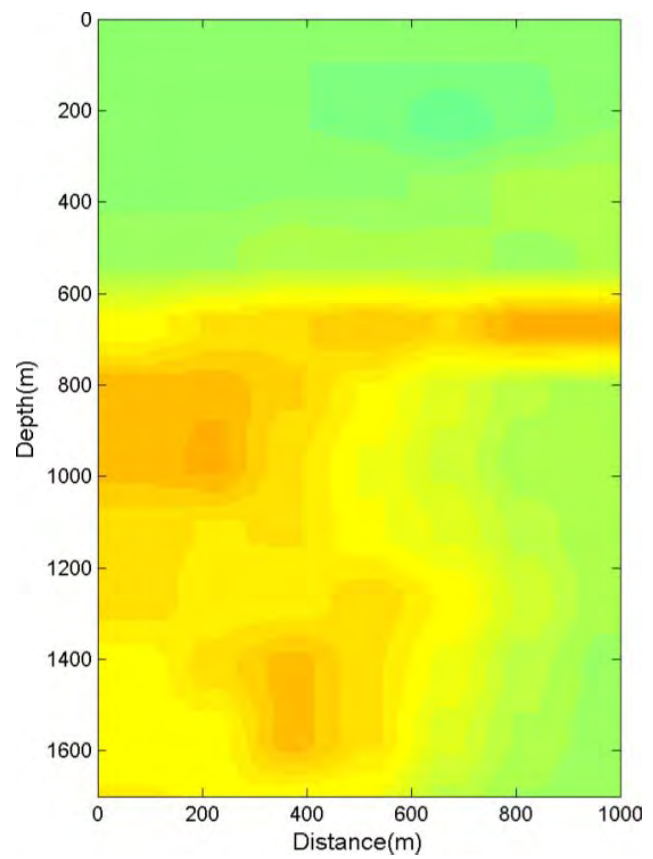

Offset 7

Figure 11-9. Double-difference tomography results of the velocity difference profiles between the monitoring well and the offset VSP source locations for the time-lapse offset VSP surveys at the Aneth oil field in Utah for monitoring $\mathrm{CO}_{2}$ injection. 


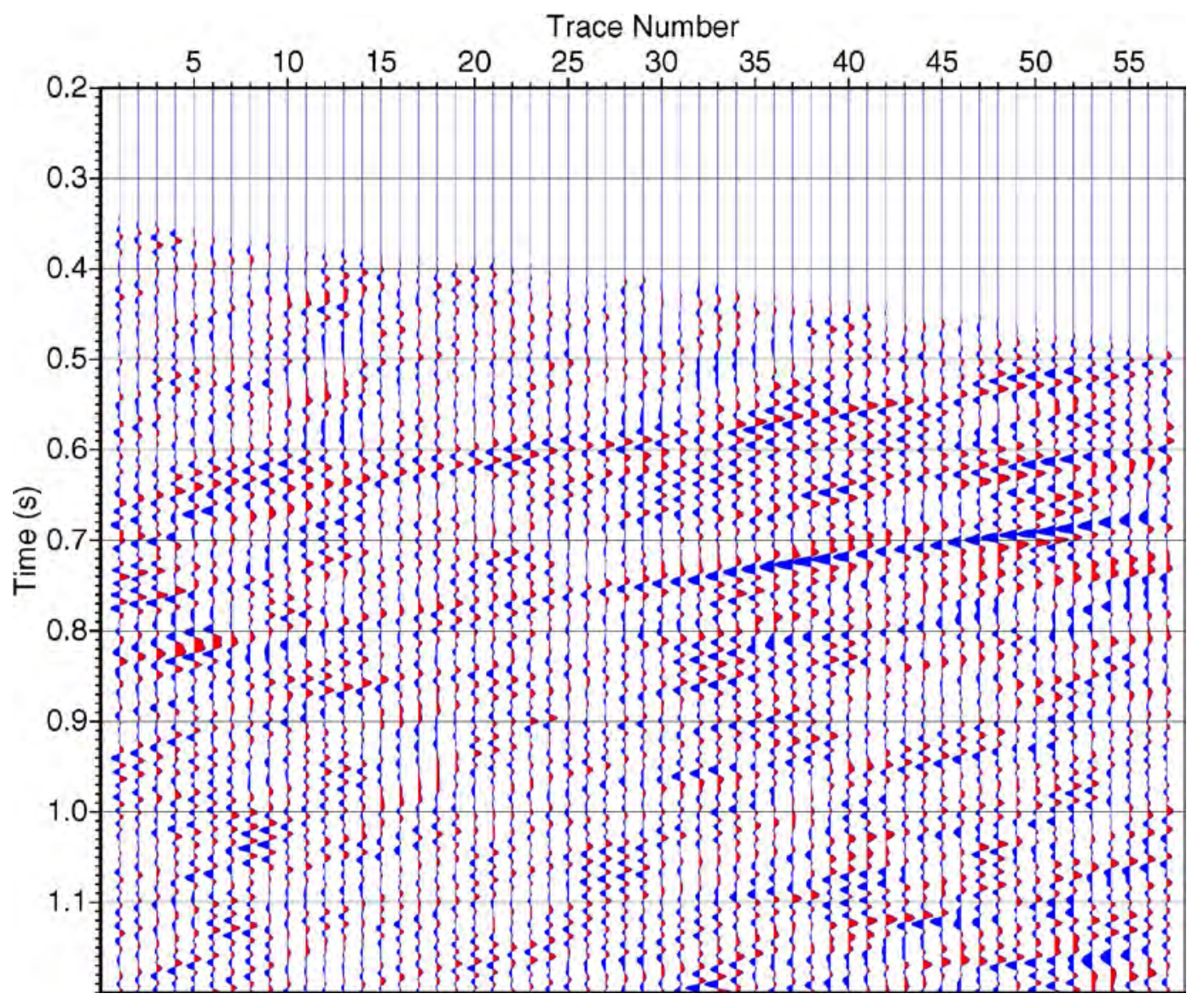

(a) Upgoing waves of baseline 2007 VSP data for Offset 6 


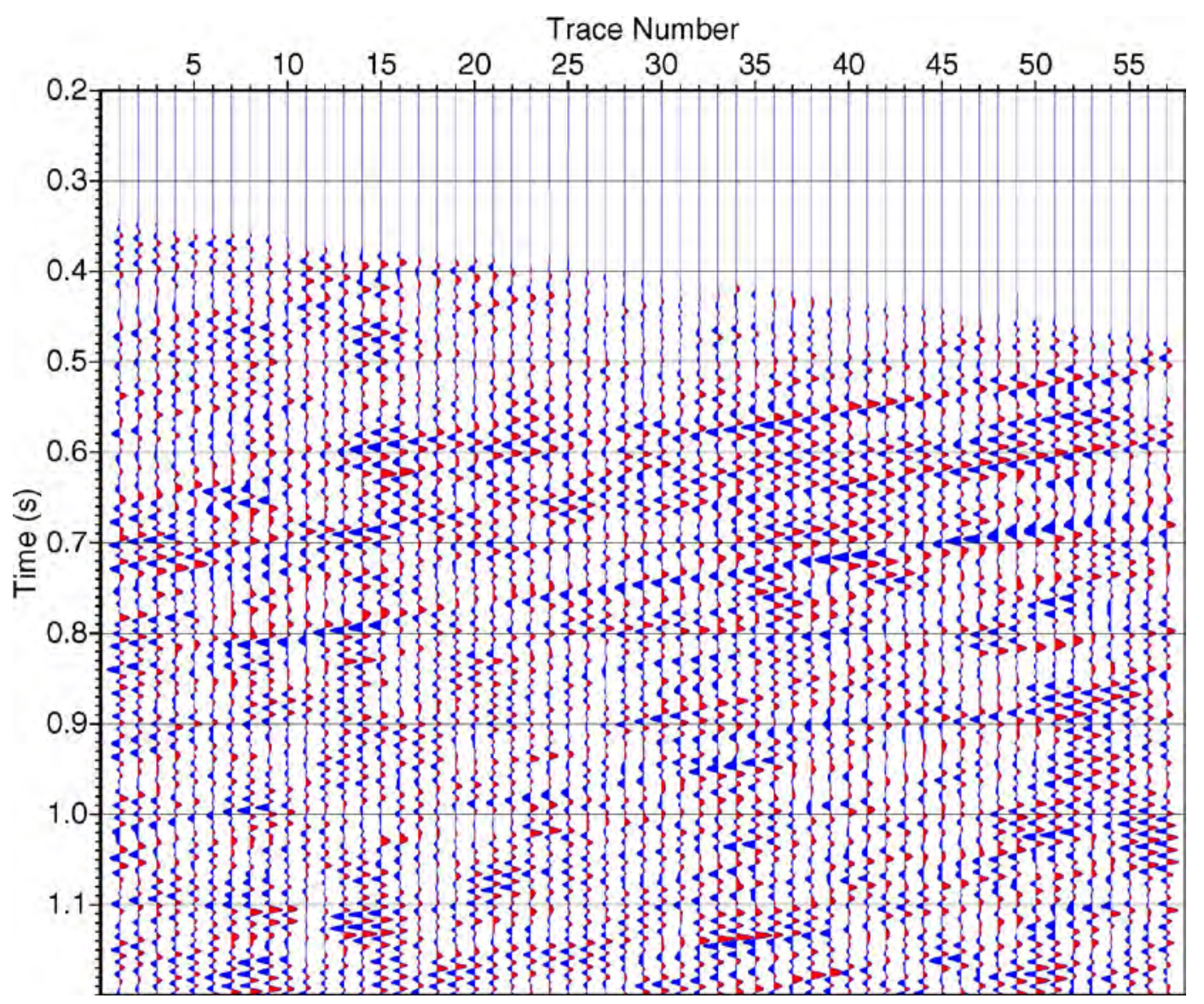

(b) Balanced upgoing waves of 2009 VSP data for Offset 6 


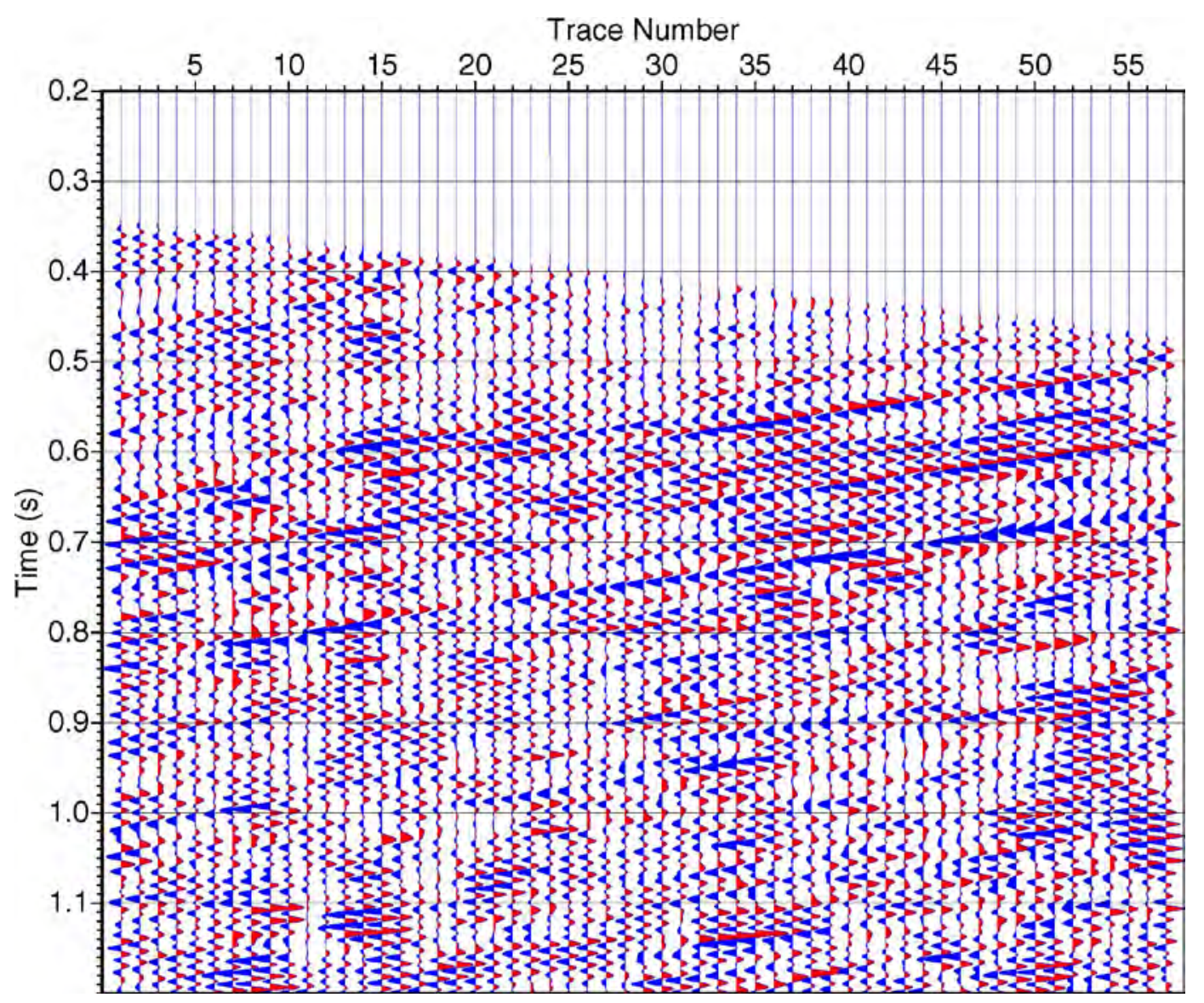

(c) Unbalanced upgoing waves of 2009 VSP data for Offset 6

Figure 11-10. Comparison among the upgoing waves of the baseline (2007) VSP data (a), the balanced 2009 VSP data(b) and unbalanced 2009 VSP data for Offset 6 (c). The amplitudes in (a) and (b) are more comparable to each other compared to the amplitude differences between (a) and (c). 


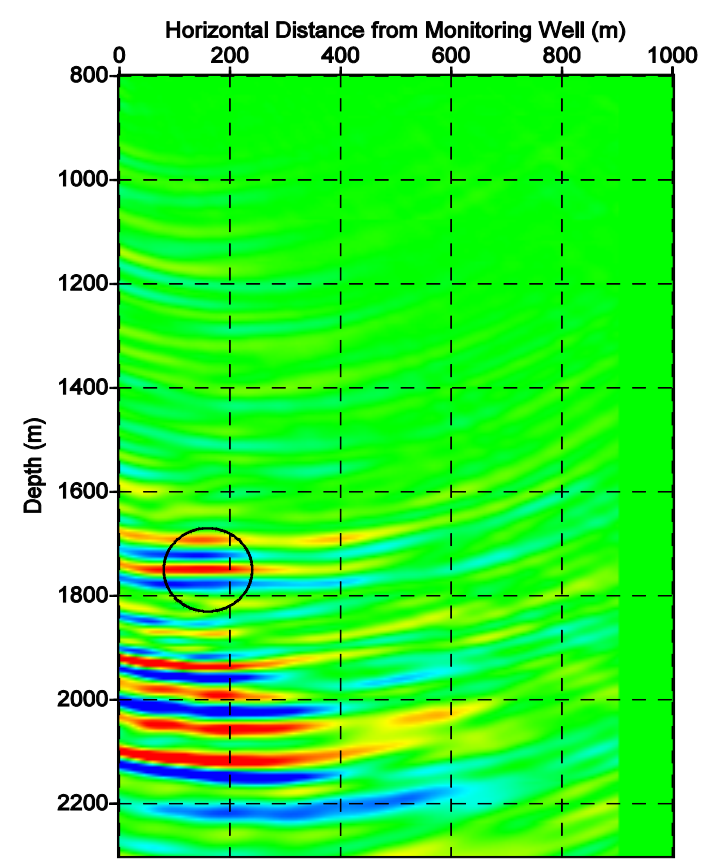

(a)

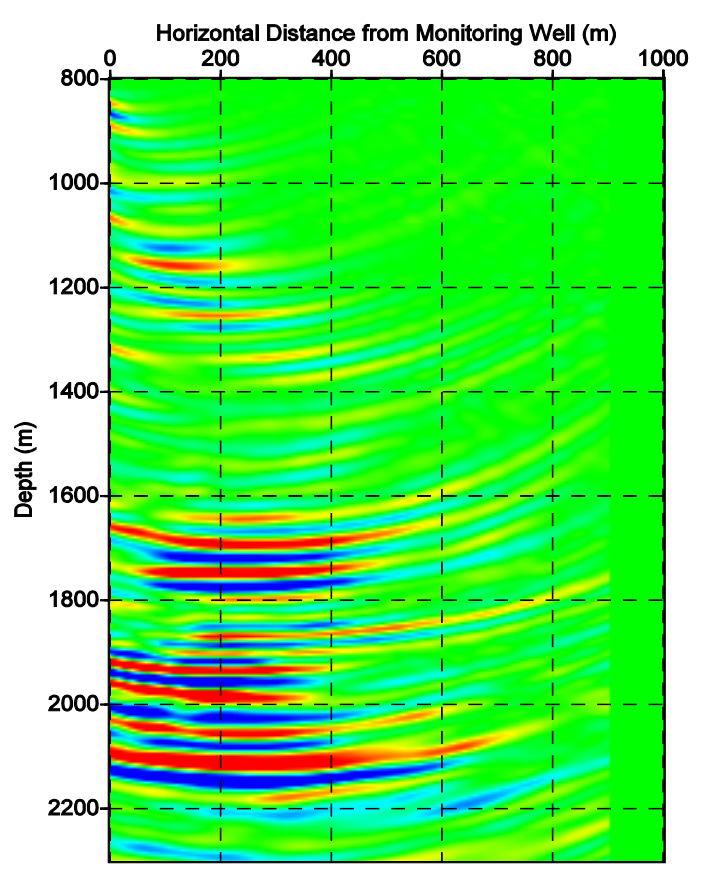

(b)

Figure 11-11. Comparison of the migration image differences (a) obtained from the balanced 2008 and 2009 offset VSP data for Offset 6 and those (b) from the original, unbalanced time-lapse data.

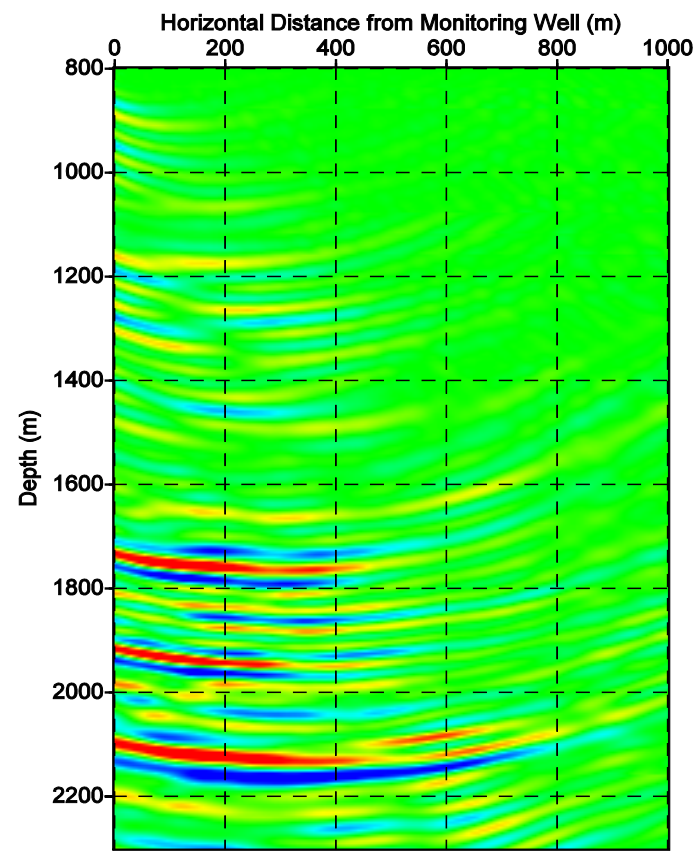

(a)

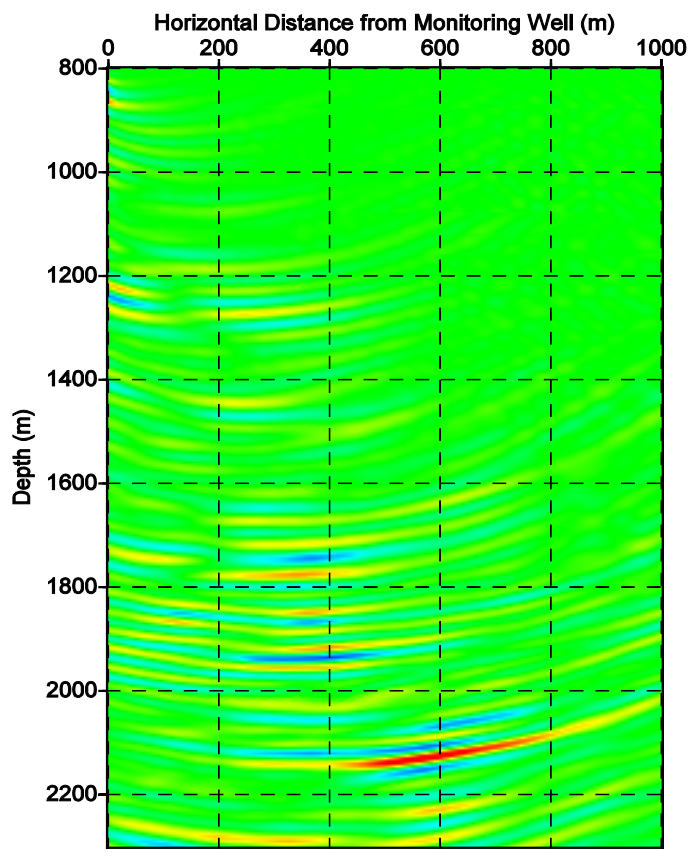

(b)

Figure 11-12. A wave-equation migration image of the upgoing waves of the 2009 VSP data for Offset 5 obtained using the tomography source offset (a) and its difference from the image obtained using the baseline source offset (b). 


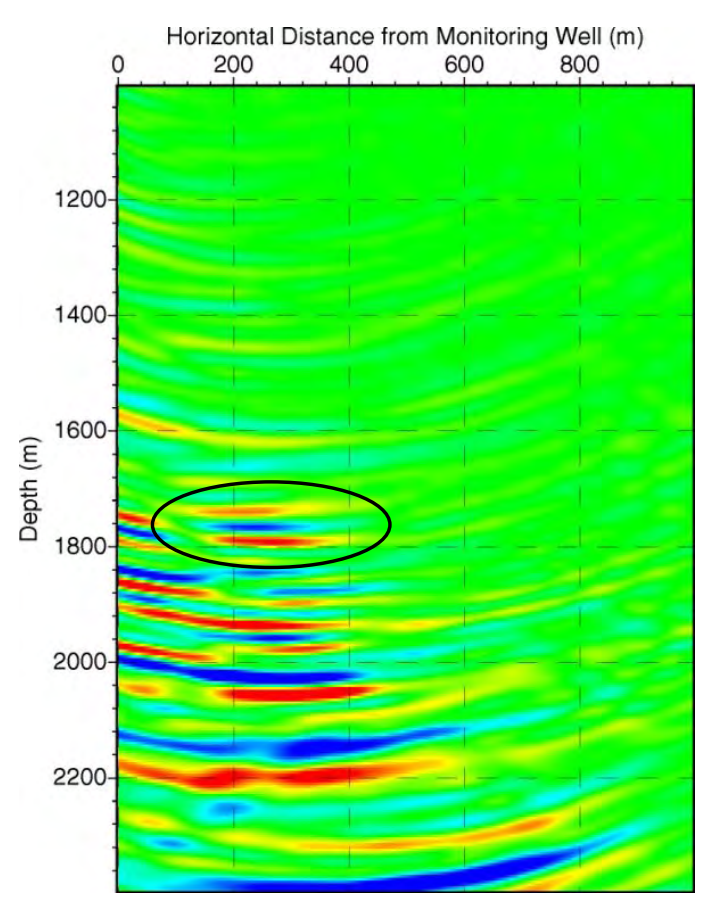

Offset 2: 2007-2008

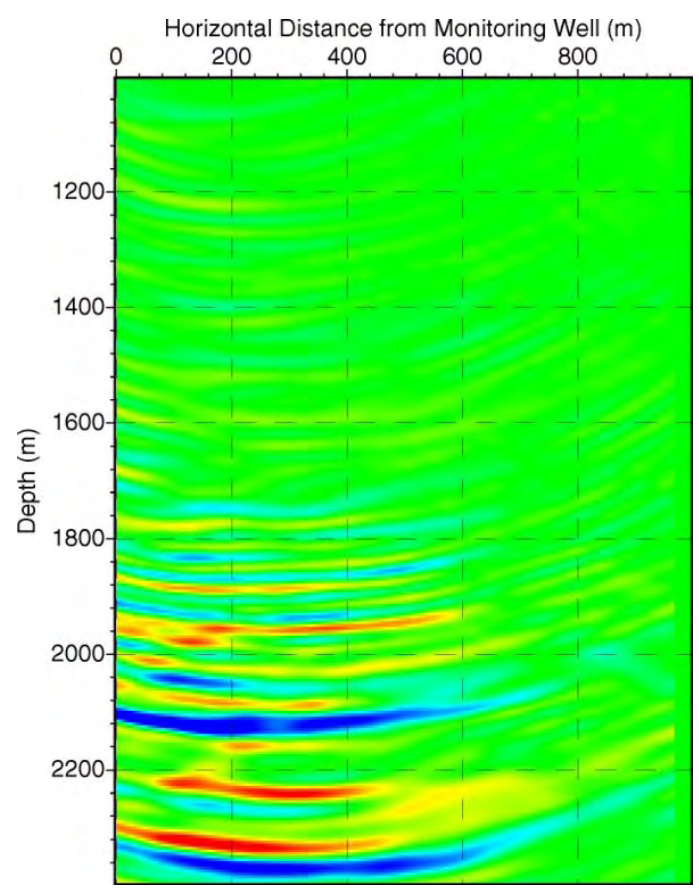

Offset 3: 2007-2008

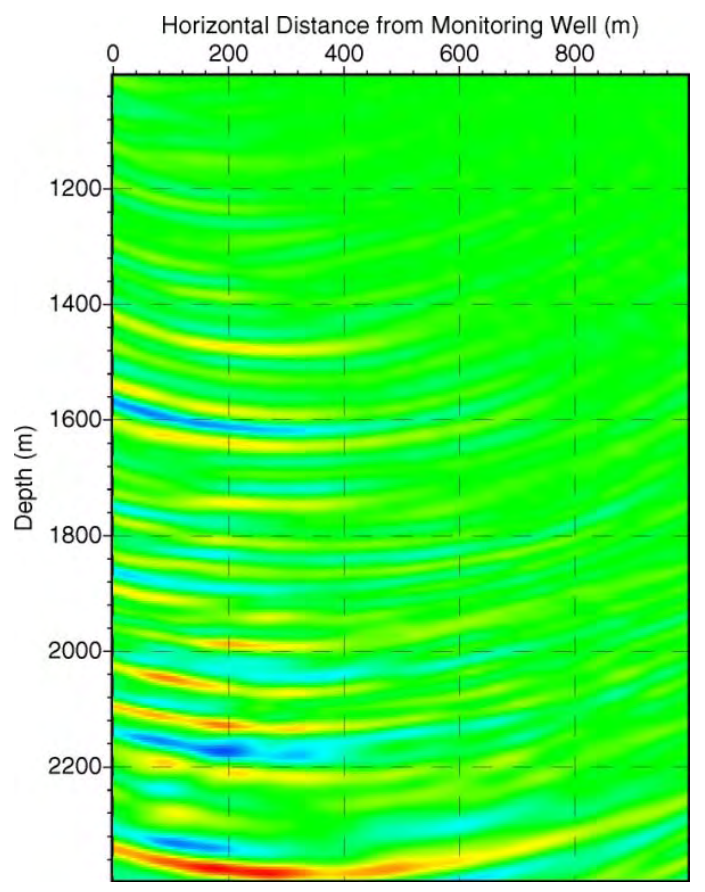

Offset 2: 2008-2009

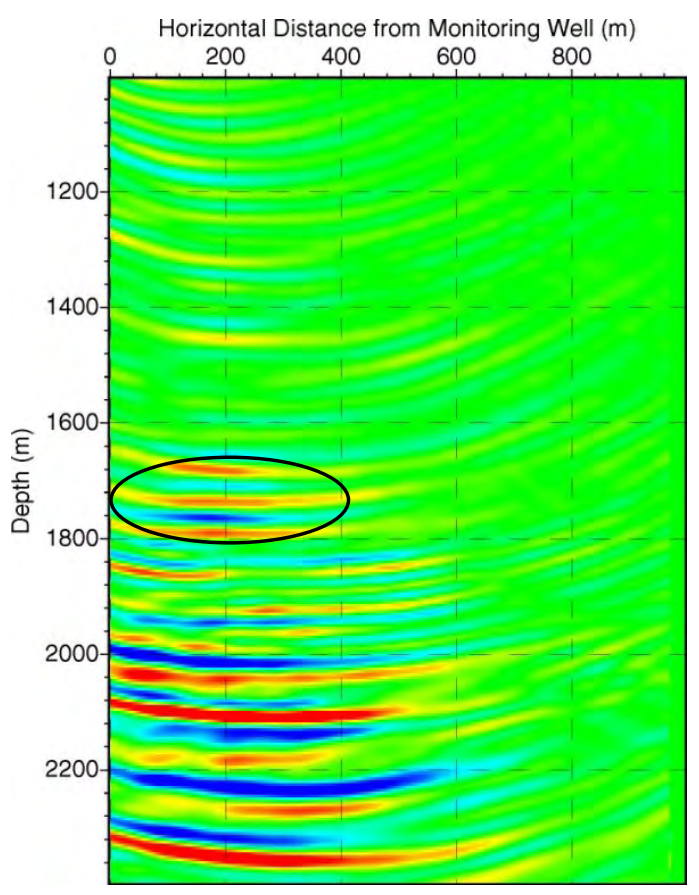

Offset 3: 2008-2009 


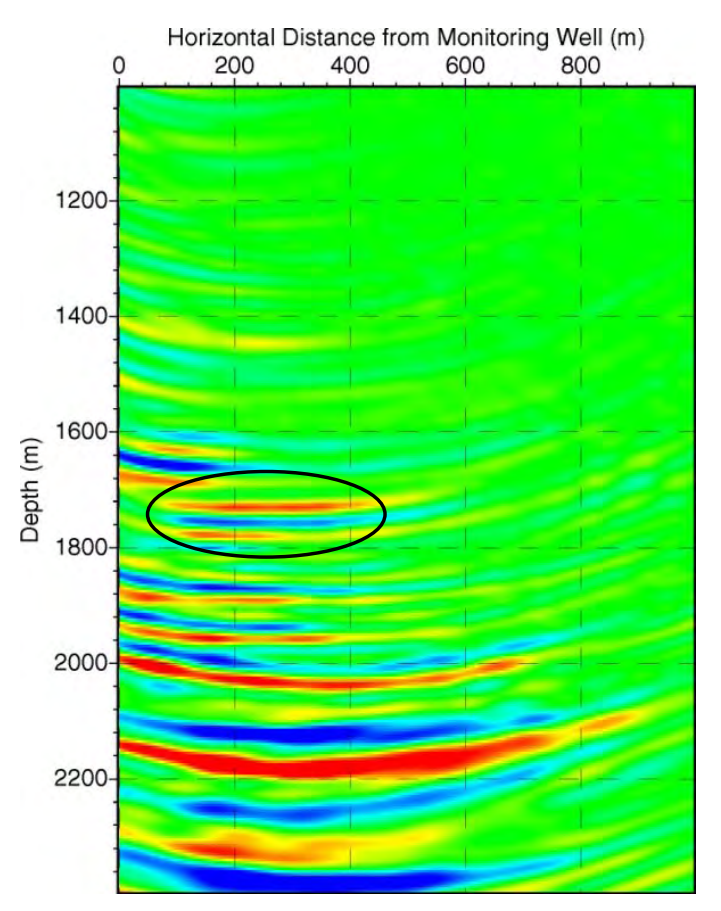

Offset 4: 2007-2008

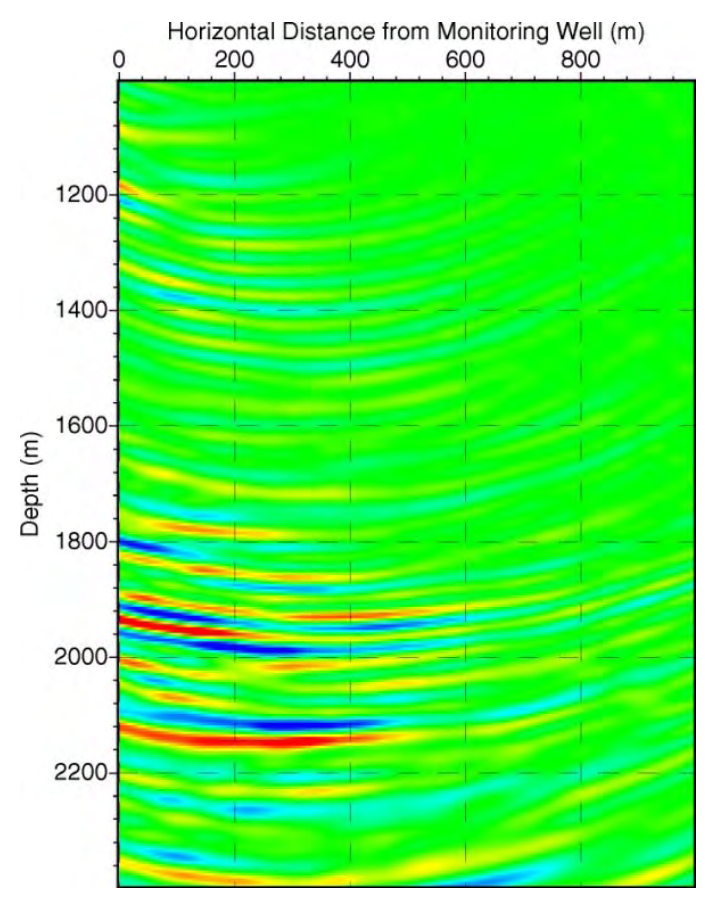

Offset 5: 2007-2008

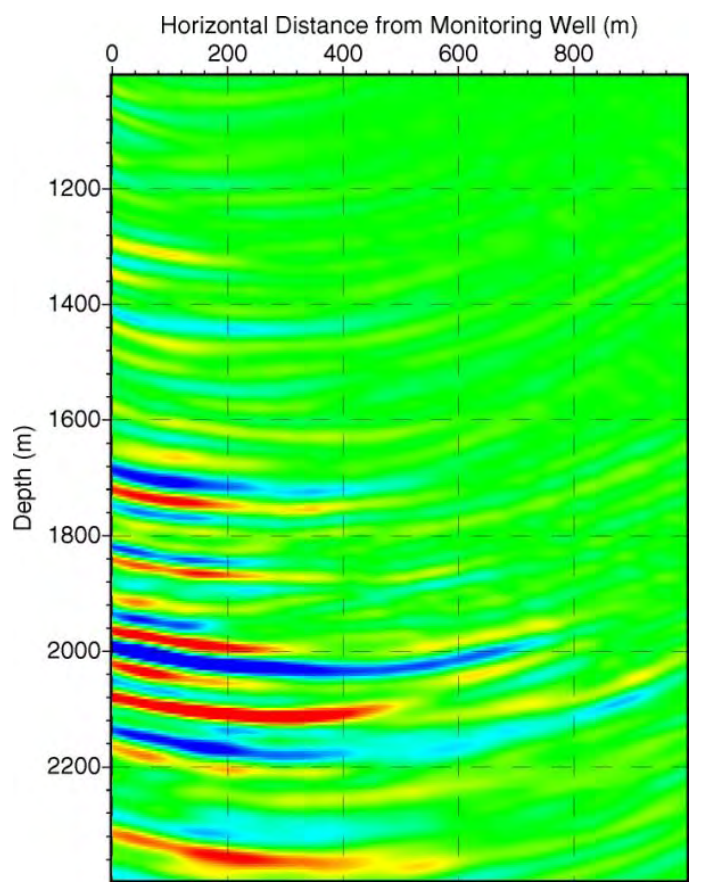

Offset 4: 2008-2009

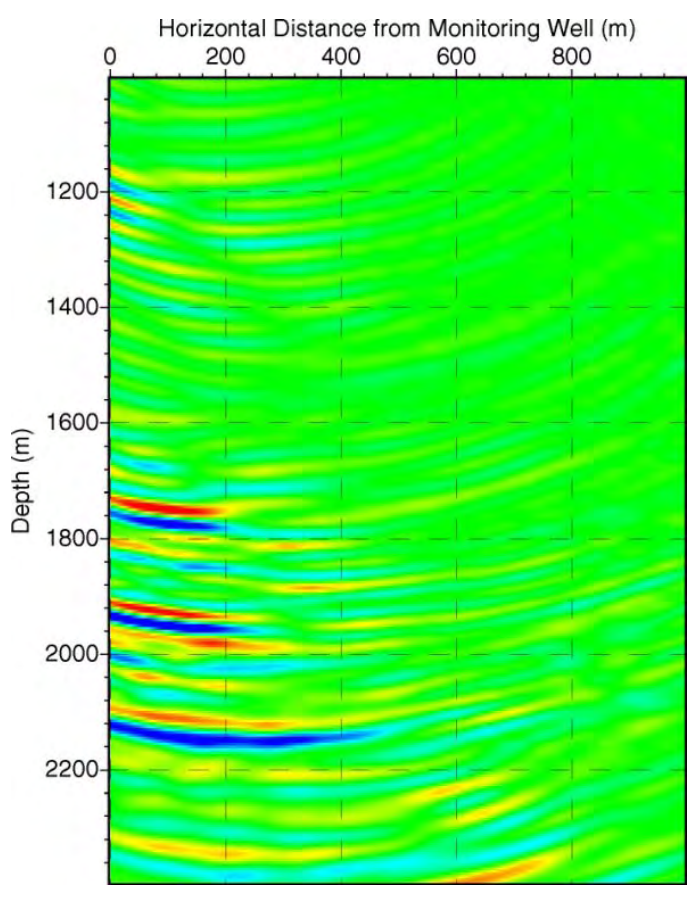

Offset 5: 2008-2009 


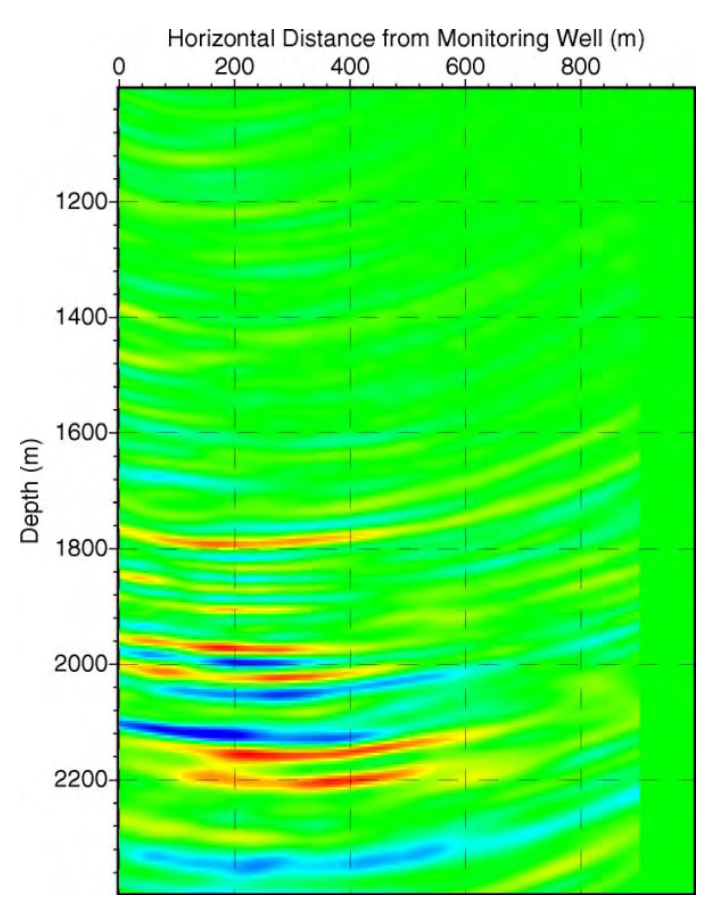

Offset 6: $2007-2008$

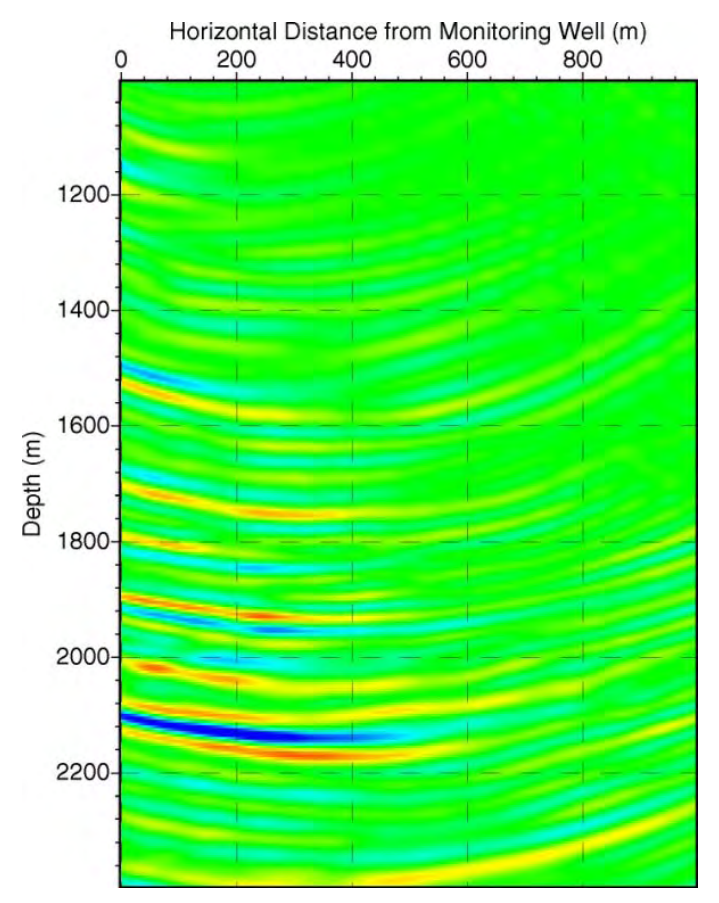

Offset 8: $2007-2008$

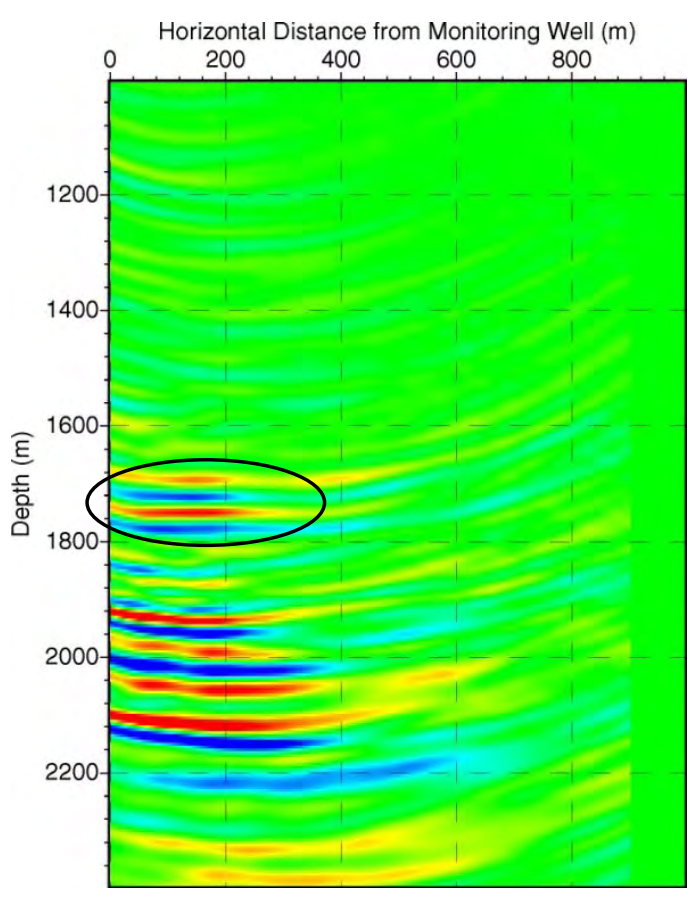

Offset 6: 2008-2009

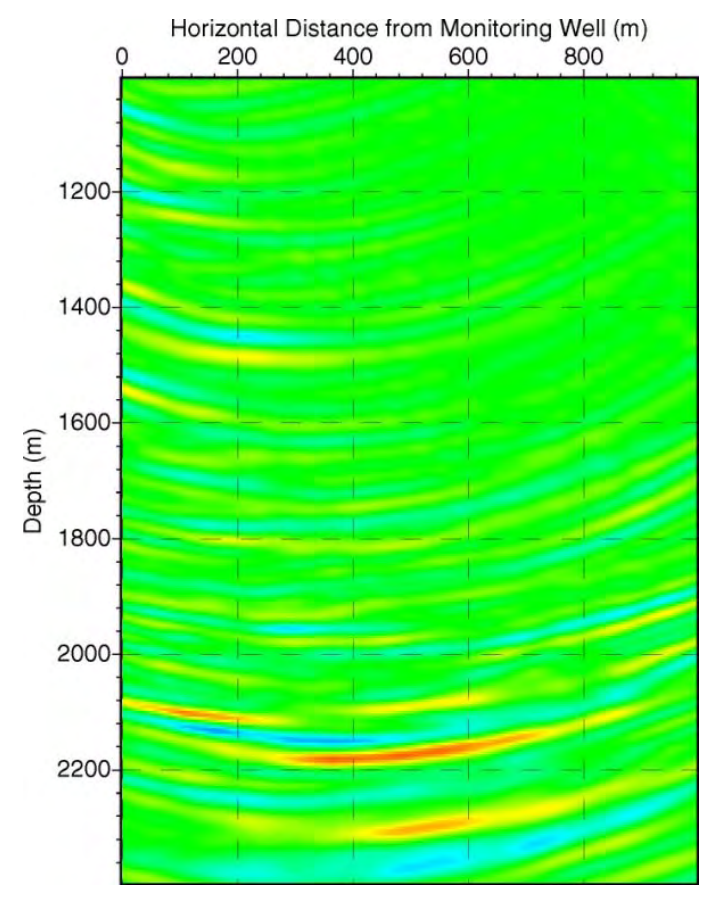

Offset 8: 2008-2009

Figure 11-13. The image profiles along the monitoring well and the offset VSP source locations show differences of migration results between 2008 and 2007 (left) and those between 2009 and 2008 (right) from Offset 2 to Offset 8. The areas in the ovals show significant changes in the reservoir. 


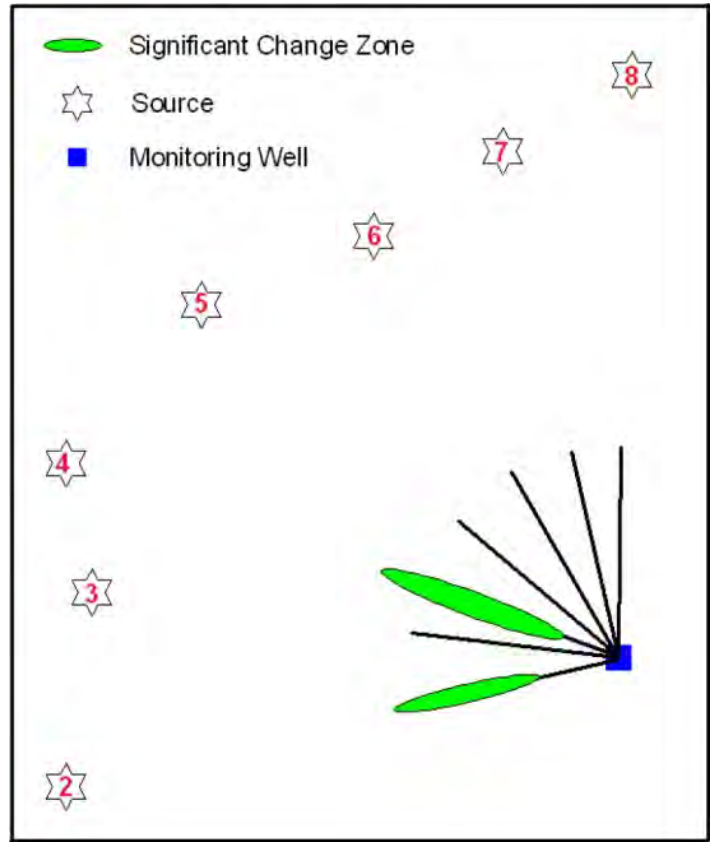

2007-2008

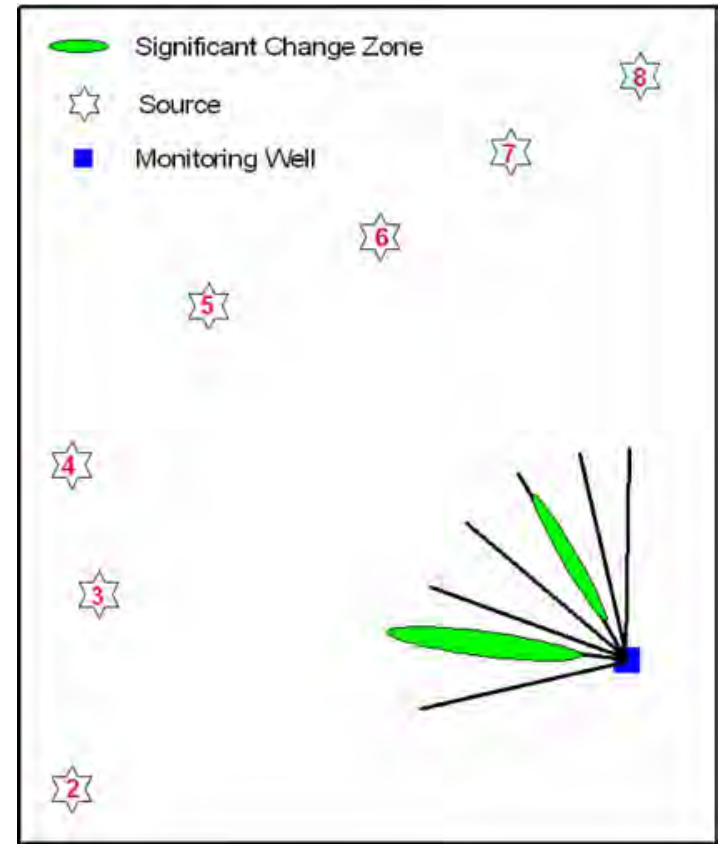

2008-2009

Figure 11-14. Illustration of the profiles along different offset VSP source locations with significant changes in migration images within the reservoir from 2007 to 2008 and from 2008 to 2009. 


\title{
CHAPTER 12 \\ MICROSEISMIC MONITORING OF $\mathrm{CO}_{2}$ ENHANCED OIL RECOVERY IN THE ANETH FIELD
}

\author{
by \\ James Rutledge and Nobukazu Soma* \\ Los Alamos National Laboratory \\ Geophysics Group \\ Mail Stop D443 \\ Los Alamos, NM 87545 USA \\ jrutledge@lanl.gov \\ *National Institute of Advanced Industrial Science and Technology, Japan
}

\begin{abstract}
We have monitored microseismicity during a $\mathrm{CO}_{2}$ enhanced oil recovery operation in the Aneth Unit of the Aneth oil field. A 60-level, 2950-ft-length (900 m) geophone array was cemented into a monitoring well with the deepest sonde placed about $90 \mathrm{ft}(27 \mathrm{~m})$ above the top of the oil reservoir. During the first year of monitoring approximately 3800 microearthquakes with moment magnitude ranging from -1.2 to 0.8 were detected within about 3 miles $(4.8 \mathrm{~km})$ of the geophone array. The events delineate two distinct structures active on opposite flanks of the Aneth Unit. Over $96 \%$ of events detected occur along a NW-SE trending fracture zone at least $5000 \mathrm{ft}$ long $(1500 \mathrm{~m})$ and located about $1100 \mathrm{ft}$ (335 m) beneath the oil reservoir, at a depth of $6950 \mathrm{ft}(2120 \mathrm{~m})$, near the top of the Leadville limestone. The time-space evolution of the seismicity and the seismic recurrence $(b$-value $=2$ ) suggest the structure is composed of a number of discontinuous fault or fracture segments. We found no clear or consistent correlations of the seismicity and moment release rates with injection and production rates in the study area. The high b-value of 2 suggest that the seismicity is not natural, tectonic seismicity and the source locations on opposite flanks of the Aneth Unit suggest it may be associated with stress changes driven by reservoir volume reduction over the fields 50plus-year production history.
\end{abstract}

\section{Introduction}

Microseismic monitoring will be a useful tool in $\mathrm{CO}_{2}$ sequestration projects for mapping pressure fronts, detecting and locating fault activation, and identifying potential leakage paths. Slip is likely to be induced on preexisting fractures or faults during $\mathrm{CO}_{2}$ injection as increased pore pressure reduces the effective normal stresses across such surfaces. Stress changes accompany larger-scale volume changes can also promote failure within or outside the target storage formations. Deployment of local seismic arrays should be required as part of the site evaluation efforts preceding $\mathrm{CO}_{2}$ injection and storage projects in order to characterize natural seismicity rates and magnitudes and for assessing the risk of inducing felt earthquakes. Evaluating seismic risk should also 
include measuring stress magnitude and orientations and identifying potentially affected faults via surface mapping and seismic imaging. Once injection operations start, monitoring and characterizing seismicity will be needed to understand the relationship of seismicity to injection and production operations, to evaluate the effect of pressure and stress changes on pre-existing structures, and, if required, to provide some feedback on efforts to mitigate felt seismicity such as changing rates and patterns of injection. On a smaller scale, monitoring microseismicity can be a useful reservoir management tool for delineating fracture flow directions and fracture orientations, and for characterizing the reservoir deformation induced as critical failure.

\section{Field Setting and Data}

Microseismic monitoring was conducted at Aneth from late 2007 through July 2009 using a vertical array of geophones deployed in a single monitoring well. The monitor well, C313SE, is located in the western portion of the Aneth Unit (Figure 12-1). C313SE had been previously plug and abandoned. The field operator, Resolute Natural Resources Company, re-opened the well to make it available for the permanent deployment of the geophone cable.

The Aneth field has been under waterflood injection for decades dating back to early 1960s (see Chapter 6). Monitoring was initiated as several square miles of the field were being converted from water to $\mathrm{CO}_{2}$ injection (Figure 12-1). Injection is fairly uniform across the study area with a regular, alternating pattern of injector and producing wells spaced at approximately $1320 \mathrm{ft}$ or $400 \mathrm{~m}$ (40-acre spacing). Oil is produced from the Pennsylvanian Desert Creek and overlying Ismay members of the Paradox formation (see Chapter 4). These carbonate strata were deposited on the southwestern flank of the Paradox evaporite basin, and are laterally equivalent to the more basinward anhydrites and salts (Peterson, 1966).

A salt-water-disposal well (SWD) was drilled to the Leadville formation approximately $1500 \mathrm{ft}$ beneath the oil reservoir and was completed with 4 laterals (Figure 1). With conversion to $\mathrm{CO}_{2}$ injection, the SWD well is needed to accommodate the produced water that is no longer re-injected into the reservoir. A sonic log over the vertical interval of the SWD was used to derive a one-dimensional (1D) P-wave velocity (Vp) model for locating the microearthquake sources (Figure 12-2). We discuss the shear velocities (Vs) below.

A 60-level geophone cable was built by VCable, LLC with sondes spaced at $50 \mathrm{ft}$ (15 m). The lower 18 levels were equipped with 3-component (3C) geophones. The upper 42 levels were vertical component only. On October 2 and 3, 2007 the cable was run in the hole tied to 2-7/8 inch production tubing and cemented into place. The geophones spanned from 2640 to $5590 \mathrm{ft}$ (805 to $1704 \mathrm{~m}$ ) in depth. The top of the oil reservoir at the monitor well is at $5681 \mathrm{ft}(1732 \mathrm{~m})$. The primary purpose of the geophone cable was for acquiring time-lapse vertical seismic profile (VSP) data (see Chapter 11), since it was unknown if there would be seismicity associated with or induced by the ongoing water injection or the start of $\mathrm{CO}_{2}$ injection. In between the VSP surveys, the array output was 
continuously monitored on a triggered acquisition system to detect and record discrete microearthquake events. A subset of 24 levels spanning the entire length of the array was used for the microseismic monitoring (Figure 12-2). The 3C geophones were oriented using 7 offset VSP source positions.

The microseismic acquisition system was based on a PC and was built by DAQ Systems of Bozeman, Montana. The system was installed on November 6, 2007. Outputs from selected channels across the array were monitored continuously to capture discrete events when transient signal levels exceeded some multiple of the background levels. The geophone outputs were sampled at $1500 \mathrm{~Hz}$. A satellite dish was also installed for remote control of the system and for uploading data. Initially we had problems with commonmode noise on the system and the satellite communications. Monitoring effectively started on March 14, 2008 when these problems were removed. Interestingly, we detected events as soon as the noise problem was fixed, so we do not know when the seismicity started or how long it may have been occurring before the monitoring began. Figure 12-3 shows the event count for about a one-year monitoring period, from March 14, 2008 to March 23, 2009 during which approximately 3800 microearthquakes were detected. Our analysis of the Aneth microseismic data is for this one-year period.

\section{Data Processing}

Figure 12-4 shows an example of waveforms for a high signal-to-noise ratio (SNR) microseismic event. The $\mathrm{P}$ and $\mathrm{S}$ phases tend to be impulsive and easy to identify. The events were initially screened by manually picking $\mathrm{P}$ arrivals on waveforms from just a few receivers. These waveforms were then clustered based on waveform similarity and re-picked using the methods of Rowe et al. (2002, 2004). The initial correlation performed on the full catalog provided a correlation matrix on which we operated with a hierarchical, agglomerative, dendrogram-based pair-group classification scheme (e.g., Lance and Williams, 1967). Following catalog clustering, we then apply an adaptive, coherency- weighted correlation method (Aster and Rowe, 2000; Rowe et al., 2002) to the waveforms in each cluster, to adjust initial picks for optimal consistency. Thirty seven clusters of similar events (multiplets) were identified in the process using a threshold correlation coefficient of 0.8 .

Correlated P picks were made on first arrival phases that could be consistently identified for all events regardless of SNR. Over the lower 8 or 10 stations the true first arrivals are weak and can only be observed on higher magnitude events. Figure 12-5 shows an example of enhancing the true first arrivals by stacking several multiplets. The weak arrivals at the base of the array correspond to ray paths critically refracted at the deeper Leadville formation (Figure 12-6).

We applied a simple master-slave location scheme to tie the weaker events to the first arrivals of the stronger events. From the event clusters, high SNR master events were formed by stacking multiplets or were chosen from a single large magnitude event of a multiplet group so that the true first arrivals could be reliably picked. For each master event the source locations (radial and depth positions with respect to the vertical receiver 
array) were determined using an iterative least-squares method to best fit all the $\mathrm{P}$ and $\mathrm{S}$ arrival times plus reflected SV phases (see below). The travel-time residuals for the master-event locations were then applied as station corrections to the remaining events of the respective clusters (slave events), while omitting the use of any arrivals from the lower 8 stations of the array.

Azimuths to the sources are determined from the horizontal-component P-wave particle motion trajectories. The particle-motion data from the cemented-in array were highly linear and consistent between receiver levels. For over 1400 events we obtained an azimuth by averaging over multiple receiver levels (up to 18 levels, on average 16 levels). Relative azimuth error was about $\pm 1^{\circ}$, measured as the standard error of the mean azimuth $(\sigma / \sqrt{ } n$, where $\sigma$ is standard deviation and $n$ is number of azimuths averaged).

\section{Source Locations}

The source locations are shown in Figure 12-7. Two isolated event groups were detected, both striking NW-SE and located on the flanks of the Aneth Unit. Over $96 \%$ of the events occur in the south group which delineates a fault zone about $5000 \mathrm{ft}(1500 \mathrm{~m})$ long. More poorly constrained locations (not shown) suggest the structure extends at least another $2500 \mathrm{ft}(750 \mathrm{~m})$ southeast, which may be the limit of detection range. The moment scalars, $M_{o}$, ranged from $1.5 \times 10^{7}$ to $1.5 \times 10^{10}$ Newton-meters. We used Hanks and Kanamori's (1979) scale, to compute moment magnitudes $M_{W}$, where $M_{W}=2 / 3\left(\log M_{o}\right)-6 . M_{W}$ for the located events ranged from -1.2 to +0.8 .

Relative errors are small particularly in depth and radial positions due to the precise or consistent arrival time picking obtain through the clustering and correlation of waveforms. The tight, clear linear resolution of the south group is the result of the precise mapping. Arrival time data errors were estimated for each station as the standard deviation of the residual misfit between the observed and computed arrival times. On average P- and S-pick errors were about $0.3 \mathrm{~ms}$. These data error were used to compute the relative location errors. Table 12-1 summarizes the average relative errors and RMS residual misfits for the south and northeast groups. Errors in estimating azimuths obtained from the particle motion data, though on average $<1^{\circ}$, result in the largest component of the relative location error when translated over the large receiver-source distances. The width of the south lineament can be entirely attributed to azimuth error. The smaller northeast group appears to have a similar strike, but is poorly constrained since azimuth error in this case will exaggerate its NW-SE extent.

\begin{tabular}{|c|c|c|c|c|}
\hline & $\begin{array}{c}\text { Azimuthal Error } \\
( \pm \mathrm{ft})\end{array}$ & $\begin{array}{c}\text { Radial Error } \\
( \pm \mathrm{ft})\end{array}$ & $\begin{array}{c}\text { Depth Error } \\
( \pm \mathrm{ft})\end{array}$ & $\begin{array}{c}\text { Mean } \\
\text { RMS residual } \\
(\mathrm{ms})\end{array}$ \\
\hline South Group & 53 & 25 & 11 & 0.63 \\
\hline Northeast Group & 214 & 23 & 8 & 2.61 \\
\hline
\end{tabular}

Table 12-1. Median relative source location errors for the two major groups and the mean RMS residuals. Radial direction is the horizontal component of the receiversource trajectory. Azimuthal error is normal to the radial direction. 
Absolute location errors are mostly affected by uncertainty in velocities, are more difficult to estimate and are usually much larger than relative errors. Because the microseismicity occurs at relatively large distances from the geophone array, the long, low-angle travel paths can be complex and the constraint of source depths are highly dependent on the velocity model and model uncertainty. To date, we have taken a simple approach to constrain the model and the source depths. Using the 7-layer Vp model shown in Figure 12-2, we kept Vp fixed and solved for Vs by searching over range of $\mathrm{Vp} / \mathrm{Vs}$ ratios, kept fixed over all layers. Figure 12-8 shows the results for the south group in which the RMS residuals shows a clear minima (best fit of data to model) for $\mathrm{Vp} / \mathrm{Vs}=$ 1.625. Vp/Vs also strongly affect the computed source depths. Using only P- and S-wave direct arrivals, the best fit model indicates the active structure is about $750 \mathrm{ft}(230 \mathrm{~m})$ below the oil reservoir (Figure 12-8).

Depths for the more distant group to the northeast are poorly constrained. As shown on right hand side of Figure 12-8, the RMS residuals do not show a clear minimum while the source depth is also highly dependent on $\mathrm{Vp} / \mathrm{Vs}$. The source locations for the northeast group shown in Figure 12-7 were computed using the same best-fit $\mathrm{Vp} / \mathrm{Vs}$ for the south group, which places the seismicity within or close to the oil reservoir. However, from Figure 12-8, depth of northeast cluster could be within or up to $1000 \mathrm{ft}$ (300 m) above the Desert Creek reservoir.

We have also used multiple reflected phases to help constrain the depth locations. Using reflected phases can in effect lengthen the aperture of the vertical array and help constrain source depths. To identify reflected arrivals, we used $\mathrm{R} * \mathrm{Z}$ analysis which is product of vertical and radial components. For inclined wave paths, $\mathrm{R} * \mathrm{Z}$ shows \pm peaks corresponding to arrivals of plane wave such as $\mathrm{P}$ and SV because amplitude of $\mathrm{R}$ and $\mathrm{Z}$ component increase together at these wave onset. Since the 3C geophone sondes at Aneth have right hand three-dimensional coordinate system (that is, $\mathrm{Z}$ signal is positive for a compression arrival from above), $\mathrm{R} * \mathrm{Z}$ will show negative peaks for the upward traveling reflected arrivals of $\mathrm{P}$ waves and positive peaks for that of SV waves.

An example of this analysis is illustrated in Figure 12-9.On the left are the forward calculated ray paths for two SV multiple-reflection paths occurring at the top of the salt and base of the salt (red paths) and top of the salt and top of the Leadville (yellow paths). The center display of Figure 12-9 shows the $\mathrm{R} * \mathrm{Z}$ traces and the corresponding computed arrivals times of these reflections and the right hand side shows an example of the synthetics radial traces computed for the velocity model of Figure 12-2. The model for the synthetic case does not include any density contrast, just velocity. The synthetics at least match the early (red paths) reflection from within the salt layer. Reflected phases along with the $\mathrm{P}$ and $\mathrm{S}$ arrivals were used to determine the best absolute locations of the master events, which were then tied in a relative sense to the remaining (slave) events using $\mathrm{P}, \mathrm{S}$ and S-minus-P travel times. Using the reflected phases moved the south group, on average, about $340 \mathrm{ft}(104 \mathrm{~m})$ deeper and $140 \mathrm{ft}(43 \mathrm{~m})$ westward. The match confirms the source depths to be close to the top of the Leadville formation. Using the same $\mathrm{Vp} / \mathrm{Vs}$ 
model, a similar analysis applied to the more distant northeast cluster indicates the source depths are near the base of the Desert Creek (Figures 12-7 and 12-10).

\section{Interpretation}

The seismicity has revealed two NW-SE striking fault zones on the flanks of the Aneth Unit. There is no evidence of the seismically active structures from the 3D seismic shot over the field, and hence, they must have little historical vertical displacement. The seismicity does not appear to be associated with $\mathrm{CO}_{2}$ injection in the oil reservoir. $\mathrm{CO}_{2}$ injection is fairly uniform across the study area, whereas the seismic activity is isolated along two structures, with the main cluster to the southeast ( $96 \%$ of all events) occurring approximately $330 \mathrm{ft}(110 \mathrm{~m})$ below the oil reservoir near the top of the Leadville (Figures 12-7 and 12-10). The best depth locations on the more distant northeast cluster may be in the reservoir, but there is no anomalous injection activity occurring there. In both cases the seismicity is occurring near the boundaries of the salt layer. From a linear regression of the event coordinates, the main cluster of seismicity has a strike of $308^{\circ}$.

\section{Tectonic Setting}

The Aneth field is within the Paradox Basin located within the eastern Colorado Plateau of southeast Utah. A recent 3D seismic survey collected over the entire Aneth Unit shows basement faults of Mississippian and Pennsylvanian age striking northwestsoutheast (Michael Tryggestad, Resolute Natural Resources, pers. comm., 2010), consistent with the prevalent structural fabric of the region (e.g. Figure 1-1). Natural seismicity on the Colorado Plateau occurs at low to moderate rates and magnitude levels. Most of the seismicity is thought to be associated with reactivated basement faults that lack surface expression and are favorably oriented with contemporary tectonic stresses (Wong and Humphrey, 1989). The current state of stress within the Plateau is northeast oriented extension (Wong and Humphrey, 1989) in contrast to previous studies that claimed a regime of west-northwest directed compression (Zoback and Zoback, 1980), Regional principle horizontal stress direction is northwest-southeast (Heidbach et al., 2007).

Ake et al. (2005) have monitored and studied induced seismicity associated with deep brine injection in the Paradox Valley, Colorado, located on the eastern Colorado Plateau, $115 \mathrm{~km}$ NNE of the Aneth study area. The injection target in the Paradox Valley is the Mississippian Leadville Limestone, the same formation used for salt water disposal beneath the Aneth field. At Aneth, the Leadville is approximately $2.3 \mathrm{~km}$ deep; at the Paradox Valley injection site it is $\sim 4.3 \mathrm{~km}$ deep. Mean salt-water disposal rates at Aneth $(1100 \mathrm{~L} / \mathrm{min}$ ) are comparable to injection rates at the Paradox Valley (800 to 1300 $\mathrm{L} / \mathrm{min}$ ). Seismicity induced during continuous injection since 1996 at the Paradox Valley site outlines distinct linear zones contained mostly within the target Leadville interval. Focal mechanism analyses reveals primarily strike slip faulting. Principle horizontal stress direction estimated from the focal mechanisms and borehole breakout data is $\sim 290^{\circ}$ $\pm 10^{\circ}$. Most of the Paradox Valley focal mechanisms form two distinct strike-slip fault plane populations with $86 \%$ striking $266^{\circ}$ and the secondary set at $311^{\circ}$, both of which 
have large resolved shear with respect to the estimated principle stress direction. If stresses are similarly oriented at Aneth, then the lineament outlined by the main group, striking at $308^{\circ}$, would also represent a fracture zone favorably oriented for shear (strikeslip if vertical or normal faulting if dipping to the NE or SW).

\section{Space Time Development of the Seismicity and Microearthquake Recurrence}

Figure 12-10 shows the space-time development of the south event group. The events density and moment release is clearly highest between 1200 to $2000 \mathrm{~m}$ from the monitor well where the seismicity is highly repetitive and, over periods of a few days, shows no clear patterns of temporal migration. Instead, the structure is at once active along this entire 800-m length. The abrupt termination or reduction of seismicity at 1200 and $2000 \mathrm{~m}$ may be associated with structural discontinuities such as cross-cutting faults or fracture zones striking NE-SW (Figure 12-10). Interestingly, the Utah Geological Survey suggested a possible NE striking fault about $300 \mathrm{~m}$ from the northwest termination of the seismicity based on structural contour irregularities at the top of the Desert Creek and core analysis that revealed fracturing and other evidence of faulting in a nearby well (see Chapters 3 and 4 and Figure 3-6). No structural evidence of this northeast-striking fault appears in the overlying DeChelly and Navajo Sandstones, and therefore, it is likely a localized structure with minimal displacement.

The temporal pattern of seismicity is enlarged in the lower portion of Figure 1210 to show greater detail. Here the larger magnitude events $\left(M_{W}>0\right)$ are highlighted in red and occur near gaps in the seismicity, suggesting that the structure is made up of discrete segments, perhaps as en echelon jogs where stress would tend to concentrate near discontinuities. We can only speculate on such substructures, however, since the singlewell array geometry and large source-receiver distances prevent further resolution.

The recurrence or the magnitude distribution of the seismicity can be represented by the Gutenberg-Richter law, $\log N=a-b M$ where $N$ is the number of events having a magnitude $\geq M$, and $a$ and $b$ are constants (Gutenberg and Richter, 1954). Figure 12-11 is the graphical representation of the recurrence for the south group of seismicity, showing the number of events exceeding a given $M$. The roll off in $N$ going to lower magnitudes represents the detection threshold, which is in part limited by the nearest events being about $1 \mathrm{~km}$ from the monitor well for this data set. From the slope fit, shown as the red line, we computed a $b$ value of 2.0 (Figure 12-11). $b$ values for tectonic seismicity are typically close to 1 and do not vary much from region to region. A value of 1 indicates, for example, that for every magnitude 3 event, there will be 10 magnitude 2 events, 100 magnitude 1 events, etc. The high b-value of 2 for Aneth is characteristic of fluidinjection induced seismicity and natural swarm seismicity and indicates a higher proportion of small events to larger ones. Unlike tectonic seismicity, there is no distinct main shock followed by a series of aftershocks. Natural swarm seismicity typically precedes volcanic eruption or is associated with migration of crustal fluids through fracture networks (Lay and Wallace, 1995). The population of earthquakes dominated by small events is generally considered an indication of many small, discontinuous faults 
accommodating strain accumulation, consistent with our interpretation of the time-space development illustrated in Figure 12-10.

\section{Correlations of Seismicity with Injection and Production}

We have looked for possible correlations of event occurrence with the rates of the various fluid injection and production in the study area. Figure 12-12 shows a comparison of cumulative seismicity and volume changes within the Desert Creek reservoir from well data within about $1 \mathrm{~km}$ of the two active structures for a two-year period. $\mathrm{CO}_{2}$ injection started about 200 days before seismic monitoring, and no meaningful correlation can be discerned over the common period of injection and monitoring (Figure 12-12, left side). The right side of Figure 12-12 shows the sum volumes of water and $\mathrm{CO}_{2}$ injected. The conversion from water to $\mathrm{CO}_{2}$ injection is fairly smooth during which there is little change in gross injection rates. Further, the net volume change, subtracting the oil and water produced from injected volumes, are very small (Figure 12-12). These areas of the field are not anomalous; gross volume changes Unit-wide during the conversion to $\mathrm{CO}_{2}$ injection did not vary much over the one-year period of this study. Pressure changes near injectors may initially drop with introduction of $\mathrm{CO}_{2}$ since it is a more compressible fluid, and thus, tend to inhibit seismicity. Further, reservoir microseismicity may be largely absent in $\mathrm{CO}_{2}$ EOR operations in general since, as in the case of Aneth, $\mathrm{CO}_{2}$ injection is usually preceded by decades of water injection. Strain energy along preexisting fractures may be largely released during the preceding years of sustained pressure recovery and maintenance.

The most significant change of injection rates at Aneth during monitoring was the initiation of SWD in the Leadville formation beneath the reservoir. The main cluster of seismicity (the south group) occurs at or close to the Leadville depth, but the seismicity is isolated at least $1200 \mathrm{~m}$ from the nearest leg of the SWD well (Figure 12-7). In Figure 12-13 we compare the moment release and the injected salt water volumes, each summed over one-week periods. If the seismicity is being driven by volume changes, the summed moment release (proportional to deformation induced) should be proportional to the summed volumes injected. Interestingly, when looking at both event groups (Figure 1213a), the moment release is greatest early on when injection rates were highest. However, the curves do not track well after day 625, particularly when injection rates drop sharply after day 700, where the moment release remains stable. Unfortunately, the correlation is also difficult to interpret or lend significance to since we were not monitoring before the SWD began. Further, the high moment release early on is mostly due to the northeast group (Figure 12-13b) which is over $3 \mathrm{~km}$ from the nearest leg of the SWD well and isolated above the Leadville injection interval by the intervening salt layer (Figure 12-7). Of course, if the seismicity was related to the pore-pressure changes caused by the SWD, one would expect the seismicity to occur in the immediate vicinity of the SWD, where pressure would be most elevated.

Although we have only detected about 70 events on the northeast structure, because the magnitudes are larger, it should be the more seismically active fracture zone based on the Gutenberg-Richter law discussed above. Because the monitor well is located 
over 2.5 miles ( $4 \mathrm{~km}$ ) from the northeast group, the greater population of small magnitude events is out of detection range. Figures 12-13b and 12-13c are displays of the moment release and event counts for the two groups separately. The northeast group became quiescent from approximately day 550 to day 750 (Figure 12-13b).

Finally, we examined a possible correlation of both oil production and nearreservoir seismicity responding to a M3.7 earthquake that occurred on June 6, 2008 at 2:10 PM local time. The source location was 7 to 8 miles (11 to $13 \mathrm{~km}$ ) northwest of the Aneth Unit (Figure 12-14) with a hypocenter depth estimated at $9.5 \mathrm{~km}$ (Kristine Pankow, Universty of Utah, pers. comm., 2010). A few days after the earthquake both production and the local seismic moment release (proportional to seismic deformation) showed increases sustained over a period of about 2 weeks. There are numerous documented cases of distant earthquakes affecting subsurface fluid production, although the mechanisms and cause-effect relationships are not well understood (Beresnev and Johnson, 1994). One could speculate that in this case a static stress transfer may have locally elevated pore pressure enhancing production and further promoting the nearreservoir seismicity already occurring. However, we believe these changes following the local earthquake may simply be a coincidence. Moment release and event counts near day 475 (April 21, 2008), preceding the M3.7 event, are comparable to the amounts following the earthquake, and there is a much larger production increase from about day 675 to 730 (Nov 5 to Dec 30, 2008) with no corresponding change in the local, microseismic moment release. Further, no correlation is evident between local moment release and the gross oil production rates from the western half of the Aneth Unit (Figure 12-14).

\section{Concluding Remarks}

Our attempts at trying to correlate the seismicity with fluid volume changes are ambiguous and inconclusive. The problems may stem from a monitoring period that is too short, and a production/injection, stress-change history of more than 50 years that preceded this study. Further, correlations in general do not necessarily imply cause-effect relationships and may simply be an indication of processes weakly coupled to some common cause. For example, SWD is tied to reservoir production rates, and seismicity and fluid volumes produced will both be affected by pore pressure changes. Interestingly, Ake et al. (2005) found no clear correlation with event occurrence and injection rates in the Paradox Valley study for a continuous 8-year monitoring period except when looking at a small subset of events near the injector. But they were able to correlate event onsets with downhole pressure thresholds.

The high b-values suggest that the seismicity is not natural tectonic seismicity and source locations on opposite flanks of the Aneth Unit suggest it may be induced by some stress changes associated with the field's 50-plus year history. Segall (1989) and Segall and Fitzgerald (1998) have shown that normal faulting can be promoted on the flanks and outside of a reservoir due to poroelastic contraction of the reservoir. The case studies of induced seismicity that they associate with their model involve pressure depletions of $10 \mathrm{~s}$ of MPa over decades of sustained production. As a result, small stress changes on the order of $1 \%$ of the reservoir pressure drawdown can occur outside of the reservoir where 
no pore volume changes occur. Such small stress changes could only promote failure on pre-existing, critically stressed structures. Large pressure depletion does not provide a driving mechanism for the Aneth case, where reservoir pressure has been sustained through years of waterflood production, but perhaps some other mechanisms, such as thermoelastic contraction caused the long-term water injection, could be invoked to explain the seismicity observed.

\section{Acknowledgment}

We thank Michael Tryggestad of Resolute Natural Resources Company for his help in coordinating this Project and providing all the supporting well log data and the production and injection data. We thank Matt Roberts, Donnie Trimble, and Bob Brady of Resolute Natural Resources Company and Dave Anderson of LANL for help and guidance in the geophone array deployment. We thanks Tom Fairbanks of LANL, J.R. Rogers and Robert Banfill of DAQ Systems for their help with data acquisition. We also thank Brian McPherson of the University of Utah and Reid Grigg of New Mexico Institute of Technology and Mining for their support. The Los Alamos National Laborartory unlimited release number for public release is: LA-UR 10-08213.

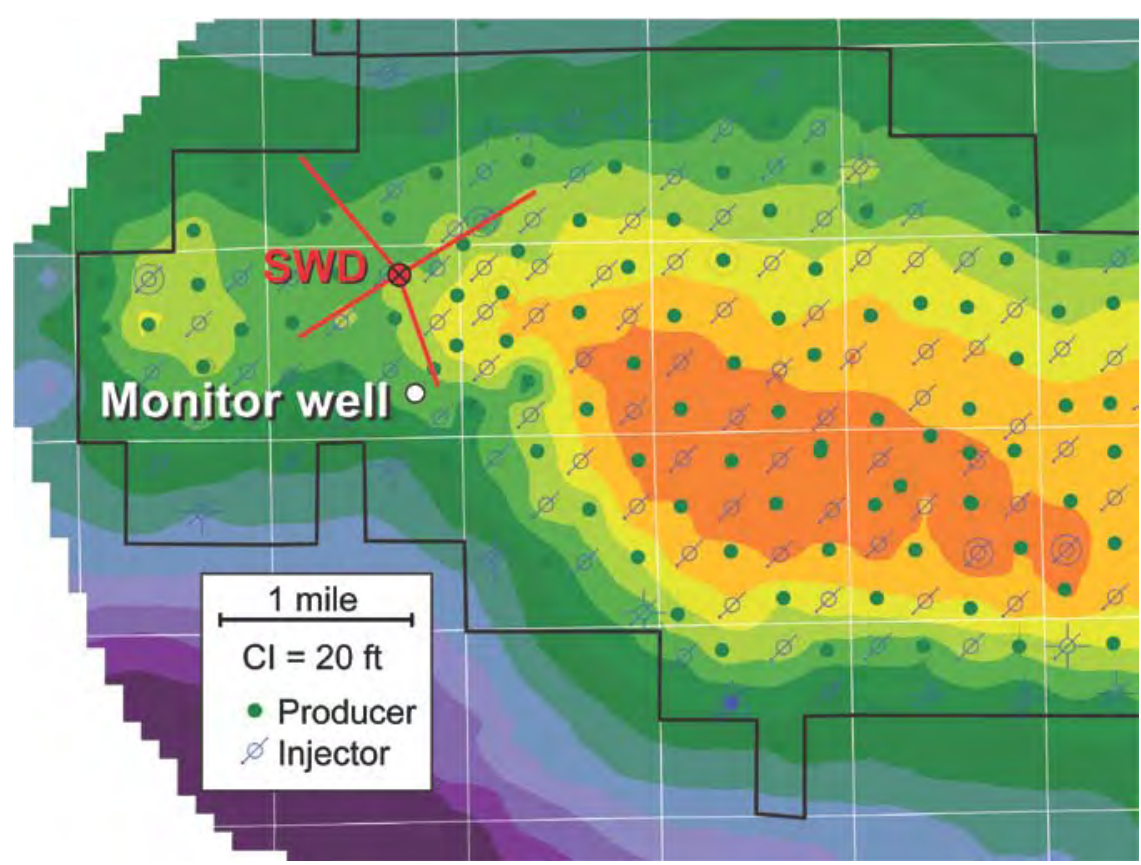

Figure 12-1. The western portion of the Aneth Unit of the Aneth field that was converted from water to $\mathrm{CO}_{2}$ injection in 2007-2008. The color contours represent the structure at the top of the Desert Creek oil reservoir. A 60-level geophone cable was cemented into the monitor well. The salt-water disposal (SWD) well was drilled about 1 $\mathrm{km}$ north of the monitor well and was completed in the underlying Leadville formation with 4 laterals (well C113-SWDW, displayed red). 


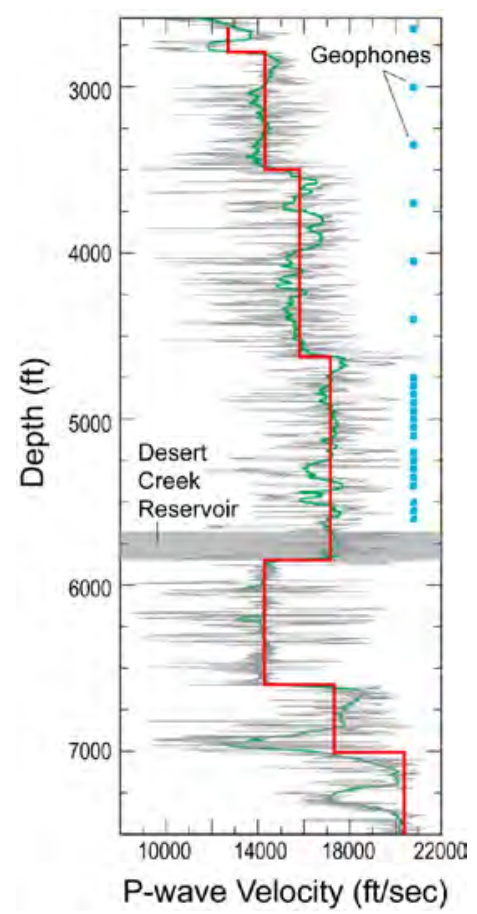

Figure 12-2. P-wave sonic log from the SWD well (Figure 12-1), smoothed with a 100-ft median window (green). A 7-layer model was selected based on the smoothed log (red). Also shown are the depth locations of the 24-geophone subset used for microseismic monitoring, and the oil reservoir interval. 


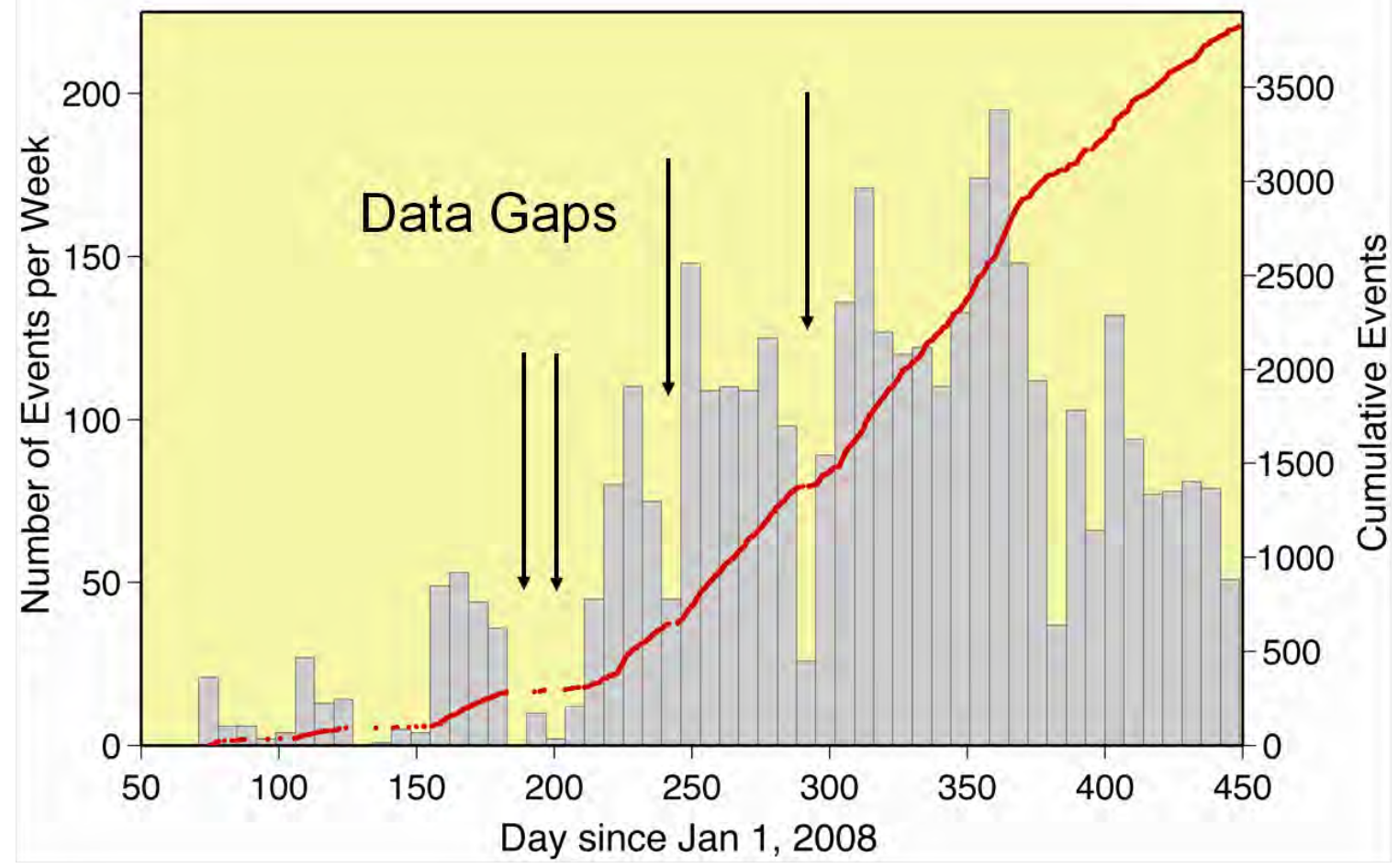

Figure 12-3. Event count for the 1st year of monitoring. 3825 events were detected over a 376 day monitoring period. The red curve is the cumulative count. The histogram shows the weekly event count. Monitoring effectively started on March 14, 2008 (day 74) after noise associated with poor grounding was removed. Events were detected right away. Monitoring was continuous except for the data gaps marked by the arrow. The seismicity was intermittent from March 14 to June 6, 2008 (day74 to 158), after which rates increase and remain at levels averaging about 10 to 20 events per day. 


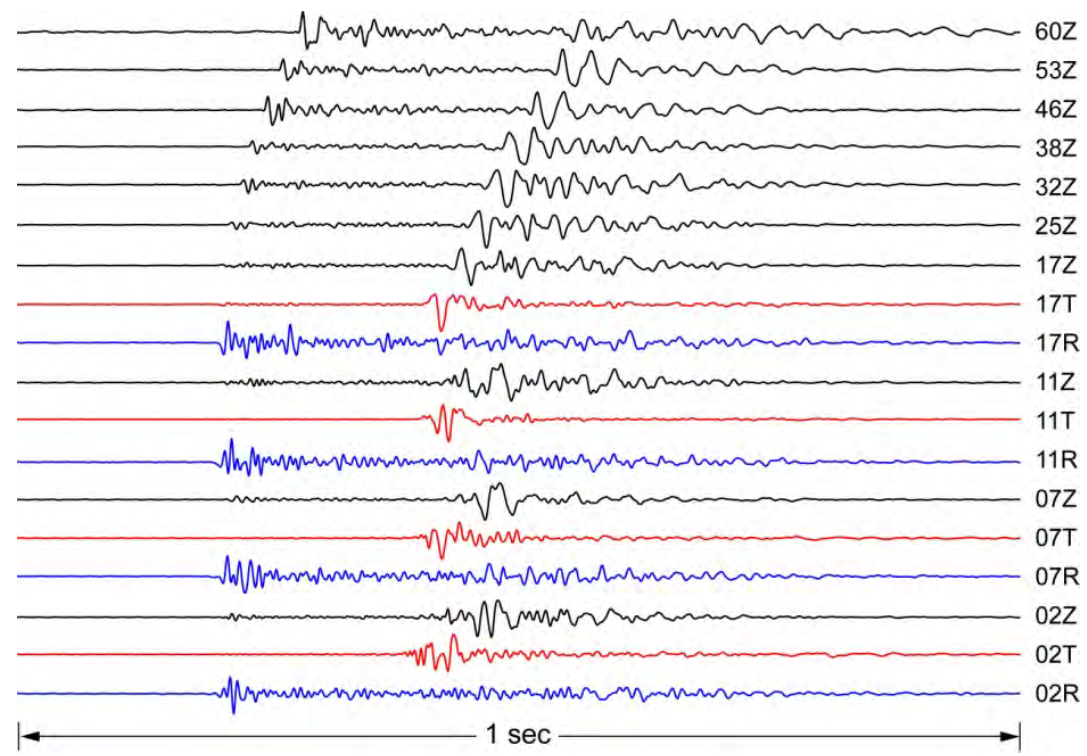

Figure 12-4. Waveform from selected channels across the geophone cable for a high signal-to-noise ratio microseismic event. Trace color indicates the component of the rotated waveforms. Black is vertical, red is transverse and blue is radial. 


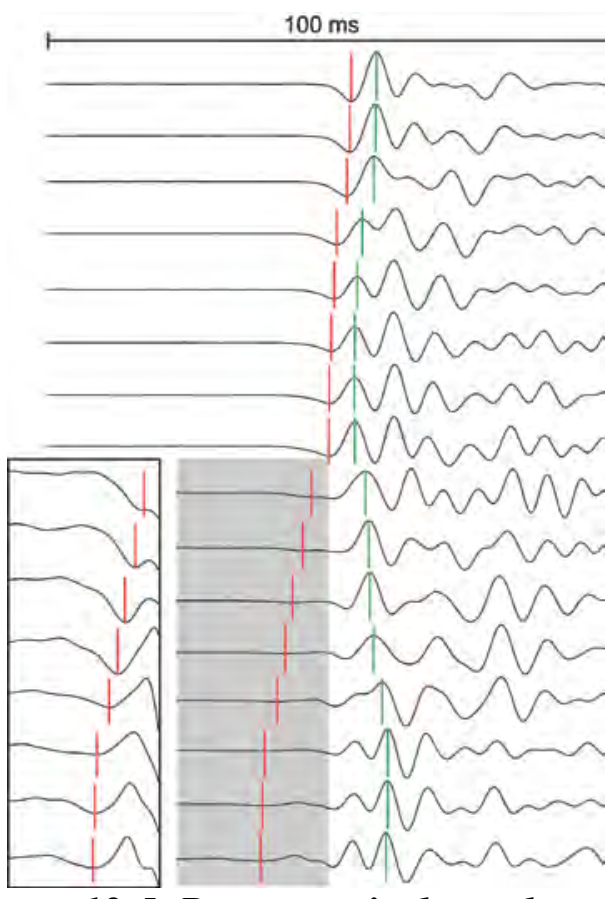

Figure 12-5. P-wave arrivals on the radial components over the lower portion of the geophone array. The waveforms are the result of summing several multiplet signals to increase signal-tonoise ratios. The correlated picks are shown in green. First arrivals picks are shown in red. The inset is an amplified view of the shaded area.

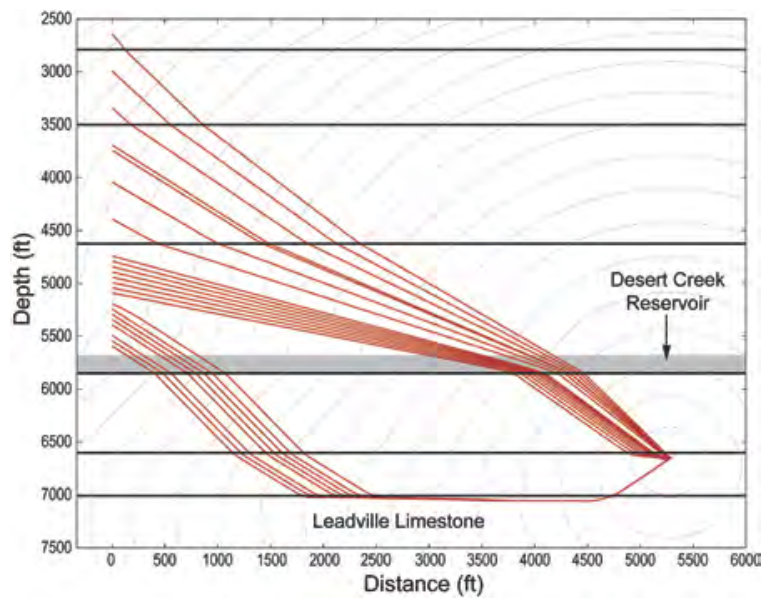

Figure 12-6. P-wave ray paths from a master-event source to 24 receivers. The critically refracted paths to the lower 8 receivers correspond to the weak arrivals shown in Figure 12-5. The wave front contours are at 20 ms intervals. 

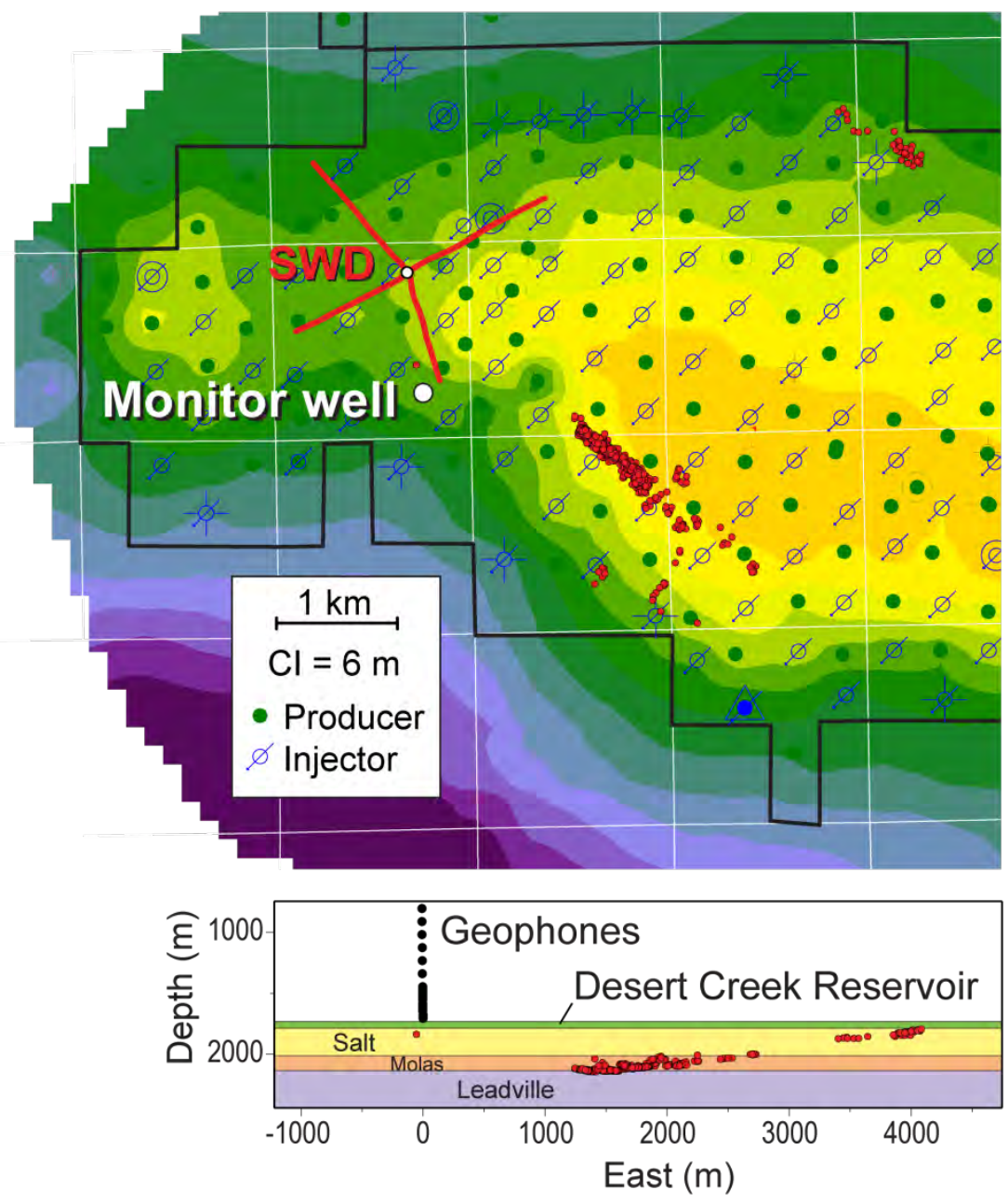

Figure 12-7. Microseismic locations occurring over a one-year period. Approximately 1400 events were located. Reflected and refracted phases were used to help constrain the depths of master event locations. The south group is constrained to the top of the Leadville and Molas formations. The more distant northeast group occurs near the base of the Desert Creek reservoir. 

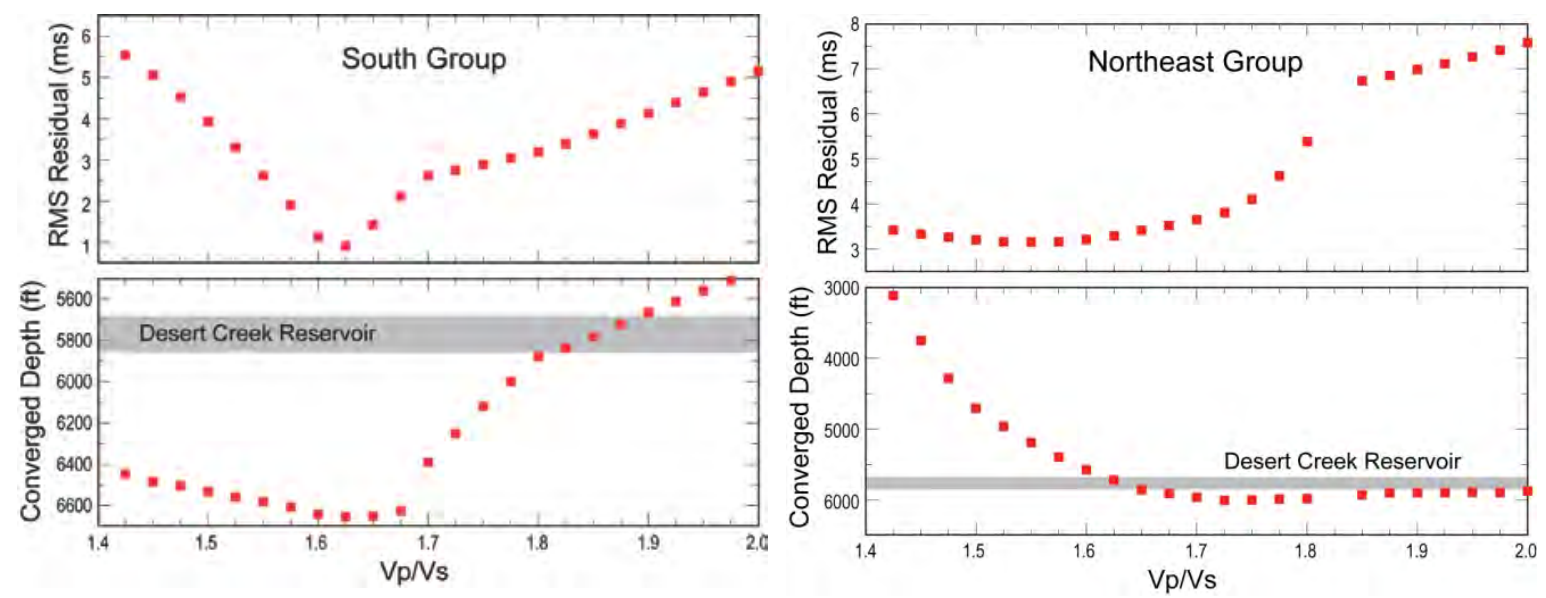

Figure 12-8. RMS residuals and converged depth computed for a range of $\mathrm{Vp} / \mathrm{Vs}$ values for an event representative of the south group of seismicity (left) and for an event representative of the northeast group of seismicity (right). .
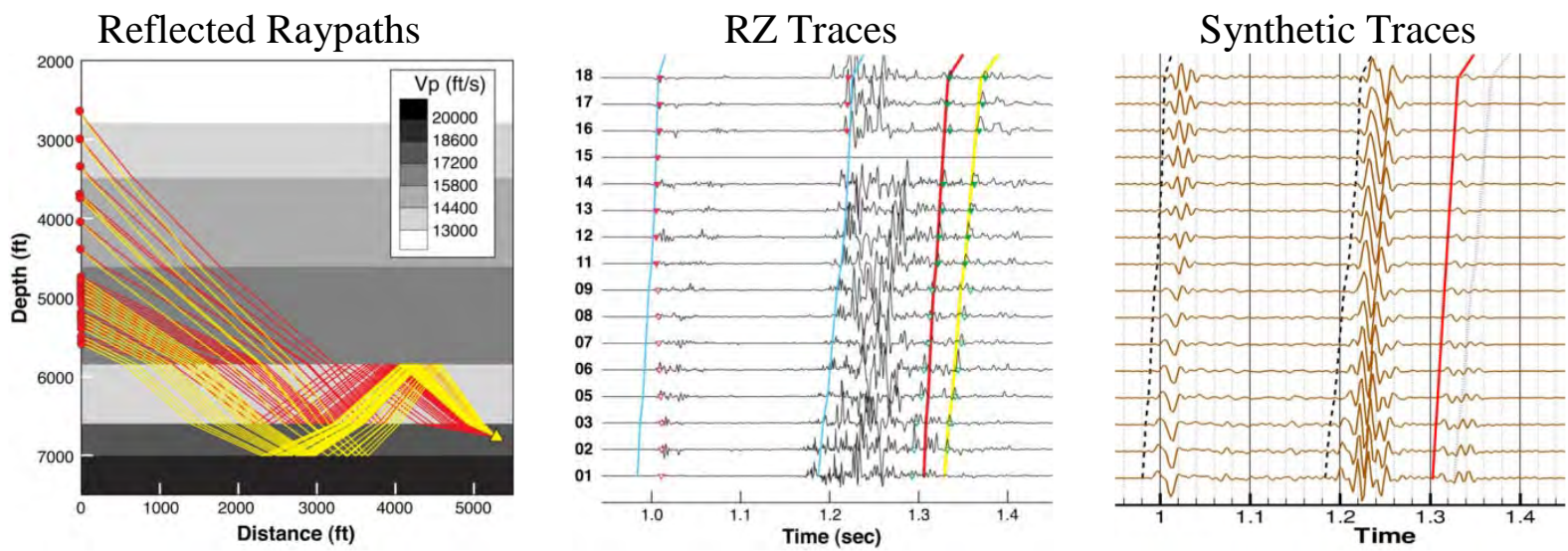

Figure 12-9. Left: Ray paths for $S V$ reflected from the top of salt and the base of salt (red) and the top of Leadville (yellow). Center: Product of the radial and vertical component traces to highlight reflected phases. The computed $S V$ reflected arrival times are indicated by the red and yellow lines. The light blue lines mark the computed $P$ and $S$ first arrivals. Right: Synthetic radial component traces to model the direct $P$ and $S$ and two-time reflected $S V$ arrival times observed in center. Only the velocity contrast of Figure 12-2 are used in the model; there is no density change among layers which results in only one reflection phase, corresponding to the upper boundary of salt layer (red raypaths on left, red highlighted arrivals on right). 

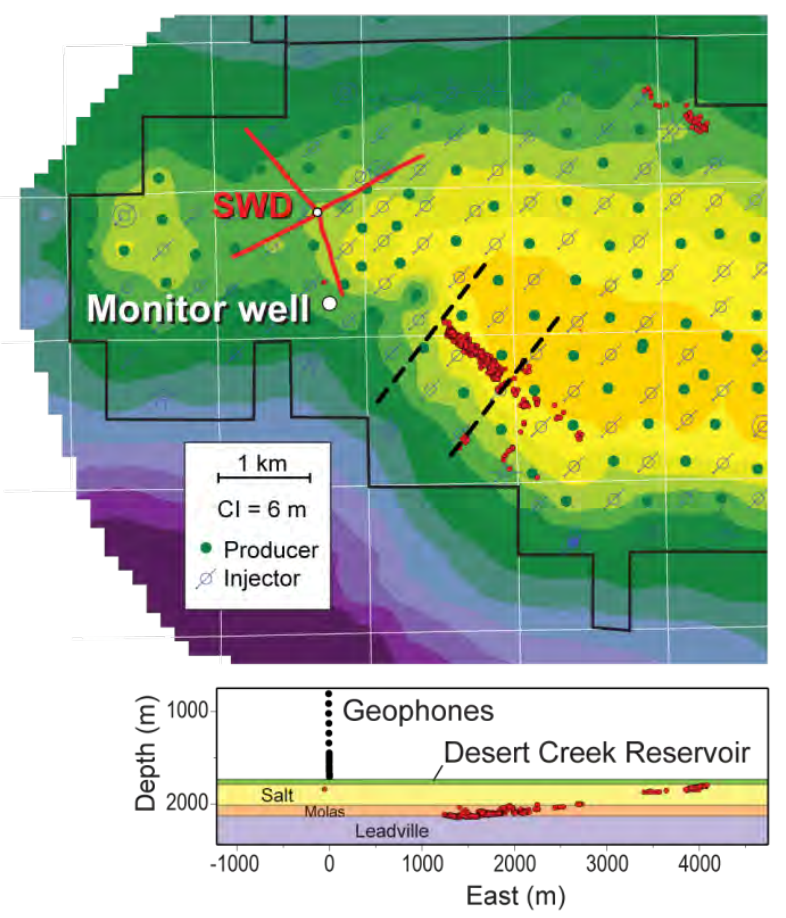
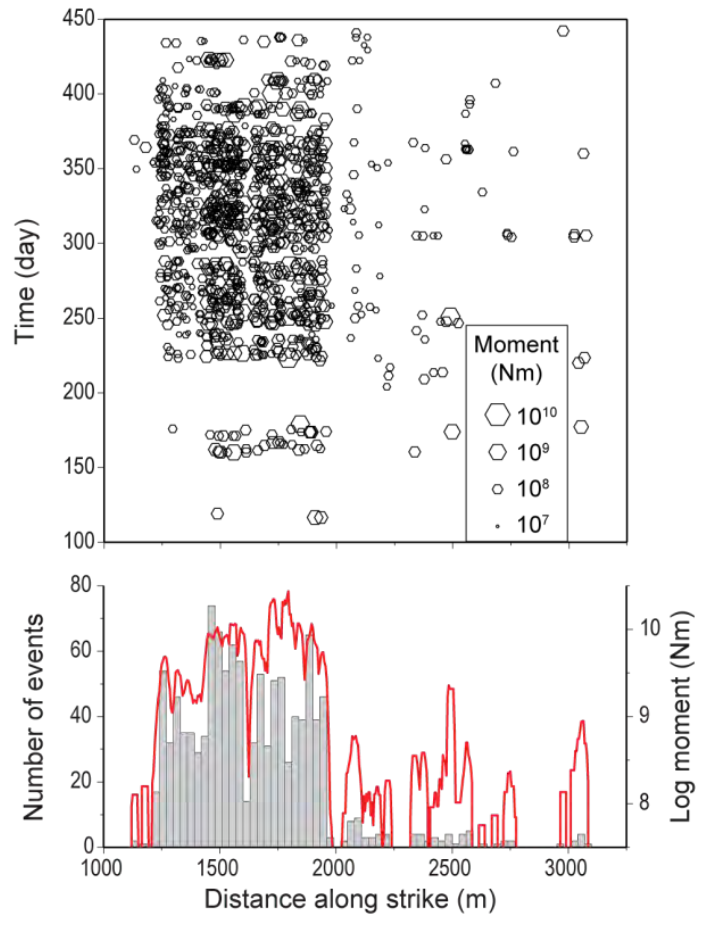

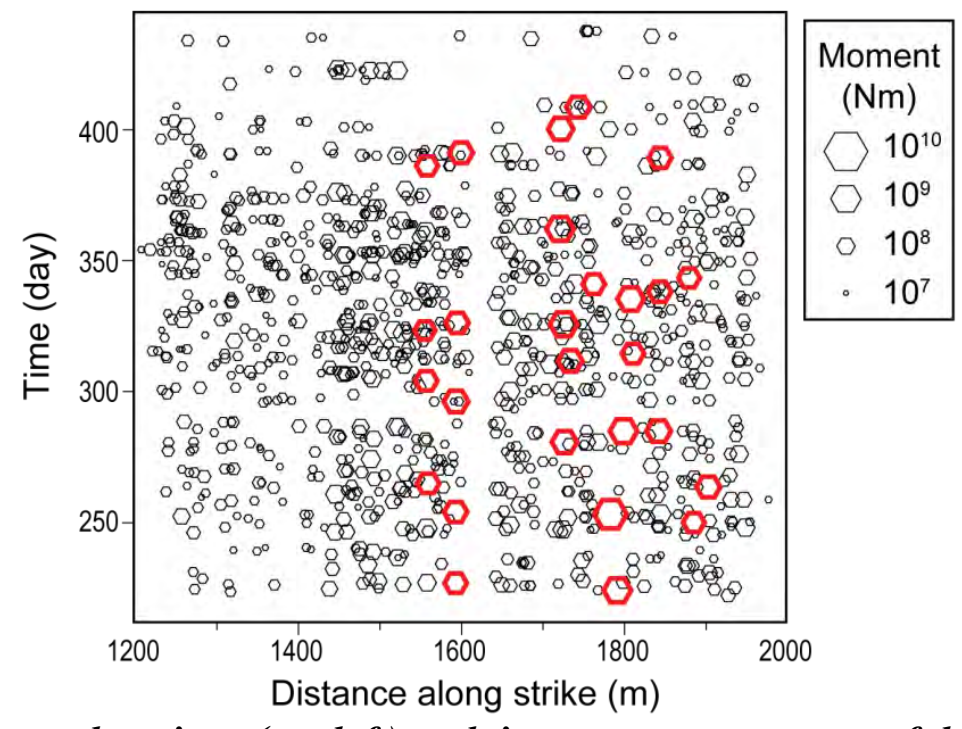

Figure 12-10. Source locations (top left) and time-space occurrence of the events for the south group plotted along source position along strike of the trend (top right). For the time-space plot, the time axis is days from Jan 1, 2008, the histogram is the event count summed over 30-m intervals and the red curve is the mean moment release summed over a 30-m window. The top panel shows the temporal distribution of events along strike with the symbol size proportional to moment. The bottom panel shows the interval from 1200 to $2000 m$ in detail with the larger magnitude $\left(M_{w}>0\right)$ events highlighted in red. The dashed lines on the map are suggested cross cutting faults inferred from the sharp terminations of seismicity near 1200 and $2000 \mathrm{~m}$ distances. 


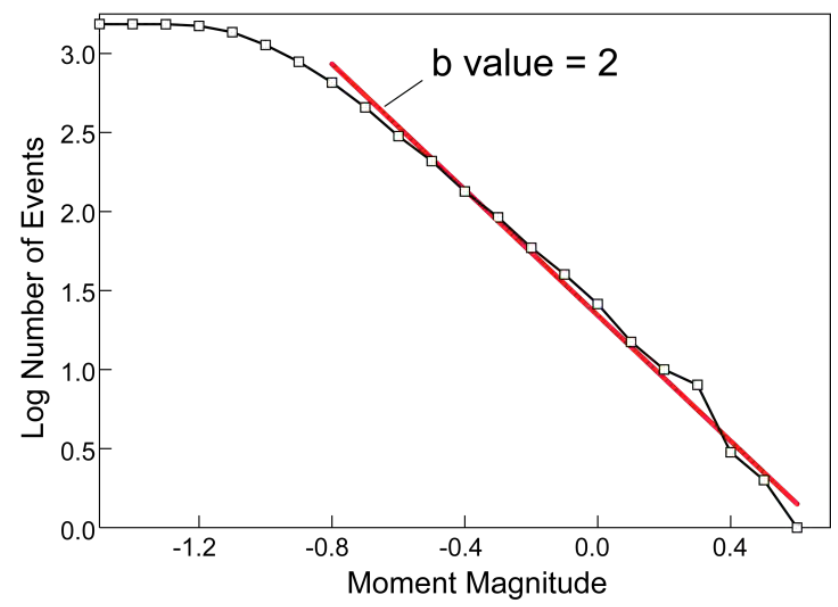

Figure 12-11. Graphical representation of the Gutenberg-Richter law for event recurrence along the main south group of events at Aneth. The linear regression represented by the red line gives a negative slope, or $b$ value, equal to 2.0. The moment magnitudes were computed using Hanks and Kanamori's (1979) scale.
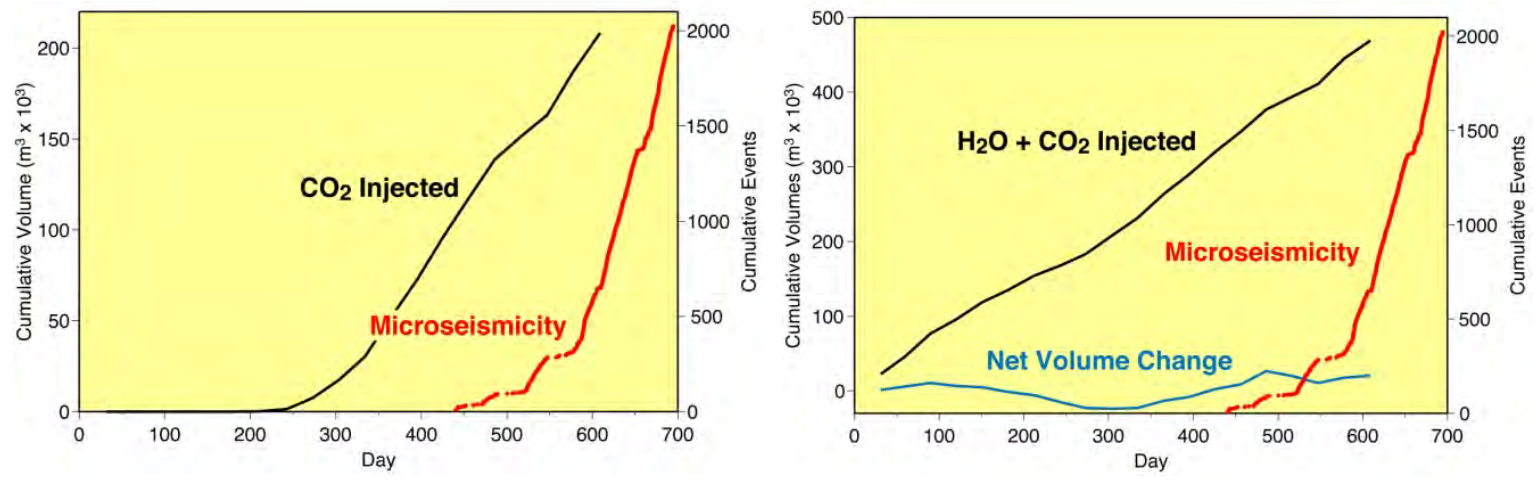

Figure 12-12.Comparison of cumulative volumes changes and cumulative microseisimicity detected. Day one is January 1, 2007; monitoring starts day 439. The volumes are sums from wells within about $1 \mathrm{~km}$ of both event groups (Figure 12-7). On the left is only $\mathrm{CO}_{2}$ volume only. On the right is the $\mathrm{CO}_{2}+\mathrm{H}_{2} \mathrm{O}$ volumes injected, representing the transition of injectors from water to $\mathrm{CO}_{2} . \mathrm{CO}_{2}$ volumes are converted to equivalent fluid volumes at reservoir conditions. Net volume is $\mathrm{H}_{2} \mathrm{O}+\mathrm{CO}_{2}$ injected minus $\mathrm{Oil}+\mathrm{H}_{2} \mathrm{O}$ produced. 

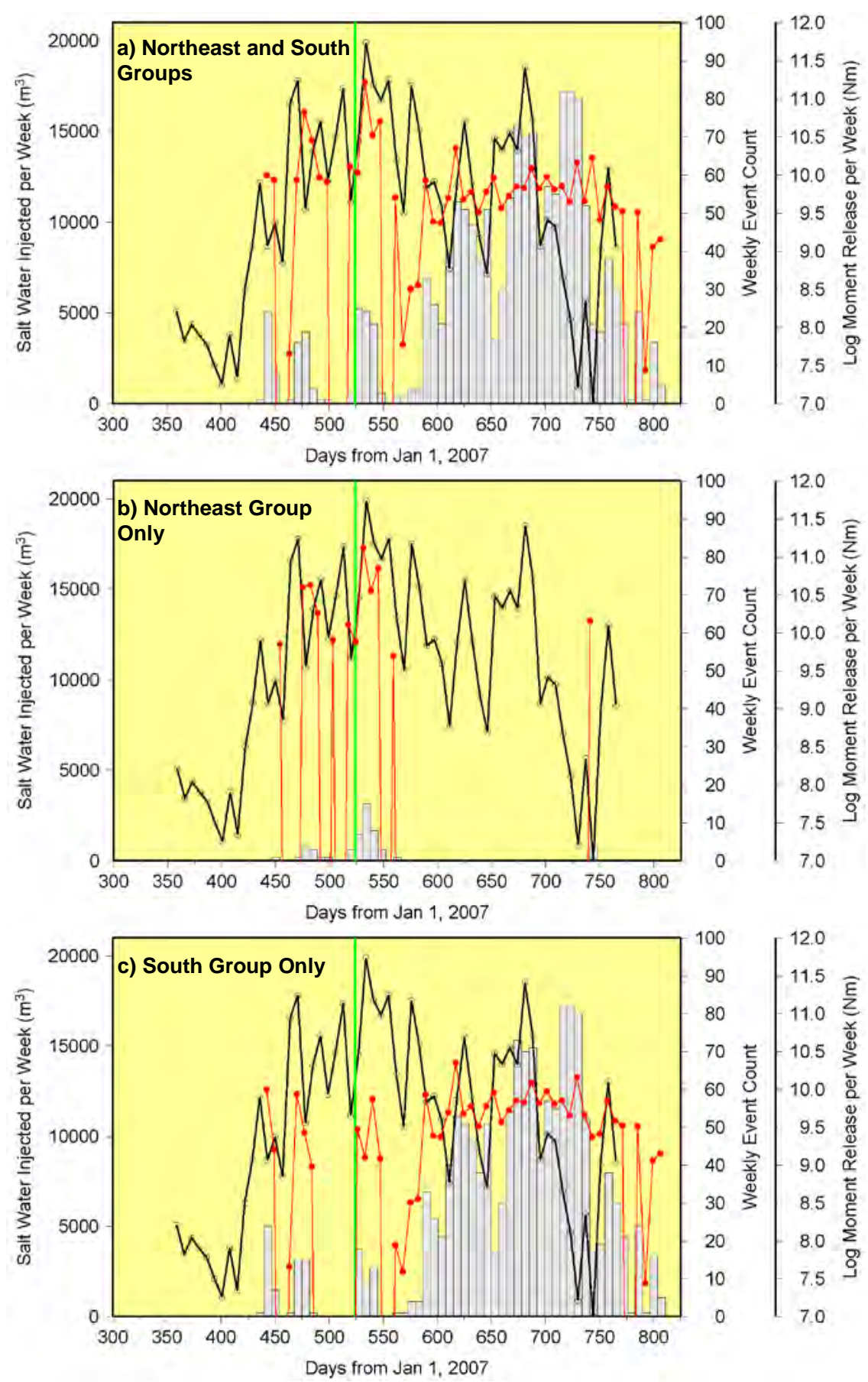

Figure 12-13. Comparison of salt water disposal (SWD) volumes and seismicity. Black is the weekly sum of SWD in well C113-SWDW (Figure 12-1). Red is the weekly sum of moment release for a) both Northeast and South event groups, b) South event group only, and c) Northeast event group only. The histograms are the corresponding weekly event count. The green vertical line is time of the June 6, 2008 Bluff M3. 7 earthquake (see Figure 12-14). 


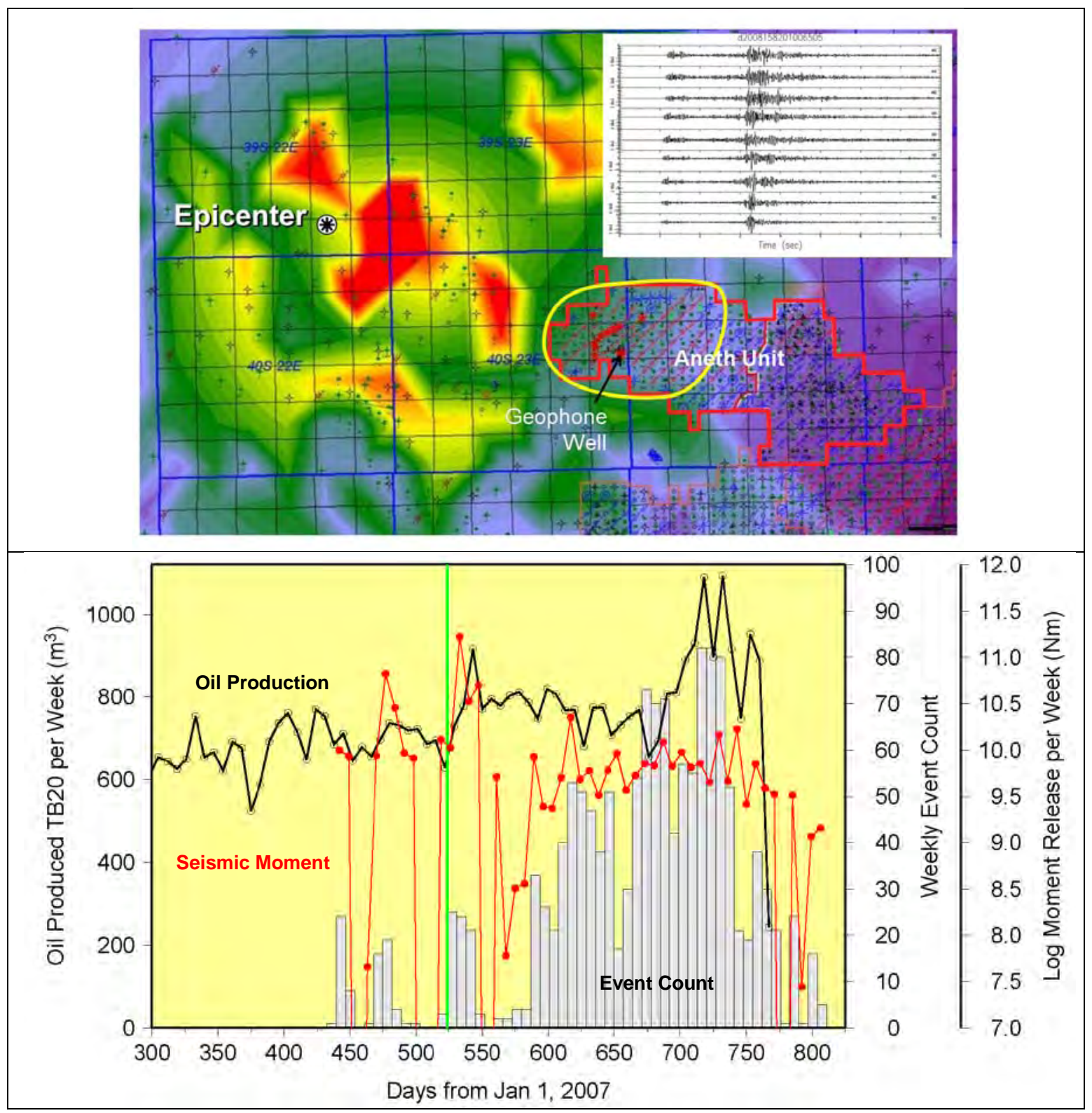

Figure 12-14. Top: Bluff June 6, 2008 M3.7 earthquake epicenter. Source depth is estimated at $9.5 \mathrm{~km}$. Each square on the map is $1 x 1$ mile. Inset show 8 seconds of vertical component waveforms from selected geophones of the borehole array. The shake intensity was computed by the University of Utah and is not based on observation, but reflects surface geology where areas of greater intensity (hot colors) are areas of basin fill. See http://quake.utah.edu/shake/1000001020/intensity.html All production within the yellow curve is co-mingled into a single tank battery. Bottom: Weekly event count (histogram) and oil production (black, from the area encircled in yellow above). The oil production curve are the sum volumes injected over one-week periods. Red are moment release summed over one-week periods for the located events shown in Figure 12-7. The green vertical line marks the occurrence of the Bluff M3.7 earthquake. 


\title{
CHAPTER 13 \\ GEOLOGIC MODEL DEVELOPMENT AND NUMERICAL SIMULATION OF THE ANETH SITE, UTAH
}

\author{
by
Si-Yong Lee
$a, b$
, Chuan Lu $u^{a, b}$, and Brian McPherson ${ }^{b}$ \\ ${ }^{a}$ Energy \& Geoscience Institute, University of Utah \\ 423 Wakara Way, Suite 300 \\ Salt Lake City, Utah 84108 USA \\ sylee@egi.utah.edu \\ ${ }^{b}$ Department of Civil and Environmental Engineering \\ University of Utah, Salt Lake City, Utah 84108 USA
}

\section{Summary}

The Southwest Regional Partnership (SWP) on Carbon Sequestration designed and deployed a medium-scale field pilot test of geologic CO2 sequestration in the Aneth oil field. This test is one of three geologic pilots conducted under the auspices of the SWP Phase II program.

The Aneth oil field is Utah's largest oil field in terms of production, yielding over 149 million barrels of oil since discovered in 1956. The Aneth site was selected specifically to demonstrate the technical requirements and efficacy of combined enhanced oil recovery (EOR) and long-term $\mathrm{CO}_{2}$ sequestration. The Aneth Unit is operated by Resolute Natural Resources and Navajo Nation Oil \&Gas Co., Inc., and these two companies operated the SWP pilot test.

The Aneth oil field is located in the Paradox basin of southwestern Utah (Figure 1-1); the primary reservoir in the field is the Pennsylvanian Desert Creek formation. Oil production in the Aneth field has declined significantly over the past 20 years despite waterflooding and horizontal drilling technologies. However, it is estimated that the Aneth Unit has a large amount of remaining oil in place with only a 33\% recovery rate, which makes the Aneth Unit ideal for a demonstration of $\mathrm{CO}_{2}$ storage capability combined with EOR. The SWP conducted extensive monitoring of the migration and fate of injected $\mathrm{CO}_{2}$ and risk mitigation.

SWP researchers at the University of Utah (UU) developed a geological model of the Aneth field and conducted numerical simulations to demonstrate efficacy of $\mathrm{CO}_{2}$ sequestration technologies within producing oil reservoirs. In this project, UU scientists focused on developing a site-specific geologic model to better understand and design $\mathrm{CO}_{2}$ storage specifically tailored to oil reservoirs. The research was primarily focused on gathering and using data specific to the Aneth site, but it is anticipated that the results of the Aneth research will be useful in a variety of $\mathrm{CO}_{2}$ EOR projects and oil fields 
elsewhere. Geologic sequestration of $\mathrm{CO}_{2}$ in the Aneth field includes continued injection of up to 150,000 tons/year $\mathrm{CO}_{2}$ for several years into the future.

This chapter of the report describes the geologic model development and numerical simulation work performed by UU scientists in collaboration with other SWP researchers. The major tasks developed and performed in this work include:

\section{- Data Acquisition}

- Digitizing well logs

- Petrophysical Properties Estimation

- Estimation of porosity

- Porosity and permeability relationship

\section{- Geologic Model Development}

\section{- Numerical Simulation}

Regarding data acquisition, available stratigraphic, petrophysical, and geophysical information from the Aneth site were collected and compiled from our partners. Acquired well logs were digitized and integrated into the model development. We reviewed the petrophysical data for estimating essential properties such as porosity and permeability. Based on the compiled geologic information/data, a site-specific static geologic model was constructed. We populated the petrophysical properties (porosity and permeability) into the static model using the porosity logs and correlation found from the petrophysical properties. The constructed static model served as an input to the subsequent numerical simulations.

We conducted numerical simulations on a conceptual model built on geological data from Section 13 and 14 of the Aneth field in southeastern Utah. Investigations on injectivity were conducted on the geological model originally built on the porositypermeability correlation indicated that the $1 \mathrm{MMt} / \mathrm{yr}$ injection rate cannot be achieved. Based on that model the maximal injectivity is $0.25 \mathrm{MMt} / \mathrm{yr}$. Then the sensitivity of injectivity on the uncertainty of permeability was investigated on several modified geological model by artificially increasing the permeability. The maximal pressure among 14 wells with the injection rate of $1 \mathrm{MMt} / \mathrm{yr}$ was evaluated. Moreover, the minimal number of wells for $1 \mathrm{MMt} / \mathrm{yr}$ injection was estimated for one geological model.

The effects of hysteresis and WAG schemes were studied with a series of numerical simulations. According to the simulations on our geological model, it was illustrated that the effects of WAG schemes and hysteresis are weak on dissolution trapping mechanisms, and there is no significant effect of a WAG scheme at least for long term residual trapping in our conceptual model. 


\section{Data Acquisition}

The location of the Aneth Unit of the Greater Aneth oil field is illustrated in Figure 13-1. The Utah Geological Survey (UGS) collected an extensive set of geologic data, scanned paper, and digital well log images, and petrophysical data from the project site and provided this data to EGI to develop the basis for the initial data acquisition. The following data were assembled for this project:

- Core plug analyses (porosity, density, and permeability)

- Geophysical well log images

- Stratigraphic formation tops data

- Well information

- Injection/production history

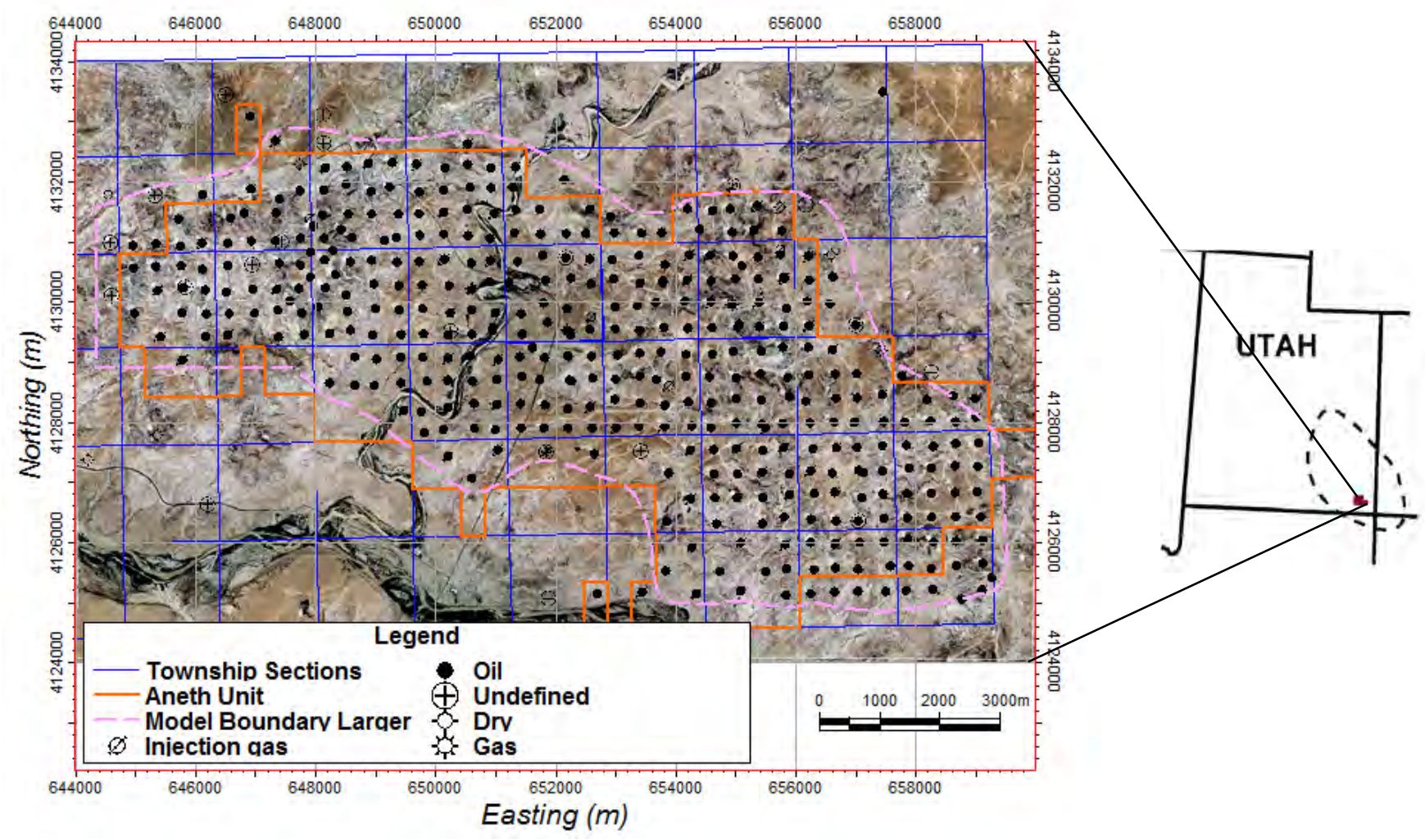

Figure 13-1. Location of Aneth Unit.

These data were catalogued and processed to form an information database for the geologic model development and numerical simulation (Section 3 and 4 [T40S R23E], respectively). Table 13-A1 in the Appendix present the core plug analysis raw data. The distribution of wells in the site (reflecting associated selected neutron porosity logs) is shown in Figure 13-2. 


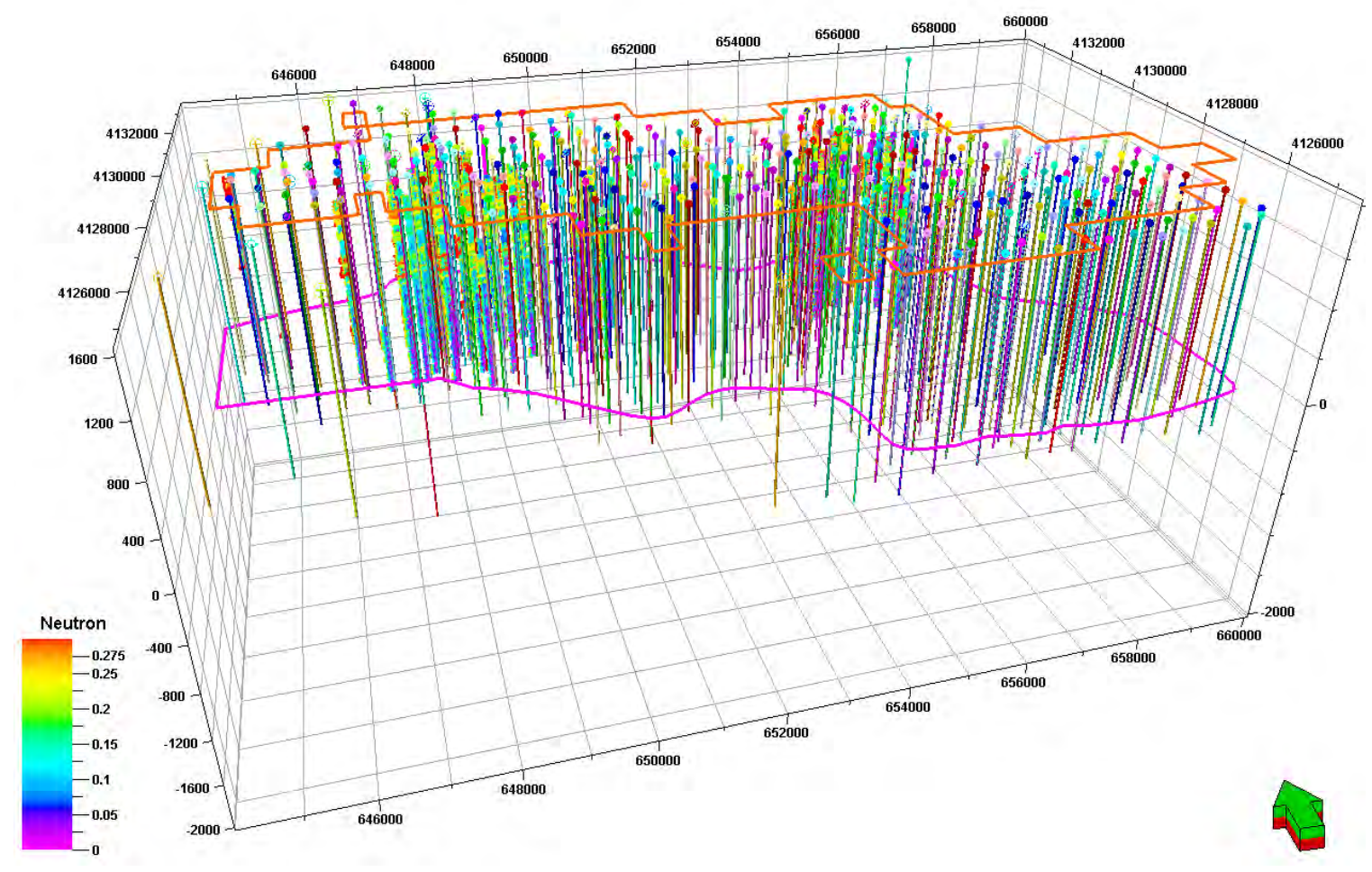

Figure 13-2. Location of wells with selected neutron porosity logs. Vertical exaggeration is $2 x$.

\section{Digitizing Well Logs}

Digitizing of well logs was accomplished using the software program NeuraLog ${ }^{\mathrm{TM}} \square$, one of the most widely-used automated log digitizing solutions in the oil and gas industry. NeuraLog's automated tracing streamlines data workflow, enhancing productivity by obtaining reliable information for time-critical projects. NeuraLog transforms scanned raster images (color, grayscale or black and white) into more useful, analysis-quality digital data.

Well log data capture, quality control, interactive LAS (Log ASCII Standard) curve editing, and calibrated raster export are straightforward through NeuraLog's GUI interface, automation and special features. Image warp and stretch are corrected by internal algorithms that are calculated from the automated calibration tied to the log's depth grid. This provides a precise data set. The image scrolls as the curve is traced for real-time verification, and LAS data accuracy can be verified instantly. Data is edited interactively to produce the best information available.

Generally, well logs are digitized by carrying out the following procedures: after the digital log image (.tif) file is loaded in NeuraLog, log tracks, scales, and grids are set up first and the depth axis is aligned and labeled. Next, a curve type is identified and 
automatic curve tracing begins with supplemental curve editing by the user, as needed. After the curve is traced, the quality control of the curve is analyzed; quality control involves direct LAS curve editing, baseline shift, and depth shift. The process is repeated for additional curves and scales and then exported as a LAS file. A complete description of the digitizing procedure can be found in the NeuraLog user's manual (http://www.neuralog.com/updates/Log/Docs/NLogUserGuide.pdf).

A total of 1,084 total well log curves from 456 wells in the Aneth Unit, provided by the Utah Geological Survey, are categorized in Table 13-1. The digitization effort concentrated on Sections 13 and 14 (T40S R23E), where the Phase II project took place. 471 well log curves from 163 wells were digitized in total (see Table 13-A2 in the Appendix). Most of these log suites contain both a gamma ray log and a neutron $\log$ for each well. Selected sample logs are included in the Appendix.

Table 13-1. Summary of well log digitizing work

\begin{tabular}{|c|c|c|}
\hline Log Type & $\begin{array}{c}\text { Number of } \\
\text { Available Logs }\end{array}$ & Number of Digitized Logs \\
\hline Gamma Ray & 388 & 163 \\
\hline Caliper & 161 & 66 \\
\hline Bulk Density & 25 & 10 \\
\hline Neutron & 254 & 129 \\
\hline Neutron Porosity & 146 & 55 \\
\hline Density Porosity & 43 & 13 \\
\hline Delta Rho & 11 & 6 \\
\hline $\mathrm{CNC}$ & 7 & 4 \\
\hline Conductivity & 6 & 3 \\
\hline Resistivity & 11 & 4 \\
\hline $\begin{array}{l}\text { Spontaneous } \\
\text { Potential }\end{array}$ & 8 & 3 \\
\hline Sonic & 5 & 1 \\
\hline Tension & 18 & 12 \\
\hline Photo-electric & 2 & 2 \\
\hline Sum & 1,085 & 471 \\
\hline
\end{tabular}


The vertical sampling interval in the geophysical logs is usually 0.5 feet, which requires an upscaling step to reduce the total number of cells to a manageable size. We used an arithmetic averaging method to estimate upscaled values. All sample values within each cell were used for averaging without being weighted. The new vertical sampling $(\Delta z)$ interval was adjusted to approximately 1 meter. Figure 13-3 shows the upscaled neutron porosity logs within the Aneth unit.

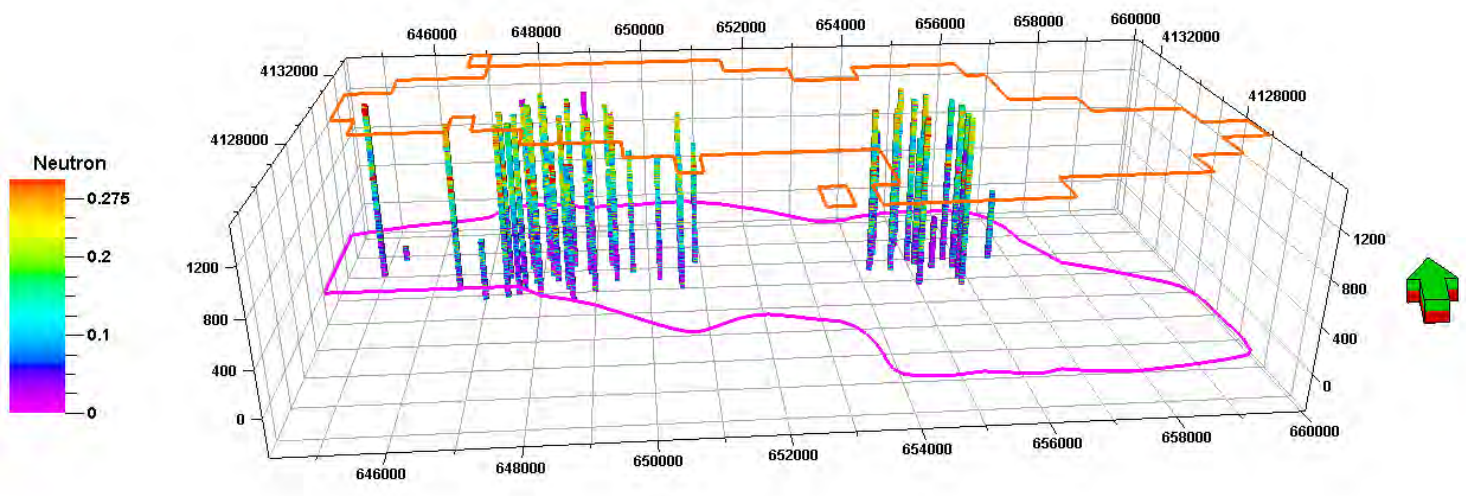

Figure 13-3. Upscaled neutron porosities. New vertical sampling $(\Delta z)$ is approximately $1 \mathrm{~m}$.

\section{Petrophysical Properties Estimation}

In order to execute reservoir simulations, petrophysical properties (e.g., porosity and permeability) should be defined within the each cell of the model domain. However, only a few direct petrophysical measurements are available from the site. Ambient porosity and gas permeability data were gleaned from core plug samples of 6 wells covering 3 formations (Ismay, Gothic shale, and Desert Creek) (see Table 13-A1 in the Appendix). These data were available from the UGS and are summarized in Table 13-2.

Table 13-2. Summary of ambient porosity and gas permeability measurements from core plug samples.

\begin{tabular}{|c|c|r|r|r|r|r|r|}
\hline \multirow{2}{*}{$\begin{array}{c}\text { Formatio } \\
\mathrm{n}\end{array}$} & $\begin{array}{c}\text { No. of } \\
\text { Samples }\end{array}$ & \multicolumn{3}{|c|}{ Porosity $(\varphi)$} & \multicolumn{3}{|c|}{ Permeability (mD) } \\
\cline { 5 - 8 } & 10 & 0.05 & 0.02 & 0.06 & 0.47 & 0.04 & 0.78 \\
\hline Ismay & 1 & 0.009 & 0.009 & 0 & 0.012 & 0.012 & 0 \\
\hline $\begin{array}{c}\text { Gothic } \\
\text { Shale }\end{array}$ & 81 & 0.09 & 0.1 & 0.07 & 5.12 & 0.31 & 18.92 \\
\hline $\begin{array}{c}\text { Desert } \\
\text { Creek }\end{array}$ & & & & Median & $\begin{array}{c}\text { Std. } \\
\text { Dev. }\end{array}$ & Mean & $\begin{array}{c}\text { Media } \\
\text { Dev. }\end{array}$ \\
\hline
\end{tabular}


Most of the samples are concentrated in the Pennsylvanian Desert Creek formation, which exhibits the highest porosity and permeability. The Gothic shale, presumed to be a cap rock formation, shows the lowest porosity $(<1 \%)$ and permeability $(\sim 0.01 \mathrm{mD})$. Note that only one sample was available for the Gothic shale. Due to the scarcity of data (6 wells), a major concern was how to define porosity and permeability parameters within the rest of the model domain.

\section{Estimation of Porosity}

Figures 13-4 and 13-5 plot the porosity estimates from porosity logs and measured ambient porosities at wells H-117 (API\# 43-037-30153) and E-418 (API\# 43037-30165), respectively. In these Figures, the blue solid line represents the porosity values estimated by taking averages of the neutron porosity and density porosity logs as:

$$
\phi=\sqrt{\frac{\phi_{n}^{2}+\phi_{d}^{2}}{2}}
$$

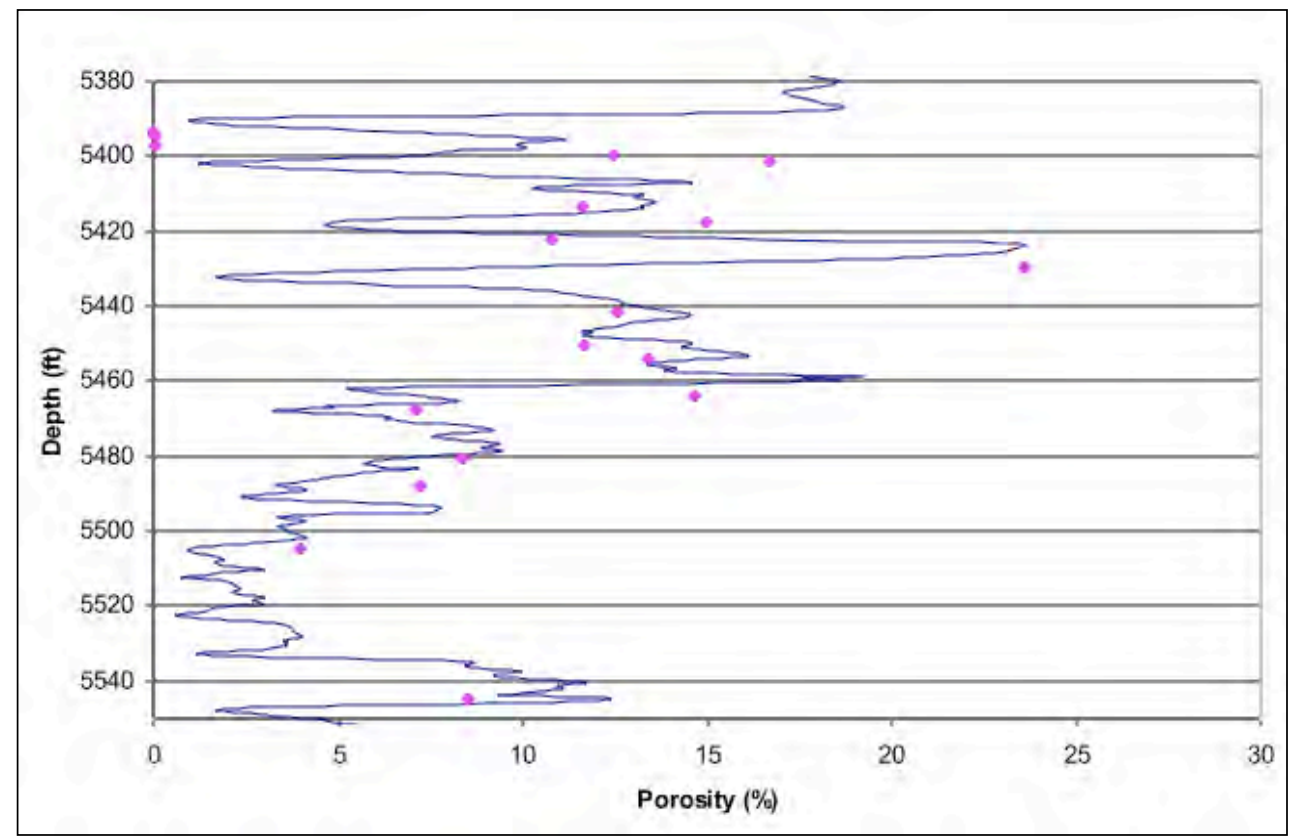

Figure 13-4. Measured ambient porosity (pink diamond) and porosity estimates (blue solid line) from porosity logs from the $\mathrm{H}-117$ well.

where $\phi_{n}$ and $\phi_{d}$ are neutron and density porosities. Pink diamonds represent the measured porosity value from core plug samples. Although there exists a significant difference in a couple of points, overall porosity estimates from well logs match the 
measured data, which suggest that the estimation of porosity using well logs is appropriate.

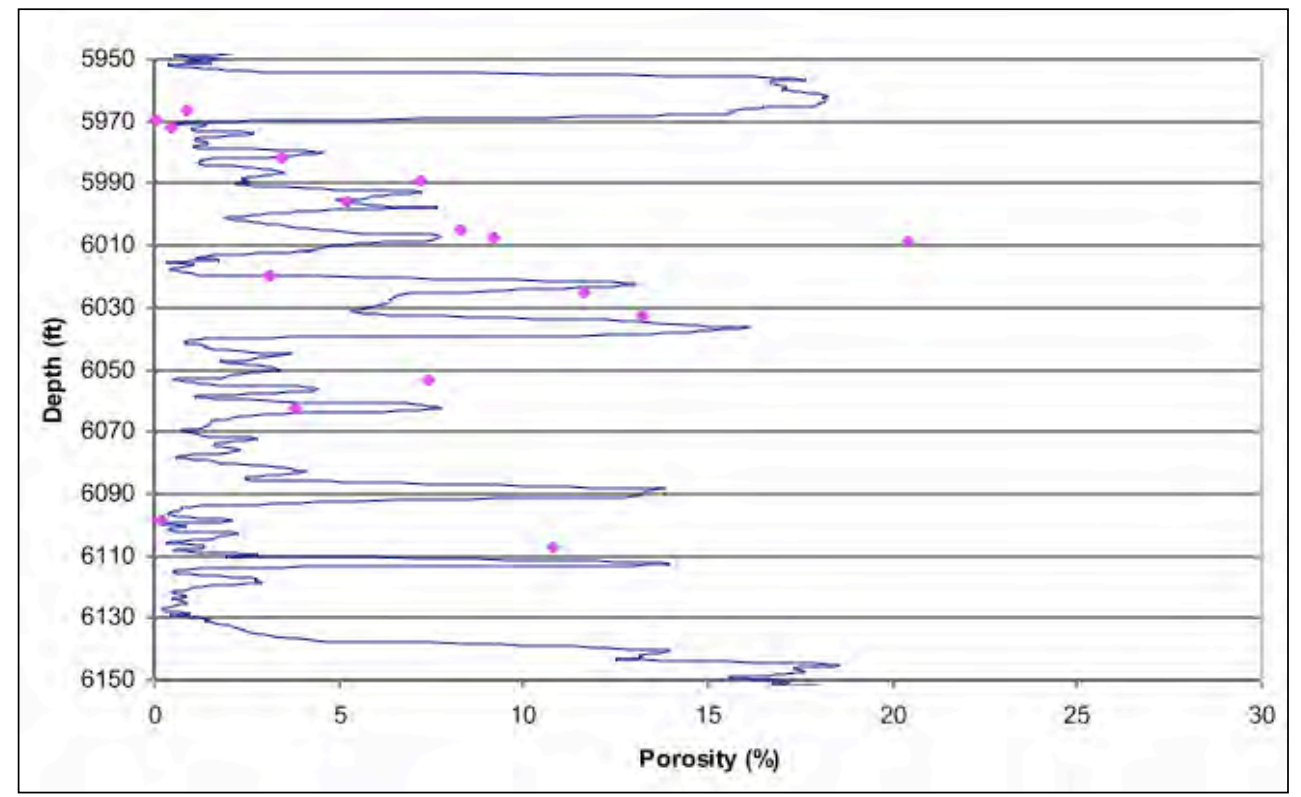

Figure 13-5. Measured ambient porosity (pink diamond) and porosity estimates (blue solid line) from porosity logs from the E-418 well.

Despite the lack of available petrophysical data at the site, the porosity logs showed general agreement with the measured data from the limited core plug samples. Thus, we used digitized porosity logs to estimate the porosity values where no petrophysical data were available in the Desert Creek formation.

\section{Porosity and Permeability Relationship}

A cross-plot of specific core plug analyses (Figure 13-6) exhibits the relationship between porosity and permeability. The cross-plot displays the approximate log-linear relationship between permeability and porosity. Considering the scarcity of samples, especially in the Ismay and Gothic shale formations, application of this relationship can be problematic. Since the log-linear relationship is commonly found in the sedimentary rocks, the correlation found in the Desert Creek formation samples was used for assigning the permeability values where no petrophysical data was available in the target formation. 


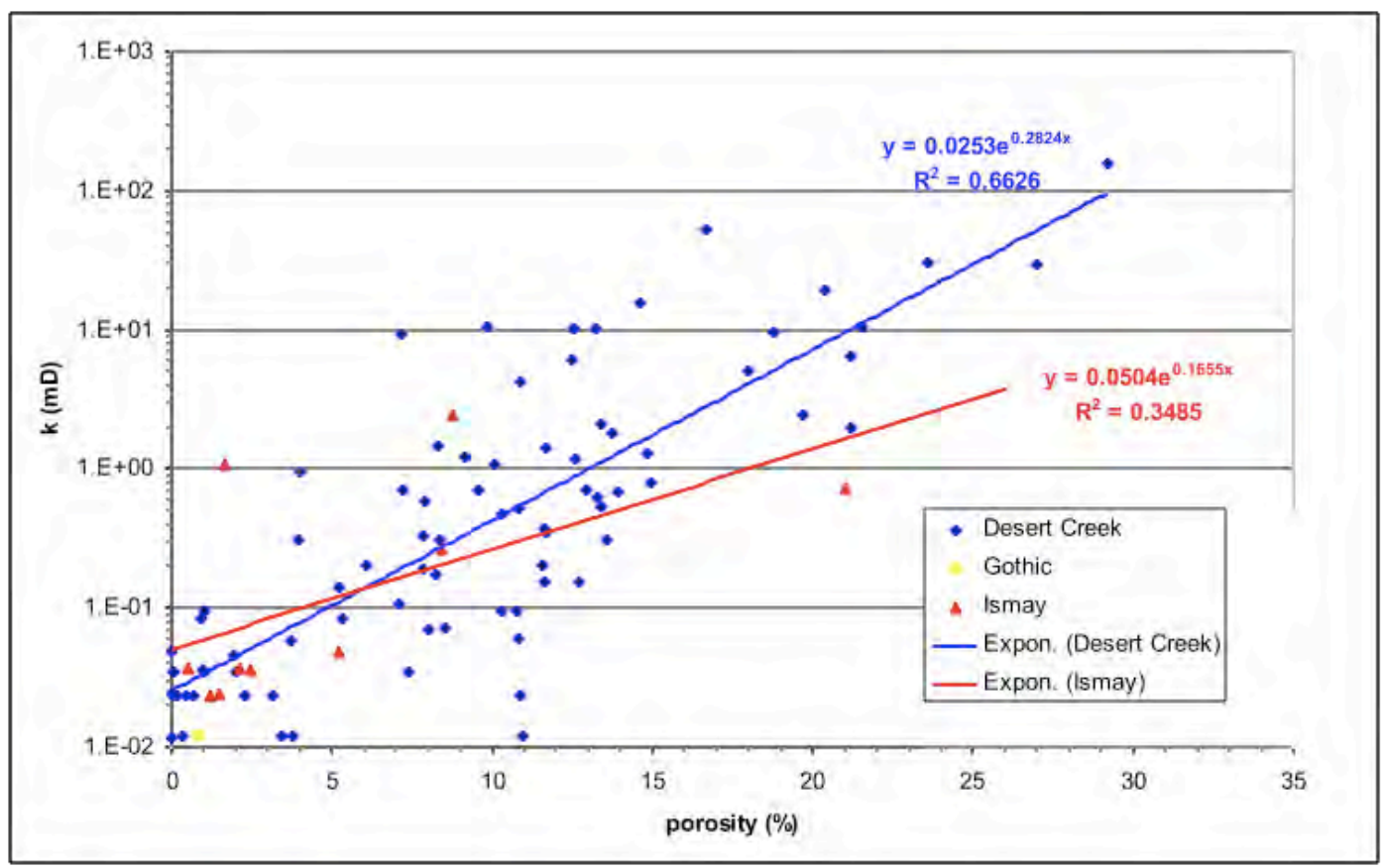

Figure 13-6. Cross-plot showing log-linear relationship between permeability and porosity measurements.

\section{Geologic Model Development}

For the static geologic model development, SWP researchers at the University of Utah analyzed the formation tops data in the Aneth field provided by Utah Geological Survey. This geologic model was constructed to cover the entire Aneth Unit with extensive formation tops data (see Figure 13-1 for the model boundary) tied to isochore data.

The software package used for the stochastic reservoir model is Petrel ${ }^{\mathrm{TM}}$, Schlumberger's 3-D integrated reservoir modeling tool. First, a detailed geologic model was established based on the formation top picks from 403 wells. The resulting static structural model within the model boundary is shown in Figure 13-7. The model domain is approximately $15 \mathrm{~km}$ by $8 \mathrm{~km}$ in the $\mathrm{x}$ and y direction. Note that the model boundary is limited approximately to the Aneth Unit boundary where the formation tops data are available. The constructed model contains 11 formations starting with the Jurassic Entrada formation on top to the Pennsylvanian Desert Creek formation at the bottom (Figure 13-7).

Figure 13-8 illustrates the grid setting of our target formation, Desert Creek formation. This study used the grid configuration of $150 \times 79 \times 53$ cells in the $\mathrm{x}$ and $\mathrm{y}$ directions, respectively, with a cell dimension of $100 \mathrm{~m}$ by 100 . Vertical cell size is equally spaced into 53 cells along each vertical grid line based on the thickness of Desert Creek formation. The active cells were allowed to be present only within the model boundary shown in Figure 13-3. The average thickness of Desert Creek Formation within the whole Aneth Unit model area is found to be approximately $53.4 \mathrm{~m}$. Gothic 
shale above the Desert Creek was found to be laterally continuous within the model domain and was assumed to work properly as a caprock in this study. The average thickness of Gothic shale is found to be approximately $4.52 \mathrm{~m}$.

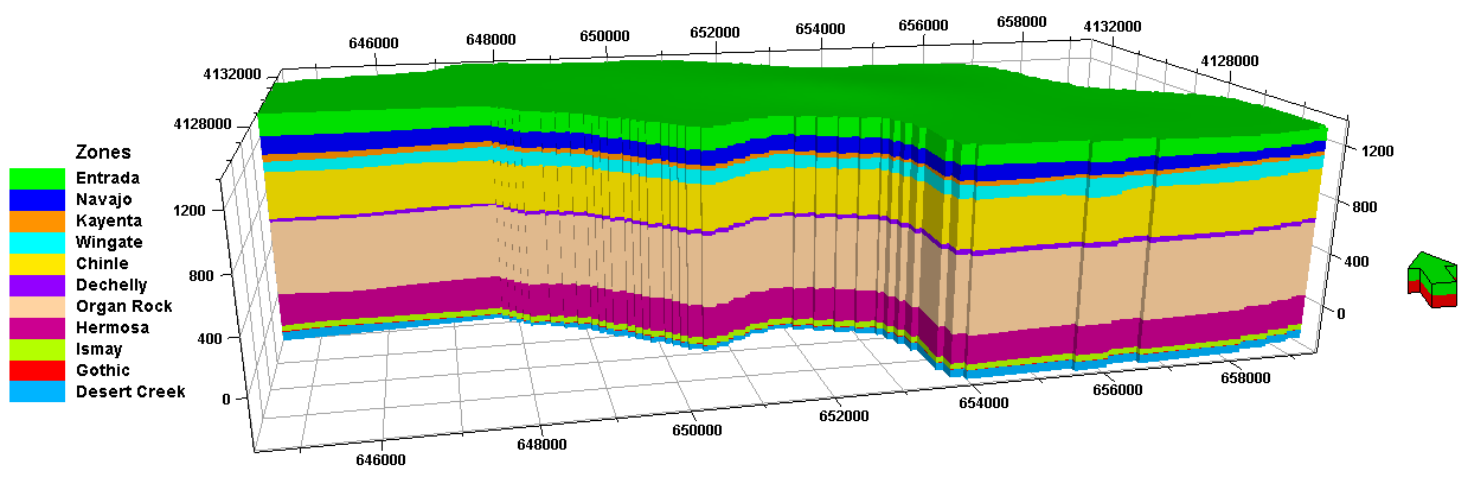

Figure 13-7. Stratigraphic distribution of geologic formations within the Aneth Unit model boundary.

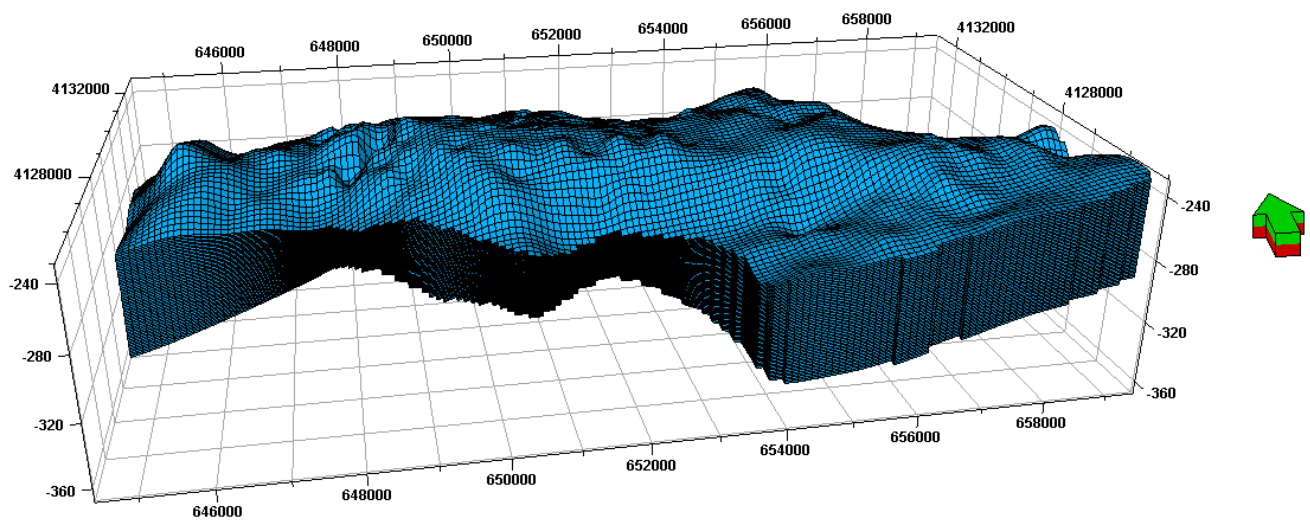

Figure 13-8. Grid settings for the Desert Creek formation with the horizontal cell dimension of $100 \mathrm{~m} \times 100 \mathrm{~m}$. Only active cells are shown out of total $150 x$ $79 x 53$ cells in $x, y$, and $z$ direction. Vertical exaggeration is 25 times.

Having established the 3-D, fine-scale grid model of the geologic formations, the petrophysical properties (porosity and permeability) can be assigned. Assuming the normal distribution in the porosities of each formation, a porosity field was generated using the Sequential Gaussian Simulation (SGS) method to create 3-D equiprobable geological images (Figure 13-9). Sample variogram from the upscaled neutron porosity logs in the Desert Creek formation were fit to the variogram model with $600 \mathrm{~m}$ for the major range, $500 \mathrm{~m}$ for the minor range, and $6 \mathrm{~m}$ for the vertical rage.

SGS is based on a multi-normal (or multi-Gaussian) assumption in the spatial distribution of a random field, which makes it favorable because of its statistical convenience. This multi-normal distribution is completely characterized by its mean and variogram function. Note that upscaled neutron porosity log values were used for 
calculating the statistics of the sample distribution in the Desert Creek formation. They also act as the conditional data thus keeping their values in the simulated porosity field. Figure 13-9 shows the simulated porosity fields.

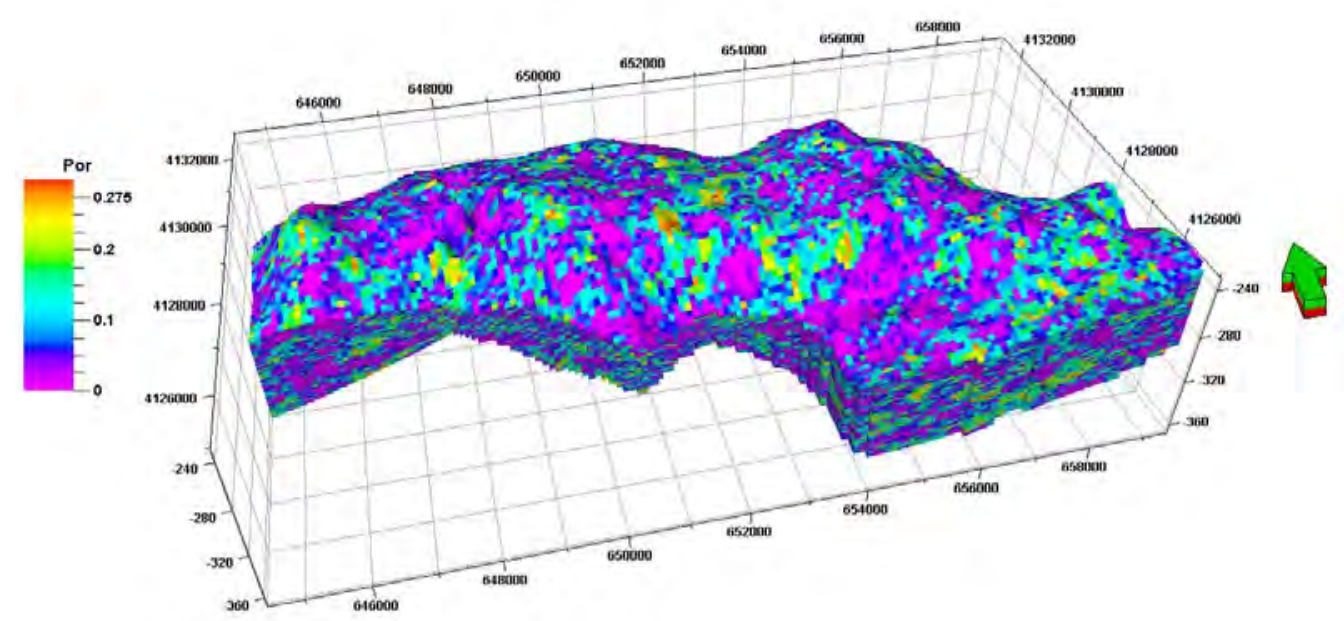

Figure 13-9. Simulated upscaled porosity fields within the Aneth unit model boundary.

Next, we applied the porosity and permeability relationship $\left(k=0.02 e^{0.2959 \phi}\right)$ from the core plug samples and assigned the permeability values accordingly from the porosity values (see Figure 13-6). As a result of this log-linear relationship, the simulated permeabilities exhibit a log-normal distribution. Whereas, the porosity field is normally distributed. Figure 13-10 illustrates the corresponding permeability field from the porosity field illustrated by Figure 13-9.

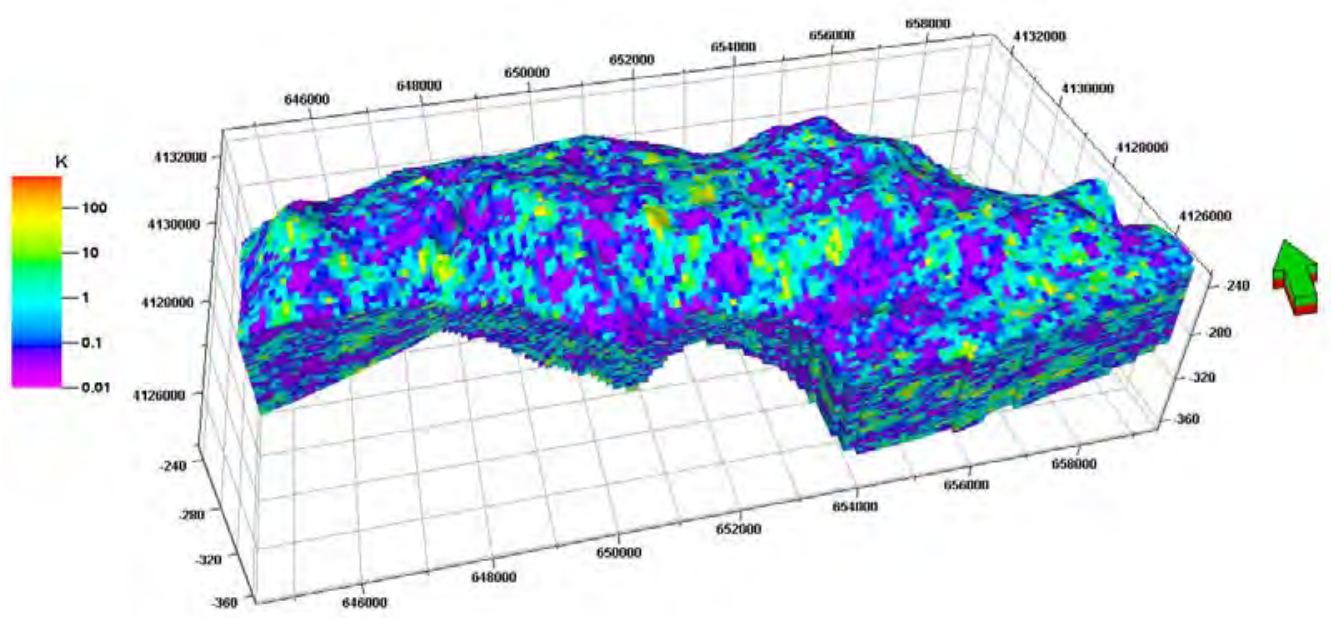

Figure 13-10. Corresponding permeability $(\mathrm{mD})$ field based on the log-linear relationship between permeability and porosity. 


\section{Grid Conversion and Upscaling for PFloTran Simulator}

For numerical simulations, we utilized PFloTran, a massively parallel subsurface multiphase, multi-component reactive transport flow simulator based on the PETSc, SAMRAI and MPI packages [Lu and Lichtner, 2006]. PFloTran's capabilities have been adopted to demonstrate the various flow and transport processes in relation to subsurface contaminant and geological $\mathrm{CO}_{2}$ sequestration [Hammond et al., 2007]. The detailed application of the PFloTran simulator is described in Section 4.

Since PFloTran is restricted to orthogonal grid models ("structured grids"), we conducted a grid conversion and remapped the porosity distribution into a new upscaled orthogonal grid by a volume-weighted averaging method to preserve the overall volume between the two grids. Each cell size has been maintained with the same horizontal cell dimension such as $100 \mathrm{~m}$ by $100 \mathrm{~m}$ in the $\mathrm{x}$ and y directions. Vertical grid spacing with the constant $\Delta \mathrm{z}$ value of $2.5 \mathrm{~m}$ were used and an additional grid setting with $\Delta \mathrm{z}=7 \mathrm{~m}$ was created for examining the effect of grid resolution (see Section 4).

Upscaling was accomplished by matching geometry, which involves matching actual $\mathrm{z}$ levels. This is typically useful when upscaling from an irregular grid to a regular grid. A simplified method for cell matching was also applied, where all cells with their center inside the upscaled cell were averaged to obtain a property value. If volume weighting is used, the entire volume of an employed line grid cell was used as the weighting mechanism. The newly-upscaled orthogonal grid maintains the same horizontal cell dimension in the $\mathrm{x}$ and $\mathrm{y}$ directions. Because of the difference $(>100 \mathrm{~m})$ in the structural highest and lowest point of the Desert Creek formation in the Aneth Unit area, the number of layers in the upscaled orthogonal grid $(\Delta \mathrm{z}=2.5 \mathrm{~m})$ did not decrease, totaling 663,600 total cells. Figure 13-11 illustrates the updated porosity distribution mapped onto the orthogonal grid setting $(\Delta \mathrm{z}=2.5 \mathrm{~m})$ after the volume-weighting method for the PFloTran simulator.

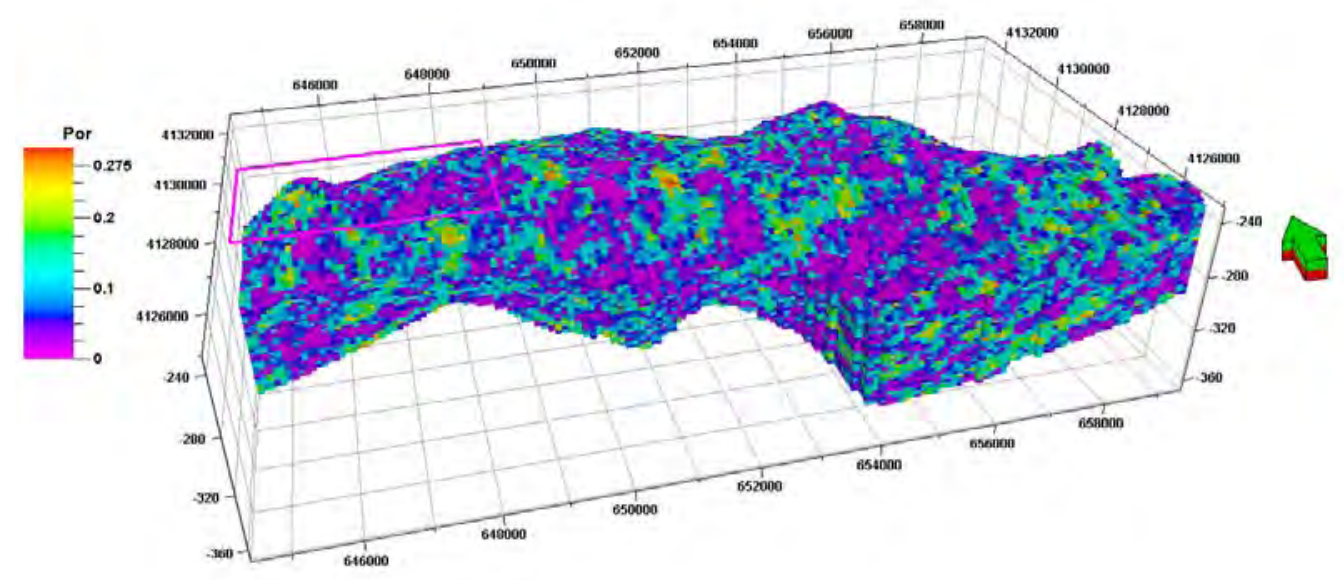

Figure 13-11. Porosity field after orthogonal grid conversion and upscaling simulator in the Aneth Unit model boundary. Subarea for the numerical simulation work given in the Section 4 is shown with the rectangular boundary. 
The constructed static model served as the primary input of subsequent numerical simulations. Since the Phase II project took place in the Sections 13 and 14 (T40S R23E), our simulation work focused only on the subarea in/near the Section 13 and 14 shown in the Figure 13-11. Figures 13-12 and 13-13 illustrate the porosity and permeability field, respectively in the modeling domain for the numerical simulation work described in the Section 4. Each property model consists of 62,608 cells ( 43 x 26 x 56) for $\Delta \mathrm{z}=2.5 \mathrm{~m}$.

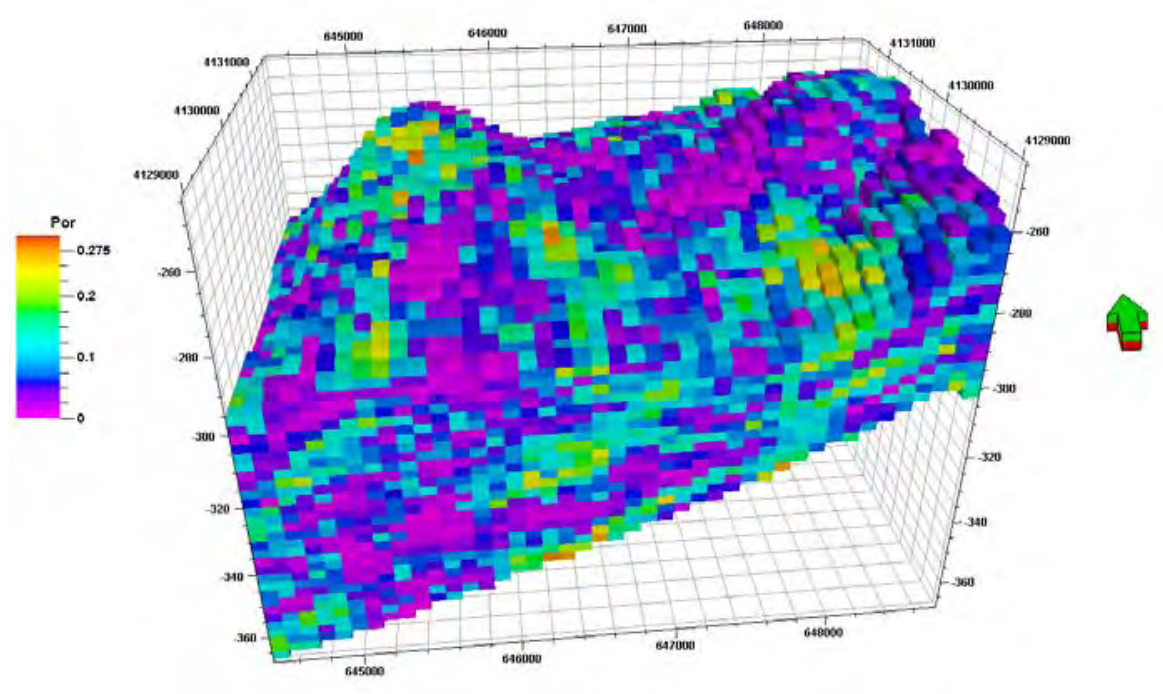

Figure 13-12. Porosity field prepared for the numerical simulation after orthogonal grid conversion and upscaling in/around the Section 13 \& 14 (T40S $R 23 E$ ). Vertical exaggeration is 25 times. $\Delta z=2.5 \mathrm{~m}$.

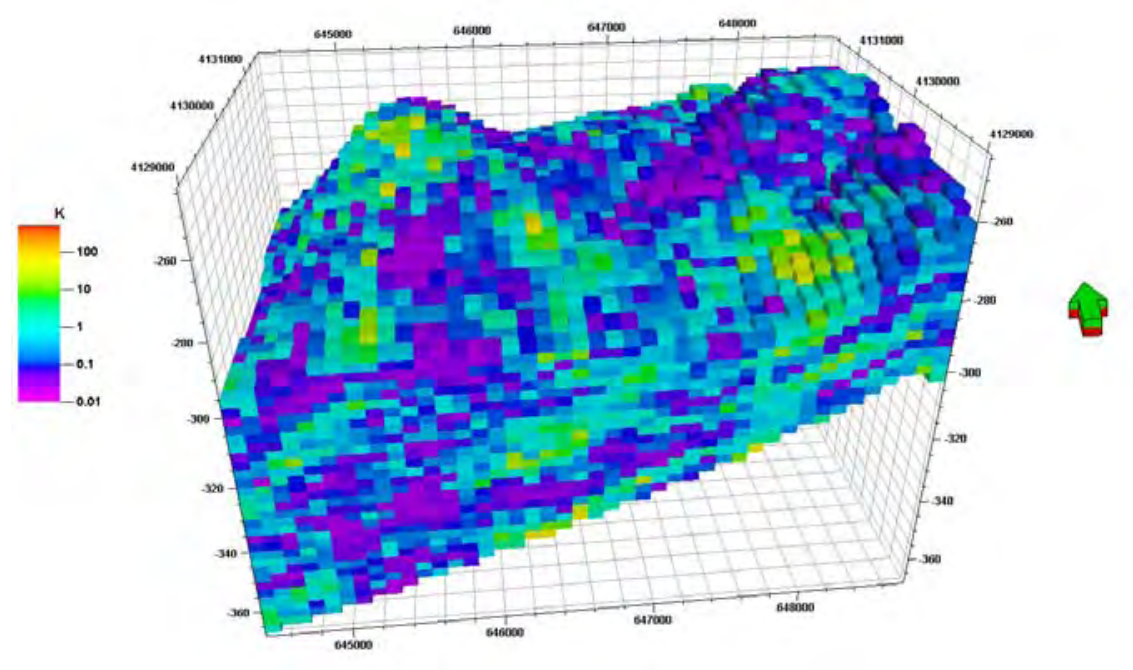

Figure 13-13. Permeability (mD) field prepared for the numerical simulation after orthogonal grid conversion and upscaling in/around the Section 13 \& 14 (T40S R23E). Vertical exaggeration is 25 times. $\Delta z=2.5 \mathrm{~m}$. 


\section{Numerical Simulation}

\section{Grid Generation for Numerical Simulation}

The computational domain mainly covers Sections 13 and 14, but was extended to include their adjacent regions. Within this domain, only the Desert Creek formation is considered, assuming the Gothic Shale is an effective barrier to prohibit the vertical migration of supercritical $\mathrm{CO}_{2}$. Two grids with a grid spacing of $100 \mathrm{~m} \times 100 \mathrm{~m} \times 7 \mathrm{~m}$ and $100 \mathrm{~m} \times 100 \mathrm{~m} \times 2.5 \mathrm{~m}$ were generated to test the effects of grid resolution, leading to $43 \times 26 \times 20$ (coarse) and 43×26x56 (fine) grids. The porosity profiles represented by these two grids are shown in Figures 13-14 a) and b), respectively.

The volume averaged porosity and permeability of the coarse and fine grid are listed in Table 13-3. In order to facilitate numerical simulations, the relative permeability and capillary pressure are arbitrarily assigned as:

$$
\begin{gathered}
p_{c}=\frac{1}{\alpha}\left(s_{e}^{-1 / r}-1\right)^{1 / n} \\
k_{r w}=s_{e}^{1 / 2}\left[1-\left(1-s_{e}^{1 / m}\right)^{m}\right]^{2} \\
k_{r g}=\left(1-s_{e}\right)^{1 / 2}\left[1-\left(1-s_{e}^{1 / m}\right)^{m}\right]^{2}
\end{gathered}
$$

where the parameters $\mathrm{m}=0.75, \alpha=0.001$. The irreducible water and gas saturation is given as 0.25 and 0.10 , respectively.

Since detailed records of bottom hole pressure of the production wells are not available, realistic history matching cannot be accomplished. To facilitate numerical simulations, we simplified the model to a two phase $\mathrm{SC} \mathrm{CO}_{2}$ / brine system and artificially assigned 14 wells in the domain according to the pattern of injection well locations in Section 13 and 14 of the Aneth Field. The well locations are listed in Table 13-4. No production wells are included in our model.

The initial and boundary conditions are set at hydrostatic conditions with a depth of $1,735 \mathrm{~m}$ for the formation top. Salinity was assumed to be $1 \mathrm{~mol} / \mathrm{kg}$.

Table 13-3. Volume averaged porosity and permeability

\begin{tabular}{|l|l|l|}
\hline Grid & coarse & fine \\
\hline average porosity & 0.0820 & 0.0816 \\
\hline average permeability $(\mathrm{mD})$ & 0.7184 & 1.196 \\
\hline
\end{tabular}


Table 13-4. Well location and depth

\begin{tabular}{|c|c|c|c|c|}
\hline Well index & Grid index & $\mathbf{X}(\mathbf{m})$ & $\mathbf{Y}(\mathbf{m})$ & Depth (m) \\
\hline 1 & $(6,9)$ & 550 & 850 & 98 \\
\hline 2 & $(6.17)$ & 550 & 1650 & 98 \\
\hline 3 & $(10,7)$ & 950 & 650 & 84 \\
\hline 4 & $(10,15)$ & 950 & 1450 & 84 \\
\hline 5 & $(14,9)$ & 1350 & 850 & 84 \\
\hline 6 & $(14,17)$ & 1350 & 1650 & 91 \\
\hline 7 & $(18,7)$ & 1750 & 650 & 70 \\
\hline 8 & $(18,15)$ & 1750 & 1450 & 84 \\
\hline 9 & $(22,9)$ & 2150 & 850 & 77 \\
\hline 10 & $(22,17)$ & 2150 & 1650 & 77 \\
\hline 11 & $(26,7)$ & 2550 & 650 & 70 \\
\hline 12 & $(26,15)$ & 2550 & 1450 & 84 \\
\hline 13 & $(30,9)$ & 2950 & 850 & 1650 \\
\hline 14 & $(30,17)$ & 2950 & & 84 \\
\hline
\end{tabular}

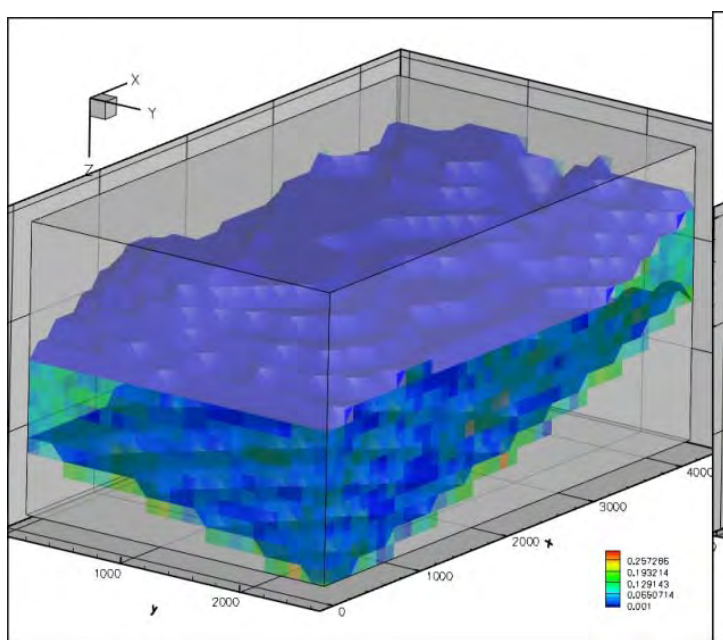

a) coarse

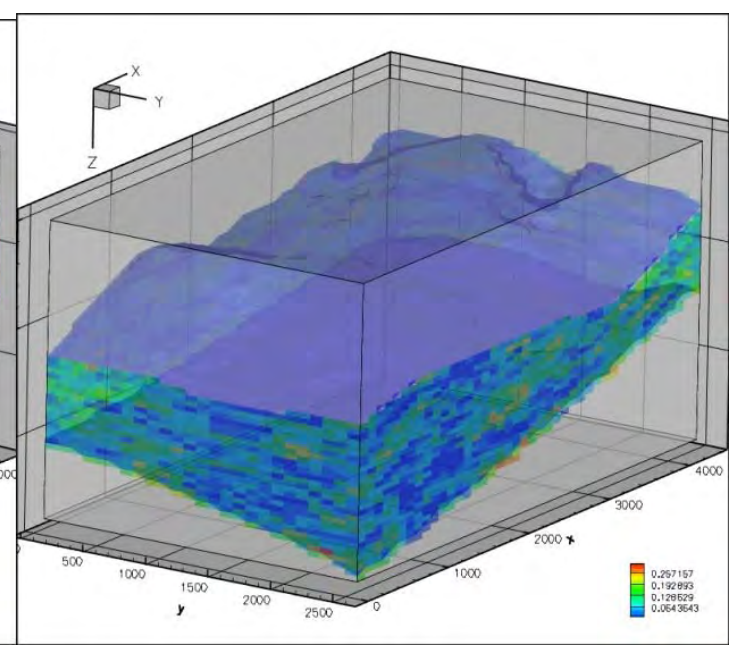

b) fine

Figure 13-14. Porosity distribution represented on coarse and fine grid 
The well locations listed in Table 13-4 are based on a cartesian (x-y) coordinate system with the origin at the northeast corner. The positive directions are east and south for the $\mathrm{x}$ and $\mathrm{y}$ axes, respectively. The depth of the injection point is referenced to the formation top at $1,735 \mathrm{~m}$ depth. The positive direction is downward.

\section{Preliminary Simulation Results}

According to the injection history, within approximately half a year, the total injection amounts were 907,241 and 885,540 mcf (i.e. 5.046E4 and 4.926E4 Tons) in Sections 13 and 14, respectively. The total injection amount in this time was $0.1 \mathrm{MMt}$, or approximately $6.43 \mathrm{~kg} / \mathrm{s}$. The injections were evenly assigned to 14 wells in our domain. Figures 13-15 a) and b) show the pressure profiles drawn as an iso-surface. Figure 13-15 indicates that the pressure distributions obtained with coarse and fine grid simulations are similar to each other. The maximum pressures achieved were 33.34 and $34.24 \mathrm{MPa}$ when injection ceased ( 0.5 years), differing by $2.6 \%$. According to these observations, investigations on pressure distributions were conducted mainly on the coarse grid. Because of low permeability, the $\mathrm{SC} \mathrm{CO}_{2}$ plume migrated slowly. Figures 13-16 a) and b) show the saturation profiles calculated on the coarse and fine grid at 100 years. On the fine grid simulation, predicted plume migration in the both vertical and horizontal directions was slightly faster than that with coarse grid, though the differences were not significant. However, the highest SC phase saturation at 100 years was 0.16 and 0.36 , as predicted by simulations on the coarse and fine grids, respectively. Although the maximum saturation differed, the size and shape of SC phase plume are still similar. The simulation results with the coarse gird is acceptable regarding area-of-review, etc. Simulations for this work were conducted mainly using a coarse grid.

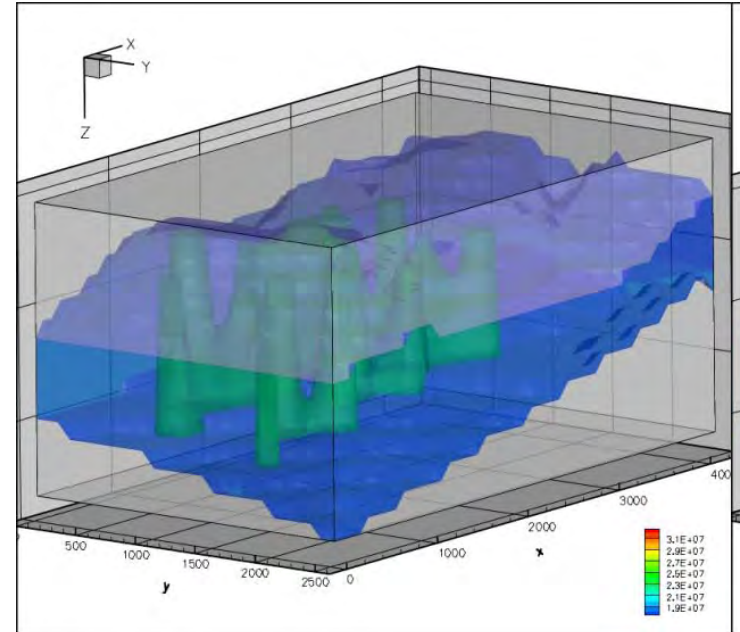

a) coarse

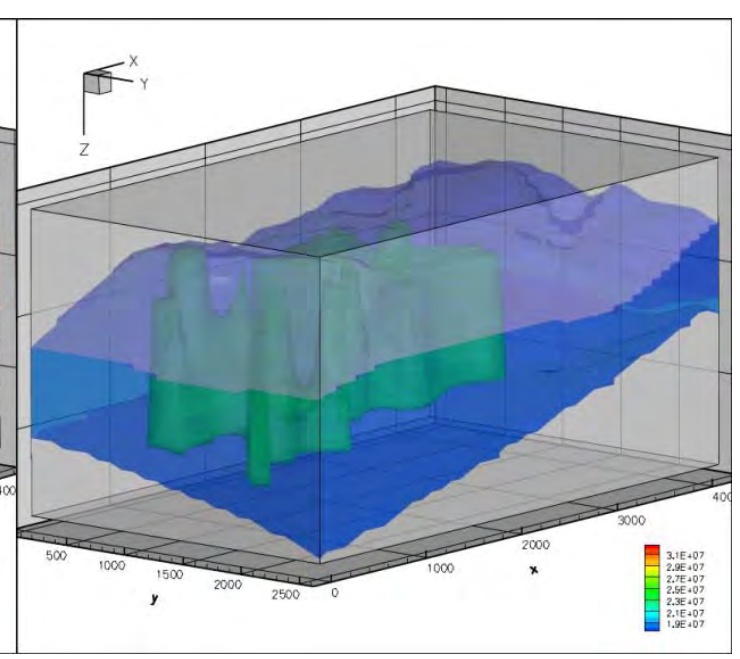

b) fine

Figure 13-15. Pressure profiles at the end of the injection period (0.5 years) on the coarse and fine grid. 


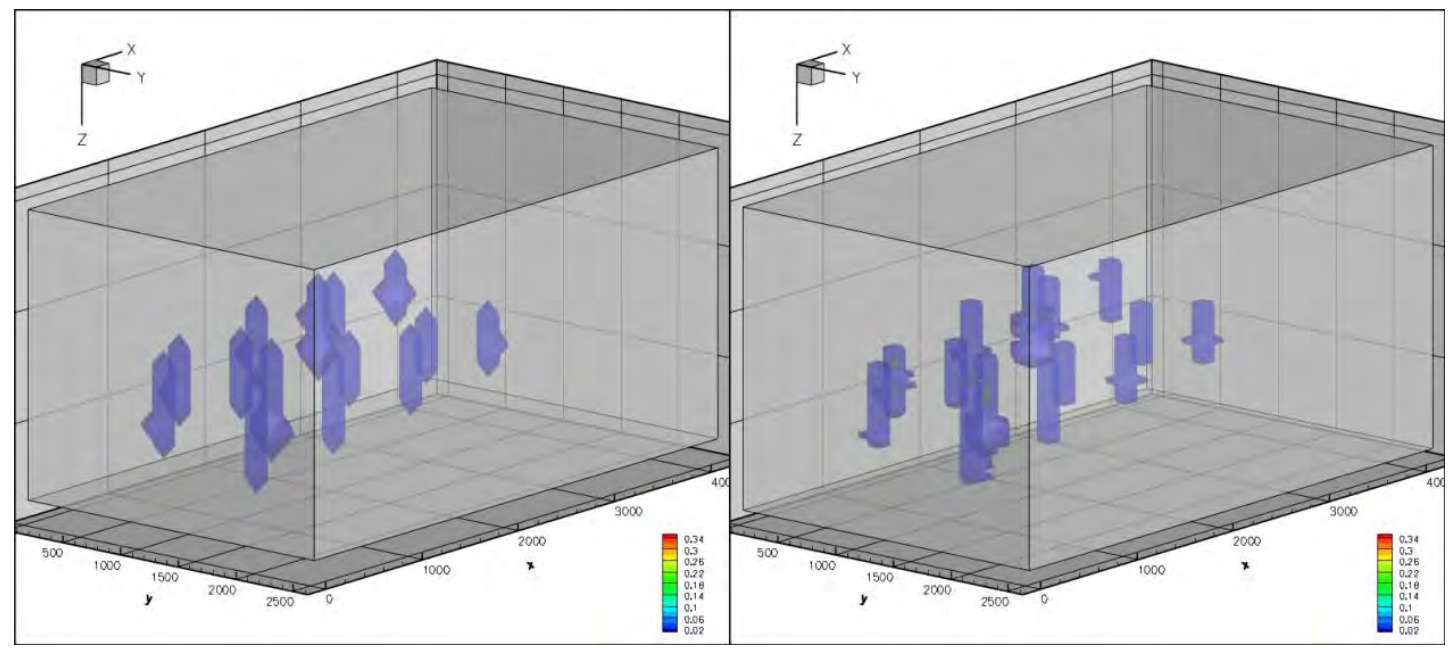

a) coarse

b) fine

Figure 13-16. Saturation profiles at the end of the injection period (100 years) on the coarse and fine grid.

\section{Optimizations to prevent over-pressuring}

Over-pressuring behavior with 1MMt/year: The lithostatic pressure is $44.2 \mathrm{MPa}$ at the depth of the formation top of the Desert Creek (1735m). This was considered the highest allowable pressure. Constrained by this threshold, the attempt to inject $1 \mathrm{MMt}$ of $\mathrm{CO}_{2}$ within 1 year into Sections 13 and 14 failed even when the injection was distributed among all 14 wells. Figure 13-17 shows the pressure profile at 1 year. In the central part of the domain, pressure exceeded the threshold. This feature is more clearly illustrated in Figure 13-17 b); the iso-surface with the lithostatic pressure envelopes the whole region containing the 14 injection wells, instead of the well vicinities. The highest pressure reached is $118 \mathrm{MPa}$, over double ambient pressure and far exceeding fracture criteria. As a result, the model suggests that it is not advisable to inject $1 \mathrm{MMt}$ of $\mathrm{CO}_{2}$ into Sections 13 and 14 in one year without well stimulation or other advanced reservoir engineering strategies. 


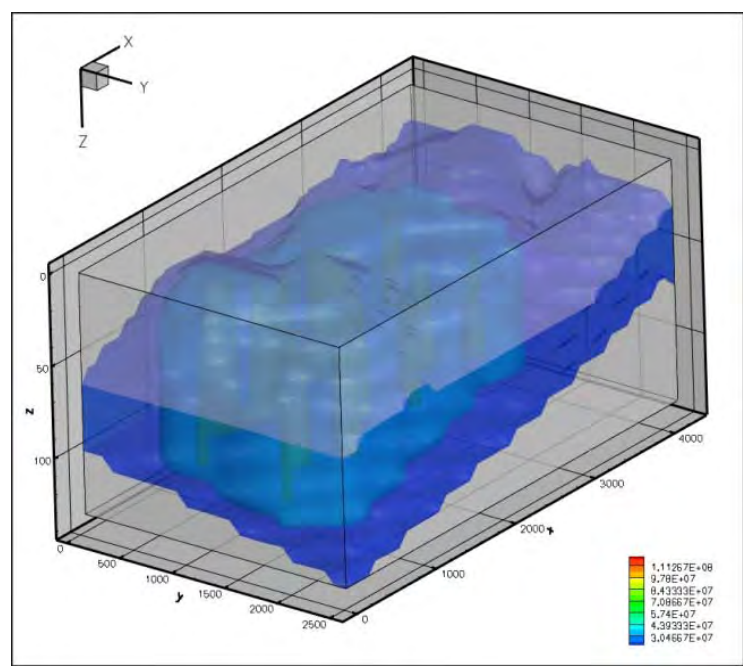

a) overall

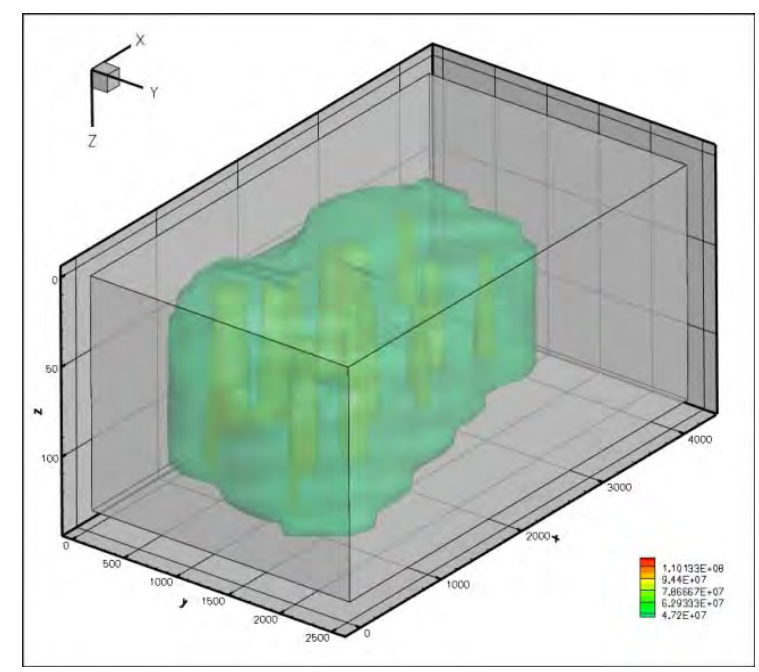

b) at 44.2MPa

Figure 13-17. Pressure iso-surface drawn at the end of injection (1 year)

Seeking the maximum injection rate: From the results of section 5.3.1, the resulting question is what is the maximum injection rate if all 14 wells are operational? We addressed this issue with four simulations. The operational conditions of maximum pressure are listed in Table 13-5.

Table 13-5. Injection rate distributions among 14 wells.

\begin{tabular}{|c|c|c|c|c|c|}
\hline & & Case 1 & Case 2 & Case 3 & Case 4 \\
\hline \multirow{14}{*}{$\begin{array}{c}\text { Injection rate } \\
(\mathrm{kg} / \mathrm{s})\end{array}$} & 1 & 1 & 0.6 & 0.6 & 0.7 \\
\hline & 2 & 1 & 0.6 & 0.6 & 0.6 \\
\hline & 3 & 1 & 0.6 & 0.4 & 0.4 \\
\hline & 4 & 1 & 0.6 & 0.4 & 0.4 \\
\hline & 5 & 1 & 0.6 & 0.6 & 0.6 \\
\hline & 6 & 1 & 0.6 & 0.6 & 0.6 \\
\hline & 7 & 1 & 0.6 & 0.6 & 0.6 \\
\hline & 8 & 1 & 0.6 & 0.6 & 0.6 \\
\hline & 9 & 1 & 0.6 & 0.4 & 0.6 \\
\hline & 10 & 1 & 0.6 & 0.6 & 0.6 \\
\hline & 11 & 1 & 0.6 & 0.8 & 0.8 \\
\hline & 12 & 1 & 0.6 & 0.6 & 0.6 \\
\hline & 13 & 1 & 0.6 & 0.8 & 0.5 \\
\hline & 14 & 1 & 0.6 & 0.8 & 0.6 \\
\hline \multicolumn{2}{|c|}{ Total (MMt/yr) } & 0.4415 & 0.2649 & 0.2649 & 0.2523 \\
\hline \multicolumn{2}{|c|}{ Highest pressure (MPa) } & 62.07 & 45.77 & 46.89 & 40.74 \\
\hline
\end{tabular}


The analysis of maximum sustainable injection rate included several steps:

1. The total injection rate was reduced to $0.4415 \mathrm{MMt} / \mathrm{year}$ and evenly distributed among the 14 wells. Figure 13-18 shows the pressure profile at 1 year. Though the high-pressure zone was much smaller than the $1 \mathrm{MMt} /$ year injection rate, it was still continuous and occupied the whole central region of the model.

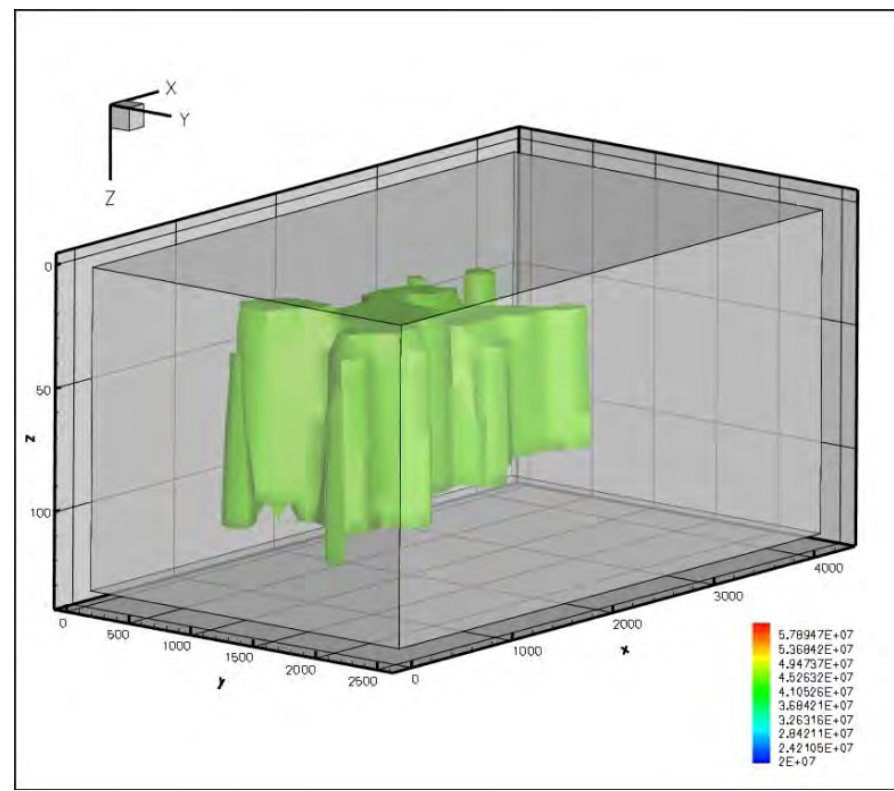

Figure 13-18. Pressure profile at year 1, Case 1 (iso-surface@p=44.2MPa).

2. The total injection rate was reduced to $0.2649 \mathrm{MMt} / \mathrm{year}$ and evenly distributed among the 14 wells. As shown in Figure 13-19, the high-pressure region only exists in the vicinity of 3 wells (Well 3, 4, 9) where the permeability is relatively low. It is possible that over-pressuring can be avoided by redistributing the injection rate among these 14 wells.

3. In order to determine the re-distribution scheme, the pressure profile was re-drawn as an iso-surface at $35 \mathrm{MPa}$, as shown in Figure 13-20. The larger isosurface dome indicated a higher pressure buildup. According to Figure 13-20, the injection rates at Well 3, 4, 9 should be decreased (by 33\% in Case 3). Wells 1, 2, 5,7 , and 8 are adjacent to the over-pressured wells, so the injection rate is not changed in Case 3. Instead, the injection rates at Wells 11, 13, and 14 were increased by $33 \%$. As a result, the over-pressurization at Wells 3, 4, and 9 was reduced. However, over-pressuring occurred at Well 11, possibly caused by the increased injection rate at Wells 13 and 14 (shown in Figure 13-21). 


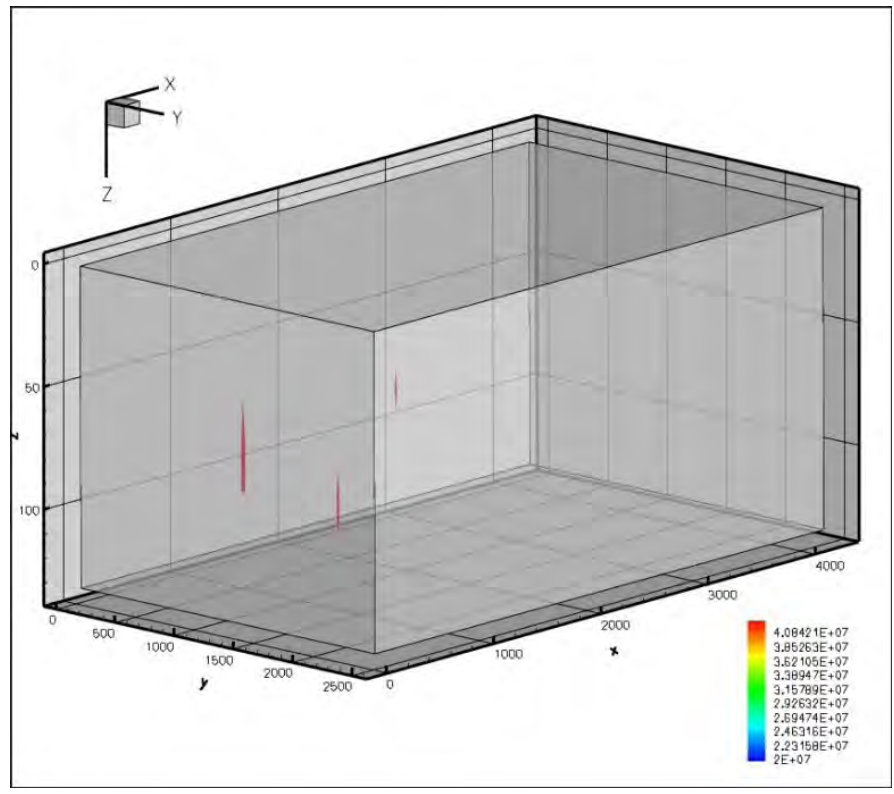

Figure 13-19. Pressure profile at 1 year, Case 2 (iso-surface@ $p=44.2 M P a)$.

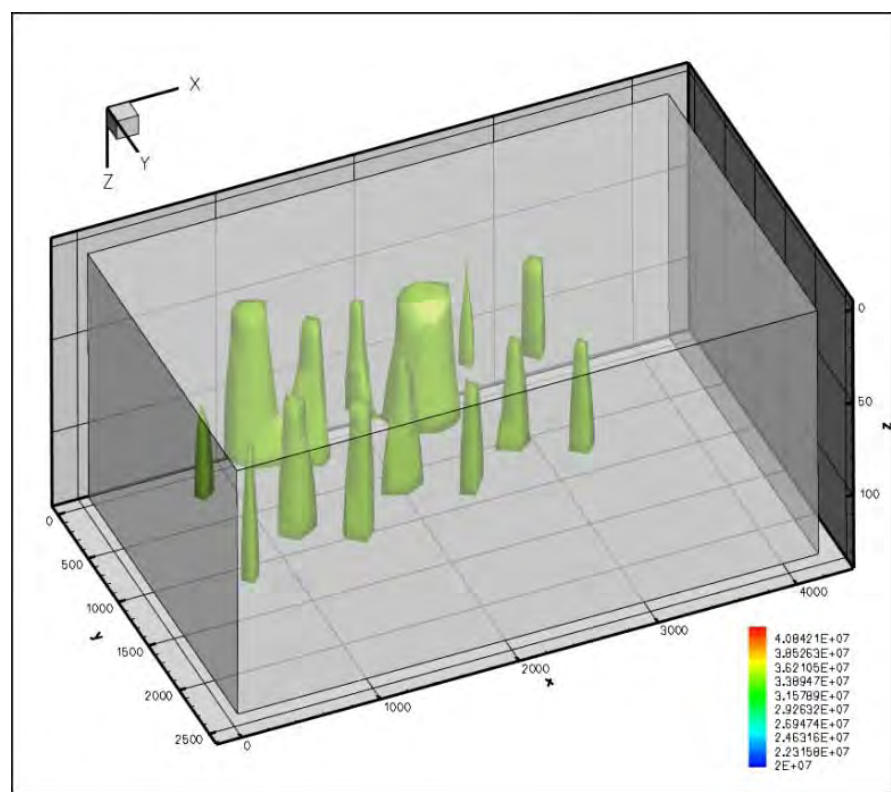

Figure 13-20. Pressure profile at 1 year, Case 2 (iso-surface@p=35MPa). 


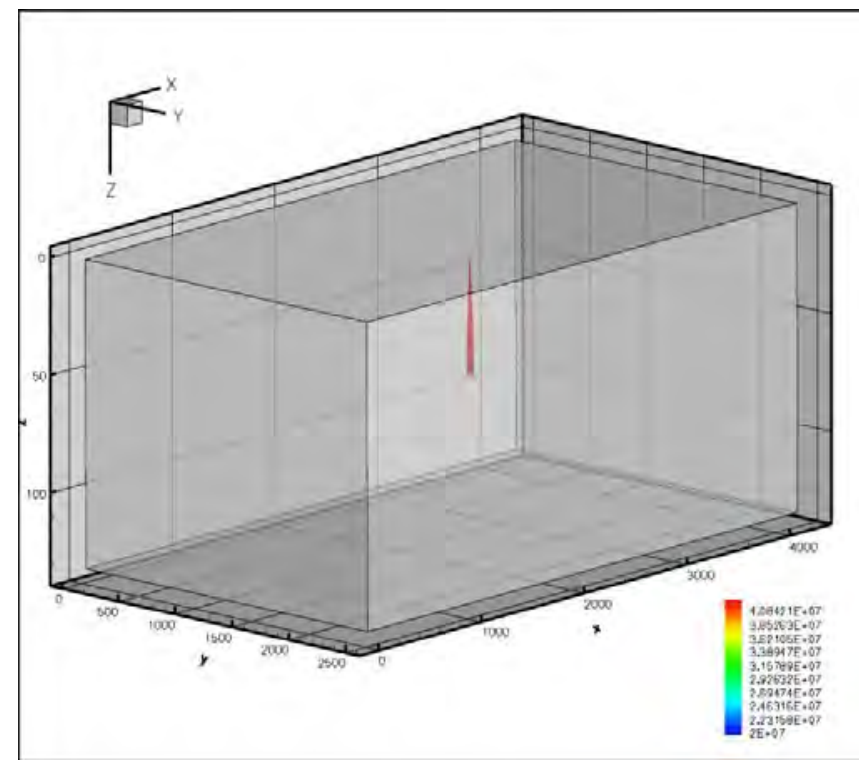

Figure 13-21. Pressure profile at 1 year, Case 3 (iso-surface@p=44.2MPa).

4. In Case 4, the injection rates at Wells 13 and 14 were reduced to $0.5 \mathrm{~kg} / \mathrm{s}, 0.6$ $\mathrm{kg} / \mathrm{s}$, while the injection rate at Well 1 was increased to $0.7 \mathrm{~kg} / \mathrm{s}$ in order to increase the distance between the wells with high injection rates. The highest pressure at year 1 decreased to $40.74 \mathrm{MPa}$. The total injection rate was $0.2523 \mathrm{MMt} / \mathrm{yr}$. According to these analyses, the suggested total injection rate should not exceed $0.25 \mathrm{MMt} / \mathrm{yr}$, which is about double the injection rate applied in the Aneth Field. Figure 13-22 shows the SC phase saturation at 100 years with this injection scheme. Because of the low permeability and relatively small amount of total $\mathrm{CO}_{2}$ injected, the $\mathrm{SC}$ plume did not reach the top of the formation at year 100 .

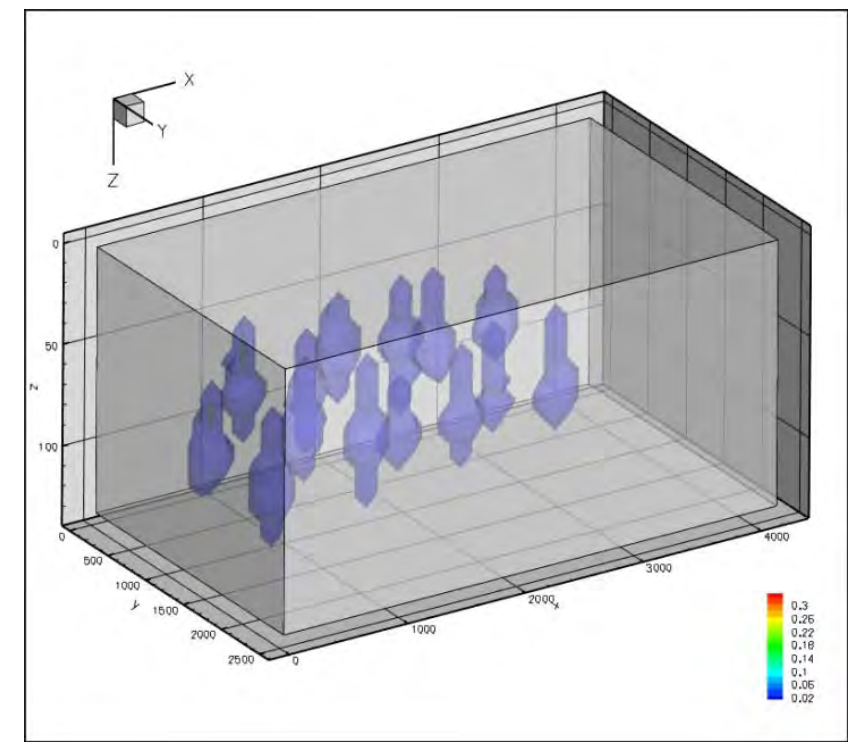

Figure 13-22. Saturation profile at 100 years, Case 4 with a total injection rate of 0.2523MMt/yr. 
Investigations on permeability uncertainty: As indicated in previous section, the target injection rate is $1 \mathrm{MMt} / \mathrm{yr}$, though our numerical prediction with the permeability and porosity listed in Table 13-2 indicates that this rate is not practical, at least not without additional advanced reservoir engineering design efforts. However, our simulations do possess some uncertainty; for example, the permeability data obtained through our porosity - permeability correlation may not be effectively representative of the local subsurface values. According to the geological report on the Aneth site, the average permeability is 6 to $20 \mathrm{mD}$, approximately 10 times higher than the value applied in our simulations. Since uncertainty in permeability values are inevitable, the investigation of its effects were investigated by 2 simulations with artificially increased permeability (5 (Case 1) and 10 (Case 2) times, 3.592 and 7.184 node by node). The total injection rate is assigned as $1 \mathrm{MMt} / \mathrm{yr}$ and evenly distributed among 14 wells, i.e. 195.7 ton/day per well.

Figures 13-23 (a) (b) and Figures 13-24 (a) (b) show the pressure profiles at the end of 1 year and saturation profiles at the end of 100 years. According to Figure 1323(a) and Figure 13-24(a), the highest pressure at the end of injection of Case 1 and 2 are 44.1 and $31.5 \mathrm{MPa}$, respectively. The highest pressure in Case 1 is just below the lithostatic pressure, and Case 2 is relatively safer. This permeability field is utilized in later investigations.

In both cases, the $\mathrm{SC} \mathrm{CO}_{2}$ plume reaches the top of the formation and accumulates beneath it. The maximum saturations are 0.634 and 0.674 in Case 1 and 2, respectively.

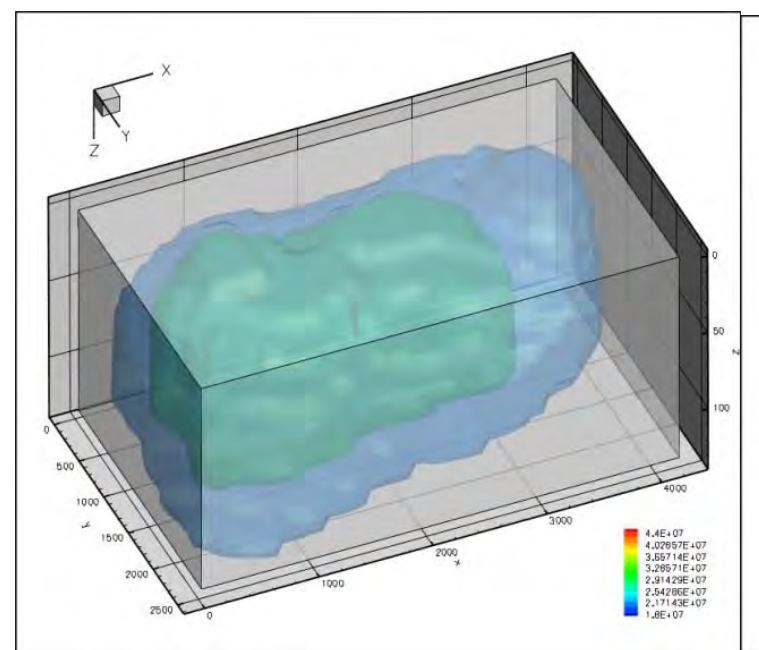

a) P@1yr permeability. 


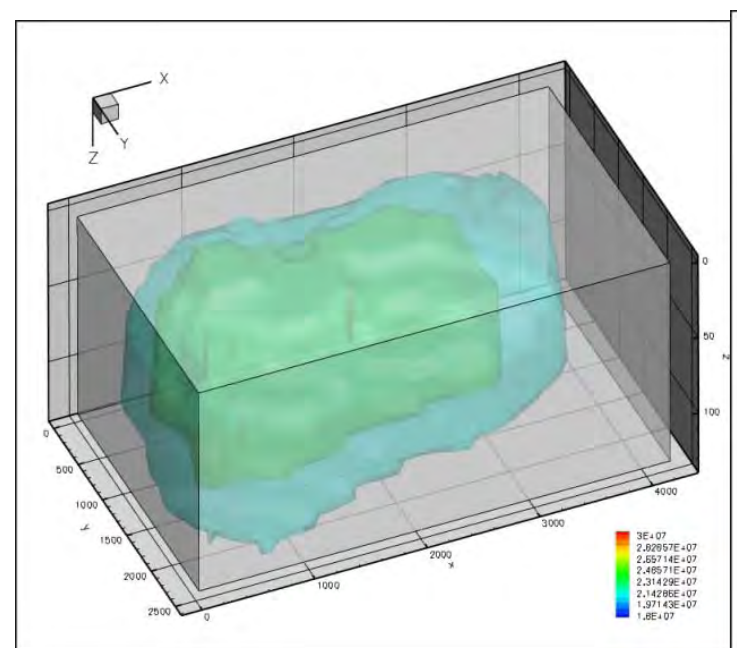

a) $P @ 1 y r$

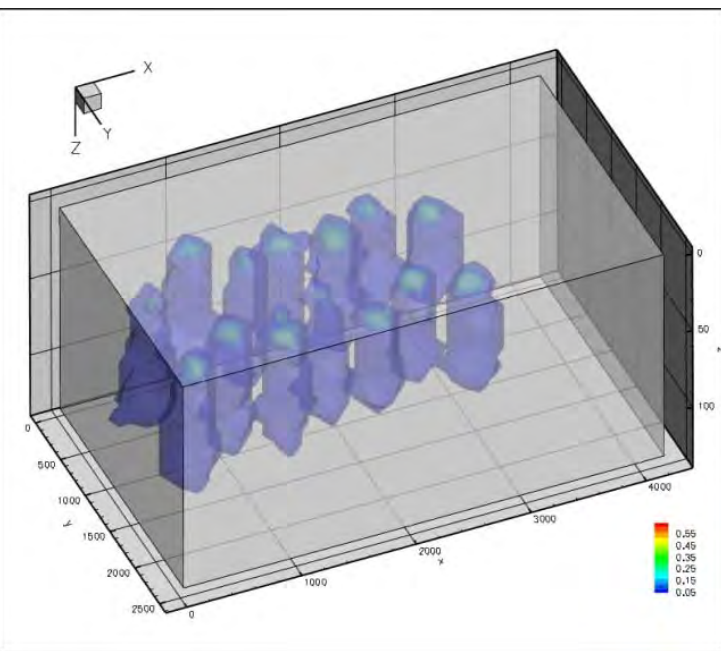

b) $S g @ 100 y r$

Figure 13-24. Pressure and saturation profile of Case 2 with artificially increased permeability.

Seeking the minimum number of injection wells: For the Aneth field Phase II testing, all injection and production wells have been completed, so this analysis does not have implications for the SWP project. However it is useful to determine the minimum number of wells for new sites under development and many depleted oil/gas fields where old wells need to be reopened or recompleted. In this work, the geological model of Aneth site is utilized as an example to identify the necessary number of wells for $1 \mathrm{MMt} / \mathrm{yr}$ injection rate.

This specific analysis included several steps:

1. according to previous simulations, half of the 14 wells should be enough to maintain the highest pressure just below the lithostatic pressure. As such, the investigation started with 8 wells. The total injection rate was evenly distributed among all wells.

2. Numerical simulations were conducted to evaluate the highest pressure and its location. Figure 13-25 showed the isosurface drawing of the pressure at 28 MPa for 6 of the wells. The well in the southeast corner had highest pressure.

3. The well associated with the highest pressure was removed for the next attempt to minimize the number of wells while at the same time maximizing pressure. For example, according to Figure 13-25, the well in the southeast corner was removed when the simulation was conducted for 5-well configuration. 


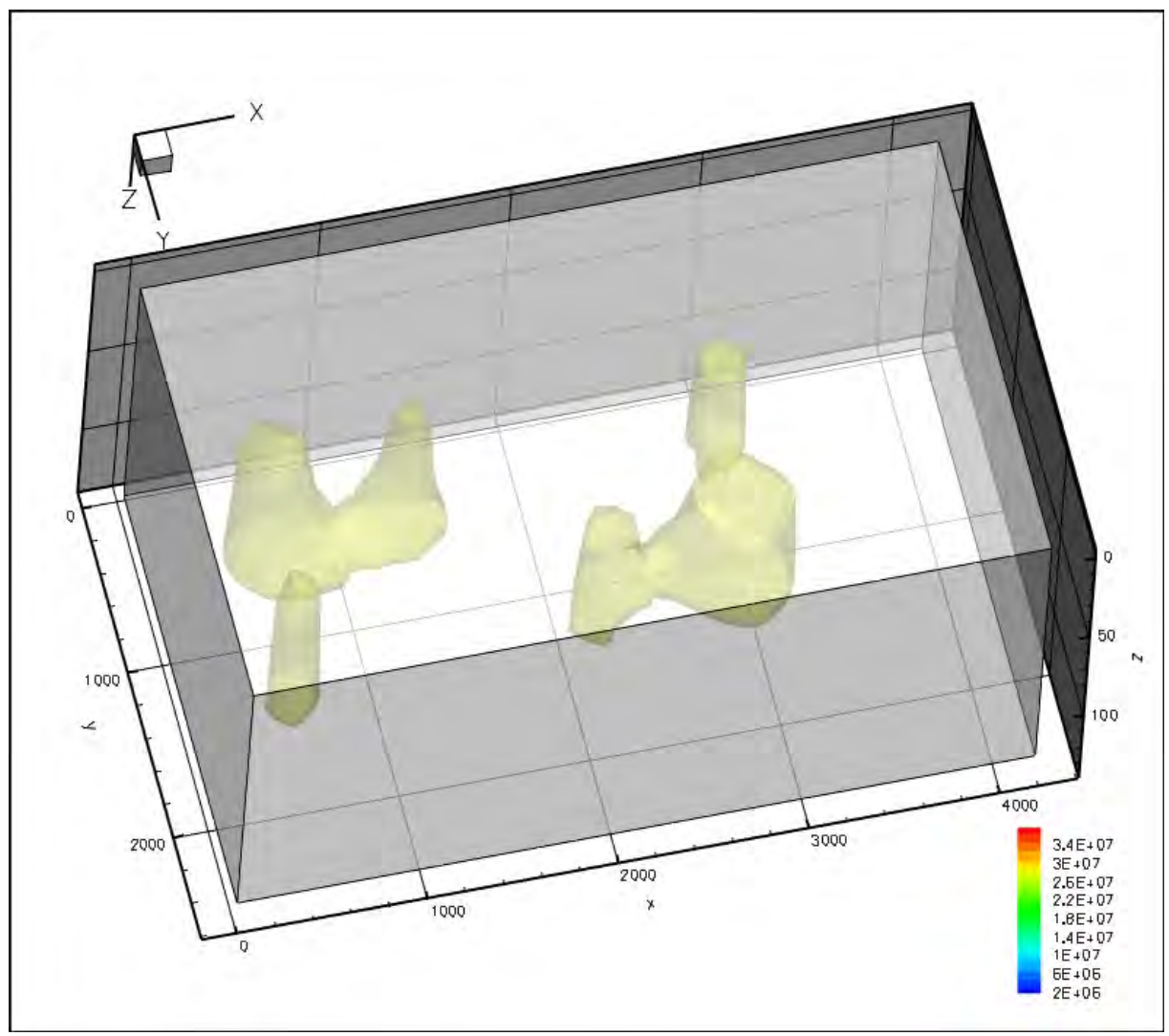

Figure 13-25. Pressure iso-surface at $28 \mathrm{MPa}$ of the 6-well configuration.

Table 13-6 shows how the highest pressure varied with the number of wells. Generally, the maximum pressure increased while number of wells decreased, though removing wells in low permeability regions sometimes can even reduce the highest pressure as shown in Table 13-6.

According to Table 13-6, the minimum number of wells can be determined under given overpressure tolerances. If the lithostatic pressure is considered as a threshold, then there should be at least 3 injection wells.

Table 13-6. Maximal pressure vs. number of injection wells.

\begin{tabular}{|c|c|}
\hline Number of Wells & Highest pressure (MPa) \\
\hline 14 & 31.50 \\
\hline 8 & 32.72 \\
\hline 7 & 32.66 \\
\hline 6 & 33.34 \\
\hline 5 & 33.70 \\
\hline 4 & 35.13 \\
\hline 3 & 38.25 \\
\hline 2 & 44.79 \\
\hline
\end{tabular}




\section{Optimizations on WAG Scheme to Enhance Residual Trapping}

It was reported that a WAG injection scheme in $\mathrm{CO}_{2}$ sequestration processes can enhance the residual trapping mechanism by the hysteresis effect. In order to investigate this aspect, hysteric relative permeability has to be applied. In this work, hysteresis in relative permeability is represented with Land's formulation [Land, 1968], in which the trapped gas saturation is a function of the minimum wetting phase saturation $\left(\mathrm{Sw}_{\min }\right)$ reached in a grid block prior to a increment in aqueous saturation. This model was adopted and further modified by [Kaluarachchi and Parker, 1992]. In that model the effective residual gas saturation, $s_{g, r}$, was given by:

$$
\begin{array}{r}
\left.\bar{S}_{g r}=\frac{1-\bar{s}_{w}}{1+R\left(1-\bar{s}_{w}\right.}\right) \\
R=\frac{1}{\bar{s}_{g r}^{\max }}-1
\end{array}
$$

where $S_{w}^{-\min }$ is the historical minimum effective water saturation, $s_{g r}^{\max }$ is the maximal irreducible gas saturation, and $\mathrm{R}$ the Land trapping coefficient.

Then the effective trapped gas saturation can be obtained by:

$$
\bar{s}_{g t}=\bar{s}_{g r}\left(\frac{\bar{s}_{w}-\bar{s}_{w}}{1-\bar{S}_{w}-\bar{s}_{w}}\right)
$$

Finally the apparent water saturation $\overline{\overline{s_{w}}}$, is defined as the sum of effective saturations of water and trapped gas:

$$
\overline{\overline{s_{w}}}=\overline{s_{w}}+\overline{s_{g t}}
$$

The non-wetting phase relative permeability function takes the same form as Rathfelder and Abriola, 1998] and [Rathfelder and Abriola, 1998] for simplicity, i.e.

$$
k_{r g}=\left(1-\overline{s_{w}}\right)^{1 / 3}\left(1-{\overline{s_{w}}}^{1 / m}\right)^{2 m}
$$

The capillary pressure and wetting phase relative permeability functions are from Parker and Lenhard [Parker and Lenhard, 1987 and Lenhard and Parker, 1987]. The capillary pressure function is obtained by:

$$
p_{c}=\frac{1}{\alpha}\left[\overline{s_{w}}-1 / m-1\right]^{1 / n}
$$

with $m=1-1 / n$ and the hysteric wetting phase relative permeability is obtained by: 


$$
k_{r w}=\bar{s}_{w}^{1 / 2}\left[1-\left(1-\frac{\bar{s}_{g r}}{1-\bar{s}_{w}^{\min }}\right)\left(1-\bar{s}_{w}^{\prime / m}\right)^{m}-\left(\frac{\bar{s}_{g r}}{1-\bar{s}_{w}^{\min }}\right)\left(1-\bar{S}_{w} \min ^{1 / m}\right)^{m}\right]^{2}
$$
forms.

By setting $\bar{s}_{g r}=0$, i.e. $\overline{\overline{s_{w}}}=\overline{s_{w}}$, Equation (29) -- (31) reduces to a non-hysteric

Figure 13-26 shows the capillary pressure, relative permeability of both the wetting and non-wetting phase on the primary drainage and 1 st order imbibition curve with the turning point at $s_{w}^{\min }=s_{w, i r}$, while $s_{g r}^{\max }=0.25$.

Four WAG schemes were investigated by simulation, as listed in Table 13-7. Case $0-3$ are set with the injection period in year 1; the total injection amount of $\mathrm{CO}_{2}$ is 1 MMt and varies with water. The shut-in and timetable of $\mathrm{CO}_{2}$ and water injection of Case $2-4$ is the same, though the water injection rates are different. Case 1 is set as a reference example with hysteric capillary pressure and relative permeability. The simulation case with non-hysteric capillary pressure and relative permeability is referred to as Case 0. Case 5 is set up to test the effect of shut-in and restart frequency.

The saturation profile at 100 years of the non-hysteric case is shown in Figure 1324(b). Figure 13-27 illustrates the saturation profiles at 100 years from case 1 to 5. Though the profiles are different from Figure 13-24 (b), they are quite similar to each other, implying similar behavior of SC plumes.

Within the simulation period, the permeability, residual and solubility trapping mechanism are more important than the mineralization trapping mechanism. Permeability trapping is determined by the formation properties and should have same effect on Case 0-5. Figure 13-28 shows the concentration profile of dissolved $\mathrm{CO}_{2}$ at 100 years. The dissolved $\mathrm{CO}_{2}$ is gathered around the $\mathrm{SC}$ phase plume; the diffusivity is relatively weak, partly because of the low porosity, permeability and short simulation period. At 100 years, about $60 \%$ of total injected $\mathrm{CO}_{2}$ remains in the SC phase, either being trapped or remaining in the free SC phase, as shown in Figure 13-29. 
Table 13-7. WAG schemes investigated (W: water injection rate [kg/s], G: $\mathrm{CO}_{2}$ injection rate $[\mathrm{kg} / \mathrm{s}]$, unit of total total injection rate is $M M t / y r)$.

\begin{tabular}{|l|l|l|l|l|l|l|l|l|}
\hline Case & 1 & \multicolumn{2}{l|}{2} & \multicolumn{2}{l|}{3} & 4 & \\
\hline Month & $\mathrm{W}$ & $\mathrm{G}$ & $\mathrm{W}$ & $\mathrm{G}$ & $\mathrm{W}$ & $\mathrm{G}$ & $\mathrm{W}$ & $\mathrm{G}$ \\
\hline 1 & - & 1.1325 & 0.0 & 1.69845 & 0.0 & 1.69845 & 0.0 & 1.69845 \\
\hline 2 & - & 1.1325 & 0.0 & 1.69845 & 0.0 & 1.69845 & 0.0 & 1.69845 \\
\hline 3 & - & 1.1325 & 0.0 & 1.69845 & 0.0 & 1.69845 & 0.0 & 1.69845 \\
\hline 4 & - & 1.1325 & 0.0 & 1.69845 & 0.0 & 1.69845 & 0.0 & 1.69845 \\
\hline 5 & - & 1.1325 & 0.0 & 0.0 & 0.25 & 0.0 & 0.5 & 0.0 \\
\hline 6 & - & 1.1325 & 0.0 & 0.0 & 0.25 & 0.0 & 0.5 & 0.0 \\
\hline 7 & - & 1.1325 & 0.0 & 0.0 & 0.25 & 0.0 & 0.5 & 0.0 \\
\hline 8 & - & 1.1325 & 0.0 & 0.0 & 0.25 & 0.0 & 0.5 & 0.0 \\
\hline 9 & - & 1.1325 & 0.0 & 1.69845 & 0.0 & 1.69845 & 0.0 & 1.69845 \\
\hline 10 & - & 1.1325 & 0.0 & 1.69845 & 0.0 & 1.69845 & 0.0 & 1.69845 \\
\hline 11 & - & 1.1325 & 0.0 & 1.69845 & 0.0 & 1.69845 & 0.0 & 1.69845 \\
\hline 12 & - & 1.1325 & 0.0 & 1.69845 & 0.0 & 1.69845 & 0.0 & 1.69845 \\
\hline Total & - & 1 & 0 & 1 & & 1 & & 1 \\
\hline
\end{tabular}

Note: Case 5, the total injection period is 8 month, spited evenly into 4 2-month period, and separated by 3 shut-in period of $4 / 3$ month each with water injection rate 0.25 $\mathrm{kg} / \mathrm{s}$.

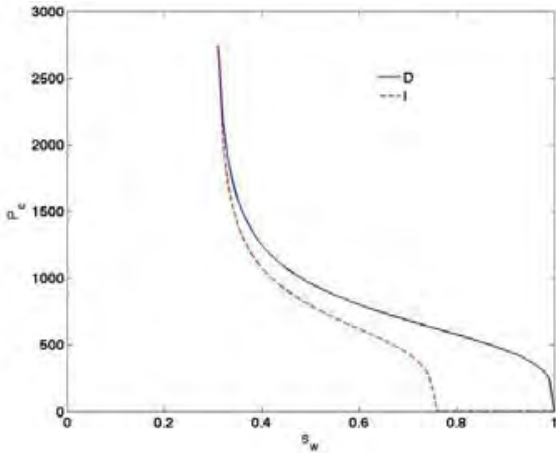

A) $\boldsymbol{P}_{c}$

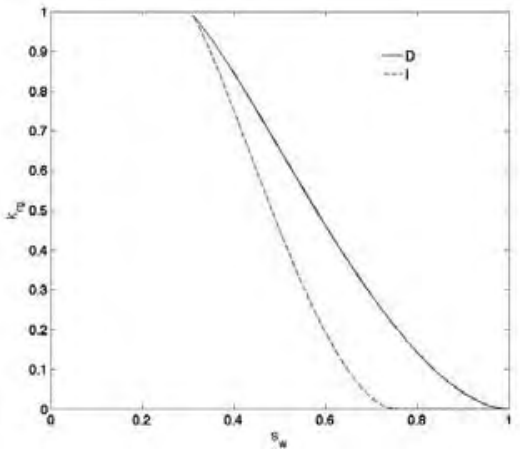

B) $\boldsymbol{k}_{r g}$

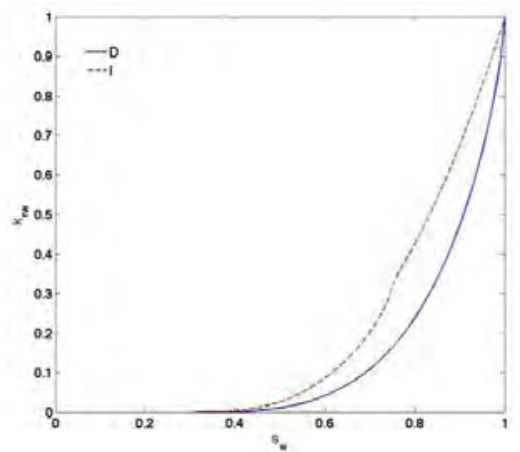

C) $\boldsymbol{k}_{r w}$

Figure 13-26. Hysteric $S-P_{c}-K_{r}$ relations. Legend ' $D$ ' stands for the primary drainage curve. Legend ' $I$ ' stands for the 1st order imbibition curve. The capillary pressure on the imbibition curve is generally lower than its value on the drainage curve of the same order; likewise for the non-wetting phase relative permeability. 


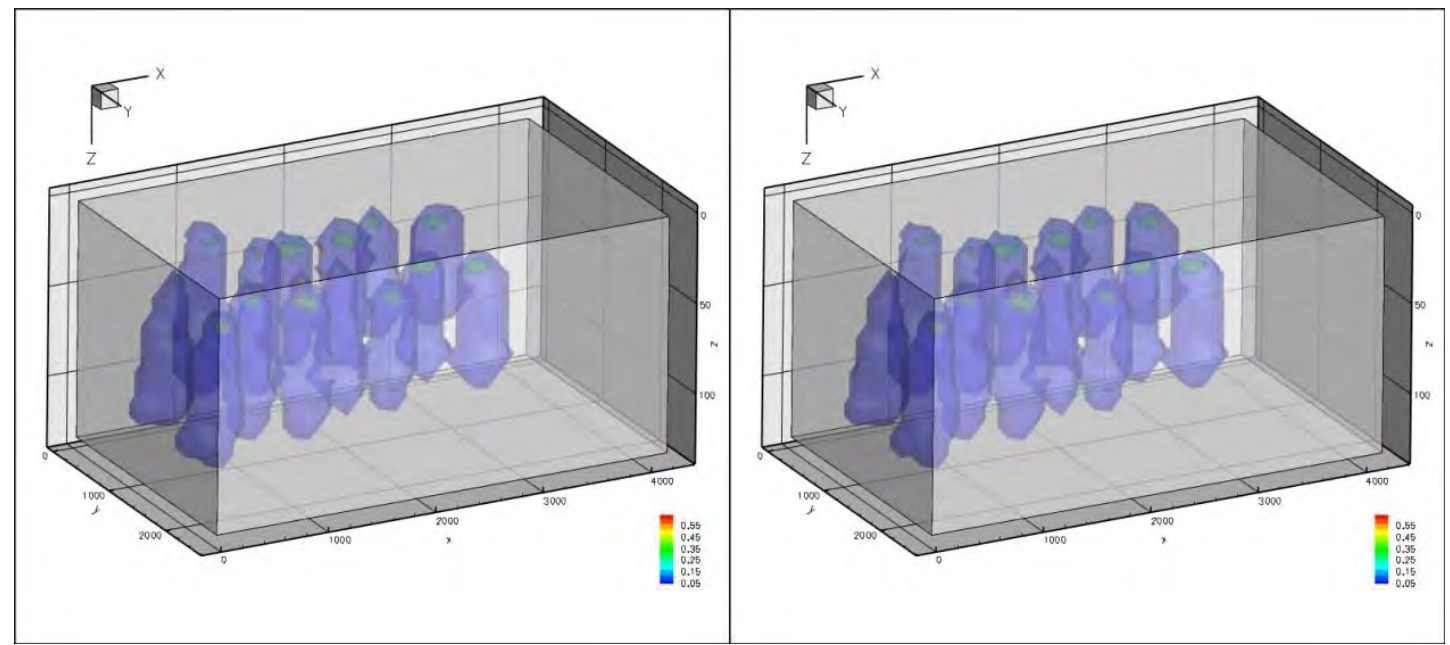

Case 1

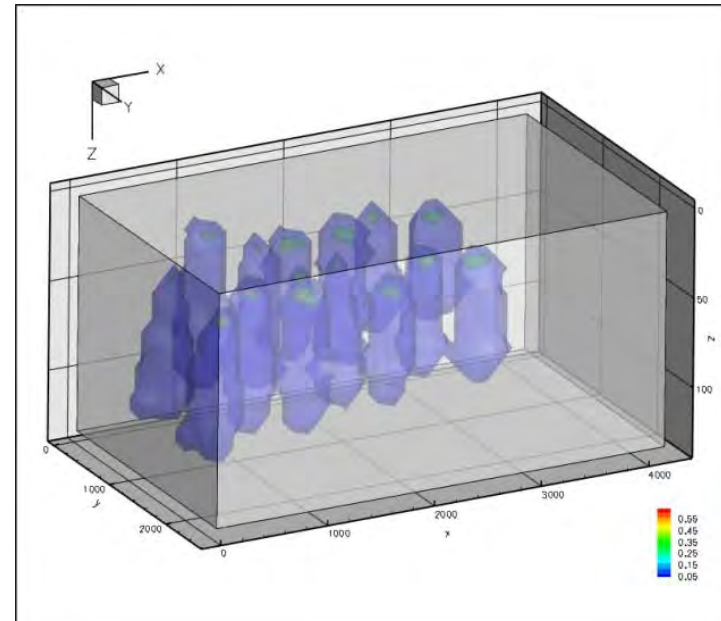

Case 3

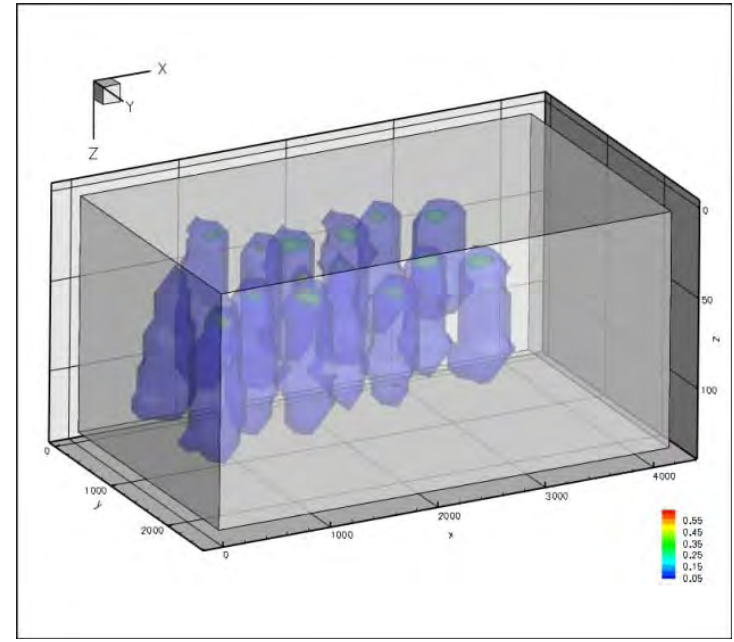

Case 2

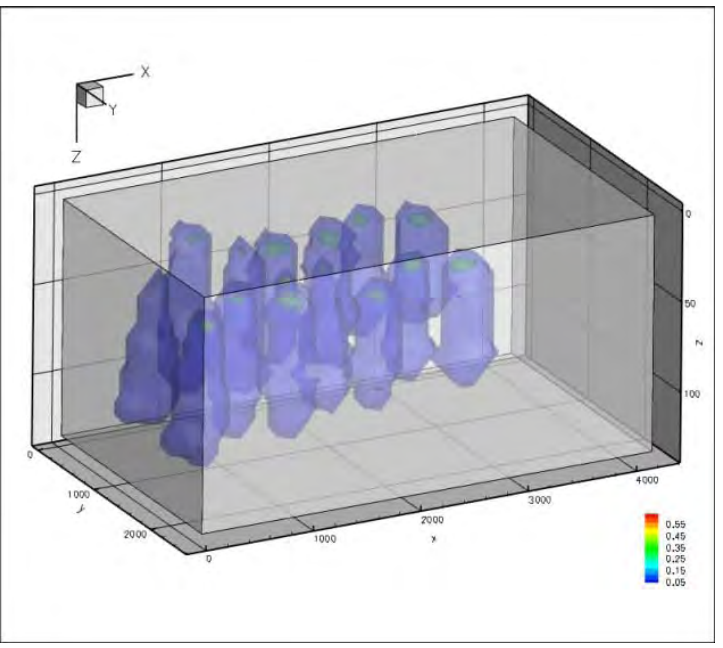

Case 4

Case 5

Figure 13-27. Saturation profiles at year 100 in Cases 1-5. 


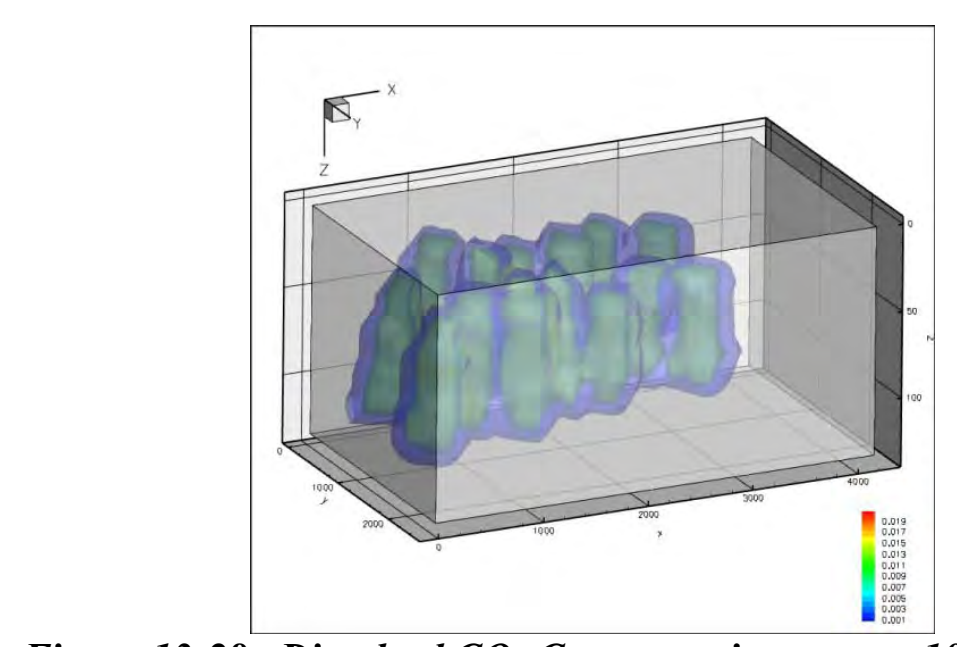

Figure 13-28. Dissolved $\mathrm{CO}_{2}$ Concentration at year 100 in Case 1.

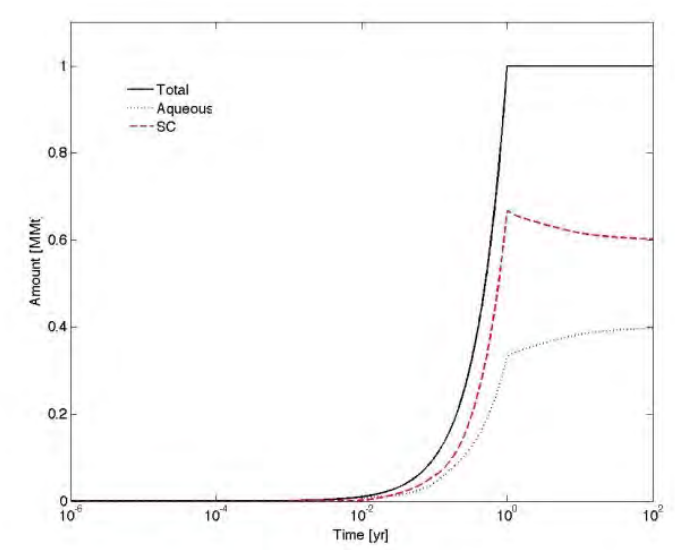

Figure 13-29. $\mathrm{CO}_{2}$ phase distribution during simulation period in Case 1.

The e ffects of $\mathrm{h}$ ysteresis a nd a $\mathrm{W}$ AG s cheme on $\mathrm{t}$ he di ssolution $\mathrm{t}$ rapping mechanism are notable in the early stage only, as shown in Figure 13-30. Generally, the dissolution trapping mechanism is weak in the non-hysteric case because of the relatively low w etting $\mathrm{p}$ hase r elative permeability, as in dicated in Figure 13-26 C). The $\mathrm{SC} \mathrm{CO}_{2}$ amount in $\mathrm{C}$ ase 0 is the h ighest am ong the 6 cases investigated. In $\mathrm{c}$ ases $\mathrm{w}$ ith $\mathrm{w}$ ater injection, the $\mathrm{S} \mathrm{C} \mathrm{C} \mathrm{O}_{2}$ amount decreases o nce fresh $w$ ater i s i njected because of $\mathrm{t}$ he dilution effect. In all $6 \mathrm{c}$ ases, the total dissolved $\mathrm{CO}_{2}$ amounts are similar at the end of simulation period.

The residual trapped $\mathrm{CO}_{2}$ amount of the non-hysteric Case 0 is stronger than the other 5 hysteric cases within the injection period because of the non-zero irreducible gas saturation imp ede the migration of $\mathrm{S} \mathrm{C}$ pha se at $\mathrm{l}$ ow $\mathrm{s}$ aturation. H owever $\mathrm{t}$ his e ffect becomes w eaker w hile SC pha se s aturation i ncreases b y c ontinuous i njection. A t 100 years, the trapped $\mathrm{S} \mathrm{C} \mathrm{C} \mathrm{O}$ is a pproximately $0.236 \mathrm{MMt}$ in a $115 \mathrm{~h}$ ysteric c ases, and is around 0.1 M Mt in the non-hysteric case 0, a s shown in Figure 13-31. In Case 3 and 4, noticeable a mounts of $\mathrm{C} \mathrm{O}_{2}$ are $t$ rapped $\mathrm{w}$ ithin i njection $\mathrm{p}$ eriod $\mathrm{b}$ ecause $\mathrm{o} f \mathrm{t}$ he $\mathrm{w}$ ater 
injection tu rns regions a djacent to w ells from d rainage to imbibition status. Increasing water injection rate and volume, the stronger the imbibition effect. $\mathrm{H}$ owever, once $\mathrm{CO}_{2}$ injection is $\mathrm{r}$ einitiated, the $\operatorname{tr}$ apped $\mathrm{C} \mathrm{O}_{2}$ became $\mathrm{m}$ obile a gain. T here is no obvi ous difference in the long-term behavior in this work.

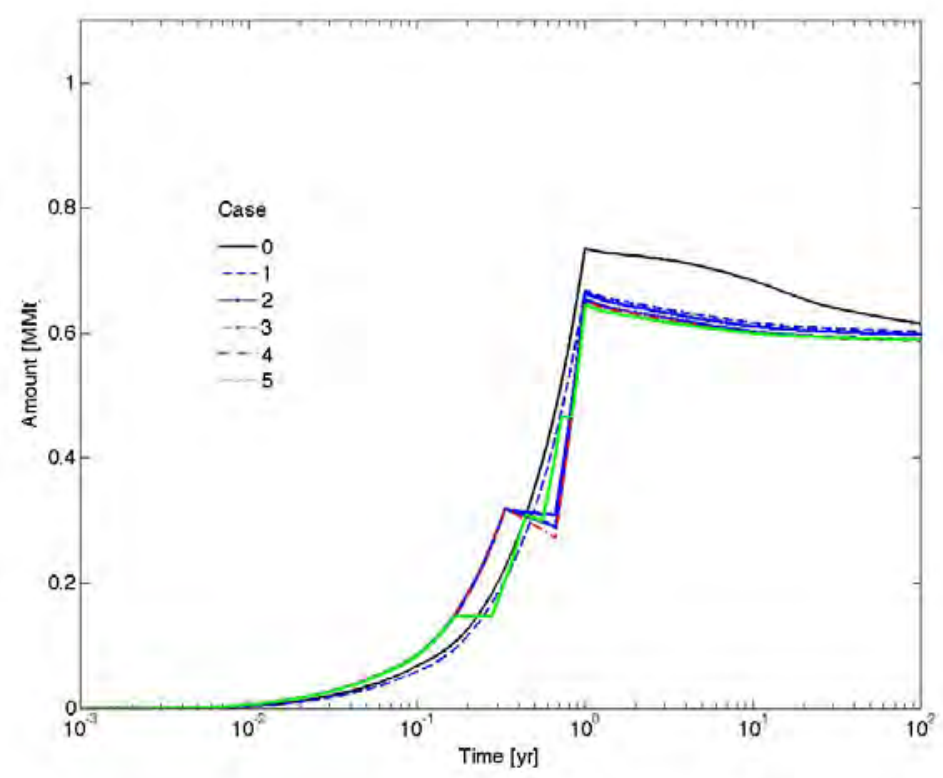

Figure 13-30. $\mathrm{CO}_{2}$ mass in the SC phase during simulation period.

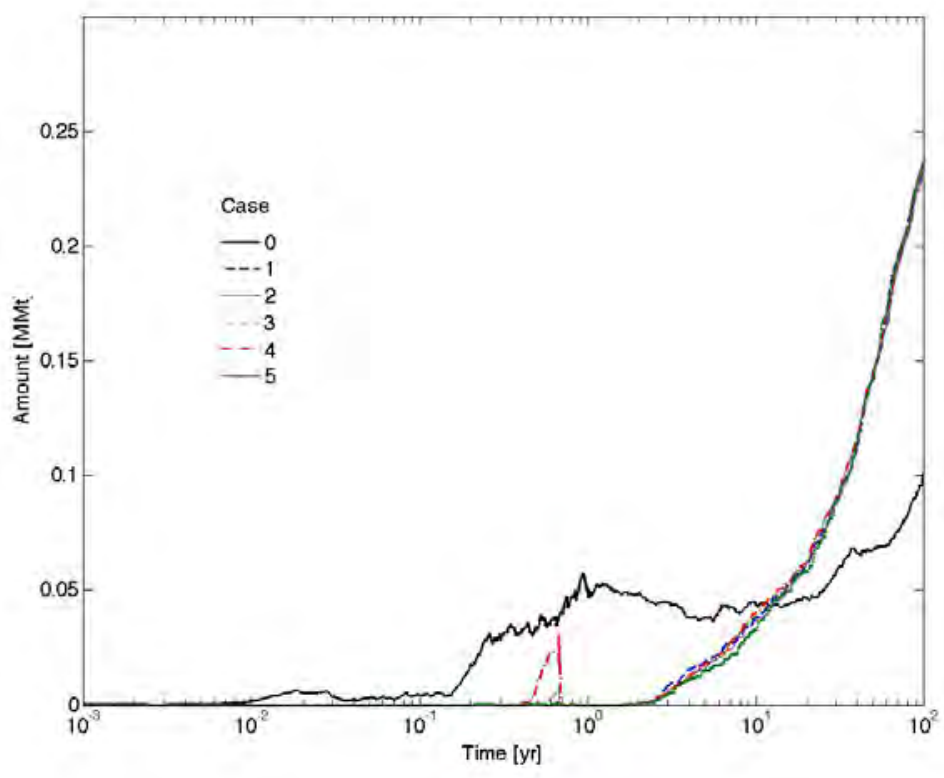

Figure 13-31. Amount of residual trapped $\mathrm{CO}_{2}$. 


\section{Concluding Remarks}

SWP researchers at the University of Utah conducted numerical simulations on a conceptual model built using geological data from Section 13 and 14 of the Aneth field in southeastern Utah. Investigations on injectivity were conducted with the original as well as an artificially increased permeability. The effects of hysteresis and WAG schemes were studied with a series of numerical simulations. Our experiences, discoveries and plans for future work may be summarized as following:

1. More d etailed formation ch aracterization i s n eeded. $\mathrm{O}$ ur empirical porosity-permeability $\mathrm{r}$ elationship is $\mathrm{n}$ ot a ccurate e nough for $\mathrm{flow} s$ imulations. Though $r$ ock por osity data $\mathrm{c}$ an $\mathrm{b}$ e obt ained t hrough $\mathrm{w}$ ell $1 \mathrm{ogs}, \mathrm{r}$ elated $\mathrm{r}$ ock permeability data is very sparse.

2. According to our estimation of the permeability and resulting numerical simulations, the maximum injection rate should not exceed $0.25 \mathrm{MMt} / \mathrm{yr}$.

3. To achieve a $1 \mathrm{MMt} / \mathrm{yr}$ injection rate, the permeability should be at least 5 times hi gher than our e stimation, though $10 \mathrm{t}$ imes hi gher pe rmeability $\mathrm{m}$ ay be more reasonable.

4. The hi ghest pr essure induced by injection w as investigated a ccording to the number of wells.

5. The effects o f W AG s chemes an $\mathrm{d} h$ ysteresis are $\mathrm{w}$ eak o $\mathrm{nd}$ issolution trapping mechanisms. This conclusion is site and model specific and should be investigated using alternative models.

6. The hysteresis effect is strong on residual trapping mechanisms. There is no significant effect of a WAG scheme at least for long term residual trapping in our conceptual model. Differences may be drawn from other sites and models. 


\section{Appendix}

Table 13-A1. Petrophysical data from core plug samples.

\begin{tabular}{|c|c|c|c|c|c|c|c|c|}
\hline $\begin{array}{l}\text { Sample } \\
\text { Number }\end{array}$ & $\begin{array}{l}\text { Sample } \\
\text { Depth } \\
\text { (ft) }\end{array}$ & Formation & $\begin{array}{l}\text { Sample } \\
\text { Length } \\
\text { (in) }\end{array}$ & $\begin{array}{c}\text { Sample } \\
\text { Diameter } \\
\text { (in) }\end{array}$ & $\begin{array}{c}\text { Ambient } \\
\text { Porosity } \\
(\%) \\
\end{array}$ & $\begin{array}{c}\text { Dry Bulk } \\
\text { Density } \\
\text { (g/cc) }\end{array}$ & $\begin{array}{c}\text { Grain } \\
\text { Density } \\
\text { (g/cc) }\end{array}$ & $\begin{array}{c}\text { Gas } \\
\text { Permeability } \\
\text { (md) }\end{array}$ \\
\hline \multicolumn{9}{|c|}{ Pure A-27-C-3 (43037162260000) } \\
\hline 1 & 5679.20 & Ismay & 2.084 & 0.975 & 2.14 & 2.67 & 2.726 & 0.037 \\
\hline 2 & 5682.20 & Ismay & 2.015 & 0.977 & 1.22 & 2.70 & 2.731 & 0.024 \\
\hline 3 & 5734.50 & Desert Creek & 2.053 & 0.976 & 13.39 & 2.33 & 2.691 & 0.528 \\
\hline 4 & 5738.50 & Desert Creek & 2.040 & 0.975 & 9.85 & 2.42 & 2.684 & 10.518 \\
\hline 5 & 5749.50 & Desert Creek & 1.993 & 0.975 & 3.75 & 2.62 & 2.718 & 0.058 \\
\hline 6 & 5759.50 & Desert Creek & 1.968 & 0.980 & 10.31 & 2.41 & 2.688 & 0.480 \\
\hline 7 & 5764.30 & Desert Creek & 2.059 & 0.983 & 7.86 & 2.50 & 2.715 & 0.190 \\
\hline 8 & 5770.00 & Desert Creek & 2.000 & 0.980 & 11.69 & 2.40 & 2.723 & 0.348 \\
\hline 9 & 5787.60 & Desert Creek & 1.980 & 0.979 & 21.19 & 2.12 & 2.688 & 1.961 \\
\hline 10 & 5806.60 & Desert Creek & 1.955 & 0.973 & 3.93 & 2.57 & 2.673 & 0.311 \\
\hline 11 & 5827.85 & Desert Creek & 1.973 & 0.974 & 1.97 & 2.65 & 2.701 & 0.046 \\
\hline 12 & 5857.10 & Desert Creek & 2.010 & 0.972 & 21.56 & 2.23 & 2.847 & 10.491 \\
\hline 13 & 5721.90 & Desert Creek & 1.995 & 0.979 & 2.02 & 2.63 & 2.682 & 0.035 \\
\hline 14 & 5755.40 & Desert Creek & 2.014 & 0.975 & 7.99 & 2.49 & 2.712 & 0.071 \\
\hline \multicolumn{9}{|c|}{ Pure 27-D-4 (43037163330000) } \\
\hline 1B & 5504.20 & Ismay & 2.078 & 0.975 & 0.53 & 2.68 & 2.694 & 0.036 \\
\hline $2 B$ & 5507.50 & Ismay & 2.053 & 0.971 & 5.22 & 2.55 & 2.695 & 0.049 \\
\hline 3B & 5510.20 & Ismay & 2.041 & 0.977 & 8.40 & 2.51 & 2.743 & 0.262 \\
\hline $4 \mathrm{~B}$ & 5541.20 & Ismay & 2.056 & 0.972 & 1.48 & 2.65 & 2.695 & 0.024 \\
\hline
\end{tabular}

13-A1 


\begin{tabular}{|c|c|c|c|c|c|c|c|c|}
\hline $5 \mathrm{~B}$ & 5558.80 & Ismay & 2.058 & 0.973 & 1.66 & 2.65 & 2.694 & 1.066 \\
\hline $6 \mathrm{~B}$ & 5568.70 & Ismay & 2.050 & 0.974 & 2.47 & 2.61 & 2.673 & 0.036 \\
\hline $7 \mathrm{~B}$ & 5581.30 & Ismay & 2.080 & 0.977 & 8.79 & 2.47 & 2.707 & 2.446 \\
\hline $8 \mathrm{~B}$ & 5593.50 & Ismay & 2.048 & 0.975 & 21.05 & 2.20 & 2.791 & 0.720 \\
\hline $9 \mathrm{~B}$ & 5621.00 & Desert Creek & 2.070 & 0.973 & 21.22 & 2.10 & 2.668 & 6.461 \\
\hline $10 \mathrm{~B}$ & 5623.00 & Desert Creek & 2.053 & 0.972 & 13.31 & 2.31 & 2.661 & 0.629 \\
\hline $11 \mathrm{~B}$ & 5651.00 & Desert Creek & 2.047 & 0.973 & 13.59 & 2.31 & 2.671 & 0.313 \\
\hline 12B & 5670.00 & Desert Creek & 2.063 & 0.971 & 14.83 & 2.37 & 2.782 & 1.281 \\
\hline 13B & 5680.50 & Desert Creek & 2.095 & 0.975 & 10.81 & 2.40 & 2.687 & 0.515 \\
\hline 14B & 5699.50 & Desert Creek & 2.025 & 0.979 & 10.09 & 2.43 & 2.698 & 1.083 \\
\hline 15B & 5725.40 & Desert Creek & 2.043 & 0.972 & 18.01 & 2.20 & 2.680 & 5.041 \\
\hline 16B & 5742.00 & Desert Creek & 2.055 & 0.974 & 29.22 & 1.99 & 2.816 & 157.602 \\
\hline 17B & 5777.80 & Desert Creek & 2.057 & 0.974 & 0.91 & 2.72 & 2.747 & 0.085 \\
\hline \multicolumn{9}{|c|}{ Texaco Aneth H-117 (43037301530000) } \\
\hline $1 \mathrm{C}$ & 5393.70 & Desert Creek & 2.050 & 0.974 & 0.02 & 2.68 & 2.683 & 0.048 \\
\hline $2 \mathrm{C}$ & 5401.30 & Desert Creek & 2.036 & 0.975 & 16.69 & 2.22 & 2.666 & 52.588 \\
\hline $3 C$ & 5413.60 & Desert Creek & 2.021 & 0.974 & 11.62 & 2.40 & 2.719 & 0.155 \\
\hline $4 \mathrm{C}$ & 5417.40 & Desert Creek & 1.979 & 0.973 & 14.98 & 2.30 & 2.707 & 0.782 \\
\hline $5 \mathrm{C}$ & 5422.30 & Desert Creek & 1.996 & 0.973 & 10.79 & 2.39 & 2.678 & 0.094 \\
\hline $6 \mathrm{C}$ & 5429.80 & Desert Creek & 1.996 & 0.973 & 23.61 & 2.11 & 2.763 & 30.022 \\
\hline $7 \mathrm{C}$ & 5441.70 & Desert Creek & 1.965 & 0.973 & 12.56 & 2.34 & 2.678 & 10.250 \\
\hline $8 \mathrm{C}$ & 5450.50 & Desert Creek & 1.955 & 0.973 & 11.68 & 2.40 & 2.715 & 1.408 \\
\hline $9 \mathrm{C}$ & 5454.30 & Desert Creek & 1.987 & 0.980 & 13.39 & 2.38 & 2.750 & 2.106 \\
\hline $10 C$ & 5464.20 & Desert Creek & 1.993 & 0.971 & 14.63 & 2.32 & 2.718 & 15.490 \\
\hline $11 C$ & 5467.40 & Desert Creek & 1.994 & 0.974 & 7.11 & 2.59 & 2.786 & 0.106 \\
\hline
\end{tabular}

13-A2 


\begin{tabular}{|c|c|c|c|c|c|c|c|c|}
\hline $12 \mathrm{C}$ & 5480.60 & Desert Creek & 1.998 & 0.974 & 8.38 & 2.51 & 2.735 & 0.306 \\
\hline $13 C$ & 5487.70 & Desert Creek & 2.000 & 0.974 & 7.23 & 2.49 & 2.689 & 0.706 \\
\hline $14 \mathrm{C}$ & 5504.50 & Desert Creek & 1.985 & 0.972 & 4.00 & 2.58 & 2.684 & 0.951 \\
\hline $15 C$ & 5544.80 & Desert Creek & 2.024 & 0.973 & 8.52 & 2.56 & 2.795 & 0.072 \\
\hline $16 \mathrm{C}$ & 5394.80 & Desert Creek & 1.995 & 0.974 & 0.03 & 2.69 & 2.689 & 0.035 \\
\hline $17 \mathrm{C}$ & 5397.30 & Desert Creek & 1.975 & 0.975 & 0.05 & 2.67 & 2.668 & 0.035 \\
\hline $18 \mathrm{C}$ & 5400.00 & Desert Creek & 1.975 & 0.975 & 12.47 & 2.72 & 3.102 & 6.001 \\
\hline \multicolumn{9}{|c|}{ Texaco F-317 (43037301390000) } \\
\hline $1 \mathrm{D}$ & 5362.90 & Desert Creek & 2.012 & 0.972 & 10.88 & 2.41 & 2.708 & 4.284 \\
\hline $2 \mathrm{D}$ & 5366.20 & Desert Creek & 2.028 & 0.972 & 7.90 & 2.46 & 2.671 & 0.587 \\
\hline $3 D$ & 5369.70 & Desert Creek & 1.975 & 0.967 & 7.83 & 2.47 & 2.680 & 0.330 \\
\hline $4 \mathrm{D}$ & 5381.40 & Desert Creek & 2.005 & 0.971 & 5.33 & 2.55 & 2.693 & 0.083 \\
\hline $5 \mathrm{D}$ & 5385.30 & Desert Creek & 2.008 & 0.975 & 12.63 & 2.39 & 2.737 & 1.168 \\
\hline $6 \mathrm{D}$ & 5395.30 & Desert Creek & 2.000 & 0.974 & 13.73 & 2.34 & 2.713 & 1.791 \\
\hline $7 \mathrm{D}$ & 5401.50 & Desert Creek & 1.974 & 0.969 & 11.59 & 2.37 & 2.678 & 0.199 \\
\hline $8 D$ & 5440.40 & Desert Creek & 2.008 & 0.974 & 18.81 & 2.14 & 2.633 & 9.633 \\
\hline $9 \mathrm{D}$ & 5446.90 & Desert Creek & 1.995 & 0.970 & 26.98 & 2.01 & 2.757 & 29.618 \\
\hline $10 \mathrm{D}$ & 5455.50 & Desert Creek & 1.968 & 0.971 & 9.59 & 2.42 & 2.682 & 0.699 \\
\hline $11 \mathrm{D}$ & 5472.50 & Desert Creek & 1.942 & 0.974 & 8.22 & 2.46 & 2.683 & 0.171 \\
\hline $12 \mathrm{D}$ & 5510.20 & Desert Creek & 1.977 & 0.974 & 10.91 & 2.49 & 2.790 & 0.023 \\
\hline \multicolumn{9}{|c|}{ Texaco Aneth E-313 (43037302000000) } \\
\hline $1 \mathrm{E}$ & 5767.80 & Desert Creek & 1.986 & 0.972 & 10.32 & 2.40 & 2.679 & 0.094 \\
\hline $2 \mathrm{E}$ & 5778.70 & Desert Creek & 1.995 & 0.974 & 12.72 & 2.33 & 2.672 & 0.153 \\
\hline $3 \mathrm{E}$ & 5785.20 & Desert Creek & 1.973 & 0.971 & 19.73 & 2.14 & 2.669 & 2.408 \\
\hline $4 \mathrm{E}$ & 5807.90 & Desert Creek & 1.964 & 0.972 & 12.97 & 2.35 & 2.699 & 0.698 \\
\hline
\end{tabular}

13-A3 


\begin{tabular}{|c|c|c|c|c|c|c|c|c|}
\hline $5 \mathrm{E}$ & 5817.90 & Desert Creek & 2.013 & 0.975 & 13.93 & 2.34 & 2.720 & 0.688 \\
\hline $6 \mathrm{E}$ & 5832.20 & Desert Creek & 2.003 & 0.972 & 0.36 & 2.70 & 2.715 & 0.012 \\
\hline $7 \mathrm{E}$ & 5844.50 & Desert Creek & 1.989 & 0.975 & 2.30 & 2.77 & 2.840 & 0.023 \\
\hline $8 \mathrm{E}$ & 5854.30 & Desert Creek & 1.963 & 0.975 & 1.00 & 2.62 & 2.650 & 0.035 \\
\hline $9 \mathrm{E}$ & 5869.10 & Desert Creek & 2.034 & 0.976 & 0.98 & 2.70 & 2.729 & 0.036 \\
\hline $10 \mathrm{E}$ & 5872.90 & Desert Creek & 1.992 & 0.975 & 0.70 & 2.68 & 2.696 & 0.023 \\
\hline $11 \mathrm{E}$ & 5877.20 & Desert Creek & 2.009 & 0.972 & 0.01 & 2.70 & 2.701 & 0.024 \\
\hline $12 \mathrm{E}$ & 5879.50 & Desert Creek & 1.982 & 0.971 & 1.01 & 2.70 & 2.732 & 0.094 \\
\hline $13 E$ & 5889.50 & Desert Creek & 2.020 & 0.972 & 10.91 & 2.49 & 2.791 & 0.012 \\
\hline $14 \mathrm{E}$ & 5895.40 & Desert Creek & 2.002 & 0.972 & 0.12 & 2.70 & 2.703 & 0.024 \\
\hline $15 E$ & 5917.60 & Desert Creek & 2.015 & 0.975 & 6.08 & 2.60 & 2.764 & 0.202 \\
\hline \multicolumn{9}{|c|}{ Texaco Aneth E-418 (43037301650000) } \\
\hline $1 \mathrm{~F}$ & 5966.80 & Gothic & 2.024 & 0.974 & 0.87 & 2.67 & 2.690 & 0.012 \\
\hline $2 \mathrm{~F}$ & 5969.30 & Desert Creek & 1.989 & 0.973 & 0.03 & 2.68 & 2.682 & 0.012 \\
\hline $3 F$ & 5972.20 & Desert Creek & 1.984 & 0.973 & 0.45 & 2.68 & 2.697 & 0.023 \\
\hline $4 \mathrm{~F}$ & 5981.50 & Desert Creek & 2.009 & 0.973 & 3.46 & 2.64 & 2.734 & 0.012 \\
\hline $5 F$ & 5989.20 & Desert Creek & 1.970 & 0.973 & 7.19 & 2.49 & 2.681 & 9.251 \\
\hline $6 \mathrm{~F}$ & 5995.80 & Desert Creek & 1.984 & 0.973 & 5.20 & 2.57 & 2.715 & 0.141 \\
\hline $7 F$ & 6004.90 & Desert Creek & 2.003 & 0.974 & 8.32 & 2.49 & 2.714 & 1.444 \\
\hline $8 F$ & 6007.60 & Desert Creek & 2.014 & 0.974 & 9.19 & 2.51 & 2.765 & 1.202 \\
\hline $9 \mathrm{~F}$ & 6008.80 & Desert Creek & 2.001 & 0.973 & 20.42 & 2.23 & 2.804 & 19.502 \\
\hline $10 \mathrm{~F}$ & 6019.50 & Desert Creek & 1.988 & 0.972 & 3.16 & 2.60 & 2.682 & 0.024 \\
\hline $11 \mathrm{~F}$ & 6025.30 & Desert Creek & 1.980 & 0.972 & 11.63 & 2.38 & 2.689 & 0.376 \\
\hline $12 \mathrm{~F}$ & 6032.30 & Desert Creek & 1.995 & 0.973 & 13.24 & 2.48 & 2.859 & 10.082 \\
\hline $13 \mathrm{~F}$ & 6053.10 & Desert Creek & 1.974 & 0.973 & 7.40 & 2.49 & 2.684 & 0.035 \\
\hline
\end{tabular}

13-A4 


\begin{tabular}{|l|l|l|l|l|l|l|l|l|}
\hline $14 \mathrm{~F}$ & 6062.50 & Desert Creek & 2.009 & 0.972 & 3.79 & 2.59 & 2.691 & 0.012 \\
\hline $15 \mathrm{~F}$ & 6098.50 & Desert Creek & 1.996 & 0.972 & 0.19 & 2.70 & 2.705 & 0.024 \\
\hline $16 \mathrm{~F}$ & 6107.40 & Desert Creek & 2.024 & 0.973 & 10.84 & 2.50 & 2.807 & 0.060 \\
\hline
\end{tabular}


Table 13-A2. Well logs and digitizing work in the Aneth Unit. $x$ and Jrepresent an available and digitized log, respectively.

\begin{tabular}{|c|c|c|c|c|c|c|c|c|c|c|c|c|c|c|c|}
\hline No & API & GR & CAL & RHOB & NEUT & NPHI & DPHI & DRHO & CNC & Conductivity & Resistivity & SP & DT / S & TEN & PEF \\
\hline 1 & 43034158210000 & & & & & & & & & $\mathrm{x}$ & $\mathrm{x}$ & $\mathrm{x}$ & & & \\
\hline 2 & 43037016900000 & $\mathrm{x}$ & $\mathrm{x}$ & & & $\mathrm{x}$ & & & & & & & & & \\
\hline 3 & 43037019600000 & $\mathrm{x}$ & & & & $\mathrm{x}$ & & & & & & & & & \\
\hline 4 & 43037061620000 & & & & & & & & & & & & & & \\
\hline 5 & 43037101950000 & $\checkmark$ & & & $\checkmark$ & & & & & & & & & & \\
\hline 6 & 43037102820000 & & & & & & & & & & & & & & \\
\hline 7 & 43037103380000 & $\checkmark$ & & & $\checkmark$ & & & & & & & & & & \\
\hline 8 & 43037104240000 & $\checkmark$ & & & $\checkmark$ & & & & & & & & & & \\
\hline 9 & 43037105270000 & $\mathrm{x}$ & & & & & & & & $\mathrm{x}$ & $\mathrm{x}$ & $\mathrm{x}$ & $\mathrm{x}$ & & \\
\hline 10 & 43037105570000 & $\checkmark$ & & & $\checkmark$ & & & & & & & & & & \\
\hline 11 & 43037106820000 & & & & & & & & & & & & & & \\
\hline 12 & 43037110680000 & $\mathrm{x}$ & & & $\mathrm{x}$ & & & & & & & & & & \\
\hline 13 & 43037110680001 & $\mathrm{x}$ & & & $\mathrm{x}$ & & & & & & & & & & \\
\hline 14 & 43037112060000 & $\checkmark$ & & & $\checkmark$ & & & & & & & & & & \\
\hline 15 & 43037112550000 & & & & & & & & & & & & & & \\
\hline 16 & 43037112560000 & $\mathrm{x}$ & & & $\mathrm{x}$ & & & & & & & & & & \\
\hline 17 & 43037112610000 & $\checkmark$ & & & $\checkmark$ & & & & & & & & & & \\
\hline 18 & 43037113370000 & $\mathrm{x}$ & & & $\mathrm{x}$ & & & & & & & & & & \\
\hline 19 & 43037138600000 & $\mathrm{x}$ & $\mathrm{x}$ & & & $\mathrm{x}$ & & & & & & & & $\mathrm{x}$ & \\
\hline 20 & 43037150830000 & $\checkmark$ & & & $\checkmark$ & & & & & & & & & & \\
\hline 21 & 43037154120000 & $\mathrm{x}$ & & & $\mathrm{x}$ & & & & & & & & & & \\
\hline 22 & 43037154120000 & $\checkmark$ & & & $\checkmark$ & & & & & & & & & & \\
\hline 23 & 43037154130000 & $\checkmark$ & & & $\checkmark$ & & & & & & & & & & \\
\hline 24 & 43037154130000 & $\checkmark$ & & & $\checkmark$ & & & & & & & & & & \\
\hline 25 & 43037154140000 & $\checkmark$ & & & $\checkmark$ & & & & & & & & & & \\
\hline 26 & 43037154140000 & $\checkmark$ & & & $\checkmark$ & & & & & & & & & & \\
\hline 27 & 43037154150000 & $\checkmark$ & & & $\checkmark$ & & & & & & & & & & \\
\hline 28 & 43037154150001 & & & & & & & & & & & & & & \\
\hline 29 & 43037154850000 & $\mathrm{x}$ & & & $\mathrm{x}$ & & & & & & & & & & \\
\hline
\end{tabular}




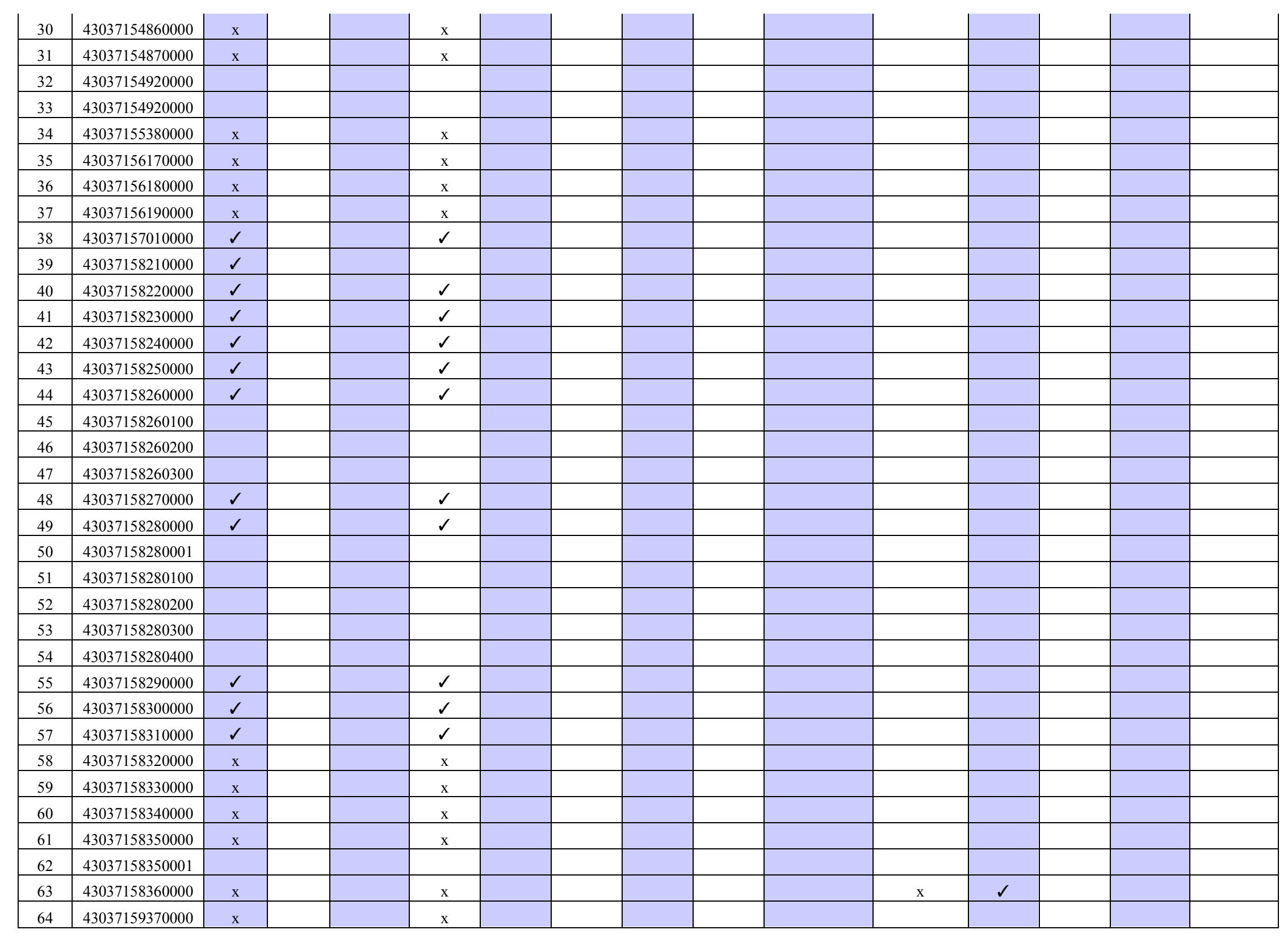




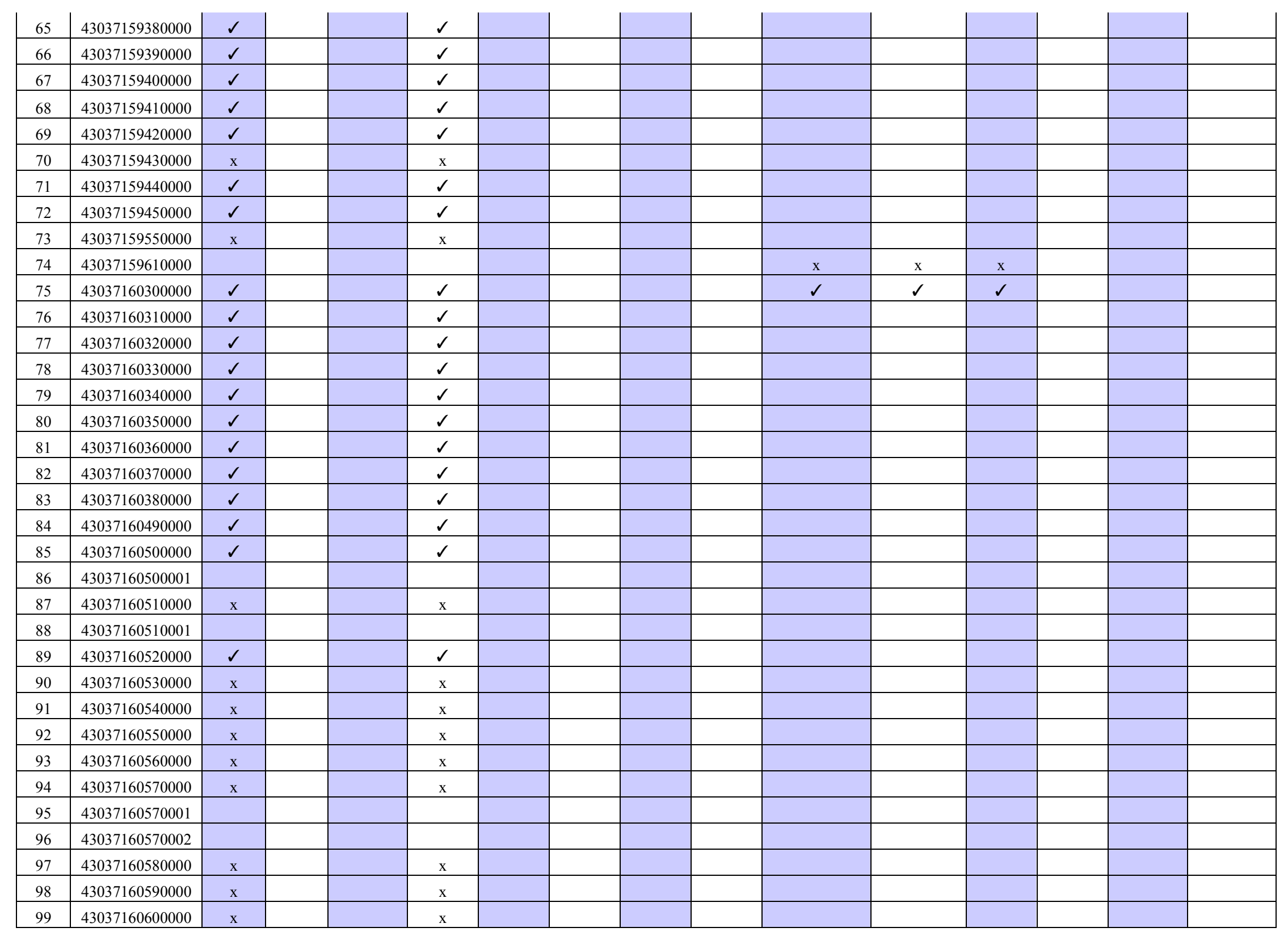

13-A8 


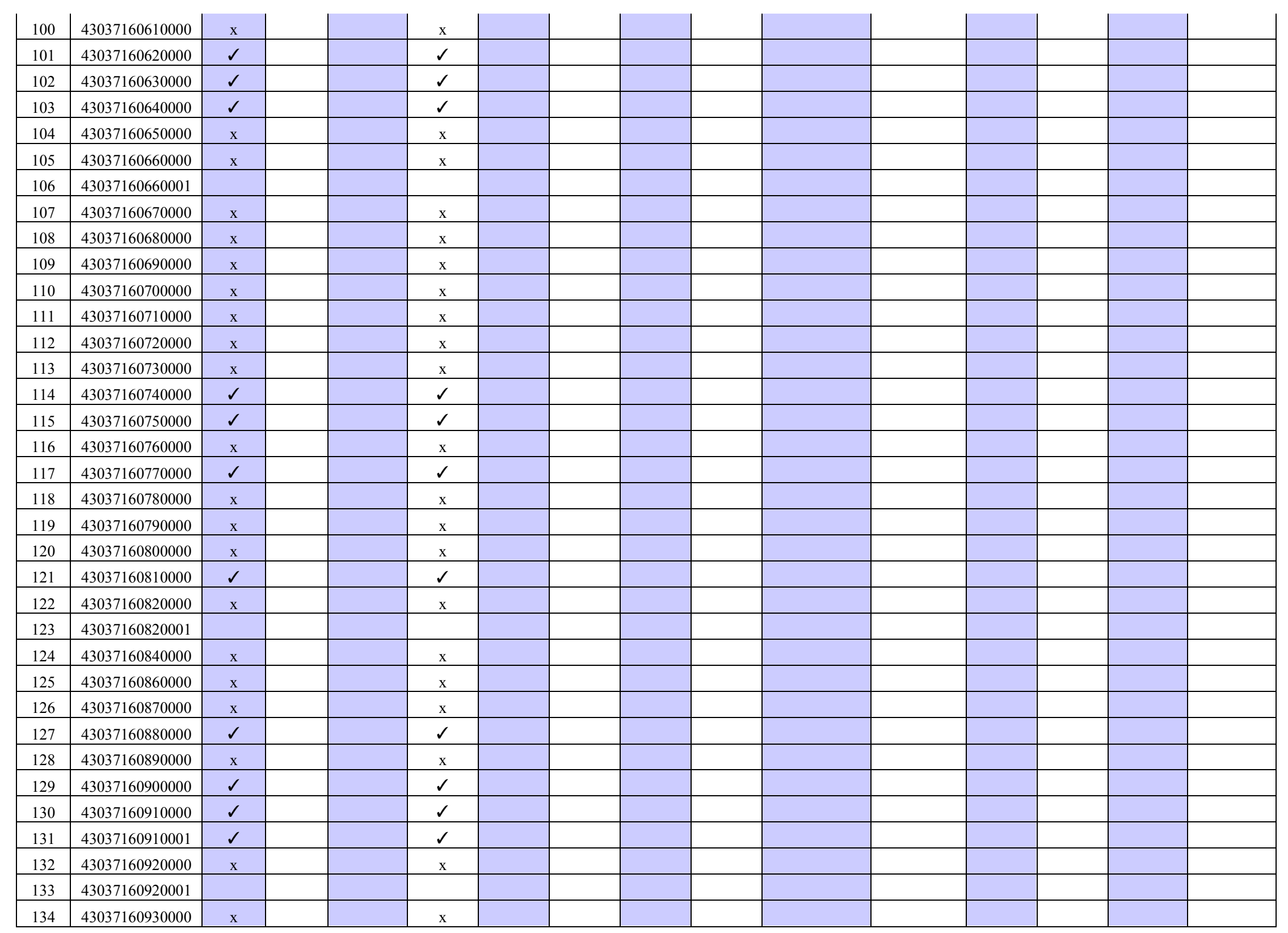




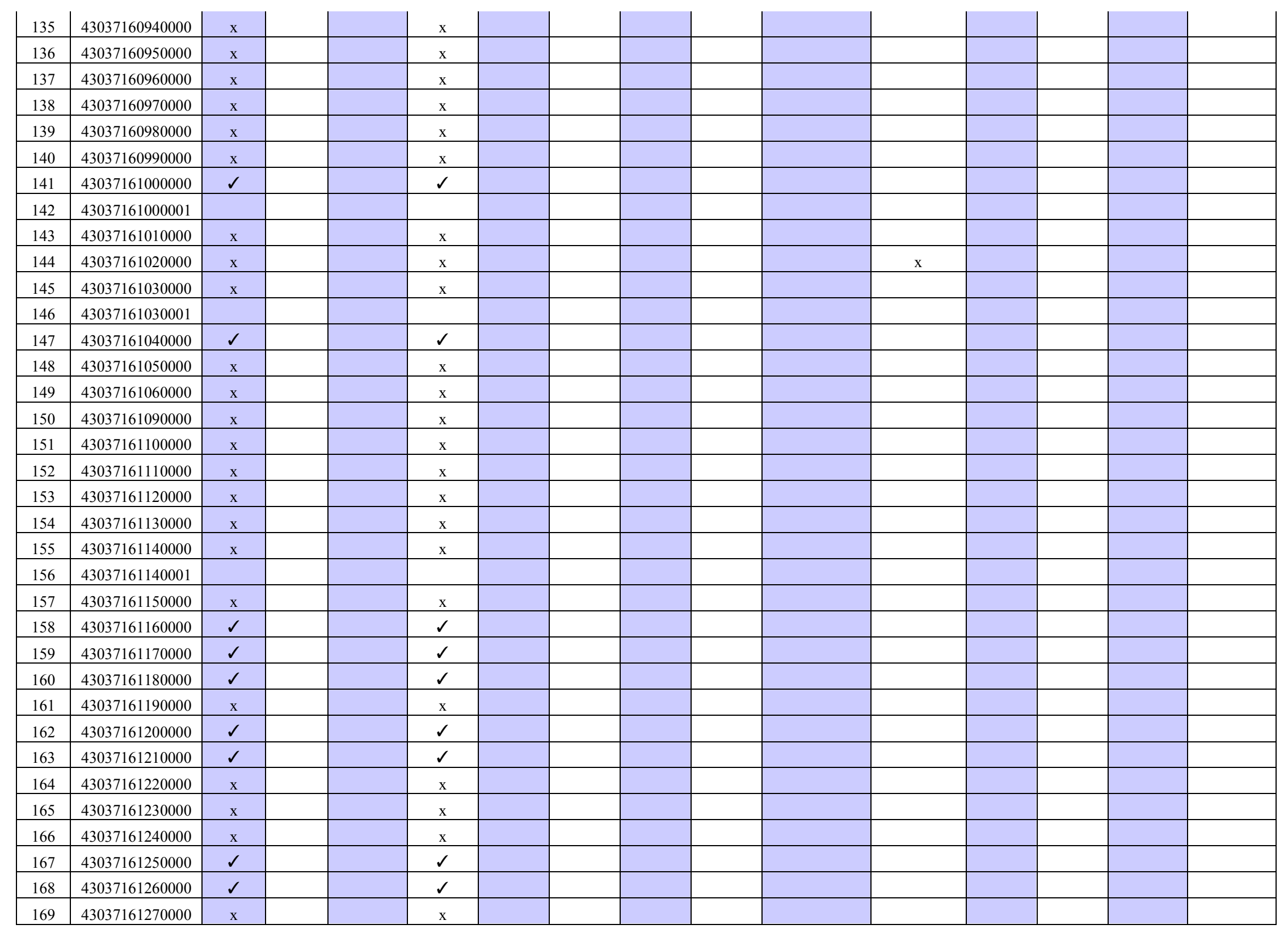

13-A10 


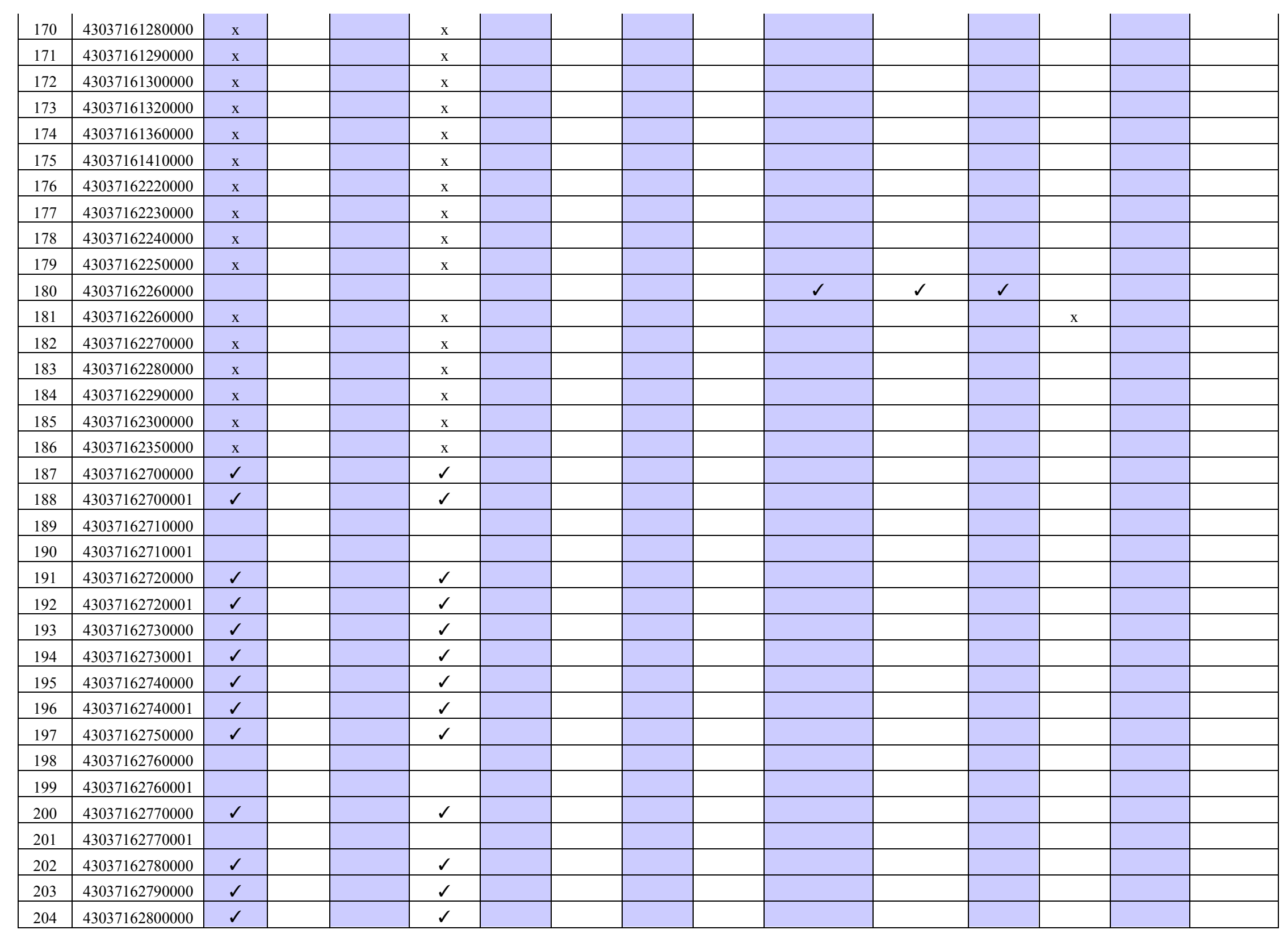

13-A11 


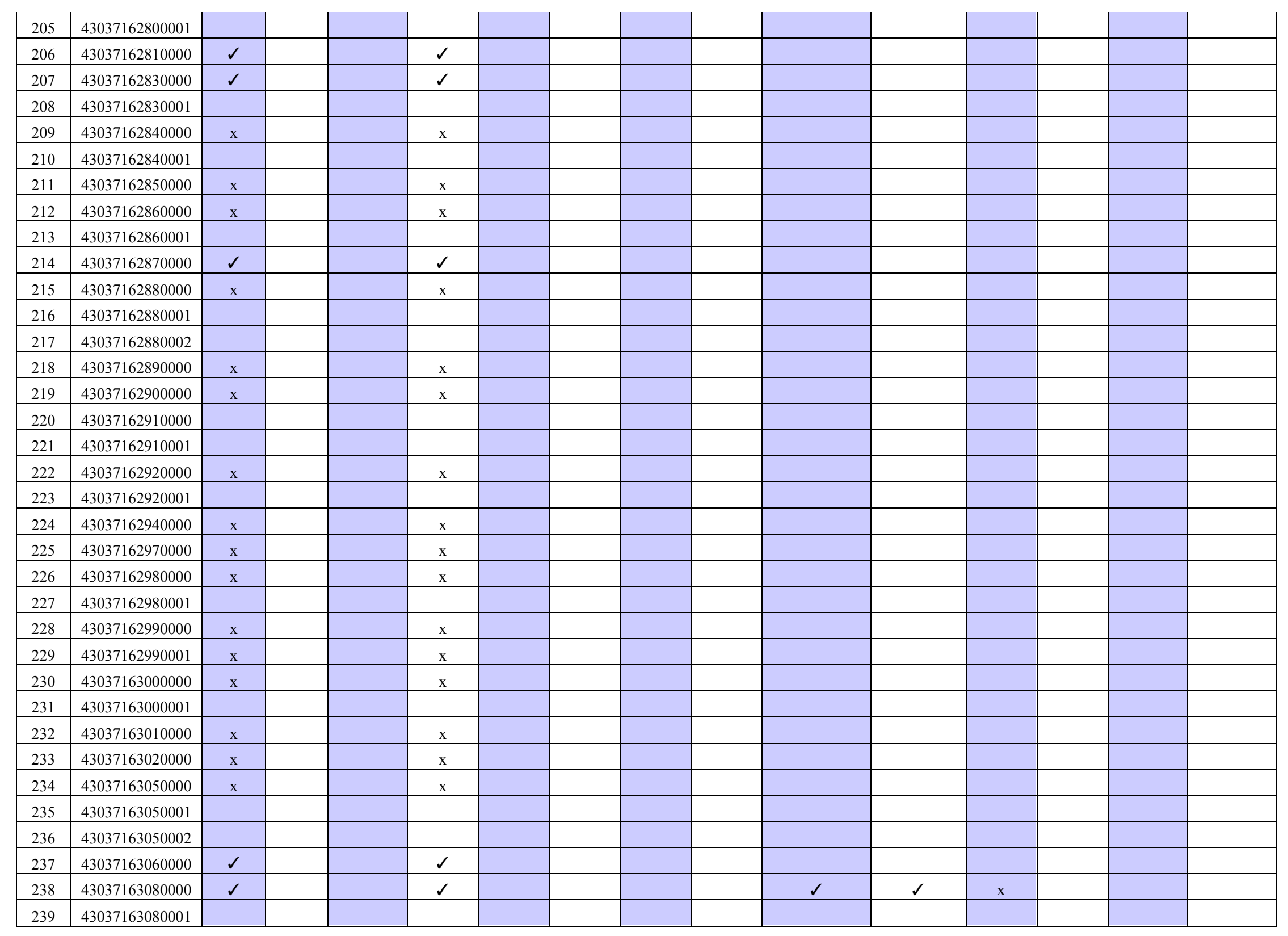

13-A12 


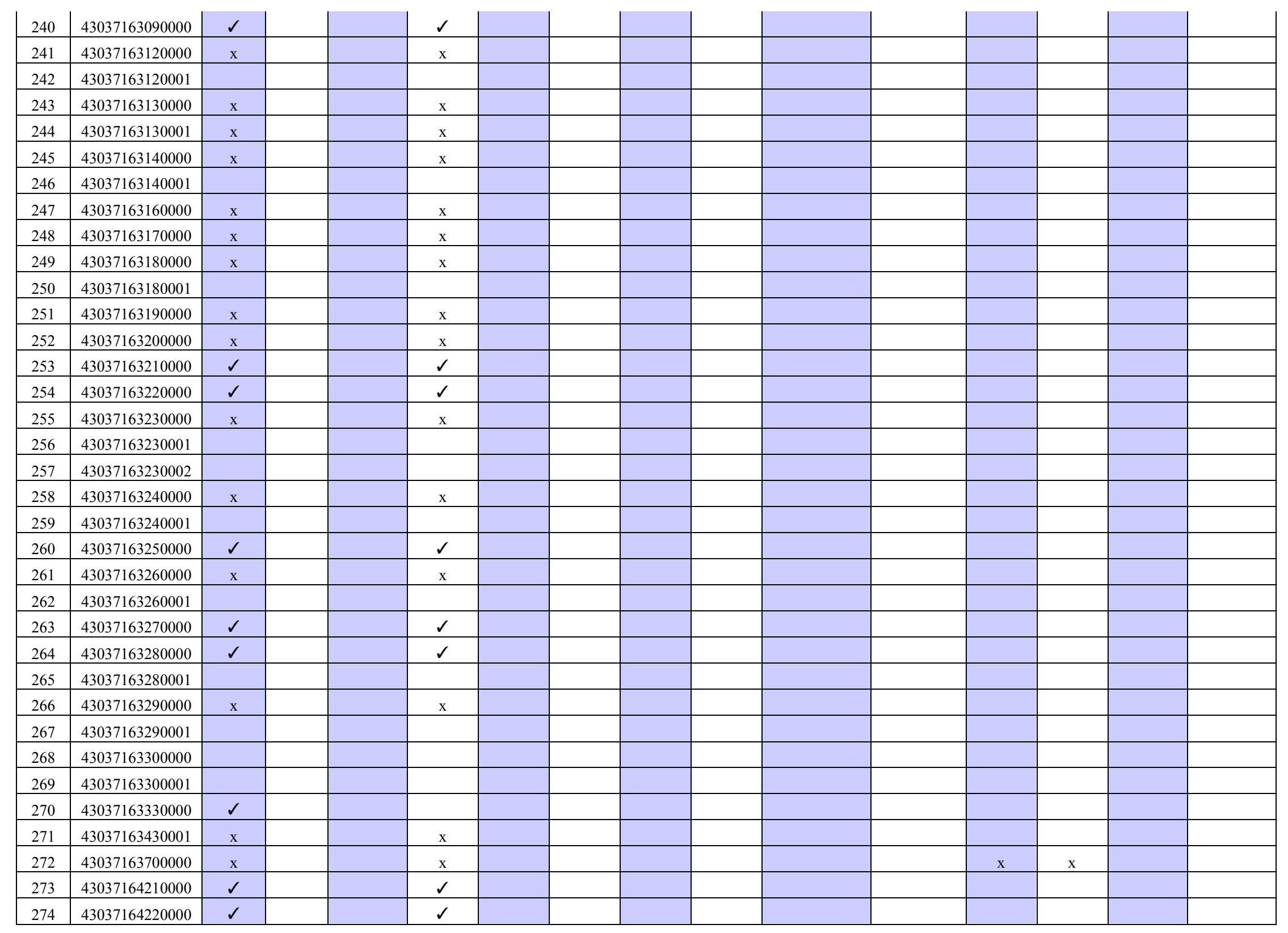

13-A13 


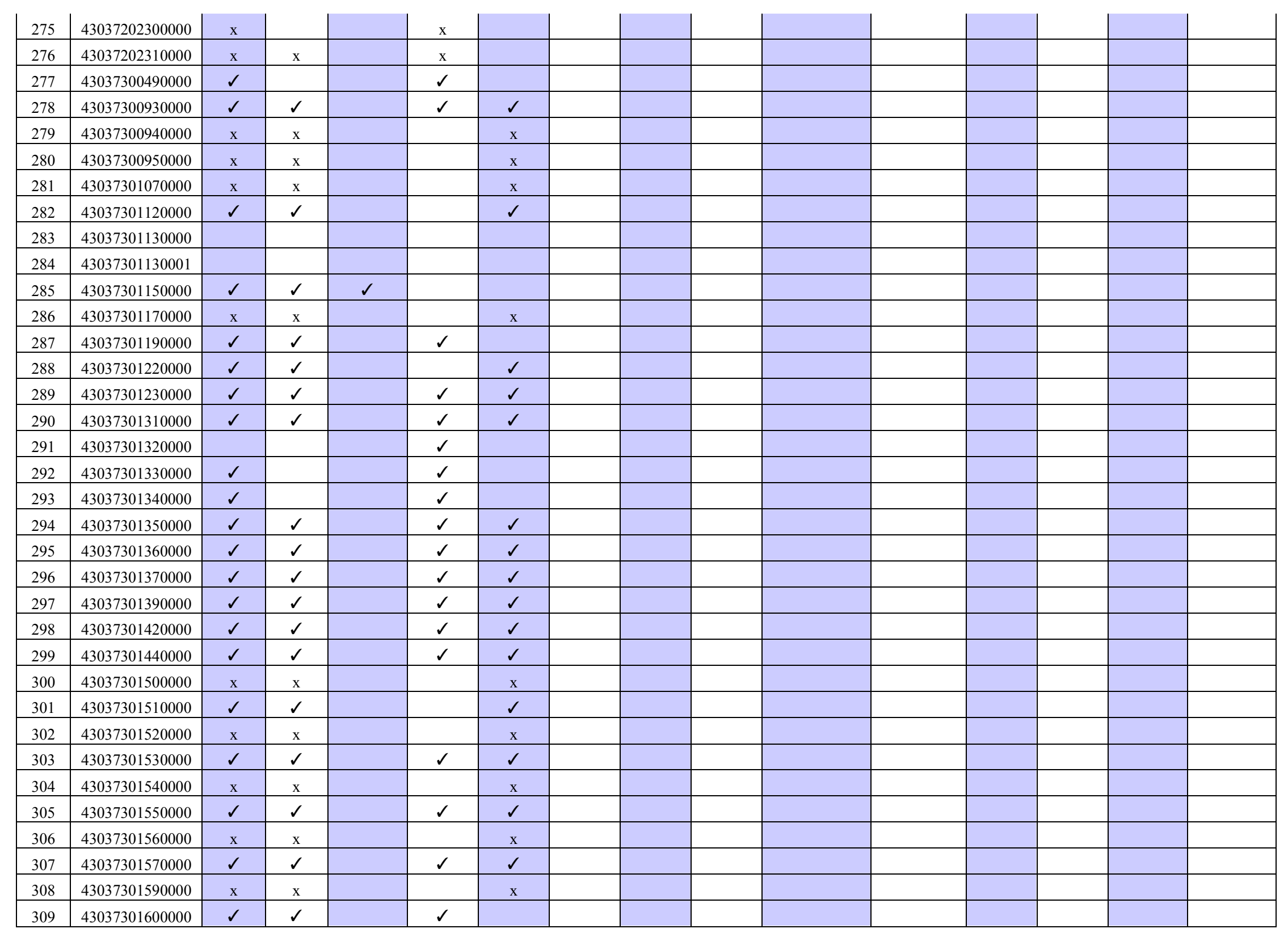

13-A14 


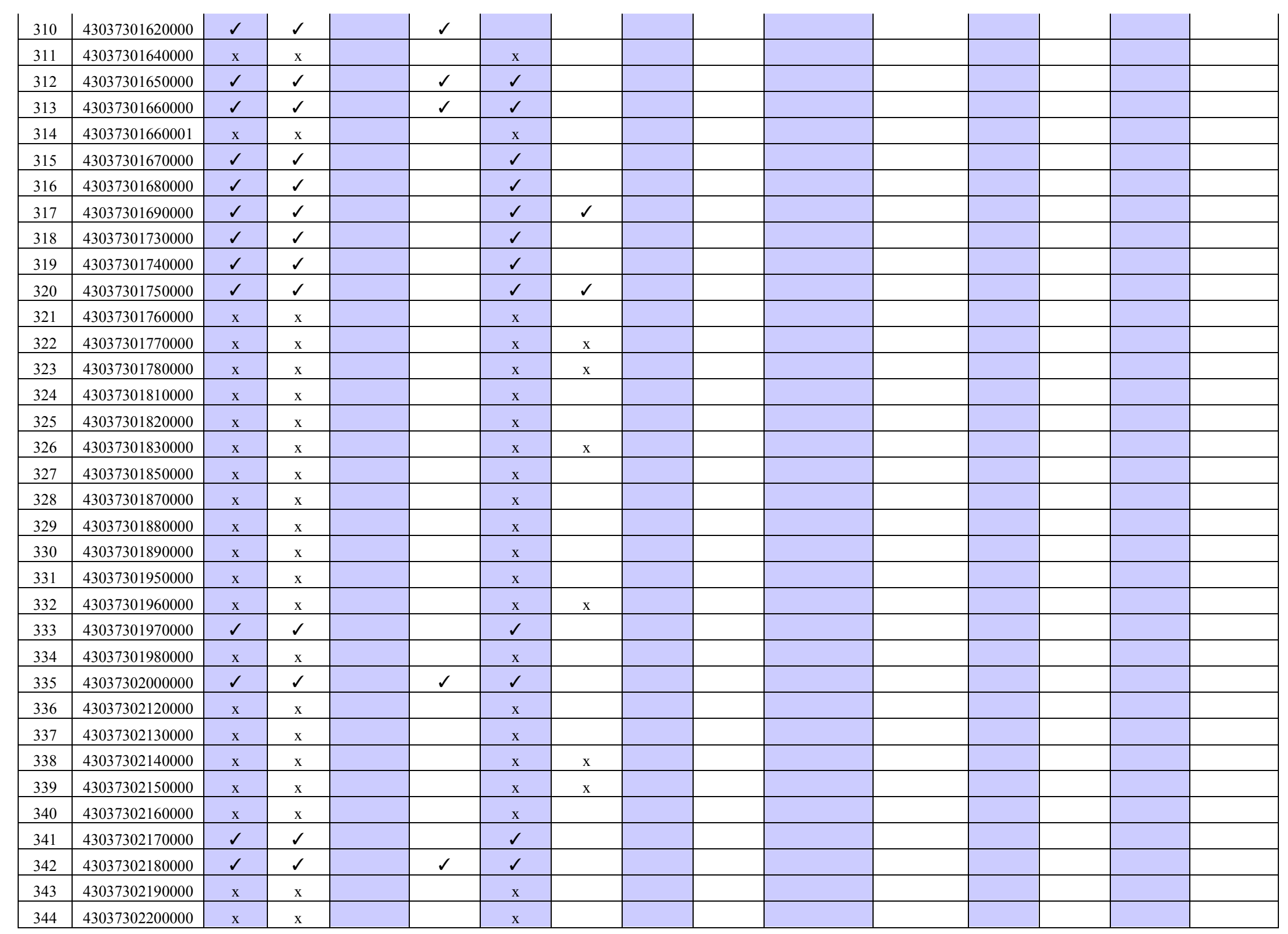

13-A15 


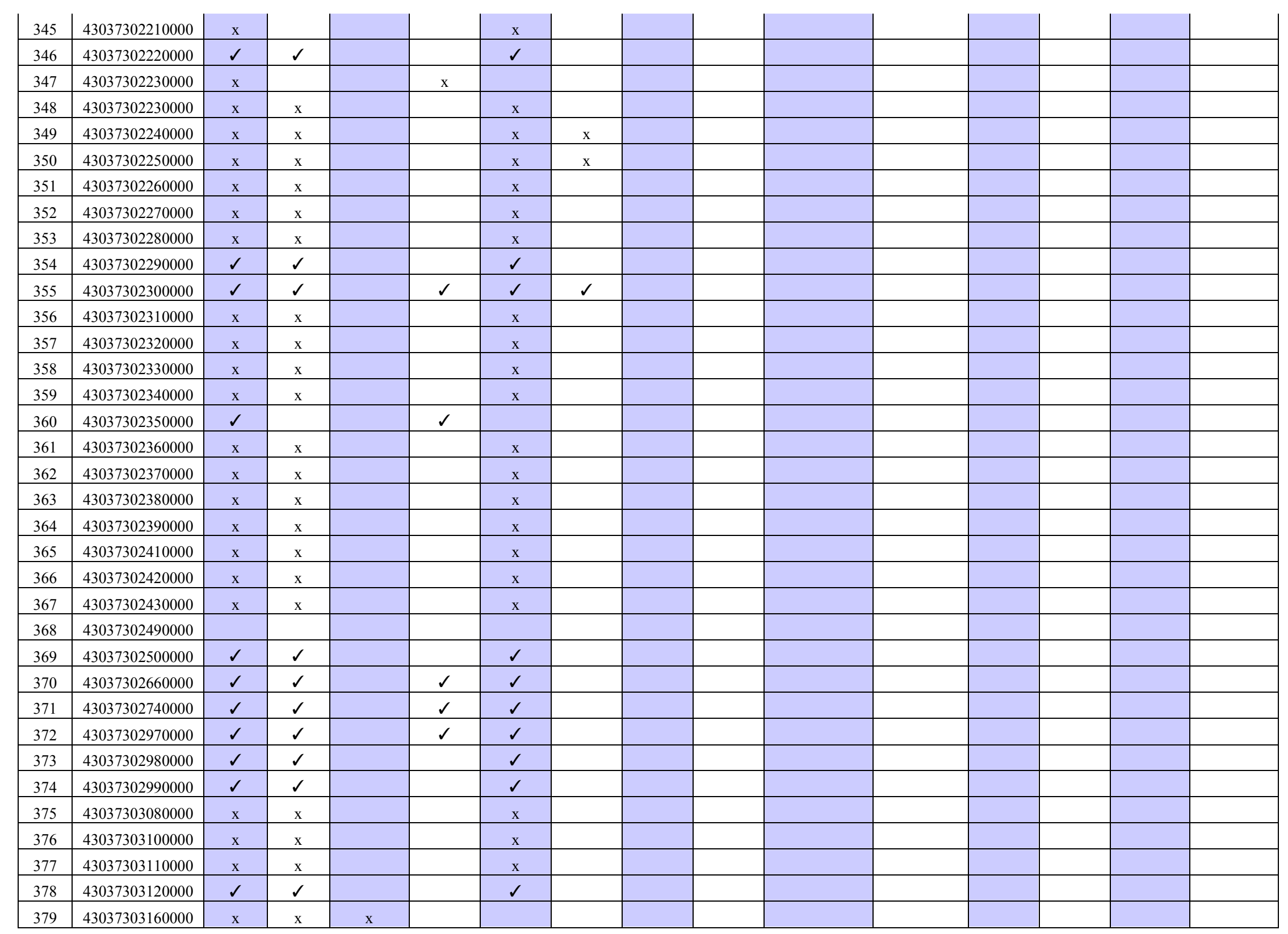

13-A16 


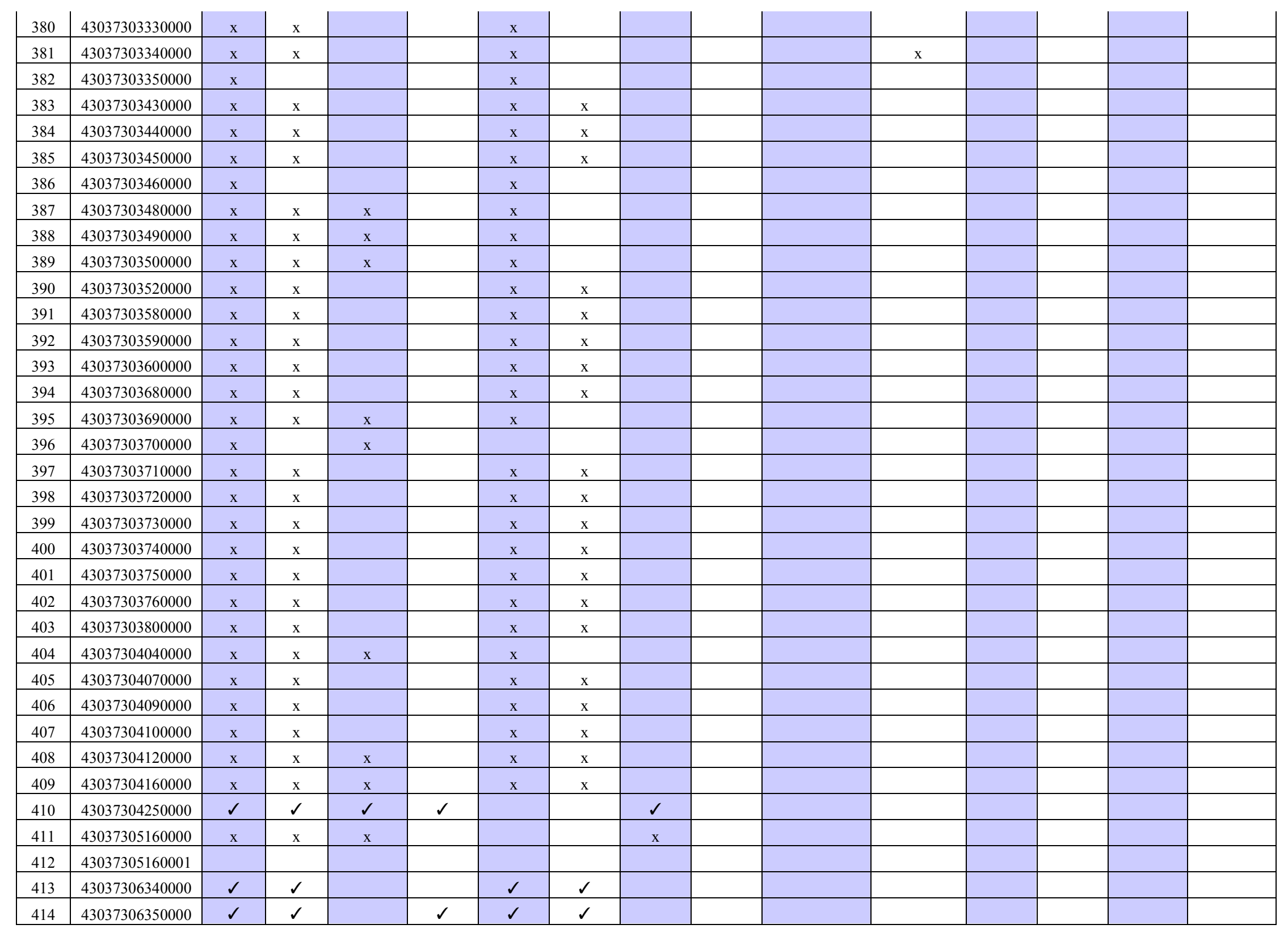

\section{3-A17}




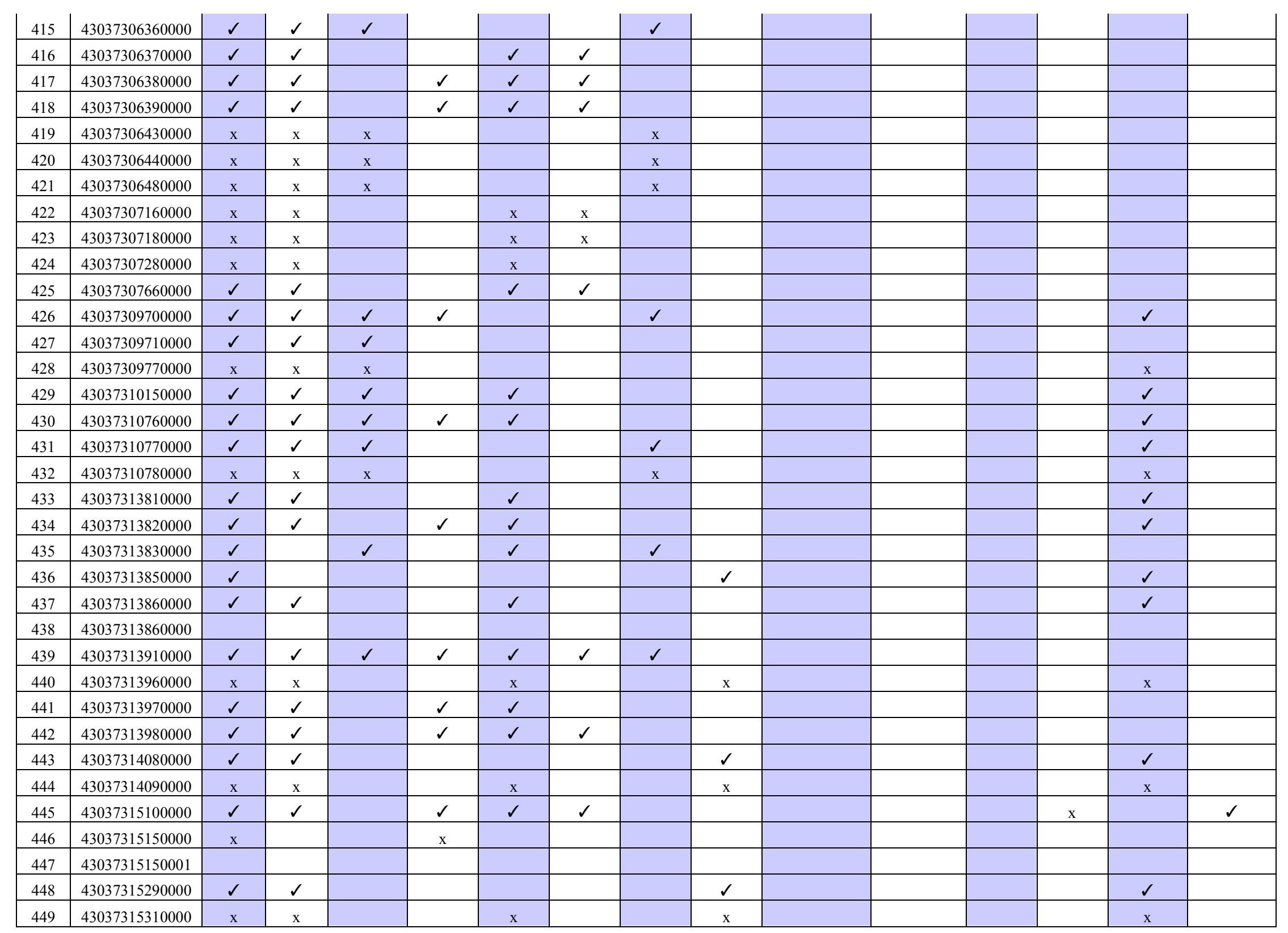

13-A18 


\begin{tabular}{|c|c|c|c|c|c|c|c|c|c|c|c|}
\hline 450 & 43037315340000 & $d$ & $d$ & & 2 & & & & & $d$ & \\
\hline 451 & 43037315370000 & $\mathrm{x}$ & & $\mathrm{x}$ & & & & $\mathrm{x}$ & & & \\
\hline 452 & 43037316840000 & $\checkmark$ & $\checkmark$ & 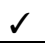 & 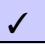 & & $\checkmark$ & & & $\checkmark$ & \\
\hline 453 & 43037318510000 & & & & & & & & & & \\
\hline 454 & 43037318520000 & $\checkmark$ & $\checkmark$ & & & $\checkmark$ & & $\checkmark$ & $\checkmark$ & & $\checkmark$ \\
\hline 455 & 43037318520100 & & & & & & & & & & \\
\hline 456 & 43037318520200 & & & & & & & & & & \\
\hline 457 & 43037318520300 & & & & & & & & & & \\
\hline 458 & 43037318820000 & & & & & & & & & & \\
\hline 459 & 43037600100000 & & & & & & & & & & \\
\hline 460 & $\mathrm{C} 413$ & $\mathrm{x}$ & $\mathrm{x}$ & & $\mathrm{x}$ & & & & & & \\
\hline
\end{tabular}




\section{REFERENCES}

Ake, J., Mahrer, K., O'Connell, D., and Block, L., 2005, Deep injection and closely monitored induced seismicity at Paradox Valley, Colorado, Bulletin of the Seismological Society of America, 95, 664-683.

Andreani, M., Gouze, P ., L uquot, L ., a nd J ouanna, P ., 2008, C hanges i n s eal c apacity of fractured c laystone caprocks i nduced b y di ssolved a nd g aseous $\mathrm{CO}_{2}$, $\mathrm{s}$ eepage: Geophysical Research Letters, v. 35, p. 6.

Aplin, A .C., a nd Larter, S .R., 2005, F luid f low, por e pr essure, wetability, and 1 eakage i n mudstone cap rocks, in Boult, P., and K aldi, J., e ditors, Evaluating fault and c ap r ock seals: American Association of Petroleum Geologists Hedberg Series, no. 2, p. 1-12.

Aster, R .C., a nd C .A. R owe, 2000, A utomatic pha se pi ck r efinement a nd s imilar ev ent association in large seismic datasets, in: $\mathrm{C}$. Thurber and N. Rabinowitz, eds., Advances in Seismic Event Location, Kluwer, Amsterdam: 231-263.

Babcock, P.A., 1978 a, Aneth (Aneth Unit), S an Juan County, Utah, in Fassett, J.E., editor, Oil and gas fields in the Four Corners area: Four Corners Geological Society Guidebook, v. II, p. 577-579.

Babcock, P.A., 1978b, A neth (McElmo C reek Unit), S an J uan County, Utah, in Fassett, J.E., editor, $\mathrm{O}$ il and $\mathrm{g}$ as fields in the $\mathrm{F}$ our $\mathrm{C}$ orners a rea: $\mathrm{F}$ our $\mathrm{C}$ orners $\mathrm{G}$ eological $\mathrm{S}$ ociety Guidebook, v. II, p. 580-583.

Babcock, P.A., 1978c, Aneth (Ratherford Unit), San Juan County, Utah, in Fassett, J.E., editor, Oil and gas fields in the Four Corners area: Four Corners Geological Society Guidebook, v. II, p. 584-586.

Babcock, P.A., 1978d, Aneth (White Mesa Unit), San Juan County, Utah, in Fassett, J.E., editor, Oil and gas fields in the Four Corners area: Four Corners Geological Society Guidebook, v. II, p. 587-590.

Beresnev, I.A., and Johnson, P.A., 1994, Elastic-wave stimulation of oil production: A review of methods and results, Geophysics, 59, 1000-1017.

Bigalke, J. and Grabner, E. W., 1997, The geobattery model: a contribution to large scale electrochemistry, Electrochemica Acta, 42, 3443-3452.

Cheng, A., L. Huang and J. Rutledge, 2010, Time-lapse VSP data processing for monitoring $\mathrm{CO}_{2}$ injection: The Leading Edge, 29, 196-199.

Chidsey, T.C., Jr., 2009, Surface and subsurface geological characterization of the Aneth Unit, Greater A neth $\mathrm{f}$ ield, $\mathrm{P}$ aradox $\mathrm{B}$ asin, $\mathrm{U}$ tah - final $\mathrm{r}$ eport: $\mathrm{U}$ tah $\mathrm{G}$ eological $\mathrm{S}$ urvey, unpublished report, 630 p., 7 plates, 8 appendices. 
Chidsey, T.C., Jr., Eby, D.E., and Lorenz, D.M., 1996, Geological and reservoir characterization of small shallow-shelf fields, southern Paradox Basin, Utah, in Huffman, A.C., Jr., Lund, W.R., a nd Godwin, L.H., e ditors, G eology and resources of the P aradox B asin: U tah Geological Association Publication 25, p. 39-56.

Coppens, F., and Mari, J.L., 1984, S pectrum equalization as a tool for improving the quality of seismic data: Geophysical Prospecting, 32, 258-281.

Couples, G.D., 2005, S eals-the role of geomechanics rocks, in Boult, P., and Kaldi, J., editors, Evaluating fault a nd $\mathrm{c}$ ap $\mathrm{r}$ ock s eals: A merican A ssociation o f P etroleum $\mathrm{G}$ eologists Hedberg Series, no. 2, p. 87-108.

Davis, G.H., 1999, S tructural geology of the C olorado P lateau r egion of s outhern Utah: with special em phasis on d eformation b ands: G eological S ociety of America S pecial P aper $342,157 \mathrm{p}$.

Fossen, H., and Bale, A., 2007, Deformation bands and their influence on fluid flow: American Association of Petroleum Geologists Bulletin, v. 91, no. 12, p. 1685-1700.

Fossen, H., Schultz, R. A., Shipton, Z. K., and Mair, K., 2007, Deformation bands in sandstone a review: Journal of the Geological Society of London, v. 164, no. 4, p. 755-769.

Gutenberg, B. and Richter, C.F., 1954, Seismicity of the Earth and Associated Phenomena, 2nd edition, Princeton U niversity P ress, Princeton, N.J., 17-19 ( "Frequency and e nergy of earthquakes").

Hammond, G .P., Lichtner, P ., and Lu, C ., 2007 , S ubsurface multiphase f low a nd multicomponent reactive transport modeling using high-performance computing, Journal of Physics: Confernce Series, 78 012025, doi: 10.1088/1742-6596/78/1/012025 .

Hanks, T .C., a nd K anamori, H ., 1979, A m oment m agnitude s cale: Journal of G eophysical Research, 84, 2348-2350.

Harr, C.L., 1996, P aradox oil and gas potential of the Ute Mountain Ute Indian Reservation, in Huffman, A.C., J r., Lund, W.R., a nd G odwin, L.H., e ditors, G eology of the P aradox Basin: Utah Geological Association Publication 25, p. 13-28.

Heidbach, O., Fuchs, K., Müller, B., Reinecker, J., S perner, B., Tingay, M., W enzel, F. (eds.), 2007, The World Stress Map - Release 2005, Commission for the Geological Map of the World, Paris.

Hintze, L.F., a nd K owallis, B .J., 2009, G eologic hi story of U tah: B righam Y oung U niversity Geology Studies Special Publication 9, 225 p. 
Ishido, T., Sugihara, M. and Tosha, T., 2006, Numerical simulation of changes in geophysical observables caused by $\mathrm{CO}_{2}$ injection into saline aquifers, Proceedings of GHGT-8, Trondheim.

Ishido, T., Nishi, Y., Sugihara, M., Temma, N. and Tosha, T., 2008, Changes in geophysical observables caused by $\mathrm{CO}_{2}$ injection into saline aquifers, Abstract H23D-0993, AGU Fall Meeting.

Kaluarachchi, J .J. and Parker, J .C. 1992, Multiphase f low w ith a s implified m odel f or oi 1 entrapment, Transport in Porous Media 7, 1-14.

Kitcho, C.H., 1981, C haracteristics of s urface faults in the Paradox B asin, in Wiegand, D.L., editor, $\mathrm{G}$ eology of $\mathrm{t}$ he $\mathrm{P}$ aradox $\mathrm{B}$ asin: $\mathrm{R}$ ocky $\mathrm{M}$ ountain A ssociation of Geologists Guidebook, p. 1-21.

Lance, G. N., and Williams, W.T., 1967, A general theory for classificatory sorting strategies. 1. hierarchical systems: The Computer Journal, 10, 271-276.

Land, C.S., 1968, Calculation of imbibition relative permeability for two and three-phase flow from rock properties, SPE Journal, 149-156.

Lay, T., and Wallace, T.C., 1995, Modern Global Seismology, Academic Press, San Diego, 393 394.

Lenhard, R .J. a nd P arker, J .C., 1987, A mo del f or h ysteretic c onstitutive r elations governing multiphase f low, 2. P ermeability-saturation $\mathrm{r}$ elations, Water $\mathrm{R}$ esource $\mathrm{R}$ esearch, 23, 2197-2206.

LI-COR, 2005, LI-8100 Automated Soil CO2 Flux System: Instruction Manual. Lincoln: LI-COR Biosciences.

Lindeberg, E., 2002, The quality of a $\mathrm{CO}_{2}$ repository - What is the sufficient retention time of $\mathrm{CO}_{2}$ stored unde rground?, in Gale, $\mathrm{J}$. a nd $\mathrm{K}$ aya, $\mathrm{Y}$., editors, $\mathrm{P}$ roceedings o $\mathrm{f} 6^{\text {th }}$ Greenhouse Gas Control Technologies Conference: Kyoto, Japan, Elsevier, p. 255-260.

Lu, C ., a nd Lichtner, P.C., 2006, $\mathrm{N}$ umerical Investigation of $\mathrm{C} \mathrm{O}_{2}$ Sequestration in $\mathrm{G}$ eologic Media $\mathrm{U}$ sing $\mathrm{t}$ he $\mathrm{M}$ assively $\mathrm{P}$ arallel $\mathrm{C}$ omputer $\mathrm{C}$ ode $\mathrm{P}$ FLOTRAN, $\mathrm{C}$ openhagen, Denmark, June.

Lu, J., W ilkinson, M., Haszeldine, R.S., and Fallick, A.E., 2009, Long-term performance of a mudrock seal in natural $\mathrm{CO}_{2}$ storage: Geology, v. 37, no. 1, p. 35-38.

Mollema, P.N., and Antonellini, M., 1996, Compaction bands - a structural analog for anti-mode 1 cracks in aeolian sandstone: Tectonophysics, v. 267, p. 209-228.

Moore, T.R., and Hawks, R.L., 1993, G reater Aneth, in Hill, B.G., and B ereskin, S.R., editors, 
Oil a nd $\mathrm{g}$ as fields of $\mathrm{U}$ tah: $\mathrm{U}$ tah G eological A ssociation P ublication 22 (Addendum), non-pagenated.

Parker, J.C., a nd Lenhard, R.J., 1987, A model for h ysteretic c onstitutive relations governing multiphase flow, 1. S aturation-Pressure relations, Water R esource R esearch, 23, 2187-2196.

Peterson, J .A., 1966, S tratigraphic vs . s tructural c ontrols on carbonate-mound a ccumulation, Aneth area, Paradox B asin: American A ssociation of P etroleum Geologist Bulletin, 50, 2068-2081.

Peterson, J.A., 1992, Aneth field - U.S.A., Paradox Basin, Utah, in Foster, N.H., and Beaumont, E.A., e ditors, $\mathrm{S}$ tratigraphic tr aps III: A merican A ssociation of $\mathrm{P}$ etroleum $\mathrm{G}$ eologists Treatise of Petroleum Geology - Atlas of Oil and Gas Fields, p. 41-82.

Peterson, J.A., and Ohlen, H.R., 1963, P ennsylvanian shelf carbonates, Paradox Basin, in Bass, R.O., e ditor, $\mathrm{S}$ helf $\mathrm{c}$ arbonates of the $\mathrm{P}$ aradox ba sin: $\mathrm{F}$ our $\mathrm{C}$ orners $\mathrm{G}$ eological $\mathrm{S}$ ociety Symposium, 4th Field Conference, p. 65-79.

Pritchett, J.W., 1995, STAR: a geothermal reservoir simulation system, Proceedings, 2959-2963, World Geothermal Congress '95, Florence.

Raich, J. W., \& Schlesinger, W. H., 1992, The Global Carbon Dioxide Flux in Soil Respiration and its Relationship to Vegitation and Climate. Tellus B , 44, pp. 81-99.

Rickett, J., and Lumley, D. E., 2001, C ross-equalization data processing for time-lapse seismic reservoir monitoring: A case study from the Gulf of Mexico: Geophysics, 66, 1015-1025.

Robson, S.G., and Banta, E.R., 1995, Ground water atlas of the United States; Segment 2, Arizona, Colorado, New Mexico and Utah: U.S. Geological Survey Hydrologic Investigations Atlas Report HA-0730-C, p. C1-C32.

Ross, C. P., Cunningham, G. B., and Weber, D. P., 1996, Inside the cross-equalization black box: The Leading Edge, 15, 1233- 1240.

Rowe, C.A., R.C. Aster, B.Borchers and C.J. Young, 2002, An automatic, adaptive algorithm for refining $\mathrm{p}$ hase $\mathrm{p}$ icks in la rge $\mathrm{s}$ eismic $\mathrm{d}$ ata $\mathrm{s}$ ets: $\mathrm{B}$ ulletin $\mathrm{S}$ eismological $\mathrm{S}$ ociety o $\mathrm{f}$ America, 92 1660-1674.

Rowe, C.A., C. H. Thurber and R. A. W hite, 2004, D ome growth behavior at S oufriere Hills Volcano, M ontserrat, $r$ evealed b y r elocation of vol canic e vent s warms: 1995 -1996, Journal of Volcanology and Geothermal Research, 134, 199-221.

Schmitt, D. R., 1999, Seismic attributes for monitoring of a shallow heated heavy oil reservoir: A case study: Geophysics, 65, 368-377. 
Segall, P., 1989. Earthquakes triggered by fluid extraction. Geology, 17, 942-946.

Segall, P., and Fitzgerald, S.D., 1998. A not e o $\mathrm{n}$ i nduced s tress $\mathrm{c}$ hanges in h ydrocarbon and geothermal reservoirs. Tectonophysics, 289, 117-128.,

Spangler, L.E., N aftz, D.L., a nd P eterman, Z.E., 1996, H ydrology, c hemical qua lity, a nd characterization of salinity in the Navajo aquifer in and near the Greater Aneth oil field, San Juan County, Utah: U.S. Geological Survey Water-Resources Investigations Report 96-4155, 90 p., 1 plate.

Stowe, C., 1972, O il and gas production in Utah to 1970: Utah Geological and Mineral Survey Bulletin 94, p. 170.

Stucchi, E., M., A., and Ciuffi, S., 2005, Seismic preprocessing and amplitude cross-calibration for a time-lapse amplitude study on seismic data from the Oseberg reservoir: Geophysical Prospecting, 53, 265-282.

Torabi, A., and Fossen, H., 2009, Spatial variation of microstructure and petrophysical properties along de formation ba nds i $\mathrm{n}$ r eservoir s andstones: A merican A ssociation of P etroleum Geologists Bulletin, v. 93, no. 7, p. 919-938.

Tosha, T., Ishido, T. and Nishi, Y., 2008, Geoelectric monitoring studies for the carbon dioxide geological storage, Abstract H13K-02, AGU Fall Meeting.

Utah Division of Oil, Gas, and Mining, 2010, Oil and gas production report, March: Online, $<$ https://fs.ogm.utah.gov/pub/Oil\&Gas/Publications/Reports/Prod/Field/Fld_Mar_2010.pdf $>$, accessed July 22, 2010.

Waldauser, F., and Ellsworth, L.W., 2000, A double-difference e arthquake location algorithm: method a nd a pplication $\mathrm{t}$ o $t$ he $\mathrm{N}$ orthern $\mathrm{H}$ ayward $\mathrm{F}$ ault, California: B ulletin of th $\mathrm{e}$ Seismological Society of America, 90, 1353-1368.

Weber, L.J., Wright F.M., Sarg, J.F., Shaw, E., Harman, L.P., Vanderhill, J.B., and Best, D.A., 1995, Reservoir delineation and performance - application of sequence stratigraphy and integration of petrophysics and engineering data, Aneth field, southeast Utah, U.S.A., in Stoudt, E.L., and Harris, P.M., editors, Hydrocarbon reservoir characterization - geologic framework a nd flow un it m odeling: S EPM ( Society for S edimentary Geology) S hort Course No. 34, p. 1-29.

Wikipedia, 2009, C onfocal 1 aser s canning $\mathrm{m}$ icroscopy: $\mathrm{O}$ nline,

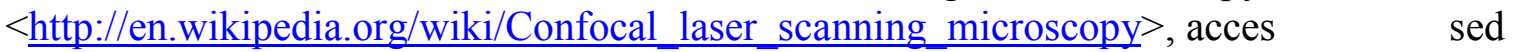
September 2009.

Wolfe, J. C., 2002, On the mathematics of using difference operators to Relocate Earthquakes: Bulletin of the Seismological Society of America, 92, 2879-2892. 
Wong, I.G., and Humphrey, J.R., 1989, Contemporary seismicity, faulting, and state of stress in the Colorado Plateau, Geological Society of America Bulletin, 101, 1127-1146.

Zhang, H., and Thurber, C., 2003, Double-difference tomography: the method and its application to the Hayward Fault, California: Bulletin of the Seismological Society of America, 93, 1875-1889.

Zhang, H ., T hurber, C ., a nd B edrosian, P ., 2009, J oint inversion f or V p, V s, a nd V p/Vs a t SAFOD, Parkfield, California: Geochem. Geophys. Geosyst., 10, Q11002.

Zhang H ., a nd T hurber, C ., 2006, D evelopment a nd a pplication of dou ble-difference s eismic tomography: Pure and Applied Geophysics, 163, 373-403.

Zhou, R., Huang, L., and Rutledge, J., 2010, M icroseismic event location for monitoring CO2 injection using double-difference tomography: The Leading Edge, 29, 208-214.

Zoback, M .D., a nd Zoback, M.L., 1980, S tate of s tress in the c onterminuous U nited S tates, Journal of Geophysical Research, 85, 6113-6156. 